\title{
I'ESIS DOCIORAL
}

MENCIÓN INTERNACIONAL

\section{Salamanca, 2014}

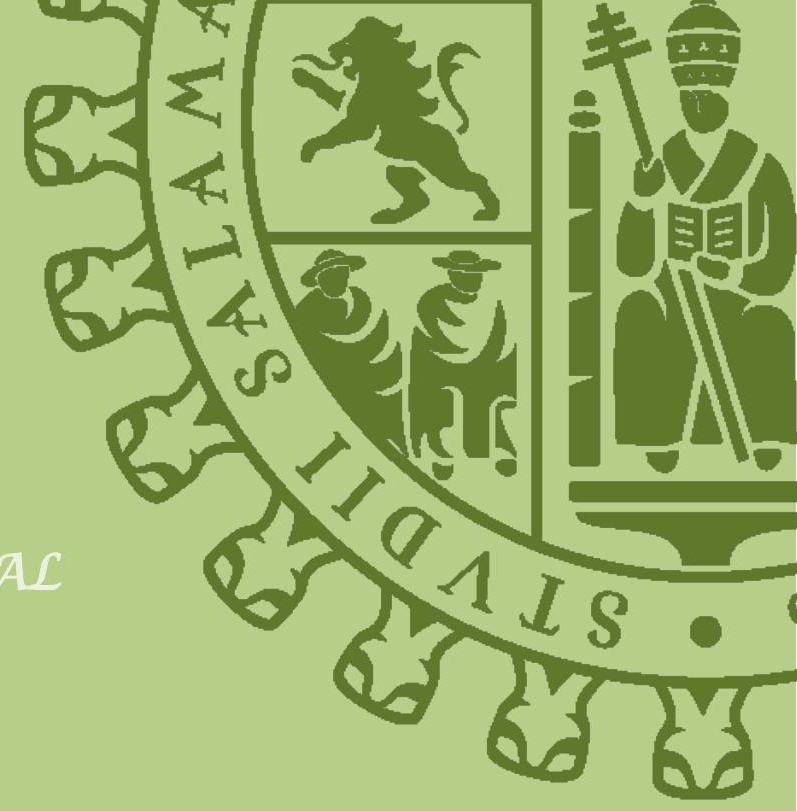

DESARROLLO Y VALIDACIÓN

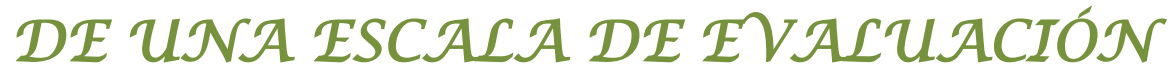

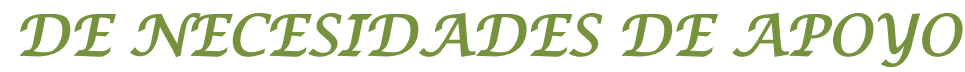

PARA $\mathcal{N} I \tilde{N} O S$ Y ADOLESCENTES

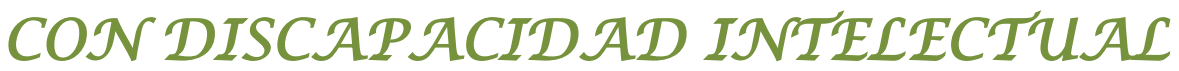

\section{Autora:}

Veróníca Marína Guillén Martín

Directores:

Miguel Ángel Verdugo Alonso

Benito Arias Martínez

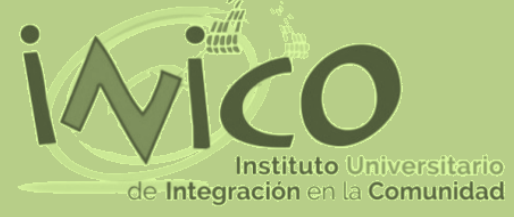

Facultad de Psícología

UNIVERSID AD DE SALAMAJNCA 

UNIVERSIDAD DE SALAMANCA, FACULTAD DE PSICOLOGÍA INSTITUTO UNIVERSITARIO DE INTEGRACIÓN EN LA COMUNIDAD

\section{TESIS DOCTORAL}

-Mención Internacional-

\section{DESARROLLO Y VALIDACIÓN DE UNA ESCALA DE NECESIDADES DE APOYO PARA NIÑOS Y ADOLESCENTES CON DISCAPACIDAD INTELECTUAL}

Verónica Marina Guillén Martín

Directores:

Miguel Ángel Verdugo Alonso

Benito Arias Martínez

Salamanca, 2014 

VNIVERSIDAD

BSALAMANCA

Miguel Ángel Verdugo Alonso, Catedrático de Psicología de la Discapacidad del Departamento de Personalidad, Evaluación y Tratamiento Psicológico e Investigador Principal del Instituto Universitario de Integración en la Comunidad (INICO) de la Universidad de Salamanca, y

Benito Arias Martínez, Profesor Titular del Departamento de Psicología de la Universidad de Valladolid e Investigador del Instituto Universitario de Integración en la Comunidad (INICO) de la Universidad de Salamanca

INFORMAN,

Que la Tesis Doctoral realizada bajo su dirección por Verónica Marina Guillén Martín, con el título 'Desarrollo y validación de una escala de necesidades de apoyo para niños y adolescentes con discapacidad intelectual', reúne los requisitos de calidad, originalidad y presentación exigibles a una investigación científica, por lo que es susceptible de ser sometida a valoración del tribunal encargado de juzgarla.

Y para que así conste y surta los efectos oportunos, firman este documento en Salamanca a 20 de octubre de 2014.

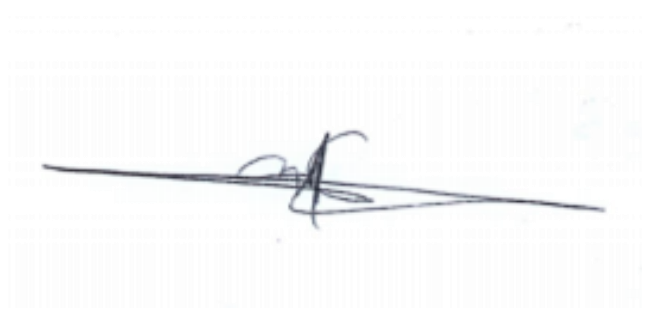

Fdo. Miguel Ángel Verdugo Alonso

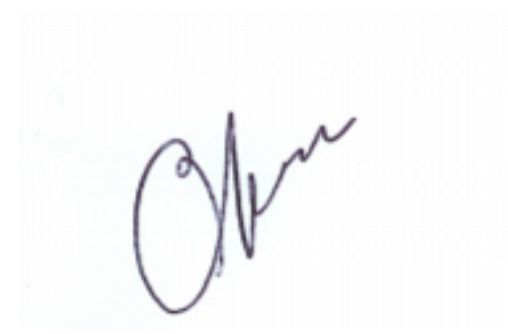

Fdo. Benito Arias Martínez 



\section{AGRADECIMIENTOS}

Toda decisión supone la aceptación de algo y, de manera irremediable, la renuncia a otras alternativas. Cuando eliges enfrentarte a una tesis doctoral otras muchas oportunidades quedan a un lado y nunca sabes si la decisión tomada fue la correcta. Sin embargo, si recibes el apoyo incondicional de las personas que te importan, cualquier camino se convierte en el adecuado. Por ello, desde que comencé a escribir mi tesis, las primeras páginas han estado reservadas a dar las gracias a todos los que habéis pasado por mi vida en estos años porque, como si os hubierais puesto de acuerdo, he recibido de cada uno de vosotros exactamente lo que necesitaba en cada momento.

Gracias a mis directores, porque vosotros habéis hecho que pudiera superar este reto. Miguel Ángel, gracias por tu interés en mi presente y en mi futuro, por tener siempre espacio en tu agenda para todo; gracias por tu flexibilidad y por tus palabras de ánimo, porque tu confianza en mis capacidades fue muchas veces la causa principal que me hizo seguir adelante. Benito, gracias por ser un genio de la metodología y decidir que merecía la pena compartir tus conocimientos conmigo; gracias por no dejar que la distancia fuera un obstáculo para que pudiera aprender de ti. Gracias también a Jim Thompson, Marc Tassé y Jos van Loon, por su paciencia, por preocuparse por mi aprendizaje y por encontrar siempre un medio para comunicarse conmigo; pero, sobre todo, gracias por convertir Normal, Columbus y Gante en un hogar para mí.

Gracias a los compañeros del INICO, por enseñarme que escribir una tesis también puede tener momentos de risas y que las penas no son tan amargas si podemos mojarlas juntos en café; y gracias a TODOS por dejarme aprender de vuestras experiencias. Gracias en primer lugar a Eva, porque no existen hojas en blanco suficientes para poder agradecer tu ayuda; gracias por estar conmigo a lo largo de todo este proceso; gracias por traspasar las fronteras de lo laboral y darme también el apoyo emocional que necesitaba cada día, porque sin ti esto no hubiera sido lo mismo; gracias, AMIGA, por tantas cosas, tantas veces. Gracias a Patry Navas, por ser compañera, aliada y consejera; gracias por enseñarme tanto sin esperar nada a cambio, por abrirme tú casa cuando lo necesitaba y por tener siempre respuesta a todas mis preguntas; gracias por ser un modelo a seguir. Gracias también a Sergio, por enseñarme que todo es posible si te esfuerzas, por compartir todas tus inquietudes e ilusiones, por dejarnos ser parte de tu mundo y no olvidarte nunca de nosotras. 
Gracias a todos los que, en algún momento, habéis compartido la sala 132 conmigo (Patry, Belén, Eva, Flavia, Larguilaura, Virginia-s, Elena, María y Antonio A.) porque, a pesar de todas las horas de trabajo en esa sala, en la que siempre hacía mucho frío o mucho calor, había muy poca gente o demasiada, siempre me sentí como en casa y no cambiaría ni uno sólo de los momentos que he vivido allí con vosotros. Gracias también a Antonio D., por traer frescura y tranquilidad a los descansos. Gracias a Esther, porque contigo de mi lado la burocracia y la moda no me parecen tan complejas y, lo que es más importante, gracias por ser la mejor defensora de mis moños. Gracias a Elena y Pilar, por tener siempre historias que contar y risas que compartir. Gracias a Manoli, por estar pendiente de todo y ser capaz de resolver de manera eficaz los problemas más difíciles. Gracias a Mónica y Fabián, porque realmente hacéis que me aparezca una sonrisa en la cara cada vez que os veo (Elia tiene garantizada una infancia llena de alegría y felicidad con vosotros). Gracias a Teresa, por su cercanía y amabilidad; gracias por hacer que sea tan sencillo hablar contigo de cualquier cosa. Gracias a Borja, por ir dejando gotas de humor y seriedad a cada paso, encontrando el equilibrio perfecto entre ambos. Gracias a Ángel y Emiliano, porque sus aportaciones, que realmente valoro, siempre llegan en los mejores momentos. Gracias a David y Dámaso, porque sé que puedo contar con vosotros cuando lo necesite. Gracias a Isa, María, Maribel, Marta y Paqui, porque son cinco grandes mujeres, cuyo esfuerzo y tesón son un gran ejemplo para todos. Y gracias también a las dos Albas, Laura y Leire, porque fuisteis un referente fundamental para mí cuando inicié esta aventura y, aún hoy, lo seguís siendo.

Además, me gustaría dar las gracias a todos los centros que han colaborado en este trabajo, porque sin su participación desinteresada nada de esto hubiera sido posible. Gracias también a todos mis alumnos de Psicología de la Discapacidad, que me han dejado aprender con ellos estrategias de enseñanza, a través de su respeto y confianza. Y gracias a AVIVA, por darle un sentido práctico a la investigación; gracias a todos los profesionales y voluntarios de la asociación por transmitirme su ilusión; gracias a Bea, Eugenio, Jose Luis y Mariví, por permitirme formar parte de ese gran proyecto; gracias a Kike, María, Pau y Vega, por crear un pequeño grupo sin fisuras; y gracias a todos los participantes de la asociación, porque me habéis ayudado más vosotros a mí que yo a vosotros.

No podría olvidarme de dar las gracias a mis amigas (especialmente a Blanca, Enar, Estrella, Marina y Paula), que siempre encuentran tiempo para reunirse conmigo; gracias por todos esos fines de semana llenos de risas, juegos y confidencias que me dan fuerzas para empezar el trabajo cada lunes. 
Por supuesto, gracias también a mi familia, por preocuparse de mi cada día de manera incondicional; por ayudarme a alcanzar este momento. Gracias a mis padres, por estar siempre ahí para mí, cuando me iba y cuando volvía, por proporcionarme todo lo que necesitaba y por darme un motivo para querer volver a casa; gracias por enseñarme a poner el foco en las cosas buenas, dejar de lado las malas y disfrutar del amplio abanico de colores que ofrece la vida. Gracias a Guille, por ser el mejor hermano del mundo; porque cambiaste mi vida totalmente cuando llegaste, y aún sigo asombrándome de la bondad y paciencia que demuestras; por favor, no te canses nunca de jugar conmigo. $Y$, con especial cariño, gracias a mis abuelos, que hacen que desee que cada día sea domingo.

Y gracias a TI, mi vida, por enseñarme que no existen límites para la felicidad; gracias por tus consejos, por tu disponibilidad y por estar siempre esperándome a la salida; gracias porque desde que estás conmigo ya no tengo miedo a nada, porque el fuego no quema si estamos juntos; gracias por aparecer en mi vida por casualidad y quedarte para siempre, porque desde el primer 'hola' me di cuenta de que por fin, entre todos los sitios, todos los lugares y todas las personas, había conseguido encontrarte. 



\section{CONSIDERACIONES A TENER EN CUENTA EN LA LECTURA DE ESTA TESIS DOCTORAL}

\section{EMPLEO GENÉRICO DEL MASCULINO}

A pesar de la tendencia actual sobre el denominado uso no sexista del lenguaje, hemos optado por el uso genérico del masculino atendiendo a las recomendaciones de la Real Academia de la Lengua (RAE). La RAE aboga por el uso del masculino como genérico e inclusivo (es decir, no solo referido a los individuos del sexo masculino, sino para designar a todos los individuos de la especie, sin distinción de sexos), como parte de naturaleza del español y sin ninguna intención sexista. La RAE defiende la economía del leguaje y resalta la relevancia del uso del masculino como genérico como medio para evitar las engorrosas repeticiones innecesarias derivadas que conlleva la continua alusión explícita a los dos sexos tanto en la forma completa (los niños y las niñas) como mediante el uso de barras (los/las niños/as), así como el inapropiado uso del arroba como signo lingüístico indicativo de la referencia a ambos sexos (niñ@s).

En cualquier caso, en aquellas ocasiones en las que hemos considerado que existía la posibilidad de sustituir el masculino genérico por un nombre que designara indistintamente a hombres y mujeres así como por formas impersonales, hemos optado por la utilización de estos últimos.

\section{SIGLAS UTILIZADAS EN EL TEXTO}

Para hacer referencia a diferentes realidades o conceptos, conocidos comúnmente por sus siglas, se presenta el nombre completo la primera vez que se hace referencia a los mismos en cada capítulo, utilizando posteriormente solo las siglas resultantes de la abreviatura del nombre en español. Por ejemplo, Organización Mundial de la Salud (OMS); Clasificación Internacional de Enfermedades (CIE).

Sin embargo, siguiendo un criterio de frecuencia de uso, en aquellos casos en los que se hace referencia a entidades o herramientas comúnmente conocidas en España por sus siglas en inglés, se utilizará el nombre completo en español y en inglés la primera vez que aparecen en cada capítulo, conservando posteriormente las siglas en inglés para hacer referencia a los mismos. Por ejemplo, Asociación Americana de Discapacidades Intelectuales y del Desarrollo (American Association on Intellectual and Developmental Disabilities [AAIDD]); Manual Diagnóstico y Estadístico de los Trastornos Mentales (Diagnostic and Statistical Manual of Mental Disorders [DSM]); Escala de Intensidad de Apoyos (Supports Intensity Scale [SIS]).

\section{USO DEL TÉRMINO DISCAPACIDAD INTELECTUAL}

Durante muchos años, ha existido un gran debate sobre la terminología más adecuada para hacer referencia al colectivo de personas con limitaciones en el funcionamiento intelectual y conducta adaptativa con inicio durante el periodo de desarrollo. Aunque tradicionalmente el término más utilizado ha sido 'retraso mental', esta terminología se considera inapropiada y estigmatizadora en la actualidad. A lo largo de este trabajo, se utilizará 'discapacidad intelectual', puesto que es el término adoptado en los últimos años por asociaciones de ámbito nacional e internacional y es el término utilizado en las últimas propuestas de diagnóstico y clasificación más reconocidas: CIE-10 y DSM-5.

Sin embargo, se ha mantenido el uso de términos anteriores con los que se ha designado esta condición en aquellos casos en los que se hace referencia literal al término utilizado en un momento temporal concreto. 


\section{TRADUCCIÓN Y ADAPTACIÓN DEL TÉRMINO CHILDREN}

La escala desarrollada en esta tesis doctoral ha sido traducida al español como 'Escala de Intensidad de Apoyos para Niños y Adolescentes', siendo el nombre utilizado de manera original en inglés Support Intensity Scale for Children. La traducción al español desde otros idiomas no debe entenderse siempre desde un punto de vista literal, sino que ha de asegurar una adaptación lingüística, social y cultural. En este sentido, mientras que en inglés el término children (literalmente niños) es utilizado de forma general para designar tanto a niños como a jóvenes sin ningún matiz negativo (children es también la palabra formal utilizada para hacer referencia a los hijos, independientemente de la edad), el uso de la palabra 'niños' en España, utilizada fuera del contexto infantil, tiene una connotación de inmadurez que durante años fue aplicada a las personas con discapacidad intelectual, lo que derivó en prácticas profesionales inapropiadas para la edad de los individuos. Así, al hacer referencia la escala a un grupo de personas con discapacidad intelectual que engloba un amplio rango de edad (5-16 años) e incluir a personas que ya se encuentran en su transición a la vida adulta, el término preferido para su traducción completa en español ha sido 'niños y adolescentes', evitando el uso peyorativo de la palabra 'niños' para referirse a los jóvenes con discapacidad intelectual.

\section{FORMATO PARA LA ELABORACIÓN DE REFERENCIAS BIBLIOGRÁFICAS}

Para la elaboración de este trabajo se ha seguido el estilo de publicaciones de la APA. Concretamente, el formato utilizado para la redacción y presentación de las referencias usadas en esta tesis doctoral corresponde con las directrices indicadas en la 6aㅡ edición del manual (American Psychological Association [APA], 2010). 


\section{ÍNDICE DE CONTENIDOS}

PRESENTACIÓN. .23

PARTE I. JUSTIFICACIÓN TEÓRICA . .31

Introducción a la Parte Teórica. . .33

CAPÍTULO 1. CAMBIOS EN LA CONCEPCIÓN DE DISCAPACIDAD INTELECTUAL: INCORPORACIÓN, EVOLUCIÓN E IMPLICACIÓN ACTUAL DE LOS APOYOS. .37

1.1. DEL PARADIGMA TRADICIONAL AL PARADIGMA SOCIAL EN EL ÁMBITO DE LA DISCAPACIDAD: EVOLUCIÓN Y CONCEPCIÓN ACTUAL ……………………………………....... 41

1.1.1. Últimos avances en el concepto de discapacidad y su repercusión en el campo de la

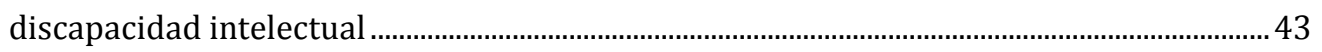

1.1.1.1. Cambios en el modelo social: apoyos para la inclusión............................................... 44

1.1.1.2. Hacia el término y constructo de 'discapacidad intelectual'. Influencia de la AAIDD en el cambio. . .46

1.2. IMPLICACIONES DEL CAMBIO EN EL DIAGNÓSTICO . .49

1.2.1. Límites y clasificación del constructo ....................................................................................... 51

1.2.2. Incorporación del concepto de conducta adaptativa en la definición y como criterio de clasificación. 53

1.3. DISCAPACIDAD INTELECTUAL Y MODELOS TEÓRICOS DE REFERENCIA …………........................... 58

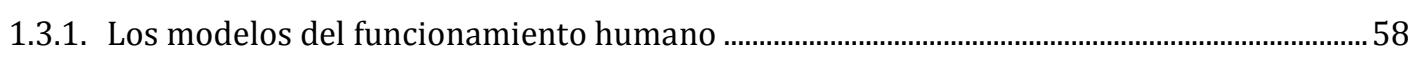

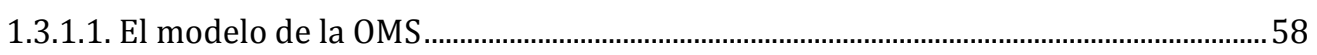

1.3.1.2. El modelo de la AAIDD ...................................................................................................6 60

1.3.1.3. Relación del modelo de la AAIDD con el modelo de la OMS.........................................62

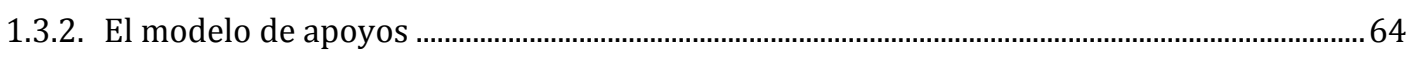

1.3.2.1. Conceptos clave del modelo de apoyos .................................................................... 71

1.3.2.2. Entendiendo el constructo de 'necesidades de apoyo': definición, perspectivas y

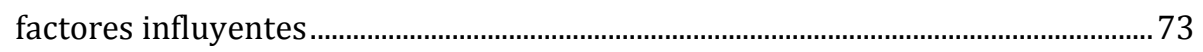

1.3.2.3. Las necesidades de apoyo como Zona de Desarrollo Próximo (ZDP)..................... 75

1.3.3. La mejora del bienestar de las personas con discapacidad intelectual: el modelo de

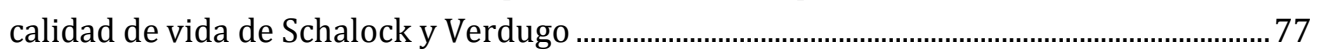

1.3.3.1. Conceptualización, dimensiones e indicadores de calidad de vida ......................... 78

1.3.3.2. Aplicabilidad del concepto de calidad de vida ............................................................ 81

1.3.3.3. Los apoyos en la comunidad: el camino hacia la calidad de vida .............................83

1.4. ESTRATEGIAS PARA LA TRANSFORMACIÓN ORGANIZACIONAL: PRÁCTICAS BASADAS EN LA EVIDENCIA, SISTEMAS DE APOYO ORIENTADOS A LOS RESULTADOS E INFLUENCIA DE LAS

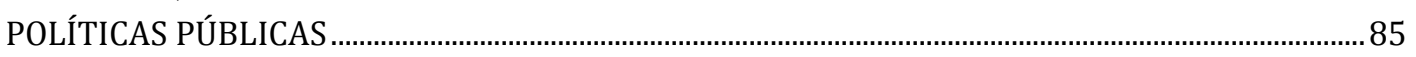

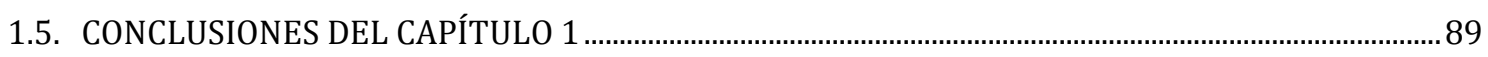


CAPÍTULO 2. EL PROCESO DE EVALUACIÓN EN PERSONAS CON DISCAPACIDAD INTELECTUAL:

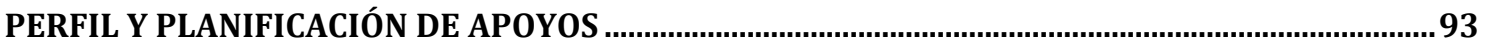

2.1. CÓMO EVALUAR PARA EL DIAGNÓSTICO Y LA CLASIFICACIÓN ……………………………………...97

2.1.1. Evaluación para el diagnóstico ………………………………………………………………...97

2.1.1.1. Cómo evaluar limitaciones intelectuales e instrumentos de medida ..................... 98

2.1.1.2. Cómo evaluar la conducta adaptativa e instrumentos de medida ......................... 100

2.1.2. Evaluación para la clasificación. Hacia un sistema de clasificación multidimensional... 104

2.1.2.1. La clasificación a través de la intensidad de las necesidades de apoyo ................ 106

2.2. EVALUACIÓN PARA EL PERFIL DE APOYOS ………………………………………………………....... 109

2.2.1. Modelos de evaluación de necesidades de apoyo ................................................................. 109

2.2.1.1. Modelo de marketing.............................................................................................. 111

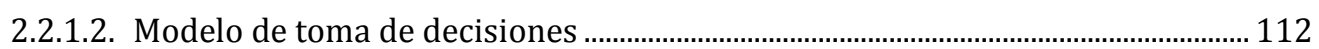

2.2.1.3. Modelo de discrepancia.................................................................................................. 112

2.2.2. Cómo evaluar necesidades de apoyo e instrumentos de medida .......................................... 113

2.2.2.1. Instrumentos de evaluación de necesidades de apoyo en el contexto español: la

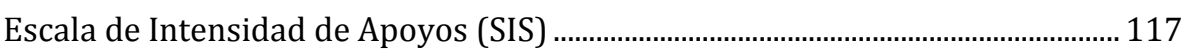

a) Desarrollo y descripción de la SIS ........................................................................... 119

b) Limitaciones de la SIS ................................................................................................. 122

2.2.3. Diferencias entre el CI, la conducta adaptativa y las necesidades de apoyo: implicaciones en la evaluación de los constructos .......................................................................................... 123

2.3. LA PLANIFICACIÓN INDIVIDUALIZADA DE APOYOS PARA PERSONAS CON DISCAPACIDAD

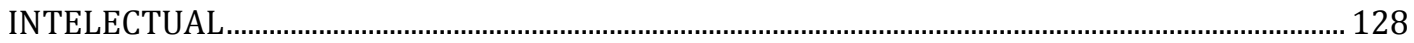

2.3.1. Del proceso de cuatro pasos al proceso de cinco componentes de la AAIDD....................129

2.3.2. Eficacia de los planes de apoyo individualizados: alineación de los apoyos y la calidad de vida en la práctica organizacional...................................................................................... 135

2.3.2.1. Calidad de vida: estrategias e instrumentos de evaluación ........................................ 136

2.3.2.2. Convergencia de la planificación de apoyos y el modelo de calidad de vida de Schalock y Verdugo: Arduin, ejemplo de aplicación en la práctica diaria...........137

2.3.2.3. Diferencias entre planes de apoyo y planes de servicio ............................................ 140

2.4. EVALUACIÓN DE NECESIDADES Y PLANIFICACIÓN DE APOYOS EN NIÑOS Y ADOLESCENTES

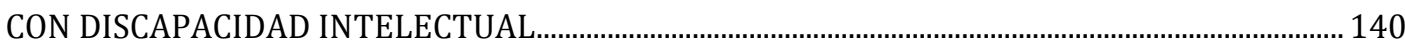

2.4.1. Diferencias entre planes de apoyo y planes de rendimiento educativo............................... 142

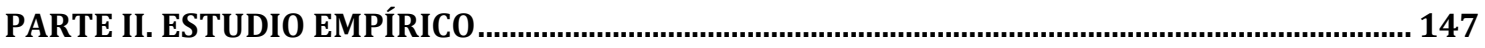

Introducción a la Parte Empírica ................................................................................................. 149 
CAPÍTULO 3. ADAPTACIÓN Y DESARROLLO DE LA SIS-C EN EL CONTEXTO ESPAÑOL 153

3.1. PLANTEAMIENTO INICIAL 156

3.2. OBJETIVOS. 158

3.3. MÉTODO 159

3.3.1 Instrumento 159

3.3.1.1. Desarrollo y descripción de la SIS-C 159

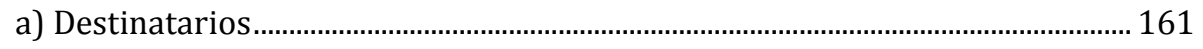

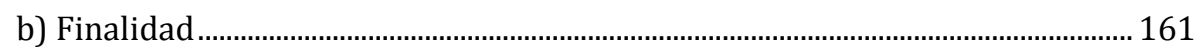

c) Estructura: dimensiones y formato de respuesta......................................................161

d) Procedimiento de aplicación ................................................................................... 164

e) Usos prácticos...................................................................................................... 164

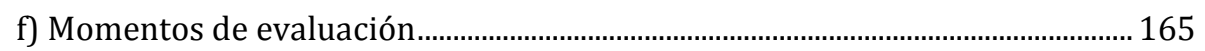

3.3.1.2. Semejanzas y diferencias con la SIS de adultos ......................................................... 166

a) Consideraciones sobre las necesidades de apoyo derivadas del desarrollo 166

b) Modificaciones de áreas y actividades evaluadas ................................................167

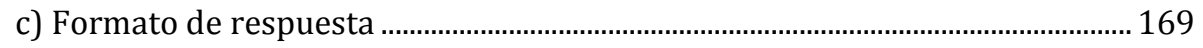

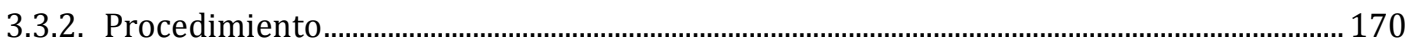

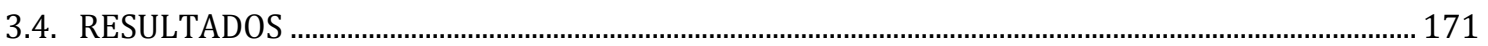

3.4.1. FASE I: Traducción/adaptación del pool de ítems inicial ..................................................... 171

3.4.2. FASE II: Consolidación de la traducción/adaptación ............................................................. 172

3.4.3. FASE III: Validación de la traducción preliminar .................................................................. 173

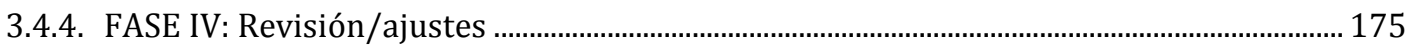

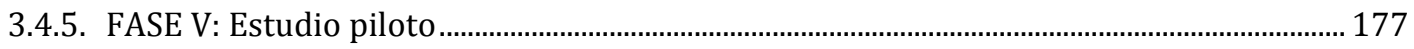

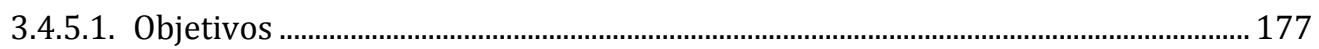

3.4.5.2. Selección de la muestra piloto y procedimiento de recogida de datos..................178

3.4.5.3. Análisis de Datos ....................................................................................................... 180

a) Teoría Clásica de los Tests (TCT) ..................................................................................... 181

b) Teoría de Respuesta a los Ítems (TRI)............................................................................ 181

3.4.6. FASE VI: Revisión/ajustes tras el estudio piloto ..................................................................... 186

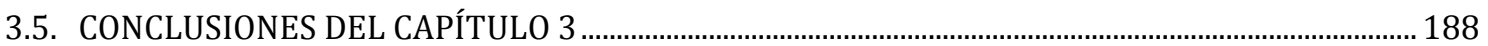

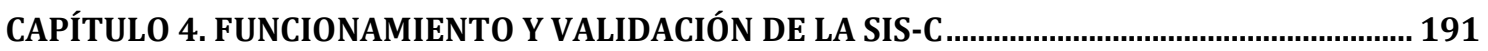

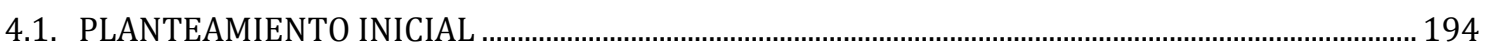

4.1.1. Análisis de las propiedades psicométricas, la fiabilidad y la validez de la escala a través de la TCT. 194

4.1.2. Evidencias de validez basadas en la estructura interna de la escala basadas en los SEM: el Análisis Factorial Confirmatorio.

4.1.3. Ajuste de los datos y calibración de los ítems según la TRI: el Modelo de Crédito Parcial (MCP) 196 


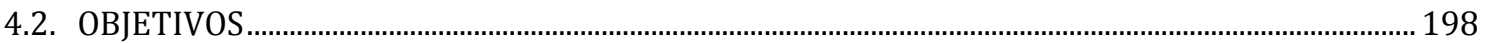

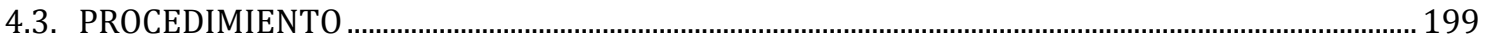

4.3.1. Contacto con los centros y selección de la muestra …………………………………............... 199

4.3.1.1. Características de los participantes evaluados ........................................................... 201

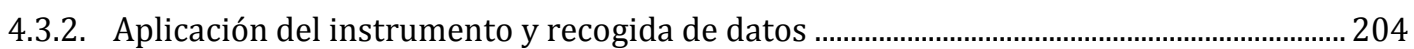

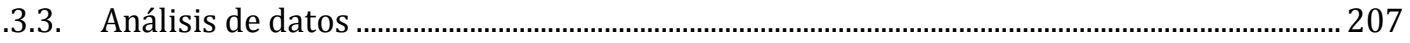

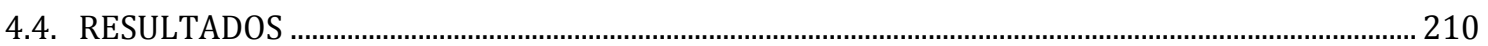

4.4.1. Objetivo 1: análisis de resultados mediante la TCT ……………………………………..... 210

4.4.1.1. Análisis descriptivo de los datos ................................................................................... 210

4.4.1.2. Análisis de la calidad de los ítems................................................................................ 213

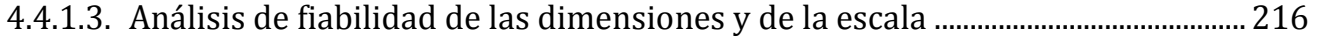

4.4.1.4. Análisis de validez de las dimensiones y de la escala ............................................. 220

4.4.2. Objetivo 2: análisis de la estructura de la escala a través del AFC (SEM) .......................... 229

4.4.2.1. Comprobación de los requisitos previos: adecuación del uso de parcels .......... 230

4.4.2.2. Especificación e identificación de los modelos ........................................................... 241

4.4.2.3. Estimación de parámetros y ajuste de los modelos................................................... 246

4.4.3. Objetivo 3: ajuste de los datos al MCP (TRI) …………………………………….............. 251

4.4.3.1. Requisitos previos: análisis de la polaridad, la varianza explicada y de la

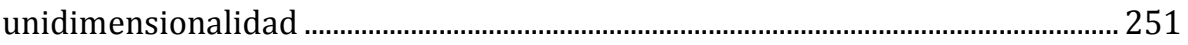

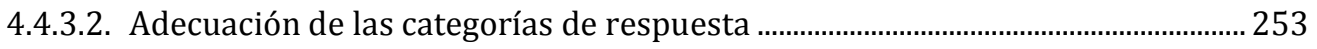

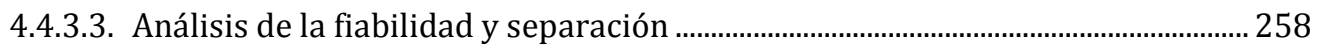

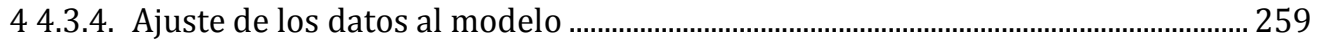

4.4.3.5. Calibración de los ítems: localización, discriminación y precisión .........................2263

4.3.4.6. Análisis de la invarianza ........................................................................................... 272

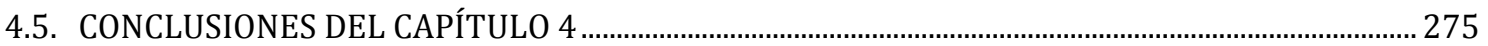

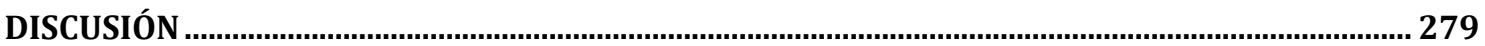

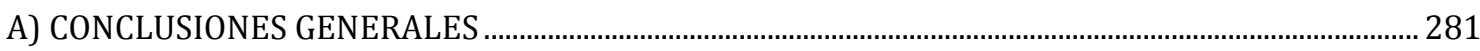

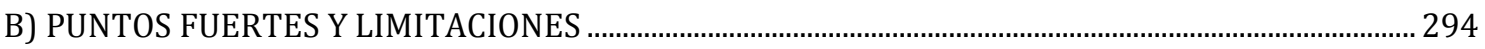

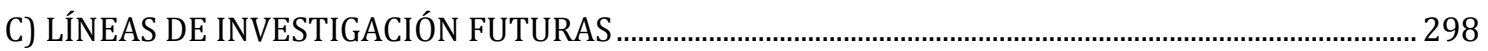

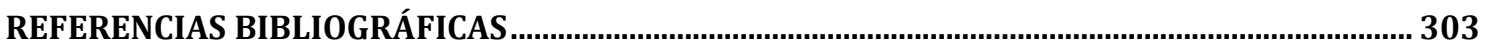




\section{ÍNDICE DE TABLAS}

Tabla 1. Evolución de los paradigmas de la discapacidad

Tabla 2. Diferencia entre los términos Integración e Inclusión. Evolución del modelo social (adaptado de Arnaiz, 2003; Moriña, 2004)

Tabla 3. Relación entre los distintos paradigmas, constructos, términos y definiciones utilizadas en el campo de la discapacidad intelectual

Tabla 4. Clasificación de la discapacidad intelectual (Verdugo, Guillén y Vicente, 2014; adaptado de APA, 2013). 57

Tabla 5. Modificación de las dimensiones del modelo de la AAIDD. De 1992 al 2002 61

Tabla 6. Comparación entre el modelo de la OMS y el modelo de la AAIDD ……………………………...63

Tabla 7. Componentes del modelo de apoyos (Luckasson et al., 1992) ........................................................ 66

Tabla 8. Relación del modelo de apoyos y modelo de tecnología del funcionamiento humano (Thompson et al., 2009)

Tabla 9. Definición de conceptos clave en el modelo de apoyos: necesidades de apoyo y sistemas de apoyos (Schalock et al., 2010; Thompson et al., 2009)

Tabla 10. Tipos de necesidades sociales (adaptado de Schalock et al., 2010, p.173; Thompson et al., 2009, p.136)

Tabla 11. Modelo conceptual de calidad de vida de Schalock y Verdugo (2002). Adaptado de Buntinx y Schalock (2010).

Tabla 12. Calidad de vida y apoyos individualizados (Schalock y Verdugo, 2007) ................................... 80

Tabla 13. Transformación de la calidad de los servicios (Tamarit, 2006)..................................................... 86

Tabla 14. Evaluación de la discapacidad intelectual (adaptado de Schalock et al., 2010).......................96

Tabla 15. Principales instrumentos utilizados en la evaluación del funcionamiento intelectual en España (adaptado de Verdugo, Guillén y Vicente, 2014)

Tabla 16. Principales instrumentos utilizados en el diagnóstico de la conducta adaptativa (Tassé, 2013; Tassé et al., 2012)

Tabla 17. Ajuste de la DABS a los criterios de la evaluación diagnóstica de conducta adaptativa .. 102

Tabla 18. Otros instrumentos utilizados para valorar la conducta adaptativa ........................................103

Tabla 19. Sistema de Clasificación Multidimensional (Schalock et al., 2010) .......................................... 105

Tabla 20. Parrilla de toma de decisiones sobre la intensidad de apoyos (Luckasson et al., 1996) . 106

Tabla 21. Modificaciones en la parrilla de toma de decisiones (Schalock, 1999) ..................................107

Tabla 22. Descriptores y clasificación de las necesidades de apoyo. Adaptado de Arnold et al. (2014a)

Tabla 23. Instrumentos de evaluación de necesidades de apoyo en personas con discapacidad intelectual

Tabla 24. Índices de medida para la evaluación de la intensidad de apoyos 120

Tabla 25. Diferencias en la evaluación de conducta adaptiva y necesidades de apoyo adaptada de Schalock et al. (2010, p.175) 
Tabla 26. Proceso de cuatro pasos para la planificación individualizada de apoyos (Luckasson et al., 2002) 130

Tabla 27. El proceso de intervención en Arduin: alineando el paradigma de apoyos y el modelo de calidad de vida (adaptado de van Loon et al., 2010) 138

Tabla 28. Alineación entre las dimensiones de calidad de vida y las áreas de la SIS (van Loon et al., 2010, p.198) 139

Tabla 29. Características generales de la SIS-C. Ficha técnica 160

Tabla 30. Estructura general de la SIS-C. Sección II-Evaluación de Necesidades de Apoyo (Verdugo,

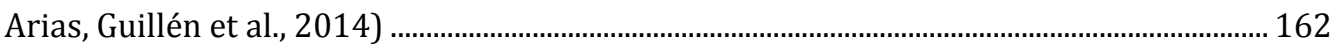

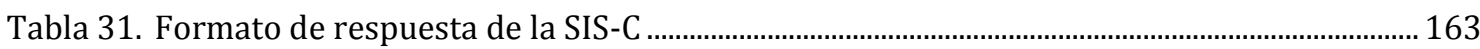

Tabla 32. Relación entre los contenidos de la SIS y la SIS-C.................................................................... 168

Tabla 33. Relación entre las áreas de la SIS para Niños y Adolescentes, las áreas de la SIS y las dimensiones del Modelo de Calidad de Vida (van Loon et al., 2010) .................................... 169

Tabla 34. Comparación del índice de frecuencia de apoyo en la SIS y la SIS-C....................................170

Tabla 35. Resumen del proceso de adaptación y desarrollo de la SIS-C en España .............................. 171

Tabla 36. Características sociodemográficas del grupo de jueces expertos $(\mathrm{n}=8)$............................... 173

Tabla 37. Errores cometidos durante el proceso inicial de traducción ...................................................176

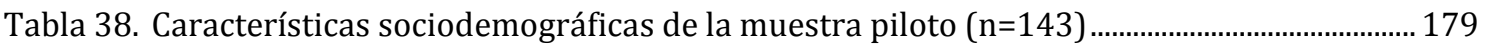

Tabla 39. Resultados del estudio piloto analizados bajo los supuestos de la TCT ............................... 184

Tabla 40. Resultados del estudio piloto analizados bajo los supuestos de la TRI .................................185

Tabla 41. Criterios de distribución de la muestra establecidos por la AAIDD ......................................200

Tabla 42. Características sociodemográficas de la muestra $(\mathrm{n}=814)$.................................................... 202

Tabla 43. Contingencia entre 'edad' y 'nivel de DI' ................................................................................ 203

Tabla 44. Relación del niño evaluado con el informante 1 ….................................................................... 206

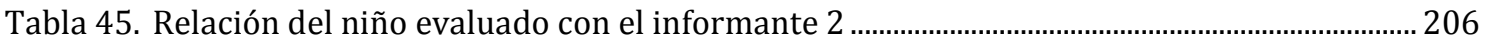

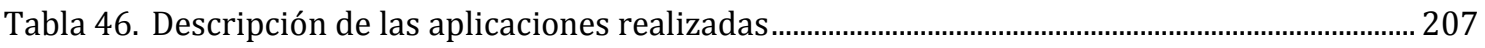

Tabla 47. Análisis de datos en relación con la TCT (objetivo 1) ...............................................................2 208

Tabla 48. Análisis complementarios a través del AFC (objetivo 2) y la TRI (objetivo 3) .................... 209

Tabla 49. Análisis descriptivo de las dimensiones de la escala (índices y gráficos) ............................. 212

Tabla 50. Índices de la calidad psicométrica de los ítems..........................................................................2215

Tabla 51. Consistencia interna de las dimensiones y de la escala (alfa de Cronbach) ......................... 217

Tabla 52. Errores típicos de medida de las dimensiones y de la escala................................................ 218

Tabla 53. Fiabilidad intereveluadores de las dimensiones y de la escala ................................................. 219

Tabla 54. Fiabilidad test-retest de las dimensiones y de la escala .......................................................... 220

Tabla 55. Intercorrelaciones entre las subescalas de la SIS-C y la puntuación total............................ 2224

Tabla 56. Correlaciones entre necesidades de apoyo y los problemas médicos y conductuales ..... 225

Tabla 57. Descriptivos y resultados de la prueba de contraste para la variable 'género'................... 225

Tabla 58. Descriptivos y resultados de la prueba de contraste para la variable 'edad' ....................... 226 
Tabla 59. Resultados más significativos del contraste de medias por pares de la variable 'edad' .. 227

Tabla 60. Descriptivos y resultados de la prueba de contraste para la variable 'nivel de DI' 228

Tabla 61. Resultados del contraste de medias por pares de la variable 'nivel de DI' 229

Tabla 62. Requisitos previos para el uso del AFC 231

Tabla 63. Distribución y estadísticos descriptivos de los parcels establecidos. 232

Tabla 64. Evidencias de unidimensionalidad de los parcels. 233

Tabla 65. Contraste de asimetría y curtosis de los parcels 235

Tabla 66. Prueba de normalidad univariada 236

Tabla 67. Correlaciones entre los parcels. 239

Tabla 68. Valores de $\mathrm{R}^{2}$, nivel de tolerancia y factor de inflación de la varianza de los parcels........ 240

Tabla 69. Modelos sometidos a prueba mediante AFC. 242

Tabla 70. Resultados del análisis de los índices de ajuste. 250

Tabla 71. Fiabilidad compuesta y varianza media extractada 251

Tabla 72. Idoneidad de las categorías de respuesta 254

Tabla 73. Ítems con una mala adecuación de las categorías de respuesta referentes al tiempo diario de ароуо 256

Tabla 74. Índices de fiabilidad y separación de ítems y personas.. 258

Tabla 75. Resumen de ajuste global de las dimensiones y de la escala 260

Tabla 76. Ajuste interno y externo de los ítems al modelo 260

Tabla 77. Estimación de la discriminación de los ítems 268

Tabla 78. Resumen de los ítems que presentan un funcionamiento diferencial (DIF contrast) para personas con autismo y parálisis cerebral 275 


\section{ÍNDICE DE FIGURAS}

Figura 1. Modelo de competencia general (Schalock, 1999) ……………………………......................... 55

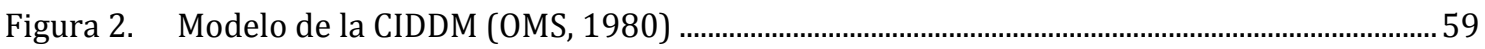

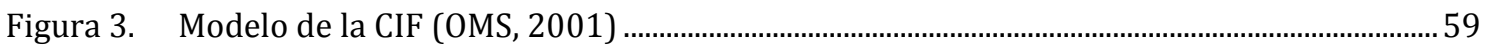

Figura 4. Progresión del modelo del uncionamiento humano (Luckasson et al., 1992; Luckasson

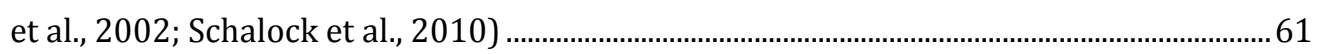

Figura 5. El modelo de apoyos de la AAMR (Luckasson et al., 1992; Luckasson et al., 2002) ..........67 67

Figura 6. El modelo de apoyos la AAIDD (Schalock et al., 2010; Thompson et al., 2009) ..................68

Figura 7. Factores predictores de las necesidades de apoyo ………………………………………….... 75

Figura 8. Comparación del término ZDP con el concepto de necesidades apoyo ……………………....76

Figura 9. Alineamiento de estrategias de apoyo con las metas personales y los resultados personales. El pensamiento de derecha a izquierda (adaptado de van Loon, 2009b) ..... 87

Figura 10. El proceso de cuatro componentes para la planificación individualizada de apoyos (Thompson, McGrew et al., 2002)

Figura 11. Proceso de cinco componentes para la evaluación, planificación y provisión de apoyos (Thompson et al., 2009; Schalock et al. 2010).

Figura 12. Distribución de las fases de desarrollo de la escala en los capítulos de la parte empírica 151

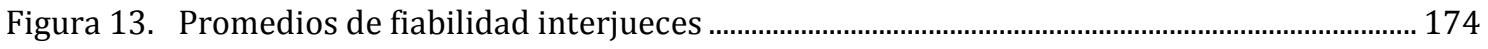

Figura 14. Gráfico de acuerdos (Bangdiwala) para cada área de la SIS-C (Jiménez, 2009)................ 175

Figura 15. Representación de la contingencia entre 'edad' y 'nivel de $\mathrm{DI}^{\prime}$ '........................................... 203

Figura 16. Representación de la contingencia entre 'edad' y 'género' ...................................................... 204

Figura 17. Representación de la contingencia entre 'género' y 'nivel de DI' .......................................... 204

Figura 18. Características sociodemográficas de los informantes .......................................................... 205

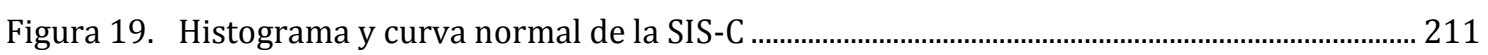

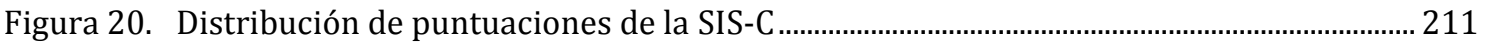

Figura 21. Distancias entre la varianza del error y varianza empírica de las áreas evaluadas ....... 218

Figura 22. Correlaciones entre las puntuaciones de la SIS-C y una estimación previa de necesidades

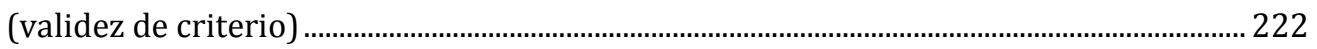

Figura 23. Outliers de los parcels. Subescala A ……….......................................................................... 237

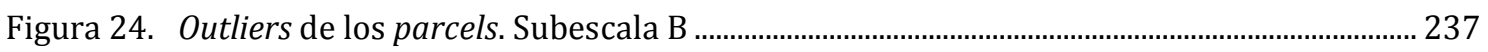

Figura 25. Outliers de los parcels. Subescala C.......................................................................................... 237

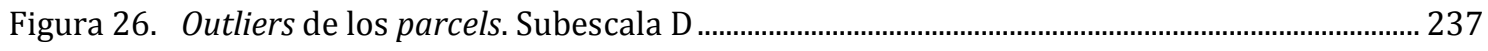

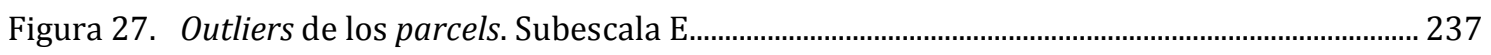

Figura 28. Outliers de los parcels. Subescala F........................................................................................ 237

Figura 29. Outliers de los parcels. Subescala G …………………………………………………....... 237

Figura 30. Relación entre parcels. Subescala A ....................................................................................... 238 
Figura 31. Relación entre parcels. Subescala B ..................................................................................... 238

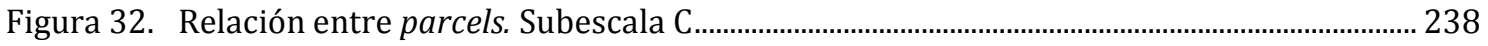

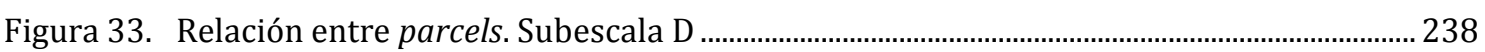

Figura 34. Relación entre parcels. Subescala E..................................................................................... 238

Figura 35. Relación entre parcels. Subescala F ....................................................................................... 238

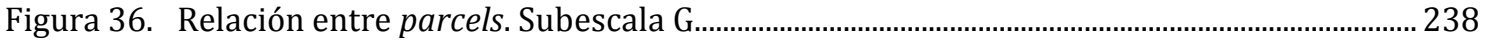

Figura 37. Especificación e identificación del modelo unidimensional (H1).......................................... 243

Figura 38. Especificación e identificación del modelo correlacional (H2) …………………………...... 244

Figura 39. Especificación e identificación del modelo jerárquico (H3)................................................. 245

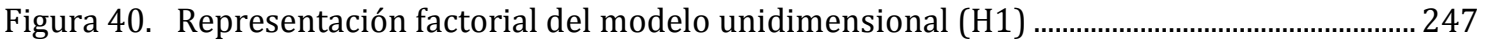

Figura 41. Representación factorial del modelo correlacional (H2) ………………………………...... 248

Figura 42. Representación factorial del modelo jerárquico (H3) .......................................................... 249

Figura 43. Análisis de la polaridad de los ítems....................................................................................... 252

Figura 44. Varianza explicada por las medidas y unidimensionalidad de las subescalas................... 252

Figura 45. Representación de las categorías de respuesta del índice tiempo diario de apoyo.......... 255

Figura 46. Infit y Outfit MNSQ. Subescala A................................................................................................. 261

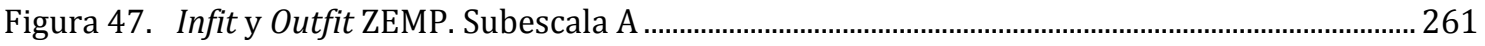

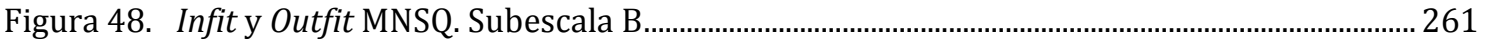

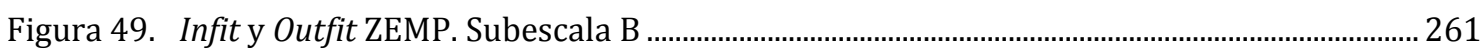

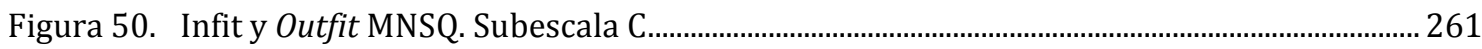

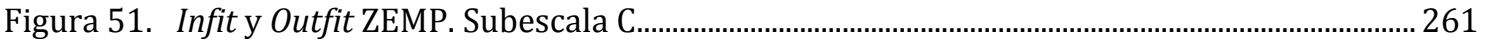

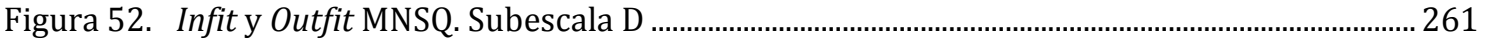

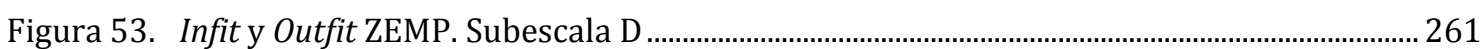

Figura 54. Infit y Outfit MNSQ. Subescala E............................................................................................. 262

Figura 55. Infit y Outfit ZEMP. Subescala E ................................................................................................. 262

Figura 56. Infit y Outfit MNSQ. Subescala F ......................................................................................... 262

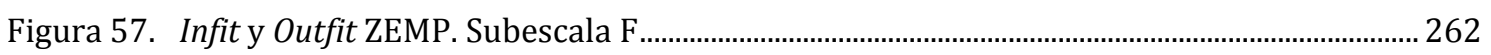

Figura 58. Infit y Outfit MNSQ. Subescala G............................................................................................. 262

Figura 59. Infit y Outfit ZEMP. Subescala G .......................................................................................... 262

Figura 60. Dificultad de los ítems por dimensiones .................................................................................... 264

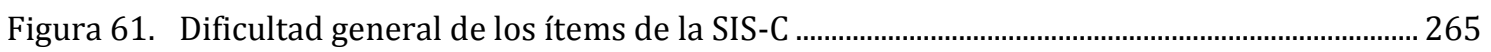

Figura 62. Curvas Características. Ítems Subescala A ………………………………………………..... 266

Figura 63. Curva Característica. Subescala A ……………………………………………………….... 266

Figura 64. Curvas Características. Ítems Subescala B ........................................................................... 266

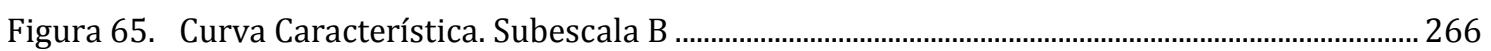

Figura 66. Curvas Características. Ítems Subescala C................................................................................ 267

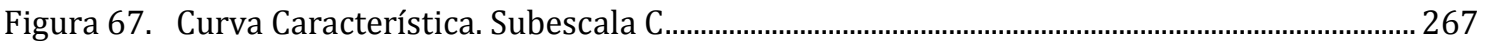


Figura 68. Curvas Características. Ítems Subescala D .............................................................................. 267

Figura 69. Curva Característica. Subescala D ....................................................................................... 267

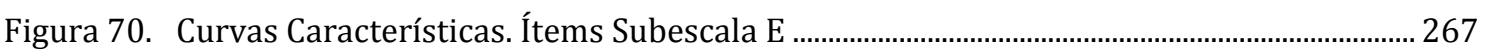

Figura 71. Curva Característica. Subescala E.......................................................................................... 267

Figura 72. Curvas Características. Ítems Subescala F............................................................................. 267

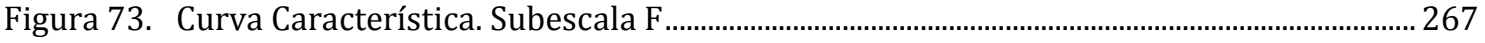

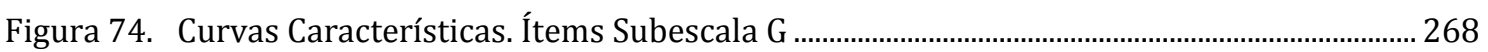

Figura 75. Curva Característica. Subescala G ………………………………………………………...... 268

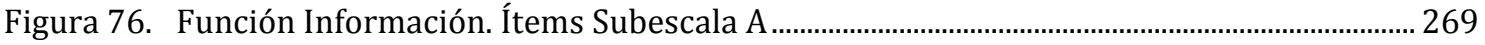

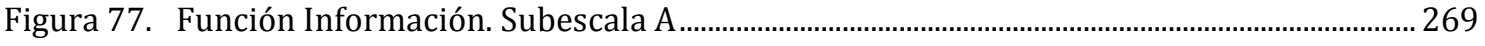

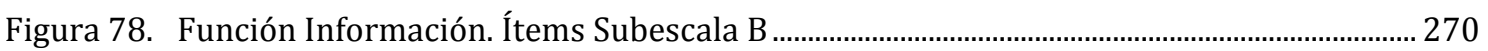

Figura 79. Función Información. Subescala B ............................................................................................ 270

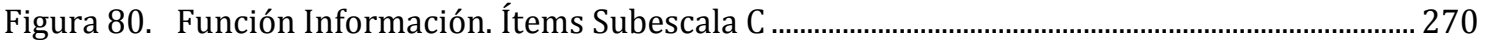

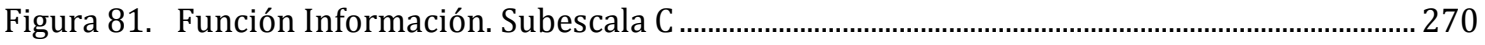

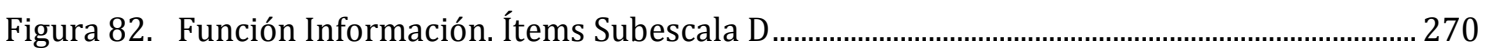

Figura 83. Función Información. Subescala D...…………………………………………………….... 270

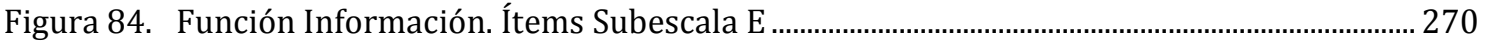

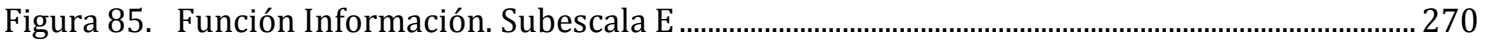

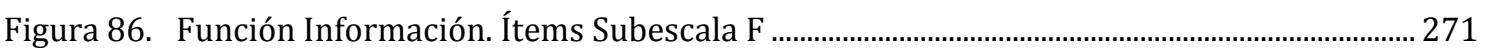

Figura 87. Función Información. Subescala F ……………………………………………………….... 271

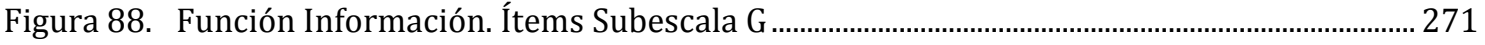

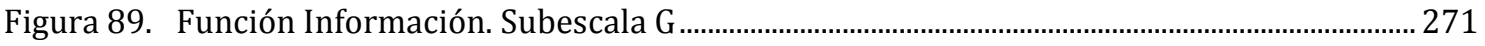

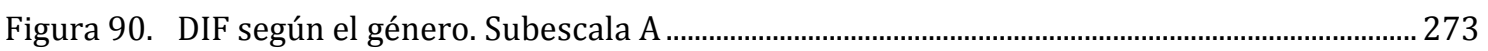

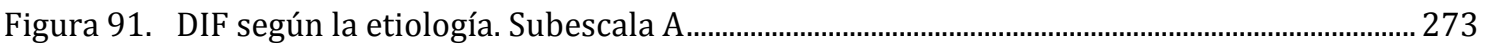

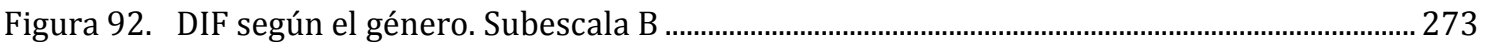

Figura 93. DIF según la etiología. Subescala B ....................................................................................... 273

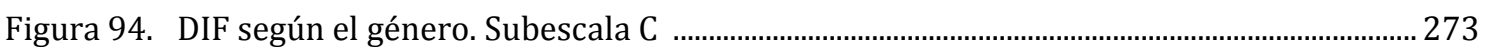

Figura 95. DIF según la etiología. Subescala C ....................................................................................... 273

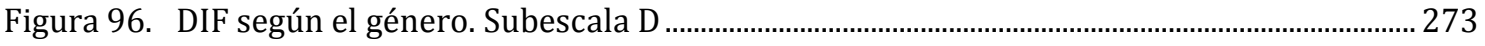

Figura 97. DIF según la etiología. Subescala D............................................................................................ 273

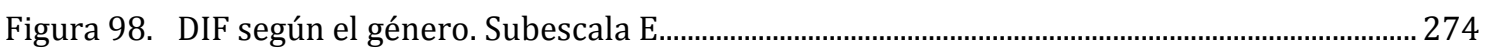

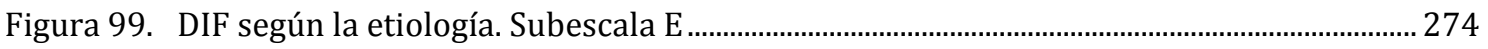

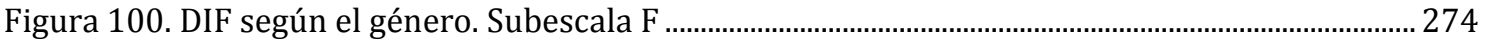

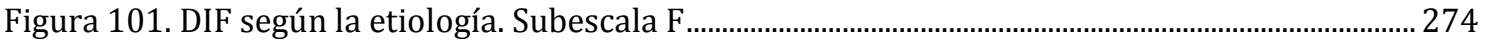

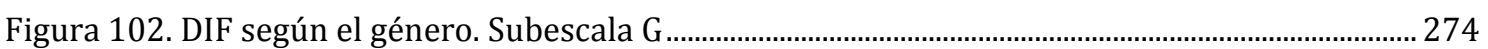

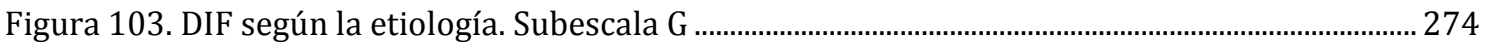





\section{PRESENTACIÓN DEL PROYECTO DE INVESTIGACIÓN}

La tesis doctoral presentada se encuentra estrechamente vinculada a dos proyectos de investigación financiados por programas estatales de $\mathrm{I}+\mathrm{D}+\mathrm{i}$ y dirigidos por uno de los directores de la tesis, Miguel Ángel Verdugo, siendo asimismo el codirector y la doctoranda miembros del equipo de investigación de ambos proyectos: (1) Desarrollo y validación de una escala de evaluación de necesidades de apoyo en niños y adolescentes con discapacidad intelectual (Ministerio de Economía y Competitividad, PSI2012-36278; 20132015); y (2) Elaboración de una escala de diagnóstico de conducta adaptativa para personas con discapacidad intelectual (Ministerio de Ciencia e Innovación, PSI2009-10953; 2010-2012), que derivó en la validación (e inminente publicación) en España del primer instrumento de diagnóstico de conducta adaptativa para personas con discapacidades intelectuales y del desarrollo.

El trabajo realizado se ha llevado a cabo desde el Instituto Universitario de Integración a la Comunidad (INICO), perteneciente a la Universidad de Salamanca, gracias a la ayuda concedida para la formación de personal investigador (FPI), financiada por el Ministerio de Ciencia e Innovación (BES-2010-036259). Asimismo, las ayudas para la realización de estancias breves en centros extranjeros obtenidas durante los años de vigencia de esta beca predoctoral (EEBB-I-2012-04202; EEBB-I-2013-06124; EEBB-I-1407992) han permitido alinear esta tesis con las líneas de investigación seguidas por la Asociación Americana de Discapacidades Intelectuales y del Desarrollo (American Association on Intellectual and Developmental Disabilities [AAIDD]) y otros países de Europa, aportando a esta tesis doctoral un matiz internacional.

Concretamente, el marco teórico general de la tesis doctoral corresponde con la actual concepción socioecológica y multidimensional de discapacidad intelectual, en la que los conceptos 'apoyo' y 'conducta adaptativa' cobran un papel fundamental en la mejora del funcionamiento humano y la calidad de vida de las personas con discapacidad intelectual. Desde este cambio conceptual, se identifica la creación de instrumentos de evaluación de necesidades de apoyo como el paso clave para diseñar y proporcionar apoyos individualizados que permitan lograr un cambio completo a nivel teórico y práctico. Sin embargo, en el contexto español solo contamos con un instrumento con suficientes garantías de validez, la Escala de Intensidad de Apoyos (Supports Intensity Scale [SIS]) para adultos con discapacidad intelectual, no existiendo en la actualidad ningún instrumento de estas características destinado a población infanto-juvenil. 
Con el objetivo de suplir esta demanda, esta tesis doctoral versa sobre el desarrollo de una escala de evaluación orientada a conocer el patrón y la intensidad de los apoyos de los niños y adolescentes con discapacidad intelectual, la Escala de Intensidad de Apoyos para Niños y Adolescentes (Supports Intensity Scale for Children [SIS-C]), basada en los supuestos de su homóloga para adultos (Thompson et al., 2004). Su desarrollo atiende a los criterios establecidos por la AAIDD para un instrumento de medida de estas características (Schalock et al., 2010): (1) es coherente al nuevo concepto de discapacidad intelectual; (2) mide la intensidad de apoyo en relación con el tipo, la frecuencia y al tiempo diario de apoyo; (3) tiene en cuenta los diversos contextos de la vida cotidiana y evalúa las necesidades de apoyo de personas con discapacidad intelectual de forma individualizada; (4) aporta información útil para la elaboración de planes individualizados de apoyos eficaces, que no supongan una provisión de apoyos inadecuada (por defecto o exceso) y facilita la mejora del funcionamiento individual y la calidad de vida; (5) permite una evaluación continua y flexible, adaptando los apoyos a los deseos de la persona y a los posibles cambios en los apoyos necesitados o nuevos intereses; (6) es robusta psicométricamente, permitiendo realizar una evaluación fiable y válida; y (7) se alinea con el proceso de evaluación de herramientas que evalúan otros constructos relacionados como el funcionamiento intelectual y la conducta adaptativa.

En este sentido, se expone en este trabajo la justificación del desarrollo de este instrumento así como el proceso seguido para su adaptación y validación en España. Para ello, se organiza la información en varios apartados, divididos a su vez en diferentes capítulos, que permiten proporcionar una estructura sencilla y coherente al proyecto de investigación realizado.

\section{PARTE I. JUSTIFICACIÓN TEÓRICA}

La tesis doctoral presentada comienza con un primer apartado en el que se desarrolla el marco teórico general, conceptualizando la discapacidad intelectual y aportando evidencias (teóricas y prácticas) de la importancia de evaluar y proporcionar apoyos individualizados para mejorar el bienestar de esta población. Para la elaboración de esta primera parte se han utilizado varias fuentes documentales (artículos de investigación, libros, capítulos de libros, tesis doctorales, trabajos de grado y actas de congresos) obtenidas a partir de búsquedas realizadas en diferentes bases de datos (ERIC, OVID, PSYCINFO, PsyBOOKS, PsycArticles, Psicodoc y SAGE Journals Online). 
Se ha revisado la literatura relacionada con el tema a través del cruce de diferentes descriptores (utilizados tanto en español como en inglés), entre los que destacan: discapacidad, discapacidad intelectual (los términos retraso mental y minusvalía fueron también utilizados con el objeto de obtener información de otras concepciones tradicionales), apoyo, intensidad de apoyo, necesidades de apoyo, paradigma, modelo, evaluación, instrumento, herramienta, escala, calidad de vida, niños, adolescentes (disability, intellectual disability, learning disability, mental retardation, handicap, support, support intensity, support needs, framework, model, assessment, evaluation, instrument, tool, scale, quality of life, children). Asimismo, se incluyeron en las búsquedas las siglas específicas SIS y SIS-C para encontrar estudios similares relacionados con el desarrollo de estos instrumentos en otros países. Con la información obtenida en esta revisión, se elaboró esta justificación teórica, compuesta por dos capítulos:

- Capítulo 1. Cambios en la concepción de discapacidad intelectual: incorporación, evolución e implicación actual de los apoyos. Este primer capítulo, centrado en los conceptos de discapacidad y apoyos, pretende dar respuesta a tres cuestiones fundamentales: (a) presentar la definición actual de discapacidad intelectual y comprender el cambio de mentalidad con respecto a paradigmas tradicionales; (b) clarificar los constructos de apoyos y necesidades de apoyo así como sus implicaciones dentro del campo de la discapacidad intelectual; y (c) examinar los resultados que se pretenden conseguir bajo este nuevo concepto de discapacidad y analizar su implantación en las organizaciones.

- Capítulo 2. El proceso de evaluación en personas con discapacidad intelectual: perfil y planificación de apoyos. El segundo capítulo se centra en la evaluación e intervención basada en apoyos y da respuesta a tres cuestiones relacionadas: (a) analizar los diferentes instrumentos utilizados en la evaluación de necesidades de apoyo de las personas con discapacidad; (b) presentar herramientas destinadas a evaluar otros constructos relacionados, como el cociente intelectual y la conducta adaptativa, estableciendo similitudes y diferencias con estos; (c) comprender la importancia de la evaluación de las necesidades como base para una provisión de apoyos eficaz; y (d) poner de manifiesto la carencia y utilidad del desarrollo de estos instrumentos, especialmente notable y relevante en el contexto infantil. 


\section{PARTE II. ESTUDIO EMPÍRICO}

En el segundo apartado de esta tesis se presenta el proceso y los resultados de la investigación empírica realizada, en la que se desarrolla el objetivo central sobre el que versa esta tesis doctoral: la adaptación y validación de la SIS-C en el contexto español. Para la elaboración de este estudio ha sido necesario realizar búsquedas bibliográficas en las fuentes anteriormente mencionadas, destinadas en este caso a identificar y comprender los mejores procedimientos de construcción y adaptación de herramientas de evaluación, atendiendo siempre a las directrices de la Comisión Internacional de los Tests (International Test Commission [ITC]).

Asimismo, ha sido necesario acceder a documentación en español e inglés que esclareciera la naturaleza de las diversas metodologías que se han utilizado para conocer la fiabilidad, validez, estructura, ajuste y calibración de la escala a través de las palabras clave: Teoría Clásica de los Tests, TCT (Classical Test Theory, CTT); Modelos de Ecuaciones Estructurales y Análisis Factorial Confirmatorio, AFC (Structural Equations Modeling, SEM, and Confirmatory Factorial Analysis, CFA); Teoría de Respuesta a los Ítems, TRI (Item Response Theory, IRT), y a diferentes programas estadísticos que permitieran realizar los análisis pertinentes (SPSS, Factor, Lisrel, Winsteps). En este sentido, la parte del estudio empírico queda dividida en dos apartados, que darán respuesta a objetivos diferenciados.

- Capítulo 3. Desarrollo de la SIS-C en el contexto español. En este capítulo se recoge el proceso de desarrollo de los ítems de la escala al contexto español, atendiendo a tres objetivos generales: (a) traducir y adaptar los ítems a través de la creación de varios comités de profesionales; (b) analizar la concordancia entre jueces con relación a la apropiada categorización de los ítems; y (c) realizar un estudio piloto que determine la pertinencia del uso del instrumento en España y aporte feedback sobre sus limitaciones, permitiendo realizar mejoras que optimicen la consiguiente administración del mismo.

- Capítulo 4. Funcionamiento y validación de la SIS-C. En este último capítulo empírico se presentan las propiedades psicométricas y la adecuación del uso del instrumento en el contexto español. Para ello, se realiza un análisis exhaustivo del funcionamiento de la SIS-C a partir de la aplicación del instrumento a una muestra de 814 participantes españoles siguiendo las principales metodologías de análisis actualmente utilizadas en la construcción de escalas: (1) TCT; (2) AFC; y (3) TRI. 


\section{DISCUSIÓN}

Finalmente, esta tesis doctoral se cierra con un apartado de discusión, donde se recogen los puntos fundamentales de la parte teórica y los resultados obtenidos en la parte empírica, aportando conclusiones generales en relación con toda la información presentada. De la misma manera, los puntos fuertes y las limitaciones de la investigación, así como las principales pautas para la mejora de la calidad del trabajo, son tratados en esta parte. A propósito de las futuras líneas de investigación, destaca la creación de baremos nacionales e internacionales y el uso de los datos de este trabajo en otro proyecto de investigación (financiado por la Junta de Castilla y León, SA120U13; 2013-2016), cuya finalidad reside en la comparación de las necesidades de apoyo de niños y adolescentes con discapacidad intelectual con las necesidades típicas de sus iguales sin discapacidad, lo que dará un enfoque más completo a la investigación realizada en este campo. 




\section{INTRODUCCIÓN A LA PARTE TEÓRICA}

Considerando el innegable papel que la sociedad desempeña en la vida de cualquier persona, han sido numerosos los filósofos y pensadores que desde hace más de mil años han intentado dar respuesta a las causas y consecuencias de la socialización del ser humano. Autores como Aristóteles o Tomás de Aquino argumentaban que la razón que convierte el ser humano en un animal social reside en el hecho de que no se baste a sí mismo para atender a las necesidades de la vida y precise de la ayuda de otros para conocer y conseguir lo necesario para su subsistencia y desarrollo. El ser humano nace en el seno de una sociedad determinada y condiciona su supervivencia a la ayuda de los demás durante un tiempo incomparablemente más largo que otros animales. Asimismo, aún cuando nuestra supervivencia no depende de los otros, los apoyos son una herramienta utilizada diariamente para aumentar y potenciar nuestra capacidad, para llegar allí donde no podríamos llegar solos y potenciar nuestro rendimiento. No obstante, a pesar de la importancia del apoyo social, reconocido como una de las causas fundamentales del desarrollo humano a nivel tanto filogenético como ontogenético, los apoyos no han sido utilizados para la mejora del funcionamiento y del bienestar de las personas con discapacidad hasta hace apenas 20 años.

La reciente aparición de los apoyos en el modo de comprender de la discapacidad ha supuesto un cambio radical con el pensamiento anterior. Tradicionalmente, la discapacidad era entendida desde una perspectiva organicista y psicopatológica que defendía que las limitaciones residían en el individuo, y los apoyos o la modificación del contexto no eran una vía tenida en cuenta para la mejora de la participación y el bienestar. Concretamente, la discapacidad intelectual se situaba como un trastorno en el cerebro de la persona, teniendo la evaluación un sentido predominantemente intelectual, con fines diagnósticos y la intervención un matiz de 'arreglo'. En este sentido, la comprensión socioecológica de la discapacidad defendida actualmente por los investigadores y profesionales de mayor influencia internacional en este campo (Luckasson et al., 1992; Luckasson et al., 2002; Schalock, 2004; Schalock, Luckasson et al., 2007; Schalock y Luckasson, 2013a, 2013b; Schalock et al., 2010; Thompson et al., 2009; Verdugo y Schalock, 2010; Wehmeyer et al. 2008) afirma que las posibles diferencias existentes entre las personas con y sin discapacidad residen, principalmente, en la intensidad del apoyo que la sociedad ha de proporcionar para garantizar su completa participación en las distintas actividades del entorno. 
Concretamente, a lo largo del capítulo 1 se pone de manifiesto la importancia del contexto en la vida de las personas con discapacidad. Asimismo, y de manera específica se relacionan los apoyos con las dimensiones del funcionamiento humano, el bienestar y la calidad de vida de las personas con discapacidad intelectual, reflejando el cambio conceptual y práctico sufrido en las últimas décadas en relación con diferentes ámbitos de la vida de las personas con discapacidad intelectual.

No obstante, a pesar del gran avance que supuso la llegada del paradigma socioecológico de la discapacidad, esta tesis no se centra únicamente en el paso a este nuevo paradigma, sino también en las modificaciones y mejoras científicas que se han ido dando progresivamente dentro del mismo. El modelo del funcionamiento humano, el modelo de los apoyos y el modelo de calidad de vida, elementos centrales del cambio conceptual de la discapacidad, han sido considerablemente mejorados en los últimos años, dando una perspectiva y un conocimiento cada vez más precisa sobre la discapacidad y promoviendo las prácticas basadas en la evidencia, que han derivado en el incremento de los resultados personales mejorados.

A partir de la reciente importancia otorgada al contexto como variable reguladora del funcionamiento y la calidad de vida de las personas con discapacidad intelectual, los apoyos se convierten en el elemento clave para lograr los resultados esperados, dando nombre al actual paradigma de apoyos en el que se enmarca el concepto de discapacidad intelectual. No obstante, debemos tener en cuenta que no todas las personas con discapacidad son iguales ni necesitan todos los apoyos disponibles en cada momento, por lo que los apoyos proporcionados deben ser individualizados. Para poder conseguir un verdadero cambio, tanto la nueva comprensión de la discapacidad intelectual como sus consecuencias prácticas deben llegar a las organizaciones que trabajar diariamente con las personas con discapacidad intelectual. En este sentido, resulta evidente la importancia de evaluar de manera específica las características individuales y contextuales de cada persona con el objeto de ayudar a los profesionales en el desarrollo de planes individualizados basados en necesidades e intereses personales.

En el capítulo 2 se ofrecen algunas de las mejoras en la evaluación de las personas con discapacidad, incluyendo su importancia en el diagnóstico, la clasificación y la elaboración de perfiles de apoyos. Se presentan, además, los principales avances relacionados con la planificación de apoyos, proporcionando ejemplos de buenas prácticas y considerando la importancia de su alineamiento con la evaluación de la calidad de vida. 
Sin embargo, la evaluación de las personas con discapacidad intelectual es aún un tema pendiente, especialmente en determinados colectivos, consecuencia específica de la falta de instrumentos de evaluación que: (a) sean capaces de evaluar con precisión constructos de reciente aparición en el campo de la discapacidad intelectual (e.g., necesidades de apoyo), lo que ha propiciado que la evaluación siga muy centrada en elementos tradicionales como el cociente intelectual; (b) estén orientados a la evaluación de niños y adolescentes, ya que el desarrollo de instrumentos ha estado fuertemente centrado en adultos durante muchos años; y (c) hayan sido desarrollados y validados de manera específica con muestra española, lo que ha supuesto una gran limitación para las organizaciones de nuestro contexto.

Estos tres criterios, desarrollados en diferentes argumentaciones a lo largo de la parte teórica, evidencian la importancia de desarrollar un instrumento de evaluación de necesidades de apoyo para niños y adolescentes con discapacidad intelectual en el contexto español, objetivo que formará el eje central de la parte empírica de esta tesis doctoral. 



\section{Capitulo}

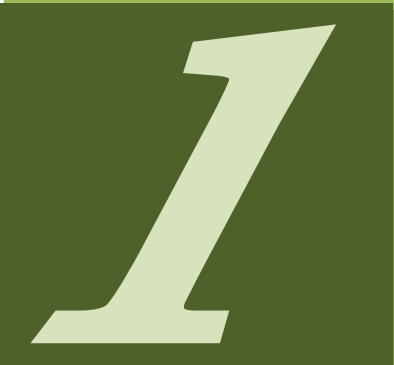

Cambios en la concepción de discapacidad intelectual: incorporación, evolución e implicación actual de los apoyos 



\section{CAMBIOS EN LA CONCEPCIÓN DE DISCAPACIDAD INTELECTUAL: INCORPORACIÓN, EVOLUCIÓN E IMPLICACIÓN ACTUAL DE LOS APOYOS}

En este primer capítulo se realiza una aproximación a la evolución de la concepción de discapacidad intelectual, dando un énfasis especial a las aportaciones de la Asociación Americana de Discapacidades Intelectuales y del Desarrollo (American Association on Intellectual and Developmental Disabilities [AAIDD]), considerada el mayor referente internacional de investigación e intervención con las personas con discapacidad intelectual. El objetivo de este planteamiento longitudinal reside en la importancia de obtener una visión completa y global del marco histórico de la discapacidad intelectual, comprendiendo de manera exhaustiva los cambios e implicaciones (teóricas y prácticas) que ha supuesto la presencia central de los apoyos en el modelo actual.

De manera inicial, se describen los cambios que ha sufrido el paradigma subyacente a la discapacidad, concepto general dentro del que se engloban las discapacidades intelectuales y del desarrollo. El concepto de discapacidad ha evolucionado de una perspectiva psicopatológica centrada en los déficits a una perspectiva multidimensional y socioecológica centrada en el papel que los apoyos y el contexto tiene en el bienestar de la persona. Estos cambios en la concepción de discapacidad tienen una relación directa con la 'psicología positiva' (Schalock, 2004; Shogren, Wehmeyer, Buchanan y López, 2006), definida en 1998 por Seligman como el estudio científico del bienestar y las fortalezas humanas. Esta nueva comprensión, quedó reflejada en los constructos establecidos y ha sido plasmada en los distintos términos y definiciones utilizados. Asimismo el diagnóstico de discapacidad intelectual ha sufrido cambios, siendo la conducta adaptativa el elemento clave en la ruptura con el diagnóstico tradicional de la discapacidad intelectual, basado casi con exclusividad en el déficit intelectual.

Sin embargo, no basta con conocer el cambio al nuevo concepto socioecológico para entender la discapacidad intelectual desde la perspectiva actual, sino que también es preciso conocer los cambios que han aparecido dentro del nuevo paradigma y que, aún hoy, siguen modificando el modo de entender, evaluar e intervenir con las personas con discapacidad. Por ello, destacamos y describimos posteriormente en este capítulo tres modelos que han surgido en los últimos años dentro del campo de la discapacidad y que reflejan la importancia del contexto como elemento clave en el desarrollo de las personas con discapacidad intelectual: el modelo del funcionamiento humano, el modelo de apoyos y el modelo de calidad de vida. 
- En primer lugar, se presenta la reciente aparición y evolución de los modelos del funcionamiento humano de la AAIDD (Luckasson et al., 1992; Luckasson et al., 2002; y Schalock et al., 2010) y de la Organización Mundial de la Salud (OMS) $(1980,2001)$ como marco teórico global de la discapacidad, desde los que también se pone de manifiesto la envergadura del cambio subyacente.

- A continuación, partiendo de la importancia que el contexto y los apoyos van adquiriendo en el nuevo planteamiento de discapacidad, se detalla la influencia que los apoyos tienen en la vida cotidiana de las personas con discapacidad intelectual y su mayor presencia. Se describe el modelo de apoyos propuesto por la AAIDD, destacando las modificaciones sufridas en los últimos años para dar una mayor cabida a los apoyos individualizados. Desde la aplicación del concepto de apoyos en el ámbito de la discapacidad, estos se han convertido en una herramienta de presencia obligada en todas las organizaciones que trabajan con personas con discapacidad; en este sentido, se especifican también en este punto algunas de las implicaciones prácticas y criterios básicos que han de tenerse en cuenta para asegurar la consecución de los resultados deseados.

- En último lugar, se aborda el concepto de calidad de vida como uno de los objetivos prioritarios en el trabajo con cualquier persona con discapacidad. Este concepto surge en el ámbito de la discapacidad como fruto de una visión más positiva de la misma, derivada de una mejor comprensión y de las evidencias de la mejora en el funcionamiento que supone la provisión y mantenimiento de apoyos individualizados. Asimismo, se ofrece una justificación sobre la elección del modelo de calidad de vida de Schalock y Verdugo (2002) como línea base para la concepción, la medición y la aplicabilidad de este concepto.

Posteriormente, tras un repaso general sobre el cambio acontecido en los últimos años con relación a la comprensión teórica de la discapacidad intelectual, se reserva un apartado al consecuente cambio organizacional derivado del mismo. Así, para finalizar, este capítulo se cierra con una serie de conclusiones que ponen de manifiesto la relación práctica existente entre los tres modelos planteados y su papel en la satisfactoria implantación del paradigma de apoyos dentro del ámbito específico de la discapacidad intelectual. Asimismo, se exponen en este apartado final las relaciones existentes entre los principales elementos de esta nueva comprensión: fortalezas, apoyos, contexto y calidad de vida, describiendo la mejora del cambio en la atención de los servicios dirigidos a las personas con discapacidad intelectual a lo largo de los últimos años. 


\subsection{DEL PARADIGMA TRADICIONAL AL PARADIGMA SOCIAL EN EL ÁMBITO DE LA DISCAPACIDAD: EVOLUCIÓN Y CONCEPCIÓN ACTUAL}

La forma de entender la discapacidad ha evolucionado de manera significativa a lo largo de la historia, marcando las actitudes e interacciones de la sociedad hacia las personas con discapacidad. Mercer (1992) defiende que los diferentes modos de entender la discapacidad se han ido moviendo desde un paradigma funcionalista, objetivista y basado en la homogeneidad de la población (con unas características determinadas que la persona con discapacidad ha de tener) a un paradigma social que recoge diferentes modelos y conceptos y que se enmarca dentro de una población heterogénea, donde todos tenemos capacidades diferentes que deben ser atendidas y potenciadas por el contexto por medio de los apoyos.

Scheerenberger (1983) afirma que hay una historia de la deficiencia/discapacidad desde los albores de la humanidad, por lo que resulta difícil delimitar en periodos claros esa amplia historia. Sin embargo, a pesar de las limitaciones y el reduccionismo derivado de establecer puntos de corte específicos que no reflejen el progreso del cambio de concepciones, numerosos autores de finales del siglo $\mathrm{XX}$ intentaron identificar $\mathrm{y}$ corroborar diferentes modos de entender la discapacidad en torno a una serie de paradigmas o enfoques (e.g., Aguado, 1995; Casado, 1991; DeJong, 1989; Pledger, 2003; Puig de la Bellacasa, 1990; Scheerenberger, 1983, Verdugo, 1994). A pesar de las diferentes disciplinas de trabajo de estos autores dentro del campo de la discapacidad y los diferentes momentos en que los paradigmas han sido establecidos o estudiados, se puede observar una relación muy estrecha entre las delimitaciones que marcan los modos de entender y atender a la discapacidad propuestos.

En general, la investigación actual (e.g., Jiménez y Huete, 2010; Palacios, 2008; Toboso y Arnau, 2008; Verdugo, 1994, 2006), partiendo de las aportaciones de estos autores, acepta la existencia de tres grandes paradigmas: (1) el paradigma tradicional; (2) el paradigma medico-rehabilitador; y (3) el paradigma social. A continuación, presentamos una síntesis (Tabla 1) que recoge las aportaciones de todos los autores mencionados. Esta tabla ha sido elaborada con el objetivo de clarificar las relaciones y descripciones desarrolladas por los autores mencionados sobre las características específicas de cada periodo con relación a tres categorías o enunciados clave en el cambio de paradigma: (a) la explicación de la discapacidad; (b) la respuesta de la sociedad; y (c) la situación de las personas con discapacidad. 
Tabla 1. Evolución de los paradigmas de la discapacidad

\begin{tabular}{|c|c|c|c|}
\hline $\begin{array}{l}\text { PARADGIMA } \\
\text { DISCAPACIDAD }\end{array}$ & Explicación de la discapacidad & Respuesta Social & $\begin{array}{l}\text { Situación de las } \\
\text { personas con } \\
\text { discapacidad }\end{array}$ \\
\hline \multirow[t]{2}{*}{$\begin{array}{l}\text { Paradigma } \\
\text { Tradicional } \\
\text { Refleja la } \\
\text { sociedad antigua } \\
\text { y llega hasta } \\
\text { finales del s. XIX }\end{array}$} & $\begin{array}{l}\text { Considera que la discapacidad tenía } \\
\text { su origen en causas míticas o } \\
\text { religiosas (castigo de Dios, obra del } \\
\text { demonio...), y que las personas con } \\
\text { discapacidad eran una carga para la } \\
\text { sociedad, sin nada que aportar a la } \\
\text { comunidad, por lo que debían ser } \\
\text { retiradas de la sociedad. }\end{array}$ & $\begin{array}{l}\text { (a)Eliminar u (b) ocultar } \\
\text { algo que se percibe } \\
\text { como una desviación } \\
\text { indeseada, dando } \\
\text { asistencia básica para la } \\
\text { supervivencia. }\end{array}$ & $\begin{array}{l}\text { Se encuentran en una } \\
\text { posición de } \\
\text { marginación, } \\
\text { inferioridad, rechazo. }\end{array}$ \\
\hline & $\begin{array}{l}\text { CENTRADO EN EL DÉFITICT } \\
\text { INDIVIDUAL }\end{array}$ & PASIVA & SIN DERECHOS \\
\hline \multirow[t]{2}{*}{$\begin{array}{l}\text { Paradigma } \\
\text { Médico- } \\
\text { Rehabilitador } \\
\text { Surge a } \\
\text { principios del } \\
\text { siglo XX }\end{array}$} & $\begin{array}{l}\text { Se empieza a comprender que la } \\
\text { discapacidad tiene una causa } \\
\text { científica y no sobre natural. }\end{array}$ & $\begin{array}{l}\text { Las respuestas se basan } \\
\text { en la atención médica } \\
\text { como base no sólo de la } \\
\text { supervivencia, sino } \\
\text { también de la } \\
\text { supervivencia y la } \\
\text { rehabilitación. }\end{array}$ & $\begin{array}{l}\text { Las personas con } \\
\text { discapacidad } \\
\text { son objeto de } \\
\text { actuaciones } \\
\text { tecnificadas, que se } \\
\text { programan sin tener en } \\
\text { cuenta sus preferencias } \\
\text { y deseos. }\end{array}$ \\
\hline & $\begin{array}{l}\text { CENTRADO EN EL DÉFITICT } \\
\text { INDIVIDUAL }\end{array}$ & ACTIVA & SIN DERECHOS \\
\hline \multirow[t]{2}{*}{$\begin{array}{l}\text { Paradigma } \\
\text { Social } \\
\text { Surge a finales } \\
\text { del siglo XX }\end{array}$} & $\begin{array}{l}\text { La discapacidad no es una } \\
\text { consecuencia religiosa ni científica, } \\
\text { sino social. El problema se ubica, } \\
\text { por tanto, dentro de la sociedad en } \\
\text { vez de dentro del individuo. }\end{array}$ & $\begin{array}{l}\text { Persigue la equiparación } \\
\text { de oportunidades, la no } \\
\text { discriminación y la } \\
\text { participación plena } \\
\text { (educación, empelo...). } \\
\text { Se promueve la } \\
\text { autonomía personal y la } \\
\text { vida independiente. } \\
\text { Se relaciona por primera } \\
\text { vez con los apoyos y la } \\
\text { calidad de vida (relación } \\
\text { con el modelo de apoyos } \\
\text { y de calidad de vida). }\end{array}$ & $\begin{array}{l}\text { Las personas con } \\
\text { discapacidad deben ser } \\
\text { provistas de apoyos } \\
\text { individualizados que } \\
\text { atiendan a sus intereses } \\
\text { y necesidades } \\
\text { individuales, } \\
\text { minimizando asimismo } \\
\text { las barreras demandas } \\
\text { del entorno para poder } \\
\text { participar en el entorno } \\
\text { normalizado. }\end{array}$ \\
\hline & $\begin{array}{l}\text { CENTRADO EN LAS FORTALEZAS } \\
\text { INTERACCION PERSONA-AMBIENTE }\end{array}$ & ACTIVA & CON DERECHOS \\
\hline
\end{tabular}

Esta clasificación resulta de gran utilidad para comprender la evolución en la comprensión de las personas con discapacidad y poder entender mejor el cambio al que estamos asistiendo en la actualidad. Sin embargo, es innegable que esta división no refleja con precisión las implicaciones de los avances conseguidos en las últimas décadas. Por ello, resulta interesante detallar en mayor profundidad la evolución sufrida en la conceptualización de la discapacidad desde el modelo de la rehabilitación hasta el modelo socioecológico (incluyendo la evolución acontecida dentro del mismo hasta llegar a la comprensión actual), ya que ha supuesto un gran esfuerzo y un cambio constante en el que poco a poco se han adquirido ventajas y privilegios para las personas con discapacidad que han sido progresivamente ampliadas al campo de la discapacidad intelectual. 


\subsection{1. Últimos avances en el concepto de discapacidad y su repercusión en el campo de la discapacidad intelectual}

La aparición de la importancia de los apoyos en la vida de las personas con discapacidad se produjo a mediados de los años 70, empezando a forjar las primeras líneas del cambio del paradigma médico hacia un modelo más social. Aunque a mediados del siglo XX aparecía la Declaración de los Derechos Humanos (Naciones Unidas, 1948), en 1975 fue necesario divulgar y concretar específicamente el significado de principios como el de igualdad de oportunidades en relación con el colectivo de personas con discapacidad intelectual (Declaración de los Derechos del Retrasado Mental, ONU), relacionándose directamente estas aportaciones con el surgimiento del principio de normalización (Wolfensberger, 1972) y otros principios como el de integración y desinstitucionalización. La promoción de las vidas normalizadas potenció que las personas con discapacidad fueran trasladadas progresivamente desde entornos segregados a entornos comunitarios e integrados en la sociedad (Braddock y Parish, 2002), de tal manera que se hizo necesario identificar las demandas de los nuevos contextos y los apoyos que potenciaran las capacidades y compensasen las deficiencias de esta población para poder hacer efectiva esa integración.

No obstante, fue necesario que transcurrieran más de dos décadas para que las Normas Uniformes sobre la igualdad de oportunidades para las personas con discapacidad (ONU, 1993) dieran lugar a la adopción de un verdadero compromiso moral y político por parte de los gobiernos de cara a poner en marcha medidas específicas para defender los derechos y mejorar la calidad de vida de las personas con discapacidad intelectual (Navas, Gómez, Verdugo y Schalock, 2012; Verdugo, Navas, Gómez y Schalock, 2012). En este sentido, hasta la última década del siglo XX no empiezan a verse los cimientos del nuevo paradigma, que supondría un verdadero cambio en la concepción, evaluación e intervención en la discapacidad intelectual (Verdugo, 1994).

En resumen, Schalock y Verdugo (2013) afirman que las tres últimas décadas han supuesto un punto de inflexión en el modo de ver la discapacidad en general, aunque ha tenido un especial importancia en el ámbito de la discapacidad intelectual, que venía sufriendo un cierto retraso con respecto a la atención especializada recibida por personas con otras discapacidades tras la segunda Guerra Mundial. Concretamente, estos autores identifican tres fases: (a) Fase I (entre 1960 y principios de los 1970): dudas y dificultades, caracterizadas por ver la discapacidad como un defecto de la persona y la segregación de las personas con discapacidad intelectual como modo principal de vida.; (b) Fase II (entre 
finales de los 70 y principios de los 80 ): se genera un desacuerdo entre el paradigma presesenta, las observaciones de la vida de las personas con discapacidad intelectual y las predicciones no válidas con respecto a su potencial. Empieza un movimiento basado en los derechos civiles y la desinstitucionalización, el enfoque en la conducta adaptativa y el potencial de aprendizaje de las personas, el movimiento de autodefensa, y la exitosa integración de algunas personas en entornos normalizados; y (c) Fase III (desde mediados de los 80 hasta la actualidad): como resultado de la fase II, empieza a emerger un nuevo paradigma basado en los desarrollos científicos y sociales que envuelven la vida de las personas con discapacidad desde una perspectiva de apoyos.

Esta nueva concepción, que aboga por los derechos de las personas con discapacidad y la importancia de su participación en entornos normalizados, empieza a reflejarse en las políticas sociales, como la Ley de Integración Social del Minusválido (LISMI [Ley 13/1982, BOE de 7 de abril]) o la Ley de Igualdad de Oportunidades, No Discriminación y Accesibilidad Universal de las personas con discapacidad (LIONDAU [Ley 51/2003, BOE de 2 de diciembre]). Asimismo, se empiezan a desarrollar normativas específicas para garantizar los derechos de los niños y adolescentes con discapacidad intelectual, elaborándose, prioritariamente, pautas concretas a seguir en el contexto educativo (Informe Warnock, 1990; Declaración de Salamanca, 1994).

\subsubsection{Cambios en el modelo social: apoyos para la inclusión}

El énfasis contextual que aporta esta nueva concepción de la discapacidad incluye los apoyos como medio para garantizar que aquellas características personales y ambientales difícilmente modificables (e.g., edad, lenguaje, cultura...) no tengan un impacto negativo en la vida de las personas con discapacidad (Shogren, Luckasson y Schalock, 2014). En este sentido, se comenzaron a realizar revisiones sobre la eficacia de los apoyos para la integración de personas con discapacidad en contextos normalizados, poniéndose de manifiesto que la intervención seguía estando dirigida a la adaptación de la persona a un entorno determinado.

Así, aparece el concepto 'inclusión' (que progresivamente sustituirá al de 'integración') como propuesta orientada a la modificación del contexto (provisión de facilitadores y eliminación de barreras) por encima del cambio de la persona. Desde esta perspectiva, la diversidad debe ser aceptada y atendida desde todos los contextos, resultando clave su importancia en el contexto escolar (Arnaiz, 2003; Moriña, 2004; 
Muntaner, 2010) como base para lograr una completa inclusión social. Recientemente, la Convención sobre los Derechos de las Personas con Discapacidad (Naciones Unidas, 2006) ha establecido obligaciones para proteger los derechos de las personas con discapacidad y alcanzar su igualdad, autonomía y participación a través de la inclusión. En la Tabla 2, se observan las principales diferencias entre los conceptos 'integración' e 'inclusión'.

Tabla 2. Diferencia entre los términos Integración e Inclusión. Evolución del modelo social (adaptado de Arnaiz, 2003; Moriña, 2004)

\begin{tabular}{|c|c|c|}
\hline & \multicolumn{2}{|c|}{ MODELO SOCIAL } \\
\hline & INTEGRACIÓN SOCIAL & INCLUSIÓN SOCIAL \\
\hline Foco & Centrado en el diagnóstico & $\begin{array}{l}\text { Centrado en la disminución de } \\
\text { discrepancias capacidades/entorno }\end{array}$ \\
\hline Principios & $\begin{array}{l}\text { Basado en los principios de igualdad } \\
\text { y competición }\end{array}$ & $\begin{array}{l}\text { Basado en principios de equidad, } \\
\text { cooperación y solidaridad (valoración de } \\
\text { las diferencias como oportunidad de } \\
\text { enriquecimiento de la sociedad) }\end{array}$ \\
\hline Inserción & $\begin{array}{l}\text { La inserción es parcial y } \\
\text { condicionada }\end{array}$ & La inserción es total e incondicional \\
\hline Transformación & Exige solo cambios superficiales & $\begin{array}{l}\text { Exige rupturas en los sistemas } \\
\text { (transformaciones profundas) }\end{array}$ \\
\hline Ubicación & $\begin{array}{l}\text { Ubica a las personas con } \\
\text { discapacidad en entornos específicos } \\
\text { para desarrollar habilidades } \\
\text { necesarias en la vida normalizada }\end{array}$ & $\begin{array}{l}\text { Se centra en el apoyo social, } \\
\text { proporcionado desde el contexto } \\
\text { normalizado }\end{array}$ \\
\hline $\begin{array}{l}\text { Concepción de } \\
\text { las limitaciones }\end{array}$ & $\begin{array}{l}\text { Disfraza las limitaciones para } \\
\text { aumentar la posibilidad de inserción. }\end{array}$ & $\begin{array}{l}\text { No disfraza las limitaciones, porque son } \\
\text { reales. }\end{array}$ \\
\hline Quién se adapta & $\begin{array}{l}\text { Se basa en la normalización de la } \\
\text { vida del alumno } \\
\text { El alumno se adapta a la vida }\end{array}$ & $\begin{array}{l}\text { Plantea el reconocimiento y la } \\
\text { valoración de la diversidad como una } \\
\text { realidad y un derecho humano }\end{array}$ \\
\hline & normalizada & El contexto se abre para abarcar a todos \\
\hline
\end{tabular}

En este sentido, algunos autores (Palacios y Romañach, 2006; Romanach, 2010; Romanach y Lobato, 2005; Rodríguez y Ferreira, 2008) afirman que las diferencias existentes entre el modo en que se está empezando a entender la discapacidad actualmente y la concepción con la que se inició el paradigma social supone cambios tan sustanciales que se puede hablar del surgimiento de un cuarto paradigma, el paradigma de de la diversidad, que reconoce definitivamente las diferencias humanas y utiliza el término diversidad funcional para hacer referencia a cualquier persona, superando la dicotomía capacidades/discapacidades que se mantiene en el modelo social.

Sin embargo, mientras que el termino discapacidad aproxima a todas las personas en la medida que el ser humano pasa por diferentes fases de su vida presentando algún tipo de discapacidad (física, sensorial, mental...) causada por limitaciones más o menos 
estables (envejecimiento, situación transitoria...), el término 'diversidad' resulta inespecífico en su referencia a esta población, y su utilización es más política o de divulgación que un criterio científico útil para la identificación de necesidades y la provisión de apoyos (Verdugo, 2003a).

Tanto a la ambigüedad de la definición y evaluación del término 'diversidad funcional' como a la falta de investigación en este ámbito (debido, en parte, a su reciente aparición), este cambio conceptual se ha asentado más como un compromiso moral que como un cambio de paradigma (Ferreira, 2008). Actualmente desde el ámbito social se aboga por la implantación de un enfoque centrado en la diversidad, pero considerando éste como una matización y mejora del constructo de 'discapacidad'. Se entiende que no se trata de un cambio de paradigma ya que ambas perspectivas defienden una conceptualización de la discapacidad que priorice la importancia de la provisión individualizada de apoyos desde una configuración socioecológica como recurso para asegurar los derechos y la autodeterminación de las personas con discapacidad.

\subsubsection{Hacia el término y constructo de 'discapacidad intelectual'. Influencia de la AAIDD en el cambio}

Desde los inicios, la importancia del nombre utilizado para denominar esta condición ha sido un tema de debate debido a la influencia recíproca de la terminología, la investigación y la actitud de la sociedad; es por ello que ha habido un cambio constante de la nomenclatura utilizada para designar las limitaciones intelectuales, reflejando el mejor entendimiento de la misma y transmitiendo una visión más positiva de la discapacidad.

Luckasson y Reeve (2001) señalaron cinco factores importantes que se han de tener en cuenta cuando se elige un término: (1) debe ser específico, referirse a una entidad única, permitir la diferenciación de otras entidades y mejorar la comunicación; (2) los distintos grupos implicados deben utilizarlo de forma consistente; (3) tiene que representar de forma adecuada el conocimiento actual y poder incorporar el conocimiento nuevo según ocurren los avances científicos; (4) ha de ser lo suficientemente robusto en su operacionalización para permitir su uso con múltiples propósitos, incluyendo definir, diagnosticar, clasificar y planificar los apoyos; y (5) debe reflejar un componente esencial capaz de dar nombre y comunicar valores importantes hacia un grupo. Buscando dar respuesta a las nuevas necesidades sociales, la terminología utilizada para indicar la actual 'discapacidad intelectual' ha cambiado históricamente (Schalock, Luckasson et al., 2007). 
A principios del siglo XX, los términos más utilizados eran 'debilidad mental', 'imbecilidad', 'minusvalía mental' y 'subnormalidad' (Goodey, 2005; Mercer, 1992; Schroeder, Gertz y Velázquez, 2002; Stainton, 2001; Trent, 1994; Wright y Digby, 1996). Dejando atrás esta concepción peyorativa, en el siglo XX los dos términos con mayor presencia social usados para nombrar la condición han sido 'deficiencia mental' (19081958) y 'retraso mental' (1959-2009). No obstante, aquellos términos inapropiados que tuvieron una gran presencia en el ámbito internacional (e.g., 'subnormalidad'), así como otros que surgieron particularmente en España como 'oligofrenia' y 'disminución mental', pueden ser escuchados todavía hoy en nuestro contexto de manera marginal (Verdugo, Schalock, Thompson y Guillén, 2013).

La evolución en la concepción de la discapacidad intelectual puede ilustrarse de manera rápida y sencilla en los diferentes nombres utilizados por la actual AAIDD en los últimos 100 años, así como en los nombres utilizados en sus manuales, que fueron modificados para adaptarse a la propuesta del cambio terminológico de esta condición.

En el siglo XIX, aparece por primera vez una distinción clara entre los términos enfermedad mental y deficiencia mental y llegan las primeras instituciones orientadas a la intervención terapéutica (Aguado, 1995; Braddock y Parish, 2002), separándose así la investigación e intervención de estos trastornos. Así, a finales del siglo XIX se crea uno de los primeros grupos de profesionales centrados en la prevención y tratamiento de personas con limitaciones intelectuales, denominada en 1876 Asociación de Oficiales Médicos de la Institución Americana para Personas Idiotas y Débiles Mentales (Association of Medical Officers of American Institutions for Idiotic and Feeble Minded Persons), que cambiará su nombre a principios del siglo XX (1906) por el de Asociación Americana para el estudio de los Débiles Mentales (American Association for the Study of the Feeble-Minded [AASFM]).

Posteriormente, tras la publicación en 1993 del primer manual encargado de definir y clasificar esta condición, que ya recoge el término 'deficiencia', los miembros de la AAFSM votan por el cambio de nombre a la Asociación Americana de Deficiencia Mental (American Association on Mental Deficiency [AAMD]). Este nuevo término ofrecería una visión menos negativa de las personas y dejaría atrás una concepción estigmatizadora de la discapacidad, dando así paso a un paradigma rehabilitador, que conservará el nombre hasta finales del siglo XX, con la llegada incipiente del paradigma de apoyos. 
A partir de mediados del siglo XX, con la llegada de la Declaración de los Derechos Humanos, se incorpora la importancia de los apoyos en la concepción de las personas con limitaciones en las diferentes ediciones del manual, la AAMD propondrá como terminología más aceptada 'retraso mental', y en 1987 la AAMD adoptará el nombre Asociación Americana sobre el Retraso Mental (American Association on Mental Retardation [AAMR]). Aunque a finales del siglo XX ya se empieza a discutir un nuevo cambio de terminología por las connotaciones negativas que había adquirido el término 'retraso', afirmando que éste no comunica dignidad o respeto y que, de hecho, a menudo da lugar a la devaluación de estas personas (Finlay, Lyons y Taylor, 2005; Hayden y Nelis, 2002; Rapley, 2004; Snell y Voorhees, 2006).

Finalmente, en 2007, la AAMR cambia su nombre de manera coherente a la nueva concepción, quedando sustituida por el de Asociación Americana de Discapacidades Intelectuales y del Desarrollo (American Association on Intellectual and Developmental Disabilities [AAIDD]). En 2010, tras dos décadas de debate sobre la necesidad e importancia de cambiar el término por el carácter peyorativo con el que estaba empezando a utilizarse el término retraso mental, se publica la undécima edición del manual de la asociación, donde finalmente se recoge el término discapacidad intelectual, relegando por completo el término 'retraso mental' como categoría diagnóstica y dando más valor (aunque todavía solo de manera teórica) a la evaluación de la conducta adaptativa (Schalock y Luckasson, 2004; Glidden, 2006; Greenspan, 2006). Aunque ambos términos hacen referencia al mismo grupo de población, el término 'discapacidad intelectual' es más conveniente por las siguientes razones (Schalock, Luckasson et al., 2007; Verdugo y Schalock, 2010): (a) refleja el cambio hacia un constructo socioecológico; (b) se alinea mejor con las prácticas profesionales actuales, centradas en conductas funcionales y factores contextuales; (c) proporciona un fundamento lógico para la provisión de apoyos; (d) es menos ofensivo para las personas con discapacidad; y (e) es más consistente con la metodología internacional.

Asimismo, Wehmeyer et al. (2008) abogan por una doble definición del término (operativa y constitutiva), que no solo cambie el modo en que se trabaja con esta población, sino también la forma en que se entiende y se reacciona ante las personas con discapacidad intelectual. A lo largo de este capítulo se hará referencia a ambas, a la operativa, en la medida que se trabaje con los criterios diagnósticos y a la constitutiva que enmarca a la discapacidad dentro de modelos multidimensionales y socioecológicos que permiten la relación de este constructo con otros dentro de un conocimiento más general. 


\subsection{IMPLICACIONES DEL CAMBIO EN EL DIAGNÓSTICO}

Las modificaciones realizadas en la concepción de la discapacidad intelectual han sido incorporadas a los criterios diagnósticos establecidos por la AAIDD. En su mayor parte, estos criterios han sido aceptados por la Asociación Psiquiátrica Americana (American Psychiatric Association [APA]) y la Organización Mundial de la Salud (OMS), cuyos sistemas de clasificación cuentan con un gran reconocimiento y seguimiento en ámbitos científicos y profesionales internacionales. A pesar de que el término haya ido cambiando con el tiempo para irse adaptando a un modelo socioecológico que recoge todos los aspectos que intervienen en las limitaciones o dificultades de la persona, podemos observar que dicha definición mantiene las raíces de sus inicios.

En 1952, la APA publica el primer Manual de Diagnóstico de Trastornos Mentales (Diagnostic and Statistical Manual of Mental Disorders [DSM]) como una modificación de la Clasificación Internacional de las Enfermedades (CIE-6 [OMS, 1948]), en la que por primera vez aparecen de manera explícita los trastornos mentales. En este primer manual, ya aparecían los tres criterios de diagnóstico fundamentales para la discapacidad intelectual: (1) funcionamiento intelectual, (2) conducta adaptativa y (3) edad de aparición durante el desarrollo. Desde entonces, ha habido numerosos cambios en la formulación y reajustes, pero los tres criterios (con mayor o menos peso), se han mantenido hasta las versiones actuales de los correspondientes manuales: CIE-10 (OMS, 1992) y DSM-5(APA, 2013).

En este sentido, existe una equivalencia directa entre las aportaciones de la AAIDD y las implicaciones que han ido surgiendo en los manuales mencionados, pudiendo observarse una evolución paralela entre la investigación desarrollada desde la AAIDD y los manuales de la APA (Tabla 3).

Mientras que el DSM-5 ya ha aceptado el cambio terminológico y ha dado un papel fundamental a la conducta adaptativa dentro del diagnóstico, la CIE-10 se encuentra aún estrechamente relacionada con concepciones más antiguas referentes a la discapacidad intelectual como una cuestión mental que concierne principalmente al Cociente Intelectual (CI). No obstante, destacamos que la CIE-10 ha supuesto una mejora de la comprensión de esta discapacidad con respecto a la ofrecida por las tres ediciones anteriores (OMS, 1955, 1967, 1978), y se espera que la CIE-11 (prevista para su publicación en 2015) incluya nuevas modificaciones coherentes a las diferentes novedades incluidas en el DSM-5. 
Tabla 3. Relación entre los distintos paradigmas, constructos, términos y definiciones utilizadas en el campo de la discapacidad intelectual

\begin{tabular}{|c|c|c|c|c|}
\hline PARADIGMA & $\begin{array}{l}\text { CONSTRUCTO } \\
\text { SUBYACENTE }\end{array}$ & $\begin{array}{l}\text { TERMINOLOGÍA } \\
\text { CLÍNICA }\end{array}$ & DEFINICIÓN MANUAL DE AAMD/AAMR/AAIDD & DEFINICIÓN APA (DSM) \\
\hline \multirow{4}{*}{$\begin{array}{l}\text { PARADIGMA } \\
\text { ASISTENCIAL/ } \\
\text { REHABILITIADOR }\end{array}$} & $\begin{array}{l}\text { DEFICIENCIA } \\
\text { MENTAL } \\
\text { Institucionalización }\end{array}$ & $\begin{array}{l}\text { RETRASO } \\
\text { MENTAL }\end{array}$ & $\begin{array}{l}1959 \text { AAMD } \\
\text { Heber: Retraso mental hace referencia a un funcionamiento } \\
\text { intelectual general por debajo de la media que comienza durante } \\
\text { el periodo de desarrollo y que se asocia con deficiencias en uno o } \\
\text { más de los siguientes conceptos: (1) maduración, (2) aprendizaje, } \\
\text { (3) adaptación social. }\end{array}$ & $\begin{array}{l}1952 \\
\text { DSM-I: Estos trastornos se clasificaron como 'síndrome } \\
\text { cerebral crónico con deficiencia mental' y 'deficiencia } \\
\text { mental'. }\end{array}$ \\
\hline & $\begin{array}{l}\text { DEFICIENCIA } \\
\text { MENTAL } \\
\text { Institucionalización }\end{array}$ & $\begin{array}{l}\text { RETRASO } \\
\text { MENTAL }\end{array}$ & $\begin{array}{l}1961 \text { AAMD } \\
\text { Heber: Retraso mental hace referencia a un funcionamiento } \\
\text { intelectual general por debajo de la media que comienza durante } \\
\text { el periodo de desarrollo y que se asocia con deficiencias en } \\
\text { conducta adaptativa. }\end{array}$ & $\begin{array}{l}1968 \\
\text { DSM-II: Retraso mental hace referencia a un funcionamiento } \\
\text { intelectual general subnormal que comienza durante el periodo } \\
\text { de desarrollo y que se asocia con déficits o bien de adaptación } \\
\text { social de aprendizaje o bien de maduración, o con ambos. }\end{array}$ \\
\hline & $\begin{array}{l}\text { DEFICIENCIA } \\
\text { MENTAL } \\
\text { Institucionalización }\end{array}$ & $\begin{array}{l}\text { RETRASO } \\
\text { MENTAL }\end{array}$ & $\begin{array}{l}1973 \text { AAMD } \\
\text { Grossman: Retraso mental hace referencia a un funcionamiento } \\
\text { intelectual general significativamente inferior a la media que } \\
\text { coexiste con déficits en conducta adaptativa, y que se manifiesta } \\
\text { durante el periodo de desarrollo. }\end{array}$ & $\begin{array}{l}1980 \\
\text { DSM-III: Las características principales del retraso mental son: } \\
\text { (1) funcionamiento intelectual general significativamente } \\
\text { inferior a la media, (2) con el resultado de, o asociado a, déficits o } \\
\text { deficiencias en conducta adaptativa, (3) con edad de aparición } \\
\text { antes de los } 18 \text { años (p. 36). }\end{array}$ \\
\hline & $\begin{array}{l}\text { DEFICIENCIA } \\
\text { MENTAL } \\
\text { Institucionalización }\end{array}$ & $\begin{array}{l}\text { RETRASO } \\
\text { MENTAL }\end{array}$ & $\begin{array}{l}1983 \text { AAMD } \\
\text { Grossman: Igual que en } 1973 .\end{array}$ & $\begin{array}{l}1987 \\
\text { DSM-III-R: Las características principales del retraso mental } \\
\text { son: (1) funcionamiento intelectual general significativamente } \\
\text { inferior a la media, (2) déficits o deficiencias en funcionamiento } \\
\text { adaptativo, (3) con edad de aparición antes de los } 18 \text { años. }\end{array}$ \\
\hline \multirow{3}{*}{$\begin{array}{l}\text { PARADIGMA } \\
\text { DE APOYOS }\end{array}$} & $\begin{array}{l}\text { RETRASO MENTAL } \\
\text { Integración }\end{array}$ & $\begin{array}{l}\text { RETRASO } \\
\text { MENTAL }\end{array}$ & $\begin{array}{l}1992 \text { AAMR } \\
\text { Luckasson et al.: Retraso mental hace referencia a limitaciones } \\
\text { sustanciales en el funcionamiento actual. Se caracteriza por un } \\
\text { funcionamiento intelectual inferior a la media significativamente, } \\
\text { que coexiste junto con limitaciones en dos o más de las siguientes } \\
\text { áreas de habilidades adaptativas: comunicación, autocuidado, } \\
\text { vida en el hogar, habilidades sociales, uso de la comunidad, } \\
\text { autodirección, salud y seguridad, habilidades académicas } \\
\text { funcionales, ocio y trabajo. El retraso mental se manifiesta antes } \\
\text { de los } 18 \text { años. }\end{array}$ & $\begin{array}{l}1994 \\
\text { DSM-IV: La característica esencial del retraso mental es } \\
\text { funcionamiento intelectual significativamente inferior a la media } \\
\text { (Criterio A), acompañado de limitaciones significativas en la } \\
\text { habilidades adaptativas en al menos dos de las siguiente áreas: } \\
\text { comunicación, cuidado personal, vida en el hogar, habilidades } \\
\text { sociales/interpersonales, utilización de los recursos de la } \\
\text { comunidad, autodirección, habilidades académicas funcionales, } \\
\text { ocio y trabajo, salud y seguridad (Criterio B). El inicio es anterior } \\
\text { a los } 18 \text { años (Criterio C). }\end{array}$ \\
\hline & \multirow{2}{*}{$\begin{array}{l}\text { DISCAPACIDAD } \\
\text { INTELECTUAL } \\
\text { Inclusión }\end{array}$} & $\begin{array}{l}\text { RETRASO } \\
\text { MENTAL }\end{array}$ & $\begin{array}{l}\text { 2002 AAMR } \\
\text { Luckasson et al.: Retraso mental es una discapacidad } \\
\text { caracterizada por limitaciones significativas en el funcionamiento } \\
\text { intelectual y la conducta adaptativa que se manifiesta en } \\
\text { habilidades sociales, prácticas y conceptuales. Esta discapacidad } \\
\text { comienza antes de los } 18 \text { años. }\end{array}$ & $\begin{array}{l}2000 \\
\text { DSM-IV-TR: Igual que en } 1994 .\end{array}$ \\
\hline & & $\begin{array}{l}\text { DISCAPACIDAD } \\
\text { INTELECTUAL }\end{array}$ & $\begin{array}{l}\text { 2010 AAIDD } \\
\text { Schalock et al.: Discapacidad Intelectual es una discapacidad } \\
\text { caracterizada por limitaciones significativas en el funcionamiento } \\
\text { intelectual y la conducta adaptativa que se manifiesta en } \\
\text { habilidades sociales, prácticas y conceptuales. Esta discapacidad } \\
\text { comienza antes de los } 18 \text { años. }\end{array}$ & $\begin{array}{l}\mathbf{2 0 1 0} \\
\text { DSM-5: La discapacidad intelectual (trastorno del desarrollo } \\
\text { intelectual) se caracteriza por déficits en las habilidades } \\
\text { mentales generales (Criterio A) y limitaciones en el } \\
\text { funcionamiento adaptativo diario en comparación con los iguales } \\
\text { en edad, genero y cultura (Criterio B). Aparece durante el } \\
\text { periodo de desarrollo (Criterio C). }\end{array}$ \\
\hline
\end{tabular}


El enfoque actual de la discapacidad refleja la importancia del contexto y tiene una serie de implicaciones (denominadas premisas) que forman parte fundamental de la definición operativa de la discapacidad, ya que aportan pautas específicas de la evaluación e interpretación de los criterios establecidos. Estas premisas son consideras parte explícita de la definición porque aclaran el contexto en el cual la definición se plantea, y a la vez indican como debe ser aplicada. Por ello, la actual definición de discapacidad intelectual no se presenta por si sola, sino que se acompaña de un conjunto de cinco premisas (Luckasson et al., 2002; Schalock et al., 2010) que completan las cuatro premisas propuestas por primera vez en el modelo de 1992 (Luckasson et al.):

1. Las limitaciones en el funcionamiento presente deben considerarse en el contexto de ambientes comunitarios típicos de los iguales en edad y cultura.

2. Una evaluación válida ha de tener en cuenta la diversidad cultural y lingüística, así como las diferencias en comunicación y en aspectos sensoriales, motores y conductuales.

3. En una persona, las limitaciones coexisten habitualmente con capacidades.

4. Un propósito importante de la descripción de limitaciones es el desarrollo de un perfil de necesidades de apoyo.

5. Si se mantienen apoyos apropiados durante un largo periodo, el funcionamiento de la persona con discapacidad generalmente mejorará.

Además de la definición y las premisas, desde una definición operativa de la discapacidad intelectual es necesario establecer específicamente los límites del constructo, aportando así un criterio objetivo para el diagnóstico y la clasificación.

\subsubsection{Límites y clasificación del constructo}

El retraso mental/discapacidad intelectual es una categoría diagnóstica definida arbitrariamente que ha cambiado sustantiva y frecuentemente a lo largo de los años (Landesman y Ramey, 1989). Actualmente, la AAIDD (Schalock et al., 2010) defiende que para realizar el diagnóstico de discapacidad intelectual, deben aparecer limitaciones significativas en funcionamiento intelectual y conducta adaptativa durante el desarrollo, estableciéndose generalmente la edad de 18 años como límite de edad. Con relación al análisis de las limitaciones significativas en el funcionamiento intelectual y la conducta adaptativa, se utilizan las puntuaciones de corte como criterio para determinar quién es miembro de la categoría y quién no. 
Las puntuaciones de corte suelen establecerse aproximadamente dos desviaciones típicas por debajo de la media y han de obtenerse partir de la evaluación estandarizada a través de un test validado y baremado en el contexto determinado. Concretamente, el criterio relativo al funcionamiento intelectual hace referencia a un $\mathrm{CI}$ inferior a 70. Por su parte, las limitaciones significativas en conducta adaptativa reflejan un desempeño significativamente inferior a la media en: (a) uno de los tres tipos de conducta adaptativa siguientes: conceptual, social o práctica; o (b) una puntuación general en una medida estandarizada de habilidades conceptuales, sociales y prácticas

Para la interpretación de estas puntuaciones, es necesario tener en cuenta que cualquier puntuación obtenida está sujeta a variabilidad en función de unas potenciales fuentes de error, como son las variaciones en el rendimiento en el test, la conducta del examinador, la cooperación de quien cumplimenta el test y otras variables ambientales y personales.

Para aminorar estos sesgos, se recurre el término ‘Error Típico de Medida' (ETM), que varía dependiendo del test (e incluso por subgrupos), y sirve para cuantificar la variabilidad y proporcionar las bases para establecer el intervalo de confianza estadístico en torno a la puntuación obtenida dentro de la cual se encuentra la puntuación verdadera de la persona (suele oscilar entre 3 y 5 puntos). En este sentido, tanto en la evaluación del funcionamiento intelectual como de la conducta adaptativa el ETM del instrumento de evaluación debe considerarse cuando se interpreta la puntuación obtenida por la persona.

A pesar de la importancia que la conducta adaptativa ha tenido desde hace más de 50 años dentro del campo de la discapacidad, lo cierto es que las puntuaciones de CI han constituido durante mucho tiempo el único criterio necesario para considerar la presencia o ausencia de discapacidad intelectual así como para la clasificación diagnóstica que identificaba los niveles de gravedad de la misma.

De manera inicial, se establecieron tres categorías diagnósticas de la 'deficiencia mental u oligofrenia': Morón (CI entre 51 y 70); Imbécil (CI entre 21 y 50); e Idiota (CI entre 0 y 20). Sin embargo, con la llegada del término 'retraso mental', estos tres grupos quedaron sustituidos por cuatro categorías basadas en los baremos de Standford-Binet, estableciéndose además un cambio de nomenclatura por el uso peyorativo que estos términos estaban empezando a tener dentro de la sociedad: Retraso Mental Ligero (CI entre 66 y 50); Moderado (CI entre 49 y 33); Severo (CI entre 32 y 16); y Profundo (CI entre 0 y 16). 
Posteriormente, se empezaron a desarrollar tests de inteligencia con media $100 \mathrm{y}$ desviación típica 15, lo que hizo necesario revisar las puntuaciones de corte. Finalmente, la clasificación del retraso mental quedó compuesta de la siguiente forma: Ligero (CI entre 55 y 70); Moderado (CI entre 40 y 55); Severo (CI entre 25 y 40) y Profundo (CI entre 0 y 25). Actualmente, si bien el DSM-5 (APA, 2013) mantiene estas cuatro categorías de la discapacidad intelectual (Ligera, Moderada, Severa, Profunda), el criterio clasificatorio no se centra en la puntuación de $\mathrm{CI}$, sino en nivel de conducta adaptativa, por su mayor relación con la provisión de apoyos y la asignación de recursos.

\subsubsection{Incorporación del concepto de conducta adaptativa en la definición y como criterio de clasificación}

Ya en los años cincuenta, se estableció que el grado de limitación intelectual estaba relacionado con el grado de dependencia social del sujeto. Sin embargo, la adopción del criterio tradicional de inadaptación, entendida únicamente como consecuencia de un bajo CI, fue objeto de numerosas críticas referidas a la dificultad de medir con fiabilidad el fracaso en adaptación social, y que apuntaban la posibilidad de que los déficits en adaptación social pudieran deberse a causas diferentes a las habilidades mentales deficitarias (Kanner, 1957).

Finalmente, las limitaciones adaptativas fueron incluidas como criterio diagnóstico independiente del CI en la definición de discapacidad intelectual establecida en 1959 por la AAMD, siendo progresivamente incorporadas en los manuales de diagnóstico y clasificación internacional más reconocidos (Lecavalier, Tasse y Levesque, 2002). Sin embargo, el término específico 'conducta adaptativa' no fue acuñado hasta 1973, y ha sido frecuentemente intercambiado por el de habilidades adaptativas hasta muy recientemente (Navas, Verdugo, Arias y Gómez, 2010), reflejo de la falta de acuerdo que ha existido tradicionalmente sobre la naturaleza del constructo.

Aunque este concepto siempre ha conservado su rol, no adquiere un papel fundamental hasta el año 1992, con la novena edición de la AAMR, cuando la definición de conducta adaptativa empezó a hacer referencia no sólo a las capacidades o limitaciones del propio individuo, sino también al impacto que sobre las mismas pudiera ocasionar el entorno con el que la persona interactúa (Navas, Verdugo y Tassé, 2013), llegando su aplicación práctica aún con mayor retraso debido a la falta de consenso sobre la estructura empírica del constructo. 
Navas (2012) recoge numerosas investigaciones sobre la conducta adaptativa de finales del siglo XX donde se aprecia que algunos estudios proponen una aproximación unifactorial de la misma, relacionándola con un factor de independencia (Bruininks, McGrew y Maruyama, 1988; Bruininks, Woodcock, Weatherman y Hill, 1985; Nihira, Foster, Shellhaas, Leland, 1967), mientras que otros evidencian aproximaciones multifactoriales (Greenspan y Granfield, 1992; Kamphaus, 1987; Meyers, Nihira y Zetlin, 1979; Thompson, McGrew y Bruininks, 1999; Widaman, Gibbs y Geary, 1987; Widaman, y McGrew, 1996; Widaman, Stacy y Borthwick-Duffy, 1993). Aunque pronto empezó a haber un consenso sobre la multidimensionalidad del constructo, debido a las amplias críticas recibidas a la aproximación unifactorial (Widaman, Borthwick-Duffy y Little, 1991), se seguía sin llegar a un acuerdo sobre cuál era la naturaleza y relación de esas dimensiones.

Con el objeto de unificar criterios, en 1992, la AAIDD (entonces AAMR) propuso un nuevo concepto de conducta adaptativa que pretendía proporcionar una definición operativa del término, reconociendo su relación con el contexto (Bruininks, Thurlow y Gilman, 1987) y especificando un conjunto de 10 habilidades adaptativas necesarias para lograr un funcionamiento exitoso en el día a día: 'comunicación', 'autocuidado', 'vida en el hogar', 'habilidades sociales', 'comunidad', 'autodirección', 'salud y seguridad', 'habilidades académicas funcionales', 'tiempo libre' y 'trabajo'. No obstante, aunque la idea teórica era muy adecuada, no se consiguió un contraste empírico que garantizase la existencia de estas 10 áreas, lo que fue criticado por diversos autores (Montero, 2003; Verdugo, 2003b; Widaman y McGrew, 1996) y seguía dificultando su uso diagnóstico.

Aunque el fracaso de las 10 áreas propuestas fue inevitable, la adopción del término habilidades adaptativas en la definición de 1992 y la investigación sobre la misma permitieron reconocer una serie de elementos clave a tener en cuenta en las sucesivas investigaciones (Schalock, 1995a; Verdugo, 1999): (a) las limitaciones en habilidades adaptativas coexisten con otra serie de fortalezas personales; (b) las limitaciones y las capacidades deben ser documentadas dentro del contexto de entornos comunitarios típicos para los iguales; (c) si la persona no presenta limitaciones significativas en habilidades adaptativas, entonces no podrá establecerse el diagnóstico de retraso mental; (d) a diferencia de lo que sucedía en definiciones anteriores, desaparecen las conductas 'desadaptativas' a la hora de hablar de comportamiento adaptativo, considerando que la evaluación de éstas ha de realizarse dentro de una dimensión relativa a 'consideraciones psicológicas y emocionales'; y (e) subrayar el carácter evolutivo de la conducta adaptativa y la importancia de cada una de las áreas en función de la edad del individuo. 
A partir de estas evidencias sobre la naturaleza de la conducta adaptativa y a la falta de una estructura de la misma, autores como Schalock (1999) o Greenspan (Greenspan, 1997; Greenspan y Driscoll, 1997; Greenspan y Love, 1997; Greenspan, Switzky y Granfield, 1996) comienzan a plantearse si inteligencia y conducta adaptativa pueden ser incluidas dentro de un marco teórico común de competencia global influido por el contexto (Greenspan, 1999). Desde esta concepción, se podría implementar un modelo heurístico para abordar la discapacidad intelectual que resultaría en una mejora de lo que hasta ese momento se conocía acerca de tal condición, aportando validez a la estructura multifactorial de la conducta adaptativa.

Para ello, y basándose en las aportaciones de Widaman y McGrew (1996), estos autores plantean un modelo de competencia general que proporciona un gran paralelismo entre los dominios que definen la inteligencia y aquellos que forman parte de la conducta adaptativa (Figura 1): (a) competencia física o motora; (b) habilidades de vida independiente; (c) habilidades cognitivas, comunicativas y académicas; y (d) habilidades de competencia social. Quedan así fuera del modelo los problemas de comportamiento, incluídos tradicionalmente dentro de la concepción del funcionamiento adaptativo de manera errónea (Borthwick-Duffy, 2007; Greenspan, 1999; Tassé, 2009; Thompson y Wehmeyer, 2008). Recientemente, se ha demostrado que estos problemas de comportamiento solo correlacionan con la conducta adaptativa en el caso de personas con autismo (Kearny y Healy, 2011).

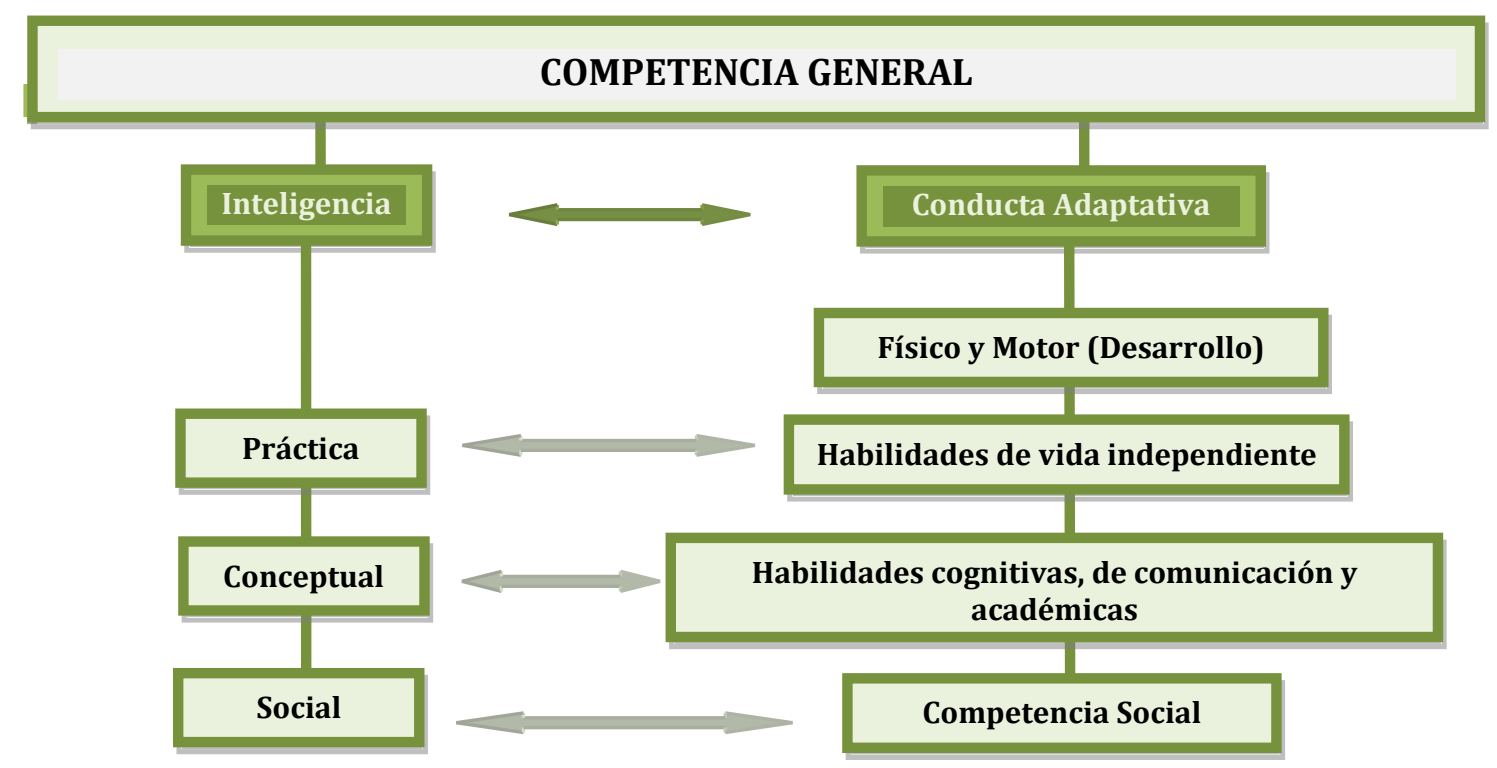

Figura 1. Modelo de competencia general (Schalock, 1999) 
Posteriormente, la dimensión referente a la competencia física y motórica sería eliminada a la hora de hablar de conducta adaptativa, considerando que su evaluación ha de realizarse en el contexto de la dimensión de salud al no ser significativa su relación con el resto de dominios de conducta adaptativa (Harries, Guscia, Kirby, Nettelbeck y Taplin, 2005). Comenzaron así a definirse tres dimensiones de ejecución (conceptual, práctica y social) de cara a la evaluación de la discapacidad intelectual, dimensiones que podían ser definidas a partir de los siguientes indicadores:

(1) Indicadores de habilidades prácticas: actividades básicas e instrumentales de la vida diaria, funcionamiento motor, vida en comunidad, habilidades ocupacionales, habilidades de cuidado personal.

(2) Indicadores de habilidades conceptuales: lenguaje expresivo y receptivo, habilidades de lectura y escritura, uso del dinero, comunicación no verbal.

(3) Indicadores de habilidades sociales: amistades, interacción con otros, participación en actividades grupales, competencia emocional, adaptación personal y adaptación social, solución de problemas, autodirección, responsabilidad, socialización, autocontrol y autoestima, sensibilidad y perspicacia.

Las consiguientes propuestas de la AAIDD aceptaron la carencia de investigación que fundamentara la propuesta de 10 áreas de habilidades adaptativas y se adoptó este enfoque triárquico de conducta adaptativa, quedando conceptualizada en relación con la inteligencia y definida como "el conjunto de habilidades conceptuales, sociales y prácticas que han sido aprendidas por las personas para funcionar en su vida diaria" (Luckasson et al., 2002, p.31; Schalock et al., 2010, p.15).

En este sentido, la última edición del manual de la AAIDD (Schalock et al., 2010) supone una evolución de la concepción de discapacidad intelectual innegable que culmina en el asentamiento del término 'discapacidad intelectual' y en la centralidad del constructo de 'conducta adaptativa' como componente diagnóstico. Para conseguirlo, se dan pautas específicas sobre su evaluación, determinando que para hablar de limitaciones significativas en conducta adaptativa debe haber dos desviaciones típicas por debajo de la media en al menos uno de los tres dominios en los que se divide el concepto (conceptual, práctica y social) o en el cómputo global de la misma.

Consecuentemente, el manual DSM-5 (APA, 2013) acepta el cambio terminológico propuesto (cambiando el término 'retraso mental' por 'discapacidad intelectual') y aporta un mayor peso a la conducta adaptativa (aunque ya aparecía en su primer manual, 1952), 
definiendo la misma en términos de habilidades conceptuales, sociales y prácticas, y proponiendo que la existencia de limitaciones significativas en una de las áreas sería suficiente para el diagnóstico. Asimismo, el DSM-5 introduce la clasificación de la discapacidad (ligera, moderada, severa y profunda) en los niveles de conducta adaptativa (Tabla 4), dando un papel secundario al criterio tradicional y reduccionista del CI tanto en el diagnóstico como en la clasificación de la discapacidad intelectual.

Tabla 4. Clasificación de la discapacidad intelectual (Verdugo, Guillén y Vicente, 2014; adaptado de APA, 2013)

\begin{tabular}{|c|c|}
\hline NIVEL & CRITERIOS DSM-5 \\
\hline \multirow{3}{*}{ LIGERA } & $\begin{array}{l}\text { - DOMINIO CONCEPTUAL: Están afectados el pensamiento abstracto, flexibilidad } \\
\text { cognitiva, memoria a corto plazo y uso funcional de las habilidades académicas } \\
\text { (leer, manejar el dinero...). }\end{array}$ \\
\hline & $\begin{array}{l}\text { - DOMINIO SOCIAL: Comparadas con los iguales, las personas con discapacidad } \\
\text { intelectual ligera son inmaduras en las interacciones y corren el riesgo de ser } \\
\text { manipulados. }\end{array}$ \\
\hline & $\begin{array}{l}\text { - DOMINIO PRÁCTICO: Necesitan algún apoyo para completar tareas complejas } \\
\text { de la vida diaria. }\end{array}$ \\
\hline \multirow{3}{*}{ MODERADA } & $\begin{array}{l}\text { - DOMINIO CONCEPTUAL: Se necesita asistencia continua para completar } \\
\text { actividades conceptuales básicas del día a día, y podría ser necesario que otros } \\
\text { tuvieran que tomar algunas responsabilidades de la persona con discapacidad. }\end{array}$ \\
\hline & $\begin{array}{l}\text { - DOMINIO SOCIAL: La lengua oral es mucho menos compleja que la de las } \\
\text { personas sin discapacidad. Podrían no interpretar algunas claves sociales } \\
\text { correctamente. Se necesita apoyo para establecer relaciones sociales exitosas. }\end{array}$ \\
\hline & $\begin{array}{l}\text { - DOMINIO PRÁCTICO: Pueden desarrollar varias habilidades y destrezas con } \\
\text { apoyo adicional y un largo periodo de enseñanza. }\end{array}$ \\
\hline \multirow{3}{*}{ SEVERA } & $\begin{array}{l}\text { - DOMINIO CONCEPTUAL: Las habilidades conceptuales son limitadas. La } \\
\text { persona tiene poca comprensión del lenguaje y de los conceptos numéricos. Los } \\
\text { cuidadores tienen que proporcionar apoyo extenso para actividades cotidianas. }\end{array}$ \\
\hline & $\begin{array}{l}\text { - DOMINIO SOCIAL: El lenguaje hablado es muy limitado tanto en vocabulario } \\
\text { como en gramática. El discurso lo forman solo palabras o frases simples que } \\
\text { pudieran mejorarse con medios alternativos. La comunicación se centra en el } \\
\text { aquí y el ahora. }\end{array}$ \\
\hline & $\begin{array}{l}\text { - DOMINIO PRÁCTICO: La persona requiere apoyo para todas las actividades de } \\
\text { la vida diaria y supervisión constante. }\end{array}$ \\
\hline \multirow{3}{*}{ PROFUNDA } & $\begin{array}{l}\text { - DOMINIO CONCEPTUAL: Las habilidades conceptuales engloban el mundo } \\
\text { físico y no procesos simbólicos. La persona podría usar algún objeto para el } \\
\text { autocuidado o el ocio y adquirir algunas habilidades visoespaciales (señalar...). } \\
\text { Sin embargo, los problemas motores y sensoriales que suelen ir asociados } \\
\text { pueden impedir el uso funcional de objetos. }\end{array}$ \\
\hline & $\begin{array}{l}\text { - DOMINIO SOCIAL: La persona tiene una comprensión muy limitada tanto en } \\
\text { comunicación verbal como gestual. Podría llegar a entender instrucciones muy } \\
\text { simples y expresar deseos y emociones básicas a través de una comunicación } \\
\text { simple y no verbal. }\end{array}$ \\
\hline & $\begin{array}{l}\text { - DOMINIO PRÁCTICO: La persona es dependiente en todos los aspectos, aunque } \\
\text { podría participar en algunas actividades básicas, especialmente si no hay grandes } \\
\text { afectaciones motoras o sensoriales. }\end{array}$ \\
\hline
\end{tabular}




\subsection{DISCAPACIDAD INTELECTUAL Y MODELOS TEÓRICOS DE REFERENCIA}

Además de la definición operativa de la discapacidad intelectual (Wehmeyer, 2008; Schalock, Luckasson et al., 2007; Schalock et al., 2010; Verdugo y Schalock, 2010), existe una definición constitutiva que define el constructo en relación con otros constructos relacionados y ayuda a comprender la naturaleza de los fundamentos de la discapacidad intelectual. Esta definición constitutiva implica una comprensión socioecológica y multidimensional de la discapacidad que puede ser explicada a través de diferentes modelos teóricos. Un modelo teórico es una representación abstracta de una realidad (i.e., discapacidad) que permite comprender y responder de manera sencilla y global a sus características, causas y consecuencias, reflejando las ideas subyacentes del paradigma bajo el que fue desarrollado y evolucionando con el mismo (i.e., paradigma de apoyos).

Concretamente, dentro del marco actual de la discapacidad intelectual, existen tres modelos principales que organizan su comprensión desde tres perspectivas diferentes (Buntinx y Schalock, 2010): (1) el modelo del funcionamiento humano (que cuenta con dos marcos de referencia: el modelo de la OMS, que puede ser aplicado a cualquier discapacidad, y el modelo de la AAIDD, centrado en discapacidad intelectual); (2) el modelo de apoyos; y (3) el modelo de calidad de vida. Claes, van Hove, Vandevelde, van Loon y Schalock (2012) afirman que los modelos del funcionamiento humano (que definen la discapacidad como las limitaciones del funcionamiento humano dentro de un contexto social que representa una desventaja sustancial para el individuo) son los modelos de referencia general que guían la comprensión de la discapacidad y el trabajo con este colectivo, siendo considerado el modelo de apoyos como una operativización del papel de los apoyos y el modelo de calidad de vida la clarificación de los resultados esperados.

\subsubsection{Los modelos del funcionamiento humano}

\subsubsection{El modelo de la OMS}

En 1980, ante la inminente llegada del paradigma social de la discapacidad intelectual, la OMS desarrolla por primera vez un sistema de clasificación destinada a clasificar las consecuencias de las limitaciones relacionadas con la salud (Clasificación Internacional de Deficiencias Discapacidades y Minusvalías [CIDDM]), desde donde se describe el impacto de una condición de salud o patología en el funcionamiento humano como: (a) la exteriorización de una patología en la anatomía y funciones corporales (deficiencia); (b) patologías objetivadas que se manifiestan en las actividades de la 
persona (discapacidad); y (c) las consecuencias sociales de esas patologías (minusvalía), todo ello como parte de un sistema causal, lineal e unidireccional donde, la minusvalía es consecuencia directa de una discapacidad iniciada a partir de una deficiencia (Figura 2).

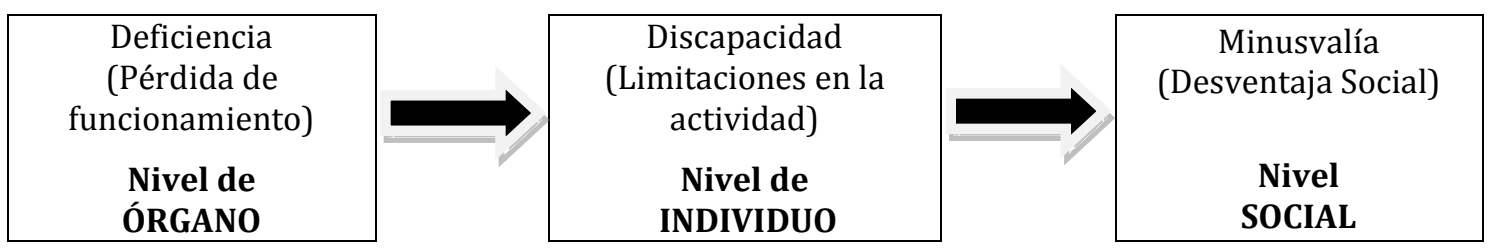

Figura 2. Modelo de la CIDDM (OMS, 1980)

Aunque este modelo suponía una primera aproximación al nuevo concepto de la discapacidad en la medida que contemplaba el impacto de la misma a nivel social, pocos años más tarde (en 1993) se empezaron a hacer nuevas propuestas que reflejaban la importancia de los factores contextuales (ambientales y personales) como elemento indispensable dentro del funcionamiento humano. Asimismo, las nuevas propuestas planteaban que la desventaja social no es una simple consecuencia lineal de una deficiencia o discapacidad, sino que también influye en su optimización o decremento.

Ante la necesidad de incluir estas modificaciones, se desarrolló un nuevo modelo basado en una actitud más positiva hacia la discapacidad y con un mayor énfasis en el entorno y las capacidades personales, dando pautas para la comprensión y codificación de la salud (Figura 3). Este nuevo modelo fue culminado por la OMS en 2001, con la publicación de la Clasificación Internacional del Funcionamiento, la Discapacidad y la Salud (CIF). Esta clasificación tuvo una gran acogida y recientemente ha sido desarrollada una clasificación destinada específicamente para niños y jóvenes (OMS, 2007).

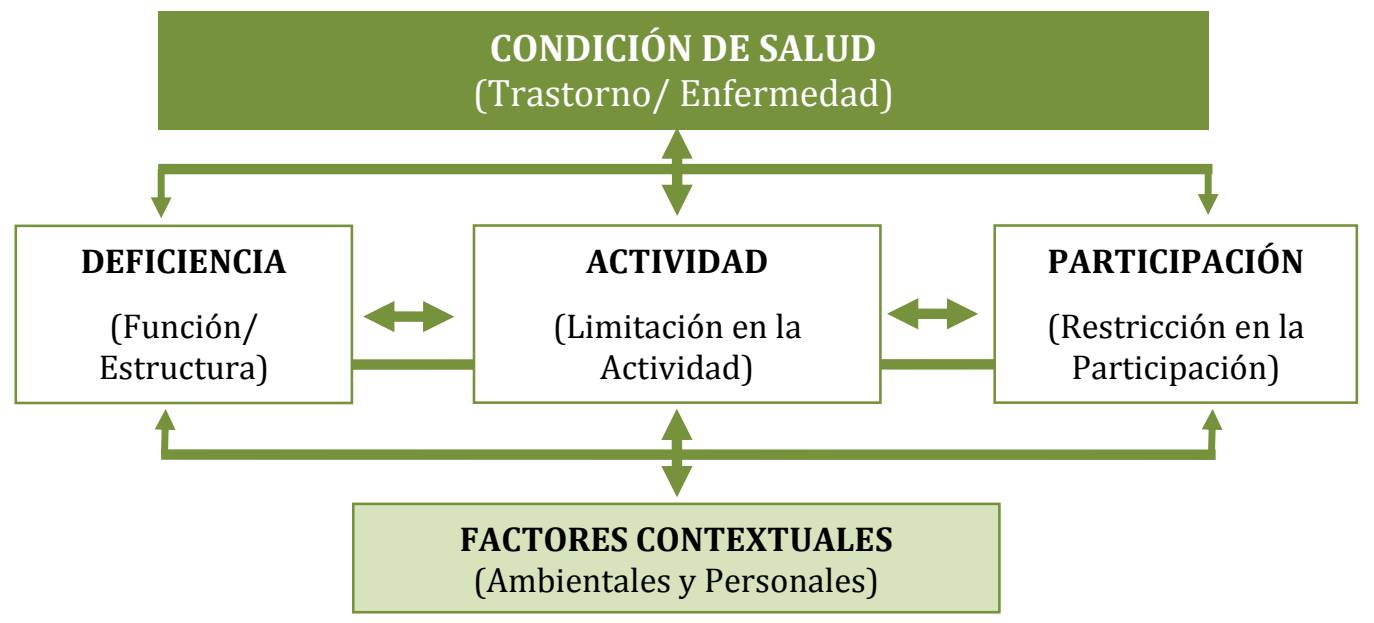

Figura 3. Modelo de la CIF (OMS, 2001) 


\subsubsection{El modelo de la AAIDD}

A partir de la aparición del primer modelo de la OMS (1980), y atendiendo a sus características y consideraciones generales sobre las implicaciones de la discapacidad y otros trastornos de la salud, desde la AAIDD (entonces AAMRR) se desarrolla un modelo del funcionamiento humano específico para las personas con discapacidad intelectual (Luckasson et al., 1992). Concretamente, se plantea un modelo multidimensional que incluye tres características personales (1-funcionamiento intelectual y conducta adaptativa; 2-consideraciones psicológicas y emocionales; 3-salud física y etiología); y un cuarto factor relacionado con las demandas del contexto, resaltando a su vez dentro del modelo la importancia del papel de los apoyos.

A pesar de que este modelo supuso un punto de inflexión y generó interés por trabajar en la identificación de los apoyos necesarios para ayudar a las personas con discapacidad intelectual a participar en su comunidad, asumir roles sociales, y experimentar una mayor satisfacción (Verdugo, 2003a), fueron muchas las críticas recibidas (Borthwick-Duffy, 1994; Jacobson, 1994; Jacobson y Mulick, 1996; MacMillan, Gresham y Siperstein, 1993; Verdugo, 1994). Por ello, en 2002 (Luckasson et al.) se propone un nuevo modelo que recoge las investigaciones y aportaciones que acontecieron durante esos 10 años (e.g., conducta adaptiva, apoyos, calidad de vida), superando esas críticas y desencadenando un mayor apoyo por parte del ámbito científico.

Entre las modificaciones realizadas, destacamos aquellas relacionadas con las dimensiones que componen el modelo. Estos cambios se recogen en la Tabla 5 y pueden ser resumidos en cuatro puntos principales: (1) la dimensión relacionada con el funcionamiento intelectual y la conducta adaptativa se divide en dos elementos, dándole así mayor entidad a esta última; (2) las consideraciones de salud física y mental pasan a formar una única dimensión denominada Salud; (3) se incorpora la dimensión Participación, evidenciando la importancia de la inclusión; y (4) se especifican los factores ambientales, incluyéndolos dentro de un marco social y cultural.

No obstante, a pesar de este reflejo de una mayor comprensión del constructo, se mantiene el término 'retraso mental', porque se considera que no se está descubriendo nada nuevo. Esta decisión sería posteriormente criticada (Finlay et al., 2005; Verdugo, 1999; Verdugo, 2003b) por el carácter peyorativo adquirido por el término, defendiendo que la aparición de un nuevo constructo subyacente hace necesaria una nueva etiqueta que refleje este cambio ante la sociedad y fomente actitudes positivas. 
Tabla 5. Modificación de las dimensiones del modelo de la AAIDD. De 1992 al 2002

\begin{tabular}{ll}
\hline \multicolumn{1}{c}{1992} & \multicolumn{1}{c}{$\mathbf{2 0 0 2 / 2 0 1 0}$} \\
\hline $\begin{array}{ll}\text { I. Función Intelectual y Conducta adaptativa } & \text { I. Capacidades Intelectuales } \\
\text { II. Conducta Adaptativa }\end{array}$ \\
$\begin{array}{ll}\text { II. Consideraciones Psicológicas/Emocionales } \\
\text { III. Salud Física y Etiológica }\end{array}$ & III. Salud Física, Mental y Etiológica \\
& IV. Participación \\
IV. Consideraciones Ambientales & V. Contexto (Ambiente y Cultura) \\
\hline
\end{tabular}

Además, en el modelo del funcionamiento humano de 2002, Luckasson et al. aportan una mayor centralidad al concepto de apoyos como puente clave entre las capacidades y las demandas del entorno, lo que supuso que se asentara por completo el paradigma de apoyos iniciado en la época de los 80. En este sentido, si bien en el manual de 2010 (Schalock et al.) se recogen más mejoras de la comprensión del constructo (destacando el cambio terminológico que refleja la naturaleza socioecológica de la discapacidad y la mayor descripción de la calidad de vida como resultado esperado de una vida con apoyos), el modelo del funcionamiento humano continua describiéndose a través de las mismas dimensiones y presentando la misma apariencia (Figura 4).

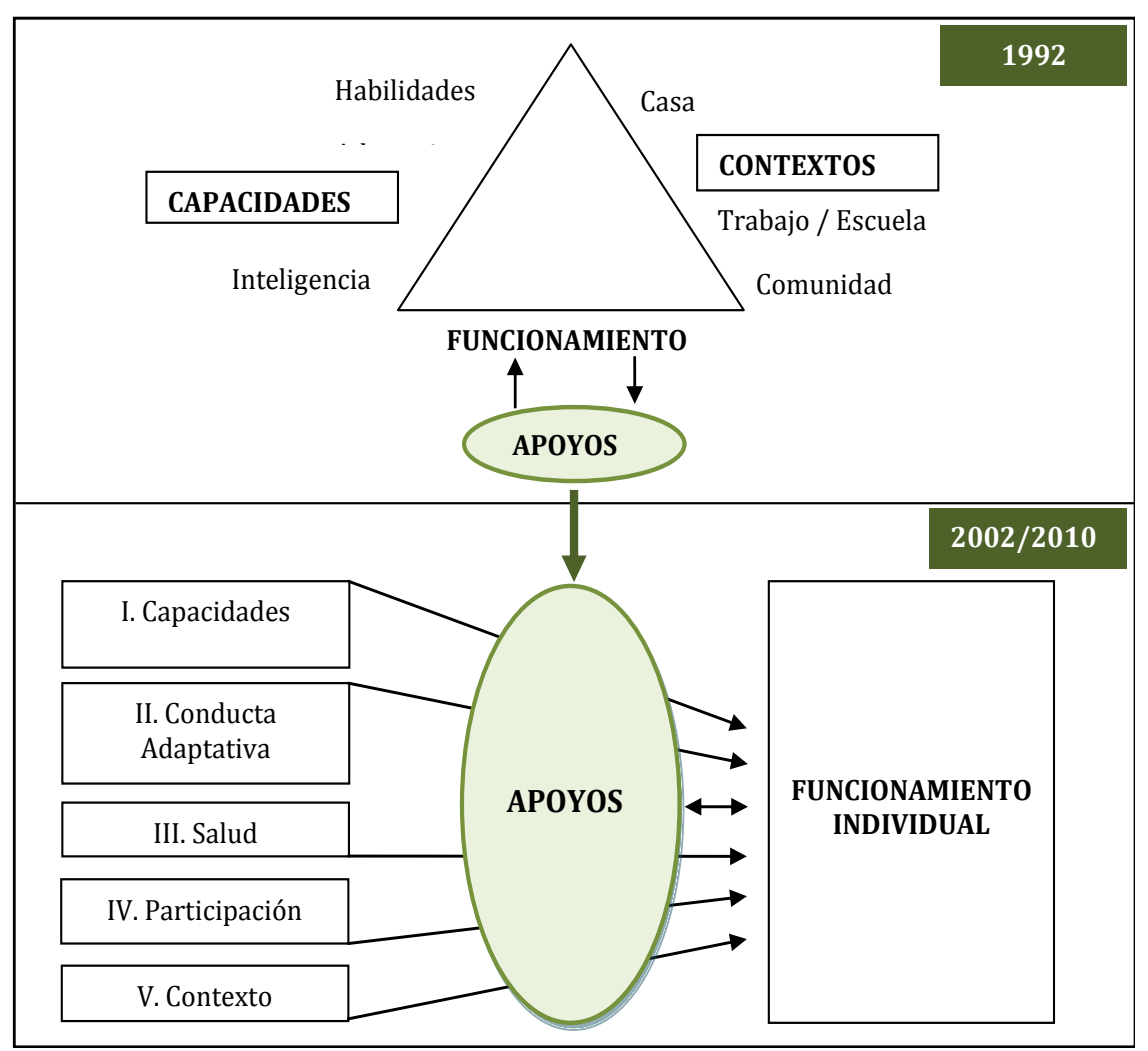

Figura 4 . Progresión del modelo del funcionamiento humano (Luckasson et al., 1992; Luckasson et al., 2002; Schalock et al., 2010) 
En resumen, la novena (Luckasson et al., 1992), la décima (Luckasson et al., 2002) y ahora la undécima (Schalock et al., 2010) definición de discapacidad intelectual propuestas por la AAIDD han tenido un impacto sustancial en la instauración de cambios en su concepción y también en las prácticas profesionales (Verdugo y Schalock, 2010). Atendiendo al cambio teórico, la discapacidad intelectual deja de ser considerada como un rasgo absoluto del individuo, y pasa a ser entendida como una expresión de la interacción entre la persona (con un funcionamiento limitado) y el entorno en el que se encuentra. Consecuentemente, la tarea de los profesionales ya no es diagnosticar a los individuos en virtud de su CI, sino identificar aquellos apoyos necesarios para ayudar a las personas a participar en su comunidad, asumir roles valorados socialmente, y experimentar una mayor satisfacción y realización; entendiéndose que el apoyo acompaña al individuo, se basa en las capacidades (no en las limitaciones), ofrece oportunidades y facilita la consecución de altas cotas de normalización (Martorell, 1994).

\subsubsection{Relación del modelo de la AAIDD con el modelo de la OMS}

El paralelismo adquirido con respecto a la nueva concepción de discapacidad patente en la evolución del modelo de la OMS y la evolución de los modelos de la AAIDD, centrados en la discapacidad intelectual, se debe a un mejor entendimiento de la discapacidad y a la finalidad asumida por ambos modelos de aumentar y mejorar la inclusión social de cualquier persona con discapacidad en todos los ámbitos de su vida. Ambos modelos se iniciaron estableciendo sus bases de la discapacidad en las anomalías biológicas (Switzy y Greenspan, 2003), reflejo directo de que la medicina fue la primera disciplina en proporcionar descripciones de la discapacidad, y han ido evolucionando hasta llegar a una descripción funcional, centrada en la actuación de la persona en tareas que se requieren para desenvolverse con éxito en la sociedad.

Actualmente, estos modelos defienden que las descripciones funcionales (y no las anomalías biológicas por sí mismas) proporcionan información sobre la manera en que el nivel real de habilidades de la persona está adaptado (o no) a las demandas del entorno y son estas descripciones las que identifican y crean apoyos que ayudan a la persona a participar en una variedad de entornos y actividades (OMS, 2001). Concretamente, las descripciones funcionales llevan a identificar diferentes métodos de solución que se adecúen a cada situación concreta. 
Estos métodos se diferencian entre ellos en el punto donde se focaliza el apoyo ya que, desde el nuevo modelo, el objetivo de los apoyos no se restringe únicamente a disminuir las limitaciones de la persona, sino más bien a mejorar su inclusión exitosa en la comunidad a través de un amplio número de recursos: (a) el uso de estrategias específicas para el aprendizaje de las habilidades necesarias; (b) la adquisición de instrumentos (i.e., ayudas técnicas, nuevas tecnologías...) que un individuo podría usar para mejorar su participación en entornos o actividades concretas; (c) la modificación del diseño y las demandas de los entornos en que la persona se desenvuelve y de las diferentes actividades que realiza; o (d) la combinación de estos apoyos.

En este sentido, en la medida que ambos modelos persiguen objetivos similares, las relaciones entre los componentes y elementos de estos pueden ser fácilmente representadas. En la Tabla 6 podemos apreciar de manera clara y sencilla cómo cada dimensión propuesta por el nuevo modelo de la AAIDD (Schalock et al., 2010) tiene correspondencia directa con cada uno de los componentes de la clasificación vigente de la OMS (2001), reflejándose en ambas la importancia del contexto social del individuo.

Tabla 6. Comparación entre el modelo de la OMS y el modelo de la AAIDD

\begin{tabular}{|c|c|c|c|c|c|}
\hline \multirow[b]{2}{*}{ AAIDD } & \multicolumn{5}{|c|}{ Clasificación Internacional de Funcionamiento (OMS) } \\
\hline & $\begin{array}{l}\text { Condición } \\
\text { Salud }\end{array}$ & $\begin{array}{l}\text { Función y } \\
\text { Estructura }\end{array}$ & Actividad & Participación & $\begin{array}{c}\text { Factores } \\
\text { Contextuales }\end{array}$ \\
\hline $\begin{array}{l}\text { I. Capacidades } \\
\text { Intelectuales }\end{array}$ & & $\mathbf{X}$ & & & \\
\hline $\begin{array}{l}\text { II. Conducta } \\
\text { Adaptativa }\end{array}$ & & & $\mathbf{X}$ & & \\
\hline III. Salud & & & & $\mathbf{X}$ & \\
\hline IV. Participación & $\mathbf{X}$ & & & & \\
\hline V. Contexto & & & & & $\mathbf{X}$ \\
\hline
\end{tabular}

No obstante, a pesar de las similitudes existentes en el modelo de la CIF y el modelo de la AAIDD, Buntinx (2006a) afirma que existen tres diferencias principales entre ambos modelos: (1) el modelo de la AAIDD ha sido desarrollado como un sistema especial para personas con discapacidad intelectual mientras que el modelo de la CIF se ha desarrollado de manera general en relación con todo tipo de limitaciones de la salud; (2) mientras que en el modelo de la CIF la presencia e importancia de los apoyos se encuentra implícita dentro de los factores del contexto, el modelo de la AAIDD propone los apoyos 
como un elemento con entidad propia que forma el eje central del modelo; y (3) aunque el modelo de la AAIDD habla de la importancia de la clasificación y del uso de sistemas de clasificación multidimensionales, no proporciona códigos de clasificación.

\subsubsection{El modelo de apoyos}

La concepción de la discapacidad como un estado de funcionamiento en lugar de cómo un rasgo intrínseco tiene implicaciones importantes en el papel que juega el entorno (como facilitador o barrera) en los resultados conseguidos por las personas con discapacidad intelectual. En este sentido, Schalock et al. (2010) defienden tres implicaciones principales relacionadas con el rol que el entorno y los apoyos deben cumplir en la vida de las personas con discapacidad: (1) las necesidades de apoyo que resulten del desajuste persona-ambiente se puede abordar a través del uso adecuado de apoyos individualizados en vez de centrarse solamente en 'arreglar a la persona'; (2) la mejora del funcionamiento y el logro de resultados dependerán del grado en que estos apoyos individualizados se basen en una planificación y aplicación seria; y (3) los apoyos son un puente entre lo que es y lo que puede ser.

Teniendo en cuenta estas nuevas implicaciones, las personas con discapacidad intelectual dejan de ser vistas como personas con un menor CI y comienzan a ser identificadas a través del nivel e intensidad de sus necesidades de apoyo. A pesar de que hay una relación recíproca entre deficiencias y necesidades de apoyo, según la cual mayores limitaciones personales van asociadas con una mayor intensidad de las necesidades de apoyo, es más probable que un enfoque centrado en reducir la discrepancia entre las competencias de una persona y las exigencias de su entorno, más que otro centrado en los déficits, identifique los apoyos necesarios para mejorar el funcionamiento humano y los resultados personales (Thompson et al., 2009; Thompson y Viriyangkura, 2013).

En este marco teórico, donde los apoyos son la pieza de unión principal entre las capacidades, las demandas y los resultados, es imprescindible desarrollar un modelo específico de apoyos que ayude a mejorar su incorporación en la promoción de la competencia, la capacitación y la autodeterminación de las personas con discapacidad intelectual. Para ello, es necesario comprender los supuestos relacionados con los apoyos: (a) se basan en un enfoque ecológico que entiende que la conducta depende de la evaluación de la discrepancia entre las capacidades y habilidades de una persona y las 
habilidades adaptativas y competencias requeridas para funcionar en su ambiente; (b) el riesgo idiosincrático y los factores protectores de la salud física y psicológica, los ambientes y sus demandas, y las discapacidades asociadas pueden influenciar los apoyos que mejoran el funcionamiento individual; (c) la discrepancia entre habilidades y requisitos se evalúa en función de posibles áreas de apoyo; (d) la intensidad de los apoyos requeridos se determina para cada una de las áreas de apoyo; (e) los apoyos cumplen varias funciones que actúan para reducir la discrepancia entre una persona y sus requisitos ambientales; (f) las fuentes de las funciones de apoyo son diversas, y han de primar aquellas fuentes de apoyo natural; y (g) los resultados personales deseados no siempre han de centrarse en la mejora de las capacidades individuales, sino también en la mejora del bienestar.

Con el objetivo de alcanzar una comprensión exhaustiva de los apoyos que permita a las organizaciones proveer apoyos de manera coherente a las asunciones del nuevo paradigma, en 1992 (Luckasson et al.), surge un modelo de apoyos que revela su definición y componentes principales (Tabla 7). En este momento, los apoyos se conceptualizan por primera vez dentro del ámbito de la discapacidad y quedan definidos como "recursos y estrategias que promueven los intereses y las causas de individuos con o sin discapacidades: que les capacitan para acceder a recursos, información y relaciones en entornos de trabajo y de vida integrados, y que incrementen su interdependencia o independencia, productividad, integración en la comunidad y satisfacción" (p. 101). No obstante, el modelo de apoyos se relaciona de manera directa con el modelo del funcionamiento humano y, como éste, irá sufriendo modificaciones a la luz de las investigaciones realizadas en los últimos años para la mejora del mismo (Luckasson et al. 2002) hasta llegar al modelo actual (Thompson et al., 2009; Schalock et al., 2010).

En 2002 (Luckasson et al.) se propone una nueva definición que, respetando los puntos clave de la definición de 1992, recoge aspectos de los apoyos investigados a lo largo de esa década (Martorell, 1994; Steman y van Gennep, 1996). Así, los apoyos pasan a definirse como "recursos y estrategias que pretenden promover el desarrollo, educación, intereses y bienestar personal de una persona y que mejoran el funcionamiento individual” (p. 186). Esta nueva definición concreta mejor los requisitos que han de cumplir los diferentes recursos y estrategias utilizados para poder ser considerados apoyos: (a) permitir a las personas acceder a recursos, información y relaciones en ambientes integrados: (b) originar un incremento de la integración y una mejora del desarrollo personal; y (c) poder ser evaluados a partir de sus resultados. 
Tabla 7. Componentes del modelo de apoyos (Luckasson et al., 1992)

\section{CARACTERÍSTICAS CLASIFICACIÓN}

\begin{tabular}{|c|c|c|}
\hline \multirow[t]{2}{*}{$\begin{array}{l}\text { FUENTES DE } \\
\text { APOYO }\end{array}$} & $\begin{array}{l}\text { Personales } \\
\text { Otros (naturales) }\end{array}$ & $\begin{array}{l}\text { Recursos y estrategias proporcionados por personas o equipamiento en determinados entornos que: (a) posibilitan el logro de } \\
\text { resultados personales y rendimiento deseados; (b) están normalmente disponibles y son culturalmente apropiados en al ambiente } \\
\text { respectivo; y (c) están apoyados por recursos dentro del ambiente y facilitados por la coordinación de servicios humanos. Se recogen } \\
\text { dentro de esta categoría los apoyos de la propia persona, de familia y amigos y otros apoyos informales. }\end{array}$ \\
\hline & $\begin{array}{l}\text { Tecnología } \\
\text { Servicios }\end{array}$ & $\begin{array}{l}\text { Todo tipo de apoyos proporcionados por profesionales, servicios (especializados o genéricos) que se diseñan o trabajan para prestar } \\
\text { apoyos y que no forman parte de los 'entornos naturales' de la persona. }\end{array}$ \\
\hline \multirow{8}{*}{$\begin{array}{l}\text { FUNCIONES DE } \\
\text { APOYO }\end{array}$} & Enseñanza & $\begin{array}{l}\text { Supervisión; ofrecimiento de feedback; organización del entorno de aprendizaje. } \\
\text { Formación; evaluación; apoyo en clases inclusivas. } \\
\text { Instrucción; recogida de datos; instrucción individualizada. }\end{array}$ \\
\hline & Amistad & $\begin{array}{l}\text { Defensa; transporte compartido; supervisión; instrucción. } \\
\text { Evaluación; comunicación; entrenamiento; ofrecimiento de feedback. } \\
\text { Reciprocidad; hacer amigos y romper con amigos; socialización. }\end{array}$ \\
\hline & $\begin{array}{l}\text { Planificación } \\
\text { económica }\end{array}$ & $\begin{array}{l}\text { Trabajar con seguro; defender la obtención de beneficios. } \\
\text { Apoyo en el control del dinero; protección y ayuda legal. } \\
\text { Planificación; consideraciones sobre ayuda en los ingresos y planificación. }\end{array}$ \\
\hline & $\begin{array}{l}\text { Asistencia al } \\
\text { empleado }\end{array}$ & $\begin{array}{l}\text { Asesoramiento; provisión/empleo de ayudas técnicas. } \\
\text { Supervisión del entrenamiento; mejora del rendimiento laboral. } \\
\text { Ayuda/intervención en crisis; adaptaciones del empleo y rediseño de las tareas laborales. }\end{array}$ \\
\hline & Apoyo Conductual & $\begin{array}{l}\text { Análisis funcional; instrucción multicomponente; énfasis en la manipulación de los antecedentes. } \\
\text { Manipulación de eventos ecológicos y contextuales; enseñanza de conducta adaptativa. } \\
\text { Construcción de ambientes con consecuencias efectivas. }\end{array}$ \\
\hline & Ayuda en el hogar & $\begin{array}{l}\text { Cuidado personal; transferencia y movilidad; vestido y aseo; modificaciones arquitectónicas. } \\
\text { Aparatos de comunicación; apoyo conductual; control de la comida y alimentación; mantenimiento del hogar. } \\
\text { Respiro en el cuidado; asistente personal; equipos de salud en el hogar; servicios domésticos. }\end{array}$ \\
\hline & $\begin{array}{l}\text { Acceso y uso de la } \\
\text { comunidad }\end{array}$ & $\begin{array}{l}\text { Programa de transporte compartidos; entrenamiento en transporte; habilidades de protección personal. } \\
\text { Implicación en el ocio y tiempo libre; oportunidades de tomar conciencia de la comunidad; modificaciones del vehículo. } \\
\text { Oportunidades de uso de la comunidad y de interactuar con servicios genéricos. }\end{array}$ \\
\hline & Asistencia sanitaria & $\begin{array}{l}\text { Citas médicas; intervenciones médicas; supervisión; aparatos de alerta médica. } \\
\text { Procedimientos de emergencia; movilidad (ayudas técnicas); citas de asesoramiento; toma de medicación. } \\
\text { Conciencia de riesgos; entrenamiento en seguridad; terapia física y actividades relacionadas; asesoramiento. }\end{array}$ \\
\hline \multirow{4}{*}{$\begin{array}{l}\text { INTENSIDADES DE } \\
\text { APOYO }\end{array}$} & Intermitente & Apoyos episódicos, caracterizados por su carácter incidental, se dan porque hacen falta en un momento determinado y a corto plazo. \\
\hline & Limitado & Apoyos caracterizados por su consistencia a lo largo del tiempo, se ofrecen por un tiempo limitado pero sin naturaleza intermitente. \\
\hline & Extenso & Apoyos caracterizados por la implicación regular, en varios contextos-situaciones y no tienen un límite en su tiempo de aplicación. \\
\hline & Generalizado & $\begin{array}{l}\text { Apoyos consistentes que se proporcionan de manera muy estable e intensa y cuya duración en el tiempo y diversidad de contextos- } \\
\text { situaciones puede ser muy amplia (incluso toda la vida). Implican más miembros del personal y mayor intrusión. }\end{array}$ \\
\hline $\begin{array}{l}\text { RESUTADOS } \\
\text { DESEADOS }\end{array}$ & & $\begin{array}{l}\text { Incrementar el nivel de habilidades adaptativas/capacidades funcionales } \\
\text { Fomentar la adquisición de los objetivos de la habilitación relacionados con el bienestar y el funcionamiento de la persona } \\
\text { Potenciar las características del entorno relacionadas con la presencia en la comunidad, la elección, la participación, etc. }\end{array}$ \\
\hline
\end{tabular}

\section{DESCRIPCIÓN/EJEMPLOS}

Potenciar las características del entorno relacionadas con la presencia en la comunidad, la elección, la participación, etc. 
Asimismo, en 2002 (Luckasson et al.) la representación del modelo de apoyos sufre cambios y se añaden las áreas de apoyo como uno de los componentes centrales a tener en cuenta por el modelo (Figura 5). Al enfatizarse el papel del entorno en esta décima edición del manual, se considera necesario que dentro de este modelo de apoyos se reflejen de manera explícita los diferentes entornos normalizados típicos para cualquier persona, proponiéndose nueve áreas de apoyo fundamentales: 'desarrollo humano', 'enseñanza y educación', 'vida en el hogar', 'vida en la comunidad', 'empleo', 'salud y seguridad'

\section{2}

\begin{tabular}{|c|}
\hline Fuentes de Apoyo \\
\hline Resultados Deseados \\
\hline
\end{tabular}

\section{2}

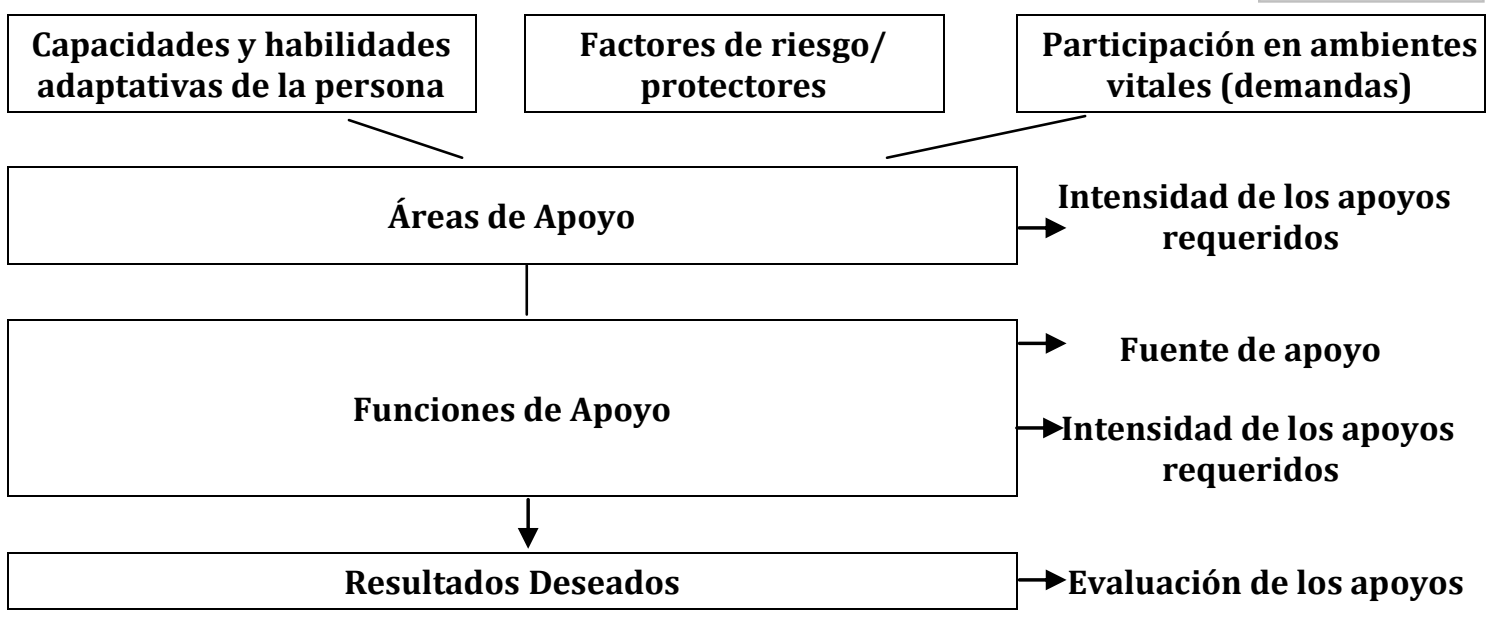

Figura 5. El modelo de apoyos de la AAMR (Luckasson et al., 1992; Luckasson et al., 2002)

Finalmente, el actual modelo de apoyos reconoce la definición de apoyos presentada anteriormente (Thompson et al., 2009, p.136; Schalock et al., 2010, p. 48), pero difiere sustancialmente de los modelos previos en sus características esenciales, superando las críticas recibidas sobre la complejidad e imprecisión de sus componentes (Greenspan y Switzky, 2003). Por ello, este último modelo se desarrolla de manera parsimoniosa, recogiendo de manera explícita la concepción socioecológica de la discapacidad y no describiendo la posible naturaleza de estos, sino la importancia de su enfoque individualizado. 
Asimismo, el actual modelo de apoyos (Figura 6), se conceptualiza de manera coherente al modelo del funcionamiento $\mathrm{y}$, coherentemente, incluye tres pilares (Thompson et al., 2009): (1) el desajuste entre las competencias y las demandas, que genera una serie de necesidades de apoyo; (2) la planificación individualizada e implementación de los apoyos necesitados y (3) los resultados personales mejorados como consecuencia de la alineación de los constructos anteriores.

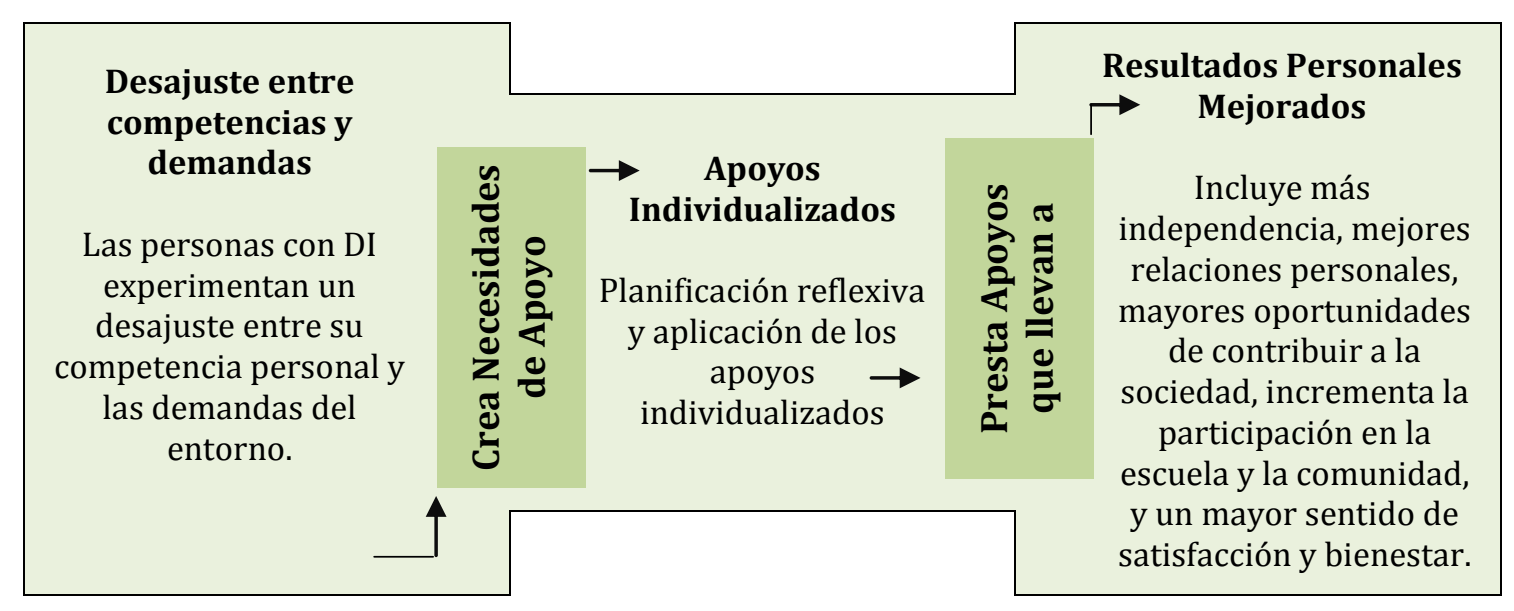

Figura 6. El modelo de apoyos la AAIDD (Schalock et al., 2010; Thompson et al., 2009)

En relación con la importancia e implicaciones del modelo de apoyos, Schalock et al. (2010) y Wehmeyer et al. (2008), a partir de varias referencias previas (Instituto de Medicina, 1991; Luckasson et al., 1992; Luckasson et al., 2002; OMS, 2001) destacan las bases críticas que darán forma a esta concepción de los apoyos dentro del modelo y que deberán ser tenidas en cuenta en el proceso de planificación y provisión de los mismos para asegurar su adecuado uso:

- Base contextual de los apoyos: refleja tres temas centrales; (a) el medio, la perspectiva, el entorno o las circunstancias en las que se da la conducta; (b) la realidad es continua y cambiante e incluye a los miembros que transforman el entorno y, a su vez, son transformados por el entorno; y (c) la persona es un determinante activo de su desarrollo y funcionamiento.

- Base ecológica de los apoyos: existe una evidencia clara de que la congruencia entre los individuos y sus entornos facilita el funcionamiento humano. La facilitación de tal congruencia incluye determinar el perfil e intensidad de las necesidades de apoyo para cada persona particular y proporcionar los apoyos individualizados necesarios para mejorar su funcionamiento humano. 
- Base igualitaria de los apoyos: El igualitarismo es la creencia en la igualdad humana, atendiendo especialmente a los derechos sociales, políticos, y económicos. El resultado global de estas tendencias legales y de prestación de servicios ha sido un énfasis en el papel de apoyos individualizados, basados en las necesidades de apoyo de cada persona en su contacto para la mejora del funcionamiento humano. Cabe destacar en este punto que la base igualitaria de las apoyos no defiende que todas las personas deban recibir los mismos apoyos (lo cual seguiría generando diferencias); sino aquellos que necesiten para conseguir resultados y condiciones igualitarios.

A partir de las bases de los apoyos, es fácil deducir que, tal y como hemos venido explicando en este capítulo, el objetivo de los apoyos no se centra exclusivamente en que la persona pueda hacer algo por sí misma, sino que deben orientarse a conseguir otro tipo de resultados personales relacionados con los derechos, el bienestar, la participación y la mejora de la calidad de vida (Thompson et al., 2009). Consecuentemente, el modelo de apoyos actual (Schalock et al., 2010; Thompson et al., 2009) ilustra una doble perspectiva desde la que los apoyos pueden trabajar para reducir la discrepancia entre lo que una persona es capaz de hacer y lo que demandan las actividades: (1) mejorando las capacidades personales; y (2) reduciendo las demandas ambientales. Estas dos funciones globales deben estar alineadas para optimizar la eficacia de los apoyos y conseguir la mejora de la participación de las personas con discapacidad en contextos ordinarios (aumentando su inclusión y bienestar).

Aprovechando esta distinción, Thompson et al. (2009) relacionan este modelo de apoyos con la Tecnología del Funcionamiento Humano (Human Performance Technology [HPT]), desde la que el funcionamiento humano es resultado de las interacciones entre la conducta y el desempeño de una persona y su entorno (Gilbert, 1978; Wile, 1996). Este modelo diferencia conceptualmente entre 'apoyos de entrenamiento y tratamiento', destinados principalmente a mejorar las habilidades intrínsecas del individuo (apoyos internos), y aquellos apoyos dirigidos a realizar adaptaciones ambientales y sociales que reduzcan las consecuencias de esa condición (apoyos externos). En este sentido, Thompson et al. (2009) recoge un listado de ejemplos de apoyos (Tabla 8) que son necesitados por personas con discapacidad y que pueden incluirse en la teoría del desempeño humano de Wile (1996). 
Tabla 8. Relación del modelo de apoyos y modelo de tecnología del funcionamiento humano (Thompson et al., 2009)

\begin{tabular}{|c|c|c|}
\hline TIPO & ELEMENTO & EJEMPLO (APOYO PARA PERSONAS CON DISCAPACIDAD) \\
\hline \multirow{5}{*}{ EXTERNO } & $\begin{array}{l}\text { 1. Sistemas } \\
\text { organizacionales }\end{array}$ & $\begin{array}{l}\text { - Aprobación de leyes y políticas públicas que ofrezcan } \\
\text { incentivos para contratar a las personas con discapacidad. } \\
\text { - Establecimiento de estándares empresariales para } \\
\text { construir y reformar entornos de vivienda y comunitarios } \\
\text { basándose en principios de diseño universal. }\end{array}$ \\
\hline & 2. Incentivos & $\begin{array}{l}\text { - Elaboración de un contrato conductual que incluya el } \\
\text { refuerzo positivo de las conductas de mantenimiento del } \\
\text { hogar en condiciones de salubridad e higiene. } \\
\text { - Aumento de las oportunidades de participación en } \\
\text { actividades de preferencia por ganar más dinero debido a } \\
\text { un buen desempeño laboral. }\end{array}$ \\
\hline & 3. Apoyo Cognitivo & $\begin{array}{l}\text { - Avisos por parte de un compañero de trabajo para cambiar } \\
\text { de una actividad a otra. }\end{array}$ \\
\hline & 4. Herramientas & $\begin{array}{l}\text { - Utilización de sistemas alternativos o aumentativos de } \\
\text { comunicación para aumentar la comunicación expresiva. } \\
\text { - Uso de una calculadora para facilitar el intercambio } \\
\text { correcto de dinero al hacer compras. }\end{array}$ \\
\hline & 5. Entorno físico & $\begin{array}{l}\text { - Permiso para la realización de exámenes en una zona de la } \\
\text { clase con menos distracciones. } \\
\text { - Reducción de la altura de los archivadores para que puedan } \\
\text { ser utilizados por una persona en silla de ruedas. }\end{array}$ \\
\hline \multirow{3}{*}{ INTERNO } & $\begin{array}{l}\text { 6. Habilidades/ } \\
\text { conocimiento }\end{array}$ & $\begin{array}{l}\text { - Adiestramiento acerca del modo en que se usa un servicio } \\
\text { local de salud. } \\
\text { - Utilización de historias sociales para preparar a una } \\
\text { persona para su visita a la conducta del médico. }\end{array}$ \\
\hline & & $\begin{array}{l}\text { - Realización de ejercicio para mejorar la vitalidad y } \\
\text { resistencia física. }\end{array}$ \\
\hline & $\begin{array}{l}\text { 7. Capacidad } \\
\text { Inherente }\end{array}$ & $\begin{array}{l}\text { - Utilización de la motivación intrínseca para mejorar el } \\
\text { desempeño en actividad o situación. } \\
\text { - Combinación de los trabajos y otras actividades con los } \\
\text { puntos fuertes de la persona relacionados con los mismos. }\end{array}$ \\
\hline
\end{tabular}

No obstante, es necesario destacar que, si bien desde este modelo se defiende que la característica principal de los apoyos ha de ser siempre su capacidad de adaptarse a cada persona y situación específica, se expone también de manera explícita la importancia de intentar sobreponer los apoyos naturales de la persona a cualquier otro tipo de apoyos para conseguir los resultados deseados. Esta afirmación refleja los resultados obtenidos en recientes estudios (Claes et al., 2012, Petito y Cummins, 2000; Petry, Maes y Vlaskamp; 2005, Renty y Roeyers, 2006), donde se manifiesta que los apoyos naturales tienen un mayor impacto en la calidad de vida las personas con discapacidad. De manera complementaria, el estudio realizado por Downing y Pecham-Hardin (2007), referente a los beneficios de la inclusión escolar, puso de manifiesto que los apoyos naturales tenían beneficios no solo para quien los recibía, sino también para aquellos que los facilitaban. 
Según Hahn (1993), fracasar en nuestro objetivo por un mundo que incluya a todos, ya no depende de la incapacidad de algunas personas para adaptarse a las demandas de la sociedad, sino de la propia sociedad y del entorno creado por el ser humano para ajustarse a las necesidades y aspiraciones de cada persona. Y es que, adoptar un enfoque basado en el paradigma de apoyos requiere un compromiso explícito de planificación y un cambio en el modo de hacerlo por parte de todos.

En este sentido, los apoyos deben entenderse como un componente de prevención primaria (Schalock et al., 2010) que puede evitar muchas de las consecuencias negativas derivadas de las discrepancias existentes entre las capacidades de las personas con discapacidad intelectual y el entorno. Por ejemplo, proporcionar apoyos que garanticen la participación dentro de la comunidad y alcanzar los resultados deseados, si bien no proporciona de manera directa un mejor funcionamiento de la persona, sí permite potenciar el desarrollo personal y evitar otras consecuencias negativas adicionales (emocionales...) que podrían derivarse a la falta de oportunidades.

\subsubsection{Conceptos clave del modelo de apoyos}

El modelo de apoyos se refiere de manera directa el concepto de apoyos a través de otros dos constructos clave que operativizan el mismo a través de la evaluación e intervención. Por un lado, es importante conocer las necesidades de apoyo de la persona con discapacidad y, a partir de estas necesidades, crear sistemas de apoyo que permitan la consecución de los resultados planteados. Así, si bien estos constructos se encuentran estrechamente relacionados, es necesario realizar una distinción precisa del campo de actuación de cada uno de ellos para poder optimizar su comprensión y la eficacia de los apoyos proporcionados (Tabla 9).

Tabla 9. Definición de conceptos clave en el modelo de apoyos: necesidades de apoyo y sistemas de apoyos (Schalock et al., 2010; Thompson et al., 2009)

\begin{tabular}{ll}
\hline Término & Definición \\
Necesidades de apoyo & $\begin{array}{l}\text { Constructo psicológico que hace referencia al patrón y la intensidad de los } \\
\text { apoyos necesarios para que una persona participe en actividades } \\
\text { relacionadas con el funcionamiento humano típico. }\end{array}$ \\
Sistemas de apoyo & $\begin{array}{l}\text { Uso planificado e integrado de estrategias y recursos de apoyo } \\
\text { individualizado que engloba los múltiples aspectos del funcionamiento } \\
\text { humano en distintos contextos. }\end{array}$ \\
\hline
\end{tabular}


Thompson et al. (2009) defienden que no siempre los apoyos que recibe una persona se corresponden con sus necesidades de apoyo. En ocasiones, los apoyos que se reciben no llegan a cumplir los apoyos que se necesitarían para participar de manera satisfactoria en las diferentes actividades y, lo que es más frecuente, la mayoría de las veces los apoyos que reciben las personas con discapacidad son superiores a los que realmente necesitan, dándose una sobreprotección que impide el desarrollo y el aprendizaje de la persona, limitando su potencial y el logro de los resultados esperados (Stancliffe y Keane, 2000).

Tradicionalmente, de acuerdo al paradigma asistencial que ha estado vigente a principios del siglo XX, las personas con discapacidad recibían una atención total, dando los profesionales a la persona todo lo necesario para la supervivencia (comida, alojamiento...) independientemente de la capacidad de cada uno para desarrollar las actividades de la vida diaria. Asimismo, en otros muchos ámbitos de las personas con discapacidad esa sobreprotección se convertía en falta y escasez de apoyos. Por ejemplo, en referencia a la autodeterminación (al no tratarse como una necesidad vital), los profesionales no ofrecían a las personas con discapacidad ningún tipo de apoyo que les permitiría desarrollarse en ese sentido; no había oportunidades de elección, sino imposiciones marcadas desde la sobreprotección de la seguridad médica y social.

Sin embargo, actualmente, la sobreprotección y las bajas expectativas sobre las personas con discapacidad se consideran formas de discriminación en la medida que disminuyen las capacidades y aprendizajes de la persona y fomentan un menor desarrollo, lo que podría tener consecuencias negativas en la vida de la persona con discapacidad (Sanders, 2006). Asimismo, Thompson et al. (2009) defienden que todas las personas necesitarán todos los apoyos disponibles ni necesitarán los mismos apoyos en las diferentes áreas ni a lo largo de su vida. Es por ello que los profesionales del campo de la discapacidad afirman que la identificación de necesidades de apoyo debe permitir establecer sistemas de apoyos que aporten apoyos individualizados ajustados diferentes áreas de la vida diaria de las personas con discapacidad, los cuales, mantenidos a lo largo del tiempo y adaptados a cada persona, mejoren no solo el bienestar físico, sino también el bienestar psicológico de la persona, incrementando sus habilidades, su participación y su calidad de vida (Luckasson et al., 2002; Schalock et al., 2010). En este sentido, se puede apreciar que, precisamente, el constructo de 'necesidades de apoyo' se convierte en la base que sustenta el modelo de apoyos, por lo que los siguientes apartados irán destinados a conocer un poco mejor su naturaleza e implicaciones. 


\subsubsection{Entendiendo el constructo de 'necesidades de apoyo': definición, perspectivas y factores influyentes}

El concepto de necesidad generalmente se refiere a una condición caracterizada por la ausencia de algo requerido y ha recibido diferentes matices dependiendo del ámbito específico de actuación en el que fuese tratada. Dentro de la literatura profesional relativa a la salud, el concepto de necesidad se ha referido tradicionalmente a una condición caracterizada por "una alteración en la salud y el bienestar" (Donabedian, 1973, p. 62) o "lo que es necesario para la salud y el bienestar de un organismo" (Harré y Lamb, 1988, p. 409), siendo definida específicamente dentro de la psicología como "un estado de motivación resultante de un sentimiento de insatisfacción o privación en el sistema biológico demostrado por un impulso para completar esa carencia” (Colman, 2001, p.631).

Por último, para su aplicación concreta dentro del campo de la discapacidad, se recogieron las aportaciones realizadas por Bradshaw (1972) sobre la naturaleza de las necesidades sociales, incluyendo así las necesidades de las personas con discapacidad intelectual dentro de una tipología general que permite dividir las necesidades de cualquier persona según las expectativas sobre las que se fundamentan los juicios de valor (Tabla 10). Actualmente, se defiende que la personas con discapacidad intelectual tienen las mismas necesidades que las personas sin discapacidad pero, además, podrían manifestar otras necesidades extraordinarias y/o necesitar apoyos específicos (en términos de tipo, frecuencia y duración de los mismos) para identificar, expresar y suplir esas necesidades (Thompson y Viriyangkura, 2013).

De esta manera, las necesidades de apoyos, según su uso y conceptualización dentro de nuestra concepción de discapacidad intelectual, han sido definidas como un constructo psicológico referido a la intensidad de apoyo que una persona requiere pare participar en las actividades relacionadas con el funcionamiento humano normativo (Thompson et al., 2009, p.136) y serían identificadas a través del input de la persona y otros informadores (Schalock et al., 2010; Thompson, Hughes et al., 2002; Thompson et al., 2004; Thompson, Wehmeyer y Hughes, 2010; Thompson y Viriyangkura, 2013).

En este sentido, se defiende que las necesidades de apoyo deben ser la base para proporcionar apoyos individualizados que, mantenidos a lo largo del tiempo y adaptados a cada persona, mejoren el bienestar de la persona, incrementando sus habilidades, su participación y su calidad de vida, equiparándose sus resultados personales a los de la población general en mayor medida. 
Tabla 10. Tipos de necesidades sociales (adaptado de Schalock et al., 2010, p.173;

Thompson et al., 2009, p.136)

\begin{tabular}{|c|c|}
\hline TIPO & DESCRIPCIÓN \\
\hline $\begin{array}{l}\text { Necesidades } \\
\text { normativas }\end{array}$ & $\begin{array}{l}\text { Se basan en el establecimiento, por parte de un experto o grupo de expertos, } \\
\text { profesionales o científicos sociales, de los niveles de satisfacción } \\
\text { teóricamente deseables. Con su experiencia y conocimiento, los expertos } \\
\text { señalan qué resultados deberían esperarse y qué niveles de servicios son } \\
\text { necesarios para alcanzarlos. Cambian con el tiempo, como resultado de los } \\
\text { avances del conocimiento científico y tecnológico, y también con la } \\
\text { modificación de los valores de la sociedad. }\end{array}$ \\
\hline $\begin{array}{l}\text { Necesidades } \\
\text { expresadas }\end{array}$ & $\begin{array}{l}\text { Son las tradicionalmente denominadas 'demandas'. Es la necesidad } \\
\text { manifestada en algún servicio hacia el que se puedan canalizar solicitudes de } \\
\text { ayuda. Dichas necesidades pueden manifestarse a través de tasas de } \\
\text { utilización de servicios, listas de espera, etc. Para la mayoría de las } \\
\text { decisiones que hacen referencia a la planificación y realización de } \\
\text { presupuestos, el factor crítico es la utilización. Si un servicio es utilizado se } \\
\text { suele financiar; en caso contrario, no. Sin embargo, el hecho de que un } \\
\text { servicio sea utilizado no implica necesariamente que sea adecuado para las } \\
\text { necesidades de la población, ya que la solicitud de un servicio depende de los } \\
\text { servicios disponibles en un momento dado; la oferta de recursos siempre } \\
\text { condiciona la demanda. Por otra parte, existen intervenciones sociales, sobre } \\
\text { todo aquellas que solemos englobar bajo el rótulo de prevención, que } \\
\text { normativamente, son las más pertinentes, y que raramente obedecen a una } \\
\text { demanda de los afectados por la necesidad. }\end{array}$ \\
\hline $\begin{array}{l}\text { Necesidades } \\
\text { percibidas o } \\
\text { experimentadas }\end{array}$ & $\begin{array}{l}\text { Son las basadas en la percepción de cada persona o grupo de personas sobre } \\
\text { determinada carencia. Es, por tanto, una apreciación subjetiva, condicionada } \\
\text { por factores psicológicos y psicosociales particulares. Sin embargo, desde } \\
\text { una perspectiva comunitaria no se puede negar que cuando muchos } \\
\text { miembros de una comunidad sienten lo mismo, ese hecho tiene estatuto de } \\
\text { realidad social y que la verdad de lo social no es patrimonio de los expertos } \\
\text { detentadores del saber científico o técnico. }\end{array}$ \\
\hline $\begin{array}{l}\text { Necesidades } \\
\text { comparativas }\end{array}$ & $\begin{array}{l}\text { Las expectativas en este caso se centran en la comparación entre los datos de } \\
\text { la población objetivo y los de otro grupo. Si un grupo recibe menos un } \\
\text { servicio que otro grupo o puntúa muy por encima o por debajo de la media } \\
\text { en alguna medida o indicador, se dice que hay una necesidad, ya que hay una } \\
\text { población que está siendo desatendida. Este tipo de juicios se suelen utilizar } \\
\text { en los diagnósticos de salud. Estas comparaciones conllevan extrapolaciones } \\
\text { de información ya disponible. Las expectativas comparativas varían según la } \\
\text { similaridad de los grupos. Esta aproximación no contempla la posibilidad de } \\
\text { que existan necesidades no atendidas por ningún servicio existente, que, por } \\
\text { tanto, permanecerían ocultas. }\end{array}$ \\
\hline
\end{tabular}

Paralelamente, dando un significado más completo al concepto de necesidades de apoyo, Thompson, Hughes et al. (2002) y Thompson et al. (2004) elaboraron un modelo de necesidades de apoyo donde se recogen aquellos factores principales que determinan (y predicen) el patrón y la intensidad de las necesidades de apoyo de las personas con discapacidad intelectual. En la Figura 7, se presenta la ilustración del modelo desarrollado, donde puede apreciarse la naturaleza de los factores propuestos. 


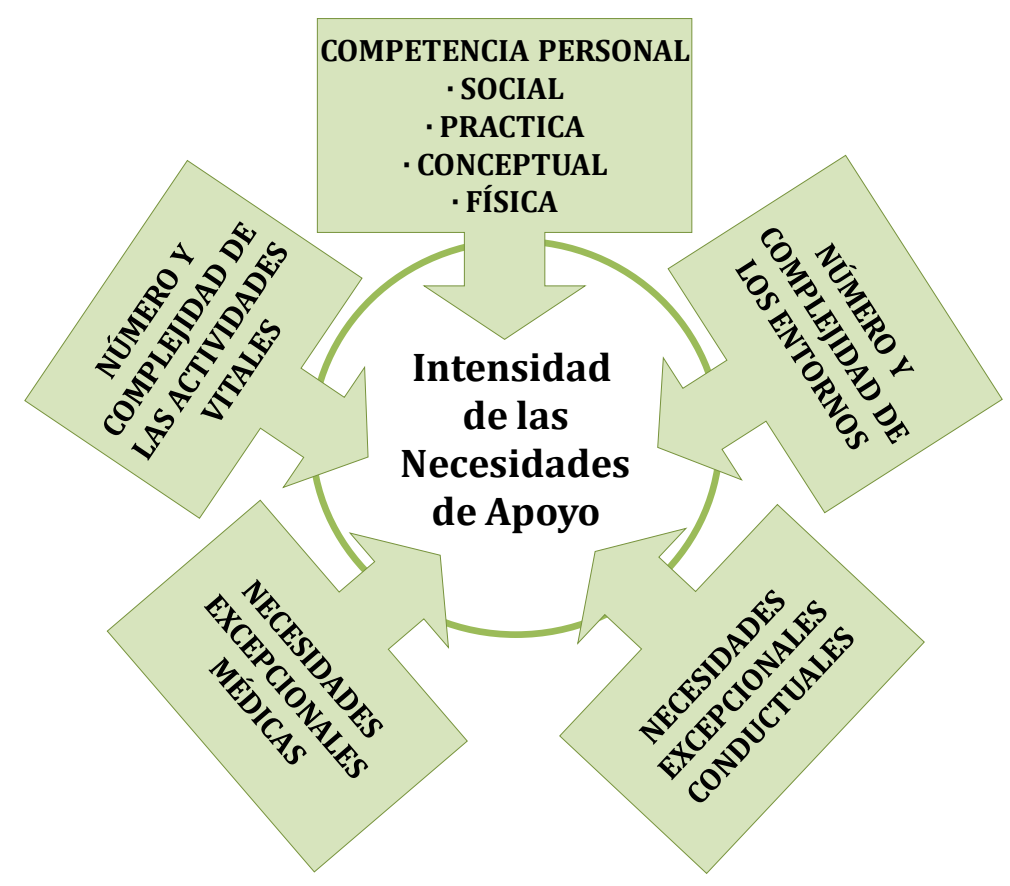

Figura 7. Factores predictores de las necesidades de apoyo

Dentro de estos cinco factores, destaca la presencia del componente competencia personal, ya que, en general, un mayor nivel de competencia se relaciona con una menor intensidad de las necesidades de apoyo y viceversa (Thompson y Viriyangkura, 2013). Sin embargo, no sólo las competencias personales (sociales, prácticas, conceptuales y físicas) son predictivas de las necesidades de apoyo de una persona; existen otros factores personales (relacionados con necesidades excepcionales médicas y conductuales) y ambientales (número y complejidad de los entornos y actividades vitales en los que la persona participa) que reflejan el innegable papel del contexto en la vida diaria de las personas con discapacidad intelectual (Shogren, 2013; Shogren, Luckasson et al., 2014).

\subsubsection{Las necesidades de apoyo como Zona de Desarrollo Próximo (ZDP)}

Según Vygotsky (1979), la Zona de Desarrollo Próximo (ZDP) es la diferencia entre el nivel real de desarrollo para resolver un problema con autonomía y el nivel de desarrollo potencial, es decir, aquello que somos capaces de conseguir con ayuda. En otras palabras, los apoyos son la herramienta de paso entre lo que se sabe hacer y lo que se podría llegar a conseguir, cubriendo las necesidades de la persona para llegar a un nivel superior de funcionamiento. 
Innegablemente, este concepto se encuentra muy relacionado con el modelo de apoyos, pues la zona de desarrollo próximo marcará el grado de apoyo que necesita una persona para alcanzar un resultado esperado en un momento determinado. A continuación, en la Figura 8, puede verse la correspondencia directa existente entre la propuesta de Vigotsky y la concepción de los apoyos tal y como se reconoce en el modelo actual de discapacidad intelectual.

\begin{tabular}{lll}
\hline $\begin{array}{c}\text { Teoría de la ZDP de } \\
\text { Vygotsky (1979) }\end{array}$ & $\begin{array}{c}\text { Modelo de Discapacidad } \\
\text { Intelectual (Schalock et al., 2010 }\end{array}$ \\
\cline { 3 - 3 } Nivel Potencial & Resultado Esperado \\
ZDP & & \\
& & Necesidad de apoyo \\
Nivel Real & 0 & \\
\hline
\end{tabular}

Figura 8. Comparación del término ZDP con el concepto de necesidades apoyo

Aunque ambas perspectivas están relacionadas y provocan un decremento en el nivel de competencia de la persona cuando los apoyos desaparecen, podemos encontrar algunas diferencias en sus implicaciones prácticas.

Si profundizamos un poco más en el concepto de la ZDP, encontramos que, en la mayoría de los casos, la finalidad general de esta teoría es que la persona vaya adquiriendo progresivamente diferentes destrezas (convirtiendo las habilidades ubicadas en su nivel potencial en parte de su capacidad real), alcanzando así nuevos retos y logrando cada vez niveles más altos de autonomía y competencia. De esta manera, los apoyos irán retirándose progresivamente en un proceso de andamiaje.

No obstante, como ya se ha mencionado anteriormente, dentro del campo de la discapacidad los apoyos no siempre buscan que la persona adquiera determinadas capacidades. En muchas ocasiones, los apoyos proporcionados a las personas con discapacidad estarán directamente orientados al logro de resultados, con el único objetivo de conseguir un mayor bienestar personal y una mejora de la calidad de vida. 


\subsubsection{La mejora del bienestar de las personas con discapacidad intelectual: el modelo de calidad de vida de Schalock y Verdugo}

Desde la llegada del modelo rehabilitación a mediados del siglo XX comenzaron a crearse servicios destinados al trabajo directo con las personas con discapacidad intelectual. Sin embargo, el objetivo del trabajo ha ido evolucionando con el cambio al paradigma social. Según van Loon (2009a, 2009b), mientras que el foco del trabajo con las personas con discapacidad estuvo de manera inicial centrado en la calidad de los cuidados, actualmente se considera que cualquier intervención tiene que tener como principal objetivo la calidad de vida individual de los usuarios.

Desde finales del siglo XX el concepto 'calidad de vida' ha sido uno de los conceptos más desarrollados e investigados en muchas disciplinas y ha sido utilizado con diferentes propósitos. En los años 80, se incorporó al campo de la discapacidad por varias razones, entre las que destacan que: (a) captaba la nueva comprensión socioecológica de la discapacidad; y (b) coincidía con las expectativas de los receptores de servicios y apoyos, quienes esperaban que estos influyeran de forma significativa y positiva en su bienestar personal (Schalock, Gardner et al., 2007).

El constructo de 'calidad de vida' integra los cambios establecidos en el actual paradigma de apoyos de discapacidad intelectual, sirviendo como marco de referencia para redefinir las prácticas de los profesionales y la gestión del rol de las organizaciones que proporcionan servicios y apoyos a las personas con discapacidades intelectuales y del desarrollo (Schalock y Verdugo, 2012, 2013b, 2014). Por ello, el concepto de calidad de vida se ha convertido en un área de especial interés para las aplicaciones prácticas y la investigación en los campos de la educación y educación especial, la salud física y mental, los servicios sociales (e.g., discapacidades intelectuales y del desarrollo, mayores), las familias, las organizaciones y las políticas públicas (Schalock y Verdugo, 2002, 2007, 2008, 2014).

No obstante, aún en la actualidad no existe un consenso claro sobre que es la calidad de vida, y existen muchos modelos de calidad de vida, que pueden ser clasificados en tres grandes grupos (Gómez, 2010): (a) centrados calidad de vida individual o personal (e.g., Campbell, Converse y Rodgers, 1976; Cummins, 1997, 2000; 2005; Felce y Perry, 1995, 1996; Petry et al., 2005; Petry, Maes y Vlaskamp, 2007; Schalock y Verdugo, 2002); (b) centrados en la calidad de vida familiar (e.g., Brown, Schalock y Brown, 2009; Schippers y van Boheemen, 2009; Summers et al., 2005; Werner, Edward y Baum, 2009; 
Zuna, Turnbull y Summers, 2009); y (c) orientados únicamente a conocer la calidad de vida relacionada con la salud (e.g., Byrne-Davis, Bennett y Wilcock, 2006; Ferrans, Zerwic, Wilbur y Larson, 2005; Kreitler y Kreitler, 2006; Rahtz, Sirgy y Lee, 2004; Taillefer, Dupois, Roberge y LeMay, 2003; Velarde y Ávila, 2002).

De entre todos los modelos presentados, el modelo de calidad de vida de Schalock y Verdugo (2002) es hoy uno de los más aceptados dentro del marco de la discapacidad (Schalock y Verdugo, 2007, 2008, 2013a), ya que cuenta con amplias evidencias de fiabilidad y validez (e.g., Gómez, Arias, Verdugo y Navas, 2011; Gómez, Verdugo y Arias, 2010; Gómez, Verdugo, Arias y Arias, 2011; Wang, Schalock, Verdugo y Jenaro, 2010), incluyendo estudios internacionales sobre la apropiada adecuación transcultural de sus dimensiones e indicadores (Jenaro et al., 2005; Keith, y Schalock, 2000; Schalock, Keith, Verdugo, y Gómez, 2010; Schalock et al., 2005).

A continuación se explica este modelo con mayor profundidad, pudiendo observarse el ajuste de sus características a los principios de conceptualización y aplicabilidad que la comunidad científica establece como fundamentales para el desarrollo cualquier modelo teórico (Schalock, 2000).

\subsubsection{Conceptualización, dimensiones e indicadores de calidad de vida}

El concepto de calidad de vida ha pasado de ser considerado una noción sensibilizadora, hacia las personas como eje central de los esfuerzos, a convertirse en un constructo social que guía las prácticas profesionales en los programas, la evaluación de resultados y la mejora continua de la calidad. La calidad de vida se entiende hoy tal y como fuera definida originariamente en el modelo propuesto por Schalock y Verdugo (2002) como: "un estado deseado de bienestar personal que: (a) es multidimensional; (b) tiene propiedades universales y propiedades ligadas a la cultura; (c) tiene componentes objetivos y subjetivos; y (d) está influenciado por características personales y factores ambientales".

En definitiva, una persona puede tener calidad de vida cuando sus necesidades personales están satisfechas y tiene la oportunidad de enriquecer su vida en las principales áreas de actividad vital para cualquier persona. La calidad de vida, por tanto, tiene componentes subjetivos y objetivos que se pueden medir, y se entiende desde un enfoque multidimensional de ocho dimensiones identificadas por numerosos indicadores (Tabla 11). 
Tabla 11. Modelo conceptual de calidad de vida de Schalock y Verdugo (2002). Adaptado de Buntinx y Schalock (2010)

\begin{tabular}{|c|c|c|c|}
\hline FACTORES & DIMENSIONES & DESCRIPCIÓN & INDICADORES \\
\hline \multirow{3}{*}{ Bienestar } & Bienestar Emocional (BE) & $\begin{array}{l}\text { Hace referencia a sentirse tranquilo, seguro, sin } \\
\text { agobios, no estar nervioso. }\end{array}$ & $\begin{array}{l}\text { Satisfacción, Autoconcepto y Ausencia de estrés o } \\
\text { Sentimientos negativos. }\end{array}$ \\
\hline & Bienestar Físico (BF) & $\begin{array}{l}\text { Tener buena salud, sentirse en buena forma } \\
\text { física, tener hábitos de alimentación saludables. }\end{array}$ & $\begin{array}{l}\text { Incluye los indicadores: Atención Sanitaria, Sueño, } \\
\text { Salud y sus alteraciones, Actividades de la vida diaria, } \\
\text { Acceso a ayudas técnicas y Alimentación. }\end{array}$ \\
\hline & Bienestar Material (BM) & $\begin{array}{l}\text { Tener suficiente dinero para comprar lo que se } \\
\text { necesita y se desea tener, tener una vivienda y } \\
\text { lugar de trabajo adecuados. }\end{array}$ & $\begin{array}{l}\text { Vivienda, Lugar de trabajo, Salario (Pensión, Ingresos) } \\
\text { Posesiones (bienes materiales), Ahorros (o posibilidad } \\
\text { de acceder a caprichos) }\end{array}$ \\
\hline \multirow[b]{2}{*}{ Independencia } & Autodeterminación $(A U)$ & $\begin{array}{l}\text { Decidir por sí mismo y tener oportunidad de } \\
\text { elegir las cosas que quiere, cómo quiere que sea } \\
\text { su vida, su trabajo, su tiempo libre, el lugar } \\
\text { donde vive, las personas con las que está. }\end{array}$ & $\begin{array}{l}\text { Metas y Preferencias Personales, Decisiones, } \\
\text { Autonomía y Elecciones. }\end{array}$ \\
\hline & Desarrollo Personal (DP) & $\begin{array}{l}\text { Se refiere a la posibilidad de aprender distintas } \\
\text { cosas, tener conocimientos y realizarse } \\
\text { personalmente. }\end{array}$ & $\begin{array}{l}\text { Limitaciones/capacidades, Acceso a nuevas } \\
\text { Tecnologías, Oportunidades de aprendizaje, } \\
\text { Habilidades relacionadas con el trabajo (u otras } \\
\text { actividades) y Habilidades funcionales (competencia } \\
\text { personal, conducta adaptativa, comunicación). }\end{array}$ \\
\hline \multirow{3}{*}{ Participación Social } & Derechos (DE) & $\begin{array}{l}\text { Ser considerado igual que el resto de la gente, } \\
\text { que le traten igual, que respeten su forma de ser, } \\
\text { opiniones, deseos, intimidad, derechos. }\end{array}$ & $\begin{array}{l}\text { Intimidad, Respeto, Conocimiento y Ejercicio de } \\
\text { derechos. }\end{array}$ \\
\hline & Inclusión Social (IS) & $\begin{array}{l}\text { Ir a lugares de la ciudad o del barrio donde van } \\
\text { otras personas y participar en sus actividades } \\
\text { como uno más. Sentirse miembro de la sociedad, } \\
\text { sentirse integrado, contar con el apoyo de otras } \\
\text { personas. }\end{array}$ & Integración, Participación, Accesibilidad y Apoyos. \\
\hline & Relaciones Interpersonales (RI) & $\begin{array}{l}\text { Relacionarse con distintas personas, tener } \\
\text { amigos y llevarse bien con la gente (vecinos, } \\
\text { compañeros, etc.). }\end{array}$ & $\begin{array}{l}\text { Relaciones Sociales, Tener amigos claramente } \\
\text { identificados, Relaciones familiares, Contactos sociales } \\
\text { positivos y gratificantes, Relaciones de pareja y } \\
\text { Sexualidad. }\end{array}$ \\
\hline
\end{tabular}


Desde su aparición, uno de los principales objetivos del modelo de calidad de vida reside en aportar una nueva línea de trabajo que permita (Schalock y Verdugo, 2007, 2008): (a) incrementar el bienestar personal; (b) alinear el concepto de calidad de vida con la herencia cultural y étnica de cada individuo; (c) promover el cambio individual, en los programas y en la comunidad; (d) aumentar el grado de control personal y de oportunidades individuales ejercido por la persona en referencia a sus actividades, intervenciones y contextos; y (e) ocupar un papel prominente en la recogida de evidencias, especialmente para identificar predictores significativos de una vida de calidad y para valorar el grado en que los recursos seleccionados mejoran los efectos positivos.

Sin embargo, los autores afirman que solo será posible obtener los resultados deseados en la medida en que logremos conocer las relaciones positivas entre los apoyos individualizados y cada una de las dimensiones de calidad de vida. Para demostrar esta relación, se recogen en la Tabla 12 algunas de los ejemplos propuestos por Schalock y Verdugo (2007) sobre el objetivo que deben perseguir los apoyos dentro del marco de cada una de las dimensiones del modelo de calidad de vida.

Tabla 12. Calidad de vida y apoyos individualizados (Schalock y Verdugo, 2007)

\begin{tabular}{ll}
\hline DIMENSIÓN & EJEMPLOS DE APOYOS INDIVIDUALIZADOS \\
\hline Autodeterminación & Elecciones, control personal, decisiones, metas personales \\
Bienestar Emocional & $\begin{array}{l}\text { Aumento de la seguridad, ambientes estables, feedback positivo, } \\
\text { previsibilidad, mecanismos de autoidentificación (e.g., espejos, } \\
\text { etiquetas con el nombre) }\end{array}$ \\
Bienestar Físico & Atención médica, movilidad, bienestar, ejercicio, nutrición \\
Bienestar Material & Propiedad, posesiones, empleo \\
Derechos & Privacidad, procesos adecuados, responsabilidades cívicas, \\
respeto y dignidad \\
Desarrollo Personal
\end{tabular}


Finalmente, es importante tener en cuenta que los apoyos mencionados deben de ser implementados atendiendo a las peculiaridades de cada persona y situación específicas, cumpliendo una serie de requisitos para poder conseguir una mejora real en la calidad de vida de la persona (Schalock y Verdugo, 2007, 2008): (a) estar centrados en la persona (basados en los intereses de la persona, sus preferencias, necesidades y red de apoyos naturales); (b) ser receptivos (basados en el diálogo entre la persona y los participantes en el plan de apoyos); (c) ser flexibles a lo largo de la vida; (d) ser activos (es decir, que pongan en igualdad de condiciones las oportunidades con los conciudadanos, habiliten a la persona, generen inclusión social efectiva e incrementen la participación de la comunidad y la sociedad); y (e) estar basados en datos (basados en las necesidades de apoyos y evaluados de acuerdo con los resultados personales).

\subsubsection{Aplicabilidad del concepto de calidad de vida}

El concepto de calidad de vida proporciona un marco de referencia integrador para promover el bienestar individual y familiar, mejorar la provisión de apoyos por parte de las organizaciones que atienden a personas con discapacidad intelectual y optimizar mediante el desarrollo de políticas públicas la prestación de servicios sociales. En otras palabras, para poder hablar de una completa aplicación del concepto de calidad de vida, este debe implantarse en los distintos planos del sistema social afectados: microsistema, mesosistema y macrosistema (Schalock y Verdugo, 2007, 2008).

a) Microsistema, o contexto social inmediato, como la familia, hogar, grupo de iguales y lugar de trabajo, que afecta directamente a la vida de la persona. Las ocho dimensiones del modelo sirven como marco de referencia para desarrollar Programas de Apoyo Individual. La evaluación integral de las necesidades de apoyo de la persona requiere de una estructura organizadora, como es el modelo multidimensional de calidad de vida, para gestionar adecuadamente la información diversa proveniente de distintos profesionales y personas involucradas en los apoyos. La mejor manera de lograr la síntesis necesaria de la información existente es utilizando ese marco referencial. Además, el modelo de calidad de vida sirve como referencia básica para el desarrollo de programas individuales y también para la valoración de resultados personales. 
b) Mesosistema, o vecindario, comunidad, agencias de servicios y organizaciones, que afecta directamente al funcionamiento del microsistema. Las organizaciones ocupan el lugar central habitualmente. $\mathrm{Y}$ en ellas es necesario contar con información personal de sus usuarios centrada en los resultados en calidad de vida. A partir de ella se planifican estratégicamente las actividades y apoyos de cambio y mejora organizacional. La información de evaluación de la calidad de vida de los usuarios es esencial para la mejora continua de la calidad y la redefinición de las organizaciones.

c) Macrosistema, o los patrones culturales más amplios, tendencias socio-políticas, sistemas económicos y otros factores relacionados con la sociedad, que afectan directamente a nuestros valores, creencias y al significado de palabras y conceptos. Las aplicaciones del concepto de calidad de vida en el macrosistema permiten orientar una nueva manera de planificar y valorar las políticas sociales. Sustituir los discursos generalistas por el análisis de resultados concretos de las políticas implementadas es el camino entendible por todos para una valoración adecuada de la eficacia de las acciones emprendidas. Los indicadores sociales, con una carga importante de los resultados personales evaluados, pueden ir describiendo los avances sociales progresivos en provisión de apoyos individualizados, inclusión, participación, independencia y bienestar.

Una vez analizada esta perspectiva de sistemas dentro de la que se enmarca el concepto de calidad de vida, podemos afirmar que este constructo de 'calidad de vida' es coherente y se alinea con un enfoque centrado en los derechos de la persona (Convención de la ONU de 2006), ya que su estructura multidimensional permite integrar indicadores relevantes que ejemplifiquen el ejercicio de los derechos (Navas et al., 2012; Verdugo, Navas et al., 2012).

Asimismo, destacamos que el modelo de Schalock y Verdugo sobre la calidad de vida es el marco de referencia principal para la valoración de resultados y avances en el ejercicio de los derechos de las personas con discapacidad intelectual. Este modelo ha sido ampliamente relacionado con la planificación de apoyos, la evaluación de servicios y el aumento de la participación social a través de actuaciones organizacionales y sociopolíticas (Giné, 2004), alineándose sus objetivos con los artículos de la Convención de Derechos (Verdugo et al., 2012; Schalock y Verdugo, 2013a) y convirtiéndose en una referencia clave para el cambio organizacional (Schalock y Verdugo, 2012, 2013b, 2014). 


\subsubsection{Los apoyos en la comunidad: el camino hacia la calidad de vida}

La llegada del paradigma de apoyos al ámbito de la discapacidad propone como uno de los principales resultados deseados el aumento de la calidad de vida de las personas con discapacidad. Asimismo, la comunidad es el contexto de una vida de calidad, por lo que resulta esencial que las personas puedan participar en la comunidad para mejorar su calidad de vida (van Loon, 2009). Sin embargo, resulta evidente que las personas con discapacidad intelectual se enfrentan a retos importantes en su desarrollo, mostrando con frecuencia dificultades para participar en actividades de la vida diaria en sus comunidades, manifestando características de 'candidez', 'credulidad' o 'inocencia' en su comportamiento que las hacen vulnerables al abuso y explotación por parte de otros (Greenspan, 2012; Greenspan et al., 2001).

En este sentido, para conseguir que las personas con discapacidad intelectual puedan participar en la sociedad y sean capaces de enfrentar sus retos, es necesario que reciban apoyos individualizados. En este sentido, alinear los apoyos individualizados con las dimensiones Inclusión Social y Autodeterminación se ha convertido en el elemento clave para optimizar el incremento general de la calidad de vida de las personas con discapacidad intelectual (van Loon, 2006a).

Desde esta perspectiva, los apoyos deben ser entendidos dentro de los contextos ordinarios y conceptualizarse como el nexo de unión entre la discapacidad y una nueva sociedad inclusiva (Abery y Fanhestock, 1994). El uso de este término, por tanto, no tiene cabida el uso de este término dentro de los contextos restrictivos todavía existentes (Taylor, 2001), los cuales se asientan de manera prioritaria en cuidados asistenciales y no refuerzan la autodeterminación.

Profundizando en la comprensión de la autodeterminación, ésta se define como una característica que permite "actuar como agente causal principal de la propia vida y hacer elecciones y tomar decisiones, que repercutan en la calidad de vida personal, libres de influencias externas o interferencias" (Wehmeyer, 1996, p.24). A pesar de que la autodeterminación puede ser desarrollada a través de programas de promoción, la investigación ha puesto de manifiesto que las limitaciones de las personas con discapacidad intelectual se relacionan con bajo control y falta de elecciones (e.g., Kishi, Teelucksingh, Zollers, Park-Lee y Meyer, 1988; Parsons, McCarn y Reid, 1993; Wehmeyer y Metzler, 1995), siendo necesaria la provisión de apoyos específicos para el fomento de la capacidad de elección de estas personas (Shevin y Klein, 2004; West y Parent, 1992). 
Con el objetivo establecer estrategias específicas (habilitación personal, defensa, entrenamiento en habilidades, modificación medioambiental/alojamiento, tecnologías de ayuda, asistencia personal...) para la provisión de apoyos en el campo de la autodeterminación, Stancliffe (2001) examinó los resultados encontrados por diversos autores sobre aquellos elementos que afectaban a la autodeterminación de las personas con discapacidad intelectual. Entre las conclusiones, destaca una alta presencia de componentes ambientales (por encima de otros personales) y la necesidad de crear cambios sociales, ya que, precisamente, existía una alta relación entre inclusión y autodeterminación: independientemente del CI, los contextos de vida menos restrictivos se asociaron frecuentemente a una mayor capacidad de elección (Nota, Ferrari, Soresi y Wehmeyer, 2007; Stancliffe, Abery y Smith, 2000; Stancliffe, Abery, Springborg y Eelkin, 2000; Wehmeyer y Bolding, 1999, 2001; Wehmeyer y Garner, 2003).

Verdugo (2009) afirma que proveer apoyos individualizados para la mejora de la calidad de vida (especialmente en relación con la inclusión social) también influye en el éxito educativo y el logro de metas en el área del empleo. Son numerosos los ejemplos que confirman la importancia de cubrir las necesidades de apoyo de las personas con discapacidad dentro de entornos ordinarios, incluyendo el contexto laboral en la vida adulta (Drake, Bond y Becker, 2012; Hunter y Ridley, 2007; Jordán de Urríes, León, Hidalgo, Martínez y Santamaría, 2014; Verdugo et al., 2012; Verdugo, Jordán de Urríes, Jenaro, Caballo y Crespo, 2006) y el contexto educativo en la infancia y la adolescencia (Ainscow, 1999, 2012; Arnaiz, 2003; Connor, Gabel, Gallagher y Morton, 2008; Echeita y Verdugo, 2004; López-López, 2012; Martínez-Figueira., 2013).

Precisamente, estos procesos de cambio hacia una mayor inclusión educativa se consideran requisito necesario para alcanzar una sociedad inclusiva (Durán et al., 2005; Laluvein, 2010). Por ello, se han elaborado diferentes estrategias destinadas a fomentar una adecuada inclusión escolar, dentro de las que destacamos la elaboración del Índice para la Inclusión (Index for Inclusion) (Booth y Ainscow, 2002; Sandoval et al., 2002), destinado a toda la comunidad educativa, desde donde se impulsan actualmente en España los procesos de atención a la diversidad.

Existen, asimismo, otros ejemplos de cómo los apoyos individualizados mejoran la calidad de vida en la medida que incrementan la participación de las personas con discapacidad en entornos normalizados (Braddock, 2002; Badia, Longo, Orgaz y GómezVela 2013; Larson, Lakin, Anderson y Kwak, 2001; Smith, Prouty y Lakin, 2001). No obstante, es necesario continuar trabajando en este tema, ya que los apoyos siguen 
proporcionándose hoy de manera más frecuente por profesionales dentro de servicios asistenciales que de manera natural, dentro de la comunidad y con propósitos de mejora de la calidad de vida (Braddock, Hemp y Rizzolo, 2008; Ferguson, Ferguson y Brodsky, 2008; Thompson y Viriyangkura, 2013).

En resumen, la inclusión en entornos normalizados es la clave fundamental de cambio y mejora de la calidad de vida de las personas con discapacidad intelectual (Schalock, 1996; Shogren, Wehmeyer, Palmer y Paek 2013) por lo que los apoyos y, por ende, las organizaciones deben funcionar como puente directo entre las personas con discapacidad y su comunidad, facilitando el proceso de inclusión y promocionando la autodeterminación (Guscia, Harries, Kirby, Nettelbeck y Taplin, 2006; van Loon, 2006a; van Loon y Van Hove, 2001).

\subsection{ESTRATEGIAS PARA LA TRANSFORMACIÓN ORGANIZACIONAL: PRÁCTICAS BASADAS EN LA EVIDENCIA, SISTEMAS DE APOYO ORIENTADOS A LOS RESULTADOS E INFLUENCIA DE LAS POLÍTICAS PÚBLICAS}

La investigación ha puesto de manifiesto la importancia del contexto en la vida de las personas con discapacidad intelectual y la importancia de los apoyos proporcionados desde las organizaciones que atienden a esta población (Shogren, Luckasson et al., 2014). Desde la actual concepción de discapacidad, el papel de las organizaciones no se reduce a prestar servicios, sino que su misión se amplia y los recursos proporcionados deben conectar a las persona con la sociedad en la que viven; sin embargo, este cambio no resulta sencillo, ya que supone una ruptura completa con los servicios tradicionales. La eficacia y eficiencia organizacional no estaban en las preocupaciones de hace unos años, donde lo prioritario era desarrollar programas y crear infraestructuras con la intención de ubicar a la persona en un espacio de protección. Sin embargo, las organizaciones, los servicios y los profesionales, tienen que cambiar del mismo modo que lo hace la sociedad para dar respuesta a las nuevas demandas, siendo la referencia actual para el cambio la calidad de vida como resultado esperado (Schalock y Verdugo, 2012, 2013b, 2014).

En este sentido, al igual que ocurría con el cambio de paradigma, las organizaciones han ido sufriendo cambios paulatinos hasta llegar a comprender su papel como facilitadores (y no cuidadores) de la persona con discapacidad (Bradley, 1994). En la Tabla 13 se puede observar con claridad que no existe una transformación directa desde la 
institucionalización hasta la pertenencia comunitaria. Existe un proceso transitorio de desinstitucionalización donde la persona con discapacidad deja de estar de manera permanente en las organizaciones, pero aún existe un cierto sesgo que no le deja sentirse parte de la sociedad, convirtiéndose así en clientes de servicios específicos que siguen buscando un cambio individual.

No obstante, aunque hoy en día ya parece estar claro el papel de unión que ha de suponer la organización entre la persona con discapacidad intelectual y la comunidad, aún quedan muchos pasos que dar para poder hablar de una implantación plena del nuevo paradigma en la práctica organizacional.

Tabla 13. Transformación de la calidad de los servicios (Tamarit, 2006)

\begin{tabular}{llll}
\hline & INSTITUCIONAL & DE INTEGRACIÓN & EN LA COMUNIDAD \\
\hline ¿Quién lo recibe? & Paciente & Cliente & Ciudadano \\
\hline $\begin{array}{l}\text { ¿ué se planifica? } \\
\begin{array}{l}\text { ¿Quién toma las } \\
\text { decisiones? }\end{array}\end{array}$ & Los cuidados & Las habilidades & El futuro \\
\hline $\begin{array}{l}\text { ¿Qué principios } \\
\text { guían? }\end{array}$ & $\begin{array}{l}\text { Limpieza, salud y } \\
\text { seguridad }\end{array}$ & $\begin{array}{l}\text { Habilidades y } \\
\text { socialización }\end{array}$ & $\begin{array}{l}\text { La persona con su } \\
\text { círculo de apoyos }\end{array}$ \\
\hline $\begin{array}{l}\text { ¿Qué determina la } \\
\text { calidad? }\end{array}$ & La práctica profesional & $\begin{array}{l}\text { La realización de } \\
\text { programas y objetivos }\end{array}$ & $\begin{array}{l}\text { La calidad de vida del } \\
\text { individuo }\end{array}$ \\
\hline
\end{tabular}

Por ello, considerando el gran salto que supone para las organizaciones esta transformación y con el objetivo de garantizar cambio eficaz es necesario desarrollar estrategias de cambio. En este sentido, debemos tener en cuenta que las estrategias se definen como la integración de visiones, misiones y valores en un plan de actuación diseñado para alcanzar resultados personales (Schalock, Gardner et al., 2007). En este contexto, Schalock y Verdugo (2012, 2013), recogiendo la investigación de los últimos años (e.g., Schalock, Verdugo, Bonham, Fantova y van Loon, 2008) recogen una serie de estrategias básicas para la eficacia organizacional y el cambio de los sistemas de pensamiento en los que están presentes tanto las prácticas como las políticas públicas.

En relación directa a las prácticas diarias, podemos afirmar que, actualmente, en el campo de la discapacidad intelectual las buenas prácticas para el diagnóstico, clasificación e intervención se basan en la ética profesional, los estándares profesionales, el juicio clínico, y el conocimiento procedente de la investigación (Schalock y Luckasson, 2004). De este modo, surge recientemente el concepto 'prácticas basadas en la evidencia', definidas 
como aquellas prácticas basadas en las mejores evidencias actuales obtenidas de fuentes creíbles que han usado métodos fiables y válidos y han sido claramente articulados y apoyadas tanto teórica como empíricamente (Schalock, Verdugo y Gómez, 2011).

De manera relacionada, en los últimos años, está tomando mayor relevancia el concepto 'resultados basados en la evidencia' (van Loon et al., 2013) que hace explícita una concepción del pensamiento de derecha a izquierda (Schalock, 1995b). Desde un paradigma de apoyos y de ajuste de sistemas, es importante ajustar la metodología sobre cómo apoyar a las personas en la dirección de una metodología centrada en la persona (aportación-rendimiento-resultados), pero debe hacerse con un pensamiento de derecha izquierda (Figura 9), donde el interés se centra en los resultados personales (objetivos) en lugar de en la aportación de la organización (normas) (Schalock y Verdugo, 2007, 2012, 2013; Schalock, Verdugo et al., 2008; van Loon, 2009b). Al contrario que en las ideas tradicionales, donde los gerentes se centran en las acciones que podrían conducir a los resultados deseados, el pensamiento de derecha a izquierda requiere que se especifiquen primero esos resultados (fundamentalmente centrados en la mejora de la calidad de vida), actuando posteriormente la organización para alcanzarlos (Andrews, 2004; Drucker, 1994).

\begin{tabular}{|c|c|c|c|}
\hline Concepción Tradicional & Aportación & $\begin{array}{l}\text { Rendimiento } \\
\text { Sistemas de apoyos }\end{array}$ & Resultados \\
\hline $\begin{array}{l}\text { Pensamiento de derecha a } \\
\text { izquierda }\end{array}$ & Aportación & $\begin{array}{l}\text { Rendimiento } \\
\text { Sistemas de apoyos }\end{array}$ & Resultados \\
\hline
\end{tabular}

Figura 9. Alineamiento de estrategias de apoyo con las metas personales y los resultados personales. El pensamiento de derecha a izquierda (adaptado de van Loon, 2009b)

De nuevo en este punto se pone de manifiesto la importancia de los apoyos individualizados, sugiriéndose la creación de sistemas que puedan ser utilizados con diferentes propósitos. Un modelo de sistemas de apoyos proporciona una estructura para la organización y mejora los resultados del funcionamiento individual (que son interdependientes y acumulativos), incluyendo el uso de estrategias de evaluación y provisión de apoyos individualizados en contextos múltiples y englobando diferentes fuentes, tecnologías, ambientes y servicios profesionales (Schalock y Verdugo, 2012; Thompson et al., 2010). 
Asimismo, las estrategias de apoyo deberían estar alineadas con las metas personales, los resultados personales esperados y la evaluación de necesidades de apoyo. En este sentido, se aboga por la importancia de basar estar estrategias en los principios y valores actuales de inclusión, equidad, capacitación y bienestar subjetivo, así como por la necesidad de contar con un equipo específico capaz de evaluar el impacto de las estrategias empleadas (Schalock y Luckasson, 2013a, 2013b). Concretamente, la autoevaluación, el liderazgo y los equipos de aprendizaje (Schalock et al., 2007; Schalock, Gardner et al. 200; van Loon, 2009b), son consideradas las principales estrategias de cambio que necesitan las organizaciones para implantar una perspectiva centrada en la persona (Claes, Van Hove, Vandevelde, van Loon, y Schalock, 2010).

De manera coherente, desde finales del siglo XX, el paradigma de apoyos ha dado lugar a numerosos cambios significativos en las políticas y prácticas destinadas a las personas con discapacidad intelectual (Shogren, 2013; Shogren et al. 2009; Shogren y Turnbull, 2010). Asimismo, destaca en este sentido la influencia significativa que las políticas públicas ejercen en la sociedad en general y sobre las personas con discapacidad en particular (Schalock y Verdugo 2012, 2013). Se puede apreciar una relación interactiva y dinámica entre la práctica organizacional, las politicas públicas y las asunciones en el campo. Por un lado, la política pública influye en el proceso de diagnóstico y clasificación mediante guías sobre los criterios de diagnósticos y elegibilidad. A la inversa, los cambios en los sistemas de planificación y sus principios subyacentes influyen en la percepción de las características de las personas con discapacidad, lo que a su vez tiene un gran impacto sobre como designan y prestan apoyos los servicios públicos (Shogren et al., 2009).

La novedosa orientación en los resultados y su relación con las prácticas centradas en la evidencia han dado como resultado la mejora clínica y la decisión política relacionado con la calidad de vida de las personas con discapacidad intelectual (Schalock et al., 2014; van Loon et al., 2013), lo que permite, a su vez, seguir investigando e interviniendo en esta línea. Schalock et al. (2010) recogen tres cambios fundamentales que ya han empezado a obtenerse: (a) el enfoque de apoyos ha servido para agrupar prácticas de Planificación Centrada en la Persona (PCP), oportunidades de desarrollo y crecimiento personal, inclusión y autodeterminación; (b) la consecuente aplicación de apoyos individualizados ha dado lugar a la mejora del funcionamiento humano y el logro de resultados personales; y (c) se está utilizando el nivel de intensidad de necesidades de apoyo como componente básico para la asignación de recursos y planificación de servicios y sistemas. 


\subsection{CONCLUSIONES DEL CAPÍTULO 1}

Los apoyos han sido siempre tenidos en cuenta como un recurso de interés en la vida del ser humano, sin embargo, su relevancia en la mejora del funcionamiento y la calidad de vida de las personas con discapacidad es relativamente reciente. En este capítulo se ha podido observar cómo el constructo de 'apoyos' se ha ido introduciendo en los últimos años en la concepción de la discapacidad hasta llegar a convertirse en el eje central de la definición, la evaluación y la intervención realizada con las personas con discapacidad intelectual.

Mercer (1992) defiende que el avance en la comprensión de la discapacidad intelectual acontecido en el pasado siglo relaciona, bidireccionalmente, la investigación y el trabajo realizado con las personas con discapacidad. A medida que se consigue una mejor comprensión de las implicaciones de la discapacidad, la inclusión de las personas con discapacidad en el contexto normativo así como su calidad de vida se han convertido en un derecho incuestionable (Navas et al., 2012; Verdugo et al., 2012), quedando de manifiesto que los apoyos son la herramienta fundamental e imprescindible que deben usar las organizaciones para conseguir dicho resultado.

Desde esta perspectiva, los apoyos, y su provisión individualizada, quedan conceptualizados como el mejor medio para garantizar la participación (y no la mera presencia) de las personas con discapacidad. Además, se defiende que para garantizar su efectividad y eficacia, estos han de integrar todas las circunstancias del entorno social que comprometen la vida de la persona (Shogren, 2013; Shogren, Luckasson et al., 2014), teniendo así no solo un impacto directo en su funcionamiento, sino también en su calidad de vida (Schalock y Verdugo, 2002, 2007, 2008, 2013a). Este paradigma de apoyos refleja por primera vez la idea de que estos puedan no dirigirse directamente a mejorar las capacidades personales, sino que puedan estar orientados al logro de resultados personales a través de la adaptación del contexto (facilitadores).

Consecuentemente, esta nueva concepción dejará atrás una perspectiva basada en el déficit y una intervención basada en los cuidados asistenciales. Se empieza a dar visibilidad a la discapacidad dentro de la sociedad y se aboga por una actuación profesional orientada al incremento de la calidad de vida. El paulatino cambio en la concepción de discapacidad que estamos experimentando se refleja directamente en el área específica de la discapacidad intelectual (Schalock, Luckasson et al., 2007; Schalock, 2011; Schalock et al., 2010) e implica una concepción positiva, multidimensional y 
socioecológica (Schalock, 1995a; Verdugo, 1999) que precisa de un cambio consecuente tanto en la terminología utilizada para designar esta condición (de retraso mental a discapacidad intelectual) como en sus diferentes definiciones.

Con relación a la definición operativa, comienza a surgir una visión innovadora que da un peso primordial en el diagnóstico a la conducta aprendida para adaptarse típicamente a una sociedad determinada (Montero, 1993). Este énfasis deriva de la comprensión de que será la conducta adaptativa, por encima del rendimiento intelectual obtenido en una prueba de $\mathrm{CI}$, lo que determinará los apoyos, recursos y servicios que necesita la persona para desarrollarse (APA, 2013).

Acerca de la definición constitutiva, destaca la aparición y desarrollo de varios modelos teóricos aceptados en la última propuesta de la AAIDD (Schalock et al., 2010), así como en las publicaciones científicas relacionadas (Bradley et al. 2010; Schalock et al. 2007; Shogren et al. 2010; Snell, Luckasson y Borthwick-Duffy, 2010; Schalock, 2011; Schalock et al., 2012; Schalock y Luckasson, 2013a, 2013b; Thompson et al., 2009; Verdugo y Schalock, 2010; Wehmeyer et al. 2008): 'el modelo de funcionamiento humano', 'el modelo de apoyos' y 'el modelo de calidad de vida'. Estos tres modelos tienen importantes implicaciones relacionadas (Buntinx y Schalock, 2010; Claes et al., 2012), ya que explican: (a) el papel del entorno (Shogren, 2013; Shogren, Luckasson et al., 2014); (b) el significado de centrar la atención en el bienestar personal (Claes et al., 2010; van Loon y Van Hove, 2001); y (c) la importancia del rol que juegan los apoyos individualizados en la obtención de resultados esperados (Thompson et al., 2009).

Como resumen general, y sirviendo como línea base para dar paso al segundo capítulo teórico, podemos afirmar que nos hemos trasladado desde una orientación centrada en las limitaciones individuales a un punto de vista social. Actualmnete, se reconoce que la persona con discapacidad tiene unas cualidades y unas necesidades específicas, que han de ser cubiertas para poder llevar una vida plena dentro de una sociedad determinada (Butterworth, 2002). Estos avances han quedado reflejados en una mejor comprensión de cuatro componentes principales (Schalock et al., 2004), todos ellos analizados de manera exhaustiva dentro de este capítulo: (1) el funcionamiento intelectual; (2) la conducta adaptativa; (3) los apoyos individualizados como base de una buena intervención, capaz de disminuir las diferencias entre las capacidades y las demandas del entorno; y (4) el bienestar personal, dentro del que destaca la calidad de vida de la persona como resultado esperado. 
A su vez, estos cuatro componentes han afectado a varios aspectos clave en este campo, pasando de manera transversal por varios niveles de concreción: (1) el paradigma subyacente; (2) la terminología utilizada; (3) la definición, que marcará los criterios diagnósticos y el desarrollo de modelos teóricos congruentes; y (4) las prácticas organizacionales, ya que este hecho a obligado a los proveedores de servicios a focalizarse en la mejora de la calidad de vida de las personas con discapacidad intelectual (Schalock, 1996; Schalock, Verdugo et al., 2008; van Loon et al., 2013).

En este sentido, la adecuada evaluación de los componentes descritos será primordial para poder implantar en las organizaciones intervenciones eficaces (basadas en la nueva concepción socioecológica de discapacidad intelectual), así como para poder corroborar los resultados esperados del cambio de paradigma. Por ello, daremos un papel especial en el segundo capítulo a la evaluación de las personas con discapacidad intelectual, recogiendo la importancia del proceso evaluativo y del papel que juegan dentro de éste los diversos constructos implicados. De manera especial, nos centraremos en la evaluación de las necesidades de apoyo, por su papel central dentro de las planificaciones individualizadas, consideradas la estrategia fundamental para llevar a cabo el cambio de paradigma planteado. 



\section{Capítulo}

$\mathcal{E}[$ Proceso de Evaluación en Personas con Discapacidad Intelectual:

Perfíl y Planificación de Apoyos 



\section{EL PROCESO DE EVALUACIÓN EN PERSONAS CON DISCAPACIDAD INTELECTUAL: PERFIL Y PLANIFICACIÓN DE APOYOS}

Desde la aparición del paradigma de apoyos presentado a lo largo del capítulo anterior, y de manera congruente con los cambios que este supuso en la concepción y trabajo con las personas con discapacidad, el proceso de evaluación en el campo de la discapacidad intelectual ha sido entendido como la herramienta fundamental para orientar la práctica diaria hacia la perspectiva socioecológica de apoyos planteada a nivel teórico. De esta manera, la evaluación queda operativizada actualmente en este campo como un proceso de recogida sistemática de información dirigida a cumplir tres funciones diferentes: (1) diagnóstico; (2) clasificación; y (3) perfil/planificación de apoyos.

Schalock et al. (2010) proponen que estas tres funciones dan respuesta a las dos grandes cuestiones que dominan todas las prácticas profesionales que conciernen a las personas con discapacidad intelectual: el diagnóstico y la clasificación responden a la pregunta tradicional de cómo pueden entenderse los problemas en el funcionamiento de un individuo. Sin embargo, esta primera pregunta no es suficiente para poder garantizar un trabajo individualizado y permitir que las personas con discapacidad obtengan los resultados personales deseados; por lo que el tercer paso del proceso de evaluación, que surge con la llegada del paradigma de apoyos, hará frente a la segunda pregunta, que intenta dar respuesta a cómo apoyar a la persona para que tenga una vida de calidad.

En definitiva, se trata de tres componentes que han de ser tenidos en cuenta de manera diferenciada ya que, en función de cuál sea el objetivo de la evaluación, se debe concretar el tipo de información que se debe recoger, los instrumentos a utilizar y/o los criterios de evaluación (Tabla 14). Ha de tenerse en cuenta también que cualquier evaluación tiene como característica principal la flexibilidad y el ajuste específico a las características de la persona evaluada. Se debe adaptar, por tanto, el objetivo de la evaluación a la persona concreta con discapacidad que se va a evaluar y a sus necesidades específicas, para poder ajustar también todos los parámetros que guían dicha evaluación. En resumen, el proceso de evaluación debe cumplir tres criterios básicos: (a) ajustar el proceso y los instrumentos de evaluación a la persona y al propósito concreto de la evaluación; (b) asegurar la validez de la información que se recoge en la evaluación de todas las dimensiones pertinentes; y (c) garantizar la utilidad de la evaluación realizada; que debe realizarse con una intención determinada y buscando un beneficio para la persona con discapacidad evaluada. 
Tabla 14. Evaluación de la discapacidad intelectual (adaptado de Schalock et al., 2010)

\begin{tabular}{|c|c|c|c|}
\hline & $\begin{array}{l}\text { FUNCIÓN DE } \\
\text { EVALUACIÓN }\end{array}$ & PROPÓSITO ESPECÍFICO & $\begin{array}{l}\text { INSTRUMENTOS Y } \\
\text { MÉTODOS DE MEDIDA }\end{array}$ \\
\hline \multirow[b]{2}{*}{$\begin{array}{l}\text { ¿Cómo se pueden } \\
\text { entender los } \\
\text { problemas en el } \\
\text { funcionamiento } \\
\text { de un individuo? }\end{array}$} & Diagnóstico & $\begin{array}{l}\text { Establece la presencia de DI } \\
\text { Establece elegibilidad para: } \\
\text {-Servicios } \\
\text {-Beneficios } \\
\text {-Protección legal }\end{array}$ & $\begin{array}{l}\text { Tests de CI } \\
\text { Escalas de conducta } \\
\text { adaptativa } \\
\text { Edad de aparición }\end{array}$ \\
\hline & Clasificación & $\begin{array}{l}\text { Apoyos } \\
\text { Investigación } \\
\text { Reembolso/financiación } \\
\text { Características } \\
\text { seleccionadas }\end{array}$ & $\begin{array}{l}\text { Escalas de intensidad de } \\
\text { apoyos } \\
\text { Tests de CI } \\
\text { Conducta adaptativa } \\
\text { Evaluaciones ambientales } \\
\text { Factores de riesgo } \\
\text { Etiologías } \\
\text { Medidas de salud }\end{array}$ \\
\hline $\begin{array}{l}\text { ¿Cómo se puede } \\
\text { apoyar mejor a } \\
\text { esta persona para } \\
\text { que lleve una } \\
\text { buena vida? }\end{array}$ & $\begin{array}{l}\text { Perfil de } \\
\text { apoyos }\end{array}$ & $\begin{array}{l}\text { Mejora del funcionamiento } \\
\text { humano } \\
\text { Mejora de resultados } \\
\text { personales } \\
\text { Mejora en las elecciones de } \\
\text { las personas } \\
\text { Mejora en derechos } \\
\text { humanos }\end{array}$ & $\begin{array}{l}\text { Escalas de intensidad de } \\
\text { apoyos } \\
\text { Planes Centrados en la } \\
\text { Persona (PCP) } \\
\text { Planificación individual } \\
\text { Planes autodirigidos } \\
\text { Inventario ecológico }\end{array}$ \\
\hline
\end{tabular}

Aunque desde finales del siglo XX se diferencian estas tres funciones de evaluación de las personas con discapacidad intelectual, Luckasson et al. (1992) aún presentaban un especial interés en la función diagnóstica y clasificatoria, manifestado mayor preocupación por el conocimiento de si la persona era susceptible o no de pertenecer a un grupo determinado. Progresivamente, Luckasson et al. (2002) y Schalock et al. (2010) empezaron a abogar por una mayor centralidad de la función orientada a conocer el perfil de apoyos su relación más directa con la intervención (planificación) y con la mejora directa del bienestar de la persona con discapacidad.

Así, para el desarrollo de este segundo capítulo se hará un paso general por las tres funciones de la evaluación, presentando diferentes métodos de medición del Cociente Intelectual (CI), la conducta adaptativa y las necesidades de apoyo como constructos de especial importancia; exponiendo, a su vez, las semejanzas y diferencias de los instrumentos de medida de estos constructos. Debido a la gran repercusión de la evaluación como fase clave del diagnóstico, la clasificación y la intervención hablaremos en este punto también de los instrumentos de medida existentes, reflejándose una gran carencia de escalas de evaluación relacionada con los constructos de reciente aparición, los cuales, a su vez, son necesarios para poder alinear las prácticas diarias con los nuevos modelos de discapacidad intelectual y calidad de vida. 
Enlazando con esta argumentación, se expondrá también el proceso de evaluación intrínseco a los propios programas de intervención y la importancia de la continua revisión de las necesidades de apoyo. A través de los instrumentos pertinentes, se podrá garantizar la completa adaptación del programa al individuo en cada momento, ajustando progresivamente la intervención a las posibles mejoras del funcionamiento humano y la derivadas de mantener un apoyo adecuado durante un largo periodo de tiempo (Schalock, Luckasson et al., 2007). Asimismo, se relacionan en este capítulo la evaluación de los apoyos y la evaluación de la calidad de vida en personas con discapacidad intelectual, entendiendo la calidad de vida como uno de los principales beneficios de una vida con apoyos.

Finalmente, para terminar el capítulo, se reflexiona sobre la importancia de realizar una evaluación de necesidades de apoyo previa a la planificación, poniendo a su vez de manifiesto la falta de instrumentos que evalúen necesidades de apoyo en personas con discapacidad intelectual, especialmente orientados a la evaluación de niños y adolescentes, lo que está suponiendo un obstáculo para comenzar a realizar planificaciones individualizadas.

La necesidad de desarrollo de un nuevo instrumento para los jóvenes, a la luz de los existentes para adultos y las propiedades que estos han manifestado tanto de manera psicométrica como práctica, dará paso a la parte empírica de esta tesis, donde se presenta el desarrollo de un instrumento de evaluación de necesidades de apoyo para niños y adolescentes con discapacidad intelectual.

\subsection{CÓMO EVALUAR PARA EL DIAGNÓSTICO Y LA CLASIFICACIÓN}

\subsubsection{Evaluación para el diagnóstico}

El diagnóstico de discapacidad intelectual ha constituido un tema de interés principal para todos aquellos que intentan comprender este fenómeno y acercarse un poco más al complejo entramado de intervención en este campo (Navas, Verdugo y Gómez, 2008). En la investigación actual, destacan cuatro objetivos principales para realizar este diagnóstico: (a) examinar la presencia o ausencia de discapacidad intelectual; (b) establecer la idoneidad de los servicios; (c) establecer la idoneidad para obtener determinados beneficios; y (d) conocer la necesidad de protección legal. (Schalock et al., 2010). 
Concretamente, para realizar en la actualidad un diagnóstico de discapacidad intelectual deben aparecer, durante el desarrollo, limitaciones significativas en funcionamiento intelectual y conducta adaptativa. Estas limitaciones han de ser establecidas mediante el uso de medidas estandarizadas en la población general (incluyendo personas con y sin discapacidad), comparadas en cada situación con las características individuales de la persona evaluada (lengua, edad, cultura...) e interpretadas teniendo en cuenta las características técnicas del test (error de medida...).

\subsubsection{Cómo evaluar limitaciones intelectuales e instrumentos de medida}

Históricamente el marco teórico que ha conceptualizado el funcionamiento intelectual ha estado caracterizado por una visión de la inteligencia como factor único (e.g., Spearman, 1904), representado de manera práctica por el CI. Desde la aparición de este modelo, el recelo hacia la inteligencia como factor unidimensional y la desconfianza del poder del CI para evaluar inteligencia y servir como base del diagnóstico de la discapacidad intelectual (Arnold, Riches y Stancliffe, 2011) han ido aumentando, creándose otros marcos conceptuales para la inteligencia: (1) como un fenómeno jerárquico (e.g., Carroll, 1997) y (2) como constructo multidimensional (e.g., Gardner, 1998; Horn y Cattell, 1966; Naglieri y Das, 1997).

Especialmente, la investigación actual está empezando a enfocarse en la inteligencia entendida como factor múltiple. Sternberg (1985) creó un modelo tripartito de la inteligencia, caracterizado por tres componentes: analítico, creativo y práctico. De manera relacionada, Greenspan (Greenspan, 1997, 2006; Greenspan y Love, 1997; Greenspan et al., 1996) defendía un modelo triparto de la inteligencia compuesto por componentes conceptuales, prácticos y sociales que fue incluido dentro de un modelo de competencia general, pasando finalmente estos tres factores a relacionarse de manera directa con el constructo de 'conducta adaptativa' (Schalock et al., 2010; Thompson y Wehmeyer, 2008).

No obstante, la concepción de la inteligencia como factor único y el reduccionismo del CI continúan hoy guiando el diagnóstico, puesto que ofrecen la evaluación psicométrica de la inteligencia más sólida (Gottfredson, 2002). Barr (2007) afirmaba que las teorías subyacentes a las escalas de evaluación utilizadas se relacionan con las prácticas diarias, situándose la gran mayoría de los tests de inteligencia existentes para el diagnóstico de la discapacidad intelectual dentro del enfoque de medida del CI (Tabla 15). 
Tabla 15. Principales instrumentos utilizados en la evaluación del funcionamiento intelectual en España (adaptado de Verdugo, Guillén y Vicente, 2014)

\begin{tabular}{|c|c|c|c|c|}
\hline ESCALA & REFERENCIAS & DESCRIPCIÓN & & \\
\hline \multirow{3}{*}{$\begin{array}{l}\text { Escalas de Inteligencia } \\
\text { Wechsler } \\
\text { (Wechsler Intelligence Scale, } \\
4 \text { th edition) }\end{array}$} & \multirow{3}{*}{ Wechsler (2012) } & \multirow{3}{*}{$\begin{array}{l}\text { Instrumentos } \\
\text { administrados } \\
\text { individualmente y } \\
\text { diseñados para } \\
\text { evaluar la inteligencia } \\
\text { en distintos rangos de } \\
\text { edad. }\end{array}$} & $\begin{array}{l}\text { WPPSI-IV } \\
\text { Wechsler } \\
\text { Preschool and } \\
\text { Primary Scale of } \\
\text { Intelligence }\end{array}$ & $\begin{array}{l}\text { Evalúa el funcionamiento cognitivo de niños desde } 2 \\
\text { años y } 6 \text { meses hasta } 7 \text { años y } 3 \text { meses. Ofrece un CI } \\
\text { verbal, un CI manipulativo y una puntuación global } \\
\text { de CI Incluye un índice de lenguaje general y, en la } \\
\text { etapa de mayor edad, un índice de velocidad de } \\
\text { procesamiento. }\end{array}$ \\
\hline & & & $\begin{array}{l}\text { WISC-IV } \\
\text { Wechsler } \\
\text { Intelligence Scale } \\
\text { for Children }\end{array}$ & $\begin{array}{l}\text { Evalúa el CI de niños (de } 6 \text { a } 16 \text { años) a través de } \\
\text { cuatro dominios: comprensión verbal, razonamiento } \\
\text { perceptivo, memoria de trabajo y velocidad de } \\
\text { procesamiento. }\end{array}$ \\
\hline & & & $\begin{array}{l}\text { WAIS-IV } \\
\text { Wechsler Adults } \\
\text { Intelligence Scale }\end{array}$ & $\begin{array}{l}\text { Evalúa el CI de los adultos mayores de } 16 \text { años. Está } \\
\text { formado por quince pruebas, diez principales y cinco } \\
\text { opcionales, que se agrupan en cuatro índices: } \\
\text { comprensión verbal, razonamiento perceptivo, } \\
\text { memoria de trabajo y velocidad de procesamiento. }\end{array}$ \\
\hline $\begin{array}{l}\text { Escala McCarthy de Aptitudes y } \\
\text { Psicomotricidad } \\
\text { (McCarthy Scales of Children's } \\
\text { Abilities [MSCA] }\end{array}$ & McCarthy (2006) & \multicolumn{3}{|c|}{$\begin{array}{l}\text { Permite valorar las habilidades cognitivas y motoras de niños de entre } 21 / 2 \text { y } 81 / 2 \text { años. Consta de } \\
18 \text { subtests agrupados en seis escalas: verbal, perceptivo-manipulativa, numérica, general cognitiva } \\
\text { y memoria. El conjunto de las tres primeras escalas proporcionan el Índice General Cognitivo (GCI). }\end{array}$} \\
\hline $\begin{array}{l}\text { Batería de Evaluación de } \\
\text { Kaufman para Niños } \\
\text { (Kaufman Assessment Battery } \\
\text { for Children }[\mathrm{K}-\mathrm{ABC}] \text { ) }\end{array}$ & $\begin{array}{l}\text { Kaufman y } \\
\text { Kaufman (1997) }\end{array}$ & \multicolumn{3}{|c|}{$\begin{array}{l}\text { Evalúa la habilidad cognitiva y los conocimientos académicos para sujetos entre } 21 / 2 \text { y } 12 \text { 1/2 años. } \\
\text { Consta de dos grandes escalas: una de procesamiento mental (secuencial y simultáneo) y otra de } \\
\text { conocimientos que evalúa los conocimientos adquiridos y el nivel de aprendizaje escolar. La } \\
\text { batería presenta, además, una escala no verbal para evaluar a los niños con dificultades lingüísticas. }\end{array}$} \\
\hline $\begin{array}{l}\text { Test de Inteligencia No Verbal } \\
\text { (Test of Nonverbal Intelligence, } \\
\text { 2nd edition [TONI-2]) }\end{array}$ & $\begin{array}{l}\text { Brown, } \\
\text { Sherbenou, y } \\
\text { Johnsen (1995) }\end{array}$ & \multicolumn{3}{|c|}{$\begin{array}{l}\text { Permite la estimación del CI de personas entre } 5 \text { y } 85 \text { años mediante la evaluación de la capacidad } \\
\text { para resolver problemas abstractos de tipo gráfico, eliminando la influencia del lenguaje y de la } \\
\text { habilidad motriz. }\end{array}$} \\
\hline
\end{tabular}




\subsubsection{Cómo evaluar la conducta adaptativa e instrumentos de medida}

Para establecer el diagnóstico de discapacidad intelectual no debe tenerse solo en cuenta el funcionamiento intelectual, sino que también han de considerarse las limitaciones significativas en conducta adaptativa. No obstante, la carencia tradicional de instrumentos que proporcionan información relevante sobre las habilidades de adaptación de las personas con discapacidad intelectual ha derivado en el uso exclusivo de medidas de CI para hacer el diagnóstico (e.g., Brown et al., 1995; Kaufman y Kaufman, 1997; McCarthy, 2006; Wechsler, 2012) o, en su caso, en el uso de otro tipo de recursos de evaluación que ofrecían una aproximación a la conducta adaptativa, pero sin proporcionar una medida específica y diagnóstica.

En el contexto internacional, existen más de 200 pruebas de evaluación de conducta adaptativa identificadas; sin embargo la mayoría de ellos no cumplen los requisitos necesarios que han de cumplir los instrumentos de diagnóstico (Schalock et al., 2010; Tassé, 2013; Tassé et al., 2012): (1) estar baremados sobre la población general (población con y sin discapacidad intelectual), que incluyan las dimensiones específicas de habilidades conceptuales, sociales y prácticas (excluyendo habilidades motoras y problemas de conducta); (2) incluir medidas de todos los aspectos de la conducta adaptativa, aunque no sean evaluados por otros instrumentos estandarizados existentes; (3) contener ítems con alto poder de discriminación con el objetivo de minimizar los falsos positivos y los falsos negativos, para lo cual será fundamental tener en cuenta el error típico de medida del test; (4) contemplar que la conducta adaptativa de la persona con discapacidad intelectual incrementa en complejidad con la edad y puede verse influida por la disponibilidad de oportunidades, por factores culturales y por la presencia de discapacidades de tipo físico que pudieran limitar el desempeño de una actividad concreto; (5) medir el comportamiento típico (no en el rendimiento máximo); y (6) evaluar la conducta adaptiva presente, es decir, en el momento de la evaluación.

En la Tabla 16, podemos observar la descripción de los cinco instrumentos más utilizados en el diagnóstico de la conducta adaptativa, la mayoría de ellos sólo disponibles en inglés. Recientemente se ha publicado en España el ABAS-II (Montero y FernándezPinto, 2013), pero aún no contamos en España con datos sobre el uso y grado de aceptación de estos instrumentos dentro de la comunidad clínica. En cualquier caso, se está esperando la próxima publicación de la DABS (Verdugo, Arias y Navas, en prensa), considerada la escala más adecuada para la evaluación diagnóstica de la conducta adaptativa (Tassé, 2013). 
Tabla 16. Principales instrumentos utilizados en el diagnóstico de la conducta adaptativa (Tassé, 2013; Tassé et al., 2012)

\begin{tabular}{|c|c|c|}
\hline ESCALA & REFERENCIAS & DESCRIPCIÓN \\
\hline $\begin{array}{l}\text { Escala de Diagnóstico de } \\
\text { Conducta Adaptativa } \\
\text { (Diagnostic Behavior Scale } \\
\text { [DABS]) }\end{array}$ & $\begin{array}{l}\text { Tassé et al. (en prensa) } \\
\text { Adaptación española: Verdugo, Arias } \\
\text { et al. (en prensa) }\end{array}$ & $\begin{array}{l}\text { Instrumento orientado al diagnóstico de limitaciones significativas en conducta adaptativa. } \\
\text { Existen tres versiones del instrumento ( } 4-8 \text { años; } 9-15 ; 16-21) \text {. Incluye tres subescalas: } \\
\text { habilidades conceptuales, sociales y prácticas. Aporta una puntuación general y una para } \\
\text { cada subescala. }\end{array}$ \\
\hline $\begin{array}{l}\text { Sistema de Evaluación de la } \\
\text { Conducta Adaptativa- II } \\
\text { (Adaptive Behavior } \\
\text { Assesment System [ABAS-II]) }\end{array}$ & $\begin{array}{l}\text { Harrison y Oakland (2003). } \\
\text { Adaptación española: Montero y } \\
\text { Fernández-Pinto (2013) }\end{array}$ & $\begin{array}{l}\text { Evalúa la conducta adaptativa desde el nacimiento hasta los } 89 \text { años. Tiene diferentes } \\
\text { versiones dependiendo de la edad. Incluye } 10 \text { áreas que aportan una puntuación para cada } \\
\text { uno de los tres dominios principales (social, práctico y conceptual) y una puntuación } \\
\text { general. }\end{array}$ \\
\hline $\begin{array}{l}\text { Las Escalas Vineland-II de } \\
\text { Conducta Adaptativa } \\
\text { (Vineland Adaptive Behavior } \\
\text { Scale, 2nd edition) }\end{array}$ & Sparrow, Cicchetti y Balla (2005) & $\begin{array}{l}\text { Escala de evaluación del comportamiento adaptativo (desde el nacimiento hasta los } 90 \\
\text { años) más utilizada a nivel internacional. No existe una adaptación en español reconocida } \\
\text { oficialmente. Se compone de tres subescalas: Vineland-S (encuesta); Vineland-E (para } \\
\text { facilitar el diagnóstico y planificación de apoyos); Vineland-C (entorno escolar). } \\
\text { Proporciona medidas en: comunicación, habilidades de la vida diaria, socialización, } \\
\text { habilidades motoras y conducta desadaptada. }\end{array}$ \\
\hline $\begin{array}{l}\text { Escala de Conducta } \\
\text { Adaptativa-Escuela, } \\
\text { Segunda Edición } \\
\text { (Adaptive Behavior Scale- } \\
\text { School, 2nd Edition [ABS-S:2]) }\end{array}$ & Lambert, Nihira y Leland (1993) & $\begin{array}{l}\text { Revisión de la escala de conducta adaptativa de la AAMR desarrollada con el objetivo de } \\
\text { proporcionar información las habilidades adaptativas de las personas con discapacidad } \\
\text { intelectual de entre } 3 \text { y } 18 \text { años. Además de la versión escolar recomendada para el } \\
\text { diagnóstico ABS-S: } 2 \text {, existe otra para versión relacionada con ámbitos residenciales y de la } \\
\text { comunidad ABS-RC: } 2 \text {. }\end{array}$ \\
\hline $\begin{array}{l}\text { Escala de Conducta } \\
\text { Independiente Revisada } \\
\text { (Scales of Independent } \\
\text { Behavior - Revised [SIB-R]) }\end{array}$ & $\begin{array}{l}\text { Bruininks, Woodcock, Weatherman y } \\
\text { Hill (1996) }\end{array}$ & $\begin{array}{l}\text { Proporciona una puntuación de independencia utilizada con propósitos diagnósticos, } \\
\text { planificación de programas y evaluación de resultados. Evalúa conducta adaptativa y } \\
\text { desadaptativa de personas de entre } 3 \text { meses y } 40 \text { años en } 14 \text { subescalas agrupadas en } \\
\text { cuatro dominios: destrezas motoras, destrezas sociales y comunicativas, destrezas de vida } \\
\text { personal y destrezas de vida en comunidad. }\end{array}$ \\
\hline
\end{tabular}


La DABS es la única escala de conducta adaptativa existente capaz de cumplir todos requisitos para un instrumento de diagnóstico, habiendo siendo desarrollada de manera específica con ese objetivo. Presentamos a continuación (Tabla 17) un resumen de los criterios establecidos (Schalock et al., 2010; Tassé et al., 2012, Tassé, 2013) así como una breve descripción de cómo la DABS ha sido construida sobre estos supuestos, quedando así patente la importancia y adecuación del uso de la misma dentro del proceso diagnóstico de la discapacidad intelectual.

Tabla 17. Ajuste de la DABS a los criterios de la evaluación diagnóstica de conducta adaptativa

\section{CRITERIOS PARA ESCALAS DE DESCRIPCIÓN DE LA DABS}

- Durante su desarrollo, fue aplicada a personas tanto con

Estar baremados sobre la población general (población con y sin discapacidad intelectual). discapacidad como sin ella, permitiendo evaluar de manera fiable dos desviaciones típicas por debajo de la media general (eficacia en el diagnóstico de las personas con discapacidad ligera).

Ofrecer una medida específica de habilidades adaptativas conceptuales, sociales y prácticas así como una medida global de conducta adaptativa.

- Incluye una puntuación general y una puntuación específica para cada una de las tres habilidades adaptativas (conceptuales, prácticas, sociales), estructura contrastada mediante un Análisis Factorial Confirmatorio (AFC) (Arias, Verdugo, Navas y Gómez, 2013).

- Excluye cualquier ítem relacionados con habilidades motoras y problemas de conducta.

Contener ítems específicos de conducta adaptativa que, a su vez, cuenten con alto poder de discriminación con el objetivo de minimizar los falsos positivos y los falsos negativos en la realización del diagnóstico.

- Incluye aspectos de la conducta adaptativa que actualmente no son evaluados por ninguna escala como: ingenuidad, prudencia, credulidad y habilidades relacionadas con el empleo de las nuevas tecnologías (Greenspan 2006, 2012).

- El innovador uso de la Teoría de Respuesta a los Ítems (TRI) en su baremación ha optimizado la capacidad de la DABS para identificar correctamente si una persona presenta discapacidad (sensibilidad) o no (especificidad), superando la eficacia de otros instrumentos (Balboni et al., 2014).

- Se recogen tres versiones de la escala orientadas

Contemplar que la conducta adaptativa de la persona con discapacidad intelectual incrementa en complejidad con la edad y puede verse influida por la disponibilidad de oportunidades, por factores culturales que pudieran ejercer su influencia en la expresión de la conducta adaptativa.

Medir el comportamiento típico (no en el rendimiento máximo) en el momento de la evaluación. diferentes edades $(4-8 ; 9-15 ; 16-21)$ que recogen las peculiaridades de cada uno de los grupos de edad establecidos a través de la selección de los 75 mejores ítems para cada uno de los rangos de edad establecidos (25 para cada una de las tres habilidades).

- Se contempla la opción de respuesta 'No Aplicable', para aquellas actividades que la persona no tiene la oportunidad de desarrollar (cultura...).

- Recoge diferentes adaptaciones del instrumentos para los diferentes contextos (e.g. Verdugo, Arias et al., en prensa).

- Los ítems no hacen referencia a la potencialidad de a persona, sino a su funcionamiento diario actual, atendiendo más al desempeño diario que a la capacidad para adquirir nuevas habilidades. 
No obstante, aunque la carencia de instrumentos de diagnóstico de conducta adaptativa es evidente (especialmente en España), contamos en nuestro contexto con otro tipo de herramientas de evaluación de la conducta adaptativa capaces de aportar información relevante sobre el funcionamiento adaptativo para realizar clasificaciones o planes de intervención (Tabla 18). Teniendo presente que estos instrumentos no han sido diseñados y validados con objetivos diagnósticos, estos pueden ser utilizados para proporcionar información sobre las personas con discapacidad intelectual que resulte de utilidad para los profesionales que trabajan en las diferentes organizaciones y servicios.

Tabla 18. Otros instrumentos utilizados para valorar la conducta adaptativa

\begin{tabular}{|c|c|c|}
\hline INSTRUMENTO & DESCRIPCIÓN & REFERENCIAS \\
\hline \multirow{3}{*}{$\begin{array}{l}\text { Sistema de } \\
\text { Valoración- } \\
\text { Enseñanza- } \\
\text { Evaluación de } \\
\text { Destrezas } \\
\text { Adaptativas }\end{array}$} & \multirow{3}{*}{$\begin{array}{l}\text { Formado por tres instrumentos que } \\
\text { permiten vincular la evaluación } \\
\text { normativa de la conducta adaptativa de } \\
\text { una misma persona (Inventory for Client } \\
\text { Agency Planning [ICAP]), con la } \\
\text { evaluación criterial de sus habilidades } \\
\text { adaptativas (Checklist of Adaptive Living } \\
\text { Skills [CALS]) y con el diseño de } \\
\text { intervenciones concretas en función de } \\
\text { estas evaluaciones (Adaptive Living } \\
\text { Skills Curriculum [ALSC]). Se recomienda } \\
\text { usarlas conjuntamente, pero pueden } \\
\text { usarse de manera independiente. }\end{array}$} & $\begin{array}{l}\text { ICAP } \\
\text { Bruininks, Hill, Weatherman y } \\
\text { Woodcock (1986) } \\
\text { Montero (1993) }\end{array}$ \\
\hline & & $\begin{array}{l}\text { CALS } \\
\text { Morreau y Bruininks, } 1991 \\
\text { Morreau, Bruininks, y Montero } \\
(2002)\end{array}$ \\
\hline & & $\begin{array}{l}\text { ALSC } \\
\text { Bruininks, Morreau, Gilman y } \\
\text { Anderson (1991) } \\
\text { Gilman et al. (2002) }\end{array}$ \\
\hline \multirow{3}{*}{$\begin{array}{l}\text { Programas } \\
\text { Conductuales } \\
\text { Alternativos } \\
(P C A)\end{array}$} & \multirow{3}{*}{$\begin{array}{l}\text { Trilogía de programas elaborada como } \\
\text { materiales de apoyo que orientan a los } \\
\text { profesionales en el desarrollo y } \\
\text { planificación de programas destinados a } \\
\text { la adquisición de habilidades básicas. }\end{array}$} & $\begin{array}{l}\text { Verdugo (1996). Programa de } \\
\text { Orientación al Trabajo (POT) }\end{array}$ \\
\hline & & $\begin{array}{l}\text { Verdugo (2012). Programa de } \\
\text { Habilidades Sociales (PHS) (2a ed.) }\end{array}$ \\
\hline & & $\begin{array}{l}\text { Verdugo (2000). Programa de } \\
\text { Habilidades de Vida Diaria (PVD) }\end{array}$ \\
\hline
\end{tabular}

De manera adicional, en el ámbito internacional se cuenta con la escala Developmental Disability Profile (DDP) (Brown et al., 1986), que proporciona información sobre tres dominios: adaptación, inadaptación y salud. Esta escala tiene una fiabilidad y validez comparables a las de otros instrumentos de conducta adaptativa utilizados en el diagnóstico y ha sido usada en el proceso de determinación de subvenciones. Su uso principal ha estado centrado en la evaluación de la competencia personal (conducta adaptativa), pero también se ha utilizado en la elaboración de planes individualizados de apoyo para estimar las necesidades de las personas con discapacidad intelectual. 


\subsubsection{Evaluación para la clasificación. Hacia un sistema de clasificación multidimensional}

Cuando hablamos de la clasificación los objetivos no están tan definidos como en el caso del diagnóstico, ya que la información sobre las personas con discapacidad intelectual se puede agrupar con varias finalidades, variando los medios utilizados para realizar las clasificaciones en función del objetivo. A pesar de los peligros del etiquetaje que pueden derivarse de la clasificación (Gallagher, 1976), las categorías no tienen por sí mismas un cariz negativo, sino que lo adquieren si se utilizan de modo peyorativo, hecho bajo el cual suele haber un problema actitudinal (Verdugo, 2003b). El único objetivo de la clasificación reside en conocer similitudes y diferencias entre individuos y grupos, y ha sido probada su adecuación para favorecer el progreso de las personas con discapacidad en varios ámbitos: educación, empleo, servicios de salud mental y otros (Fidler y Hodapp, 1998).

Tradicionalmente, se ha estudiado la clasificación de la discapacidad únicamente con fines diagnósticos, por lo que las personas con discapacidad intelectual son clasificadas mayoritariamente con relación al CI o la conducta adaptativa. Sin embargo, lo cierto es que existen otras muchas clasificaciones orientadas a unificar grupos alrededor de criterios específicos e interesantes para un objetivo concreto, ya sea de investigación o de intervención (Florian y McLaughlin, 2008; Navas, Verdugo y Gómez, 2008; Sturmey, 1999; Verdugo, 2003b; Vig, 2005). En 2006, Simeonson, Grandlund y Bjork-Akesson consolidan la importancia de un sistema de clasificación multidimensional, que no se centrara sólo en una única dimensión de la vida de la persona con discapacidad. Schalock y Luckasson (2013a, 2013b) defienden que para conocer con precisión a una persona con discapacidad debe utilizarse una evaluación multidimensional que, al menos, de respuesta a todos los dominios que componen el modelo de discapacidad intelectual (Tabla 19).

A pesar de su importancia teórica, la clasificación multidimensional apenas ha encontrado aún cabida en la práctica, siendo actualmente la clasificación centrada en un único criterio (unidimensional) la mantenida por los sistemas de clasificación internacionales (OMS, 2001; APA, 2013). No obstante, sí puede observarse un fuerte cambio conceptual en la medida que se ha superado la necesidad de clasificar siempre a las personas con discapacidad intelectual en función de su CI. La clasificación por niveles de severidad más relacionada con el diagnóstico, se relaciona en estos momentos con la conducta adaptativa en el DSM-5 (APA, 2013); pues se asume, literalmente, que la conducta adaptativa tiene en cuenta el entorno de la persona en mayor medida dentro de la evaluación que el criterio de CI. 
Tabla 19. Sistema de Clasificación Multidimensional (Schalock et al., 2010)

\begin{tabular}{|c|c|c|}
\hline DIMENSIONES & MEDIDAS & CLASIFICACIÓN \\
\hline $\begin{array}{l}\text { Capacidad } \\
\text { Intelectual }\end{array}$ & $\begin{array}{l}\text { Aplicación individualizada de tests } \\
\text { de CI }\end{array}$ & Niveles de CI \\
\hline $\begin{array}{l}\text { Conducta } \\
\text { Adaptativa }\end{array}$ & Escalas de conducta adaptativa & Niveles de conducta adaptativa \\
\hline \multirow{4}{*}{ Salud } & Inventarios de salud y bienestar & Estado de salud \\
\hline & Medidas de salud mental & Estado de salud mental \\
\hline & & Factores de riesgo \\
\hline & Evaluacion etiologica & Grupos etiológicos \\
\hline \multirow{4}{*}{ Participación } & $\begin{array}{l}\text { Escalas de integración en la } \\
\text { comunidad }\end{array}$ & Grado de integración en la comunidad \\
\hline & $\begin{array}{l}\text { Escalas de implicación en la } \\
\text { comunidad }\end{array}$ & Grado de implicación en la comunidad \\
\hline & Medidas de relaciones sociales & Nivel de interacciones sociales \\
\hline & Medidas de la vida en el hogar & Level of in-home activities \\
\hline \multirow[t]{2}{*}{ Contexto } & $\begin{array}{l}\text { Evaluación del ambiente (físico, } \\
\text { social y actitudinal) }\end{array}$ & Estado del ambiente \\
\hline & Evaluación personal & Estado personal \\
\hline \multirow{2}{*}{ Apoyos } & Escalas de necesidades de apoyos & Nivel de necesidades de apoyo \\
\hline & Evaluación de la conducta funcional & Perfil de necesidades de apoyo \\
\hline
\end{tabular}

Otra de las razones que han orientado el cambio de la clasificación diagnóstica hacia la conducta adaptativa ha sido su innegable relación directa con el concepto de apoyos y necesidades de apoyo, componentes centrales del modelo actual de la discapacidad intelectual. En este sentido, las necesidades de apoyo y las continuas evidencias de su funcionalidad están haciendo cada vez más presente este criterio clasificatorio dentro de los servicios que atienden a personas con discapacidad intelectual.

Como muestra de la progresiva presencia de clasificaciones basadas en la intensidad de las necesidades de apoyo señalamos la clasificación diagnóstica de los Trastornos del Espectro Autista (TEA) en el DSM-5 (APA, 2013), que queda representada en función de categorías que reflejan diferentes niveles de apoyo (requiere apoyo, requiere apoyo sustancial, y requiere apoyo muy sustancial). Asimismo, es necesario señalar en este punto que los niveles de dependencia en España reflejados por la Ley 39/2006 de Promoción de la Autonomía Personal y Atención a las Personas en situación de Dependencia (Ley de Dependencia) también están determinados por un criterio de apoyos (dependencia moderada, dependencia severa y gran dependencia).

Concretamente, la clasificación a través de las necesidades de apoyo supuso uno de los primeros avances en la clasificación de las personas con discapacidad, resultando el primer intento por ofrecer una clasificación que no tuviera exclusivamente en cuenta el 
déficit de funcionamiento de la persona. Debido a su gran importancia, pasamos a continuación a describir de manera más precisa la incorporación del concepto de necesidades de apoyo como criterio clasificatorio.

\subsubsection{La clasificación a través de la intensidad de las necesidades de apoyo}

Uno de los mayores cambios propuestos desde del manual de 1992 (Luckasson et al.) fue la incorporación de un sistema de clasificación basado en la intensidad de las necesidades de apoyo de la persona con discapacidad intelectual (intermitente, limitado, extenso y generalizado), aportando la posibilidad de utilizar otros criterios clasificatorios, complementarios a la clasificación diagnóstica, que respondieran a objetivos distintos. Sin embargo, esta propuesta causó una gran confusión entre profesionales e investigadores quienes, erróneamente, pensaron que esta clasificación suponía una sustitución total de las categorías diagnósticas tradicionales y que la intensidad de apoyos era un concepto totalmente subjetivo (Vig y Jedrysek, 1996). Pocos meses más tarde, Luckasson, Schalock, Snell y Spitalnik (1996) clarificaron el carácter adicional (no sustitutorio) de la clasificación de la intensidad de apoyos y propusieron una parrilla de toma de decisiones con indicadores objetivos para facilitar su identificación y categorización (Tabla 20).

Tabla 20. Parrilla de toma de decisiones sobre la intensidad de apoyos (Luckasson et al., 1996)

\begin{tabular}{lllll}
\hline & Intermitente & Limitado & Extenso & Generalizado \\
\hline $\begin{array}{l}\text { TIEMPO } \\
\text { Duración }\end{array}$ & $\begin{array}{l}\text { El que sea } \\
\text { necesario }\end{array}$ & $\begin{array}{l}\text { Tiempo } \\
\text { limitado, a } \\
\text { veces continuo }\end{array}$ & $\begin{array}{l}\text { Habitualmente } \\
\text { continuo }\end{array}$ & $\begin{array}{l}\text { Posiblemente a } \\
\text { lo largo de toda } \\
\text { la vida }\end{array}$ \\
\hline $\begin{array}{l}\text { TIEMPO } \\
\text { Frecuencia }\end{array}$ & $\begin{array}{l}\text { Infrecuente, de } \\
\text { baja frecuencia }\end{array}$ & $\begin{array}{l}\text { Regular, anticipado, podría ser alta } \\
\text { frecuencia }\end{array}$ & $\begin{array}{l}\text { Alta frecuencia, } \\
\text { constante }\end{array}$ \\
\hline $\begin{array}{l}\text { CONTEXTOS } \\
\text { Vida diaria, trabajo, } \\
\text { ocio y tiempo libre, } \\
\text { salud, comunidad, } \\
\text { etc. }\end{array}$ & Pocos, 1-2 & Varios contextos, pero no todos & $\begin{array}{l}\text { Todos o casi } \\
\text { todos }\end{array}$ \\
$\begin{array}{l}\text { RECURSOS } \\
\text { Profesionales } \\
\text { tecnológicos } \\
\text { asistencia }\end{array}$ & $\begin{array}{l}\text { Consultas o } \\
\text { comentarios } \\
\text { ocasionales, } \\
\text { habitual tabla de } \\
\text { horarios, } \\
\text { supervisión }\end{array}$ & $\begin{array}{l}\text { Contacto } \\
\text { ocasional o } \\
\text { limitado en el } \\
\text { tiempo, pero } \\
\text { frecuente }\end{array}$ & $\begin{array}{l}\text { Contacto con } \\
\text { profesionales } \\
\text { regular y continuo, } \\
\text { semalmente } \\
\text { contacto constante } \\
\text { con profesionales }\end{array}$ & $\begin{array}{l}\text { constante y } \\
\text { supervisión por } \\
\text { profesionales }\end{array}$ \\
\hline & $\begin{array}{l}\text { Apoyos } \\
\text { naturales, alto } \\
\text { grado de elección } \\
\text { yautonomía }\end{array}$ & $\begin{array}{l}\text { Mezcla de apoyos naturales y } \\
\text { basados en servicios, menor grado } \\
\text { de elección y autonomía }\end{array}$ & $\begin{array}{l}\text { Apoyos basados } \\
\text { en el servicio } \\
\text { controlado por } \\
\text { otros }\end{array}$ \\
\hline
\end{tabular}


Aunque esta clasificación ayudó a comprender el constructo de 'necesidades de apoyo', generó muchas críticas desde el ámbito clínico, entre las que destaca el solapamiento existente entre las categorías apoyo limitado y apoyo extenso en los criterios referentes al tiempo (frecuencia), contextos y disrupción. Por ello, en 1999, Schalock describe de nuevo esta parrilla de toma de decisiones y aporta una serie de mejoras a la misma, realizando una descripción más exhaustiva de los criterios de las categorías de clasificación propuestas y evitando solapamientos (Tabla 21).

Tabla 21. Modificaciones en la parrilla de toma de decisiones (Schalock, 1999)

\begin{tabular}{lll}
\hline & Limitado & Extenso \\
\hline $\begin{array}{l}\text { TIEMPO } \\
\text { Frecuencia }\end{array}$ & $\begin{array}{l}\text { Menos frecuente, quizás } \\
\text { semanalmente }\end{array}$ & Más frecuente, quizá generalmente \\
\hline $\begin{array}{l}\text { CONTEXTOS } \\
\text { Vida diaria, trabajo, } \\
\text { ocio y tiempo libre, } \\
\text { salud, comunidad... }\end{array}$ & Varios contextos, quizá 3 ó 4 & $\begin{array}{l}\text { Varios contextos, quizás 4-5, } \\
\text { pero no todos }\end{array}$ \\
\hline DISRUCPIÓN & $\begin{array}{l}\text { Apoyos naturales considerables, } \\
\text { algún grado de elección y } \\
\text { autonomía }\end{array}$ & $\begin{array}{l}\text { Algunos apoyos basados en el } \\
\text { servicio, control considerable de } \\
\text { otros }\end{array}$ \\
\hline
\end{tabular}

A pesar de este intento por mejorar y afianzar la clasificación basada en la intensidad de las necesidades de apoyo, continuaron las críticas a esta propuesta de agrupación y al modo en que se planteaba el proceso la toma de decisiones (Arnold, Riches y Stancliffe, 2014a). Greenspan y Switzky (2003) afirmaban que el sistema de clasificación de las intensidades de apoyo propuesto no era útil, pues se trataba más de un pronóstico que de una clasificación. No obstante, estos autores sí apoyaban la importancia de la clasificación de las necesidades, proponiendo una revisión de este planteamiento que garantizara que la evaluación de la intensidad de apoyos cumpliera cuatro criterios: (a) englobar un amplio rango de dimensiones vitales; (b) proporcionar a una puntuación que reflejara la relevancia de resultados críticos; (c) ser utilizada para diagnosticar a aquellos que tienen discapacidades y diferenciales de aquellos que no la tienen; y (d) ubicar a las personas que se cualificaran sobre un continuo desde muy necesitado a nada necesitado.

Finalmente, el modelo actual de discapacidad desarrollado por la Asociación Americana de Discapacidades Intelectuales y del Desarrollo (American Association on Intellectual and Developmental Disabilities) [AAIDD]) (Schalock et al., 2010) no recoge de manera explícita las categorías de intensidad de apoyos expuestas en las ediciones anteriores del manual. No obstante, sí se refleja la importancia de un sistema de 
clasificación multidimensional donde se presenta el nivel de las necesidades de apoyo (obtenido a partir de los resultados de escalas de intensidad de apoyos estandarizadas), como uno de los criterios clasificatorios principales que han de ser utilizados en la evaluación de las personas con discapacidad. Actualmente, el debate sigue abierto y recientemente Arnold et al. (2014a) han propuesto un nuevo sistema de clasificación más preciso que recoge el papel del contexto y la diferencia entre apoyos y necesidades de apoyo (Tabla 22).

Tabla 22. Descriptores y clasificación de las necesidades de apoyo. Adaptado de Arnold et al. (2014a)

\section{Modificador temporal}

Tiempo limitado/temporal

La persona solo necesitará este nivel de apoyo por un corto periodo de tiempo, normalmente desde una semana hasta aproximadamente seis meses.

Intermitenteocasional

En desarrollo La persona solo necesita apoyo ocasionalmente, por ejemplo uno o dos días a la semana o solo algunos meses del año. La persona necesita este nivel de apoyo de manera regular y durante más de seis meses.

\section{Nivel/Calificador}

Apoyo: en este contexto, el apoyo hace referencia a la asistencia proporcionada por otra persona. Apoyo natural: hace referencia al apoyo disponible para cualquier persona en la misma comunidad.

Ninguno/sin apoyo formal Ningún apoyo es necesitado a mayores del apoyo que ya existe de manera natural para las personas que viven en esa comunidad.

La persona solo necesita del apoyo una, dos o pocas veces al día o

Ligero una supervisión ocasional, apoyo físico o verbal además del apoyo que ya está disponible de manera natural.

Moderado La persona necesita apoyo directo varias horas cada día, además del apoyo que ya esté disponible de manera natural.

La persona necesita apoyo directa fácilmente disponible 24 horas

Sustancial al día, además del apoyo que ya esté disponible de manera natural. La persona podría estar sola sin apoyo o supervisión dos horas.

Generalizado La persona necesita apoyo directo de dos o más personas algunas veces al día, además de otras necesidades de apoyo sustanciales.

Sistema de Apoyo

Consistente: regular, constante

Estable: una vez establecido, sin cambios ni fluctuaciones

Consistente y estable

Inconsistente o inestable

Ausente

En crisis
La persona está bien apoyada a través de un sistema de apoyos consistente y estable.

La persona recibe apoyo aunque la red de apoyo de la persona es inconsistente o inestable para cubrir el nivel de necesidades de apoyo de la persona. La persona podría no recibir siempre el nivel de apoyos que necesita, o el sistema de apoyo ha cambiado y ya no será capaz de cubrir las necesidades de la persona en el futuro. La persona requiere apoyo pero no tiene una buena red de apoyo. La persona requiere apoyo y la red de apoyo y el sistema de apoyo de la persona es incapaz de proporcionar el apoyo necesario, lo que pone a la persona o a otros en riesgo y peligro de daño severo. 
En definitiva, si bien las investigaciones sobre la intensidad de los apoyos aún no están tan avanzadas como para poder establecer un punto de corte que identifique la presencia o ausencia de discapacidad, la información ofrecida por las escalas de necesidades de apoyos es muy útil a la hora de realizar perfiles individualizados que optimicen la planificación y provisión de apoyos (Thompson y Viriyangkura, 2013).

\subsection{EVALUACIÓN PARA EL PERFIL DE APOYOS}

Snell y Drake (1994) concluyeron que la etiqueta de discapacidad es necesaria en términos de elegibilidad, pero un perfil de necesidades de apoyo es esencial para poder diseñar y proporcionar los apoyos que necesita cada persona con discapacidad intelectual. Este perfil aporta resultados con dos finalidades diferentes (Schalock et al., 2010); por un lado, generar información aplicable a la toma de decisiones en un amplio abanico de temas legales y, por otro, de manera primordial, ayudar en el proceso de planificación de apoyos proporcionados por profesionales, familiares y amigos. En este sentido, estos perfiles de apoyos cuentan con cuatro características principales: (1) son individuales y cambiantes; (2) están orientados a la consecución de resultados deseados o valorados por la persona; (3) se relacionan con la mejora de la calidad de vida y la participación, no sólo con el aprendizaje; y (4) buscan, preferentemente, apoyos naturales.

En este capítulo, se presentan algunas características fundamentales a tener en la construcción de un buen perfil de apoyos y en la consecuente planificación individualizada de apoyos. En este sentido, la evaluación de las necesidades de apoyo se presenta como el eje central de ambos procesos, la cual ha de ser establecida dentro de un modelo de evaluación de necesidades de apoyo determinado y llevada a cabo a través de las herramientas pertinentes. Con este objetivo, se describen en este apartado los modelos e instrumentos de evaluación de necesidades, justificando las implicaciones y la elección de aquellos más apropiados para enmarcar la evaluación de las necesidades de apoyo en el ámbito de la discapacidad intelectual.

\subsubsection{Modelos de evaluación de necesidades de apoyo}

Una de las taxonomías de necesidades más conocidas fue la creada por Maslow a mediados del siglo XX. El triángulo de Maslow (1943) hace referencia a aquellas necesidades propias del ser humano (necesidades fisiológicas, de seguridad, de afiliación, 
de reconocimiento y de autorrealización), diferenciando aquellas necesidades básicas de otras de orden secundario y estableciendo una jerarquía de las necesidades para la supervivencia, pero manteniendo la importancia de satisfacer todas esas necesidades para poder llevar una vida digna. En este sentido, analizando las necesidades extraordinarias de las personas con discapacidad con esas necesidades propias del ser humano, podemos plantear que las personas con discapacidad necesitan apoyos para poder cubrir con satisfacción esas necesidades humanas.

Tradicionalmente, no se han proporcionado los apoyos que las personas con discapacidad necesitaban para llevar una vida de calidad, siendo las necesidades de orden primario las únicas cubiertas desde el paradigma asistencial de la discapacidad. Así, marcando una desconexión con las creencias anteriores, Thompson y Viriyangkura (2013) resaltan que desde el actual modelo de la discapacidad todas las fases de este modelo propuesto por Maslow han de ser prioritarias en la medida que estas lo sean para la persona con discapacidad, reflejando así la naturaleza más subjetiva de este constructo (Kotler y Armstrong, 2008).

Esta subjetividad de las necesidades humanas ya fue recogida en 1987, cuando Mckillip definió la necesidad como un juicio de valor de tener una carencia que puede ser solucionada. Posteriormente, cuando Pérez (1991) analiza esta definición, reconoce de manera explícita que las personas con diferentes valores (culturales, sociales, religiosos...) percibirán diferentes necesidades, apreciando la importancia de las creencias y expectativas personales y sociales en la comprensión de una determinada necesidad. Así, la evaluación de necesidades individuales dentro de un contexto social específico, constituye el elemento fundamental para la identificación de una necesidad como tal y para la determinación de su magnitud (Hernández, 1995).

De manera complementaria, Witkin y Altschuld (1995) definieron la evaluación de necesidades como un conjunto de procedimientos sistemáticos llevado a cabo con el propósito de establecer prioridades y tomar decisiones acerca de cómo mejorar un programa o una organización y de la distribución de los recursos. En este sentido, la aparición de este tipo de estudios en el ámbito social surge según Tejedor (1990), por tres razones principales: (1) la justificación del gasto público que demandan de los poderes políticos las fuerzas sociales en un contexto democrático; (2) la coyuntura de expansión de servicios sociales que hoy se vive; y, paradójicamente, (3) la escasez de recursos disponibles para invertir en esos servicios sociales. Es decir, se trata de maximizar la 
intervención a partir del conocimiento real de la necesidad que se plantea, estableciendo objetivos e intereses prioritarios en el proceso de planificación de apoyos.

En definitiva, la evaluación de necesidades representa una modalidad de investigación social aplicada que permite acercarse al estudio de las carencias o problemas percibidos en un ámbito determinado con el objetivo de poder priorizar aquellas más significativas y planificar nuestra intervención de manera que sea lo más efectiva tanto para la persona como para el proveedor. Para abordar su estudio, existen tres modelos teóricos sobre cómo evaluar necesidades (Chacón, 1989; Mckillip, 1987):

\subsubsection{Modelo de marketing}

Desde esta perspectiva la evaluación de necesidades se define como un proceso de feedback, para aprender y adaptarse a las necesidades de una población concreta (MartiCosta y Serrano-García, 1983; Nieckerns, Purga y Noriega, 1980). En este sentido, la evaluación de necesidades es considerada como un medio inevitable para la supervivencia y el desarrollo organizacional, ya que su principal tarea reside en satisfacer los deseos del mercado mediante el diseño, comunicación y prestación de productos y servicios apropiados y competitivamente viables (Kotler, 1982).

Es decir, el modelo de marketing, concibe las necesidades como deseos y el análisis de necesidades conllevaría determinar y apostar por los servicios que las poblaciones objetivo están dispuestas a utilizar. Para lograr este objetivo, es necesario seguir tres pasos fundamentales: (1) selección de la población objetivo, que real o potencialmente pueda elegir los servicios y que sea capaz de realizar el intercambio; (2) selección de la posición competitiva: Distinguir lo servicios propios de los ofrecidos por otras instituciones; (3) desarrollo de una combinación de marketing efectiva, seleccionando el rango y la calidad de los servicios que maximizan su utilización por parte de la población objetivo.

La perspectiva de marketing puede ser útil para una planificación organizacional, pero es cuestionable que sea aplicable en un análisis de necesidades a título individual, tal y como se pretende con el actual modelo de la discapacidad. El enfoque del marketing define las necesidades de la población objetivo por la intersección entre las capacidades de una organización y las elecciones expresadas por la población objetivo, pero considerando a esta como homogénea. Además, no hace una clara distinción entre necesidades y deseos, necesaria para el desarrollo de planes de apoyos individualizados. 


\subsubsection{Modelo de toma de decisiones}

Este modelo es una adaptación del Análisis Multiatributivo de Utilidad (AMU) (Edwards y Newman, 1982; Kenney y Reiffa, 1976; Pitz y McKillip, 1984) y se basa en tres supuestos: (1) es más probable que se utilicen los resultados de una investigación aplicada si se atiende a los valores y a la información que necesitan los potenciales usuarios de la investigación; (2) las personas que deben adoptar decisiones muestran sesgos en sus juicios cuando se enfrentan al análisis de necesidades; (3) ningún indicador ni criterio simple evalúa un constructo perfectamente, por lo que resulta más acertado el uso de indicadores múltiples.

El modelo de toma de decisiones hace explícitos los valores y el papel que juegan en el análisis de necesidades. Habitualmente se introducen en la evaluación los valores de los usuarios de la investigación, pero recoge también la de los investigadores o la de otros grupos afectados. El principal inconveniente de este modelo es su complejidad y, además, corre el riesgo de satisfacer más las necesidades del evaluador que del evaluado, por el sesgo que supone recoger de manera explícita la opinión de éste.

\subsubsection{Modelo de discrepancia}

El modelo de discrepancia (Witkin, 1977) es el más utilizado en numerosos ámbitos sociales en general y en especial en el campo de la discapacidad, ya que incide en las expectativas de cada persona $\mathrm{y}$, a la vez, se basa en el conocimiento del rendimiento normativo a través de tres fases: (1) establecimiento de fines y objetivos: Definir lo que debería ser; (2) evaluación del nivel de funcionamiento actual: Determinar lo que es; (3) identificación de discrepancias y diferencias entre lo que es y lo que debería ser.

Durante la fase de establecimiento de fines y objetivos se hacen explícitas las expectativas sobre los resultados. Lo más usual es entrevistar a un grupo de expertos sobre las dimensiones que definen el funcionamiento adecuado dentro del área objeto de análisis. Estas expectativas son indicadores de lo que debería ser el valor óptimo de una dimensión en un momento y circunstancia concreta. El segundo paso consiste en evaluar el rendimiento actual del servicio en cada una de las dimensiones definidas previamente El tercer paso es la identificación de la discrepancia. La necesidad viene definida por aquella medida de ejecución que sea inferior a los niveles deseados determinados por los expertos (atendiendo al desempeño de los iguales en las actividades deseadas). 
Aunque todos los modelos podrían ser aplicados de un modo u otro al trabajo realizado por los diferentes centros y servicios del entorno de las personas con discapacidad, este último modelo es más conveniente para la evaluación de necesidades de apoyo extraordinarias. Se considera que el modelo de la discrepancia recoge los puntos fuertes de las otras aportaciones y propone un sistema que se ajuste perfectamente a la actual concepción de la discapacidad intelectual: (a) refleja la importancia de diferentes contextos; (b) presenta un matiz multidimensional; (c) tiene en cuenta las necesidades en comparación con los iguales (d) da prioridad a los resultados; y (e) busca un proceso continuo de feedback que mejore el funcionamiento de la organización en su conjunto y que responda a las necesidades y deseos individuales de los usuarios.

\subsubsection{Cómo evaluar necesidades de apoyo e instrumentos de medida}

Teniendo como referencia el modelo de la discrepancia, la evaluación de las personas con discapacidad intelectual conlleva numerosas evaluaciones tanto sobre diferentes aspectos de la persona como del entorno. Entre ellos, Thompson et al. (2009. destacan la importancia de la evaluación de necesidades extraordinarias, es decir, los apoyos y ayudas que la persona precisa (lo que es) y que no serían necesitadas por otras personas de la misma edad y condición (lo que debería ser). En este sentido, el objetivo último de la evaluación de las necesidades reside en conocer la intensidad de los apoyos (tipo, frecuencia y tiempo diario de apoyo) que la persona ha de recibir para poder completar de manera satisfactoria las tareas cotidianas y superar con éxito las necesidades que cualquier persona presenta (y cubre) en su vida diaria.

Las herramientas de evaluación de necesidades de apoyo son una pieza primordial en el desarrollo de planes centrados en la persona y tienen una gran importancia práctica para los equipos de planificación, ya que la evaluación de las necesidades de apoyo contribuye a un proceso de planificación exitoso (Schalock et al., 2010). Sin embargo, una de las grandes limitaciones que aparecen en las ciencias sociales, ámbito donde se ubica la investigación en discapacidad, es la dificultad de medir constructos psicológicos de manera cuantitativa. Como cualquier otro constructo psicológico, las necesidades de apoyo de una persona no son directamente observables, de manera que el conocimiento del mismo solo puede ser realizado a partir de pruebas indirectas. Por ello, el desarrollo de escalas, instrumentos y herramientas de evaluación elaboradas debe ser valorado como un esfuerzo digno que pretende suplir el obstáculo de medir aquello que no podemos observar de manera directa. 
Por tanto, las necesidades de apoyo de una persona pueden medirse con diferentes niveles de precisión y con diferentes objetivos a través de autoinformes, observaciones, entrevistas... que indiquen la intensidad de las necesidades de apoyo; siendo la más aconsejable una escala o test de evaluación. Según autores como Salvia e Isseldyke (1995) y Verdugo (1994), las escalas de medición son una de las herramientas más aconsejados en la evaluación de niños y adolescentes con discapacidad intelectual ya que permiten obtener datos en situaciones estructuradas o tipificadas para describir el objeto de la evaluación. Sin embargo, no cualquier escala es válida. Estos autores manifiestan que el proceso de estandarización es esencial en estas escalas, es decir, es fundamental que la información obtenida con el test sea consistente y que se garanticen las mismas condiciones de aplicación para poder comparar la ejecución de la persona evaluada con la norma o con el criterio establecido. Este proceso e estandarización requiere un duro trabajo por lo que, debido a la reciente aparición de la importancia de los apoyos en la vida de las personas con discapacidad, existe una gran escasez de instrumentos fiables y válidos encargados de medir la intensidad de las necesidades de apoyo de esta población específica.

Ante esta situación de escasez de herramientas, y conociendo la importancia de la evaluación de las necesidades de apoyo, los profesionales del ámbito de la discapacidad intelectual empezaron a utilizar instrumentos existentes de competencia general como medio para inferir las necesidades de apoyo, obteniendo así un medio para poner en práctica las orientaciones generadas por el nuevo marco teórico. Destaca especialmente el extendido uso de instrumentos como el ICAP en España (añadido al uso de la escala DDP, en otros países), desarrollados previamente para la evaluación de conducta adaptativa pero que no resultaron ser óptimos para el diagnóstico (Tassé et al., 2012).

Sin embargo, aunque los constructos de conducta adaptativa y necesidades de apoyo están relacionados, no son iguales: aunque que a partir de los instrumentos de conducta adaptiva es posible conocer aquellas áreas donde las personas presenta más carencias o necesidades para adaptarse a una vida típica, es imposible determinar la intensidad de estas necesidades o la naturaleza de los apoyos que debían ser proporcionados para cubrir esas necesidades, lo que supone el objetivo de las escalas de necesidades de apoyo. La CIF fue utilizada también para inferir necesidades de apoyo en el caso de una persona con parálisis cerebral (Chiorino, 2004); sin embargo, su uso esporádico y su objetivo prioritariamente cualitativo no la convierte en una buena opción para la evaluación estandarizada de necesidades. 
Así las cosas, desde 1992, aunque más intensamente desde 2002 (Luckasson et al.; Thompson, Hughes et al.), investigadores y profesionales de atención directa empiezan a reclamar el desarrollo específico de una escala de evaluación de las necesidades de apoyo. No obstante, aún en 2012, cuando Schalock y Verdugo analizaron las causas por las que las planificaciones de apoyos no siempre eran llevadas a cabo por las diferentes entidades y asociaciones (a pesar de las evidencias de su repercusión en la calidad de vida e inclusión), encontraron que una de las razones principales era, precisamente, la falta de herramientas específicas de evaluación de necesidades de apoyo destinadas a personas con discapacidad intelectual; lo que limitaba, a su vez, la implementación de estrategias adecuadas de provisión de apoyos.

Presentamos a continuación los cuatro instrumentos para medir necesidades de apoyo en personas con discapacidad intelectual existentes en la actualidad, poniéndose de manifiesto la necesidad de seguir investigando en esta línea. Si bien es cierto que existen otros instrumentos destinados a evaluar necesidades en otras poblaciones específicas, entre los que destacan aquellos que pueden ser aplicados a personas con discapacidad intelectual que padezcan algún trastorno de salud mental asociado (Roy, Matthews, Clifford, Fowler y Martin, 2002; Xeniditis, Slade, Thornicroft y Bouras, 2003), queremos exponer aquí aquellos instrumentos de necesidades de apoyo desarrollados y utilizados para la evaluación de cualquier persona con discapacidad intelectual.

En la Tabla 23 se muestran las características fundamentales de estas herramientas de evaluación, aportando información obtenida a partir de publicaciones sobre los instrumentos y de revisiones realizadas previamente sobre instrumentos utilizados para la medición de necesidades de apoyo en población con discapacidad intelectual (Ibáñez, 2009; Howard Research, 2007; Thompson y Viriyangkura, 2013).

En resumen, han sido diversas las investigaciones que se han llevado a cabo en relación con instrumentos de estas características, entre las que destacan los estudios sobre el SNAP (Gould, 1998), el NC-SNAP (Hennike, Myers, Realon y Thompson, 2002), el ICAN (Llewellyn, Parmenter, Chan, Riches y Hindmarsh, 2005), y la SIS (Thompson et al., 2004). Sin embargo, sólo la SIS ha sido altamente aceptada en el ámbito internacional y es capaz de medir las necesidades de apoyo de manera coherente a la nueva concepción de discapacidad intelectual planteada por la AAIDD (respetando las áreas de evaluación propuestas en el modelo teórico de apoyos y considerando la intensidad de apoyos en términos de tipo, frecuencia y tiempo diario de apoyo). 
Tabla 23. Instrumentos de evaluación de necesidades de apoyo en personas con discapacidad intelectual

\begin{tabular}{|c|c|c|c|c|}
\hline INSTRUMENTO & OBJETIVO & $\begin{array}{c}\text { ESTRUCTURA DE LA ESCALA } \\
\text { (Dominios y formato de respuesta) }\end{array}$ & $\begin{array}{c}\text { PROPIEDADES } \\
\text { (Fiabilidad y Validez) }\end{array}$ & REFERENCIAS \\
\hline \multirow{2}{*}{$\begin{array}{l}\text { Perfil de Evaluación } \\
\text { de Necesidades de } \\
\text { Servicios (Service } \\
\text { Need Assessment } \\
\text { Profile [SNAP]) }\end{array}$} & \multirow{2}{*}{$\begin{array}{l}\text { Diseñado para medir las necesidades de } \\
\text { apoyo de cualquier individuo con } \\
\text { discapacidad para conocer los servicios } \\
\text { de apoyo de día y residencia que } \\
\text { necesitan con objetivos de distribución } \\
\text { y económicos. Se obtiene un perfil de } \\
\text { apoyos que permite conocer los } \\
\text { servicios de apoyo necesitados por la } \\
\text { persona, detallando el tiempo del } \\
\text { personal de trabajo. }\end{array}$} & \multirow{2}{*}{$\begin{array}{l}\text { Cinco dominios: } \\
\text { - Cuidado personal } \\
\text { - Salud física } \\
\text { - Apoyo conductual } \\
\text { - Apoyo nocturno } \\
\text { - Apoyo social } \\
\text { Las puntuaciones de los ítems oscilan de1 a } 5\end{array}$} & \multirow{2}{*}{$\begin{array}{l}\text { Consistencia Interna: } .97 \\
\text { Validez de constructo: } .46 \\
\text { Validez convergente: } \\
\quad \text {-SIS: .79 }\end{array}$} & $\begin{array}{l}\text { Escala Original } \\
\text { Gould (1998) }\end{array}$ \\
\hline & & & & $\begin{array}{l}\text { Otras citas relacionadas: } \\
\text { Guscia, Harries, Kirby, } \\
\text { Nettelbeck y Taplin (2005) } \\
\text { Guscia et al. (2006) }\end{array}$ \\
\hline \multirow{3}{*}{$\begin{array}{l}\text { Perfil de Evaluación } \\
\text { de Necesidades de } \\
\text { Carolina del Norte } \\
\text { (North Carolina } \\
\text { Service Need } \\
\text { Assessment Profile } \\
\text { [NC-SNAP]) }\end{array}$} & \multirow{3}{*}{$\begin{array}{l}\text { Conocer las necesidades de apoyo de } \\
\text { cualquier persona con discapacidad con } \\
\text { objetivos económicos y de asignación } \\
\text { de recursos como sustituto del ICAP. Se } \\
\text { obtiene una puntuación por cada } \\
\text { dominio, siendo la puntuación general } \\
\text { la misma que la más alta. }\end{array}$} & \multirow{3}{*}{$\begin{array}{l}\text { Tres dominios: } \\
\text { - Vida Diaria } \\
\text { - Cuidados de Salud } \\
\text { - Comportamiento } \\
\text { Las puntuaciones de los ítems oscilan de } 1 \text { a } 5\end{array}$} & Consistencia interna .97 & $\begin{array}{l}\text { Escala Original } \\
\text { Hennike et al. (2002) }\end{array}$ \\
\hline & & & Test-retest.92 & $\begin{array}{l}\text { Otras citas relacionadas: } \\
\text { Hennike (2002) }\end{array}$ \\
\hline & & & $\begin{array}{l}\text { Validez convergente } \\
\text {-SIS: .72 }\end{array}$ & $\begin{array}{l}\text { Hennike, Myers, Realon y } \\
\text { Thompson }(2006)\end{array}$ \\
\hline \multirow{2}{*}{$\begin{array}{l}\text { Instrumento para } \\
\text { Clasificar las } \\
\text { Necesidades de } \\
\text { Apoyo de las } \\
\text { Personas con } \\
\text { Discapacidad } \\
\text { (Instrument to Classify } \\
\text { Support Needs for } \\
\text { people with disability } \\
\text { [I-CAN]) }\end{array}$} & \multirow{2}{*}{$\begin{array}{l}\text { Identificar y clasificar necesidades de } \\
\text { apoyo para adultos con discapacidades } \\
\text { en diferentes dominios basados en el } \\
\text { marco de la CIF con el objetivo de } \\
\text { realizar planificaciones } \\
\text { individualizadas de sistemas. }\end{array}$} & \multirow{2}{*}{$\begin{array}{l}\text { - Cuatro subescalas de Salud y Bienestar } \\
\text { (Salud Física; Salud Emocional y Mental; } \\
\text { Conductual y Servicios de Salud) } \\
\text { - Siete subescalas sobre actividades de } \\
\text { participación (demandas y tareas generales, } \\
\text { comunicación, vida doméstica- autocuidado, } \\
\text { movilidad, interacciones y relaciones } \\
\text { interpersonales, aprendizaje a lo largo de la } \\
\text { vida, comunidad-vida social y cívica) } \\
\text { - Intereses y felicidad personal } \\
\text { Puntuaciones basadas en } 2 \text { escalas tipo Likert } \\
\text { (frecuencia y nivel de apoyo) de } 6 \text { opciones }\end{array}$} & Interevaluadores: .89 & $\begin{array}{l}\text { Escala Original } \\
\text { Lewellyn et al. (2005) }\end{array}$ \\
\hline & & & Validez de criterio: .60 & $\begin{array}{l}\text { Otras citas relacionadas: } \\
\text { Riches, Parmenter, Llewellyn, } \\
\text { Hindmarsh y Chan (2009a; } \\
\text { 2009b) } \\
\text { Arnold et al. (2014a) }\end{array}$ \\
\hline \multirow{4}{*}{$\begin{array}{l}\text { Escala de Intensidad } \\
\text { de Apoyos (Supports } \\
\text { Intensity Scale [SIS]) }\end{array}$} & \multirow{4}{*}{$\begin{array}{l}\text { Proporciona un Índice de Necesidades } \\
\text { de Apoyo para la asignación de recursos } \\
\text { y servicios en adultos con discapacidad } \\
\text { intelectual, así como un Perfil de } \\
\text { Necesidades de Apoyo orientado a la } \\
\text { planificación. }\end{array}$} & \multirow{4}{*}{$\begin{array}{l}\text { - Seis áreas de apoyo(Hogar, Comunidad; } \\
\text { Empleo; Desarrollo Personal; Salud y } \\
\text { Seguridad; Social) } \\
\text { - Escala suplementaria (Defensa) } \\
\text { - Necesidades Excepcionales Medicas y } \\
\text { Conductuales } \\
\text { Las puntuaciones se recogen en tres índices } \\
\text { de medida (tipo, frecuencia y tiempo diario de } \\
\text { apoyo), cada uno de ellos evaluado del } 0 \text { al } 4\end{array}$} & \multirow{4}{*}{$\begin{array}{l}\text { Consistencia interna: .97 } \\
\text { Interveluadores: .87 } \\
\text { Validez de constructo } .51\end{array}$} & $\begin{array}{l}\text { Escala Original } \\
\text { Thompson et al. (2004) }\end{array}$ \\
\hline & & & & $\begin{array}{l}\text { Otras citas relacionadas: } \\
\text { Hughes, Thompson y } \\
\text { Wehmeyer (2011) }\end{array}$ \\
\hline & & & & $\begin{array}{l}\text { Thompson, Tassé y } \\
\text { McLaughlin (2008) }\end{array}$ \\
\hline & & & & $\begin{array}{l}\text { *Adaptaciones: Schalock, } \\
\text { Thompson y Tassé (2008) }\end{array}$ \\
\hline
\end{tabular}




\subsubsection{Instrumentos de evaluación de necesidades de apoyo en el contexto español: la Escala de Intensidad de Apoyos (SIS)}

En la actualidad, sólo uno de los instrumentos previamente descritos ha demostrado sus adecuadas propiedades psicométricas en diferentes países incluyendo su adaptación y validación en España: la SIS. Este instrumento se desarrolló originalmente en 2004 (Thompson et al.), ante la demanda de contar con una escala de evaluación de la intensidad de las necesidades de apoyo como recurso clave para cubrir las discrepancias existentes entre las capacidades de la persona y las demandas de su entorno, alcanzando así los resultados personales deseados (Thompson, Hughes et al., 2002).

Hasta ese momento, sólo existían dos escalas de necesidades de apoyo (SNAP y NC-SNAP), las cuales no contaban aún con una adecuada validación psicométrica y, además, estaban más orientadas a aportar una puntuación única (de manera similar a la medición del criticado CI) que un perfil que permitiera el desarrollo de un plan individualizado. Con el mismo objetivo que la SIS, y casi de manera paralela, se desarrolló también el ICAN. Sin embargo, éste presentaba grandes limitaciones y tuvo menor acogida en el ámbito internacional; de hecho, aun hoy la escala ICAN sigue incorporando nuevas modificaciones para incrementar su presencia dentro de este campo (Arnold et al., 2014a).

Este instrumento ha sido adaptado y aplicado internacionalmente con numerosas garantías de fiabilidad y validez en 13 idiomas, entre ellos español (Verdugo, Arias e Ibáñez, 2007) y catalán (Giné et al., 2007), y se han obtenido numerosas evidencias sobre el buen funcionamiento de la misma (Buntinx, Van Unen, Speth y Groot, 2006; Cottini, Fedeli, Leoni y Croce, 2008; Claes, Van Hove, van Loon, Vandevelde y Schalock, 2009a; Giné et al., 2006; Ibáñez, 2009; Kuppens, Bossaert, Buntinx, Molleman y van den Abbeele, 2010; Lamoureux-Hebert y Morin, 2009; Schalock, Thompson et al., 2008; Verdugo, Arias, Ibáñez y Gómez, 2006; Verdugo, Arias, Ibáñez y Schalock, 2010; Verdugo Ibáñez y Arias, 2007); incluyendo su pertinencia para la evaluación de personas con una discapacidad diferente a la intelectual (Bossaert et al., 2009; Cruz, Jenaro, Pérez y Robaina, 2010; Jenaro, Cruz, Pérez, Robaina y Vega, 2011; Smit, Sabbe y Prinzie, 2011).

Asimismo, ha sido demostrada su alta relación con las puntuaciones clínicas (Weiss, Lunsky, Tassé y Durbin, 2009) y su eficacia para predecir apoyos extraordinarios y asignar (Chou, Lee, Chang y Yu, 2013; Fortune et al., 2008; Giné et al., 2014; Wehmeyer et al., 2009), estando especialmente puesto su énfasis en el diseño y planificación de apoyos individualizados (van Loon, 2006b, 2009a, 2009b). 
En este sentido, Thompson et al. (2009) manifestaban que la SIS era la escala de evaluación de necesidades de apoyo que mejor cumplía los requisitos recogidos por la Asociación Nacional de Directores Estatales de los Servicios de Discapacidades del Desarrollo (National Association of State Directors of Developmental Disabilities Services [NASDDDS]) para poder considerar que un instrumento de evaluación es útil: (a) ser fácilmente puesto en práctica y ser utilizado por profesionales, no profesionales y personas implicadas con una amplio rango de habilidades; (b) generar logros y resultados consistentes cuando se utilice a través de todas las áreas y ámbitos de servicio; (c) estar centrado en la persona; (d) proporcionar información accesible y comprensible a un amplio rango de prestadores; (e) identificar las necesidades de apoyo de personas con condiciones cambiantes y complejas; (f) generar resultados aplicables a la toma de decisiones en un amplio ámbito de temas; y (g) estar diseñado para integrar en el proceso de planificación de apoyos las perspectivas de personas que están recibiendo apoyo, sus familias, amigos y profesionales.

Por su parte, Ibáñez (2009) resume algunos de los puntos fuertes de la SIS, abogando por su adecuación, frente a los otros instrumentos utilizados, manifestando que: (1) refleja los cambios en las expectativas relativas a las personas con discapacidad; (2) asume que las personas con discapacidad deben realizar actividades apropiadas a su edad cronológica; (3) enfatiza las descripciones funcionales de la discapacidad referenciando los contextos de su vida diaria; (4) contempla el funcionamiento del individuo en su globalidad y lo aborda asumiendo que pueden existir problemas conductuales y médicos de carácter excepcional que pueden afectar a dicho rendimiento; (5) permite unificar un lenguaje y criterios de trabajo al aportar una medida cuantitativa y estandarizada de la intensidad de los apoyos y estar adaptado a más de 10 países; (6) obliga a todos los implicados en la evaluación y planificación de apoyos, incluida la propia persona con discapacidad, a considerar actividades normalizadas que pudieran no haberse tenido en cuenta hasta ese momento; (7) ofrece abiertamente la oportunidad de participar en el proceso de planificación de apoyos a todos aquellos que conozcan bien a la persona evaluada, generando un rol activo; (8) genera una descripción funcional de la persona fácil de comprender y muy útil de cara a intervenir, frente a lo que aportan otros instrumentos de evaluación existentes; (9) está estrechamente relacionado con la PCP, aportando información muy valiosa para el desarrollo de planes de apoyo individualizados; y (10) es un instrumento más adecuado que los utilizados tradicionalmente para financiar recursos económicos. 
Asimismo, la escala se asienta en siete aspectos fundamentales (Thompson et al., 2004) que aportan un marco teórico concreto, aportando validez de contenido a la SIS, así como pautas para su uso: (1) todas las personas de la sociedad son iguales entre sí y tienen derecho a obtener acceso a las oportunidades que la sociedad ofrece y a buscar un desarrollo óptimo; (2) todas las personas deben ser comprendidas en relación al contexto en el que viven; (3) el funcionamiento individual de una persona debe entenderse siempre como una interacción entre la persona y su entorno, no de forma unilateral a partir de un trastorno un defecto; (4) los apoyos deben garantizar que las personas con discapacidades consigan obtener acceso a los recursos sociales, políticos y económicos de la sociedad y lo mantengan; (5) es necesario evaluar la intensidad de las necesidades de apoyo (a través del tipo, la frecuencia y el tiempo diario de apoyo) para superar las diferencias entre la competencia personal y las expectativas, exigencias y posibilidades del entorno; (6) todo el mundo debe tener la oportunidad de participar en cualquier actividad, con todo el apoyo que necesite; y (7) la SIS está diseñada para utilizarse en combinación con un plan individualizado de apoyos centrados en la persona y busca una mejor conexión entre el plan de apoyos, las necesidades y elecciones individuales.

Todas las características y ventajas de este instrumento mencionadas anteriormente justificaron la elección de esta escala como herramienta para ser traducida, adaptada al español (Verdugo, Arias et al., 2007) y utilizada en la evaluación de las necesidades de apoyo de las personas con discapacidad intelectual.

\section{a) Desarrollo y descripción de la SIS}

La SIS fue desarrollada de manera original en Estados Unidos por la AAIDD durante varios años mediante un proceso que incluyó (Thompson, Hughes et al., 2002): (a) una extensa revisión de la bibliografía para identificar ítems iniciales, potenciales indicadores de las necesidades de apoyo; (b) la realización de sesiones de trabajo, con 50 profesionales dedicados al campo de las discapacidades intelectuales, empleando la metodología Q para establecer la validez de contenido y la agrupación inicial de los ítems; y (c) la realización de cuatro estudios de campo donde se recogieron datos de más de 1.800 personas con discapacidad intelectual.

Finalmente, la versión definitiva de la escala consta de tres secciones que recogen todas las áreas de apoyo planteadas por la AAIDD (Luckasson et al., 2002; Schalock et al., 2010), incluyendo la importancia de las necesidades excepcionales de apoyo médico y conductual planteadas en el modelo (Thompson et al., 2004). 
- Secciones 1 y 2: Escala de intensidad de apoyo y Escala suplementaria de protección y defensa

Esta herramienta trata de evaluar la intensidad de necesidad de apoyo normativo u objetivo (valorado por un profesional en términos estándar) requerida por una persona. Para su valoración, se establecen tres categorías fundamentales: frecuencia, tiempo diario de apoyo y tipo de apoyo, evaluadas cada una de ellas a través de una escala de clasificación de cinco opciones de respuesta. A continuación, en la Tabla 24, se presentan y describen las categorías de respuesta de los tres índices de medida, así como la relación numérica que corresponde a cada una de las categorías presentadas (0-4), incrementando su valor en la medida que aumenta la intensidad del apoyo.

Tabla 24. Índices de medida para la evaluación de la intensidad de apoyos

\begin{tabular}{lll}
\hline FRECUENCIA DE APOYO & TIEMPO DE APOYO DIARIO & TIPO DE APOYO \\
\hline 0=Nunca o menos de una vez al mes & 0=Nada & 0=Ninguno \\
$\begin{array}{l}\text { 1=Al menos una vez al mes, pero no } \\
\text { una vez a la semana }\end{array}$ & 1=Menos de 30 minutos & 1=Supervisión \\
2=Al menos una vez a la semana, & 2 horas minutos y & 2=Incitación verbal/ \\
pero no una vez al día & gestual \\
$\begin{array}{l}\text { 3=Al menos una vez al día pero no } 2 \text { y 4 horas } \\
\text { una vez cada hora }\end{array}$ & 4=4 horas o más & 4=Ayuda física parcial \\
4=Cada hora o con más frecuencia & & \\
\hline
\end{tabular}

Sección 1, Escala que proporciona el índice de intensidad de los apoyos necesitados. Está compuesta por 49 actividades agrupadas en seis categorías (subescalas) referentes a las principales áreas cotidianas de evaluación de apoyos propuestas por la AAIDD (Luckasson et al., 2002): 'vida en el hogar', 'vida en la comunidad', 'aprendizaje a lo largo de la vida', 'empleo', 'salud y seguridad', y 'actividades sociales'. Cada ítem corresponde a una actividad y ha de ser evaluado a través de los tres índices de medida anteriormente mencionados. Se suman las puntuaciones directas de todos los ítems (incluyendo los tres parámetros) de cada subescala para formar la puntuación de cada área y después se suman todas las puntuaciones para obtener la puntuación total de la escala. Las puntuaciones directas obtenidas, tras ser transformadas en puntuaciones estandarizadas y percentiles (a través de los baremos establecidos), servirán para obtener el perfil y el nivel de intensidad necesidades de apoyo. 
Sección 2, Escala suplementaria de protección y defensa. Mide ocho actividades que oscilan entre la estimulación y la aceptación hasta la oportunidad y el acceso. No se contempla su medición dentro del índice y perfil de necesidades de apoyo, sino que se trata de una escala suplementaria que obtiene una información de manera independiente. Se puntúa de manera más cualitativa, recogiendo aquellas cuatro actividades en las que la persona presenta mayores necesidades de apoyo. No obstante, los últimos estudios realizados sobre la SIS han puesto de manifiesto el buen funcionamiento de esta sección, y también las altas correlaciones obtenidas con las de áreas de apoyo de la sección 1, valorándose la posibilidad y pertinencia futura de incluir esta escala suplementaria dentro del índice y perfil de intensidad de necesidades de apoyo generales (Shogren, Thompson et al., 2014).

- Sección 3: Escala de necesidades excepcionales de apoyo médico y conductual

Este apartado valora las necesidades de apoyo en 15 condiciones médicas y 12 problemas de conducta diferentes en los que una persona puede requerir niveles sustanciales de apoyo. En esta ocasión, la intensidad de los apoyos se mide en una escala Likert de tres puntos $(0=$ no tiene la condición o no necesita apoyo, $1=$ necesita algún apoyo y 2 = necesita apoyo extenso), teniéndose en cuenta de manera complementaria si la puntuación en cada uno de los dos dominios es mayor de 5 y si hay al menos un 2 rodeado, pero sin incluir estas áreas en el perfil de intensidad de apoyos. Así, la interpretación de esta sección se realiza de la siguiente forma: si la respuesta a alguna de estas dos preguntas es afirmativa, es probable que la persona tenga necesidades de apoyos mayores que otra persona con un índice de necesidades similar, lo que ha de tenerse en cuenta a la hora de diseñar el plan.

En cuanto al formato de cumplimentación, debido a la complejidad de la escala, el proceso más apropiado de aplicación de la misma es mediante una entrevista (con la presencia de un entrevistador cualificado y formado en el uso de la escala) y con un enfoque predominantemente objetivo, basado en la observación (es alguien que conoce bien a la persona con discapacidad quien ha de contestar a las preguntas). No obstante, también se recoge la posibilidad de que la propia persona con discapacidad aporte información sobre sus necesidades de apoyo, desarrollándose para ello una guía específica sobre cómo realizar la entrevista a personas con discapacidad intelectual (Tassé, Schalock, Thompson y Wehmeyer, 2005). 


\section{b) Limitaciones de la SIS}

A pesar de los números puntos fuertes que presenta la escala SIS, ésta también ha recibido numerosas críticas. Thompson y Viriyangkura (2013) realizaron una revisión general sobre artículos relacionados con el uso de este instrumento y han detectado diferentes causas derivadas de sus características que generan confusión en las aplicaciones y que ponen de manifiesto la necesidad de que un profesional cualificado y entrenado en el uso de la escala forme parte del proceso de evaluación:

En primer lugar, encontraron que la escala resulta compleja por su formato de respuesta. Tal y como se ha explicado previamente, la escala mide la intensidad de las necesidades de apoyo de la persona con discapacidad, utilizando tres índices de medida (tipo, frecuencia y tiempo diario de apoyo), siendo necesaria la participación durante el proceso de cumplimentación de un profesional capaz de diferenciar estos tres índices y distinguir las diferentes categorías de respuesta de cada uno de ellos (ver Tabla 24).

En segundo lugar, también había sido objeto de debate si la evaluación de las necesidades de apoyo debiera ser o no limitada únicamente a aquellas actividades en las que la persona participa en la actualidad y en los entornos en los que realmente la realiza. Los autores de la SIS (Thompson et al., 2004) sugieren que es necesario estimar el apoyo que necesitaría la persona evaluada para participar en todas las actividades de la vida diaria propuestas en entornos normativos, incluidas aquellas que, por algún motivo, no se realizan. Sin embargo, otros autores (Arnold et al., 2011; Riches et al., 2009a) defienden que la medida de las necesidades de apoyo debe basarse en el entorno especifico del niño y que podría ser problemático e impreciso estimar necesidades de apoyo en actividades que el niño no realiza.

En respuesta, Thompson y Viriyangkura (2013) argumentan que, a pesar de las críticas, nadie ha propuesto una alternativa fiable y válida para poder medir las necesidades de apoyo e interpretarlas con un baremo estandarizado sin que todos los evaluados hayan cumplimentado el mismo banco de ítems. Además, estos autores defienden que, aunque esta situación cree inseguridad en quien está cumplimentando la escala, con la presencia de un entrevistador cualificado, los resultados son positivos en último término, pues obliga a los informantes a plantearse la vida de la persona con discapacidad participando en actividades cotidianas normativas e inclusivas.

En cualquier caso, si bien es cierto que resulta imprescindible que la persona que cumplimente la escala estime las necesidades de apoyo de la persona en todos los ítems 
propuestos para obtener el índice estandarizado, el objetivo final de la escala es establecer planes de apoyo individualizados y coherentes a la vida de cada persona. Así, tras obtener un índice cuantitativo y estandarizado de las necesidades de apoyo que permita conocer la intensidad de necesidades de apoyo de la persona y pueda establecerse el acceso a un determinado tipo de recursos basado en estas necesidades, sería conveniente acudir de manera cualitativa y específica a cada una de las áreas e ítems que resulten sustanciales en la vida y el entorno del niño, elaborando un plan individualizado de apoyos adaptado no solo a sus necesidades, sino también a sus características e intereses.

Por último, también han existido algunas controversias en cuanto a la estructura de la escala. Aunque, en general, los diferentes estudios han revelado una estructura multidimensional en las diferentes adaptaciones de la SIS (e.g., Kuppens et al., 2010; Thompson et al., 2004; Verdugo, Arias et al., 2007), que da sentido a la importancia de obtener un perfil de apoyos que aporte una puntuación diferenciadas para cada una de las áreas evaluadas, Harries et al. (2005) encontraron que la escala respondía a una sola dimensión, que correlacionaba altamente con la conducta adaptativa.

\subsubsection{Diferencias entre el $\mathrm{CI}$, la conducta adaptativa y las necesidades de apoyo: implicaciones en la evaluación de los constructos}

El proceso de evaluación de tres componentes del que se hablaba en la parte inicial de este capítulo, ponía de manifiesto que la evaluación del CI (entendida como medida de inteligencia), de la conducta adaptativa (habilidades conceptuales, sociales y prácticas) y de las necesidades de apoyo (fundamental para establecer un perfil de apoyos) conforman las tres principales medidas relacionadas con la evaluación de las personas con discapacidad intelectual. A pesar de que se trata de tres constructos diferenciados, su alta relación y la falta de conocimiento sobre las implicaciones de cada uno de ellos, han provocado que, frecuentemente, se haya utilizado los datos obtenidos en la evaluación de uno de los constructos para la estimación de los otros.

No obstante, la investigación actual permite conocer las limitaciones que esto supone y determinar los criterios específicos que han de presentar los instrumentos de medición de cada uno de estos conceptos, limitando el rango de actuación de cada uno de ellos. Por ello, conviene dedicar un apartado no sólo a conocer de manera diferencia qué es y cómo se evalúa cada uno de los constructos mencionados, sino también a comprender las características concretas que han de reflejar las correspondientes escalas evaluativas. 
A principios del siglo XX el CI era la única medida utilizada para el diagnóstico y la clasificación de la discapacidad intelectual. Sin embargo, a medida que las investigaciones se iban desarrollando y aparece el constructo de 'conducta adaptativa' como concepto esencial en el diagnóstico (dejando atrás la visión reduccionista que comprendía el CI como única medida de la discapacidad intelectual), se plantea un modelo de competencia personal que marca la relación estrecha existente entre ambos constructos. No obstante, aunque la mayoría de estudios que han investigado la relación entre el CI y la conducta adaptativa han obtenido que existen correlaciones altas (Harrison y Oakland, 2003; Sparrow et al., 2005), es necesario realizar un análisis exhaustivo de la diferencia entre ambos constructos.

Tassé (2013) defiende que no siempre limitaciones en el funcionamiento intelectual conllevan de manera necesaria limitaciones en la conducta adaptativa y que, complementariamente, las personas que muestran una mejor conducta adaptativa no siempre presentan un CI más elevado. En cuanto a las diferencias en la evaluación destacamos que, mientras que el CI tiende a mantenerse, la conducta adaptativa incrementa con la edad hasta llegar a estabilizarse en la vida adulta. Asimismo, el CI se mide mediante pruebas de rendimiento máximo (hasta donde el individuo es capaz de llegar), estando por el contrario la conducta adaptativa relacionada con el rendimiento típico (funcionamiento cotidiano, no potencial), siendo necesario que la baremación de las pruebas de evaluación correspondientes contemple estas peculiaridades (Tassé, 2013; Tassé et al., 2012; Schalock et al., 2010; Schalock et al., 2012).

Con la llegada del concepto 'necesidades de apoyo' como elemento clave en el proceso de evaluación asentado por Luckasson et al. (2002), se hace indispensable concretar las semejanzas y diferencias entre este constructo y los anteriores para realizar una evaluación precisa y diferenciada. Con relación al CI, han sido numerosos los estudios realizados a partir de la SIS que han puesto de manifiesto que las puntuaciones en esta escala correlacionan solo de manera moderada con el nivel de CI de la persona (e.g., Thompson et al., 2004; Ibáñez, 2009). Sin embargo, tanto el constructos de necesidades de apoyo como el de conducta adaptativa hacen referencia al funcionamiento típico de las personas con discapacidad intelectual, lo que ha generado correlaciones más elevadas entre ambos en todos los estudios realizados al respecto. Aunque las correlaciones obtenidas fueron negativas en todos los estudios (a mayores puntuaciones en conducta adaptiva corresponden menores necesidades de apoyo y viceversa) el grado de 
correlación variaba entre unos estudios y otros, siendo heterogéneas las conclusiones obtenidas sobre la diferenciación de los componentes que subyacen a estos conceptos.

Thompson, Hughes et al. (2002) encontraron correlaciones débiles entre conducta adaptativa (medida a través del ICAP) y la intensidad de las necesidades de apoyo (a partir de las puntuaciones obtenidas en la versión preliminar de la SIS). La mayoría de correlaciones entre las áreas que componen las escalas de evaluación utilizadas fueron no significativas y, en aquellos casos en los que lo la relación resultó significativa, no se alcanzaron correlaciones superiores a .79, por lo que se concluyó que si bien estas escalas estaban midiendo constructos relacionados en ciertos aspectos, no evaluaban el mismo constructo, no siendo posible intercambiar el uso de estos instrumentos. Posteriormente, en 2004, Thompson et al. examinaron las correlaciones entre las puntuaciones de la SIS y dos medidas de conducta adaptativa (ICAP y VABS). De manera coherente a los resultados anteriores, las correlaciones entre los dominios de la SIS y el ICAP fueron moderados, oscilaron entre .23 y .68, con una correlación del total de los instrumentos de .49. Las correlaciones entre las puntuaciones de la SIS y las puntuaciones de la VABS fluctuaron entre .45 y.61, siendo la correlación entre las puntuaciones globales de los instrumentos también de 49 .

Harries et al. (2005) replicaron este estudio y encontraron correlaciones más altas que las presentadas en el estudio anterior entre la conducta adaptiva (medida a través de la ICAP y del ABS-RC:2) y la intensidad de las necesidades de apoyo (medida a través de la SIS). Concretamente, las correlaciones entre las subescalas de la SIS y las escalas de conducta adaptativa fueron significativas en todos los casos y superiores a .63, estando las correlaciones medias entre .70 y .80, y llegando a obtenerse correlaciones superiores a .90, siendo las correlaciones especialmente significativas entre las necesidades de apoyo y el dominio conceptual de la conducta adaptativa. Sin embargo, aunque las correlaciones entre ambos constructos era elevada, se realizó un análisis factorial en el que se incluyeron las subescalas de los tres instrumentos y, si bien algunas de ellas saturaban en el mismo factor (conceptual), fue imposible confirmar la presencia de un factor común subyacente a las dimensiones de conducta adaptativa y de necesidades de apoyo. Sin embargo, las evidentes muestras de unidimensionalidad abrieron el debate y plantearon la importancia de continuar la investigación en este ámbito.

En este sentido, Guscia et al. (2006), durante el proceso de desarrollo de la escala SNAP, analizaron las correlaciones de este instrumento con otros destinados a evaluar las necesidades de apoyo (SIS) y la conducta adaptativa (ICAP), con la expectativa de aportar 
evidencias de validez convergente en el desarrollo de este instrumento. Los datos pusieron de manifiesto que los resultados obtenidos por personas con discapacidad en el SNAP correlacionaban con ambos instrumentos (ICAP y SIS), siendo superiores las correlaciones obtenidas entre el SNAP y la SIS que entre el SNAP y el ICAP. No obstante destacamos que, dentro de los análisis realizados, también se evaluaron las correlaciones existentes entre la SIS y el ICAP y se encontraron correlaciones superiores a .80. Estos resultados son superiores a los encontrados en los estudios de Thompson (Thompson, Hughes et al., 2002; Thompson et al., 2004) pero las correlaciones no llegaron a ser tan elevadas como las encontradas en el estudio llevado a cabo por Harries et al. (2005).

Más recientemente, en 2009, se realizaron varios estudios que permitieron a los autores concluir que las escalas de conducta adaptativa y las de necesidades de apoyo medían dos constructos diferentes. En primer lugar, Wehmeyer et al. (2009) realizaron un estudio en el que comparaban las puntuaciones de la SIS con las obtenidas en la escala DDP (Brown et al., 1986), encontrando que la relación entre la suma de las seis áreas que componen la SIS y la dimensión adaptativa del DDP era de .18, siendo más alta la correlación existente entre las áreas de la SIS y la evaluación de la dimensión 'desadaptativa' (.44) . Asimismo, Claes et al. (2009a) compararon los resultados de la SIS y la Vineland, obteniendo puntuaciones significativas que oscilaron entre .37 y .89. Por último, Brown, Ouellette-Kuntz, Bielska y Elliott (2009) desarrollaron otro estudio en relación con las puntuaciones de la SIS y el inventario de conducta adaptativa SIB-R, obteniendo las correlaciones más altas de estos estudios. Sin embargo, éstas fueron inferiores a .90 y no se realizó un análisis factorial, por lo que podemos decir que en este estudio tampoco se obtuvieron resultados claros que demostraran que la conducta adaptativa y las necesidades de apoyo sean un mismo constructo.

Ante estas evidencias, desde la AAIDD (Schalock et al., 2010) se concluyó que las medidas de conducta adaptativa y la SIS estaban relacionadas pero eran diferentes. Por un lado, la conducta adaptativa hace referencia explícita al nivel de logro o realización de la competencia, a las habilidades conceptuales, sociales y prácticas; por otro lado, las necesidades de apoyo reflejan el tipo, la frecuencia y el tiempo de apoyo que cada persona necesita para cubrir las demandas del entorno. En definitiva, si bien es cierto que las escalas de conducta adaptativa y de necesidades de apoyo tienen mucho en común y, en general, se obtienen correlaciones altas e inversas, es necesario usar escalas específicas para la medición de cada uno de estos constructos, ya que muestran perspectivas de trabajo diferenciadas. 
Son numerosas las publicaciones que recogen y enfatizan las diferencias en la evaluación de ambos constructos (Thompson, McGrew et al., 2002; Thompson et al., 2004; Thompson, Tassé et al., 2008; Thompson et al., 2009). En la Tabla 25 se sintetizan estas diferencias, conceptualizando las implicaciones de ambos tipos de evaluaciones y los requisitos que han de cumplir las escalas correspondientes para realizar una adecuada evaluación.

Tabla 25. Diferencias en la evaluación de conducta adaptiva y necesidades de apoyo adaptada de Schalock et al. (2010, p.175)

\begin{tabular}{|c|c|c|}
\hline CARACTERÍSTICAS & $\begin{array}{c}\text { ESCALA DE CONDUCTA } \\
\text { ADAPTATIVA }\end{array}$ & $\begin{array}{c}\text { ESCALA DE NECESIDADES } \\
\text { DE APOYO }\end{array}$ \\
\hline Constructo medido & $\begin{array}{l}\text { Las habilidades adaptativas que } \\
\text { una persona ha aprendido, es } \\
\text { una medida de rendimiento o } \\
\text { logro. }\end{array}$ & $\begin{array}{l}\text { Los apoyos extraordinarios que } \\
\text { una persona necesita para } \\
\text { participar de manera exitosa en la } \\
\text { mayoría de las actividades de la } \\
\text { vida diaria. }\end{array}$ \\
\hline Finalidad & $\begin{array}{l}\text { Determinar el patrón de } \\
\text { comportamientos adaptativos } \\
\text { que presenta la persona. }\end{array}$ & $\begin{array}{l}\text { Determinar el patrón de la } \\
\text { intensidad de los apoyos } \\
\text { necesitados para mejorar su } \\
\text { participación en casa y en la } \\
\text { comunidad. }\end{array}$ \\
\hline Usos & $\begin{array}{l}\text { Diagnosticar discapacidad } \\
\text { intelectual e identificar metas } \\
\text { educativas y formativas } \\
\text { relevantes que puedan incluirse } \\
\text { en planes educativos/ } \\
\text { formativos individualizados. }\end{array}$ & $\begin{array}{l}\text { Determinar las necesidades de } \\
\text { apoyo de una persona en } \\
\text { diferentes áreas vitales en relación } \\
\text { a otras personas con discapacidad } \\
\text { intelectual; para desarrollar un } \\
\text { plan de apoyos individualizados. }\end{array}$ \\
\hline $\begin{array}{l}\text { Contenido de los } \\
\text { ítems }\end{array}$ & $\begin{array}{l}\text { Una serie de habilidades o } \\
\text { comportamientos adaptativos, } \\
\text { observables y mediables, } \\
\text { necesarios para funcionar } \\
\text { satisfactoriamente en sociedad. }\end{array}$ & $\begin{array}{l}\text { Una variedad de actividades } \\
\text { diarias que incluyen múltiples } \\
\text { comportamientos y habilidades en } \\
\text { los que la persona se involucra } \\
\text { para participar en la sociedad. }\end{array}$ \\
\hline $\begin{array}{l}\text { Respuestas a los } \\
\text { ítems }\end{array}$ & $\begin{array}{l}\text { El nivel de dominio o } \\
\text { competencia de una persona en } \\
\text { relación con las habilidades } \\
\text { adaptativas. }\end{array}$ & $\begin{array}{l}\text { La intensidad y el patrón de los } \\
\text { apoyos extraordinarios que una } \\
\text { persona necesita para poder } \\
\text { participar en actividades vitales. }\end{array}$ \\
\hline Ítems adicionales & $\begin{array}{l}\text { Algunas escalas incluyen } \\
\text { también indicadores de } \\
\text { problemas de conducta. }\end{array}$ & $\begin{array}{l}\text { La intensidad de los apoyos } \\
\text { requerida para mantener/mejorar } \\
\text { el estado de salud y prevenir } \\
\text { resultaos negativos/perjudiciales } \\
\text { de los problemas de conducta. }\end{array}$ \\
\hline
\end{tabular}

En definitiva, si bien es cierto que las escalas de conducta adaptativa y de necesidades de apoyo tienen mucho en común y, en general, se obtienen correlaciones altas e inversas, es necesario usar escalas específicas para la medición de cada uno de 
estos constructos, ya que muestran perspectivas de trabajo diferenciadas. Por ejemplo, los instrumentos de conducta adaptativa han de poder ser utilizados como herramienta de diagnóstico, por lo que han de estar estandarizadas con población con y sin discapacidad para poder ofrecer el punto de corte concreto; sin embargo, las escalas de las necesidades de apoyo se bareman teniendo en cuenta únicamente a personas con discapacidad intelectual. Asimismo, estudios recientes han concluido que las escalas de evaluación de las necesidades de apoyo funcionan como un mejor predictor de los recursos que reciben o deben recibir la persona que las escalas de conducta adaptativa (Arnold, Riches y Stancliffe, 2014b; Giné et al., 2014; Fortune, Agosta y Bershadsky, 2011; Wehmeyer, 2009).

\subsection{LA PLANIFICACIÓN INDIVIDUALIZADA DE APOYOS PARA PERSONAS CON DISCAPACIDAD INTELECTUAL}

Los apoyos son un universo de recursos y estrategias que mejoran el funcionamiento humano; sin embargo, no todas las personas necesitarán todos los apoyos disponibles ni necesitarán los mismos apoyos en las diferentes áreas ni a lo largo de su vida (Schalock et al., 2010). Asimismo, las necesidades de apoyo de una persona difieren de otra tanto cuantitativamente (en número) como cualitativamente (en naturaleza). Es por ello que los equipos de planificación han de desarrollar e implementar apoyos individualizados, que se ajusten a las necesidades de cada persona en cada contexto y momento concretos.

Este proceso es fundamental para el desarrollo de planes de apoyo centrados en la persona y debe basarse en cuatro directrices (Thompson et al., 2009): (1) cualquier discrepancia existente entre una persona y el entorno produce una necesidad de apoyo que puede suplirse mejor a través del uso apropiado de los apoyos individualizados que centrándose en el 'arreglo' de la persona; (2) dado que estos apoyos individualizados están basados en el desarrollo y aplicación de un plan predeterminado, es probable que mejoren el funcionamiento humano y los resultados personales; (3) los apoyos son un puente entre lo que es y lo que puede ser; (4) hay una relación reciproca entre las limitaciones y las necesidades de apoyo (mayores limitaciones suelen asociarse a una mayor intensidad de necesidades de apoyo); no obstante, poner el foco en reducir el desajuste entre las competencias individuales y las demandas del entorno optimiza la identificación del sistema de apoyos necesario para mejorar el funcionamiento humano y los resultados esperados. 
Asimismo, se considera que este proceso será eficaz siempre y cuando (Claes et al., 2012): (a) se haga de forma rigurosa y ordenada; (b) se valoren las prioridades y metas individuales en la vida de la persona con discapacidad; (c) la evaluación de las necesidades de apoyo se efectúe con instrumentos fiables y válidos; (d) se supervise y evalúe todo el proceso de cambio tomando como base los resultados personales; (e) se exprese el compromiso de la sociedad; y (f) se utilicen sistemas de apoyo que incluyan prioritariamente apoyos naturales (profesionales, familiares y amigos cooperación), pero también con el uso de la tecnología, la educación y el aprendizaje de nuevas destrezas, adaptación del entorno, incentivos y fortalezas personales.

Desde la aparición del actual paradigma de apoyos surgen modelos de planificación que cumplen estas recomendaciones y criterios, abogando por la importancia de la evaluación. Sin embargo, los elementos y fases de la misma han ido variando para darle una mayor coherencia y potenciar su implementación. La investigación llevada a cabo bajo esta perspectiva en las últimas décadas ha permitido matizar los conceptos clave dentro del proceso de planificación de apoyo, mejorando así los aspectos iniciales hasta llegar al proceso de planificación que conocemos en la actualidad (Schalock et al., 2010; Thompson et al., 2009).

\subsubsection{Del proceso de cuatro pasos al proceso de cinco componentes de la AAIDD}

Basándose en las aportaciones de 1992, Luckasson et al. (2002) defienden de manera explícita que los apoyos requeridos y su intensidad se han de basar en un proceso de evaluación y realizan por primera vez un intento de establecer una serie de criterios y características principales que han de seguirse en la provisión de apoyos para conseguir los resultados deseados. Concretamente, estos autores defienden la necesidad realizar una planificación individualizada previa a partir de tres pautas fundamentales: (a) identificar de áreas de apoyo relevantes para la persona con discapacidad; (b) conocer las actividades de apoyo relevantes para cada área de apoyo y (c) determinar para el individuo del nivel de apoyos necesarios en cada área de apoyo relevante.

Sólo tras el análisis exhaustivo obtenido en estos tres pasos podrá iniciarse el proceso de redacción del plan de apoyos, que debe incluir un plan para supervisar posteriormente la adecuación de la planificación de apoyos realizada. Así, se propone un proceso de cuatro pasos para la planificación individualizada de apoyos (Tabla 26). 
Tabla 26. Proceso de cuatro pasos para la planificación individualizada de apoyos (Luckasson et al., 2002)

\author{
Desarrollo humano \\ Enseñanza y educación \\ Vida en el hogar \\ Vida en la comunidad \\ Empleo \\ Salud y seguridad \\ Conductual \\ Social \\ Protección y defensa
}

Paso 1. Identificación de áreas de apoyo relevantes

Paso 2. Identificación de actividades de apoyo relevantes para cada área de apoyo

Preferencias e intereses del individuo

Actividades en las que la persona participará con mayor probabilidad

Lugares en los que la persona participará con mayor probabilidad

\title{
Paso 3. Evaluación del nivel o intensidad de las necesidades de apoyo
}

Frecuencia

Tiempo de apoyo diario

Tipo de apoyo

\section{Paso 4. Redacción del plan de apoyos individualizado para reflejar a la persona}

Interés y preferencias del individuo

Áreas y actividades requeridas de apoyo

Lugares en los que la persona participará con mayor probabilidad

Actividades en las que participará la persona con mayor probabilidad

Funciones de apoyo específicas que responden a las necesidades de apoyo identificadas

Énfasis en los apoyos naturales

Personas responsables de proporcionar la(s) funcion(es) de apoyo(s)

Resultados Personal

Plan para supervisar la provisión de apoyos y sus resultados

Complementariamente, Thompson, McGrew et al. (2002) añaden que cualquier plan de apoyos individualizado debe estar basado en las siguientes asunciones: (a) los tipos de apoyo deben estar hechos a medida de las necesidades y preferencias del individuo; (b) la provisión de apoyos debe ser flexible; (c) algunos de los apoyos son más importantes para el individuo que otros (determinando así la importancia de la priorización); (d) la evaluación sistemática de las necesidades de apoyo debería guiar el desarrollo y la revisión del plan de apoyos individualizado; y (e) en la evaluación de los apoyos deben ser considerados múltiples factores. Teniendo en cuenta estos criterios, se modifica el proceso de cuatro pasos para convertirlo en una planificación formada por cuatro componentes más específicos e interactivos (Figura 10), que reflejará la importancia de un proceso de evaluación continua entre los componentes y será acogido con gran interés y de manera positiva por la comunidad científica. 


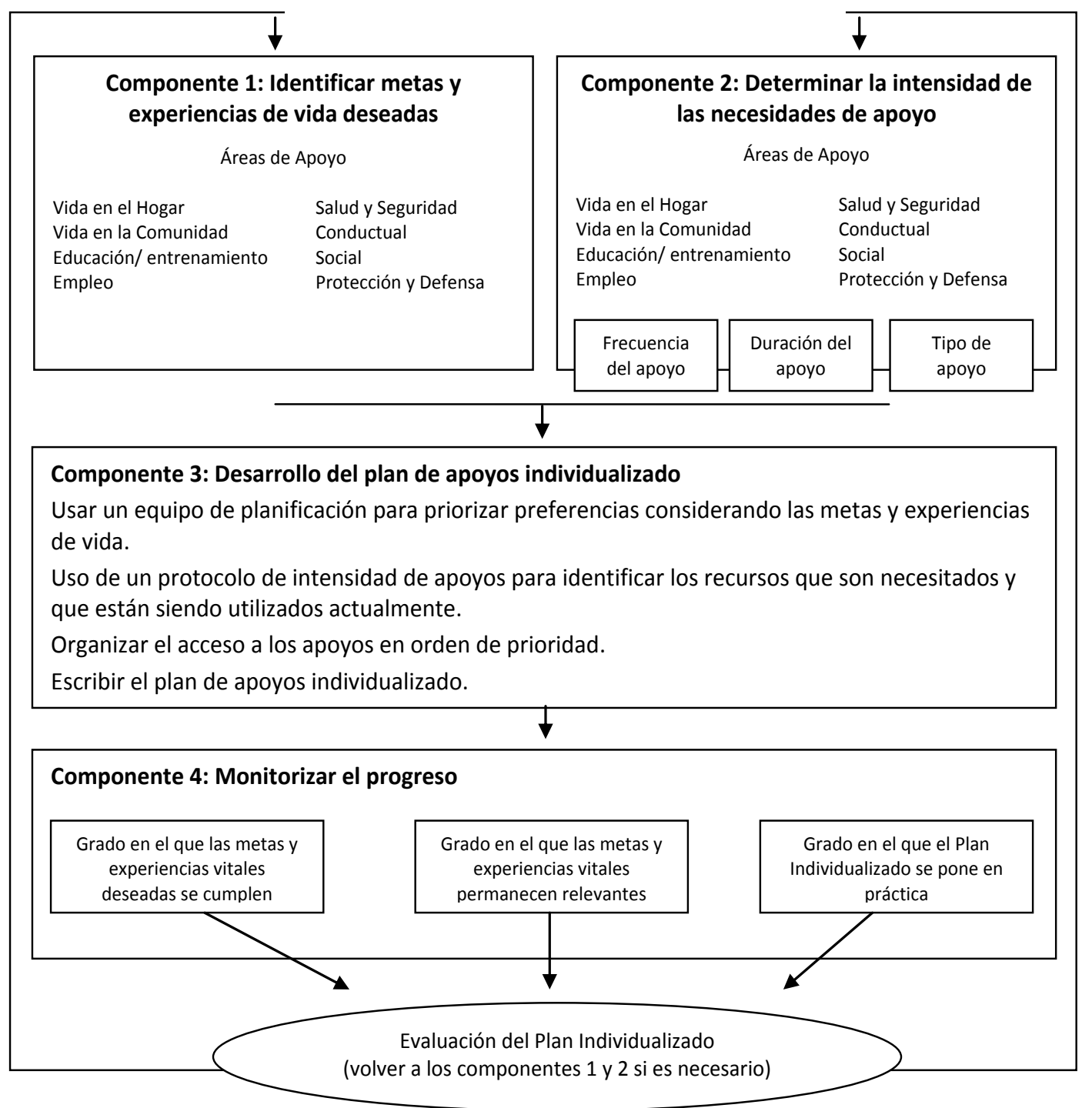

Figura 10. El proceso de cuatro componentes para la planificación individualizada de apoyos (Thompson, McGrew et al., 2002)

Ibáñez (2009) valora positivamente la propuesta de planificación y evaluación de apoyos adaptada por Thompson, McGrew et al. (2002) en cuanto a que: (1) articula el proceso basándose en componentes, favoreciendo que la recogida de información pueda suceder en paralelo o de un modo simultáneo y no necesariamente continuo; (2) define y combinan diferentes metodologías, una de tipo cualitativo representada por la entrevista que requiere la PCP y otra cuantitativa mediante la SIS, algo que viene a definir una mejor evaluación de las necesidades; (3) desarrolla un proceso completo al considerar la necesidad de realizar una supervisión y un seguimiento del plan de apoyos; y (4) hace un planteamiento dinámico y cíclico -en vez de estático y lineal-, en la medida en que la evaluación de resultados no conduce, de nuevo, hacia los componentes iniciales 1 y 2. 
Posteriormente, se matiza el proceso de cuatro componentes, dando paso a un proceso de planificación individualizada formada por cinco componentes (Schalock et al., 2010; Thompson et al., 2009) en la que se aporta una mayor presencia a la evaluación del programa: ésta deja a ser la consecuencia de otro componente para pasar a tener entidad con valor propio. En la Figura 11, podemos observar este proceso de planificación, aceptado actualmente por la AAIDD.

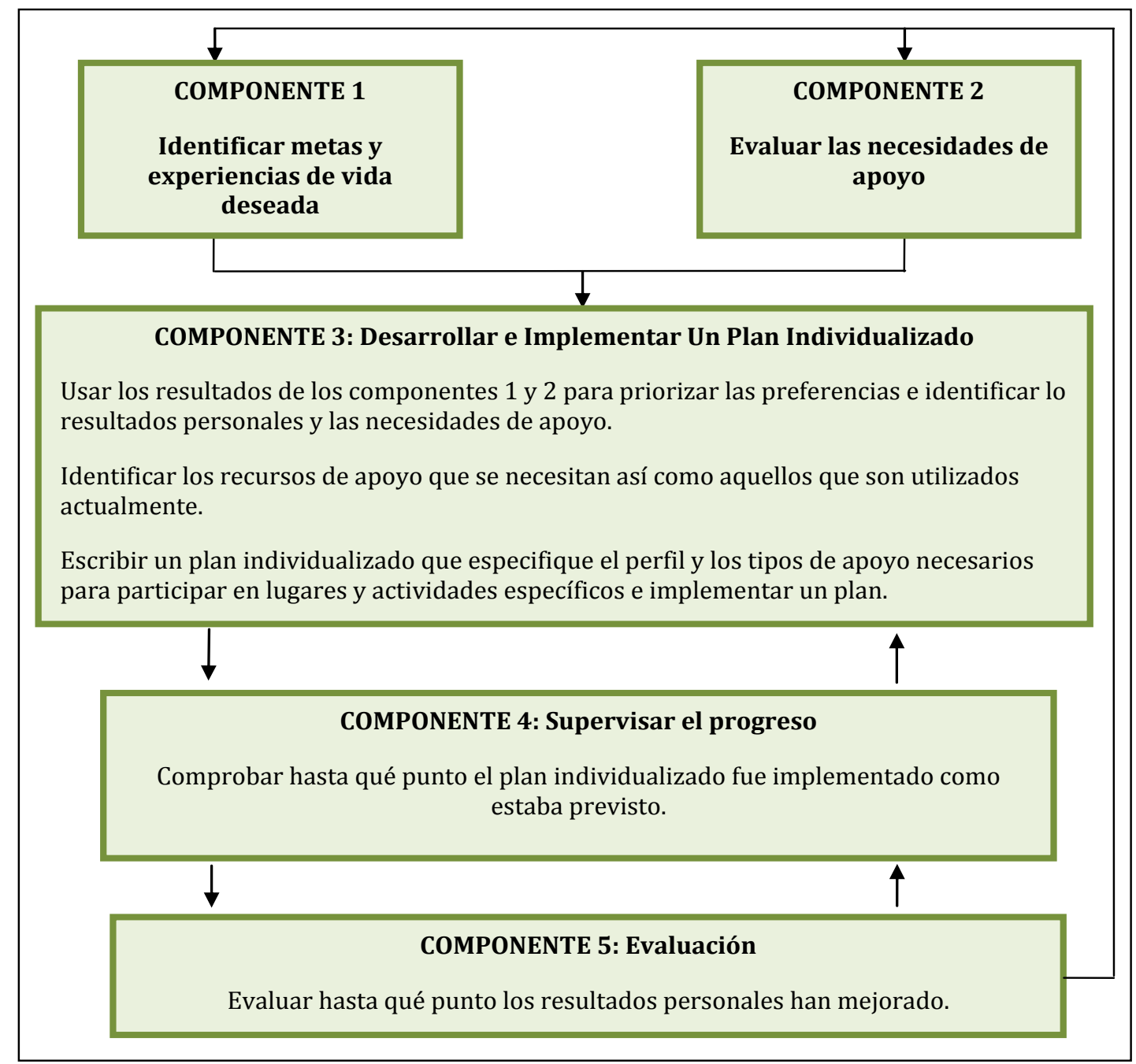

Figura 11. Proceso de cinco componentes para la evaluación, planificación y provisión de apoyos

(Thompson et al., 2009; Schalock et al. 2010)

La representación de este modelo aporta una idea rápida y visual de cuáles son las pautas a seguir en la planificación de apoyos y qué objetivos se han de cumplir en cada una de ellas. No obstante, es necesario realizar un análisis exhaustivo de los componentes para poder llegar a conocer con precisión las estrategias y herramientas procedimentales que deben estar implicadas en cada uno de ellos. Explicamos a continuación la descripción de componentes realizada por Thompson et al. (2009): 
- COMPONENTE 1. Identificar las experiencias y metas de vida deseadas: requiere el uso de los procesos de PCP, método de planificación de equipo que ofrece mejores resultados para las personas con discapacidad intelectual que los métodos tradicionales de planificación (O’Brien, 2004). Desde la PCP se requiere que la atención no recaiga sobre los profesionales y los servicios sino sobre los sueños de la persona, las preferencias personales y los intereses, relacionándose de manera estrecha con el concepto 'autodeterminación'. El objetivo es descubrir qué es importante para una persona, sin importar la carencia de recursos o limitaciones en las habilidades de la persona, e intentar llevarlo a cabo en ambientes normalizados con la ayuda de familiares y amigos. En resumen, la PCP pretende lograr una visión global de la vida esperada por una persona teniendo en cuenta aquellos aspectos que son favorables (aspectos a mantener) y aquellos que mejorarán su vida en el futuro (aspectos a cambiar).

- COMPONENTE 2. Determinar el perfil y la intensidad de las necesidades de apoyo: consiste en evaluar las necesidades de apoyo de la persona. En 1991, Pérez ya manifestó la importancia dentro de las ciencias sociales de realizar una planificación sistemática antes de iniciar una intervención, argumentado, a su vez, que la mejor planificación siempre ha de comenzar por identificar necesidades. Actualmente, se considera que esas necesidades detectadas deben ser el 'hilo conductor' de todo el proceso de intervención (Schalock y Luckasson, 2013). En este sentido, se presenta la SIS (Thompson et al., 2004) como instrumento estandarizado más usado y completo para evaluar las necesidades de apoyo de una persona, permitiendo establecer puntuaciones de necesidades a través de siete áreas de actividad e identificar necesidades de apoyo médico y conductual. No obstante, cualquier método que un equipo de planificación encuentre útil para evaluar las necesidades de apoyo puede ser utilizado de manera complementaria, incluyendo la observación directa de la persona en una variedad de actividades de la vida (e.g., Verdugo, 1994, 2003b) o entrevistas estructuradas con la persona y los miembros de su familia. La información clave a reunir es la naturaleza del apoyo extraordinario que una persona requeriría para participar con éxito en diferentes actividades diarias, especialmente aquellas asociadas con sus prioridades (identificadas en el componente 1).

Antes de continuar con la definición de los componentes, cabe destacar la complementariedad con la que deben ser tenidos en cuenta los componentes 1 y 2 . Tal y como puede observarse en la ilustración del proceso (Figura 11), no se trata de dos componentes sucesivos, sino paralelos. Para evitar el desaprovechamiento de unos recursos limitados, es necesario analizar y alinear cuidadosamente tanto las prioridades 
personales como las áreas de necesidad (Thompson et al., 2009). Si las actividades en las que se ofrecen apoyos a la persona no se basan en las preferencias del interesado, las mejoras serán insignificantes. Por otra parte, igual de erróneo sería evaluar únicamente los deseos de la persona, sin considerar atentamente los apoyos que necesita la persona para lograr sus objetivos personales. Es por ello que, para desarrollar un plan de apoyos eficaz capaz de conseguir los resultados esperados, es necesario realizar una planificación basada tanto en los intereses como en las necesidades individuales.

- COMPONENTE 3. Desarrollar un plan individualizado: consiste diseñar un plan, basado en la información recogida previamente, que dé respuesta a las necesidades e intereses evaluados y establezca prioridades de intervención. La discusión en este punto pasa del futuro al presente, siendo importante diseñar un plan de acción desde una perspectiva optimista y realista. En definitiva, lo que se busca es un plan individualizado que identifique y especifique los contextos y actividades en los que es probable que una persona participe en su vida diaria, la naturaleza e intensidad de los apoyos que serán proporcionadas y quienes serán las personas responsables de dar los apoyos.

- COMPONENTE 4. Supervisar el progreso: es necesario mantener una rigurosa supervisión de hasta qué punto el plan individual de una persona se está aplicando. La supervisión debe ser continua y sistemática por medio de reuniones programadas periódicamente para considerar la congruencia entre lo que fue planeado y lo que ha sucedido. Los equipos de planificación deberían supervisar los planes de apoyo al menos una vez al año a medida que las personas crecen y sus intereses personales cambian.

- COMPONENTE 5. Evaluación: en esta última fase se plantea examinar, a partir de los resultados personales, hasta qué punto se están cumpliendo las experiencias vitales y las metas deseadas. Es importante reconocer que las preferencias personales pueden cambiar con el tiempo y completar este componente del proceso asegurará que los planes sean revisados cuando ya no satisfagan las necesidades de una persona. Asimismo, obtener información sobre los resultados personales obtenidos contribuye a fomentar las prácticas basadas en la evidencia y en los resultados. Dentro del campo de la discapacidad intelectual existen varios marcos de referencia que pueden ser utilizados para conocer la adecuación de un programa de intervención y el grado de consecución de los objetivos planteados en el mismo. No obstante, el enfoque que cuenta con mayor fundamentación internacional para garantizar la eficacia de una planificación individualizada de apoyos, se basa en el incremento de la calidad de vida de la persona (Schalock y Verdugo, 2002, 2007, $2008,2012,2013,2014)$. 
Aunque este proceso de cinco componentes requiere una inversión significativa de tiempo y energía, es fundamental un proceso de planificación comprensiva que permita organizar los apoyos de tal manera que se correspondan con las necesidades individuales y los resultados deseados de la persona con discapacidad intelectual. No obstante, el desarrollo de estrategias prácticas que optimicen la eficacia de los programas de apoyos sigue siendo hoy en día una de las principales demandas de los profesionales.

En este sentido, se están empezando a desarrollar protocolos específicos de actuación que aportan guías concretas para el desarrollo de planes de apoyos individualizados, facilitando su implementación y asegurando la alineación de las áreas de necesidades de apoyo con las dimensiones de calidad de vida (van Loon et al., 2014). Destaca la propuesta realizada por el Gobierno de Alberta (Alberta Government, 2013) en colaboración con Robert L. Schalock, en la que se recoge que una correcta planificación conlleva la alineación horizontal y vertical de cada todos los componentes implicados en la planificación de apoyos y plantea cinco pasos fundamentales a llevar a cabo antes del diseño del plan: (1) identificar las fortalezas y objetivos vitales del individuo; (2) seleccionar las necesidades de apoyo relacionadas con las prioridades del individuo; (3) alinear estas necesidades de apoyo con los resultados esperados relacionados con el funcionamiento y el bienestar; (4) alinear necesidades de apoyo con estrategias específicas de apoyo; (5) identificar un objetivo de apoyo específico para cada estrategia de apoyo (incluyendo las aportaciones del micro, meso y macrosistema). Asimismo, desde esta guía se defiende que los planes de apoyo individualizados, además de basarse en las fortalezas del individuo y en los resultados esperados, deben suponer un compromiso escrito por parte de las personas y los servicios implicados.

\subsubsection{Eficacia de los planes de apoyo individualizados: alineación de los apoyos y la calidad de vida en la práctica organizacional}

A principios del siglo XXI, las prácticas y resultados basados en la evidencia empezaban a obtener un papel fundamental como marco de referencia para la evaluación de la calidad de los servicios de atención a personas con discapacidad (van Loon y Van Hove, 2001). Desde esa perspectiva, la eficacia de los servicios hace referencia a la mejora de la calidad de vida de las personas con discapacidad intelectual, derivada de la precisión de los apoyos proporcionados (Schalock y Verdugo, 2012, 2013b, 2014). 
Teniendo en cuenta que, en la actualidad, la mejora de la calidad de vida de las personas con discapacidad es considerad uno de los requisitos clave para garantizar la eficacia profesional, se han empezado a implementar estrategias prácticas que unen los dos marcos más potentes en el entendimiento de las personas con discapacidad: el paradigma de apoyos y el modelo de calidad de vida.

Para poder medir de manera válida el impacto que los programas de apoyos ofrecidos desde las diferentes organizaciones tienen en la calidad de vida de los usuarios, resulta necesario conocer su nivel de calidad de vida antes y después de la intervención. En este sentido, establecer comparaciones válidas que permitan conocer el impacto de los apoyos proporcionados requiere contar con instrumentos de evaluación de calidad de vida que aporten una puntuación válida sobre la satisfacción y el bienestar de las personas con discapacidad en un momento concreto.

\subsubsection{Calidad de vida: estrategias e instrumentos de evaluación}

La aplicación del concepto de calidad de vida dentro de los planes individuales de apoyo para personas con discapacidad está estrechamente relacionada con el modelo de calidad de vida de Schalock y Verdugo explicado en el capítulo 1 (pp. 77-85).

Una de las razones de la elección de este modelo es el amplio número de herramientas y estrategias de medición e intervención que la investigación ha desarrollado en torno a sus indicadores específicos (percepciones, comportamientos o condiciones específicas de cada una de las ocho dimensiones del modelo). Los indicadores de este modelo de calidad de vida han obtenido suficientes garantías de su validez, son culturalmente sensibles y, además, sirven para evaluar tanto el bienestar percibido ('autoinforme') como las experiencias de vida de la persona y sus circunstancias desde una perspectiva externa ('observación directa'), que deben ser evaluados de manera complementaria debido a las frecuentes discrepancias existentes entre ambos resultados (Janssen, Schuengel y Stolk, 2005)

Los instrumentos más relevantes para la evaluación de la calidad de vida han sido desarrollados en España bajo el modelo de Schalock y Verdugo: Escala FUMAT (Verdugo, Gómez, Arias, 2009); Escala GENCAT (Verdugo, Arias, Gómez y Schalock, 2009); Escala INTEGRAL (Verdugo, Gómez, Arias y Schalock, 2009), Escala INICO-FEAPS (Verdugo, Gómez et al., 2013) y Escala San Martín (Verdugo, Gómez, Arias, Navas, Schalock, 2014; Verdugo, Gómez, Arias, Santamaría, Navallas et al., 2013; Verdugo, Gómez et al., 2014). 
Asimismo, estas escalas han servido de referencia para la creación de otras herramientas internacionales, como es el caso de la Personal Outcomes Scale (POS) (Claes, Van Hove, van Loon, Vandevelde y Schalock, 2009b; van Loon, Van Hove, Schalock y Claes, 2008).

Además de los instrumentos previamente presentados, dirigidos a población adulta, también se han desarrollado algunos instrumentos orientados a evaluar la calidad de vida de niños y jóvenes con y sin discapacidad intelectual como el Cuestionario de Calidad de Vida Infantil -versión para niños (CVI) y versión para padres (CVIP) (Sabeh, Verdugo, Prieto y Contini, 2009) y el Cuestionario de Calidad de Vida Adolescentes (CCVA) (Gómez -Vela y Verdugo, 2009). No obstante, estas escalas no han mostrado propiedades psicométricas tan robustas como en el caso de las de adultos. Actualmente, se está desarrollando una escala de calidad de vida infantil con el objetivo de evaluar la calidad de vida en niños y adolescentes con discapacidad intelectual: la Escala KIDSLIFE (Gómez et al., 2014). Por último, se están elaborando también escalas de evaluación específicas para algunas de las dimensiones clave del modelo de calidad de vida, como es el caso de la Escala ARC-INICO de evaluación de la autodeterminación (Verdugo Gómez-Vela et al., 2013; Vicente, Verdugo, Gómez-Vela, Fernández-Pulido y Guillén, en prensa), centrada en la evaluación de este constructo en adolescentes con discapacidad.

Las herramientas de evaluación presentadas permiten obtener un perfil e índice de calidad de vida, a partir de los cuales analizar las puntuaciones de la persona en las distintas dimensiones y compararlas con el baremo. El uso de estas escalas aporta información individual útil para planificar programas y, además, permite agrupar los datos por servicios o programas para determinar un perfil organizacional y tomar decisiones generales (Schalock y Verdugo, 2013a). En este sentido, tanto las puntuaciones individuales como las puntuaciones grupales obtenidas en estas escalas de calidad de vida (en cada dimensión y en su totalidad) han de ser entendidas como variables dependientes en las prácticas basadas en la evidencia (Schalock et al., 2011).

\subsubsection{Convergencia de la planificación de apoyos y el modelo de calidad de vida de Schalock y Verdugo: Arduin, ejemplo de aplicación en la práctica diaria}

En 2001, van Loon y Van Hove publican el proceso inicial de un proceso práctico de cambio organizacional realizado en la organización holandesa de Arduin. En 1994, llega al equipo directivo de la organización un nuevo grupo de profesionales que proponen dejar a un lado los servicios asistenciales tradicionales y comienzan a fomentar la inclusión, la 
autodeterminación y el desarrollo personal, consideradas las tres dimensiones de calidad de vida necesarias para la innovación de los servicios (van Loon, 2006b). Concretamente, van Loon, Claes, Vandevelde, Van Hove y Schalock (2010) describen cómo se utilizó, a modo de estrategia procedimental, un sistema de tres componentes que combinaba la esencia de las planificaciones individualizadas de apoyos con los resultados de calidad de vida esperados (Tabla 27).

Tabla 27. El proceso de intervención en Arduin: alineando el paradigma de apoyos y el modelo de calidad de vida (adaptado de van Loon et al., 2010)

\begin{tabular}{|c|c|c|}
\hline COMPONENTES & APARTADOS & DESCRIPCIÓN \\
\hline \multirow{6}{*}{$\begin{array}{l}\text { INPUT } \\
\text { Toda la información } \\
\text { relevante sobre la } \\
\text { persona }\end{array}$} & \multirow{4}{*}{$\begin{array}{l}\text { Objetivos y } \\
\text { metas }\end{array}$} & $\begin{array}{l}\text { Intereses y deseos de la persona tratados como } \\
\text { objetivos y siguiendo un pensamiento de izquierda a } \\
\text { derecha. }\end{array}$ \\
\hline & & $\begin{array}{l}\text { Teniendo en cuenta los principios de la PCP: la } \\
\text { persona es el centro. }\end{array}$ \\
\hline & & Teniendo siempre en cuenta que pueden cambiar a lo \\
\hline & & $\begin{array}{l}\text { largo del tiempo y que es necesario un proceso de } \\
\text { evaluación continua, se realizan entrevista con las } \\
\text { personas y sus padres para obtener información } \\
\text { sobre sus intereses, preferencias y deseos. }\end{array}$ \\
\hline & $\begin{array}{l}\text { Necesidades de } \\
\text { Apoyo }\end{array}$ & $\begin{array}{l}\text { Evaluadas a partir de la SIS (Thompson et al., 2004) y } \\
\text { obtener una puntuación y un perfil de necesidades de } \\
\text { apoyo. }\end{array}$ \\
\hline & \multicolumn{2}{|c|}{ Patrón actual de calidad de vida } \\
\hline \multirow{3}{*}{$\begin{array}{l}\text { THROUGHOUT } \\
\text { Una vez recogida toda } \\
\text { la información, se crea } \\
\text { un informe que } \\
\text { proporciona una } \\
\text { visión general sobre } \\
\text { los deseos de la } \\
\text { persona, su calidad de } \\
\text { vida y sus necesidades }\end{array}$} & & \multirow{2}{*}{$\begin{array}{l}\text { Alinear los apoyos necesitados en las diferentes áreas } \\
\text { de la SIS con los dominios de calidad de vida en los } \\
\text { que se va a intervenir de manera prioritaria (van } \\
\text { Loon, 2008; van Loon et al., 2010). }\end{array}$} \\
\hline & Paso 1 & \\
\hline & Paso 2 & $\begin{array}{l}\text { Relacionar los indicadores específicos de calidad de } \\
\text { vida con las áreas de apoyo de la SIS y las metas y } \\
\text { objetivos personales. }\end{array}$ \\
\hline \multirow{2}{*}{$\begin{array}{l}\text { OUTCOMES } \\
\text { Resultados }\end{array}$} & \multicolumn{2}{|c|}{$\begin{array}{l}\text { La evaluación de los resultados personales se utilizada como evidencia del } \\
\text { impacto de las estrategias de apoyo utilizadas. En el caso de Arduin, se } \\
\text { realizaron mediante las versiones iniciales de la Escala POS. }\end{array}$} \\
\hline & \multicolumn{2}{|c|}{$\begin{array}{l}\text { Esta información era utilizada a lo largo del proceso para conocer los } \\
\text { avances y ver que todo se estaba llevando a cabo como era así como para } \\
\text { valorar la eficacia de estos programas. }\end{array}$} \\
\hline
\end{tabular}

Desde el proyecto implantado en Arduin se ponía en evidencia la importancia de contar con herramientas de evaluación que ayudaran a los profesionales a lo largo de todo el proceso de planificación e implementación de los apoyos. 
Tan pronto como la SIS estuvo disponible en holandés (Buntinx, 2006b) los profesionales de la organización empezaron a utilizar esta escala para obtener una imagen más completa y definida de las necesidades de apoyo de los usuarios. Tal y como se esperaba, la SIS supuso una gran ayuda para los profesionales y tuvo gran relevancia en la mejora de la calidad de vida de las personas con discapacidad intelectual. El uso de esta escala permitió que las personas de la red del individuo con discapacidad conocieran con exactitud los apoyos que debían proporcionar para conseguir su participación en actividades comunitarias apropiadas para su edad y coherentes con sus objetivos (van Loon 2006b, 2009a, 2009b).

De esta manera, no solo era pertinente llevar a cabo una alineación general de la calidad de vida con la planificación individualizada de apoyos, sino que también era necesario conocer la relación específica existente entre las dimensiones de calidad de vida contempladas y las áreas de necesidades de apoyo evaluadas en la SIS (van Loon, 2008; van Loon et al., 2010). Esta alineación queda representada en la Tabla 28.

Tabla 28. Alineación entre las dimensiones de calidad de vida y las áreas de la SIS (van Loon et al., 2010, p.198)

\begin{tabular}{ll}
\hline DIMENSIONES DE CDV & AREAS DE EVALUACION DE LA SIS RELACIONADAS \\
\hline Autodeterminación & Protección y defensa \\
Bienestar Emocional & $\begin{array}{l}\text { Salud y seguridad, protección y defensa, necesidades } \\
\text { extraordinarias de apoyo médico }\end{array}$ \\
Bienestar Físico & $\begin{array}{l}\text { Salud y Seguridad, necesidades extraordinarias de apoyo } \\
\text { médico }\end{array}$ \\
Bienestar Material & Empleo \\
Derechos & Protección y defensa, salud y seguridad \\
Desarrollo Personal & $\begin{array}{l}\text { Salud y seguridad, protección y defensa, necesidades } \\
\text { extraordinarias de apoyo conductual, protección y defensa }\end{array}$ \\
Inclusión Social & Vida en comunidad, actividades sociales \\
Relaciones Interpersonales & Actividades sociales \\
\hline
\end{tabular}

Esta investigación puso de manifiesto que la combinación adecuada de servicios y apoyos naturales personalizados puede conseguir una transformación organizacional que deje atrás la calidad de los cuidados para empezar a buscar la calidad de vida de los usuarios. Asimismo, los resultados reflejaron que cuando los apoyos eran evaluados a través de la SIS, y administrados con la suficiente duración, no solo mejoraban la calidad de vida de las personas con discapacidad intelectual, sino también su funcionamiento adaptativo (van Loon, 2006b; 2008; 2009b). 


\subsubsection{Diferencias entre planes de apoyo y planes de servicio}

Para finalizar este apartado, es necesario diferenciar los planes de apoyo de otro tipo de planes basados en los servicios para evitar confusiones que pudieran acarrear limitaciones para conseguir los resultados esperados. Si bien es cierto que desde la perspectiva actual los servicios se entienden como medios organizados de provisión de apoyos (Thompson et al., 2009), las planificaciones centradas en los servicios no buscan el bienestar individual. Mientras que la finalidad de los planes de apoyo es identificar los recursos y estrategias que reducirán el ajuste entre las dificultades de la persona y las actividades vitales (persona-ambiente), contemplando las experiencias y oportunidades vitales que la persona valora (resultados), la planificación de servicios se centra en los tipos de servicios a los que es necesario acceder, así como el alcance general de implicación (horas) que una persona debería tener con el proveedor.

Aunque la planificación de apoyos debe incluir una planificación de servicios, una planificación de servicios no siempre lleva asociado un plan de apoyos ni se convierte en un sustituto del mismo (Schalock et al., 2010): que un servicio determine que la población general con discapacidad intelectual demanda más horas de un determinado servicio y no de otro, organizando a sus profesionales basándose en estas evidencias, no significa que se conozcan los apoyos individualizados que cada persona que acude al servicio necesita.

\subsection{EVALUACIÓN DE NECESIDADES Y PLANIFICACIÓN DE APOYOS EN NIÑOS Y ADOLESCENTES CON DISCAPACIDAD INTELECTUAL}

Los niños y adolescentes con discapacidad intelectual, de la misma manera que todos los niños y jóvenes, deben tener garantizada la salud, la seguridad, el respeto, la educación, la participación y la posibilidad de contribuir a la vida como los otros (McConachie, Colver, Forysth, Jarvis y Parkinson, 2006). En este sentido, la Convención de las Naciones Unidas sobre los Derechos de las Personas con Discapacidad (Naciones Unidas, 2006), recuerda las obligaciones asumidas en la Convención sobre los Derechos del Niño (Naciones Unidas, 1989), afirmando que "el niño con una discapacidad física o mental deberá disfrutar de una vida plena y decente en condiciones que aseguren su dignidad, fomenten su autosuficiencia y faciliten la participación en la comunidad". Asimismo, actualmente, se defiende que la intervención individualizada en el desarrollo es uno de los elementos claves para la participación, la inclusión y el bienestar de las personas con discapacidad a lo largo de todo el ciclo vital (Schalock et al., 2010). 
Colver (2005) defiende que desde el modelo social de la discapacidad se debe fomentar que los resultados de las intervenciones optimicen la participación de los niños en el hogar, en la escuela y en la vida comunitaria. Teniendo en cuenta las premisas del paradigma de apoyos, la evaluación e implementación de apoyos individualizados se convierte en el elemento clave para: (1) permitir que los niños con discapacidad puedan desenvolverse en su vida diaria tal y como lo harían sus iguales sin discapacidad, mejorando su funcionamiento y calidad de vida desde edades más tempranas; y (2) evitar riesgos y potenciar un mayor aprendizaje de habilidades adaptativas derivadas de la provisión de apoyos (Greenspan, 2012) en la medida que la plasticidad del cerebro durante las primeras etapas del desarrollo supone una mayor capacidad de aprendizaje y de generalización del mismo (Vigotsky, 1979).

En este sentido, en los últimos ha habido años un creciente interés por conocer, evaluar e intervenir en diferentes áreas del funcionamiento de las personas con discapacidad intelectual desde edades más tempranas. Se han desarrollado numerosas herramientas de evaluación para población infantil relacionadas con los conceptos clave en el nuevo modelo (OMS, 2007), como la conducta adaptativa (e.g., Tassé et al., en prensa; Verdugo Arias et al., en prensa, Verdugo, Arias y Navas, 2014), la participación en contextos normalizados (e.g., Aymerich et al., 2005; Badia et al., 2013; Ravens-Sieberer et al., 2007) y la calidad de vida (e.g., Gómez et al., 2014; Gómez -Vela y Verdugo, 2009; Sabeh et al, 2009).

No obstante, en la actualidad, no contamos con ninguna herramienta válida que permita evaluar las necesidades de apoyo de niños y adolescentes y ofrecer información relevante para planificar apoyos individualizados antes de los 16 años. Por ello, desde la AAIDD se está construyendo una escala de similares características a la SIS (Thompson et al., 2004), pero orientada específicamente a medir la intensidad de las necesidades de apoyo de niños y adolescentes con discapacidad (Thompson, Wehmeyer et al., 2008).

Esta escala cuenta con numerosas evidencias sobre su importancia a nivel internacional (Thompson et al., 2010; Thompson, Wehmeyer, Hughes, Shogren, Palmer et al., 2014; van Loon et al., 2010) y ya han sido desarrollados estudios preliminares sobre su funcionamiento en España (Adam-Alcocer y Giné, 2013; Guillén, Verdugo y Arias, 2012; Guillén, Verdugo, Arias y Vicente, en prensa; Verdugo, Arias, Guillén y Vicente, 2014). Se espera que la llegada de este instrumento tenga una repercusión tan positiva como la obtenida por su homóloga para adultos, permitiendo dejar atrás el uso de herramientas de conducta adaptativa como única base para la estimación de apoyos. 


\subsubsection{Diferencias entre planes de apoyo y planes de rendimiento educativo}

Con la llegada del nuevo paradigma de apoyos, comenzaron a aparecer nuevos avances en el trabajo con personas con discapacidad intelectual, pero estos estuvieron fundamentalmente centrados en la etapa adulta. Con relación a la infancia, los estudios se orientaron casi con exclusividad en la educación, ya fuera a través de programas de atención temprana (e.g., Grupo de Atención Temprana [GAT], 2000, 2005) o de centros escolares (e.g., Dockrell, Peacey, Lunt, 2002; Foreman, Bourke, Mishra y Frost, 2001).

La evaluación infantil ha estado siempre muy centrada en el rendimiento (Witkin, 1984), asociándose en España al concepto de 'necesidades educativas especiales' (término que empieza a tratarse con la Ley Orgánica General del Sistema Educativo [LOGSE], de 3 de octubre de 1990), denominado en la legislación actual 'necesidades específicas de apoyo educativo' (Ley Orgánica 2/2006 de Educación [LOE]). De esta forma, los planes de intervención más utilizados en el ámbito infantil han sido los Planes Educativos Individualizados (PEI), dirigidos a la adquisición de habilidades conceptuales a corto plazo que indicaran avances en el rendimiento, estacándose así la escuela en una perspectiva de integración más que un enfoque inclusivo.

Aunque estos planes de rendimiento son individualizados, su objetivo no es el ajuste entre la persona y el entorno, sino únicamente en conseguir que la capacidad del niño alcance un rendimiento cognitivo mínimo. En este sentido, Thompson et al. (2010) defienden que si bien capacitar a los estudiantes ha de ser uno de los objetivos primarios de la educación, desde el modelo socioecológico de la discapacidad se debe intervenir en todas las dimensiones de la persona, incluyendo su contexto (material, arquitectónico y personal), con el objetivo de disminuir las discrepancias entre lo que el niño con discapacidad hace y aquello que se espera para un niño de su edad y cultura.

Al igual que los equipos escolares que trabajan con estudiantes con discapacidad están obligados a realizar planes educativos individualizados e incluir planes de logro específicos (metas de aprendizaje medibles, criterios de referencia para supervisar el progreso los planes...), los planes de apoyo individualizado deberían ser considerados también un complemento obligatorio para los planes de rendimiento, encargándose de mejorar otros aspectos clave en la educación (como la autodeterminación, la participación y las interacciones sociales), que no solo fomentarían el rendimiento y los aprendizajes de las personas con discapacidad intelectual desde edades más tempranas, sino también su calidad de vida (Thompson et al., 2009; Schalock et al., 2010; van Loon et al., 2010). 


\subsection{CONCLUSIONES DEL CAPÍTULO 2}

La definición actual de discapacidad intelectual (Schalock et al., 2010) conserva los tres procesos de evaluación (diagnóstico, clasificación y planificación de apoyos) establecidos por la AAIDD en sus modelos previos (Luckasson et al.,1992; Luckasson et al., 2002), subrayando la elaboración de un perfil apoyos para las personas con discapacidad intelectual (Schalock, Luckasson et al., 2007; Wehmeyer et al., 2008; Schalock et al., 2010) como paso previo al desarrollo e implementación de un plan individualizado.

En este sentido, la evaluación del CI, la conducta adaptativa y, especialmente, las necesidades de apoyo, es clave para poder generar nuevos modos de planificación y estrategias de intervención, centrados en calidad de vida, que eviten sistemas resistentes al cambio e inercias en el trabajo dentro de las organizaciones e instituciones (Florian y McLaughlin, 2008). No obstante, aún se requiere por parte de la comunidad científica un mayor esfuerzo investigador que arroje luz con respecto a la naturaleza y relación existente entre estos conceptos, así como la propuesta de estándares de evaluación acordes a las características de cada uno.

Las herramientas más aconsejadas para la evaluación de las personas con discapacidad intelectual son las escalas de medición, ya que permiten obtener datos en situaciones tipificadas para describir el objeto de evaluación. Sin embargo, no cualquier escala es útil. Es necesario un proceso de estandarización previo que garantice que la información obtenida en el test es consistente con el constructo específico y permita comparar la puntuación de una persona evaluada con las de su grupo de referencia (Salvia e Isseldyke, 1995; Verdugo, 1994). Este proceso requiere un duro y largo trabajo, por lo que, debido a la reciente interpretación de la discapacidad intelectual y los constructos relacionados, existe aún una gran escasez de instrumentos fiables y válidos capaces de evaluar aspectos clave de la vida de las personas con discapacidad intelectual, como son la conducta adaptativa y las necesidades de apoyo.

La falta de instrumentos de conducta adaptativa ha hecho que el diagnóstico de la discapacidad intelectual, a pesar de haber incorporado desde hace más de 50 años las limitaciones significativas en conducta adaptativa como criterio diagnóstico, esté aún, en la práctica clínica, centrado en la concepción tradicional y reduccionista del CI como única representación de la inteligencia humana. Esta carencia se relaciona, de manera bidireccional, con el desacuerdo general existente sobre la estructura de este constructo. 
Greenspan (1997) reprochó a la AAIDD haber incluido como criterio diagnóstico un elemento que aún no contaba con la suficiente investigación como para proporcionar una medida específica. Además, este autor propuso que la conducta adaptativa debía enmarcarse dentro de un modelo de competencia general relacionado con el funcionamiento intelectual pero diferente a éste, compuesto por habilidades conceptuales, sociales y prácticas. Siguiendo este criterio, se promueve la construcción de la DABS (Tassé et al., en prensa), desarrollada simultáneamente en España (Verdugo, Arias et al., en prensa), instrumento a través del cual se ha corroborado la estructura multifactorial de la conducta adaptativa (Arias et al., 2013).

Por su parte, haciendo referencia a las necesidades de apoyo, su concepción empieza a tener una fuerte presencia como línea base en la planificación individualizada de apoyos en 1992 (Luckasson et al.) y progresivamente irá adquiriendo un rol fundamental en el cambio organizacional (Schalock, Luckasson et al., 2007; van Loon, 2009). Sin embargo, para que los apoyos puedan cumplir su rol, es preciso que el examen de las necesidades de apoyo, que sirve de base para desarrollar los programas individuales, se realice mediante un análisis competente y riguroso de este constructo (Navas, Verdugo y Gómez, 2008), no en la estimación de necesidades derivada de la aplicación de escalas desarrolladas para otros fines (e.g., escalas de conducta adaptativa), como estaba ocurriendo.

Por ello, en 2002 Thompson, Hughes et al. reclamaron la construcción de un instrumento de evaluación que ofreciera información sobre las necesidades de apoyo de la personas con discapacidad que fuese útil para los equipos de planificación (a través de índices y perfiles de necesidades de apoyo). En respuesta a esta demanda, Thompson et al. (2004) validaron la SIS como un instrumento capaz de medir de forma precisa las necesidades de apoyo de las personas adultas con discapacidad intelectual (en términos de tipo, frecuencia y tiempo diario de apoyo), convirtiéndose en el principal instrumento de trabajo en el desarrollo de planes individuales.

No obstante, a pesar de los diversos intentos por desarrollar escalas de necesidades (Gould, 1998; Hennike et al., 2002; Lewellyn et al., 2005), aún hoy la carencia de instrumentos válidos en este ámbito es evidente, lo que está suponiendo un obstáculo para la implantación de planes individualizados y, en definitiva, para el cambio organizacional y la mejora de la calidad de vida (Schalock y Verdugo, 2012). 
Las tres últimas décadas de estudio científico sobre discapacidad intelectual han dado un papel principal a la investigación relacionada con las necesidades de apoyo, atendiendo de manera especial a su evaluación. A partir del análisis de sus implicaciones, ha quedado patente su importancia en la planificación de apoyos, permitiendo mejorar la calidad de vida individual y garantizar la eficacia organizacional. Sin embargo, si bien la evolución ha sido continua y progresiva, no se ha producido de manera homogénea para todos los colectivos.

Concretamente, la infancia y la adolescencia son etapas en las que el concepto de necesidades de apoyo está aún por definir y para las que existe una gran demanda de instrumentos de evaluación con los que poder guiar e implicar prácticas basadas en la evidencia (Schalock et al., 2011). Contar con una escala de estas características permitiría: (1) iniciar planes de apoyo individualizados en la infancia, que faciliten que los niños y adolescentes con discapacidad intelectual participen en las actividades cotidianas, asegurando una adecuada transición a la vida adulta; (2) trabajar de manera coherente con otras líneas de investigación orientadas a la evaluación de esta población en nuestro contexto, relacionadas especialmente con la evaluación de la conducta adaptativa (Verdugo, Navas et al., 2014) y la calidad de vida (Gómez et al., 2014); y (3) fomentar el cumplimiento de los objetivos específicos de las Naciones Unidas $(1989,2006)$ relacionados con los derechos de los niños con discapacidad intelectual.

Por tanto, atendiendo a los posibles beneficios de una vida con apoyos y a la ausencia de instrumentos de evaluación de necesidades de apoyo para niños y adolescentes con discapacidad intelectual, el estudio empírico realizado en esta tesis doctoral tiene como objetivo el desarrollo y validación de una herramienta evaluativa de estas características: la Escala de Intensidad de Apoyos para Niños y Adolescentes (Supports Intensity Scale for Children [SIS-C]), elaborada originalmente por la AAIDD (Thompson, Wehmeyer et al., 2008). 



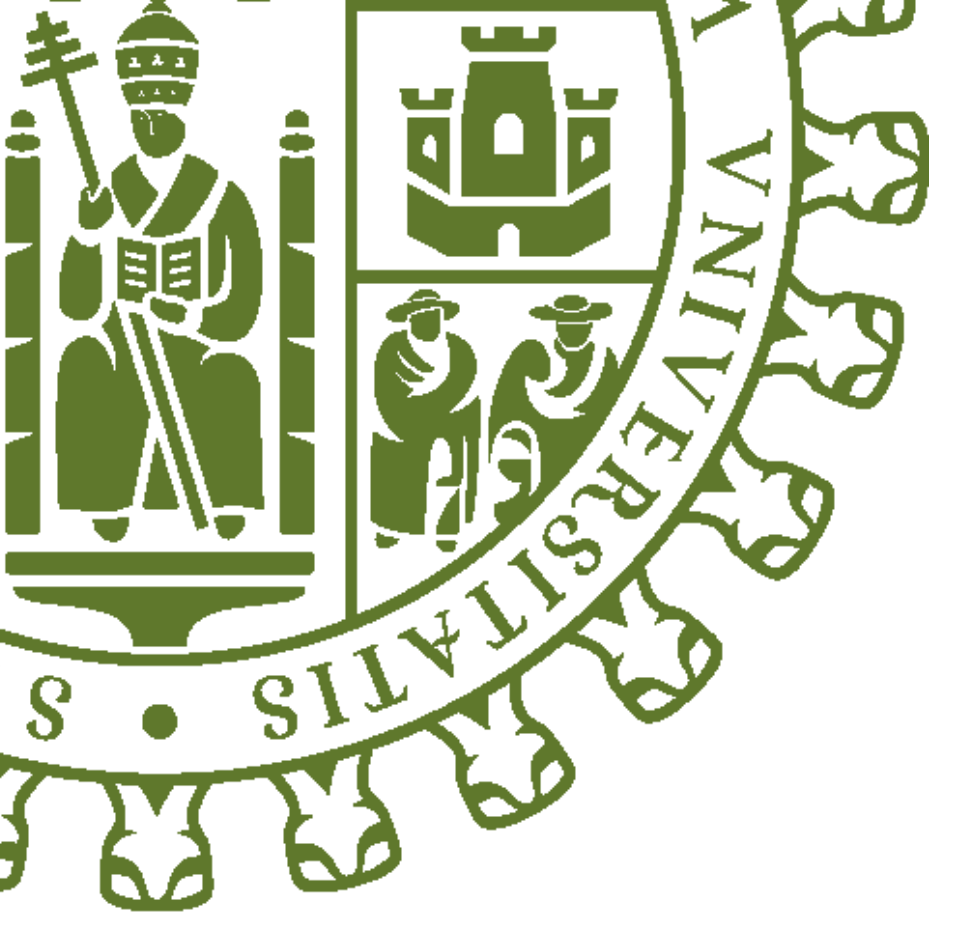





\section{INTRODUCCIÓN A LA PARTE EMPÍRICA}

Tal y como se ha reflejado en los capítulos anteriores -justificación teórica-, el modelo actual de discapacidad intelectual ha supuesto un gran avance en el modo de comprender a las personas con discapacidad. Actualmente, en contraposición a las ideas anteriores, se aboga por los derechos, la calidad de vida y la participación en la comunidad de las personas con discapacidad como objetivo principal de cualquier intervención. Sin embargo, Thompson y Viriyangkura (2013) defienden que el progreso en cualquier campo se relaciona con la capacidad de medir los constructos de interés en ese campo, no pudiéndose hablar de un completo avance hasta que no es posible medir los componentes resultantes del cambio. Por ello, entre las dificultades encontradas por los servicios y profesionales de atención directa para trabajar bajo los supuestos del paradigma actual, destaca la falta de instrumentos capaces de evaluar de manera fiable y válida aquellos constructos que aparecieron asociados al nuevo concepto de discapacidad intelectual.

Concretamente, aunque la evaluación del constructo de 'necesidades de apoyo', ha supuesto uno de los principales propósitos de investigación desde la aparición del paradigma de apoyos por la variedad y relevancia de los usos que plantea (Luckasson et al, 1992, Luckasson et al., 2002; Schalock et al., 2010), la carencia de herramientas en este ámbito es, aún, evidente. En este sentido, la falta de instrumentos de evaluación capaces de aportar información sobre los apoyos que necesitan recibir las personas con discapacidad intelectual está suponiendo un gran obstáculo para el desarrollo eficaz de intervenciones individualizadas y para la completa comprensión de la naturaleza de este constructo.

Hasta el momento, únicamente una escala cuenta con suficiente investigación que avale su utilidad para evaluar necesidades de apoyo en personas con discapacidad intelectual: la Escala de Intensidad de Apoyos (Supports Intensity Scale [SIS]), elaborada originalmente por la AAIDD (Thompson et al., 2004) y adaptada posteriormente al contexto español (Giné et al., 2006; Giné et al., 2007; Verdugo, Arias et al. 2007; Verdugo, Arias et al., 2006; Verdugo, Ibáñez et al., 2007). Esta escala es capaz de dar respuesta, a nivel internacional, a los tres objetivos clave de la evaluación de necesidades de apoyo: (1) elaborar de planes de apoyo individualizados que permitan mejorar el funcionamiento individual y la calidad de vida (objetivo principal de la escala); (2) asignar recursos y servicios basados en la intensidad y el perfil de las necesidades de apoyo, y no en una puntuación de cociente intelectual; y (3) comprobar la estructura y las dimensiones que forman el constructo de 'necesidades de apoyo'. 
Una de las razones de las altas potencialidades de la SIS reside en su especificidad, ya que ha sido diseñada ex profeso para evaluar las necesidades individuales de apoyo de los adultos con discapacidad intelectual: recoge de manera específica las actividades típicas de la vida adulta y ha sido baremada específicamente con población con discapacidad intelectual.

No obstante, la SIS no es útil para evaluar las necesidades de apoyos de los niños y jóvenes con discapacidad intelectual. Por tanto, para diseñar y elaborar planes de apoyos individualizados desde edades más tempranas, es necesario desarrollar un nuevo instrumento de similares características, pero acorde a las actividades de los niños y adolescentes. Tomando como punto de partida la SIS, dirigida a población adulta, Thompson et al. (2008) propusieron la construcción y validación simultánea en varios países de un pool de ítems encargados de evaluar las necesidades de apoyo de los niños y adolescentes con discapacidad intelectual. Surge así la Escala de Intensidad de Apoyos para Niños y Adolescentes (Supports Intensity Scale for Children [SIS-C]), desarrollada con el objetivo principal de aportar información útil que permita implementar programas de apoyos y asignar recursos personalizados desde la infancia, potenciando los resultados deseados y contribuyendo al conocimiento y consolidación del constructo de 'necesidades de apoyo'.

En líneas generales, la traducción, adaptación y validación de los ítems al español, de manera coherente a su desarrollo en otros países, está siguiendo los siete pasos que Tassé y Craig (1999) proponen como necesarios para adecuar un instrumento de forma eficaz a cualquier contexto diferente del original. Las razones principales que justifican el seguimiento de este procedimiento como guía para la adaptación española son:

(1) Los autores que proponen este procedimiento cuenta con una amplia experiencia en el desarrollo de instrumentos de evaluación, siendo dos de los autores principales de la SIS y la SIS-C en su versión original.

(2) Para la adaptación y desarrollo de la SIS para Adultos, numerosos países (e.g., Buntinx, 2008; Lamoureux-Hébert y Morin, 2008) siguieron este procedimiento, siendo actualmente también el proceso seguido para el desarrollo de la SIS-C en catalán (AdamAlcocer y Giné, 2013). Contar con una herramienta de referencia internacional para la medición de las necesidades de apoyo permitirá: (a) comparar investigaciones; (b) aportar conocimiento a la validez de recursos para el trabajo con personas con discapacidad; y (c) esclarecer de manera más completa y global el constructo de 'necesidades de apoyo'. 
(3) Recoge las recomendaciones realizadas posteriormente por otros autores a tener en cuenta en la adaptación y/o desarrollo de instrumentos de evaluación (APA, 2010; Arnold y Matus 2000; Massoubre, Lang, Jaeger, Jullien y Pellet, 2002; Muñiz, Elousa y Hambleton, 2013). Este método involucra numerosas revisiones realizadas por comités de expertos en el proceso de traducción y adaptación, incluyendo personas monolingües y bilingües. Además, como la mera traducción de ítems de un contexto a otro no implica la transferencia de sus propiedades psicométricas, se plantea un análisis exhaustivo de fiabilidad y validez del instrumento tras su aplicación a un amplio y representativo número de participantes, incluyendo la puesta en marcha de un estudio piloto previo.

Presentamos en la Figura 12 los siete pasos planteados para la construcción de la SIS-C en nuestro contexto así como la distribución de su descripción y análisis en los diferentes capítulos que forman la parte empírica de esta tesis doctoral.

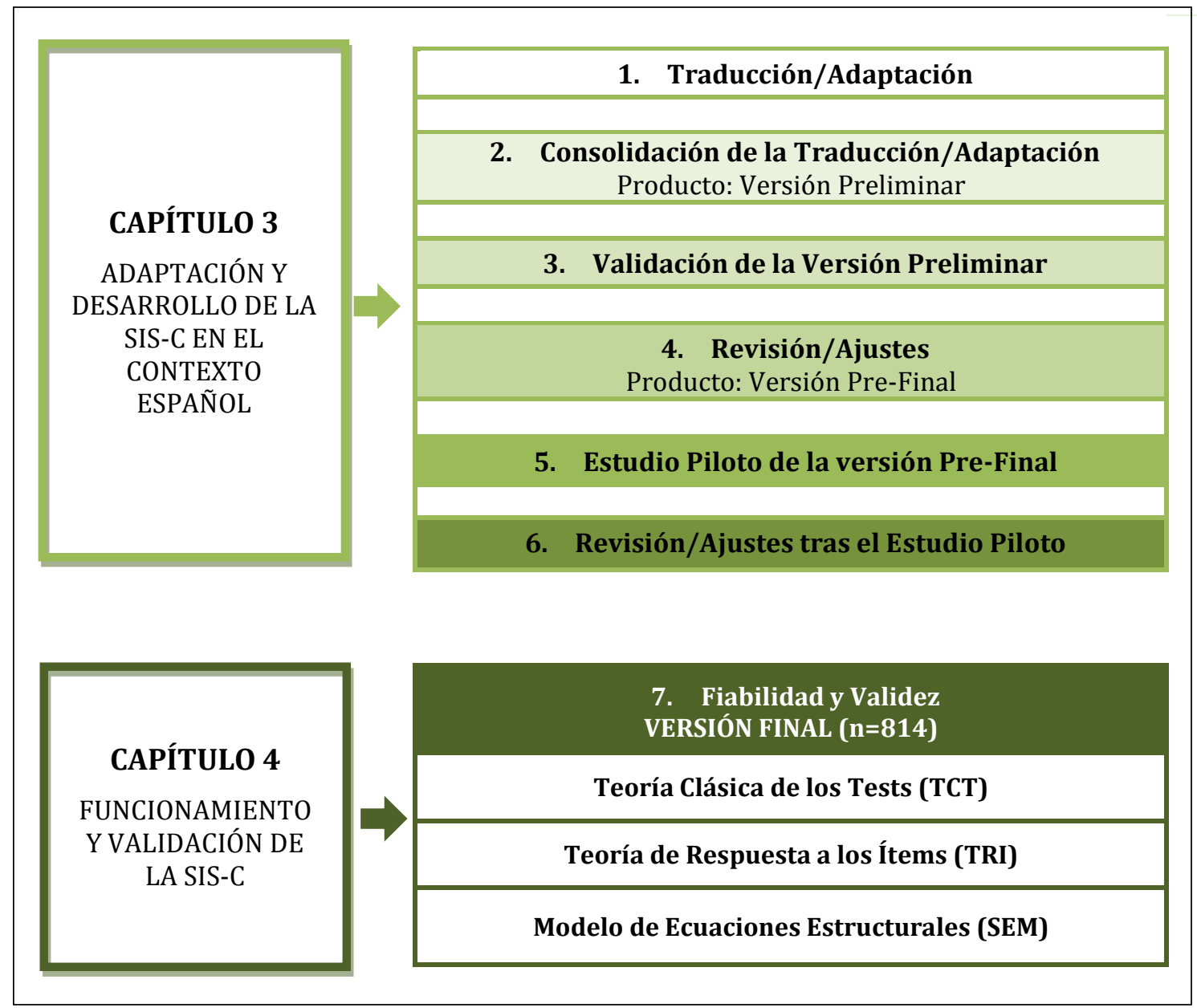

Figura 12. Distribución de las fases de desarrollo de la escala en los capítulos de la parte empírica 



\section{Capítulo}

\section{Adaptación y Desarrollo de la SIS-C en el Contexto Español}





\section{ADAPTACIÓN Y DESARROLLO DE LA SIS-C EN EL CONTEXTO ESPAÑOL}

En este primer capítulo de la parte empírica -capítulo 3-, se presenta una visión global del proceso inicial de traducción, adaptación y desarrollo en español de los ítems propuestos por la Asociación Americana de Discapacidades Intelectuales y del Desarrollo (American Association on Intellectual and Developmental Disabilities [AAIDD]) para la evaluación de necesidades de apoyo de niños y adolescentes con discapacidad intelectual. Una correcta adaptación de los mismos a las características de la muestra española será clave para la correcta validación del instrumento en nuestro contexto -capítulo 4-. Concretamente, este capítulo se divide en varios apartados que dan forma, justifican y esclarecen la información proporcionada:

- Un planteamiento inicial, donde se resume la necesidad de la construcción de una escala de estas características y permite justificar la elección la escala propuesta por la AAIDD como una de las mejores alternativas para su desarrollo dentro del contexto español.

- A continuación, manteniendo una estrecha relación con la introducción previamente presentada, se específica el objetivo de la tesis, determinando tanto el objetivo general como los objetivos específicos que se tratan a lo largo del capítulo.

- Posteriormente, se trata de manera exhaustiva el método, donde se incluyen las características del pool de ítems inicial y se propone el uso de los pasos presentados por Tassé y Craig (1999) para el desarrollo y validación del instrumento en el contexto español.

- En el apartado de resultados, se especifican las aportaciones y datos obtenidos en el proceso de traducción y adaptación de los ítems, incluyendo la realización de un estudio piloto a partir de la versión preliminar de la escala en español, analizando posteriormente los puntos débiles y fuertes del instrumento de manera orientada a la mejora de su aplicación y cumplimentación.

- Finalmente, se presentan las conclusiones del capítulo 3, desde donde se ofrece una relación entre las potencialidades del instrumento y las exigencias de la evaluación de las necesidades de apoyo dentro del actual modelo de discapacidad, dando paso al capítulo 4, relativo a la validación final del instrumento desarrollado. 


\subsection{PLANTEAMIENTO INICIAL}

En los últimos años se ha producido un gran avance conceptual en el modo de comprender la discapacidad intelectual. Desde la AAIDD (Luckasson et al., 1992; Luckasson et al., 2002; Schalock et al., 2010) y la Organización Mundial de la Salud (OMS, 2001) se deja a un lado la concepción de discapacidad entendida exclusivamente como un déficit de la persona y se propone una definición ecológico-contextual, en la que se reconocen los apoyos como un aspecto determinante para conceptualizar la discapacidad y para reducir las discrepancias existentes entre el funcionamiento de la persona y las demandas del entorno.

Atendiendo a estas nuevas aportaciones de la actual concepción de discapacidad intelectual (Schalock et al., 2010), especificadas a lo largo de la parte teórica de este trabajo, puede apreciarse la importancia de crear una herramienta capaz de evaluar con precisión, y acorde a los nuevos planteamientos teóricos, las necesidades de apoyo de los niños y adolescentes con discapacidad intelectual. En resumen, se puede justificar la creación de una escala de estas características atendiendo a las siguientes ideas:

- Las personas con discapacidad intelectual muestran con frecuencia dificultades para participar en las actividades de la vida diaria que se llevan a cabo en sus comunidades (Schalock et al., 2010). Sin embargo, estas personas constituyen un grupo muy heterogéneo dentro de la población; por tanto, sus necesidades de apoyo no deben ser entendidas de manera genérica, sino que se debe atender a las necesidades individuales de cada persona, basándose en sus características y situaciones particulares (Thompson et al., 2009).

- Las necesidades de apoyo individuales (atendiendo a sus características personales y ambientales) han de ser detectadas a partir de la información aportada por la propia persona o por aquellos que la conocen bien: padres, profesores, tutores, compañeros, etc. (Thompson, Hughes et al., 2002). Las personas que informan aportarán información sobre la implantación de apoyos individualizados que necesita la persona para mejorar su funcionamiento y reducir la discrepancia con las demandas del ambiente.

- No existe ningún instrumento de evaluación, basado en esta nueva concepción de discapacidad intelectual, que examine con precisión el perfil de la intensidad de las necesidades de apoyo de niños y adolescentes con discapacidad intelectual en las diferentes áreas relevantes de la vida. 
- Validar una escala de este tipo contribuirá significativamente a clarificar los índices de medida que subyacen en el constructo de 'necesidades de apoyo', y los resultados serán de especial relevancia para implementar planes de apoyo individuales para niños y adolescentes con discapacidad intelectual. Los profesionales de los centros y organizaciones contarán con herramientas basadas en la evidencia científica, que contribuirán a mejorar la calidad del trabajo en los servicios y, consecuentemente, a incrementar la calidad de vida de sus usuarios.

Una vez justificada la creación de una nueva herramienta de evaluación de necesidades de apoyo para niños y adolescentes con discapacidad, presentamos a continuación una serie de razones que permiten justificar, específicamente, la adaptación de los ítems de la Escala de Necesidades de Apoyos para Niños y Adolescentes (Supports Intensity Scale for Children [SIS-C]), elaborada desde la AAIDD (Thompson, Wehmeyer et al., 2008), al contexto español.

- Actualmente, los instrumentos más utilizados en España tienen su origen en indicadores construidos en otro idioma (Elousa, 2012). En los últimos años, el uso de tests como apoyo en la toma de decisiones de se ha incrementado en todos los ámbitos científicos, lo que supone invertir recursos humanos, económicos y temporales en la creación de los mismos. En este sentido, teniendo en cuenta que vivimos en un entorno cada vez más multicultural y multilingüe, la adaptación de ítems de un contexto supone gran simplificación de costes en el desarrollo de las herramientas de evaluación pertinentes.

- La adaptación de una herramienta como la SIS-C de una cultura a otra permite tener una visión compartida a nivel internacional acerca de los constructos de 'necesidades de apoyo' y 'discapacidad intelectual'. Bruner (1998) señalaba que nuestra forma de vida, adaptada culturalmente, depende de significados, conceptos $\mathrm{y}$ formas de discurso compartidos que sirven para negociar las diferencias de significado e interpretación.

- La SIS-C ha sido elaborada por autores de gran prestigio internacional en el campo de la discapacidad intelectual, vinculados a la AAIDD y principales precursores del cambio teórico. Asimismo, estos autores desarrollaron de manera previa la SIS para adultos (Thompson et al., 2004), el primer instrumento capaz de evaluar con precisión (atendiendo al tipo, frecuencia y tiempo diario de apoyo) las necesidades de apoyo de las personas con discapacidad intelectual. Esta escala está teniendo 
una gran aceptación internacional (Schalock, Thompson et al., 2008) y un alto impacto en el desarrollo de servicios y programas para personas con discapacidad intelectual en España a partir de sus validaciones en nuestro contexto (Giné et al., 2007; Verdugo, Arias et al., 2007).

- Los fundamentos de esta escala son coherentes con el marco legal español, que desarrolla una serie de apoyos económicos a personas y familias con un miembro con discapacidad, pero que carece de instrumentos adecuados a los nuevos paradigmas para realizar una evaluación.

- Contar con un instrumento como la SIS-C en español supone un complemento a la creación de otras escalas de evaluación para niños con discapacidad, elaboradas desde la AAIDD y adaptadas y desarrolladas simultáneamente en España. Destacan en este sentido la DABS (Verdugo, Arias et al., en prensa) y el desarrollo que se está llevando actualmente de la SIS-C en catalán (Adam-Alcocer y Giné, 2013).

Estos antecedentes ponen de manifiesto la necesidad de desarrollar una escala de intensidad de apoyos para niños y adolescentes con discapacidad intelectual en español, que tenga como referencia la versión original de la SIS-C en inglés, pero que se adapte y ajuste de manera específica a las características de nuestra población.

\subsection{OBJETIVOS}

El objetivo general de esta tesis es la elaboración, en el contexto español, de una escala de intensidad de apoyos para niños y adolescentes con discapacidad intelectual con edades comprendidas entre los 5 y 16 años. Se trata de una escala de evaluación multidimensional diseñada para determinar el índice y perfil de la intensidad de las necesidades de apoyo de esta población en su vida cotidiana. Los objetivos para este capítulo, que se desglosan de la finalidad general de este proyecto son:

- Traducir y adaptar al contexto español el pool de ítems que conformará la versión inicial de la Escala de Intensidad de Apoyos para Niños y Adolescentes (SIS-C).

- Realizar un estudio piloto para conocer, de manera preliminar, las propiedades psicométricas del instrumento de evaluación, extrayendo resultados y conclusiones que mejoren su funcionamiento, ajustándolo a la muestra española y optimizando su cumplimentación en futuras aplicaciones. 


\subsection{MÉTODO}

\subsubsection{Instrumento}

La construcción de la SIS-C, destinada a la evaluación de niños y adolescentes con discapacidad intelectual, se está llevando a cabo de manera simultánea al proceso de construcción de la escala en lengua inglesa (Hughes et al., 2011), de acuerdo con los planteamientos más actuales sobre la discapacidad (Luckasson et al., 2002; Schalock et al., 2010; Verdugo y Schalock, 2010) y atendiendo de manera específica a las características de la escala SIS para adultos, previamente validada (Thompson et al., 2004).

Aunque el desarrollo de la SIS-C (Thompson et al., 2008) se basa en las evidencias del buen funcionamiento de la SIS, cada una de estas escalas está destinada a una población diferente (adultos vs. niños/adolescentes), por lo que existen diferencias de contenido que hacen necesario un nuevo proceso de validación (Thompson et al., 2014). De la misma manera, llevar el desarrollo de esta escala a otros países implica, de manera inevitable, realizar un nuevo proceso de traducción y adaptación, similar al realizado para la adaptación de la SIS, pero independiente del mismo.

\subsubsection{Desarrollo y descripción de la SIS-C}

Este instrumento de evaluación ha sido desarrollado por la AAIDD utilizando un proceso de varias fases (Thompson, Wehmeyer, Hughes, Shogren, Palmer et al., 2014), que incluyó los mismos pasos seguidos en la elaboración de la SIS para adultos (Thompson, Hughes et al., 2002): (a) una revisión de la literatura; (b) el uso de la metodología Q para seleccionar los indicadores de apoyo más relevantes para niños y adolescentes (incluyendo la adaptación de los ítems de la SIS para adultos y la incorporación de otros nuevos); y (c) un extenso trabajo de campo utilizando las versiones piloto de la escala..

El pool inicial de ítems propuesto quedó recogido en la versión piloto de la SIS-C (Thompson, Wehmeyer et al., 2008), ofreciendo un banco de actividades representativas de siete contextos cotidianos para cualquier niño o adolescente. Los ítems planteados tienen como objetivo conformar una escala que evalúe las necesidades de apoyo extraordinarias de los niños y adolescentes con discapacidad intelectual, siendo imprescindible la adaptación de los mismos a las características específicas de los diferentes contextos y culturas. Concretamente, estos ítems preliminares recogen información sobre 61 actividades cotidianas distribuidas en siete contextos principales. 
En este apartado se expondrán de manera detallada las características del instrumento escogido para su desarrollo en español. Para ello, es necesario responder a una serie de preguntas indispensables para la completa comprensión del instrumento, y que han de tenerse en cuenta en cualquier investigación: por qué, a quién, qué, cómo, para qué y cuándo. A la luz de las evidencias comentadas en los apartados previos sobre la elección de la SIS-C, hemos podido conocer por qué es necesario desarrollar una herramienta de evaluación de necesidades de apoyo para niños y adolescentes con discapacidad intelectual. Por ello, en este apartado nos centraremos en dar respuesta al resto de preguntas, centradas en las características del instrumento, y que formarán la ficha técnica del mismo (Tabla 29).

Tabla 29. Características generales de la SIS-C. Ficha técnica

\begin{tabular}{|c|c|c|c|}
\hline A QUIÉN & a) & Destinatarios & $\begin{array}{l}\text { Niños y Adolescentes entre } 5 \text { y } 16 \text { años } \\
\text { Discapacidad intelectual }\end{array}$ \\
\hline QUÉ & b) & Finalidad & $\begin{array}{l}\text { Conocer las necesidades de apoyo de los niños y } \\
\text { adolescentes con discapacidad intelectual evaluados }\end{array}$ \\
\hline \multirow{3}{*}{ CóMo } & \multirow[t]{2}{*}{ c) } & \multirow[t]{2}{*}{ Estructura } & $\begin{array}{l}\text { Dimensiones: Evalúa } 7 \text { áreas de la vida cotidiana } \\
\text { A. Hogar } \\
\text { B. Comunidad } \\
\text { C. Participación Escolar } \\
\text { D. Aprendizaje Escolar } \\
\text { E. Salud y Seguridad } \\
\text { F. Actividades Sociales } \\
\text { G. Defensa (autorrepresentación) }\end{array}$ \\
\hline & & & $\begin{array}{l}\text { Formato de respuesta: } \\
3 \text { índices de medida con } 5 \text { opciones de respuesta cada uno } \\
\text { Tipo de apoyo }(0-4) \\
\text { Frecuencia de apoyo }(0-4) \\
\text { Tiempo de apoyo diario }(0-4)\end{array}$ \\
\hline & d) & $\begin{array}{l}\text { Procedimiento } \\
\text { de aplicación }\end{array}$ & $\begin{array}{l}\text { INDIVIDUAL } \\
\text { OBJETIVA (es decir, es otra persona la que responde a los } \\
\text { diferentes ítems pensando en las necesidades de apoyo del } \\
\text { niño evaluado). } \\
\text { ENTREVISTA (el complejo formato de respuesta del } \\
\text { instrumento hace necesaria la participación de un } \\
\text { entrevistador si los informantes no están familiarizados con } \\
\text { el instrumento) }\end{array}$ \\
\hline \multirow{2}{*}{ PARA QUÉ } & \multirow{2}{*}{ e) } & \multirow{2}{*}{ Usos prácticos } & $\begin{array}{l}\text { Teórico } \\
\text { Comprensión del constructo }\end{array}$ \\
\hline & & & $\begin{array}{l}\text { Práctico } \\
\text { Planificación } \\
\text { Asignación de recursos }\end{array}$ \\
\hline CUÁNDO & f) & $\begin{array}{l}\text { Momentos de } \\
\text { evaluación }\end{array}$ & $\begin{array}{l}\text { Inicial } \\
\text { Progresiva } \\
\text { Finalidad }\end{array}$ \\
\hline
\end{tabular}




\section{a) Destinatarios}

La SIS-C tiene como principal objetivo evaluar las necesidades de apoyo de niños y adolescentes de entre 5 y 16 años con discapacidad intelectual. Por tanto, cualquier persona con discapacidad intelectual que cumpla el rango de edad es susceptible de ser evaluada con este instrumento, independientemente del grado de discapacidad, etiología, presencia de discapacidades asociadas o problemas médicos o conductuales que pudieran estar influyendo en las necesidades de apoyo de la persona evaluada.

\section{b) Finalidad}

La SIS-C proporciona un procedimiento estandarizado y un recurso para medir con fiabilidad y validez la relativa intensidad de apoyos que necesitan los niños y niñas con discapacidad intelectual o con trastornos del desarrollo relacionados. A pesar de que la concepción teórica de discapacidad intelectual ha traído consigo la elaboración de diversas escalas de evaluación coherentes con esta nueva perspectiva socioecológica, la SIS-C constituye el primer intento por construir un instrumento apropiado con este propósito específico.

Al contrario de lo que ocurre en otras escalas destinadas a evalaur el rendimiento de las personass con discapacidad, en la SIS-C el foco no está puesto en lo que el niño o adolescente es capaz de hacer. Esta escala requiere realizar un cambio de perspectiva y medir la naturaleza e intensidad del apoyo que necesita recibir de otra persona para poder participar en las diferentes actividades de su vida diaria (tal y como lo harían sus iguales sin discapacidad). Consecuentemente, contar con un instrumento que permita identificar los apoyos individualizados y optimizar la provisión de los mismos desde edades más tempranas, tendrá un mayor impacto positivo en la calidad de vida de las personas con discapacidad intelectual.

\section{c) Estructura: dimensiones y formato de respuesta}

En primer lugar, se recogen las características sociodemográficas de los participantes en la evaluación: el entrevistador, los informantes y el niño o adolescente evaluado, controlando así todas las posibles variables que pudieran estar influyendo en la puntuación obtenida. 
La sección principal del instrumento corresponde con la evaluación del constructo de 'necesidades de apoyo' y se divide, a su vez, en tres apartados (Tabla 30): (a) una estimación general inicial, que permite comprobar si las percepciones generales de los informantes coinciden con los resultados obtenidos, posteriormente, de manera detallada en los diferentes ítems; (b) un conjunto de ítems que recoge posibles necesidades extraordinarias que pudieran influir directamente en las necesidades de apoyo de la persona; (c) un banco de ítems, divididos en siete áreas o dimensiones de la vida cotidiana (subescalas), que permite conocer las necesidades de apoyo diarias que presenta la persona evaluada.

El perfil de intensidad de apoyos de la persona evaluada se elabora a partir de las puntuaciones obtenidas en el último apartado de la escala (c), donde se recogen 61 actividades significativas y representativas de la vida diaria en los diferentes contextos cotidianos. En este sentido, destacamos que la escala se acompaña de un completo manual de instrucciones quee incluye ejemplos de las actividades mencionadas, así como algunas orientaciones básicas a tener en cuenta a la hora de cumplimentar el instrumento.

Tabla 30. Estructura general de la SIS-C. Sección II-Evaluación de Necesidades de Apoyo (Verdugo, Arias, Guillén et al., 2014)

\begin{tabular}{|c|c|c|c|}
\hline \multicolumn{2}{|c|}{ Evaluación } & $\begin{array}{l}\text { № de } \\
\text { Ítems }\end{array}$ & Formato de respuesta \\
\hline \multicolumn{2}{|c|}{$\begin{array}{l}\text { ESTIMACIÓN GENERAL de las necesidades de apoyo de } \\
\text { cada una de las siete áreas de evaluadas, incluyendo un } \\
\text { índice global }\end{array}$} & 8 & $\begin{array}{l}\text { Escala de clasificación de cinco } \\
\text { opciones de respuesta que oscila } \\
\text { entre } 1 \text { (no necesita apoyo extra) y } \\
5 \text { (necesita apoyo total) }\end{array}$ \\
\hline \multirow{3}{*}{$\begin{array}{l}\text { NECESIDADES } \\
\text { EXTRAORDINARIAS DE } \\
\text { APOYO ( } 32 \text { ítems) }\end{array}$} & Necesidades Médicas & 18 & \multirow{3}{*}{$\begin{array}{l}\text { Escala de clasificación de tres } \\
\text { opciones de respuesta que oscila } \\
\text { entre } 0 \text { (no necesita apoyo) y } 2 \\
\text { (siempre necesita apoyo). }\end{array}$} \\
\hline & Necesidades Conductuales & 14 & \\
\hline & TOTAL & 32 & \\
\hline \multirow{8}{*}{$\begin{array}{l}\text { NECESIDADES DE } \\
\text { APOYO ( } 61 \text { ítems) }\end{array}$} & A. Hogar & 9 & \multirow{8}{*}{$\begin{array}{l}\text { Se recogen tres índices de medida } \\
\text { (tipo, frecuencia y tiempo diario } \\
\text { de apoyo), cada uno de ellos } \\
\text { evaluado en una escala de } \\
\text { clasificación de cinco opciones de } \\
\text { respuesta (0-4). }\end{array}$} \\
\hline & B. Comunidad y Vecindario & 8 & \\
\hline & C. Participación Escolar & 9 & \\
\hline & D. Aprendizaje Escolar & 9 & \\
\hline & E. Salud y Seguridad & 8 & \\
\hline & F. Actividades Sociales & 9 & \\
\hline & G. Defensa (autorrepresentación) & 9 & \\
\hline & TOTAL & 61 & \\
\hline
\end{tabular}


Con relación al formato de respuesta del instrumento, la AAIDD considera la intensidad de las necesidades de apoyo como el conjunto del tipo, la frecuencia y el tiempo diario de apoyo que necesita una persona para desenvolverse de manera satisfactoria en su vida diaria. De manera coherente con la concepción teórica que sustenta la escala, cada uno de los 61 ítems que formarán el perfil de intensidad de apoyos son evaluados aportando una puntuación independiente para cada uno estos tres índices de medida (Tabla 31). Concretamente, se trata de tres escalas de clasificación de cinco opciones de respuesta que oscilan entre 0 y 4 .

Tabla 31. Formato de respuesta de la SIS-C

\begin{tabular}{|c|c|c|}
\hline TIPO DE APOYO & FRECUENCIA DE APOYO & $\begin{array}{l}\text { TIEMPO DE APOYO } \\
\text { DIARIO }\end{array}$ \\
\hline $\begin{array}{l}0=\text { Ninguno } \\
\text { 1= Supervisión } \\
2=\text { Incitación } \\
\text { 3= Ayuda física } \\
\text { parcial } \\
\text { 4= Ayuda física total }\end{array}$ & $\begin{array}{l}\text { 0= No significativa; raramente las necesidades de } \\
\text { apoyo del niño son diferentes a las de compañeros } \\
\text { de su misma edad. } \\
\text { 1= Infrecuente; el niño necesitará ocasionalmente } \\
\text { alguien que le preste un apoyo extraordinario que } \\
\text { los compañeros de su edad no necesitan, pero en la } \\
\text { mayoría de ocasiones no necesita apoyo extra. } \\
\text { 2= Frecuente; para que el niño participe en la } \\
\text { actividad necesitará algún apoyo extraordinario } \\
\text { aproximadamente en la mitad de ocasiones. } \\
\text { 3= Muy frecuente; en la mayoría de las ocasiones } \\
\text { en las que ocurre la actividad, el niño necesita un } \\
\text { apoyo extra que los compañeros de su edad no } \\
\text { necesitan; sólo ocasionalmente el niño no necesita } \\
\text { apoyo extra. } \\
\text { 4= Siempre; cada vez que el niño participa en la } \\
\text { actividad necesita apoyo extra que los compañeros } \\
\text { de su edad no necesitan. }\end{array}$ & $\begin{array}{l}0=\text { Nada } \\
1=\text { Menos de } 30 \text { minutos } \\
2=\text { Entre } 30 \text { minutos y } 2 \\
\text { horas } \\
3=\text { Entre } 2 \text { y } 4 \text { horas } \\
4=4 \text { horas o más }\end{array}$ \\
\hline
\end{tabular}

La escala mide la intensidad de apoyos que el niño o adolescente evaluado necesita recibir de otras personas para participar típicamente en las diferentes actividades de la infancia y la adolescencia. Sin embargo, a la hora de cumplimentar el instrumento ha de tenerse en cuenta si el niño utiliza otras ayudas electrónicas y tecnológicas en su vida diaria. En algunas ocasiones, esos servicios o tecnologías utilizados servirán para suplir por completo el apoyo de otra persona; en otras, simplemente disminuirán la intensidad en la que el apoyo dado por otra persona sea necesitado, reduciendo así la puntuación obtenida en la escala. 


\section{d) Procedimiento de aplicación}

La SIS-C se cumplimenta de manera objetiva, es decir, no es la propia persona con discapacidad quien responde a los ítems, sino que ha de ser otra persona que conozca bien a al niño con discapacidad intelectual quien ha de expresar cuales son los apoyos que éste precisa para participar en diferentes actividades de la misma manera que sus iguales sin discapacidad. Se sugiere que al menos haya dos informantes y que estos pertenezcan a diferentes ámbitos de la vida de la persona evaluada; por ejemplo, un familiar y un profesor. Los informantes deben conocer desde hace más de tres meses a la persona con discapacidad y haber tenido la oportunidad de observarlo en diferentes ámbitos de su vida cotidiana para poder cumplimentar la escala de manera precisa.

Asimismo, para eliminar los posibles errores en su cumplimentación derivados del complejo formato de la escala, Thompson y Viriyangkura (2013) recomiendan que se administre en formato de entrevista semiestructurada por un profesional cualificado (previamente entrenado en el uso del instrumento), siendo necesaria la formación específica de los informantes (charlas, instrucciones...) cuando no sea posible la cumplimentación en formato de entrevista.

\section{e) Usos prácticos}

El índice de necesidades de apoyo y el perfil que genera el instrumento servirán para obtener información objetiva sobre las necesidades de apoyo del niño o adolescente con discapacidad evaluado. Esta información, que ha de ser tenida en cuenta de manera cuantitativa y cualitativa, puede utilizarse para planificar apoyos individualizados (evaluando también los intereses de la persona), así como para ayudar a los centros, organizaciones o administraciones a asignar recursos y diseñar políticas nuevas de protección social que beneficien a las personas con discapacidad intelectual desde la infancia.

La adaptación de la escala SIS-C al español aporta una gran utilidad teórica y práctica al trabajo diario con las personas con discapacidad intelectual en nuestro contexto. A nivel teórico, el desarrollo de esta escala se encuadra dentro de los ejes y de modelos de la AAIDD, permitiendo tener una visión compartida a nivel internacional acerca de los constructos de 'discapacidad intelectual' y 'necesidades de apoyo'. Esta alineación aportando una ventaja evidente desde el punto de vista funcional y de eficacia, ya que facilita la justificación de ls fiabilidad y validez de constructo de esta escala. 


\section{f) Momentos de evaluación}

Las cinco pautas dinámicas establecidas por la AAIDD como necesarias para desarrollar e implementar un plan de apoyos individualizado de manera eficaz (ver Figura 11) consisten en: (1) la identificación de las metas y experiencias de vida deseadas; (2) la evaluación de las necesidades de apoyo; (3) el desarrollo e implementación de un plan de apoyo individualizado; (4) la supervisión del progreso; y (5) la evaluación.

Para el desarrollo de estas tareas, la SIS-C juega un papel primordial en varios momentos a lo largo del proceso, al igual que ocurrió con la SIS. Como evaluación inicial será de gran utilidad en los primeros componentes de la planificación, permitiendo contar con una línea base que oriente la intervención a través de la implementación de apoyos individualizados, basados de manera específica en la discrepancia existente entre la persona evaluada y las demandas de su entorno. Esta información, unida al conocimiento de los deseos e intereses de la persona, establecerá prioridades de intervención claras que orientarán todo el proceso de planificación de apoyos. Sin embargo, la utilidad y aplicación de la SIS-C no sólo es relevante como punto de partida, sino también en la evaluación del progreso, tanto en relación con los cambios en las necesidades de apoyo de la persona evaluada como a la eficacia de la intervención realizada, proponiendo modificaciones para obtener mejores resultados en la evaluación final, donde la importancia de la aplicación del instrumento también se vuelve evidente.

En cualquier caso, realizar un proceso de evaluación continuo así como desarrollar un plan de provisión de apoyos flexible es fundamental para implementar un plan que genere resultados positivos, ya que las necesidades de apoyo del niño (así como sus deseos e intereses) pueden disminuir como consecuencia de una mejora en el funcionamiento derivada de diversos factores (e.g., las intervenciones realizadas, el propio desarrollo evolutivo o modificaciones en los agentes ambientales).

No obstante, ateniendo a las investigación realizada por Thompson et al. (2009), debemos también tener presente que, ante determinadas circunstancias, existen apoyos que nunca pueden llegar a desaparecer completamente (o, incluso, que deben ir aumentándose con el paso del tiempo) por lo que, en estos casos, los apoyos deben entenderse como un fin en sí mismo para mejorar la participación y la calidad de vida de la persona con discapacidad. 


\subsubsection{Semejanzas y diferencias con la SIS de adultos}

La SIS-C (Thompson, Wehmeyer et al., 2008), destinada a niños y adolescentes con discapacidad intelectual ha sido desarrollada a partir de su homóloga para adultos (SIS, Thompson et al., 2004). Por ello, ambas escalas han sido desarrolladas bajo las mismas bases teóricas y cuentan con un formato y estructura similares.

Entre sus semejanzas, destaca la división de la evaluación de personas con discapacidad intelectual en diferentes contextos y la valoración de diversas actividades representativas en cada uno de ellos a partir de tres índices de medida (tipo, frecuencia y tiempo diario de apoyo), los cuales deben ser cumplimentados en una escala de clasificación de 5 opciones de respuesta (0-4), y la recogida adicional de necesidades de apoyo médicas y conductuales. Asimismo, al igual que la SIS (+16), la SIS-C (5-16 años) se elaboró con cuatro objetivos fundamentales: (1) evaluar las necesidades de apoyo; (2) determinar la intensidad de apoyos necesarios; (3) realizar un seguimiento del proceso; y (4) evaluar los resultados.

No obstante, aunque la finalidad de ambas escalas es evaluar con precisión las necesidades de apoyo de personas con discapacidad intelectual y comparten las mismas características generales, el hecho de que cada una de ellas esté destinada a una población diferente, hace necesario modificar algunos aspectos de la SIS para adaptarla apropiadamente al contexto infantil. De manera adicional, la evaluación crítica de la SIS, ha permitido mejorar algunas de las características de la versión destinada a niños y adolescentes. Concretamente, en este apartado se presentan las tres principales diferencias encontradas entre ambos instrumentos, relacionadas con: (a) la consideración de las necesidades de apoyo derivadas del desarrollo; (b) la modificación de áreas y actividades evaluadas; $y$ (c) el formato de respuesta.

\section{a) Consideraciones sobre las necesidades de apoyo derivadas del desarrollo}

Al trasladarnos a la perspectiva infantil, debemos considerar que los niños sin discapacidad también necesitan recibir apoyos para desenvolverse en su vida cotidiana, variando estos con la edad tanto en términos de prevención de conductas de riesgo como para potenciar la mejora de sus habilidades y funcionamiento (Mangrulkar, Whitman y Posner, 2001). En este sentido, el objetivo de la escala es medir, únicamente, las necesidades de apoyo que el niño con discapacidad intelectual necesita y que sus iguales no requieren para participar en las diferentes actividades de su vida cotidiana. 
Mientras que la SIS valoraba las necesidades de apoyo del adulto con discapacidad intelectual para realizar las actividades típicas de la vida diaria de manera general, la SIS-C especificará más el concepto de 'apoyos extraordinarios', ya que se requiere discernir entre aquellas necesidades del desarrollo y aquellas derivadas de la discapacidad. Por ello, en la versión para niños y adolescentes se tienen en cuenta la comparación de las necesidades de apoyo teniendo como referencia sujetos de la misma edad.

\section{b) Modificaciones de áreas y actividades evaluadas}

Con relación a las áreas e ítems evaluados, es necesario realizar una serie de modificaciones que permitan eliminar aquellas que no resulten pertinentes en la vida diaria de los niños y, por otro lado, es necesario añadir otras áreas relevantes en el contexto infantil (Thompson, Wehmeyer, Hughes, Shogren, Palmer et al., 2014).

Las subescalas de 'Aprendizaje a lo Largo de la Vida' y 'Empleo de la SIS desaparecen, dando paso a las áreas 'Participación Escolar' y 'Aprendizaje Escolar'. De esta forma, en la SIS-C aparece con gran presencia el entorno escolar debido a su alta significación en la vida de cualquier niño, quedando dividido en dos subescalas: una de ellas hace referencia a la inclusión del niño en las diferentes actividades del contexto escolar (i.e., 'Participación Escolar') y, la otra, a los aspectos más formales de adquisición de conocimientos (i.e., 'Aprendizaje Escolar'). Algunos de los ítems referentes de las áreas de la SIS eliminadas se adaptan al contexto escolar y se mantienen en estas dos subescalas.

Por otro lado, debido a la importancia que tiene en la SIS para adultos la subescala complementaria 'Protección y Defensa' (Shogren, Thompson et al., 2014), ésta deja de ser suplementaria en la SIS-C y se convierte en un área más de las propuestas en la sección principal de evaluación de necesidades de apoyo. De esta manera, las seis subescalas de las que se componía el Índice de Necesidades de Apoyo de la SIS se convierten en siete subescalas cuando adaptamos la escala a un contexto más infantil (Tabla 32). Además, esta subescala pasa a denominarse 'Defensa', haciendo referencia a la autorrepresentación, y sus ítems se relacionan de manera más directa con la 'Autodeterminación' (una de las ocho dimensiones principales del modelo de calidad de vida). Como consecuencia, las actividades más cercanas a la protección física, pasan a formar parte de los ítems de otras áreas en las que resultan más pertinentes. Por ejemplo, ítems como protegerse de acoso, que formaba parte de la subescala de 'Protección y Defensa' en la SIS, se incorporan a la evaluación del área 'Social' en la SIS -C. 
Tabla 32. Relación entre los contenidos de la SIS y la SIS-C

\begin{tabular}{lll}
\hline & SIS (85 ítems) & SIS-C (93 ítems) \\
\hline $\begin{array}{l}\text { Escala de } \\
\text { Necesidades } \\
\text { de Apoyo }\end{array}$ & 6 Subescalas & 7 Subescalas \\
& A. Vida en el Hogar (8) & 61 Actividades \\
& B. Vida en la Comunidad (8) & A. Vida en el Hogar (9) \\
$\begin{array}{l}\text { Subescalas } \\
\text { (Áreas de } \\
\text { evaluación) }\end{array}$ & C. Aprendizaje a lo Largo de la Vida (9) & C. Aprendizaje Escolar (9) \\
& E. Salud y Seguridad (8) & D. Participación Escolar (9) \\
& F. Social (8) & E. Salud y Seguridad (8) \\
\hline $\begin{array}{l}\text { Subescala } \\
\text { Suplementaria }\end{array}$ & Protección y Defensa (8) & F. Social (9) \\
\hline $\begin{array}{l}\text { Necesidades } \\
\text { excepcionales }\end{array}$ & Médicas (15) & G. Defensa (autorrepresentación)(9) \\
\hline
\end{tabular}

Asimismo, aunque áreas como 'Vida en el Hogar', 'Vida en la Comunidad' y 'Salud y Seguridad' se mantienen, en todas las dimensiones existen ítems que necesitan ser adaptados, eliminados o incorporados, no solo para atender de manera específica al contexto infantil, sino también para mejorar los resultados obtenidos en la SIS a partir de las experiencias e investigaciones de los últimos años.

Por ejemplo, se elimina el ítem preparar comidas, por no ser una actividad típica de niños y aparece el ítem mantenerse ocupado en el tiempo libre en casa que, si bien suele asociarse más al tiempo de ocio de los niños, bien podría ser también un ítem incluido en una escala para adultos. Por otro lado, ítems como el uso del baño, se mantienen en ambas escalas, aunque difiere el grado y calidad de consecución esperado. En la versión impresa de la tesis, se anexan todos los ítems de la escala, especificando en qué medida cada uno de ellos ha sido modificado en relación con la SIS para adultos, poniéndose de manifiesto el alto número de ítems que han sido variadoa en contenido y, por tanto, la necesidad de realizar una nueva validación.

Tassé (2011) propone que la validación de esta escala en el contexto infantojuvenil contribuirá a dar respuesta a los apoyos necesarios y a mejorar la calidad de vida en momentos clave del desarrollo, como son las etapas relacionadas con la infancia y la transición a la vida adulta. Por ello, ofrecemos a continuación (Tabla 33) las posibles correlaciones que pueden establecerse entre las dimensiones de calidad de vida y las áreas 
de las dos escalas de intensidad de apoyos. La dimensión de calidad de vida referente al 'Bienestar Material' no fue relacionada con ninguna de las áreas de evaluación de necesidades de apoyo de la SIS-C, ya que se considera que no es un área en el que se pueda apoyar al niño directamente, sino que depende de los adultos a su cargo.

Tabla 33. Relación entre las áreas de la SIS para Niños y Adolescentes, las áreas de la SIS y las dimensiones del Modelo de Calidad de Vida (van Loon et al., 2010)

\begin{tabular}{lll}
\hline $\begin{array}{l}\text { Dimensiones de } \\
\text { Calidad de Vida }\end{array}$ & Áreas de la SIS (van Loon et al, 2008) & Áreas de la SIS para niños \\
\hline Bienestar & Salud y Seguridad & Salud y Seguridad \\
Emocional & Protección y Defensa & Defensa (autorrepresentación) \\
& Necesidades Excepcionales & Necesidades Excepcionales \\
de Apoyo Médico y Conductual & de Apoyo Médico y Conductual \\
Relaciones & Social & Social \\
Interpersonales & & Participación Escolar \\
Bienestar & Empleo & \\
Material & Salud y Seguridad & Salud y Seguridad \\
& Protección y Defensa & Defensa (autorrepresentación) \\
Desarrollo & Necesidades Excepcionales & Necesidades Excepcionales de \\
Personal & de Apoyo Conductual & Apoyo Conductual \\
& & Aprendizaje Escolar \\
Bienestar & Salud y Seguridad & Salud y Seguridad \\
Físico & Necesidades Excepcionales & Necesidades Excepcionales \\
Autodeterminación & de Apoyo Médico y Conductual & de Apoyo Médico y Conductual \\
Inclusión & Protección y Defensa & Defensa (autorrepresentación) \\
Social & Vida en Comunidad & Vecindario y Comunidad \\
Derechos & Actividades Sociales & Actividades Sociales \\
& & Participación Escolar \\
\hline & Salud y Seguridad & Salud y Seguridad \\
\hline & Protección y Defensa & Defensa (autorrepresentación) \\
\hline
\end{tabular}

\section{c) Formato de respuesta}

Otra de las modificaciones sustanciales que la SIS-C sufre con respecto a la elaborada con anterioridad para adultos, hace referencia al formato de respuesta. Debido al complejo formato de respuesta (Thompson y Viriyangkura, 2013), especialmente problemático en el índice de frecuencia de apoyo (Ibáñez, 2009), y a la necesidad de hacer más explícito el criterio de comparación con los iguales, se modifica el contenido de las categorías de este índice en la SIS-C (Tabla 34). 
No obstante, ambas escalas se evaluan a través de los mismos tres índices de medida (tipo, frecuencia y tiempo diario de apoyo), cada uno de ellos valorado en una escala Likert de cinco opciones de respuesta (0-4).

Tabla 34. Comparación del índice de frecuencia de apoyo en la SIS y la SIS-C

\begin{tabular}{|c|c|}
\hline FRECUENCIA DE APOYOS (SIS) & FRECUENCIA DE APOYOS (SIS-C) \\
\hline $\begin{array}{l}\mathbf{0}=\text { Nunca o menos de una vez al } \\
\text { mes. }\end{array}$ & $\begin{array}{l}\mathbf{0}=\text { No significativa; raramente las necesidades de apoyo del } \\
\text { niño son diferentes a las de compañeros de su misma edad. }\end{array}$ \\
\hline $\begin{array}{l}\mathbf{1}=\text { Al menos una vez al mes, pero } \\
\text { no una vez a la semana. } \\
\mathbf{2 =} \text { Al menos una vez a la semana, } \\
\text { pero no una vez al día. }\end{array}$ & $\begin{array}{l}\text { 1= Infrecuente; el niño necesita ocasionalmente alguien le } \\
\text { que preste un apoyo extraordinario, que los compañeros de } \\
\text { su edad no necesitarán, pero en más ocasiones no } \\
\text { necesitará ningún apoyo extra. }\end{array}$ \\
\hline \multirow{3}{*}{$\begin{array}{l}\mathbf{3}=\text { Al menos una vez al día pero } \\
\text { no una vez cada hora. } \\
\mathbf{4}=\text { Cada hora o con más } \\
\text { frecuencia. }\end{array}$} & $\begin{array}{l}\text { 2= Frecuentemente; para que el niño participe en la } \\
\text { actividad necesitará apoyo extraordinario } \\
\text { aproximadamente en la mitad de ocasiones que suceda. }\end{array}$ \\
\hline & $\begin{array}{l}\text { 3= Muy frecuente; en la mayoría de las ocasiones en las que } \\
\text { ocurre la actividad el niño necesitará apoyo extra que los } \\
\text { compañeros de su edad no necesitan; sólo ocasionalmente } \\
\text { el niño no necesitará apoyo extra. }\end{array}$ \\
\hline & $\begin{array}{l}\text { 4= Siempre; en cada ocasión en la que el niño participa en la } \\
\text { actividad necesitará apoyo extra que los compañeros de su } \\
\text { edad no necesitan. }\end{array}$ \\
\hline
\end{tabular}

\subsubsection{Procedimiento}

En líneas generales, el desarrollo de SIS-C en español se realiza teniendo en cuenta los pasos que Tassé y Craig (1999) proponen como necesarios para adecuar un instrumento de forma eficaz a cualquier contexto diferente del original.

Tras el proceso de traducción y adaptación al español de los ítems originales del Test de Campo 1.0 (Thompson, Wehmeyer et al., 2008) llevado a cabo en España (Guillén et al., 2012; Jiménez, 2009) bajo las directrices de la Comisión Internacional de los Tests (International Test Comission [ITC]) (Muñiz y Hambleton, 1996; Muñiz et al., 2013), se realizó un estudio piloto. El objetivo de este estudio residía en conocer, de manera preliminar, el funcionamiento de la escala en el contexto español (Guillén et al., 2012; Guillén et al., en prensa; Verdugo, Arias, Guillén et al., 2014), recogiendo las aportaciones necesarias para continuar el proceso de validación (Tabla 35). Los datos obtenidos en cada fase se presentan de manera detallada en el apartado de resultados. 
Tabla 35. Resumen del proceso de adaptación y desarrollo de la SIS-C en España

\begin{tabular}{|c|c|c|c|}
\hline Objetivos & \multicolumn{2}{|c|}{ Fases (Tassé y Craig, 1999) } & Análisis Realizados \\
\hline \multirow{3}{*}{$\begin{array}{l}\text { Traducción y adaptación del pool } \\
\text { de ítems inicial }\end{array}$} & \multirow[t]{2}{*}{ I } & \multirow{2}{*}{$\begin{array}{l}\text { Traducción/ } \\
\text { Adaptación }\end{array}$} & $\begin{array}{l}\text { Dos traducciones } \\
\text { independientes }\end{array}$ \\
\hline & & & Síntesis de las traducciones \\
\hline & \multirow{2}{*}{ II } & \multirow{2}{*}{$\begin{array}{l}\text { Consolidación de la } \\
\text { Traducción y } \\
\text { Adaptación }\end{array}$} & $\begin{array}{l}\text { Retrotraducción hecha por } \\
\text { otro profesional }\end{array}$ \\
\hline \multirow{3}{*}{$\begin{array}{l}\text { VERSIÓN PRELIMINAR } \\
\text { Objetivo 1: Traducir y adaptar al } \\
\text { contexto español el pool de ítems } \\
\text { que conformará la versión inicial de } \\
\text { la SIS-C. }\end{array}$} & & & $\begin{array}{l}\text { Revisión realizada por un } \\
\text { traductor }\end{array}$ \\
\hline & III & $\begin{array}{l}\text { Validación } \\
\text { Preliminar }\end{array}$ & $\begin{array}{l}\text { Prueba de jueces expertos } \\
(n=8)\end{array}$ \\
\hline & IV & Revisión/Ajustes & $\begin{array}{l}\text { Revisión sobre forma y } \\
\text { contenido por el grupo } \\
\text { investigador. }\end{array}$ \\
\hline $\begin{array}{l}\text { Desarrollo específico del } \\
\text { instrumento en España }\end{array}$ & \multirow[b]{2}{*}{ V } & \multirow[b]{2}{*}{ Estudio Piloto } & $\begin{array}{l}\text { Aplicación de la escala a un } \\
\text { pequeño grupo }(\mathrm{n}=143)\end{array}$ \\
\hline Objetivo 2: Conocer de manera & & & $\begin{array}{l}\text { Análisis de datos a partir de } \\
\text { la Teoría Clásica de los Tests } \\
\text { (TCT) y la Teoría de } \\
\text { Respuesta a los Ítems (TRI) }\end{array}$ \\
\hline $\begin{array}{l}\text { Objetivo 2: Conocer de manera } \\
\text { preliminar las propiedades } \\
\text { psicométricas del instrumento de } \\
\text { evaluación, extrayendo resultados y } \\
\text { conclusiones que permitan ajustar } \\
\text { mejor el instrumento a nuestro } \\
\text { contexto en las futuras aplicaciones. }\end{array}$ & VI & $\begin{array}{l}\text { Revisión/Ajustes } \\
\text { tras el Estudio Piloto }\end{array}$ & $\begin{array}{l}\text { Revisión y ajuste del } \\
\text { instrumento a la muestra } \\
\text { española. }\end{array}$ \\
\hline
\end{tabular}

\subsection{RESULTADOS}

\subsubsection{FASE I: Traducción/adaptación del pool de ítems inicial}

La traducción inicial de los ítems supone el primer paso a realizar en cualquier proceso de adaptación transcultural de un instrumento de medida. En nuestro caso, no partíamos de un instrumento ya desarrollado desde el punto de vista metodológico, pero sí contábamos con un amplio banco de ítems previamente seleccionados a partir del cual trabajar. En este sentido, podemos decir que la construcción de este instrumento en español se está desarrollando de manera paralela y simultánea a la versión original en inglés. 
La traducción inicial de los ítems de la SIS-C (Thompson, Wehmeyer et al., 2008) fue realizada siguiendo las directrices de traducción y adaptación de la ITC (Hambleton y Bollwark, 1991; Hambleton, 1996; Muñiz y Hambleton, 1996; Muñiz et al., 2013). Estas pautas tienen como principal objetivo evitar una traducción meramente literal y asegurar la equivalencia lingüística, semántica y cultural con la escala original.

Se recomienda que los traductores no sólo conozcan los idiomas con los que se trabaja, sino que también deben ser expertos en la materia traducida para garantizar el ajuste de los contenidos. Por ello, fue el comité encargado de realizar dos traducciones del instrumento original de forma independiente estuvo formado por dos personas con buen dominio del inglés y profesionales del ámbito de la discapacidad.

Una vez finalizado este proceso de traducción en paralelo, ambos traductores se reunieron para valorar las traducciones realizadas conjuntamente. No hubo apenas desacuerdos y se llegó fácilmente a un consenso en la elección de ciertas expresiones traducidas de manera diferente. Como resultado se obtuvo la primera versión preliminar en español de la SIS-C.

\subsubsection{FASE II: Consolidación de la traducción/adaptación}

Se envió ésta primera versión de la SIS-C a una persona bilingüe, quien realizó una traducción a la inversa, reflejando que los contenidos de los ítems en español se adecuaban a los originales. Asimismo, con la colaboración de un traductor profesional, se revisó la versión del retrotraductor y se valoró la equivalencia semántica, idiomática y conceptual (Jiménez et al., 2009).

Sin embargo, aunque es habitual considerar que una traducción es muy buena cuando la equivalencia entre la versión original y la versión retrotraducida es muy alta, lo cierto es que no pueden sacarse conclusiones definitivas de este resultado. La mayoría de las veces que la relación entre la versión original y la realizada en la traducción a la inversa es casi perfecta, se puede observar una traducción muy literal en el idioma diana que no refleja una buena adaptación a la población específica (Brislin, 1986).

Teniendo en cuenta estas evidencias, en las siguientes fases se siguieron desarrollando otros medios para asegurar la validez de las traducciones y garantizar la adaptación de los ítems originales a nuestro contexto. 


\subsubsection{FASE III: Validación de la traducción preliminar}

En una tercera parte del trabajo realizado se constituyó un comité de expertos con el fin de consolidar la versión inicial de la escala. Concretamente, se buscaba asegurar la adecuación de la traducción de la escala al español, determinando la estabilidad de los juicios de los expertos sobre la asignación de los ítems a cada una de las áreas de apoyo establecidas originalmente por la SIS-C. Para ello, se realizó un análisis de concordancia entre las valoraciones de los ocho jueces (Jiménez et al., 2009).

Se solicitó la colaboración de cada uno de los jueces por correo, detallando el objetivo de la investigación y se envió la tarea de valoración a aquellos que accedieron a participar, recogiendosus datos personales. Finalmente, el comité estuvo integrado por un equipo de ocho profesionales del ámbito de la discapacidad, ya fueran investigadores del Instituto Universitario de Integración en la Comunidad (INICO) o profesionales con una amplia trayectoria dentro del movimiento asociativo de atención a personas con discapacidad intelectual (Tabla 36).

Tabla 36. Características sociodemográficas del grupo de jueces expertos (n=8)

\begin{tabular}{llll}
\hline \multirow{2}{*}{ CARACTERÍSTICAS SOCIODEMOGRÁFICAS } & $\mathbf{N}$ & $\mathbf{\%}$ \\
\hline \multirow{2}{*}{ Género } & Mujer & 3 & 37.5 \\
& Hombre & 5 & 62.5 \\
\hline \multirow{2}{*}{ Edad } & $<50$ años & 3 & 37.5 \\
& $>50$ años & 5 & 62.5 \\
\hline \multirow{2}{*}{ Profesión } & Pedagogía & 3 & 37.5 \\
& Psicología & 5 & 62.5 \\
\hline \multirow{2}{*}{ Estudios de Postgrado } & Máster & 3 & 37.5 \\
& Doctorado & 5 & 62.5 \\
\multirow{2}{*}{ Área de Trabajo } & Atención directa & 7 & 87.5 \\
\multirow{2}{*}{ Experiencia } & Investigación & 1 & 12.5 \\
Profesional & 5-10 años & 2 & 25.0 \\
\hline
\end{tabular}

Para calcular el porcentaje de acuerdo entre jueces se utilizó el programa estadístico SAS [versión 9.13] (SAS Institute, 2007). Se analizó la concordancia entre los jueces mediante el análisis de variables nominales: 0-No hay acuerdo; 1-Hay Acuerdo, y se halló el porcentaje de acuerdo, así como otras medidas más exhaustivas como el coeficiente de Holsti; Pi de Scott, Kappa de Cohen y el Alfa de Krippendorf. Los resultados pueden observarse en la Figura 13. 


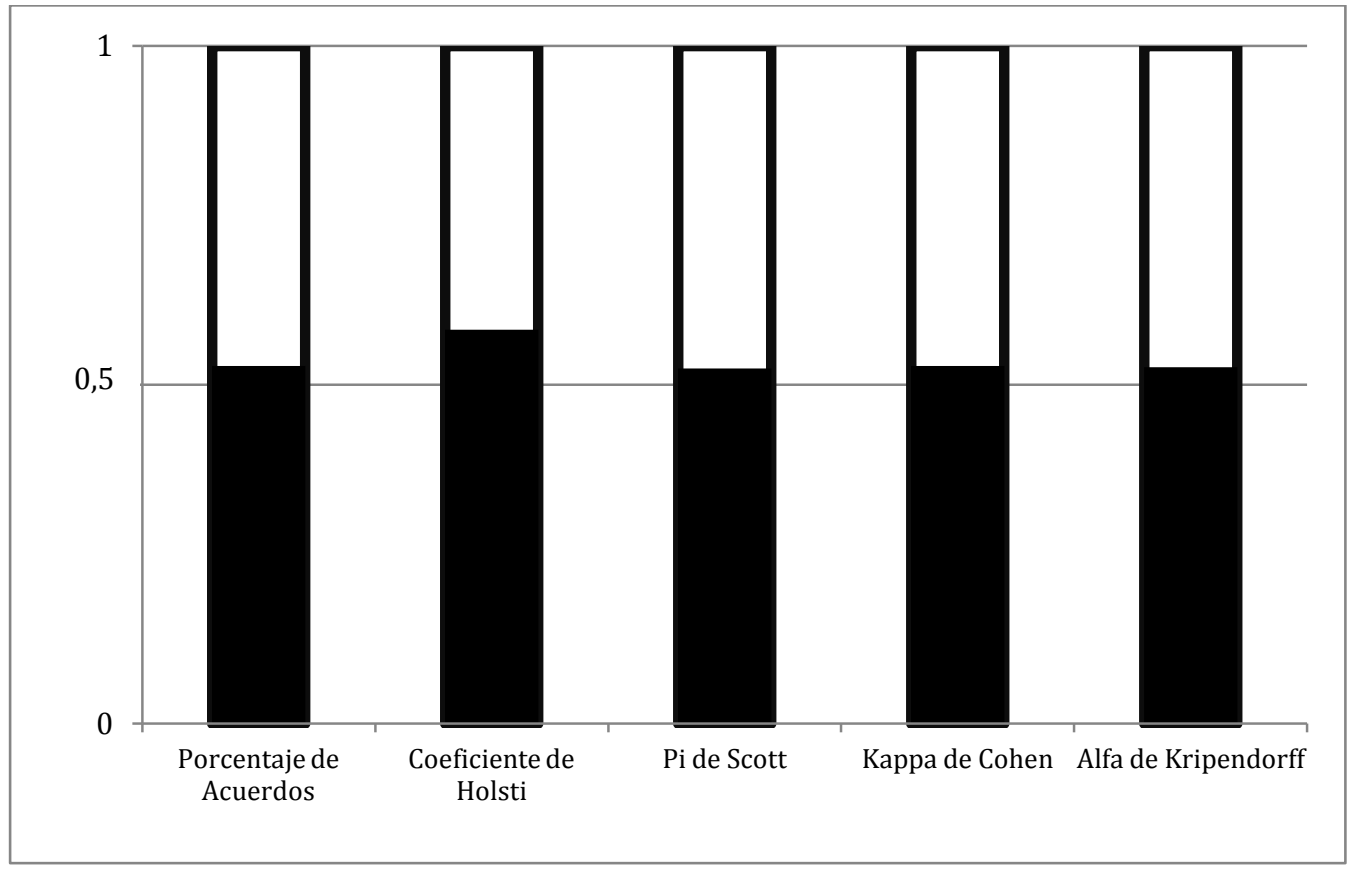

Figura 13. Promedios de fiabilidad interjueces

Tal y como puede observarse en la figura presentada, todos los índices de fiabilidad muestran coeficientes superiores a .450. En este sentido, para interpretar los datos se tuvieron en cuenta los criterios de interpretación propuestos Landis y Koch (1977). Bajo dichos criterios, los resultados obtenidos se encuentran dentro de los límites de calidad moderada (.400-.600) y, por tanto, eran susceptibles de ser aceptados para continuar con el estudio del funcionamiento del instrumento en el contexto español sin modificaciones.

Finalmente, para conocer el grado de acuerdo existente dentro de cada una de las dimensiones o áreas de la escala, se utilizaron los porcentajes de acuerdo ponderados de Bangdiwala, que a su vez vienen representados por los diagramas de acuerdo de Bangdiwala (Figura 14).

Atendiendo a su interpretación, el gráfico de acuerdo se construye como un cuadrado $n \times n$, donde ' $n$ ' es el tamaño total de la muestra. Dentro de este cuadro general, se muestran cuadrados blancos, formados a partir del análisis de los datos marginales, que reflejan el acuerdo máximo posible para cada dimensión (incluyendo las siete subescalas de la sección principal [A-G]) y la necesidades excepcionales médicas [NM] y conductuales $[\mathrm{NC}])$. Posteriormente, se añaden cuadros negros en la parte interna de los mismos para representar el grado de acuerdo real observado entre los jueces para cada dimensión. 


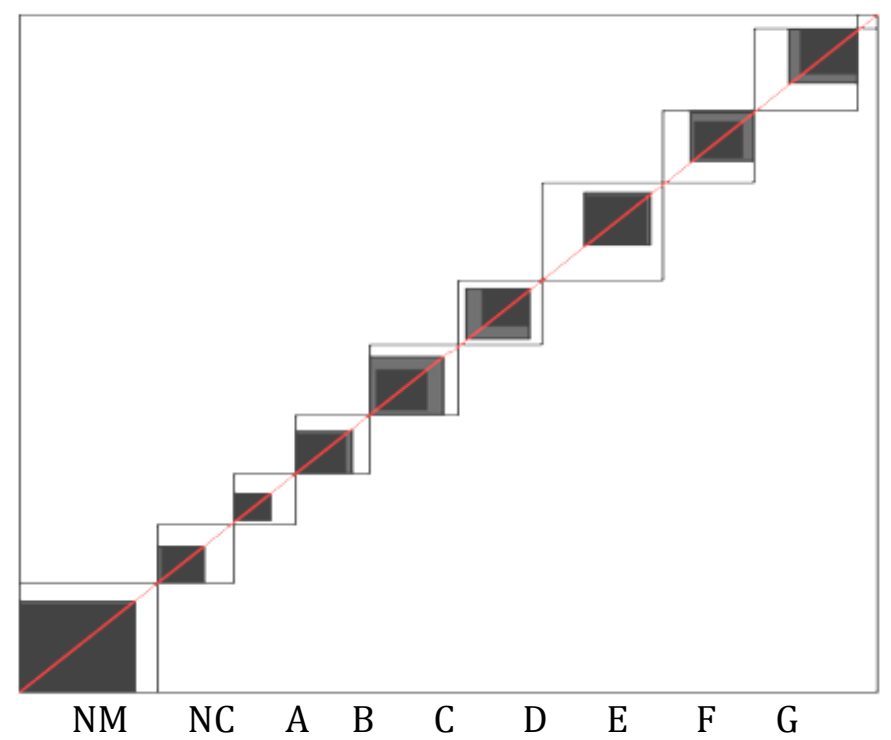

Figura 14.Gráfico de acuerdos (Bangdiwala) para cada área de la SIS-C (Jiménez, 2009)

Se puede observar en el cuadro que las dimensiones donde más acuerdo hubo fue en aquellas relacionadas con el ámbito escolar ('Participación Escolar (C)' y 'Aprendizaje Escolar (D)'), mientras que las dimensiones que reflejaron un menor grado de acuerdo fueron aquellas referidas a las dimensiones de 'Salud y Seguridad (E)' y las 'Necesidades Conductuales Excepcionales (NC)', ambas conceptualmente relacionadas. No obstante, cabe destacar que en todos los casos se superó el criterio inicialmente establecido para considerar que un índice es adecuado (índice de acuerdos ponderados superior a .40).

\subsubsection{FASE IV: Revisión/ajustes}

Como indican Solano-Flores, Contreras y Backhoff (2006), durante el proceso de traducción es prácticamente inevitable cometer algún tipo de error. Por ello, estos autores realizaron una clasificación detallada de los errores comúnmente cometidos en el proceso de traducción de ítems y propusieron un sistema de 10 dimensiones de errores que deben recibir una atención especial en la revisión final del instrumento.

Teniendo en cuenta este estudio de errores, otro comité formado por diferentes profesionales de esta investigación ajustó de nuevo el contenido final de la escala (Guillén et al., 2012), repetando, en la medida de lo posible, las aportaciones previas de las personas que formaron parte del proceso de revisión. En la Tabla 37, se recogen las modificaciones más relevantes: 
Tabla 37. Errores cometidos durante el proceso inicial de traducción

\begin{tabular}{|c|c|c|c|}
\hline \multicolumn{2}{|c|}{ Tipo de Error y Descripción (Solano et al., 2006) } & \multicolumn{2}{|c|}{ Ejemplo encontrado en la traducción y adaptación de los ítems de la SIS-C } \\
\hline \multirow{3}{*}{ 1. Gramática } & \multirow{3}{*}{$\begin{array}{l}\text { Errores gramaticales o sintaxis demasiado compleja } \\
\text { para la población destinataria. }\end{array}$} & Versión Original & $\begin{array}{l}\text { The child's support needs are rarely if ever different than same- } \\
\text { aged peers in regard to frequency. }\end{array}$ \\
\hline & & Primera Traducción & $\begin{array}{l}\text { Las necesidades de apoyo del niño son raras; si alguna vez } \\
\text { diferentes de compañeros de la misma edad respecto a la } \\
\text { frecuencia. }\end{array}$ \\
\hline & & Traducción Revisada & $\begin{array}{l}\text { Raramente las necesidades de apoyo del niño son diferentes a las } \\
\text { de compañeros de su misma edad. }\end{array}$ \\
\hline \multirow{3}{*}{ 2. Semántica } & \multirow{3}{*}{$\begin{array}{l}\text { El significado otorgado al ítem traducido difiere de su } \\
\text { significado original. }\end{array}$} & Versión Original & $\begin{array}{l}\text { Activities associated with acquiring knowledge and/or skills while } \\
\text { attending school. }\end{array}$ \\
\hline & & Primera Traducción & $\begin{array}{l}\text { Actividades asociadas con adquirir conocimiento y habilidades } \\
\text { mientras asiste al colegio. }\end{array}$ \\
\hline & & Traducción Revisada & $\begin{array}{l}\text { Actividades relacionadas con adquirir conocimientos y habilidades } \\
\text { en el colegio. }\end{array}$ \\
\hline \multirow{3}{*}{ 3. Estilo } & \multirow{3}{*}{$\begin{array}{l}\text { El estilo del ítem original no es consistente con el } \\
\text { estilo utilizado en el país destino. }\end{array}$} & Versión Original & Activities completed as a function of living in a household. \\
\hline & & Primera Traducción & Realizar actividades como parte de vivir en una casa. \\
\hline & & Traducción Revisada & Actividades realizadas en casa. \\
\hline 4. Formato & $\begin{array}{l}\text { El formato de los ítems traducidos difiere del formato } \\
\text { de los ítems originales. }\end{array}$ & No encontrado & \\
\hline \multirow{3}{*}{ 5. Convención } & \multirow{3}{*}{$\begin{array}{l}\text { La traducción del ítem no se realiza de conformidad } \\
\text { con las prácticas convencionales de la escritura de } \\
\text { ítems. }\end{array}$} & Versión Original & $\begin{array}{l}\text { In instances where a neighborhood friend provides extraordinary } \\
\text { support to an individual child, the child should still be rated as } \\
\text { needing the extraordinary support. }\end{array}$ \\
\hline & & Primera Traducción & $\begin{array}{l}\text { En los casos en donde un/a amigo/a del vecindario proporciona } \\
\text { un apoyo extraordinario a un/a niño/a aún así debería ser } \\
\text { valorado como si el/la niño/a necesitara un apoyo extraordinario. } \\
\text { En los casos en los que es un amigo del vecindario quien }\end{array}$ \\
\hline & & Traducción Revisada & $\begin{array}{l}\text { proporciona el apoyo, también debería valorarse que el niño } \\
\text { necesita un apoyo extraordinario. }\end{array}$ \\
\hline \multirow{3}{*}{ 6. Registro } & \multirow{3}{*}{$\begin{array}{l}\text { La traducción del ítem no es sensible a los diferentes } \\
\text { contextos sociales en la población destinataria o no es } \\
\text { sensible al uso común de palabras. }\end{array}$} & Versión Original & District \\
\hline & & Primera Traducción & Distrito \\
\hline & & Traducción Revisada & Comunidad \\
\hline \multirow{3}{*}{ 7. Información } & \multirow{3}{*}{$\begin{array}{l}\text { La traducción cambia la cantidad, calidad o el } \\
\text { contenido de la información proporcionada por el } \\
\text { ítem original. }\end{array}$} & Versión Original & Advocacy \\
\hline & & Primera Traducción & Defensa \\
\hline & & Traducción Revisada & Defensa(autorrepresentación) \\
\hline \multirow{3}{*}{ 8. Constructo } & \multirow{3}{*}{$\begin{array}{l}\text { Traducción inexacta de términos técnicos, inserción u } \\
\text { omisión de los mismos. }\end{array}$} & Versión Original & Operating electronic devices \\
\hline & & Primera Traducción & Manejar aparatos de casa \\
\hline & & Traducción Revisada & Manejar aparatos electrónicos \\
\hline \multirow{3}{*}{ 9. Currículum } & \multirow{3}{*}{$\begin{array}{l}\text { El ítem no representa el currículum del país } \\
\text { destinatario. }\end{array}$} & Versión Original & Co-curricular activities \\
\hline & & Primera Traducción & Actividades cocurriculares \\
\hline & & Traducción Revisada & Actividades extracurriculares \\
\hline 10. Origen & $\begin{array}{l}\text { El ítem en el lenguaje original tiene fallos que no } \\
\text { pueden corregirse en la traducción. }\end{array}$ & No encontrado & \\
\hline
\end{tabular}




\subsubsection{FASE V: Estudio piloto}

Una vez elaborada la versión pre-final del instrumento en español, incorporando las modificaciones propuestas por los diferentes profesionales implicados en las fases de traducción y adaptación, las directrices de desarrollo de instrumentos de medida propuestas por la ITC (Hambleton, 1996; Muñiz y Hambleton, 1996; Muñiz et al., 2013) resaltan la importancia de las pruebas piloto (Downing, 2006; Schmeiser y Welch, 2006; Wilson, 2005).

Por ello, se presentan a continuación los objetivos, los participantes, la recogida y análisis de datos, y los resultados obtenidos. Se incluyen asimismo en este capítulo, las conclusiones preliminares derivadas del estudio, dando paso así al último apartado, relacionado con la revisión y últimos ajustes a realizar antes de la aplicación y validación final de la escala.

\subsubsection{Objetivos}

Cuando se hace un estudio piloto, lo que se busca es encontrar, con un número menor de participantes de los necesarios para validar una escala, una muestra representativa que sea capaz de predecir cómo va a funcionar el instrumento.

El objetivo es, en último término, descubrir si existe algún problema en el formato de la escala o en alguno de sus componentes, para solucionarlo cuando aún el trabajo desarrollado no sea tan elevado que provoque grandes frustraciones, teniendo que repetir todo el proceso y pidiendo de nuevo a los profesionales de los centros que nos ofrezcan su colaboración (Verdugo, Gómez, Arias y Navas, 2010).

Para poder cumplir con esta finalidad, es necesario tener en cuenta varios aspectos durante el proceso de recogida y análisis de datos (Muñiz et al., 2013): (1) recoger 'in situ' las reacciones de las personas que realizan la prueba; (b) asegurarse de que los ítems e instrucciones son correctamente comprendidos; (3) registrar el tiempo necesario para la ejecución del cuestionario; (4) recoger información sobre posibles errores de contenido o formato que se pueden corregir antes de pasar a la siguiente fase de operaciones; y (5) obtener datos que permitirán llevar a cabo un primer análisis de ítems que indiquen la dirección y sentido de los índices psicométricos más relevantes. 
En este sentido, se tuvieron en cuenta dos fases principales dentro del estudio preliminar: (a) la aplicación de la SIS-C en español a una pequeña muestra, recogiendo de manera cualitativa las impresiones y comentarios de los informantes (objetivos 1-4); y (b) el análisis, mediante el uso de varias metodologías cuantitativas, de diferentes evidencias sobre el funcionamiento del pool de ítems traducido, valorando las propiedades psicométricas y el ajuste de los ítems, y analizando la fiabilidad y la validez tanto de las diferentes dimensiones como del instrumento en su conjunto (objetivo 5). El análisis conjunto de ambas fuentes de datos permitirá obtener la información preliminar necesaria para conocer los puntos fuertes y débiles de la escala, así como realizar las modificaciones pertinentes tanto de formato como de contenido.

\subsubsection{Selección de la muestra piloto y procedimiento de recogida de datos}

Como suele ocurrir en psicología y otras ciencias humanas y sociales (Argibay, 2009) la muestra piloto no fue seleccionada de manera representativa, sino incidental, participando en nuestra investigación sólo aquellas entidades y personas que, voluntariamente, decidieron colaborar en el proyecto de investigación presentado.

Se envío un correo a numerosas entidades de varias Comunidades Autónomas (Castilla y León, Madrid y Castilla La Mancha) explicando la finalidad del estudio, la tarea de los informantes y estableciendo un compromiso explícito de entregar a todos los centros participantes un certificado de colaboración y un informe detallado con los resultados obtenidos en el estudio.

Se eligieron estas tres comunidades por cercanía y facilidad en el desplazamiento ya que, como se ha explicado antes, cuando se realiza un estudio piloto es importante que sean los propios investigadores quienes realicen las aplicaciones para poder sacar conclusiones, no sólo sobre el análisis de los datos, sino de todo el proceso de cumplimentación del instrumento.

Se obtuvo respuesta de ocho centros dispuestos a colaborar (tres de Castilla y León, tres de Madrid y dos de Castilla la Mancha). Estos centros pertenecen a diferentes entornos (urbanos: $n=5$; rurales: $n=3$ ), tienen diferentes objetivos (centros educativos $\mathrm{n}=5$; asociaciones $\mathrm{n}=3$ ) y atienden a población con diferentes etiologías (síndrome de Down: $n=3$; parálisis cerebral: $n=1$; cualquiera: $n=4$ ); asegurando una alta representación de diferentes características personales y ambientales. 
Una vez que el centro accedió a la colaboración, se envió una carta a las familias de los niños que cumplían los requisitos (niños y adolescentes de entre 5 y 16 años con discapacidad intelectual), aplicando el instrumento solo a aquellos que recibieron el consentimiento familiar. Finalmente, se aplico el pool de ítems desarrollado en español a 143 participantes.

La muestra de 143 sujetos estuvo compuesta por niños y niñas distribuidos a lo largo de todo el continuo de edad al que hace referencia la SIS-C (5-16 años) y enmarcados dentro de los diferentes niveles de funcionamiento intelectual. En la Tabla 38 se ofrece una descripción más detallada que recoge las características sociodemográficas principales de los participantes evaluados.

Tabla 38. Características sociodemográficas de la muestra piloto $(n=143)$

\begin{tabular}{llrr}
\hline VARIABLES & CATEGORÍAS & $\mathbf{N}$ & $\mathbf{\%}$ \\
\hline Género & & & \\
& Hombre & 89 & 62.2 \\
& Mujer & 54 & 37.8 \\
& Total & 143 & 100.0 \\
\hline Edad & 5-8 años & & \\
& $9-12$ años & 18 & 12.6 \\
& 13-16 años & 46 & 32.2 \\
& Total & 79 & 55.2 \\
& & 143 & 100.0 \\
\hline Discapacidad & & & \\
& Ligera & & \\
& Moderada & 25 & 17.5 \\
& Severa o Profunda & 77 & 53.8 \\
& Total & 41 & 28.7 \\
& & 143 & 100.0 \\
\hline
\end{tabular}

Para realizar las evaluaciones de estos niños y adolescentes, fue necesario contar con la colaboración de profesionales y familiares, ya que debe ser alguien que conozca bien a la persona con discapacidad quien responda a las preguntas planteadas. Asimismo, las directrices de la cumplimentación de este instrumento sugieren la evaluación de dos informantes, siendo idóneo que uno pertenezca al ámbito familiar y otro al ámbito profesional. 
Sin embargo, la participación de los profesionales de los centros y de las familias también fue voluntaria, por lo que no siempre se pudo completar este criterio. No obstante, se consiguió un alto número de participación y el instrumento fue aplicado en el $97 \%$ de los casos a dos informantes.

Dentro de esta doble aplicación, en el $62 \%$ de los casos las evaluaciones fueron realizadas por un familiar y un profesional. En los casos en los que fue imposible la colaboración activa de la familia o de los profesionales, se pidió que, en la medida de lo posible, dos informantes pertenecientes al mismo ámbito evaluaran a la persona con discapacidad (38\%). Finalmente, se consiguió que sólo cuatro de las evaluaciones (3\%) fueran realizadas por un único informante.

En todos los casos la cumplimentación del instrumento se llevó a cabo en formato de entrevista. Los entrevistadores, fueron en su gran mayoría profesionales del INICO, aunque en un porcentaje mínimo de casos también actuaron como entrevistadores profesionales del propio centro (orientadores o maestros) que recibieron una sesión de formación previa así como el documento completo con las instrucciones pertinentes.

Asimismo, se constató que todos los entrevistadores cumplieran los requisitos y criterios propuestos por Hambleton (1996) para los aplicadores de un test: (a) deben ser elegidos de entre personas que pudieran también ser elegidos como informantes en una situación potencial; (b) estar familiarizados con los distintos matices de la cultura de que se trate; (c) tener experiencia y aptitudes para la aplicación de tests; y (d) conocer la importancia de seguir al pie de la letra los procedimientos reglados para la aplicación de los tests.

\subsubsection{Análisis de Datos}

Para analizar los datos obtenidos tras la aplicación del instrumento a la muestra participante se utilizaron dos metodologías diferentes, con el fin de aportar una visión más completa del funcionamiento y las propiedades de la escala.

Concretamente, se realizaron análisis basados en los supuestos de dos de las metodologías cuantitativas más utilizadas en el proceso de construcción de instrumentos de evaluación. A continuación, presentamos la descripción de estas metodologías, especificando el tipo de análisis realizado en cada una de ellas. 


\section{a) Teoría Clásica de los Tests (TCT)}

La TCT tiene su fundamentación en la Teoría de los Tests, modelo que asume que la puntuación empírica $(\mathrm{X})$ que obtiene un sujeto cuando se le aplica un determinado test realmente está formada por su puntuación verdadera (V) en ese test (la cual no hay manera de saber) y el error de medida (e), que inevitablemente va asociado a todo proceso de medición y que fluctua en función de las posibles variables que estén influyendo en la evaluación (factores ambientales y personales de la persona evaluada y/o características inherentes al test). En definitiva, la fórmula de este modelo lineal queda representada de la siguiente manera: $\mathrm{X}=\mathrm{V}+$ e. A partir de este modelo, se podrán desarrollar todo un conjunto de deducciones encaminadas a estimar la cuantía del error que afecta a las puntuaciones de un instrumento concreto. La lógica nos dirá que aquellas escalas capaces de controlar en mayor medida el error serán las más eficaces (Muñiz, 2003).

Con relación a la TCT, se presentan en el apartado de resultados, los datos obtenidos a partir de diferentes evidencias de consistencia, fiabilidad y validez (de los ítems, las dimensiones y el instrumento) a través del programa IBM SPSS Statistics [versión 20] (SPSS, 2010). Para el estudio de los ítems, se analizó el poder discriminativo y el índice de discriminación interna (o índice de homogeneidad corregido). Por su parte, para el análisis de las dimensiones y la escala se tienen en cuenta la fiabilidad (entendida como consistencia interna y fiabilidad interevaluadores) y la validez, tanto de criterio (atendiendo a las estimaciones previas de los profesionales), como de constructo (a partir de las correlaciones significativas entre subescalas y las correlaciones significativas entre las subescalas y la puntuación total).

\section{b) Teoría de Respuesta a los Ítems (TRI)}

De manera complementaria, se realizaron análisis basados en los supuestos de la TRI mediante el uso del programa Winsteps [versión 3.68] (Linacre, 2008). Dentro de las peculiaridades de los modelos TRI destaca su asunción de que los ítems miden una única variable latente continua, considerando, además, que las respuestas a los ítems son mutuamente independientes, de manera que la única relación posible entre ellos es la explicada por su relación con la variable latente. Es por ello que, en general, se estudia el funcionamiento de la escala a través del análisis independiente de las dimensiones que la componen, asegurada previamente la unidimensionalidad de cada una de ellas. 
En sus orígenes los modelos de TRI fueron principalmente desarrollados para tests dicotómicos de ejecución máxima, caracterizados por plantear una única opción de respuesta correcta (Lord, 1952; Rasch, 1960). La escasa aplicación tradicional de la TRI a tests de ejecución típica estuvo marcada, en gran medida, por el origen educativo/académico del que emergieron y se asentaron los modelos TRI (Chernyshenko, Stark, Chan, Drasgow y Williams, 2001; Martínez-Arias, 1999; Morizot, Ainsworth y Reise, 2007; Muñiz, 1990; Reise, 1999; Rojas y Pérez, 2001), lo que supuso un retraso temporal de la aplicación de la TRI a otras disciplinas.

Afortunadamente, en los años setenta ya se ampliaba su uso a modelos politómicos (Andrich, 1978) y, progresivamente, se empezó a demandar su inclusión en tests de ejecución típica (e.g., Kline, 1983; Roskam, 1985). Estos tests se caracterizan por plantear y evaluar un conjunto de situaciones cotidianas con el fin de obtener información respecto a un constructo concreto en la vida diaria de una persona, indagando un área no cognitiva (Martínez-Arias, 1995). En este sentido, dentro de este tipo de escalas de evaluación, suelen plantearse varias opciones de respuesta, siendo todas ellas susceptibles de reflejar la realidad de la persona con relación a un constructo (con mayor o menor intensidad), como sucede, por ejemplo, en los tests de personalidad.

Las ventajas de los modelos de TRI sobre la TCT han sido analizadas por numerosos autores desde finales del siglo XX (e.g., Andrich, 1988; Fan, 1998; Hambleton y Jones, 1993; Kolen, 1981; Muñiz, 1997; Wrigth y Stone, 1999) y resumidas por Prieto y Delgado (2003) en ocho puntos fundamentales: (1) medición conjunta; (2) objetividad específica; (3) propiedades de intervalo; (4) especificidad del error típico de medida; (5) invarianza de los parámetros en distintas muestras; (6) estimación del grado de precisión de los ítems y del test; (7) estimación de la habilidad de las personas independientemente de la prueba; y (8) personalización de las pruebas.

El análisis de estas ventajas justificó el uso de los modelos TRI en el desarrollo de cualquier instrumento, lo que ha extendido su uso y divulgación con diferentes objetivos (e.g., de Ayala, 2009; Bond y Fox, 2001; Crocker y Algina, 2008; Embretson y McCollam, 2000; Embrestson y Reise, 2000; Fidalgo, 2005; Ferrerira, Almeida y Prieto, 2011; Prieto y Delgado, 2000; Prieto y Dias, 2004). En los últimos años, se está experimentando un incremento progresivo de la aplicación complementaria de los modelos de la TRI al análisis de ítems pertenecientes a tests de ejecución típica u otro tipo de escalas (Abal, Lozzi, Aguerri, Galibert y Attorresi, 2010). 
Concretamente, la TRI ha sido utilizada recientemente en España para medir diferentes constructos relacionados con la vida diaria de las personas con discapacidad. Destaca su uso en el estudio de la sintomatología de personas con TDAH (Arias, Arias y Gómez, 2013), y la evaluación de la conducta adaptativa (Navas, 2012; Tassé, 2013) y la calidad de vida (Gómez, 2010; Verdugo, Gómez et al., 2010) de personas con discapacidad intelectual.

En este caso, teniendo en cuenta la naturaleza de nuestros datos, los análisis se realizaron a partir del Modelo de Escalas de Clasificación (Rating Scale Model [RSM]) (Andrich, 1978), considerado una extensión del modelo de Rasch para ítems politómicos y generalmente utilizado en escalas que miden personalidad, actitudes, comportamiento, etc. (Fox y Jones, 1998).

El RSM asume que los puntos de transición son los mismos para todas las categorías, es decir, que las distintas categorías de respuesta se ordenan de manera creciente y la distancia entre las mismas será igual (de Ayala, 2009). Se espera, por tanto, que las dificultades relativas (o pasos) dentro de los ítems sean invariantes (Embretson y Reise, 2000). Este hecho reduce considerablemente el coste computacional al existir un número menor de parámetros a estimar y, por tanto, requiere un tamaño de muestra menor que otros modelos, ajustándose así a las características de las muestras piloto (Navas, 2012).

Nuestros objetivos en referencia a los análisis a realizar siguiendo las directrices de la TRI se operativizan en analizar los siguientes puntos: (1) las comprobaciones previas de los supuestos relacionadas con la unidimensionalidad y análisis de la cantidad de varianza explicada por las medidas; (2) el análisis de las medidas empíricas observadas ítem-categoría, examinando la idoneidad de las categorías de respuesta; (3) la fiabilidad; (4) el ajuste de los datos (ítems, dimensiones e instrumento) al modelo planteado.

\subsubsection{Resultados}

Los resultados obtenidos en este estudio piloto (Guillén et al., 2012; Guillén, Verdugo, Arias y Vicente, en prensa) se presentan a continuación de manera resumida en la Tabla 39 (TCT) y en la Tabla 40 (TRI). Estos resultados serán, posteriormente, tenidos en cuenta y discutidos en la fase VI del proceso de validación, relacionada con las modificaciones y ajustes que han de ser realizados a la luz de los resultados del estudio piloto. 
Tabla 39. Resultados del estudio piloto analizados bajo los supuestos de la TCT

\begin{tabular}{|c|c|c|c|c|}
\hline ANÁLISIS & & CRITERIOS & RESULTADOS & INTERPRETACIÓN \\
\hline \multirow[b]{2}{*}{ Funcionamiento de los ítems } & Poder Discriminativo & $\begin{array}{l}\text { Contrastar grupos con } \\
\text { puntuaciones altas, medias y bajas } \\
\text { (Kruskal-Wallis) }\end{array}$ & $\begin{array}{l}\text { Todas las pruebas de Chi-Cuadrado resultaron } \\
\text { significativas ( }<\text { <.001), lo que hace evidente el } \\
\text { poder de discriminación de todos los ítems. }\end{array}$ & \multirow[b]{2}{*}{$\begin{array}{l}\text { Las diferentes características y } \\
\text { propiedades psicométricas de } \\
\text { los ítems son adecuadas. }\end{array}$} \\
\hline & Discriminación Interna & $\begin{array}{l}\text { Índice de Homogeneidad corregido } \\
(\mathrm{IHc})>.20\end{array}$ & $\begin{array}{l}\text { Las correlaciones significativas y superiores a } .40 \\
\text { obtenidas entre cada ítem y la puntuación total (de } \\
\text { la subescala a la que pertenece y del instrumento) } \\
\text { reflejan la existencia de un alto índice de } \\
\text { discriminación interna. }\end{array}$ & \\
\hline \multirow{2}{*}{ Fiabilidad } & Consistencia Interna & Alfa de Cronbach $>.700$ & $\begin{array}{l}\text { El Alfa de Cronbach de las subescalas y de la escala } \\
\text { en todos los casos es }>.900 \text {, indicando una alta } \\
\text { fiabilidad. }\end{array}$ & \multirow{2}{*}{$\begin{array}{l}\text { Buenas evidencias de fiabilidad } \\
\text { del instrumento y de las } \\
\text { subescalas que lo componen. }\end{array}$} \\
\hline & Interevaluadores & $\begin{array}{l}\text { Correlación de Pearson } \\
\text { significativa }\end{array}$ & $\begin{array}{l}\text { Las correlaciones de las puntuaciones de ambos } \\
\text { informantes oscilan entre } .75 \text { (Defensa) y . } 88 \\
\text { (Hogar), siendo la correlación de las puntuaciones } \\
\text { totales de } .86 \text {. }\end{array}$ & \\
\hline \multirow{3}{*}{ Validez } & De Criterio & $\begin{array}{l}\text { Correlaciones significativas entre } \\
\text { subescalas y estimaciones previas } \\
\text { de necesidades de apoyo }\end{array}$ & Superior a .40 y significativas en todos los casos. & \\
\hline & \multirow[b]{2}{*}{ De Constructo } & $\begin{array}{l}\text { Correlaciones significativas entre } \\
\text { subescalas }\end{array}$ & $\begin{array}{l}\text { Oscila entre .68 (Aprendizaje Escolar y Social) y } \\
.88 \text { (Salud y Seguridad y Defensa). }\end{array}$ & \multirow{2}{*}{$\begin{array}{l}\text { Buenas evidencias de validez de } \\
\text { instrumento y de las subescalas } \\
\text { que lo componen. }\end{array}$} \\
\hline & & $\begin{array}{l}\text { Correlaciones significativas entre } \\
\text { subescalas y el total }\end{array}$ & $\begin{array}{l}\text { Desde la más baja, .76 (Aprendizaje Escolar-Total) } \\
\text { hasta la más alta .90 (Participación Escolar-Total). }\end{array}$ & \\
\hline
\end{tabular}


Tabla 40. Resultados del estudio piloto analizados bajo los supuestos de la TRI

\begin{tabular}{|c|c|c|c|c|}
\hline ANÁLISIS & & CRITERIOS & RESULTADOS & INTERPRETACIÓN \\
\hline \multirow{2}{*}{$\begin{array}{l}\text { Unidimensionalidad de las } \\
\text { subescalas y } \\
\text { varianza explicada }\end{array}$} & $\begin{array}{l}\text { Varianza explicada por } \\
\text { la medida de los datos }\end{array}$ & Igual o superior al $60 \%$ & $\begin{array}{l}\text { Los valores de las diferentes subescalas oscilan entre } \\
64.1 \% \text { (Salud y Seguridad) y } 72.9 \% \text { (Participación } \\
\text { Escolar). }\end{array}$ & \multirow{2}{*}{$\begin{array}{l}\text { Se cumplen los criterios para la } \\
\text { unidimensionalidad de cada } \\
\text { una de las áreas evaluadas. }\end{array}$} \\
\hline & $\begin{array}{l}\text { La posible segunda } \\
\text { dimensión }\end{array}$ & $\begin{array}{l}\text { No debería recoger más de } \\
3 \text { ítems }\end{array}$ & $\begin{array}{l}\text { Los valores oscilan entre } 2.1 \text { (Comunidad) y } 2.8 \\
\text { (Defensa-autorrepresentación). }\end{array}$ & \\
\hline \multirow{3}{*}{$\begin{array}{l}\text { Idoneidad de las categorías de } \\
\text { respuesta en relación a los tres } \\
\text { índices de medida: } \\
\text { - Tipo de apoyo (0-4) } \\
\text { - Frecuencia de apoyo (0-4) } \\
\text { - Tiempo diario de apoyo (0-4) }\end{array}$} & $\begin{array}{l}\text { Noo observaciones por } \\
\text { categoría }\end{array}$ & Al menos 10 & Se cumple en todos los casos. & \multirow{3}{*}{$\begin{array}{l}\text { Las categorías de respuesta } 3 \text { y } \\
4 \text { podrían colapsarse para los } \\
\text { tres índices ya que no aportan } \\
\text { información extra por } \\
\text { separado. }\end{array}$} \\
\hline & Valores Outfit MNSQ & $<2$ & Se cumple en todos los casos. & \\
\hline & $\begin{array}{l}\text { Valores promedios de las } \\
\text { categorías }\end{array}$ & Ordenación monotónica & $\begin{array}{l}\text { Las categorías de respuesta ' } 3 \text { ' y ‘4' no tienen una } \\
\text { ordenación monotónica de los valores promedio en } \\
\text { ninguno de los tres índices de medida propuestos. }\end{array}$ & \\
\hline \multirow{2}{*}{ Fiabilidad } & $\begin{array}{l}\text { Fiabilidad de la } \\
\text { estimación }\end{array}$ & $\begin{array}{l}\text { Aceptables valores de } .80 \text { o } \\
\text { superiores. }\end{array}$ & $\begin{array}{l}\text { Todas las puntuaciones estuvieron por encima de } \\
.88 ; \text { alcanzando el nivel mínimo establecido. } \\
\text { Se alcanza } 98 \text { para la general. }\end{array}$ & \multirow{2}{*}{$\begin{array}{l}\text { Altos niveles de fiabilidad del } \\
\text { instrumento. }\end{array}$} \\
\hline & Índice de separación & $\begin{array}{l}\text { Debería tener un valor mínimo } \\
\text { de } 2 \text { para ser considerado } \\
\text { aceptable }\end{array}$ & $\begin{array}{l}\text { Índice de separación de los ítems de la escala es } \\
\text { superior a } 2 \text { en todas las dimensiones, el valor } \\
\text { superior a } 6 \text { cuando se tienen en cuenta la totalidad } \\
\text { de la escala. }\end{array}$ & \\
\hline \multirow{4}{*}{$\begin{array}{l}\text { Ajuste de los datos al modelo } \\
\text { (para las subescalas y } \\
\text { los ítems) }\end{array}$} & Índice de ajuste interno & $\begin{array}{l}\text { MNSQ }(0.5-1.5) \text {, siendo } \\
\text { inaceptable mantener } \\
\text { superiores a } 2\end{array}$ & Escala: dentro del rango. Subescalas: Dentro del & \multirow{4}{*}{$\begin{array}{l}\text { En seis de las siete } \\
\text { dimensiones, un ítem no se } \\
\text { adecúa a los índices de ajuste } \\
\text { esperados, pero en ningún caso } \\
\text { se superan los límites } \\
\text { permitidos. }\end{array}$} \\
\hline & (Infit) & $\begin{array}{l}\text { ZEMP (de }-2 \text { a } 2 \text { ) siendo } \\
\text { inaceptable mantener } \\
\text { superiores a } 2.5\end{array}$ & $\mathrm{~A} 6(\mathrm{MNSQ}=1.89) ; \mathrm{G} 1(\mathrm{MNSQ}=1.60)$ y D8 $(\mathrm{ZEMP}=2.2)$ & \\
\hline & \multirow{2}{*}{$\begin{array}{l}\text { Índice de ajuste externo } \\
\text { (Outfit) }\end{array}$} & $\begin{array}{l}\text { MNSQ }(0.5-1.5) \text {, siendo } \\
\text { inaceptable mantener } \\
\text { superiores a } 2\end{array}$ & \multirow{2}{*}{$\begin{array}{l}\text { Escala: dentro del rango. Subescalas: Dentro del } \\
\text { rango. Todos los ítems funcionan bien menos los } \\
\text { ítems: A6 (MNSQ=1.7); C7(MNSQ=1.55); } \\
\text { D1 (MNSQ=1.7) y E8 (ZEMP=-2.1). }\end{array}$} & \\
\hline & & $\begin{array}{l}\text { ZEMP (de -2 a 2) siendo } \\
\text { inaceptable mantener } \\
\text { superiores a } 2.5\end{array}$ & & \\
\hline
\end{tabular}




\subsubsection{FASE VI: Revisión/ajustes tras el estudio piloto}

Tras el análisis de los datos obtenidos en el estudio piloto, se concluyó que, en general, la escala estaba teniendo un buen funcionamiento como herramienta evaluativa de necesidades de apoyo dentro del contexto español. Destacan, en este sentido, los resultados obtenidos mediante el análisis de los datos realizado bajos los supuestos de la TCT, que reflejaron un mejor funcionamiento de la escala que los obtenidos en la TRI (metodología más rigurosa).

En relación con el análisis de los ítems, desde la TRI se pudo observar la existencia de seis ítems que no manifestaban los índices de ajuste interno (Infit) o externo (Outfit) esperados: (1) ítem 6 de la subescala 'Hogar' (dormir o echarse la siesta); (2) ítem 7 de la subescala 'Participación Escolar' (seguir las normas de clase y de la escuela); (3) ítem 1 de la subescala 'Aprendizaje Escolar' (acceder a los contenidos del currículum del nivel escolar); (4) ítem 8 de la subescala 'Aprendizaje Escolar' (acceder al currículo de educación para la salud y educación física); (5) ítem 8 de la subescala 'Salud y Seguridad' (evitar riesgos para la salud y la seguridad); y (6) ítem 1 de la subescala 'Defensaautorrepresentación' (expresar preferencias). Aunque estos resultados revelan que estos seis ítems aportan poco valor a la escala, en la revisión de su contenido no se detectó ningún problema de comprensión, adecuación o pertinencia. Este hecho, unido a que los ítems con un escaso ajuste interno y/o externo no llegaron a mostrar índices superiores a lo aceptable, y que las propiedades que manifestaron en el estudio de los mismo a través de la TCT fueron adecuadas, hizo que se considerara oportuno mantenerlos hasta poder realizar un análisis más pormenorizado con una muestra de mayor tamaño.

Por otro lado, se encontró también que no todas las categorías de respuesta estaban funcionando de la manera idónea. En concreto, la categoría de respuesta '4' en cada uno de los tres índices de medida (tipo [ayuda física total]; frecuencia [siempre]; tiempo [más de 4 horas]) no parecía ser más probable que las otras categorías inferiores en ningún punto del continuo (ni en aquellos casos en los que la persona presentaban necesidades de apoyo elevadas), no proporcionando información útil. No obstante, al colapsar las categorías de respuesta ' 3 ' y '4', se encontró un adecuado funcionamiento de las mismas, lo que pone de manifiesto que aunque la puntuación '4' no aporta información relevante en la evaluación de necesidades de apoyo, tampoco supone un obstáculo. Por ello, se tomó la decisión de mantener el formato de respuesta preliminarmente, hasta obtener una muestra mayor que permitiera usar otro tipo de modelos de TRI capaces de analizar el funcionamiento del formato de respuesta ítem a ítem. 
Asimismo, durante el proceso de administración del instrumento se detectaron una serie de aspectos formales que podían ser mejorados en las posteriores aplicaciones del mismo: (1) los datos sociodemográficos de la persona con discapacidad, ya que los informantes demandaban más opciones para categorizar los problemas, enfermedades y limitaciones asociadas a la discapacidad intelectual, por considerarlas relevantes para el análisis de las necesidades de apoyo del niño. Se optó así por incorporar espacios para recoger información detallada del diagnóstico y también características relacionadas con el ámbito educativo y el lenguaje (incluyendo las otras lenguas oficiales en España además del castellano); (2) la formación de los profesionales que cumplimentaban el instrumento de manera autónoma, quienes, además de la sesión de formación específica que recibían sobre la aplicación de la escala y la total disponibilidad de los profesionales del INICO para atender cualquier duda que pudiera surgir en el proceso, demandaban la necesidad de contar con un manual de instrucciones breve y sencillo para poder consultar durante la cumplimentación; y (3) ayudas visuales para los informantes, puesto que estos demandaban apoyo constante para entender y recordar las categorías de respuesta. Por ello, se elaboró una hoja de ayuda que se entregaba a los informantes antes de comenzar la aplicación.

Además, tras el estudio piloto realizado en la versión original del instrumento se hicieron una serie de modificaciones para hacer la cumplimentación del instrumento más atractiva, entre las que destacaban un tamaño de letra mayor y una estructuración más clara de los apartados de la escala. Estos cambios fueron establecidos en la versión 3.0 del instrumento (Thompson et al., 2012), que fue reenviada a todos los países que estaban participando en el proyecto para conjugar en la medida de lo posible todas las modificaciones e incorporarlas en las siguientes aplicaciones. Actualmente, se están recogiendo los cambios finales en la versión 5.0 (Thompson, Wehmeyer, Hughes, Shogren, Little et al., 2014).

Para concluir este proceso inicial de validación, queremos puntualizar que se ha mantenido un proceso continuo de análisis a medida que los resultados de las nuevas aplicaciones iban siendo incorporados en la matriz de datos, obteniéndose en todo momento resultados positivos. Destaca el estudio realizado con 650 participantes (Verdugo, Arias, Guillén et al., 2014) donde, además de ponerse de manifiesto las adecuadas propiedades de la escala, se realizó, de manera exploratoria, un Análisis de Componentes Principales (ACP) que reflejó la unidimensionalidad de cada área evaluada y la posible multidimensionalidad del constructo general de 'necesidades de apoyo'. 
De manera complementaria, con los datos del estudio piloto se realizaron otra serie de análisis que reflejaban, de manera preliminar, la relación existente entre diferentes variables sociodemográficas y el nivel de necesidades. Se comprobó que, tal como se esperaba, no existían diferencias significativas en las necesidades de apoyo en función del género, pero sí teniendo en cuenta la edad y el Cociente Intelectual (CI) de la persona evaluada (Guillén et al., 2012). Asimismo, se analizó la relación entre las necesidades de apoyo y otras variables, como el nivel de autodeterminación (Vicente, 2013) y los problemas de salud mental (Guillén, Verdugo, Arias y Vicente, 2013). Destaca el análisis diferencial realizado teniendo en cuenta determinadas etiologías específicas causantes de otras limitaciones asociadas, como el autismo y la parálisis cerebral. Los datos obtenidos pusieron de manifiesto la necesidad de seguir investigando en esta línea para valorar la pertinencia de realizar baremos específicos acordes a las propiedades y características de cada una de estas etiologías (Guillén Verdugo, Arias, Vicente y Navas, 2013).

Además, se realizó un estudio comparativo con una muestra preliminar de 42 sujetos sobre la relación de las necesidades de apoyo (medidas a través de la SIS-C) y la conducta adaptativa (evaluada con la DABS). Este estudio aportaba por primera vez evidencias de la relación entre estos dos constructos desde la perspectiva infantil, poniendo de manifiesto que, si bien ambos constructos correlacionan de manera significativa, no existen evidencias de que correspondan a un mismo constructo subyacente, por lo que es necesario utilizar de manera diferenciada estos instrumentos, abandonando por completo el tradicional uso de las escalas de conducta adaptativa como estrategia para estimar necesidades de apoyo en la infancia (Guillén, 2014).

\subsection{CONCLUSIONES DEL CAPÍTULO 3}

El principal objetivo de este primer capítulo empírico ha sido mostrar el complejo y riguroso proceso llevado a cabo para la elaboración en español de la SIS-C, escala dirigida a suplir la carencia de instrumentos de evaluación de necesidades de apoyo en niños y adolescentes con discapacidad intelectual. Esta escala se ha desarrollado en español de manera simultánea a la versión original en inglés y, para garantizar su adecuación a nuestro contexto, su elaboración ha teniendo en cuenta tanto los pasos propuestos por Tassé y Craig (1999) como las directrices de la ITC (Muñiz y Hambleton, 1996; Muñiz et al., 2013). 
Para garantizar la buena adaptación de un test, no es suficiente realizar una buena traducción literal de los ítems, sino que el estilo y uso del lenguaje también deben ajustarse para optimizar su comprensión. Además, resulta imprescindible atender al contenido de los ítems, pudiendo ser necesario realizar modificaciones para asegurar que la medición del constructo refleje las características de la sociedad y cultura específica a la que se pretende adaptar. En este sentido, para obtener una adecuada versión preliminar del instrumento en español, se ha contado con la colaboración de numerosos investigadores, profesionales y personas bilingües que han realizado diversas traducciones y análisis de los ítems originales, coordinados por expertos encargados del proceso de toma de decisiones. Así, a partir de las primeras traducciones, se han llevado a cabo procesos específicos de revisión para evitar problemas de adaptación que suelen surgir en los procesos iniciales, incluyendo errores de: (a) gramática; (b) semántica; (c) estilo; (d) convención; (e) registro; (f) información; (g) constructo; y (h) currículum.

Tras obtener una primera versión de la prueba de evaluación, se llevó a cabo un estudio piloto que, a través de la información cualitativa de las aplicaciones y los resultados del análisis preliminar de los datos, aportó una orientación inicial sobre lel funcionamiento de la escala en nuestro contexto y permitió hacer las modificaciones pertinentes. El estudio piloto realizado contó con la participación de 143 niños y adolescentes (5-16 años) con discapacidad intelectual. El análisis de los datos, realizado a través de dos metodologías diferentes, TCT y TRI, puso de manifiesto las adecuadas propiedades de la escala, no siendo necesario realizar cambios en su contenido. No obstante, algunos cambios de estilo y forma fueron incorporados para optimizar su uso.

En relación con la TCT, todos los ítems obtuvieron suficientes evidencias de calidad psicométrica y demostraron estar aportando un valor significativo a la medición del constructo. Asimismo, tanto las siete áreas como la escala en su conjunto obtuvieron índices excelentes de fiabilidad, reflejando precisión y consistencia. Finalmente, la escala presentó diferentes evidencias de validez, garantizando que la información obtenida mediante la SIS-C refleja la evaluación del constructo de 'necesidades de apoyo'.

La decisión de utilizar la TRI para la validación complementaria se tomó a partir de los buenos resultados de su uso en el proceso de construcción de otras herramientas dirigidas a personas con discapacidad intelectual en España (Verdugo, Arias y Navas, 2014; Verdugo, Gómez et al., 2010); resultando, a su vez, una metodología innovadora en la evaluación de las necesidades de apoyo. Dentro de la metodología TRI, se siguieron los supuestos de los Modelos de Clasificación (RSM), que suponen que las diferentes 
categorías de respuesta funcionan de la misma manera para todos los ítems, reduciendo el número de parámetros a estimar y permitiendo así su uso con muestras más pequeñas de lo habitual. Los resultados obtenidos permitieron corroborar la utilidad de la TRI para la construcción de esta herramienta y seguir utilizándola en la validación final de la misma. En general, se encontró un buen ajuste de los datos al modelo; sin embargo, seis ítems no alcanzaban los índices esperados y, además, las categorías de respuesta '3' y '4' de los tres índices de medida (tipo, frecuencia y tiempo diario de apoyo) no funcionaban de manera idónea. No obstante, en ninguno de los dos casos se obtuvieron valores fuera de lo aceptable que aportaran ruido a la evaluación de necesidades de apoyo, por lo que se decidió mantener intacto el contenido de la escala en la versión prefinal hasta poder realizar análisis más exhaustivos con una muestra de mayor tamaño.

A pesar de los buenos resultados obtenidos en el estudio piloto, el proceso de desarrollo de la escala no estuvo exento de limitaciones. Por un lado, aunque el grupo de jueces expertos puso de manifiesto que la asignación original de los ítems en cada una de las áreas evaluadas era adecuada también el contexto español, no se analizaron otros índices de actual relevancia en el desarrollo de instrumentos, como la observabilidad, la sensibilidad o la importancia (Gómez et al., 2014). No obstante, aunque hubiera sido pertinente realizar estos análisis, no se consideró que fuera necesario profundizar más en este arduo proceso, ya que este trabajo no versa sobre la selección de ítems, sino que hace referencia a la adaptación de aquellos previamente seleccionados. Por otro lado, señalamos también las limitaciones derivadas de la muestra del estudio piloto, que pueden resumirse en: (1) un número limitado de participantes; (2) una baja representatividad; y (3) un proceso de selección de participantes no aleatorizado. Sin embargo, es importante tener en cuenta que el objetivo de este estudio no era generalizar los resultados a toda la población infantil y juvenil con discapacidad intelectual sino, simplemente, obtener algunas claves sobre el funcionamiento de la SIS-C en nuestro contexto para garantizar la calidad de las futuras aplicaciones a una muestra más amplia y representativa.

En definitiva, los resultados pusieron de manifiesto la adecuación y pertinencia de continuar trabajando en la validación de este instrumento en español. Aunque se mejoraron algunas pautas del proceso de cumplimentación derivadas de la experiencia piloto, no fue necesario realizar modificaciones de contenido, lo que permitió contar con las 143 aplicaciones del estudio piloto como parte de la muestra final utilizada para el análisis definitivo de la fiabilidad y validez del instrumento. 


\section{Capitulo}

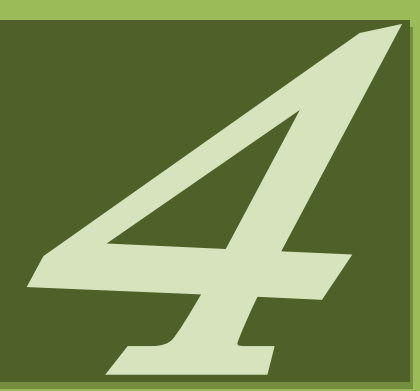

Funcionamiento y Validación de la SIS-C 



\section{FUNCIONAMIENTO Y VALIDACIÓN DE LA SIS-C}

A lo largo de este capítulo se presentan los análisis definitivos realizados para conocer las propiedades de la Escala de Intensidad de Apoyos para Niños y Adolescentes (Supports Intensity Scale [SIS-C]) desarrollada en el contexto español y el análisis exhaustivo de sus ítems, que serán claves para ajustar la validación y baremación del instrumento a la población diana. Concretamente, este capítulo se divide en varios apartados:

- Un planteamiento inicial, donde se presenta una introducción sobre las características del instrumento a analizar y las metodologías que se utilizan para la validación del instrumento. Se aportan evidencias sobre la adecuación de su uso y una descripción de sus características principales, lo que permitirá realizar una correcta interpretación de los resultados que se ofrecen posteriormente.

- El apartado de objetivos irá enfocado a definir, de manera operativa, las expectativas del funcionamiento de la escala. Se atiende de manera independiente a la los objetivos de las diferentes metodologías de análisis utilizadas y se especifica la finalidad del uso complementario de todas ellas.

- Posteriormente, se aborda el procedimiento, detallando el proceso de recogida de información y las características de todas las personas implicadas en el proceso de evaluación, controlando así posibles variables que pudieran estar influyendo de manera directa en las puntuaciones. También se presenta aquí una descripción de los análisis de datos realizados, identificando de manera clara cada uno de los resultados con los objetivos.

- En el apartado de resultados, se especifican las aportaciones y datos obtenidos en las diferentes metodologías y análisis utilizados para la construcción del instrumento.

- Finalmente, se presentan las conclusiones del capítulo 4, donde se recogen los principales resultados, haciendo una valoración crítica de los mismos y comparándolos con otros los resultados obtenidos en otros estudios similares. Este apartado dará paso al apartado final de la tesis, -conclusiones generales, discusión y futuras líneas de investigación-, donde se relacionarán de manera directa los datos obtenidos en estos capítulos empíricos con los supuestos teóricos presentados a lo largo de los capítulos 1 y 2 . 


\subsection{PLANTEAMIENTO INICIAL}

La finalidad general de este capítulo, que se corresponde con el culmen del trabajo de investigación llevado a cabo en esta tesis doctoral, consiste en conocer el funcionamiento de la escala en el contexto español, identificando si es posible relacionar los datos obtenidos a través de la aplicación de instrumento con el constructo de 'necesidades de apoyo'.

Gómez (2010) argumentaba que, tras la construcción de los ítems, el siguiente paso lógico en el proceso de validación de un instrumento de evaluación consiste en la constatación de: (a) sus propiedades psicométricas: (b) su estructura; y (c) la calibración de sus ítems. En la actualidad, son básicamente tres los modelos psicométricos que cuentan con mayor difusión (Jones y Thissen, 2007) y que pueden ser tenidos en cuenta y utilizados de manera complementaria para la consecución de los objetivos descritos: (a) el modelo de la Teoría Clásica de los Tests (TCT); (b) los modelos de medida encuadrados en los Modelos de Ecuaciones Estructurales (Structural Equation Modeling [SEM]); y (c) los modelos de Teoría de Respuesta a los Ítems (TRI).

\subsubsection{Análisis de las propiedades psicométricas, la fiabilidad y la validez de la escala a través de la TCT}

Este análisis de las propiedades psicométricas de la escala se realiza de manera tradicional desde la TCT. Este enfoque clásico permite fundamentar las puntuaciones obtenidas con un test y realizar la estimación de los errores de medida asociados a todo proceso de medición (Muñiz, 2003). Esta premisa básica implica asumir que la legitimidad y eficiencia de un instrumento depende de un bajo error de medida, lo que se asocia con una elevada fiabilidad y validez como características psicométricas de referencia.

En este sentido, uno de los análisis necesarios a realizar para conocer las propiedades psicométricas de un instrumento reside en analizar de manera específica la calidad de los ítems que lo componen. Conocer los índices de dificultad, y discriminación interna, el poder discriminativo, así como los análisis fiabilidad y validez de los ítems es indispensable para contar con una escala con buenas propiedades. No obstante, aunque obtener evidencias de la calidad de los ítems es requisito necesario para garantizar la adecuación del instrumento, no es suficiente para avalar su funcionamiento. Por ello, tras el análisis independiente de los ítems, es necesario realizar otra serie de análisis 
exhaustivos para conocer la adecuación de su uso conjunto para la medición de un constructo concreto (i.e., 'necesidades de apoyo'), analizándose diferentes evidencias de fiabilidad y validez atendiendo a las puntuaciones obtenidas en cada una de las áreas de evaluación y, en general, en el instrumento de medida. Los múltiples análisis estadísticos realizados bajo los supuestos de la TCT permitirán elaborar una versión definitiva de la SIS-C que cuente con evidencias suficientes de consistencia y validez en sus mediciones.

No obstante, a pesar de la innegable presencia y utilidad de la TCT en las investigaciones actuales relacionadas con la validación de instrumentos de medida, cada vez es más frecuente complementar los análisis propios de la TCT con otro tipo de análisis encuadrados en los llamados SEM, que arrojarán información sobre la estructura interna de la escala, proporcionando evidencias de validez del instrumento a partir del análisis factorial del constructo medido.

\subsubsection{Evidencias de validez basadas en la estructura interna de la escala basadas en los SEM: el Análisis Factorial Confirmatorio}

Los Modelos de Ecuaciones Estructurales (también llamados Modelos de Estructuras de Covarianza) pretenden ofrecer esquemas explicativos de teorías sometidas a hipótesis por el investigador con el objetivo de facilitar la comprensión de un fenómeno concreto, determinando en qué medida los datos observados apoyan un modelo teórico de múltiples relaciones entre variables que actúan como indicadores de un constructo psicológico (Orgaz, 2008). Los SEM han disfrutado de un gran desarrollo en los últimos años (e.g., Coenders, Batista-Foguet y Saris, 2005; Hershberger, 2003; MacCallum y Austin, 2000) y, actualmente, se considera que los SEM son los procedimientos más potentes en el estudio de relaciones entre grandes conjuntos de variables medidas con error.

Dentro de este marco metodológico general, Batista-Foguet y Coenders (1998) proponen el uso específico del Análisis Factorial Confirmatorio (AFC) como complemento más adecuado para solventar las limitaciones del uso exclusivo de la TCT en la búsqueda de la estructura interna del instrumento. A diferencia de otros modelos de análisis factorial (e.g., Análisis Factorial Exploratorio [AFE]), el AFC se enmarca dentro de los SEM, (concretamente, dentro de un subgrupo de los mismo denominado 'Modelos de Medida') porque se focaliza en la comprobación de la existencia de una teoría o hipótesis establecida a priori, incluyendo los planteamientos teóricos más relevantes para explicar de qué manera un conjunto de variables medidas empíricamente son un reflejo de otras 
variables latentes, es decir, no observables empíricamente (Martínez-Arias, Hernández y Hernández, 2006; Yuan y Bentler, 2007). De esta manera, para realizar un AFC el investigador debe establecer el número de factores o variables latentes del modelo, especificando qué indicadores o variables observadas pesan en cada uno de esos factores, incluyéndose la posibilidad de que haya algunos relaciones entre los factores o que funcionen de manera independiente (Fernández-Pulido, 2008).

Validar la escala por medio de la TCT y usando el AFC como medio para conocer la estructura interna de la escala permite estudiar (Thompson, 2004): (a) las evidencias acerca de la validez de constructo de los instrumentos de medida; (b) la posibilidad de reducir una gran cantidad de variables a un número menor de ellas con el fin de hacer más manejable e inteligible su uso en estudios subsiguientes; y (c) la adecuación de las teorías sobre el constructo psicológico evaluado. En el caso de la SIS-C realizar un AFC para conocer la estructura de la escala proporciona, además, un punto de comparación con los análisis de la SIS para adultos, permitiendo conocer si existe una estructura factorial similar entre ambas escalas y contribuyendo a esclarecer el constructo de 'necesidades de apoyo' en diferentes poblaciones: adultos/niños.

Sin embargo, en la actualidad, las limitaciones de la TCT son cada vez más divulgadas y el uso de otras metodologías complementarias como la TRI supone un elemento de calidad en la investigación en lo que al desarrollo de instrumentos de evaluación se refiere, habiendo sido constatada la adecuación del uso de ambas metodologías en el estudio piloto.

\subsubsection{Ajuste de los datos y calibración de los ítems según la TRI: el Modelo de Crédito Parcial (MCP)}

En el capítulo 3, se recogieron las ideas fundamentales de la TRI así como sus ventajas en relación con la TCT (Prieto y Delgado, 2003) y su adecuación como uso como complementario a ésta (Gómez, 2010). En resumen, podemos decir que defienden que los modelos TRI fueron diseñados para solventar fundamentalmente tres problemas de la TCT Reid, Kolakowsky-Hayner, Lewis y Armstrong (2007): (1) las normas utilizadas para interpretar las puntuaciones en un test son específicas de la muestra utilizada; (2) la inestabilidad de las puntuaciones que se encuentran en los extremos de la distribución de la habilidad o rasgo; y (3) se ha de administrar el test completo para obtener información significativa de cara a interpretar el nivel de habilidad o rasgo de la persona evaluada. 
El estudio piloto presentado anteriormente, se realizó bajo los supuestos del RSM, considerado un modelo logístico de un parámetro, por ser uno de los modelos más parsimoniosos para conocer el ajuste de los datos al modelo de Rasch cuando se usan ítems politómicos. En este capítulo, sin embargo, la validación del instrumento se realizará atendiendo al Modelo de Crédito Parcial (MCP).

El MCP (Masters, 1982), al igual que el modelo RSM, constituye una extensión del modelo de Rasch para ítems politómicos que permite conocer la calibración de los ítems y analizar el ajuste de de los datos. Sin embargo, este modelo, al contrario que el anterior, exige un mayor número de participantes ya que permite estimar un mayor número de parámetros. Este hecho se relaciona con la capacidad del modelo para definir empíricamente el número concreto de categorías de respuesta (así como su localización en un continuo) en cada uno de los ítems objeto de análisis, considerando que los ítems no tienen la misma dificultad en el umbral y que, por tanto, la escala de clasificación específica a cada uno de los ítems (Arias, 2008).

Explicada simplemente, la ecuación del MCP establece que la probabilidad de dar una respuesta de una calidad determinada $(X=c)$ para un sujeto, dado su nivel de habilidad (q) y el conjunto de dificultades asociadas a cada paso del ítem ( $x=d i 1$, di2, di3) corresponde a la diferencia entre la habilidad del sujeto y la dificultad (de Ayala, 2009; Embretson y Reise, 2000; Fischer y Molenaar, 1995; Masters, 1982; Nering y Ostini, 2010; Ostini y Nering, 2006; Van der Linden y Hambleton, 1997). Así, el MCP permite analizar ítems que corresponden a respuestas graduadas en varios niveles de cuantificación, como es el caso de la escala tipo Likert.

Aunque, como en el caso de todos los modelos de TRI, la definición de los MCP hace referencia directa a tests de rendimiento: respuesta correcta/incorrecta; esta puede ser y ha sido fácilmente extrapolable a la medición de otro tipo de procesos cognitivos, rasgos o estados de la persona a través del continuo presencia/ausencia del constructo psicológico medido (Rojas, Gonzales, Padilla y Pérez, 2000). Entre los estudios que actualmente utilizan los MCP para la evaluación de constructos psicológicos, destacan aquellos relacionados con escalas de depresión (e.g., Escurra y Delgado, 2012; Forkmann et al., 2010; Parkitny et al., 2011), aunque también existen otros estudios relacionadas con la discapacidad que han utilizado este modelo de crédito parcial (e.g., conducta adaptativa, [Tassé et al., en prensa, Verdugo, Arias et al., en prensa]). 


\subsection{OBJETIVOS}

El presente capítulo tiene como objetivo general la validación de una escala de evaluación de necesidades de apoyo para niños y adolescentes con discapacidad intelectual (SIS-C) en el contexto español. Los análisis necesarios para comprobar las características y el funcionamiento de esta herramienta estarán basados en tres metodologías diferentes, que ofrecerán una visión completa del funcionamiento del instrumento en nuestro contexto. Por tanto, el objetivo general expuesto puede ser dividido en tres objetivos específicos.

- Objetivo 1. Conocer las propiedades psicométricas del instrumento a través del de los supuestos de la Teoría Clásica de los Tests (TCT). En este caso, podemos encontrar cuatro objetivos operativos:

1.1. Realizar un análisis descriptivo de los datos, analizando la centralidad y la variabilidad, el estudio de la forma de la variable y los outliers.

1.2. Analizar las propiedades de los ítems que componen la escala.

1.3. Conocer la fiabilidad de la escala.

1.4. Analizar la validez de la escala y sus dimensiones a través de evidencias de contenido, de constructo y de criterio.

- Objetivo 2. Estudiar la estructura interna del instrumento, a través del Análisis Factorial Confirmatorio (AFC) como evidencia de validez factorial. Dentro de este segundo objetivo pueden establecerse tres objetivos operativos:

2.1. Comprobar la adecuación de esta metodología para el análisis de los datos.

2.2. Especificar e identificar modelos previos sobre la naturaleza de la evaluación de las necesidades de apoyo, que puedan ser sometidos a hipótesis y contrastados por los datos de la escala.

2.3. Estimar los parámetros y analizar el ajuste de cada uno de los modelos propuestos, para conocer si alguno de ellos responde a la estructura empírica obtenida por los datos de la escala.

- Objetivo 3. Analizar el funcionamiento del instrumento a partir de los supuestos de la Teoría de Respuesta a los Ítems (TRI). Esta metodología permitirá cuantificar de manera precisa la variable medida (i.e., 'necesidades de apoyo') a partir de la estimación de una serie de parámetros. Concretamente, en este apartado podemos desglosar seis objetivos operativos. 
3.1. Comprobar de manera previa los supuestos necesarios para poder llevar a cabo los análisis de manera exhaustiva y poder interpretar los resultados.

3.2. Conocer la idoneidad del sistema de categorías de respuesta.

3.3. Analizar la fiabilidad, determinando si las puntuaciones de los ítems y los parámetros de los sujetos serían replicables.

3.4. Observar el ajuste de los datos al modelo.

3.5. Calibrar los ítems, analizando su localización discriminación y precisión.

3.6. Analizar la invarianza para comprobar que la escala no manifieste un funcionamiento diferencial en personas con un nivel de habilidad similar.

Los dos primeros objetivos permitirán obtener datos acerca de la fiabilidad, validez y estructura del instrumento, aportando datos fácilmente comparables con la SIS para adultos (donde los análisis realizados se centraron en el uso de la TCT y el AFC). Por su parte, el uso de la TRI ofrecerá una perspectiva más amplia del funcionamiento de la escala, usando otro tipo de análisis más complejos y específicos que darán un carácter más innovador y riguroso al trabajo realizado.

\subsection{PROCEDIMIENTO}

A partir de la versión prefinal de la escala, derivada de los ajustes realizados tras el análisis de los datos de la prueba piloto, los pasos seguidos para concluir esta investigación responden a tres fases fundamentales: (1) contacto con los centros participantes para recopilar muestra; (2) aplicación/recogida de datos de la SIS-C; y (3) análisis de resultados sobre el funcionamiento de la escala en el contexto español.

\subsubsection{Contacto con los centros y selección de la muestra}

Coincidiendo con el proceso de recogida de datos del estudio piloto presentado en el capítulo anterior, la selección de los participantes de la muestra total participante se realizó a través de un muestro no probabilístico incidental, debido a la imposibilidad de realizar un muestreo aleatorio en la práctica. Pereda (1987) define las muestras incidentales como aquellas que se emplean porque están a disposición del investigador en un momento determinado y afirma que suelen utilizarse cuando se trabaja con personas, pues estos casos exigen un consentimiento expreso de los implicados que dificulta la realización de muestreos probabilísticos. En cualquier caso, con el objetivo de obtener una muestra lo más representativa posible se tuvieron en cuenta dos criterios mínimos: 
- Por un lado, se estableció un criterio mínimo de 610 participantes. Este número da respuesta a los criterios marcados sobre el tamaño de muestra mínimo para la construcción de instrumentos, que establecen un mínimo de cinco participantes por cada ítem y reflejan un ideal de entre 10-20 participantes. Teniendo en cuenta el número de ítems de la SIS-C (61), el número mínimo de sujetos necesarios para la validación del instrumento es 305, siendo idóneo alcanzar los mil participantes.

- En segundo lugar, se atendió a los criterios mínimos establecidos por la Asociación Americana de Discapacidades Intelectuales y del Desarrollo (American Association on Intellectual and Developmental Disabilities [AAIDD]) para el desarrollo de la SIS-C en los diferentes contextos, que establecían un número mínimo de sujetos teniendo en cuenta la contingencia de dos variables: edad y nivel de discapacidad intelectual (Tabla 41).

Tabla 41. Criterios de distribución de la muestra establecidos por la AAIDD

\begin{tabular}{|c|c|c|c|c|c|}
\hline & & \multicolumn{3}{|c|}{ NIVEL DE DISCAPACIDAD INTELECTUAL } & \multirow[b]{2}{*}{ Total } \\
\hline & & Ligera & Moderada & Severa/Profunda & \\
\hline \multirow{7}{*}{ EDAD } & 5-6 años & $20-30$ & $20-30$ & $20-30$ & $60-90$ \\
\hline & 7-8 años & $20-30$ & $20-30$ & $20-30$ & $60-90$ \\
\hline & 9-10 años & $20-30$ & $20-30$ & $20-30$ & $60-90$ \\
\hline & 11-12 años & $20-30$ & $20-30$ & $20-30$ & $60-90$ \\
\hline & 13-14 años & $20-30$ & $20-30$ & $20-30$ & $60-90$ \\
\hline & $15-16$ años & $20-30$ & $20-30$ & $20-30$ & $60-90$ \\
\hline & Total & $120-180$ & $120-180$ & $120-180$ & $360-540$ \\
\hline
\end{tabular}

Para conseguir el número necesario de participantes se envío un correo a numerosas entidades de todas las Comunidades Autónomas de España (ampliando el rango establecido para el estudio piloto). Además, se puso un anuncio en la página web del INICO solicitando colaboración voluntaria, de tal manera que muchos centros y profesionales interesados en participar establecieron directamente el contacto con el equipo investigador. Tras un primer contacto, se envío a todos aquellas entidades que manifestaron interés y aceptaron la participación una carta explicativa y un consentimiento para las familias de todos los niños de entre 5 y 16 años con discapacidad intelectual. Cada familia, de manera individual y voluntaria, decidía si permitía que realizásemos la evaluación del niño y, de manera diferenciada, si se ofrecían a colaborar ellos mismos como informantes, asegurándoles la confidencialidad de los datos en cualquier caso. 
En cualquier caso, se intentó que, en la medida de lo posible, todos los niños y adolescentes evaluados contaran con dos evaluaciones diferenciadas, por lo que en los casos en los que la familia no pudo colaborar se pidió la colaboración de un segundo profesional para completar la información. Finalmente, participaron en el estudio más de 50 entidades, con una media de participación de 15 personas por entidad, oscilando entre 3 y 63 el número de sujetos participantes de cada centro.

\subsubsection{Características de los participantes evaluados}

Se evaluó a 833 participantes de 10 Comunidades Autónomas de España y los datos fueron recogidos a lo largo de cuatro años (entre 2010 y 2013). Del total de la muestra, se eliminaron los datos de aquellos sujetos que no cumplieron los requisitos de administración del instrumento: (a) tener entre 5 y 16 años en el momento de la evaluación; (b) tener un informe profesional que determinase la presencia de discapacidad intelectual; (c) haber sido evaluados en el total de 61 ítems que componen el instrumento. Así, tras eliminar 19 sujetos, la muestra final utilizada para la validación de la escala quedó compuesta por 814 participantes. Los datos sociodemográficos de estos participantes pueden observarse en la Tabla 42.

Haciendo un análisis descriptivo de la tabla, podemos observar una mayor abundancia de hombres (64.6\%) que de mujeres (35.1\%). La media de edad fue 11.15 y la desviación típica 3.44. En cuanto al nivel de discapacidad intelectual, hubo una mayor prevalencia de las personas con discapacidad moderada (35.6\%). Con relación a la etiología, existía un alto porcentaje de personas con discapacidad que presentaban discapacidad intelectual asociada a Trastornos del Espectro Autista (TEA) (30.5\%), Síndrome de Down (13.6\%) y Parálisis Cerebral (PC) (12.4\%). En cualquier caso, se aprecia que en más del 30\% de los casos no había ninguna discapacidad o limitación asociada a la discapacidad intelectual. Asimismo, predominaron los niños escolarizados en centros de educación especial (60.6\%), siendo los colegios concertados (66.8\%) aquellos en los que se tuvo un mayor acceso para recoger muestra. En general, los niños evaluados no usaban ningún tipo de ayuda asistencial en su vida diaria (80.7\%) y, mayoritariamente, vivían en el hogar con su familia (95.6\%). Por último, destacamos que el 97.8\% hablaban como primera lengua el español (96.3\%) o alguna otra lengua oficial de Estado Español (1.5\%), ya que es importante tener en cuenta cuando se valida la escala en un contexto específico que las personas conozcan la lengua y la cultura del país para evitar sesgos de evaluación que influyan en las puntuaciones obtenidas. 
Tabla 42. Características sociodemográficas de la muestra $(n=814)$

\begin{tabular}{|c|c|c|c|c|c|}
\hline VARIABLES & $\mathbf{N}$ & $\%$ & VARIABLES & $\mathbf{N}$ & $\%$ \\
\hline Género & & & Uso de Tecnologías Asistenciales & & \\
\hline Hombre & 528 & 64.6 & $\mathrm{Si}$ & 155 & 19.1 \\
\hline Mujer & 286 & 35.1 & No & 657 & 80.7 \\
\hline Perdidos & 3 & 0.4 & Perdidos & 2 & 0.2 \\
\hline Total & 814 & 100 & Total & 814 & 100 \\
\hline Edad & & & Vivienda & & \\
\hline 5-6 años & 110 & 13.5 & Hogar Familiar & 778 & 95.6 \\
\hline 7-8 años & 108 & 13.3 & Hogar de menores & 9 & 1.1 \\
\hline 9-10 años & 100 & 12.3 & Hogar de pequeño grupo $(<7)$ & 7 & 0.9 \\
\hline 11-12 años & 148 & 18.2 & Grupo mediano (7-15) & 9 & 1.1 \\
\hline 13-14 años & 195 & 24.0 & Grandes residencias $(>15)$ & 3 & 0.4 \\
\hline $15-16$ años & 153 & 18.8 & Perdidos & 11 & 1.4 \\
\hline Total & 814 & 100 & Total & 814 & 100 \\
\hline Nivel de Discapacidad Intelectual & & & Lengua Materna & & \\
\hline Ligero & 206 & 25.3 & Castellano & 784 & 96.3 \\
\hline Moderado & 290 & 35.6 & Catalán, Euskera, Gallego, LSE & 14 & 1.8 \\
\hline Severo & 195 & 24.0 & Árabe & 3 & 0.4 \\
\hline Profundo & 65 & 8.0 & Otras (Inglés, Rumano, Ucraniano) & 3 & 0.4 \\
\hline Perdidos & 58 & 7.1 & Perdidos & 9 & 1.1 \\
\hline Total & 814 & 100 & Total & 814 & 100 \\
\hline Etiología & & & Otras limitaciones asociadas a la D & & \\
\hline Sin Especificar & 317 & 38.6 & Ninguna & 281 & 34.5 \\
\hline Síndrome de Down & 111 & 13.6 & Física & 33 & 4.1 \\
\hline Tr. del Espectro Autista & 248 & 30.5 & Sensorial & 17 & 2.1 \\
\hline Parálisis Cerebral & 101 & 12.4 & Habla/Lenguaje/Comunicación & 211 & 25.9 \\
\hline Enfermedades Raras & 35 & 4.3 & Otra (TDAH, Salud Mental...) & 82 & 10.1 \\
\hline Co-ocurrencia & 5 & 0.6 & Dos o más de las anteriores & 190 & 23.3 \\
\hline Total & 814 & 100 & Total & 814 & 100 \\
\hline Escolarización & & & Comunidad Autónoma & & \\
\hline Ordinaria & 179 & 22.0 & Andalucía & 136 & 16.7 \\
\hline Especial & 493 & 60.6 & Canarias & 86 & 10.6 \\
\hline Combinada & 74 & 9.1 & Cantabria & 27 & 3.3 \\
\hline Aula Sustitutoria & 55 & 6.8 & Castilla y León & 154 & 18.9 \\
\hline Perdidos & 13 & 1.6 & Castilla La Mancha & 101 & 12.4 \\
\hline Total & 814 & 100 & Comunidad de Madrid & 145 & 17.8 \\
\hline Tipo de Colegio & & & Comunidad Valenciana & 64 & 7.9 \\
\hline Privado o concertado & 550 & 67.5 & Extremadura & 23 & 2.8 \\
\hline Público & 252 & 31.0 & Galicia & 50 & 6.1 \\
\hline Perdidos & 12 & 1.5 & Murcia & 28 & 3.4 \\
\hline Total & 814 & 100 & Total & 814 & 100 \\
\hline
\end{tabular}


A continuación, se presenta un análisis exhaustivo sobre la relación entre la representación de las variables edad y grado de discapacidad intelectual. Este criterio resulta especialmente relevante ya que se considera que la edad influye de manera directa en las necesidades de apoyo de la persona y que será necesaria la baremación diferenciada para cada uno de los seis pares de edad que recoge el instrumento. La AAIDD estableció que al menos debía haber 20 sujetos en cada unas de las tres categorías de la variable 'discapacidad intelectual' (ligera, moderada y severa/profunda) para poder baremar posteriormente de manera independiente la escala para cada uno de estos seis grupos de edad. En nuestro caso, en 755 de los 814 sujetos se contaba con la información conjunta de ambas variables $y$, aunque la distribución de la edad no es homogénea $\left(\chi_{10}^{2}=49.531\right.$, $\mathrm{p}<.001$ ), fue posible garantizar el cumplimiento del criterio establecido, obteniéndose más de 20 participantes por subgrupo. En la Tabla 43 puede apreciarse la distribución exacta de los participantes, reflejándose estos datos, a su vez, de manera visual en la Figura 15.

Tabla 43. Contingencia entre 'edad' y 'nivel de DI'

\begin{tabular}{llcccc}
\hline & \multicolumn{2}{c}{ NIVEL DE DISCAPACIDAD INTELECTUAL } & \\
\cline { 3 - 5 } & & Ligera & Moderada & Severa/Profunda & Total \\
\hline \multirow{6}{*}{ EDAD } & 5-6 años & 48 & 27 & 32 & 107 \\
& 7-8 años & 25 & 27 & 45 & 97 \\
& 9-10 años & 21 & 32 & 39 & 92 \\
& $11-12$ años & 28 & 52 & 55 & 135 \\
& $13-14$ años & 34 & 86 & 55 & 175 \\
& $15-16$ años & 49 & 66 & 34 & 149 \\
\hline
\end{tabular}

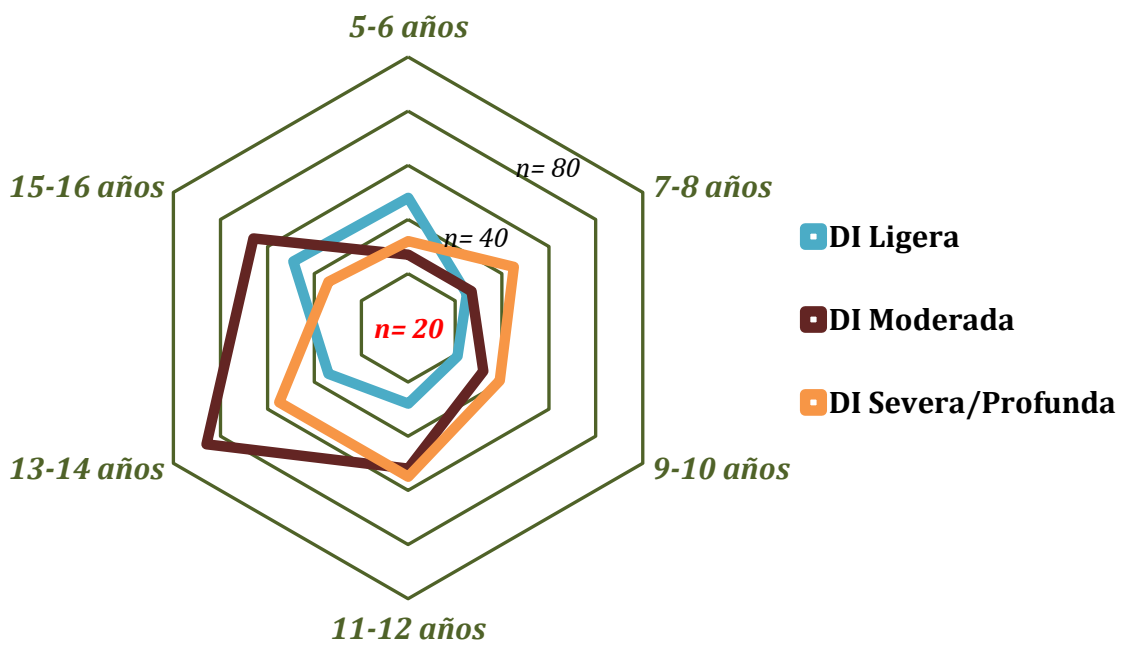

Figura 15. Representación de la contingencia entre 'edad' y 'nivel de DI' 
De manera adicional, se presentan dos gráficos (Figuras 16 y 17) obtenidos a partir de tablas de contingencia donde puede verse la representación conjunta de la variable género y las variables anteriormente presentadas (edad y nivel de discapacidad intelectual). Aunque, en general, la representación de las mujeres es menor que la de los hombres, la distribución puede considerarse homogénea en relación tanto a la variable 'edad' $\left(\chi_{5}^{2}=.528, \mathrm{p}>.01\right)$ como a la variable 'nivel de discapacidad intelectual' $\left(\chi_{2}^{2}=6.553\right.$, p>.01), comprobándose la hipótesis de equiprobabilidad de las distribuciones.

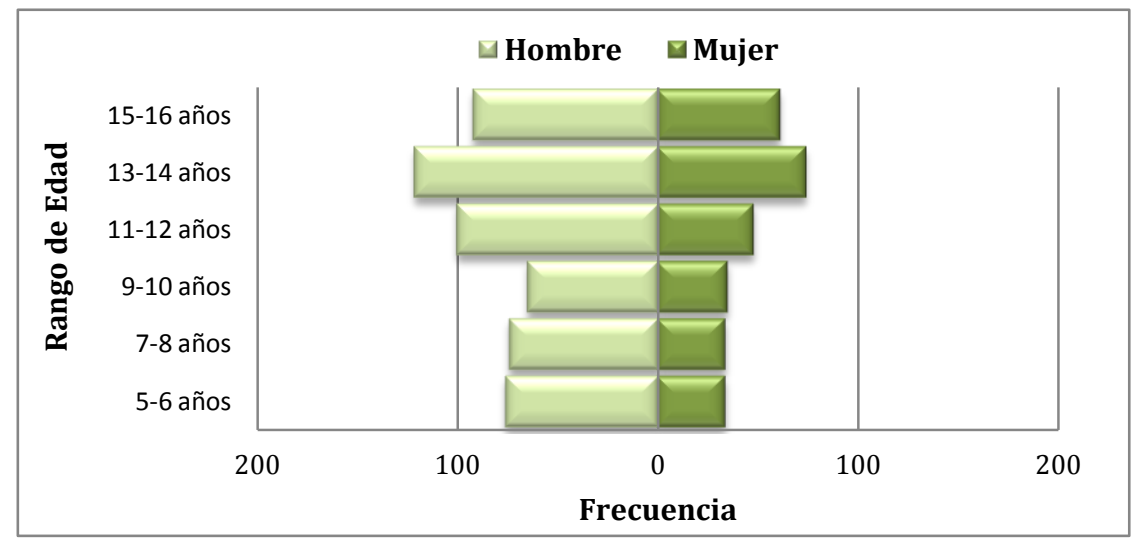

Figura 16. Representación de la contingencia entre 'edad' y 'género'

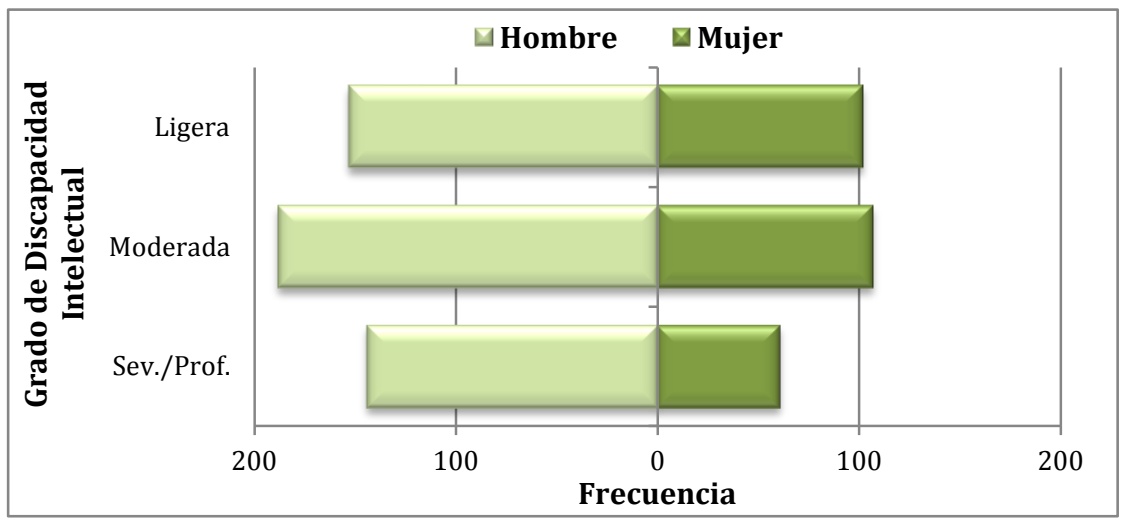

Figura 17. Representación de la contingencia entre 'género' y 'nivel de DI'

\subsubsection{Aplicación del instrumento y recogida de datos}

En la mayoría de los casos la cumplimentación del instrumento se llevó a cabo a través de una entrevista realizada por un profesional del equipo investigador $(>60 \%$ de los casos). Sin embargo, en los casos en que los profesionales cumplimentaban más de una escala o, en el caso de que conociesen la SIS para adultos, se realizaba una sesión informativa $\mathrm{y}$, posteriormente, estos cumplimentaban el instrumento de manera autónoma en los meses consiguientes con la ayuda del manual de la escala y el breve 
manual elaborado tras la aplicación del estudio piloto en el que se recogían las preguntas más frecuentes. Por el contrario, en aquellas evaluaciones en las que las familias colaboraron como informantes, debido al complejo formato de respuesta del instrumento, se optó siempre por cumplimentar la escala correspondiente en formato de entrevista.

\subsubsection{Características de informantes}

Los requisitos para que los participantes pudieran participar en el estudio fueron los siguientes: (a) conocer a la persona con discapacidad desde hacía al menos tres meses; y (b) haber tenido la oportunidad de haber observado a la persona en más de un contexto típico de su vida diaria. En general, el informador principal a partir del cual se realiza el análisis de datos (informador 1) fue un profesional. Asimismo, se solicitó la colaboración de un segundo informante, pidiéndose que, en la medida de lo posible, fuese una persona de un ámbito distinto. Finalmente, se consiguió la participación de un segundo informante en 732 de las aplicaciones, contándose en 460 de los casos con la participación de un profesional y un familiar. La distribución de los informantes quedó formada de la siguiente manera (Figura 18).

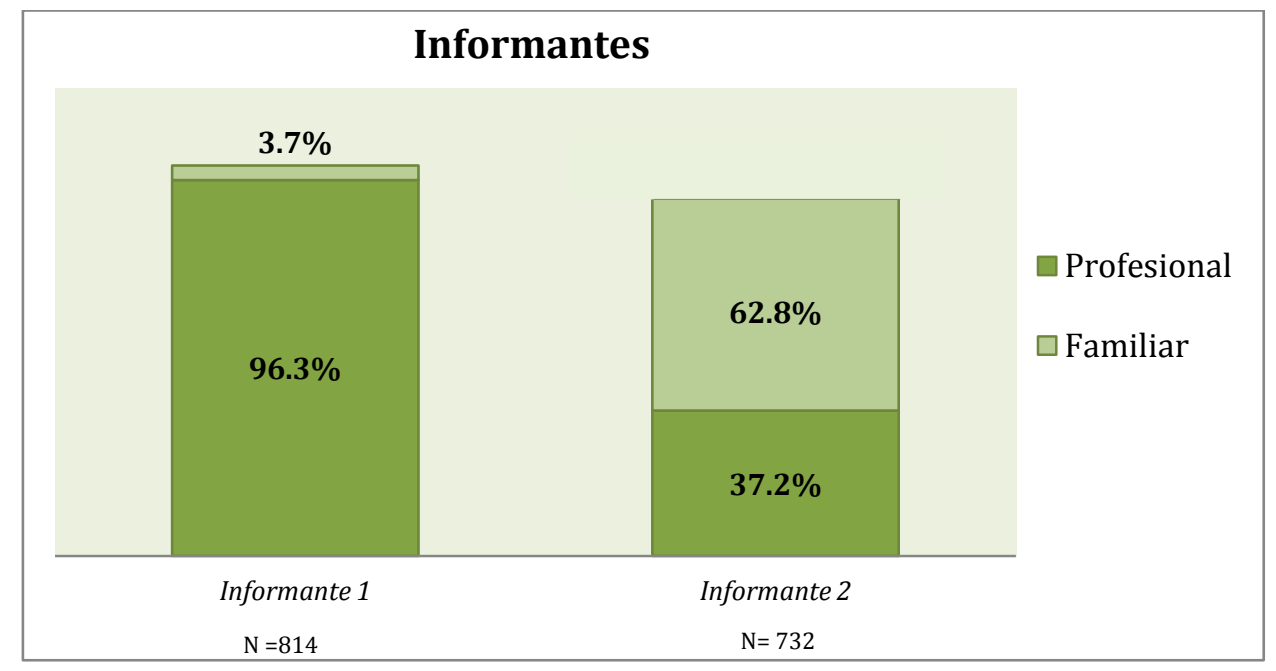

Figura 18. Características sociodemográficas de los informantes

A continuación, ofrecemos de manera más específica la relación de los informantes con cada uno de los niños evaluados (Tablas 44 y 45). Con relación al informante 1 , encontramos una fuerte predominancia del profesor de referencia como informante. Por su parte, en el caso de informante 2 , fueron las madres de las personas con discapacidad evaluada quienes realizaron la mayor parte de las evaluaciones. 
Tabla 44. Relación del niño evaluado con el informante 1

\begin{tabular}{llcc}
\hline & & Frecuencia & Porcentaje \\
\hline & Cuidador & 9 & 1.1 \\
& Profesor & 513 & 63.0 \\
& Profesor de Apoyo & 33 & 4.1 \\
& Logopeda & 44 & 5.4 \\
& Psicólogo & 60 & 7.3 \\
& Educador/Monitor & 67 & 8.3 \\
& Terapeuta & 42 & 5.2 \\
& Estimulador & 13 & 1.6 \\
& Otros & 3 & 0.4 \\
& Total Profesionales & $\mathbf{7 8 4}$ & $\mathbf{9 6 . 3}$ \\
\hline Familiar & Madre & 30 & 3.7 \\
\hline
\end{tabular}

Tabla 45. Relación del niño evaluado con el informante 2

\begin{tabular}{llrr}
\hline & & Frecuencia & Porcentaje \\
\hline \multirow{4}{*}{ Familiar } & Madre & 387 & 52.9 \\
& Padre & 67 & 9.2 \\
& Hermanos & 4 & 0.5 \\
& Abuelos & 1 & 0.1 \\
& Tíos & 1 & 0.1 \\
& Total Familiares & $\mathbf{4 6 0}$ & $\mathbf{6 5 . 7}$ \\
\hline \multirow{5}{*}{ Profesional } & 4 & 0.5 \\
& Cuidador & 75 & 12.6 \\
& Profesor & 53 & 7.7 \\
& Profesor de Apoyo & 34 & 4.8 \\
& Logopeda & 21 & 3.0 \\
& Esicólogo & 26 & 3.8 \\
& Teracador/Monitor & 13 & 1.9 \\
& Trabajador Social & 4 & 0.5 \\
& Otros & 42 & 2.4 \\
\hline & Total Profesionales & $\mathbf{2 7 2}$ & $\mathbf{3 7 . 2}$ \\
\hline
\end{tabular}

En 90 de las 732 aplicaciones mencionadas, los informantes realizaron una aplicación conjunta de la escala, consensuando las respuestas. No obstante, en 661 de los casos, las evaluaciones se realizaron a los dos informantes de manera diferenciada, por lo que pudieron ser utilizados posteriormente para conocer la fiabilidad interevaluadores. Adicionalmente, en 32 de los casos que sólo contaron con la participación a un informante, se consiguió aplicar la escala éste en dos momentos distintos, realizando una evaluación test-retest. Ofrecemos a continuación una síntesis de la interacción entre número de aplicaciones y número de informantes, así como la relación de los informantes en cada uno de los grupos establecidos (Tabla 46). 
Tabla 46. Descripción de las aplicaciones realizadas

\begin{tabular}{|c|c|c|c|c|}
\hline \multirow{2}{*}{$\begin{array}{c}\text { APLICACIONES } \\
\text { POR NIÑO }\end{array}$} & \multicolumn{2}{|c|}{ INFORMANTES } & \multirow{2}{*}{$N$} & \multirow{2}{*}{$\%$} \\
\hline & NÚMERO & RELACIÓN & & \\
\hline \multirow{8}{*}{ Una } & \multirow{3}{*}{ Uno } & Profesional & 44 & 5.4 \\
\hline & & Familiar & 06 & 0.6 \\
\hline & & Total & 50 & 6.1 \\
\hline & \multirow{4}{*}{ Dos } & Profesional-Familiar & 09 & 1.6 \\
\hline & & Profesional-Profesional & 54 & 6.2 \\
\hline & & Familiar-Familiar & 10 & 1.5 \\
\hline & & Total & 71 & 8.8 \\
\hline & Total & & 121 & 14.9 \\
\hline \multirow{7}{*}{$\begin{array}{c}\text { Dos } \\
\text { (Fiabilidad) }\end{array}$} & \multirow{2}{*}{ Uno (Test-Retest) } & Profesional & 32 & 3.9 \\
\hline & & Total & 32 & 3.9 \\
\hline & \multirow{4}{*}{ Dos (F. Interevaluadores) } & Profesional-Familiar & 431 & 52.9 \\
\hline & & Profesional-Profesional & 216 & 26.5 \\
\hline & & Familiar-Familiar & 14 & 1.7 \\
\hline & & Total & 661 & 81.2 \\
\hline & Total & & 693 & 85.1 \\
\hline TOTAL & & & 814 & 100 \\
\hline
\end{tabular}

\subsection{Análisis de datos}

Para cumplir con la finalidad general de este proyecto, orientada a la adaptación y validación de la SIS-C dentro del contexto español, se han realizado numerosos análisis para comprobar numerosos aspectos de la calidad y eficacia de su funcionamiento, atendiendo de manera independiente a cada uno de los objetivos y metodologías específicas planteadas en la parte inicial del capítulo.

Para empezar, se han analizado las propiedades psicométricas de la escala a través de la TCT, utilizando para ello el uso del paquete estadístico IBM SPSS Statistics [versión 20] como recurso principal de análisis. Asimismo, se ha empleado el programa Factor [versión 9.2] de Lorenzo-Seva y Ferrando (2006) para realizar aquellos análisis que precisaban conocer las correlaciones policóricas, más adecuadas que las correlaciones de Pearson cuando se trabaja con variables no continuas. En cuanto al AFC, realizado de manera complementaria para conocer la estructura factorial del instrumento, se ha empleado el programa LISREL [versión 8.8] (Jöreskog y Sorbom, 2006). Asimismo, los análisis relacionados con la TRI, realizados bajo los supuestos del MCP (Masters, 1982), han sido ejecutados con el software estadístico Winsteps [versión 3.68] (Linacre, 2008).

En las Tablas 47 y 48 se puede observar de manera específica el tipo y naturaleza de los análisis realizados dentro de estas líneas de trabajo. Los resultados obtenidos se describirán y analizarán a lo largo del siguiente apartado (4.4). 
Tabla 47. Análisis de datos en relación con la TCT (objetivo 1)

\begin{tabular}{|c|c|c|c|}
\hline & Objetivos Operativos & & Análisis realizado \\
\hline \multirow{21}{*}{$\begin{array}{l}\mathbf{T} \\
\mathbf{C} \\
\mathbf{T}\end{array}$} & \multirow{5}{*}{ 1.1. Análisis descriptivo del instrumento } & \multirow{2}{*}{ Centralidad y variabilidad } & Centralidad: media, mediana \\
\hline & & & Variabilidad: desviación típica, amplitud intercuartil \\
\hline & & \multirow{2}{*}{ Estudio de la forma de la variable } & Índices: asimetría y curtosis \\
\hline & & & Prueba de bondad de ajuste \\
\hline & & Outliers & Diagrama de caja y bigotes \\
\hline & \multirow{7}{*}{ 1.2. Análisis de los ítems } & Índice de dificultad & Media \\
\hline & & \multirow{2}{*}{ Poder Discriminativo } & Desviación Típica (DT) \\
\hline & & & Prueba Kruskal-Wallis \\
\hline & & Índice de discriminación Interna (IDi) & Índice de homogeneidad corregido $\left(\mathrm{r}_{\mathrm{ix}-\mathrm{i}}\right)$ \\
\hline & & Índice de discriminación externa (IDe) & Correlación entre ítems y una estimación inicial de necesidades \\
\hline & & Índice de fiabilidad & IDi*DT \\
\hline & & Índice de validez & IDe*DT \\
\hline & \multirow{6}{*}{$\begin{array}{l}\text { 1.3. Fiabilidad de las dimensiones y de la } \\
\text { escala }\end{array}$} & & Alfa de Cronbach \\
\hline & & Consistencia Interna & Alfa Estratificado \\
\hline & & & Alfa y Theta Ordinales \\
\hline & & Error típico de medida & Desviación Típica de los errores de medida existentes \\
\hline & & Fiabilidad interveluadores & Correlaciones de Pearson \\
\hline & & Test-retest & Correlaciones de Spearson \\
\hline & \multirow{3}{*}{$\begin{array}{l}\text { 1.4. Validez de las dimensiones y } \\
\text { la escala }\end{array}$} & Contenido & Revisión bibliográfica \\
\hline & & Criterio & Criterio externo \\
\hline & & Constructo & $\begin{array}{l}\text { Contraste de hipótesis mediante pruebas no paramétricas } \\
\text { (U de Mann Whitney y Kruskal-Wallis) }\end{array}$ \\
\hline
\end{tabular}


Tabla 48. Análisis complementarios a través del AFC (objetivo 2) y la TRI (objetivo 3)

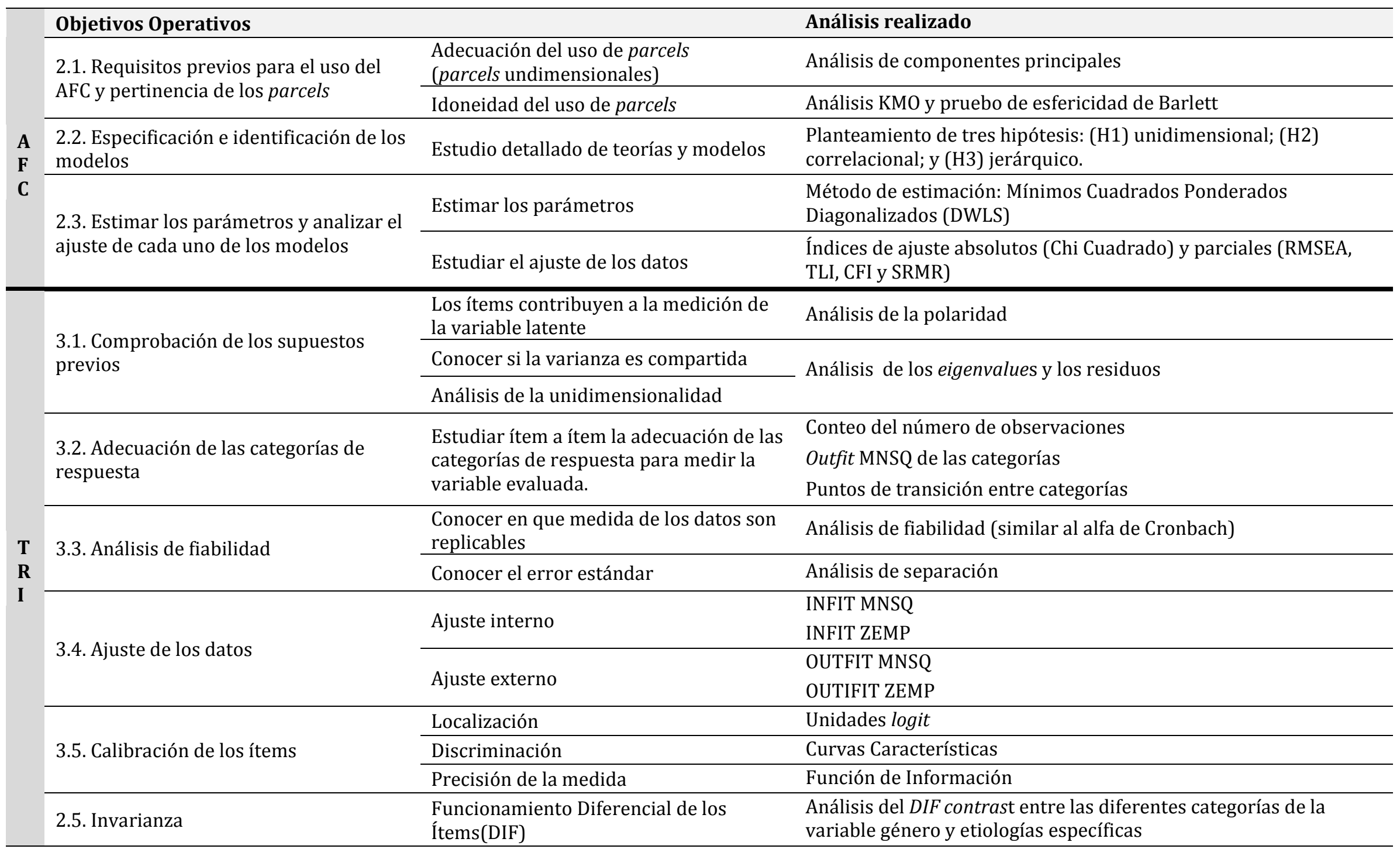




\subsection{RESULTADOS}

\subsubsection{Objetivo 1: análisis de resultados mediante la TCT}

\subsubsection{Análisis descriptivo de los datos}

A la hora de trabajar y explorar las propiedades de un instrumento de medida es importante analizar las características de los datos obtenidos en la aplicación, ya que los estadísticos descriptivos permiten organizar y resumir un conjunto amplio de datos en unos pocos datos o gráficos específicos (Carlucci y Wright, 2012). Por ello, en primer lugar, estudiaremos la centralidad y la variabilidad de los datos obtenidos en las aplicaciones de la SIS-C, incluyendo también el análisis de la forma de la variable y de la existencia de outliers.

Para el estudio de la centralidad del instrumento se tienen en cuenta la media y la mediana. En nuestros datos, la media obtenida en las puntuaciones del instrumento fue 463.18 y la mediana 491. Teniendo en cuenta que nos encontramos ante una escala donde el posible rango de puntuación oscila entre 0-732 (los datos reales oscilaron ente 27-732), estos datos nos muestran, de manera descriptiva, que las puntuaciones obtenidas en la SIS-C por niños y adolescentes españoles con discapacidad intelectual tienden a ser altas. En cuanto a la variabilidad, la desviación típica y la amplitud intercuartil son los estadísticos a interpretar. Los datos de la escala muestran una desviación típica de 174.1 y una amplitud intercuartil de 275.5, lo que demuestra que los datos no tienen a aglutinarse alrededor de la media, sino que existe una indudable dispersión de los mismos a lo largo del continuo.

Por otro lado, el estudio de la forma de la variable supone un elemento clave en el análisis descriptivo de los datos, ya que de sus resultados derivará la posterior toma de decisiones respecto al consiguiente uso de pruebas paramétricas (si se cumple el supuesto de normalidad) o no paramétricas (si se viola el supuesto de normalidad). Para ello, es necesario conocer los índices de asimetría y curtosis y comprobar su adecuación a través de las pruebas pertinentes de bondad de ajuste. A modo ilustrativo, estos resultados pueden apreciarse a partir de la creación de un histograma (Figura 19). En nuestro caso, tanto el índice de asimetría (-.40) como el de curtosis (-.79) fueron negativos. De manera coherente a lo mostrado previamente por los índices de centralidad y variabilidad, la asimetría negativa refleja una tendencia a los valores altos y la forma platicúrtica representa un reducido grado de concentración alrededor de los valores centrales. 
A pesar de que los índices descriptivos ya parecían mostrar una falta de normalidad, se realizó la prueba de bondad de ajuste de Kolmogorov-Smirnoff para contar con una prueba definitiva sobre la normalidad de los datos, obteniéndose evidencias estadísticas de la violación del supuesto de normalidad ( $\mathrm{p}<.001)$.

Por último, se realizó un estudio de los outliers, es decir, de aquellos datos que se alejan excepcionalmente del centro. Es importante conocer la existencia de datos outliers y comprobar si su presencia se debe a errores en los datos o a otros posibles problemas de codificación que deban ser corregidos antes de continuar con el análisis del instrumento ya suelen influir en los valores de centralidad. En el caso de nuestra muestra, podemos observar que no existe ningún outlier en la puntuación total del instrumento (Figura 20).

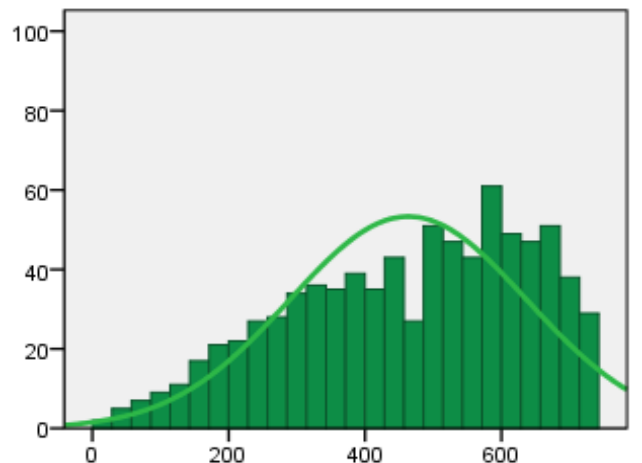

Figura 19. Histograma y curva normal de la SIS-C

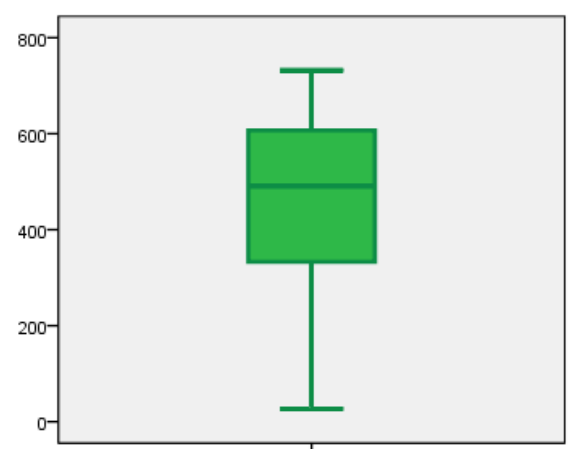

Figura 20. Distribución de puntuaciones de la SIS-C

Una vez analizado descriptivamente el instrumento, es importante realizar también un análisis descriptivo de las dimensiones y de cada uno de los ítems para tomar una decisión lo más ajustada posible a la distribución de los datos. Presentamos a continuación los índices y gráficos de todas las subescalas (Tabla 49). Destacamos que todas las pruebas de bondad de ajuste marcaron una fuerte falta de normalidad en los datos $(\mathrm{p}<.001)$ y que, en general, los resultados en las dimensiones e ítems fueron similares a los obtenidos teniendo en cuenta el instrumento en su totalidad, lo que determina el uso posterior de pruebas no paramétricas. No obstante, es importante señalar algunas diferencias encontradas en la subescala 'Aprendizaje Escolar' (y, consecuentemente, en varios de sus ítems), donde se obtuvieron distribuciones leptocúrticas y aparecieron algunos outliers (los cuales, tras comprobarse que no se debían a ningún problema de codificación, sino a la diversidad de los participantes, decidieron mantenerse). 
Tabla 49. Análisis descriptivo de las dimensiones de la escala (índices y gráficos)

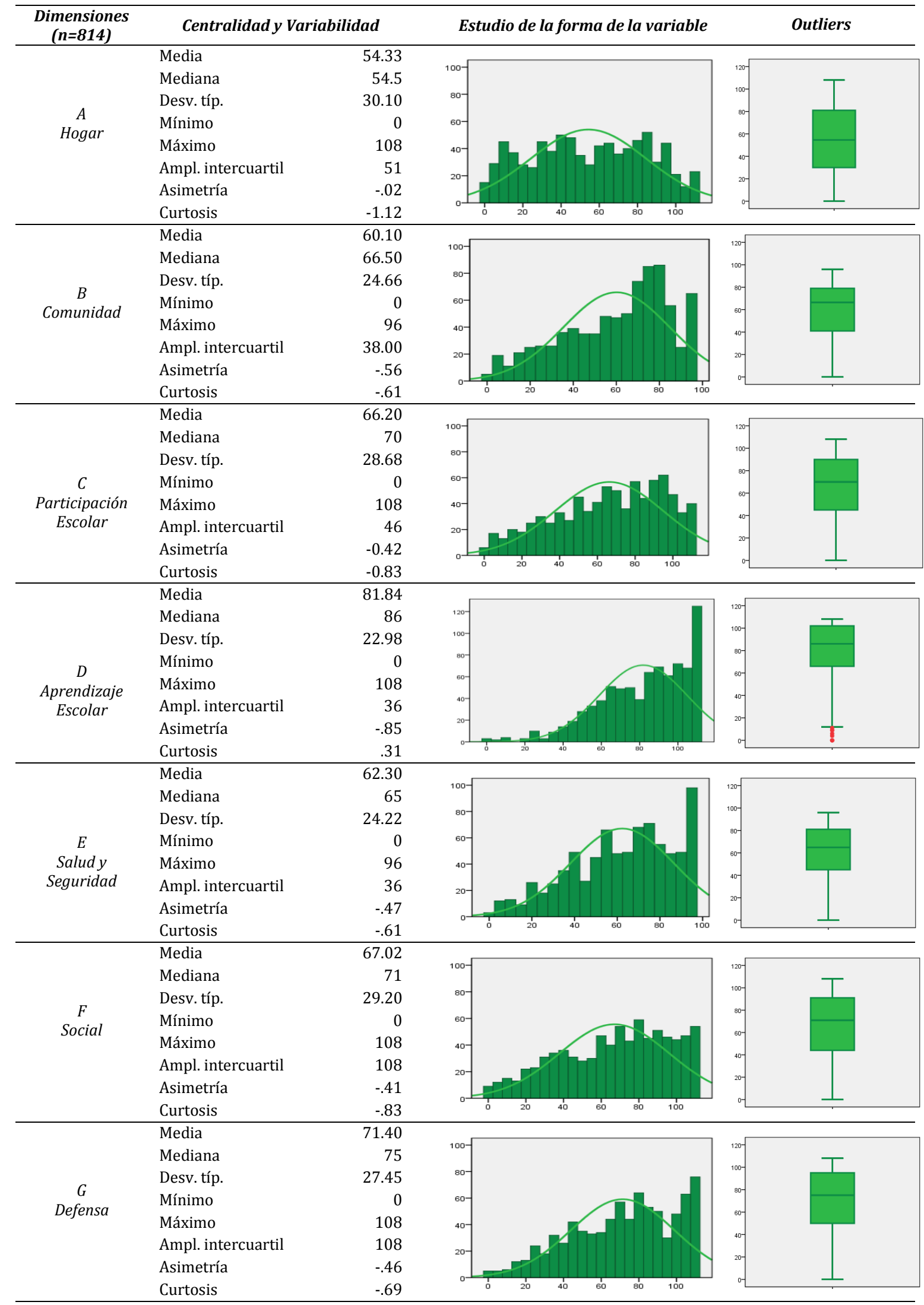




\subsubsection{Análisis de la calidad de los ítems}

Teniendo como referencia los pasos establecidos para la construcción de un test propuestos por García (1993), el análisis de los ítems debe realizarse previamente al estudio completo de la fiabilidad y validez del instrumento, ya que la puntuación total de un instrumento depende, en último término, de la calidad de los ítems que lo forman.

Concretamente, en el estudio de la calidad de los ítems de la SIS-C se realizaron tres tipos de análisis diferenciados que corresponden con los recomendados por Crocker y Algina (2008): (a) índices de dificultad y poder discriminante (o discriminativo) del ítem, los cuales describen la distribución de las respuestas al ítem; (b) índices de discriminación del ítem, que describen el grado de relación entre la respuesta al ítem y algún criterio de interés (interno o externo al propio test); y (c) índices de fiabilidad y validez del ítem, que se calcula atendiendo, respectivamente, a la varianza del ítem y su índice de discriminación interna y externa,.

Los resultados obtenidos pueden observarse en la Tabla 50; no obstante, previamente a la presentación de la misma se describe de manera detallada algunas características a tener en cuenta de los análisis realizados.

En relación con el Índice de Dificultad (ID) y el Poder Discriminativo (PD) de los ítems, tradicionalmente se ha trabajado con la media y la desviación típica (DT) de cada uno de ellos. En general, suele considerarse la media como referente del índice de dificultad (mejor entendido como índice de intensidad de constructo en este caso, ya que no existen respuestas correctas o incorrectas) y el poder discriminativo puede entenderse como la desviación típica. No obstante, y debido a que la naturaleza de los datos no refleja una distribución normal, conviene tener en cuenta otros referentes complementarios. Con relación al índice de dificultad, la mediana es un estadístico de centralidad más preciso en el caso de distribuciones no paramétricas; por su parte, el poder discriminativo de los ítems pueden ser más apropiadamente interpretado a partir de la prueba no paramétrica de Kruskal-Wallis. Para realizar este análisis, se dividió a los participantes en tres grupos (delimitados por los cuartiles 1 y 3 de la puntuación total en necesidades de apoyo) y se contrastó las diferencias entre los rangos promedio de cada ítem en función de que cada participante hubiese sido clasificado en uno de los tres grupos. Para su interpretación, valores significativas $(\mathrm{p}<.01)$ en el Chi Cuadrado representarán un buen poder discriminativo. 
Los Índices de Discriminación proporcionan información sobre el valor que está aportando dicho ítem a la medición total realizada con la escala. En este caso, se realizaron análisis para determinar tanto los índices de discriminación interna (IDi) como los índices de discriminación externa (IDe). En relación con el IDi, se tuvieron dos criterios de referencia: en primer lugar, la puntuación obtenida en la subescala a la que pertenecía cada ítem y, en segundo lugar, a la puntuación total obtenida en la escala. En ambos casos se tuvo como referencia las correlaciones producto-momento de Pearson $\left(\mathrm{r}_{\mathrm{i}, \mathrm{t}}\right)$, pero utilizando de manera específica el llamado índice de homogeneidad corregido (IHc), caracterizado por eliminar el ítem analizado de la puntuación total, de la que forma parte y con la que se compara $\left(\mathrm{r}_{\mathrm{i}, \mathrm{t}-\mathrm{i}}\right)$, lo que aporta un resultado más preciso ya que evita el aumento artificial del índice causado por la presencia del ítem en las dos variables correlacionadas (Peters y Van Vorhis, 1940). En cuanto al IDe, el procedimiento es similar al llevado a cabo para el IDi, pero la referencia con la que se correlaciona el ítem no es intrínseca al propio test, sino un criterio externo. En este caso, como se explicó en el apartado de instrumento del capítulo 3 (3.3.1), se pidió a los informantes una estimación inicial (de 1 a 5) sobre las necesidades de apoyo de la persona evaluada (para cada subescala y para el índice general), utilizando el criterio de necesidades de apoyo de los profesionales para correlacionarlo con las puntuaciones dadas. Finalmente, hay que tener en cuenta que para interpretar estos índices suele tomarse como valor de referencia .20, debiendo eliminarse todos los ítems que presentan coeficientes inferiores por ser indiferenciadores. En nuestro caso, todos los coeficientes fueron superiores a 40 .

Por último, para hallar los Índices de Fiabilidad (IF) y Validez (IV) es necesario tener en cuenta la desviación típica así como los índices de IDi e IDe. Concretamente, el IF de cada ítem será el resultado directo de la multiplicación de su DT y su IDi, mientras que el IV ser obtendrá de la multiplicación de la DT y la IDe. De nuevo, se contarán con dos criterios diferenciados para cada uno de ellos dependiendo de si la referencia tomada es el índice de discriminación relacionado con el instrumento en general o la dimensión específica a la que pertenece. Su interpretación debe hacerse en relación a la varianza máxima posible del ítem $\left(S_{\text {imax }}\right)$, que depende a su vez del número de opciones de respuesta. Para facilitar esta interpretación se presentan los índices relativos, resultado de dividir el IF y el IV entre el $S_{\text {imax }}$, lo que ofrece índices que oscilan entre 0-1 y que pueden ser interpretados con el mismo criterio que el ID, es decir, considerando aceptables todos aquellos coeficientes que se encuentren por encima de .20. De nuevo, todos los ítems cumplieron este criterio. 
Tabla 50. Índices de la calidad psicométrica de los ítems

\begin{tabular}{|c|c|c|c|c|c|c|c|c|c|c|}
\hline \multirow[t]{2}{*}{ ÍTEM } & \multicolumn{2}{|c|}{$\begin{array}{c}\text { PD (Contraste } \\
\text { Kruskal- } \\
\text { Wallis) }\end{array}$} & \multicolumn{2}{|c|}{ IDi (IHc) } & \multicolumn{2}{|c|}{ IDe } & \multicolumn{2}{|c|}{$\begin{array}{c}\text { IFr } \\
\text { (Si.IHc/Simax) }\end{array}$} & \multicolumn{2}{|c|}{$\begin{array}{c}\text { IVr } \\
\text { (Si.IDe/Simax) }\end{array}$} \\
\hline & $\chi^{2}$ & p & Dimensión & Escala & Dimensión & Escala & Dimensión & Escala & Dimensión & Escala \\
\hline A2 & 380.1 & .000 & .86 & .74 & .69 & .67 & .62 & .53 & .50 & .49 \\
\hline A3 & 452.4 & .000 & .88 & .81 & .73 & .73 & .57 & .52 & .47 & .47 \\
\hline A4 & 413.1 & .000 & .88 & .77 & .72 & .70 & .58 & .51 & .48 & .46 \\
\hline A7 & 471.0 & .000 & .84 & .80 & .69 & .70 & .62 & .59 & .51 & .52 \\
\hline A8 & 455.9 & .000 & .79 & .77 & .64 & .68 & .60 & .58 & .49 & .52 \\
\hline A9 & 433.8 & .000 & .80 & .78 & .67 & .68 & .57 & .55 & .47 & .48 \\
\hline B1 & 465.1 & .000 & .87 & .83 & .74 & .75 & .57 & .54 & .48 & .49 \\
\hline B2 & 496.4 & .000 & .86 & .83 & .71 & .75 & .55 & .53 & .45 & .48 \\
\hline B7 & 506.4 & .000 & .82 & .85 & .61 & .70 & .54 & .56 & .40 & .46 \\
\hline B8 & 497.2 & .000 & .90 & .86 & .67 & .72 & .57 & .55 & .43 & .46 \\
\hline C1 & 408.8 & .000 & .76 & .77 & .58 & .65 & .47 & .47 & .36 & .40 \\
\hline $\mathrm{C} 2$ & 492.7 & .000 & .88 & .85 & .69 & .74 & .59 & .57 & .46 & .50 \\
\hline C3 & 505.6 & .000 & .86 & .86 & .68 & .73 & .54 & .54 & .43 & .46 \\
\hline $\mathrm{C4}$ & 421.6 & .000 & .76 & .78 & .59 & .68 & .49 & .51 & .38 & .44 \\
\hline C5 & 509.0 & .000 & .88 & .85 & .69 & .74 & .63 & .61 & .49 & .54 \\
\hline C6 & 392.9 & .000 & .71 & .76 & .52 & .61 & .40 & .42 & .29 & .34 \\
\hline C7 & 466.1 & .000 & .82 & .80 & .59 & .66 & .57 & .56 & .41 & .46 \\
\hline C8 & 515.6 & .000 & .86 & .84 & .63 & .71 & .64 & .62 & .46 & .52 \\
\hline C9 & 541.1 & .000 & .90 & .88 & .67 & .76 & .67 & .65 & .49 & .56 \\
\hline D9 & 454.3 & .000 & .83 & .80 & .62 & .65 & .45 & .44 & .34 & .35 \\
\hline E1 & 500.4 & .000 & .80 & .84 & .66 & .72 & .57 & .60 & .47 & .52 \\
\hline E2 & 464.4 & .000 & .81 & .79 & .64 & .68 & .54 & .52 & .43 & .45 \\
\hline E3 & 475.0 & .000 & .81 & .81 & .62 & .67 & .50 & .49 & .38 & .41 \\
\hline E4 & 516.8 & .000 & .88 & .87 & .68 & .73 & .57 & .56 & .44 & .47 \\
\hline E5 & 450.1 & .000 & .85 & .80 & .61 & .66 & .49 & .47 & .36 & .39 \\
\hline E6 & 455.0 & .000 & .83 & .79 & .61 & .67 & .47 & .45 & .34 & .37 \\
\hline E7 & 441.3 & .000 & .83 & .78 & .59 & .66 & .50 & .47 & .36 & .39 \\
\hline E8 & 517.1 & .000 & .86 & .86 & .70 & .72 & .57 & .57 & .46 & .48 \\
\hline F1 & 495.6 & .000 & .88 & .85 & .72 & .73 & .59 & .57 & .48 & .49 \\
\hline F2 & 423.4 & .000 & .81 & .77 & .57 & .62 & .59 & .56 & .41 & .45 \\
\hline F3 & 523.7 & .000 & .85 & .85 & .65 & .71 & .59 & .58 & .45 & .49 \\
\hline F4 & 507.0 & .000 & .85 & .84 & .61 & .68 & .50 & .50 & .36 & .40 \\
\hline F5 & 446.4 & .000 & .79 & .78 & .59 & .65 & .53 & .52 & .40 & .44 \\
\hline F6 & 511.9 & .000 & .88 & .84 & .72 & .74 & .60 & .57 & .49 & .50 \\
\hline F7 & 541.6 & .000 & .89 & .86 & .71 & .75 & .59 & .58 & .47 & .50 \\
\hline F8 & 379.4 & .000 & .79 & .74 & .55 & .62 & .60 & .56 & .41 & .46 \\
\hline F9 & 437.6 & .000 & .76 & .80 & .58 & .68 & .49 & .52 & .38 & .44 \\
\hline G1 & 482.2 & .000 & .79 & .83 & .58 & .74 & .57 & .60 & .42 & .53 \\
\hline G2 & 454.8 & .000 & .87 & .81 & .57 & .65 & .51 & .48 & .34 & .38 \\
\hline G3 & 488.6 & .000 & .88 & .83 & .57 & .67 & .49 & .46 & .32 & .37 \\
\hline G4 & 500.0 & .000 & .87 & .83 & .62 & .73 & .53 & .50 & .38 & .44 \\
\hline
\end{tabular}




\subsubsection{Análisis de fiabilidad de las dimensiones y de la escala}

Para estudiar la fiabilidad del instrumento y de los siete dominios de evaluación que lo componen se han utilizado distintos métodos de análisis que tradicionalmente han sido utilizados como evidencias de fiabilidad. Por un lado, a partir de los resultados de los 814 sujetos con discapacidad intelectual evaluados se han analizado la consistencia interna y el error típico de medida. Asimismo, a través de la doble aplicación del instrumento en situaciones concretas a dos grupos de submuestras específicas, se han podido analizar otras dos evidencias de fiabilidad: la fiabilidad interevaluadores y la fiabilidad test-retest.

En cuanto al índice de Consistencia Interna, ésta puede ser entendida directamente como la correlación existente entre los ítems que componen un instrumento (DeVellis, 2003). Atendiendo a esta definición, se realizó un análisis de las correlaciones entre todos los ítems de la escala y se obtuvieron correlaciones significativas al nivel .01, oscilando estas correlaciones en todos los casos entre .37 y .85. Haciendo un análisis más profundo de los datos, podemos apreciar que los índices de correlación más bajos se obtuvieron entre los ítems del área de hogar y los pertenecientes a la subescala 'Aprendizaje Escolar', quedando establecidos los índices más elevados entre los ítems pertenecientes a las mismas subescalas.

No obstante, a pesar de que los resultados obtenidos a través de este procedimiento fueron adecuados, se utilizó también el alfa de Cronbach como evidencia de consistencia interna. El alfa de Cronbach refleja un estudio más preciso de la consistencia de un instrumento porque trabaja con el grado de covarianzas entre los ítems (Muñiz, 2003) y, además, es capaz de aportar una puntuación general, por lo que se ha convertido en el coeficiente más extendido en el análisis de la consistencia interna. Otra de las ventajas del uso del alfa de Cronbach es la facilidad de su interpretación ya que, al igual que se interpreta cualquier correlación, se toma de referencia la magnitud obtenida, de manera que, cuanto más elevado y cercano a la unidad sea el valor del coeficiente alfa de Cronbach, mayor garantía existe de que el instrumento sea consistente. Según Nunnally y Bernstein, (1994) un coeficiente de fiabilidad se considera adecuado cuando se trata de un instrumento de investigación si es superior a .700 y debe ser superior a .900 cuando las puntuaciones piensan utilizarse en el ámbito profesional. Como se puede apreciar en la Tabla 51, tanto las distintas áreas evaluadas como la escala obtuvieron adecuados coeficientes de valores superiores a .950, lo que revela una alta precisión de la medida del instrumento. 
Tabla 51. Consistencia interna de las dimensiones y de la escala (alfa de Cronbach)

\begin{tabular}{lcc}
\hline Áreas evaluadas & Alfa de Cronbach & № de ítems \\
\hline A. Hogar & .961 & 9 \\
B. Comunidad & .966 & 8 \\
C. Participación Escolar & .958 & 9 \\
D. Aprendizaje Escolar & .964 & 9 \\
E. Saludy Seguridad & .955 & 8 \\
F. Social & .959 & 9 \\
G. Defensa & .967 & 9 \\
TOTAL &. $\mathbf{9 9 1}$ & $\mathbf{6 1}$ \\
\hline
\end{tabular}

Sin embargo, la consistencia interna total de una escala multidimensional suele ser subestimada por el alfa de Cronbach. Una forma de mejorar este coeficiente es estratificarlo en subescalas dependiendo del contenido para hallar un mejor valor estimado de la consistencia interna. Este coeficiente es especialmente relevante cuando la puntuación total obtenida en la escala viene derivada de la suma de las puntuaciones directas derivadas de cada una de las subescalas, como es el caso de la SIS-C. Teniendo esto en cuenta, se analizó el alfa estratificado del instrumento, llegando a obtenerse un coeficiente de .993, ligeramente superior al alfa de Cronbach convencional. Asimismo, y debido a la naturaleza ordinal de las categorías de respuesta, se analizaron también otros índices más precisos para este tipo de datos basados en los eigenvalues de los componentes principales y en las relaciones policóricas de los datos, obteniéndose un Alfa Ordinal de 993 y un Theta de Armor de.994, encontrándose aquí el índice de consistencia interna más elevado.

Por su parte, la fiabilidad entendida como ausencia de error se puede analizar a través del Error Típico de Medida (ETM), el cual no es más que la desviación típica de los errores de medida existentes en un test (Muñiz, 2003). En este caso, se presenta los ETM de las subescalas y del instrumento, que han ser interpretados en relación a su DT y ser significativamente inferiores a esta para poder hablar de una buena fiabilidad. En la Tabla 52 y en la Figura 21, se puede observar que los ETM y la varianza de error asociada a las dimensiones de la escala no alcanzan una magnitud demasiado elevada en comparación con la desviación típica y la varianza empírica de las puntuaciones en las diferentes dimensiones de la escala analizada.

Se presenta también en la tabla el ETM relativo, resultado de dividir el ETM entre la desviación típica, que aporta un índice que oscila de 0 a 1, más sencillo de interpretar. 
En este sentido, destacamos que, si bien en el alfa de Cronbach se buscaban puntuaciones cercanas a 1, en este caso las puntuaciones más cercanas a cero son las que nos van a indicar una mejor fiabilidad, ya que buscamos la 'ausencia de error'. En nuestros datos, todos los errores típicos relativos fueron inferiores a .20, siendo especialmente reseñable el bajo ETM de la escala en su conjunto, inferior a .10.

Tabla 52. Errores típicos de medida de las dimensiones y de la escala

\begin{tabular}{lccccc}
\hline Áreas evaluadas & DT & $\begin{array}{c}\text { Varianza } \\
\text { Empírica }\end{array}$ & ETM & $\begin{array}{c}\text { Varianza } \\
\text { del Error }\end{array}$ & $\begin{array}{c}\text { ETM/DT } \\
\text { (Relativo) }\end{array}$ \\
\hline A. Hogar & 30.10 & 906.01 & 5.94 & 35.28 & .20 \\
B. Comunidad & 24.66 & 608.11 & 4.55 & 20.70 & .18 \\
C. Participación Escolar & 28.68 & 822.54 & 5.88 & 34.57 & .20 \\
D. Aprendizaje Escolar & 22.98 & 528.08 & 4.36 & 19.01 & .19 \\
E. Saludy Seguridad & 24.22 & 586.61 & 5.14 & 26.42 & .20 \\
F. Social & 29,20 & 852.64 & 5.91 & 34.92 & .20 \\
G. Defensa & 27.45 & 753.50 & 4.99 & 24.90 & .18 \\
TOTAL & $\mathbf{1 7 4 . 0 4}$ & 30289.92 & $\mathbf{1 6 . 4 8}$ & 271.59 & $\mathbf{. 0 9}$ \\
\hline
\end{tabular}

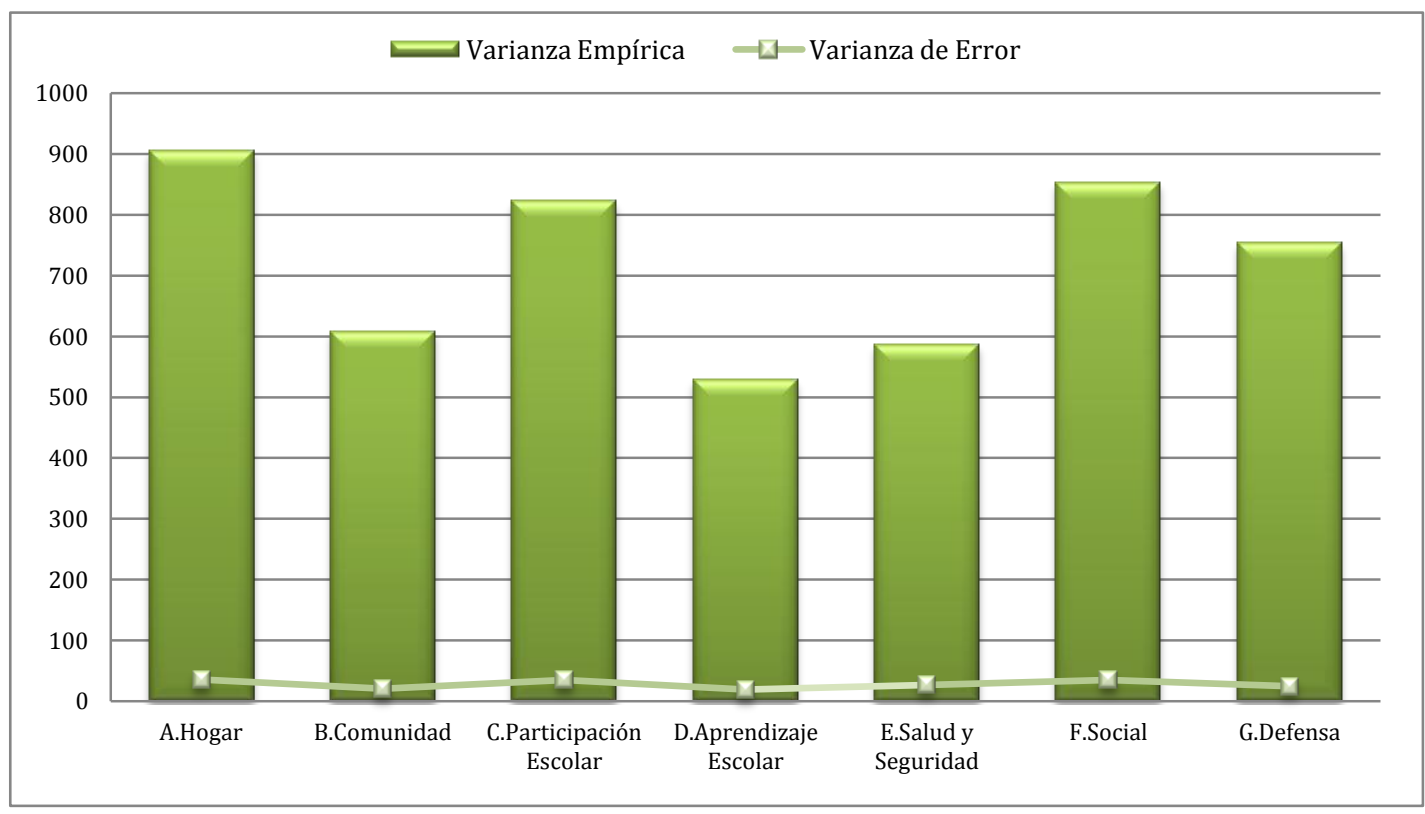

Figura 21. Distancias entre la varianza del error y varianza empírica de las áreas evaluadas

Adicionalmente, fue posible aportar otra evidencia de fiabilidad, la Fiabilidad Interevaluadores, ya que en el $81.2 \%$ de las 814 aplicaciones realizadas los sujetos fueron evaluados por dos informantes de manera independiente, obteniéndose así dos puntuaciones distintas susceptibles de ser correlacionadas 
Si la escala es fiable, se espera que los ítems funcionen de una manera objetiva y las puntuaciones sobre necesidades de apoyo otorgadas para cada una de las actividades no diverjan según quien sea informante, manteniéndose estables independientemente de la persona que realice la aplicación. En nuestro caso, el 52.9\% de las aplicaciones realizadas a dos informantes la escala fueron realizadas por un profesional y a un familiar, quedando el resto realizadas por dos miembros del mismo ámbito (26.5\% realizado por dos profesionales y el $1.7 \%$ por dos familiares).

La correlación existente entre las puntuaciones totales obtenidas en los casos en los que dos informantes evaluaron al mismo sujeto $(n=661)$ fue de .953 , oscilando las correlaciones de las diferentes áreas que componen el instrumento entre .907 y .954 (Tabla 53). Esta correlación puede ser considerada idónea teniendo en cuenta la correlación de Cichetti (1994), quien estableció el valor .400 como límite inferior para considerar una correlación aceptable y determinó que correlaciones superiores a .750 podían ser categorizadas como excelentes. Asimismo, se analizaron las correlaciones entre las puntuaciones de los dos informantes teniendo en cuenta únicamente las evaluaciones dobles realizadas por personas de distinto ámbito (profesional-familiar; $n=416$ ). Como se puede observar en la tabla, aunque el nivel de las correlaciones disminuye, es destacable que las correlaciones siguen estando en el rango de excelentes (>.750).

Tabla 53. Fiabilidad intereveluadores de las dimensiones y de la escala

\begin{tabular}{lcc}
\hline Áreas evaluadas & $\begin{array}{c}\text { Fiabilidad Interevaluadores } \\
\text { (todos) }\end{array}$ & $\begin{array}{c}\text { Fiabilidad } \\
\text { Interevaluadores } \\
\text { (profesional-familiar) }\end{array}$ \\
\hline A. Hogar & .954 & .864 \\
B. Comunidad & .928 & .826 \\
C. Participación Escolar & .938 & .842 \\
D. Aprendizaje Escolar & .907 & .793 \\
E. Saludy Seguridad & .919 & .803 \\
F. Social & .923 & .820 \\
G. Defensa & .907 & .786 \\
TOTAL & .950 & $\mathbf{8 6 7}$ \\
\hline
\end{tabular}

Finalmente, siguiendo uno de los procedimientos más eficaces utilizados para conocer la fiabilidad de un test (García, 1993; Martínez-Arias, 2006; Muñiz, 2003), se utilizó el método del Test-Retest, el cuál analiza la relación entre dos mediciones realizadas en diferentes momentos temporales, lo que proporciona una medida de la estabilidad temporal de las puntuaciones $y$, por tanto, de fiabilidad de la escala. 
Con este objetivo, en una submuestra de 32 de los casos, se aplicó la escala en dos momentos temporales distanciados por dos meses, garantizando así que había transcurrido un tiempo considerable para no recordar las respuestas dadas en la primera administración, pero no lo suficientemente amplio como para que el propio desarrollo humano o el progreso de una intervención hubieran causado cambios en las necesidades de apoyo de los participantes. El tiempo fue la única variable modificada, manteniéndose los mismos informantes y el mismo entrevistador en las dos aplicaciones. En la Tabla 54 podemos observar como la correlación obtenida entre la primera y la segunda aplicación fue .943 para el total de la escala, siendo las de las diferentes superiores a .780, pudiéndose hablar de una correlación excelente en todos los casos siguiendo la clasificación de Cichetti.

Tabla 54. Fiabilidad test-retest de las dimensiones y de la escala

\begin{tabular}{lc}
\hline Áreas evaluadas & Fiabilidad Test-Retest \\
\hline A. Hogar & .903 \\
B. Comunidad & .782 \\
C. Participación Escolar & .856 \\
D. Aprendizaje Escolar & .999 \\
E. Saludy Seguridad & .913 \\
F. Social & .782 \\
G. Defensa & .837 \\
TOTAL &. $\mathbf{9 4 3}$ \\
\hline
\end{tabular}

\subsubsection{Análisis de validez de las dimensiones y de la escala}

La investigación actual implicada en el desarrollo de tests educativos y psicológicos (e.g., Linn y Gronlund, 2000; Prieto y Delgado, 2010; Taylor, 2002;) habla de tres tipos de validez fundamentales: validez de contenido, validez de criterio y validez de constructo. Siguiendo estas aportaciones, que ya fueron tenidas en cuenta en la validación de la SIS (Ibáñez et al., 2009), se ofrece a continuación un análisis de los tres tipos de validez.

La Validez de Contenido consiste en la evaluación de la correspondencia de las variables incluidas en una escala y su definición conceptual (Hair, Black, Babin, Anderson y Tatham, 2006), es decir, garantizar que los elementos que conforman una escala evalúan el constructo teórico concreto para el que han sido diseñados, ajustándose al planteamiento teórico que define dicho constructo. 
Uno de los procedimientos que se encuentran en la base de la obtención de evidencias de validez de contenido es realizar una sólida revisión y fundamentación bibliográfica que garantice que las decisiones tomadas para la elaboración de la escala y el pool de ítems que la forman se sustentan en el modelo teórico subyacente al constructo evaluado y en los resultados obtenidos por la investigación y la utilización de otras herramientas de evaluación afines.

En este sentido, la creación de los ítems de a SIS-C por diferentes autores de la SIS para adultos y miembros de la AAIDD, supone una prueba de la validez de contenido, pues garantiza que su desarrollo es coherente con el de otra escalas de necesidades de apoyo previamente validada y adaptada a otros países (Schalock, Thompson et al., 2008) y con la nueva concepción de discapacidad intelectual (Schalock et al., 2010). Además, se ha seguido un proceso rigurosos de elaboración de la escala (descrito en el apartado 'instrumento' del capítulo 3 [3.3.1]), de manera que el conjunto total de ítems de la escala fue sometido, primero en su versión original y de nuevo en su posterior adaptación al español, a un grupo de expertos que aseguraron la idoneidad de los ítems para medir necesidades en las diferentes áreas cotidianas. Además, el equipo investigador ha realizado numerosas reuniones con el fin de discutir los enunciados de los ítems y mejorar su contenido, potenciando así su comprensión y la validez de las evaluaciones.

Tambiñen fue analizada la Validez de Criterio, definida como el grado en el que las medidas de un test son consistentes con otras medidas externas que deberían estar relacionadas con ellas (Hair et al., 2006), incluyendo, por ejemplo, la opinión de expertos (Holman y Bruininks, 1985). Concretamente, se estableció como criterio externo la valoración inicial aportada por los informantes (sección II: 'estimación general') en relación con las necesidades de apoyo de la persona con discapacidad en cada área evaluada y de manera general. Para el análisis de la discriminación externa de los ítems, se correlacionaron estas estimaciones con cada uno de los ítems, siendo necesario ahora correlacionar las estimaciones con cada subescala para conocer su validez de criterio.

Esta estimación fue solicitada en todas las evaluaciones, sin embargo, esta información solo fue proporcionada en 777 de los casos, considerándose las restantes como missing data. Los resultados obtenidos a través del coeficiente de Pearson mostraron correlaciones significativas al 1\% en todos los casos (Figura 22), obteniéndose las correlaciones más altas en vida en el hogar (.79) y las más bajas en el área de defensa (.68). Así, teniendo en cuenta que este índice es aceptable a partir de .35 (Hamill, Brown y Bryant, 1992), los resultados obtenidos reflejan buenas evidencias de validez de criterio. 


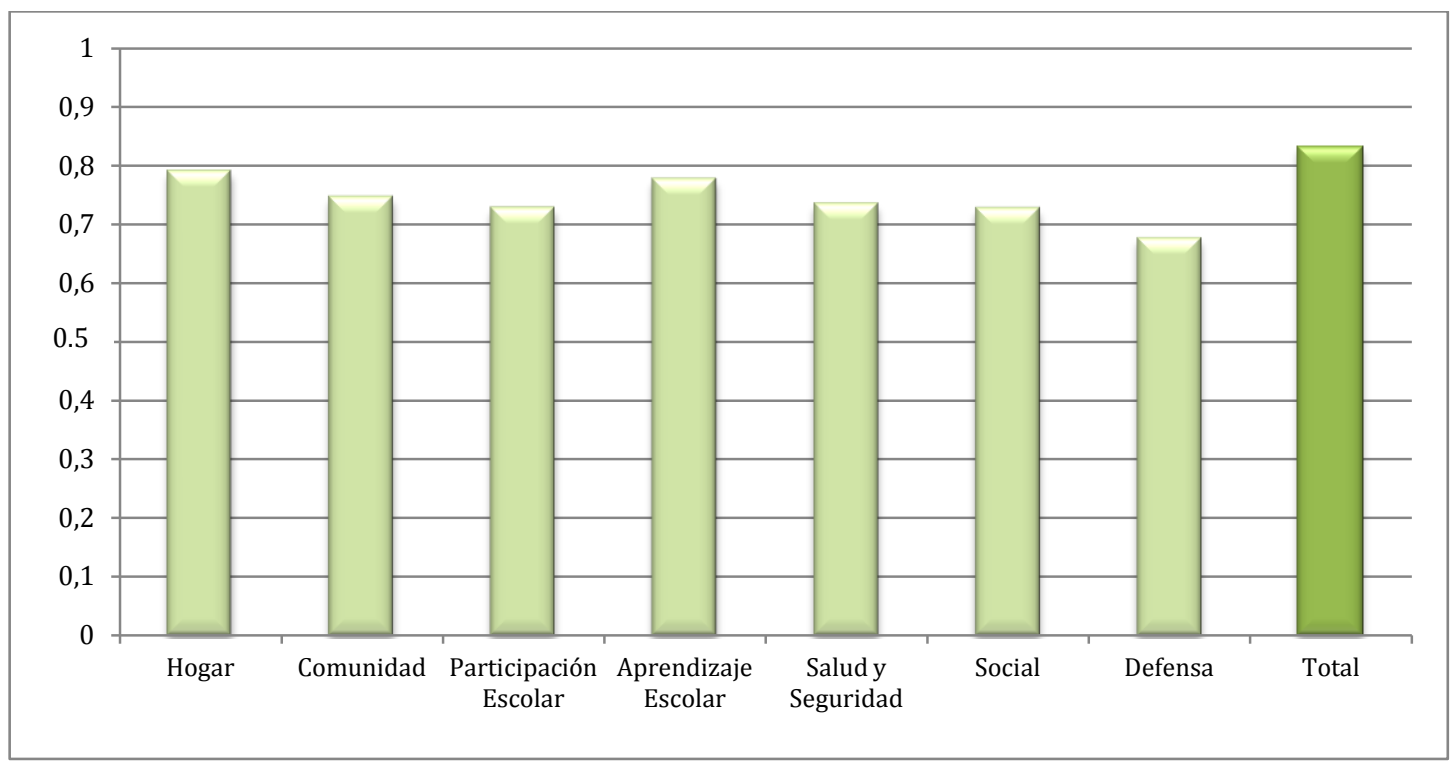

Figura 22. Correlaciones entre las puntuaciones de la SIS-C y una estimación previa de necesidades (validez de criterio)

Finalmente, para conocer el grado en que el conjunto de ítems de la escala (entendidos como variables observadas) representan el constructo latente teórico que pretenden evaluar (Taylor, 2002), se analiza la Validez de Constructo. Con este propósito y siguiendo los análisis realizados en la SIS para adultos (Ibáñez, 2009; Verdugo, Arias et al., 2007; Verdugo, Arias et al., 2010) sometieron a prueba varias hipótesis basadas tanto en la relación entre diferentes componentes que conforman la escala como en su relación con otra serie de variables independientes (i.e., sociodemográficas). Concretamente, para realizar el contraste de hipótesis se siguió el procedimiento de tres pasos propuesto por Linn y Grounlund (2000) para demostrar este tipo de validez: (a) seleccionar varios constructos que respondan a la realización de una prueba; (b) hacer una hipótesis para cada constructo; y (c) examinar cada hipótesis lógica o empíricamente.

De acuerdo con estos autores y conforme a los planteamientos desarrollado en la validación de la SIS se analizan las siguientes hipótesis: (1) si las subescalas de la SIS-C miden varios aspectos del mismo constructo, las puntuaciones en subescalas deberían correlacionar significativamente entre sí, así como con la puntuación total obtenida en el instrumento; (2) si las personas con problemas de conducta o médicos tienen con frecuencia mayores necesidades de apoyo, las áreas de la SIS deben correlacionar con las puntuaciones en necesidades excepcionales médicas y conductuales. Asimismo, se realizan otra serie de hipótesis con relación a variables sociodemográficas; (3) si el género no se describe como una variable relacionada con las necesidades de apoyo, entonces se espera 
que las puntuaciones no difieran dependiendo del género de la persona evaluada; (4) aunque en la SIS de adultos la expectativa era que no hubiera diferencias en las puntuaciones dependiendo de la edad de los sujetos, se espera que la edad de los niños y adolescentes sí influya en las puntuaciones en necesidades de apoyo; y (5) si las personas con discapacidad intelectual profunda tienden a presentar discapacidades múltiples y mayores necesidades de apoyo, habrá diferencias significativas en las puntuaciones obtenidas en la SIS-C por personas con diferentes niveles de discapacidad intelectual.

Para el contraste de la hipótesis 1 y 2 se tuvieron en cuenta las correlaciones Producto-Momento de Pearson, siendo necesario para el resto de las hipótesis planteadas realizar métodos de comparación de medias (h3-h5). En estos casos, la falta de normalidad de los datos obligó al uso de pruebas no paramétricas, utilizándose U de Mann-Whitney como sustituto de la $\mathrm{T}$ de Student para el contraste de medias de variables con dos categorías (i.e., género) y el método de Kruskal-Wallis como sustituto del ANOVA en los casos de variables con más de dos categorías (i.e., edad y niveles de discapacidad intelectual). Destacamos en este momento la falta de posibilidad de realizar pruebas post hoc para conocer las relaciones entre pares de categorías cuando se trabaja con pruebas el método de Kruskall-Wallis; por ello, en aquellos casos donde las diferencias de grupo son significativas, es necesario utilizar la prueba U de Mann-Whitney e ir comprobando, de manera independiente, las relaciones entre cada categoría de la variable y el resto.

Hipótesis 1: las puntuaciones en subescalas correlacionan significativamente entre sí, así como con la puntuación total obtenida en el instrumento

Con relación a la primera hipótesis, cabe destacar que las puntuaciones entre las subescalas así como entre las subescalas y el total fueron significativas al $1 \%$. Concretamente, las correlaciones entre subescalas fueron superiores a .72, correspondiendo este límite inferior a las relaciones entre 'Vida en el Hogar' y 'Participación Escolar'. Asimismo, las correlaciones más altas se obtuvieron entre las dimensiones de 'Salud y Seguridad' y 'Comunidad' y entre 'Salud y Seguridad' y 'Defensa', alcanzado correlaciones superiores a .90. Por su parte, la correlación entre las dimensiones y la puntuación total del instrumento fue superior a .89 en todos los casos, asentándose las correlaciones más bajas en la dimensión 'Vida en el Hogar’ y las más altas en 'Participación Escolar' (Tabla 55). A la luz de estos resultados podemos afirmar que se cumple la hipótesis planteada. 
Tabla 55. Intercorrelaciones entre las subescalas de la SIS-C y la puntuación total

\begin{tabular}{lccccccc}
\hline & HOG & COM & PE & AE & SS & SOC & DEF \\
HOG & & & & & & & \\
COM & .84 & & & & & & \\
PE & .88 & .90 & & & & & \\
AE & .72 & .81 & .84 & & & & \\
SS & .78 & .97 & .86 & .84 & .88 & .90 & \\
SOC & .79 & .85 & .88 & .71 & .91 & .90 & .93 \\
DEF & .74 & .85 & .85 & .85 & .94 & .94 & .93 \\
Total & .89 & .94 & .96 & .90 & .94 & & \\
\hline
\end{tabular}

Nota: HOG Hogar, COM Comunidad y vecindario, PE Participación Escolar, AE Aprendizaje Escolar, SS Salud y Seguridad, SOC Social, DEF Defensa.

Hipótesis 2: las puntuaciones en las áreas de la SIS-C deben correlacionar con las puntuaciones recogidas en el apartado de necesidades médicas y conductuales

En la segunda hipótesis se recoge la posibilidad de que las personas con necesidades excepcionales de naturaleza médica y conductual asociadas a la discapacidad intelectual presenten, en general, mayores necesidades de apoyo para realizar las diferentes actividades de su vida cotidiana.

Los resultados obtenidos permiten afirmar que se cumple nuestra hipótesis. Existe una relación significativa $(\mathrm{p}<.01)$ en todos los casos entre la puntuación obtenida en el índice de necesidades de apoyo de la SIS-C y la puntuación obtenida en la subescala de necesidades excepcionales médicas y conductuales (Tabla 56).

Haciendo un análisis detallado de los datos, se aprecia que las necesidades de apoyo médicas, en comparación con las conductuales, tienen una mayor correlación con las necesidades presentadas en la mayoría de las áreas cotidianas, especialmente con relación al apoyo requerido para la vida en el hogar. No obstante, los problemas de conducta tienen una mayor relación con aquellas actividades relacionadas con el área social.

Finalmente, tal y como cabría esperar, destacamos que las correlaciones obtenidas entre ambos apartados incrementan cuando se tienen en cuenta conjuntamente las necesidades médicas y conductuales. 
Tabla 56. Correlaciones entre necesidades de apoyo y los problemas médicos y conductuales

\begin{tabular}{llccc}
\hline & \multirow{2}{*}{ SIS-C } & \multicolumn{3}{c}{ Parte I. Necesidades de Apoyo Excepcionales } \\
\cline { 3 - 5 } & & Médico & Conductual & TOTAL \\
\hline & A. Hogar & .50 & .31 & .50 \\
Barte II. & B. Comunidad & .39 & .30 & .42 \\
Evaluación de & C. Participación Escolar & .42 & .34 & .46 \\
Intensidad de & D. Aprendizaje Escolar & .35 & .23 & .36 \\
Apoyos & E. Salud y Seguridad & .37 & .29 & .41 \\
& F. Social & .33 & .35 & .41 \\
& G. Defensa & .34 & .27 & .37 \\
& TOTAL & .42 & .33 &. $\mathbf{4 6}$ \\
\hline
\end{tabular}

Hipótesis 3: las puntuaciones en la SIS-C no varían en función del género de la persona evaluada

Para la comprobación de esta hipótesis se realizó un contraste de medias utilizando la prueba no paramétrica de U de Mann-Whitney (ó W de Wilcoxon), consecuencia de la falta de normalidad encontrada en el análisis inicial de distribución de los datos. Los resultados de esta prueba pusieron de manifiesto que, tal y como proponía en la hipótesis de partida, el género de la persona evaluada no se relacionaba con sus puntuaciones en necesidades de apoyo. En la Tabla 57, se presentan los estadísticos descriptivos de cada una de las categorías de la variable género (hombre-mujer), los resultados del contraste y el tamaño del efecto. Tanto en el análisis de las puntuaciones de cada dimensión como en el total de la escala, se observó que no existían diferencias significativas en función del género ( $p>.01)$ y se mostró un bajo tamaño del efecto $(r<.10)$.

Tabla 57. Descriptivos y resultados de la prueba de contraste para la variable 'género'

\begin{tabular}{lccccccc}
\hline Dimensiones & $\begin{array}{c}\text { Media (dt) } \\
\text { Hombres }\end{array}$ & $\begin{array}{c}\text { Media (dt) } \\
\text { Mujeres }\end{array}$ & $\begin{array}{c}\text { U de Mann- } \\
\text { Whitney }\end{array}$ & $\begin{array}{c}\text { W de } \\
\text { Wilcoxon }\end{array}$ & $\mathbf{Z}$ & $\mathbf{p}$ & $\mathbf{r}$ \\
\hline Hogar & 53.02 & 56.64 & 70172.00 & 209828.00 & -1.66 & .090 & .05 \\
Comunidad & $(29.32)$ & $(31.29)$ & & & & & \\
& 59.42 & 61.33 & 71572.00 & 211228.00 & -1.23 & .210 & .04 \\
Participación Esc. & $(24.67)$ & $(24.63)$ & & & & & \\
& 66.25 & 66.33 & 74163.00 & 213819.00 & -0.34 & .740 & .01 \\
Aprendizaje Esc. & $(28.02)$ & $(29.80)$ & & & & & \\
& 81.70 & 82.11 & 73742.50 & 213398.50 & -.551 & .580 & .02 \\
Saludy Seguridad & $(22.73)$ & $(23.46)$ & & & & & \\
\multirow{2}{*}{ Social } & 61.43 & 63.91 & 70972.00 & 210628.00 & -1.42 & .160 & .04 \\
& $(24.26)$ & $(24.09)$ & & & & & \\
Defensa & 67.01 & 67.00 & 74838.50 & 214494.50 & -0.21 & .830 & .01 \\
& $(28.55)$ & $(30.41)$ & & & & & \\
TOTAL & 71.09 & 71.92 & 73504.50 & 213160.50 & -0.62 & .530 & .01 \\
& $(26.82)$ & $(28.64)$ & & & & & \\
& 459.92 & 469.25 & 72194.00 & 211850.00 & -.95 & .340 & .03 \\
\hline
\end{tabular}


Hipótesis 4: las puntuaciones en la SIS-C varían en función de la edad del niño o adolescente evaluado

Para la comprobación de esta hipótesis se utilizó la prueba no paramétrica de Kruskal-Wallis, que funciona como un ANOVA en muestras que no se distribuyen normalmente. Concretamente, basándonos en las aportaciones de la AAIDD, la hipótesis de partida plantea la existencia de diferencias significativas en las puntuaciones dependiendo de la edad de las personas evaluadas. Para ello, se divide la muestra en pares de edad, formando así seis grupos diferentes (Tabla 58).

Tabla 58. Descriptivos y resultados de la prueba de contraste para la variable 'edad'

\begin{tabular}{|c|c|c|c|c|c|c|c|c|}
\hline Dimensiones & $\begin{array}{c}\text { Media } \\
\text { (dt) } \\
5-6 \\
\end{array}$ & $\begin{array}{c}\text { Media } \\
\text { (dt) } \\
7-8 \\
\end{array}$ & $\begin{array}{c}\text { Media } \\
\text { (dt) } \\
9-10 \\
\end{array}$ & $\begin{array}{c}\text { Media } \\
\text { (dt) } \\
11-12 \\
\end{array}$ & $\begin{array}{c}\text { Media } \\
\text { (dt) } \\
13-14 \\
\end{array}$ & $\begin{array}{c}\text { Media } \\
\text { (dt) } \\
15-16\end{array}$ & $\begin{array}{c}\chi^{2} \\
\text { (g.l) }\end{array}$ & $\mathbf{p}$ \\
\hline Hogar & $\begin{array}{c}59.62 \\
(27.32)\end{array}$ & $\begin{array}{c}63.71 \\
(28.95)\end{array}$ & $\begin{array}{c}65.10 \\
(26.18)\end{array}$ & $\begin{array}{c}57.81 \\
(30.79)\end{array}$ & $\begin{array}{c}47.55 \\
(29.01)\end{array}$ & $\begin{array}{c}41.94 \\
(29.77)\end{array}$ & $\begin{array}{c}65.16 \\
(5)\end{array}$ & .000 \\
\hline Comunidad & $\begin{array}{c}60.68 \\
(24.97)\end{array}$ & $\begin{array}{c}66.07 \\
(23.62)\end{array}$ & $\begin{array}{c}66.63 \\
(21.23)\end{array}$ & $\begin{array}{c}61.79 \\
(26.21)\end{array}$ & $\begin{array}{c}58.03 \\
(23.91)\end{array}$ & $\begin{array}{c}52.16 \\
(24.48)\end{array}$ & $\begin{array}{c}35.47 \\
(5)\end{array}$ & .000 \\
\hline Participación Esc. & $\begin{array}{c}68.45 \\
(30.61)\end{array}$ & $\begin{array}{c}75.87 \\
(26.41)\end{array}$ & $\begin{array}{c}76.12 \\
(22.38)\end{array}$ & $\begin{array}{c}69.59 \\
(28.43)\end{array}$ & $\begin{array}{c}60.74 \\
(27.14)\end{array}$ & $\begin{array}{c}55.34 \\
(29.56)\end{array}$ & $\begin{array}{c}57.21 \\
(5)\end{array}$ & .000 \\
\hline Aprendizaje Esc. & $\begin{array}{c}79.01 \\
(27.83)\end{array}$ & $\begin{array}{c}85.69 \\
(24.18)\end{array}$ & $\begin{array}{c}87.91 \\
(18.22)\end{array}$ & $\begin{array}{c}84.99 \\
(20.60)\end{array}$ & $\begin{array}{c}81.30 \\
(21.63)\end{array}$ & $\begin{array}{c}74.84 \\
(23.11)\end{array}$ & $\begin{array}{c}29.36 \\
(5)\end{array}$ & .000 \\
\hline Salud y Seguridad & $\begin{array}{c}57.63 \\
(27.85)\end{array}$ & $\begin{array}{c}67.98 \\
(23.59)\end{array}$ & $\begin{array}{c}68.35 \\
(20.95)\end{array}$ & $\begin{array}{c}64.44 \\
(24.90)\end{array}$ & $\begin{array}{c}61.56 \\
(21.63)\end{array}$ & $\begin{array}{c}74.84 \\
(23.11)\end{array}$ & $\begin{array}{c}27.63 \\
(5)\end{array}$ & .000 \\
\hline Social & $\begin{array}{c}69.05 \\
(31.75)\end{array}$ & $\begin{array}{c}75.94 \\
(27.87)\end{array}$ & $\begin{array}{c}76.42 \\
(22.60)\end{array}$ & $\begin{array}{c}67.24 \\
(31.07)\end{array}$ & $\begin{array}{c}63.41 \\
(22.35)\end{array}$ & $\begin{array}{c}56.57 \\
(23.75)\end{array}$ & $\begin{array}{c}42.66 \\
(5)\end{array}$ & .000 \\
\hline Defensa & $\begin{array}{c}67.77 \\
(32.32)\end{array}$ & $\begin{array}{c}77.73 \\
(27.39)\end{array}$ & $\begin{array}{c}78.22 \\
(22.44)\end{array}$ & $\begin{array}{c}72.82 \\
(28.35)\end{array}$ & $\begin{array}{c}70.70 \\
(25.19)\end{array}$ & $\begin{array}{c}64.52 \\
(26.87)\end{array}$ & $\begin{array}{c}24.26 \\
(5)\end{array}$ & .000 \\
\hline TOTAL & $\begin{array}{l}462.22 \\
(191.5)\end{array}$ & $\begin{array}{l}513.01 \\
(171.7)\end{array}$ & $\begin{array}{l}518.75 \\
(139.7)\end{array}$ & $\begin{array}{l}478.68 \\
(178.6)\end{array}$ & $\begin{array}{l}443.31 \\
(162.3)\end{array}$ & $\begin{array}{l}402.80 \\
(171.5)\end{array}$ & $\begin{array}{c}43.98 \\
(5)\end{array}$ & .000 \\
\hline
\end{tabular}

Podemos observar, de manera descriptiva, que las puntuaciones en necesidades extraordinarias de apoyo tienden a incrementar entre los 5 y los 10 años, mostrando que a medida que aumenta la edad del niño y los iguales dejan de necesitar apoyos, los niños con discapacidad van necesitando progresivamente más apoyos extraordinarios. Sin embargo, alcanzada la adolescencia, se aprecia una disminución de los apoyos necesitados por las personas con discapacidad intelectual en la realización las actividades rutinaria de la vida cotidiana evaluadas. 
Teniendo en cuenta conjuntamente los seis grupos en los que la variable edad ha sido dividida, se observan diferencias significativas tanto en la puntuación de cada una de las subescalas como en la puntuación total de la escala. No obstante, se realiza complementariamente un análisis por pares de categorías para poder observar el contraste entre cada uno de los grupos.

Se encontraron diferencias significativas entre la mayoría de los pares de edad en los que se ha subdividido la muestra, observándose un mayor tamaño del efecto en la variable cuando las comparaciones incluían el par de edad 15-16 años. En la Tabla 59 se presentan los datos de aquellas comparaciones significativas $(\mathrm{p}<.01)$ que obtuvieron un tamaño del efecto superior a 20 .

Tabla 59. Resultados más significativos del contraste de medias por pares de la variable 'edad'

\begin{tabular}{|c|c|c|c|c|c|c|}
\hline \multicolumn{2}{|c|}{ Categorías } & \multirow{2}{*}{$\begin{array}{c}\begin{array}{c}\text { U de Mann- } \\
\text { Whitney }\end{array} \\
5533.00\end{array}$} & \multirow{2}{*}{$\begin{array}{c}\text { Wde } \\
\text { Wilcoxon }\end{array}$} & \multirow{2}{*}{$\begin{array}{c}Z \\
-4.74\end{array}$} & \multirow{2}{*}{$\begin{array}{c}p \\
.000\end{array}$} & \multirow{2}{*}{$\begin{array}{c}\boldsymbol{r} \\
.29\end{array}$} \\
\hline $5-6$ & Hogar & & & & & \\
\hline $15-16$ & Participación Escolar & 6275.00 & 18056.00 & -3.52 & .000 & .22 \\
\hline \multirow{4}{*}{$\begin{array}{c}7-8 \\
13-14\end{array}$} & Hogar & 7208.50 & 26318.50 & -4.55 & .000 & .26 \\
\hline & Participación Escolar & 7000.00 & 26110.00 & -4.83 & .000 & .28 \\
\hline & Social & 7750.50 & 26860.50 & -3.81 & .000 & .22 \\
\hline & TOTAL & 7722.50 & 26832.50 & -3.84 & .000 & .22 \\
\hline \multirow{8}{*}{$\begin{array}{c}7-8 \\
15-16\end{array}$} & Hogar & 4933.50 & 16714.50 & -5.54 & .000 & .34 \\
\hline & Comunidad & 5385.00 & 17166.00 & -4.79 & .000 & .30 \\
\hline & Participación Escolar & 4931.00 & 16712.00 & -5.55 & .000 & .34 \\
\hline & Aprendizaje Escolar & 5849.50 & 17630.50 & -4.02 & .000 & .25 \\
\hline & Salud y Seguridad & 5921.00 & 17702.00 & -3.90 & .000 & .24 \\
\hline & Social & 5152.50 & 16933.50 & -5.18 & .000 & .32 \\
\hline & Defensa & 5865.50 & 17646.50 & -3.99 & .000 & .25 \\
\hline & TOTAL & 5179.00 & 16960.00 & -5.13 & .000 & .32 \\
\hline \multirow{3}{*}{$\begin{array}{c}9-10 \\
13-14\end{array}$} & Hogar & 6312.00 & 25422.00 & -4.96 & .000 & .29 \\
\hline & Participación Escolar & 6516.50 & 25626.50 & -4.66 & .000 & .27 \\
\hline & Social & 7106.50 & 26216.50 & -3.81 & .000 & .22 \\
\hline \multirow{8}{*}{$\begin{array}{c}9-10 \\
15-16\end{array}$} & Hogar & 4235.00 & 16016.00 & -6.00 & .000 & .38 \\
\hline & Comunidad & 4985.00 & 16766.00 & -4.68 & .000 & .29 \\
\hline & Participación Escolar & 4506.50 & 16287.50 & -5.52 & .000 & .35 \\
\hline & Aprendizaje Escolar & 5143.50 & 16924.50 & -4.41 & .000 & .28 \\
\hline & Salud y Seguridad & 5393.50 & 17174.50 & -3.97 & .000 & .25 \\
\hline & Social & 4647.50 & 16428.50 & -5.28 & .000 & .33 \\
\hline & Defensa & 5374.50 & 17155.50 & -4.00 & .000 & .25 \\
\hline & TOTAL & 4679.50 & 16460.50 & -5.22 & .000 & .33 \\
\hline \multirow{5}{*}{$\begin{array}{l}11-12 \\
15-16\end{array}$} & Hogar & 8016.50 & 19797.50 & -4.38 & .000 & .25 \\
\hline & Comunidad & 8615.00 & 20396.00 & -3.59 & .000 & .21 \\
\hline & Participación Escolar & 8186.50 & 19967.50 & -4.15 & .000 & .24 \\
\hline & Aprendizaje Escolar & 8340.00 & 20121.00 & -3.96 & .000 & .23 \\
\hline & TOTAL & 8429.00 & 20210.00 & -3.83 & .000 & .22 \\
\hline
\end{tabular}


Hipótesis 5: las puntuaciones en la SIS-C varían en función del nivel de discapacidad intelectual de la persona evaluada

Para conocer si el grado de discapacidad intelectual influye de manera directa en las puntuaciones obtenidas en la SIS-C, se lleva a cabo de nuevo la prueba de KruskalWallis para grupos independientes. Atendiendo a los grupos de subdivisión de la muestra propuestos por la AAIDD, se establecen para este estudio tres categorías para la variable de estudio: (1) discapacidad intelectual ligera; (2) discapacidad intelectual moderada; y (3) discapacidad intelectual severa o profunda. La hipótesis expuesta aboga por la relación directa entre las variables, de tal manera que se espera que personas con menor nivel de discapacidad intelectual presenten menos necesidades de apoyo que aquellos con un nivel de discapacidad más severo. Los resultados obtenidos (Tabla 60) revelan que, como se esperaba, existen diferentes significativas $(\mathrm{p}<.01)$ entre los grupos tanto en el resultado total de la escala como en cada una de las áreas evaluadas.

Tabla 60. Descriptivos y resultados de la prueba de contraste para la variable 'nivel de DI'

\begin{tabular}{|c|c|c|c|c|c|}
\hline Dimensiones & $\begin{array}{l}\text { Media }(d t) \\
\text { DI Ligera }\end{array}$ & $\begin{array}{c}\text { Media }(d t) \\
\text { DI Moderada }\end{array}$ & $\begin{array}{c}\text { Media (dt) } \\
\text { DI Severa/Profunda }\end{array}$ & $\begin{array}{c}\chi^{2} \\
(g . l)\end{array}$ & $p$ \\
\hline Hogar & $\begin{array}{c}29.97 \\
(22.08)\end{array}$ & $\begin{array}{l}46.10 \\
(24.13)\end{array}$ & $\begin{array}{l}81.41 \\
(19.86)\end{array}$ & $\begin{array}{l}374.99 \\
(2)\end{array}$ & .000 \\
\hline Comunidad & $\begin{array}{l}38.39 \\
(22.52)\end{array}$ & $\begin{array}{l}57.16 \\
(21.14)\end{array}$ & $\begin{array}{l}78.53 \\
(14.59)\end{array}$ & $\begin{array}{c}324.55 \\
(2)\end{array}$ & .000 \\
\hline Participación Esc. & $\begin{array}{c}40.92 \\
(25.21)\end{array}$ & $\begin{array}{l}60.83 \\
(23.38)\end{array}$ & $\begin{array}{c}89.45 \\
(16.07)\end{array}$ & $\begin{array}{l}354.85 \\
(2)\end{array}$ & .000 \\
\hline Aprendizaje Esc. & $\begin{array}{c}60.77 \\
(23.01)\end{array}$ & $\begin{array}{l}80.92 \\
(18.38)\end{array}$ & $\begin{array}{c}97.47 \\
(14.11)\end{array}$ & $\begin{array}{l}299.81 \\
(2)\end{array}$ & .000 \\
\hline Salud y Seguridad & $\begin{array}{l}39.50 \\
(21.65)\end{array}$ & $\begin{array}{l}60.76 \\
(20.01)\end{array}$ & $\begin{array}{l}79.58 \\
(15.36)\end{array}$ & $\begin{array}{l}313.24 \\
(2)\end{array}$ & .000 \\
\hline Social & $\begin{array}{l}42.31 \\
(26.40)\end{array}$ & $\begin{array}{l}61.74 \\
(24.60)\end{array}$ & $\begin{array}{l}88.68 \\
(17.51)\end{array}$ & $\begin{array}{l}304.86 \\
(3)\end{array}$ & .000 \\
\hline Defensa & $\begin{array}{l}45.63 \\
(24.07)\end{array}$ & $\begin{array}{l}69.07 \\
(22.89)\end{array}$ & $\begin{array}{c}91.18 \\
(16.82)\end{array}$ & $\begin{array}{c}316.74 \\
(2)\end{array}$ & .000 \\
\hline TOTAL & $\begin{array}{l}297.48 \\
(146.92)\end{array}$ & $\begin{array}{c}436.61 \\
(135.38)\end{array}$ & $\begin{array}{c}606.30 \\
(100.779)\end{array}$ & $\begin{array}{c}374.53 \\
(2)\end{array}$ & .000 \\
\hline
\end{tabular}

Posteriormente, se realizó un análisis pormenorizado de las relaciones existentes entre las distintas categorías de esta variable para conocer con precisión en qué medida las puntuaciones medias de los participantes varían en función del nivel de discapacidad. En la Tabla 61 pueden verse los resultados obtenidos, encontrándose que existen diferencias significativas $(\mathrm{p}<.01)$ y tamaños del efecto medio-altos $(.33<\mathrm{r}>.77)$ entre todas las categorías, tanto en cada dimensión de la escala como en su puntuación total. 
Tabla 61. Resultados del contraste de medias por pares de la variable 'nivel de DI'

\begin{tabular}{|c|c|c|c|c|c|c|}
\hline Categorías & & $\begin{array}{l}\text { U de Mann- } \\
\text { Whitney }\end{array}$ & $\begin{array}{c}\text { W de } \\
\text { Wilcoxon }\end{array}$ & $\mathbf{Z}$ & $\mathbf{p}$ & $\mathbf{r}$ \\
\hline \multirow{8}{*}{$\begin{array}{l}\text { Ligero } \\
\text { Moderado }\end{array}$} & Hogar & 18198.00 & 39313.00 & -7.35 & .000 & .33 \\
\hline & Comunidad & 16167.00 & 37282.00 & -8.65 & .000 & .39 \\
\hline & Participación Escolar & 16726.00 & 37841.00 & -8.29 & .000 & .37 \\
\hline & Aprendizaje Escolar & 14663.00 & 35778.00 & -9.61 & .000 & .43 \\
\hline & Salud y Seguridad & 13738.00 & 34853.00 & -10.20 & .000 & .46 \\
\hline & Social & 17362.50 & 38477.50 & -7.89 & .000 & .35 \\
\hline & Defensa & 14249.50 & 35364.50 & -9.87 & .000 & .44 \\
\hline & TOTAL & 14413.50 & 35528.50 & -9.77 & .000 & .44 \\
\hline \multirow{8}{*}{$\begin{array}{l}\text { Ligero } \\
\text { Sev./Prof. }\end{array}$} & Hogar & 3116.50 & 24231.50 & -16.36 & .000 & .76 \\
\hline & Comunidad & 3837.50 & 24952.50 & -15.86 & .000 & .74 \\
\hline & Participación Escolar & 3305.50 & 24420.50 & -16.23 & .000 & .75 \\
\hline & Aprendizaje Escolar & 4574.50 & 25689.50 & -15.42 & .000 & .72 \\
\hline & Salud y Seguridad & 4181.50 & 25296.50 & -15.63 & .000 & .73 \\
\hline & Social & 4546.00 & 25661.00 & -15.37 & .000 & .71 \\
\hline & Defensa & 3876.00 & 24991.00 & -15.84 & .000 & .73 \\
\hline & TOTAL & 2905.50 & 24020.50 & -16.50 & .000 & .77 \\
\hline \multirow{8}{*}{$\begin{array}{l}\text { Moderado } \\
\text { Sev./Prof. }\end{array}$} & Hogar & 9822.50 & 52017.50 & -14.98 & .000 & .64 \\
\hline & Comunidad & 14240.00 & 56435.00 & -12.61 & .000 & .54 \\
\hline & Participación Escolar & 11624.00 & 53819.00 & -14.02 & .000 & .60 \\
\hline & Aprendizaje Escolar & 16742.50 & 58937.50 & -11.32 & .000 & .48 \\
\hline & Salud y Seguridad & 16636.00 & 58831.00 & -11.33 & .000 & .48 \\
\hline & Social & 14108.50 & 56303.50 & -12.68 & .000 & .54 \\
\hline & Defensa & 16147.00 & 58342.00 & -11.60 & .000 & .49 \\
\hline & TOTAL & 11581.50 & 53776.50 & -14.04 & .000 & .60 \\
\hline
\end{tabular}

\subsubsection{Objetivo 2: análisis de la estructura de la escala a través del AFC (SEM)}

La validez factorial de un instrumento se relaciona de manera directa con otras formas de validez reflejadas anteriormente. El uso del AFC permite analizar la calidad y adecuación de los instrumentos para medir un constructo determinado. Para ello, se realiza un contraste entre la estructuras interna obtenida a través de los datos empíricos con las estructuras propuestas por los modelos teóricos correspondientes. No obstante, antes de llevar a cabo esta tarea es necesario seguir una serie de pasos que aporten rigurosidad al proceso de análisis. Estas pautas pueden resumirse en tres grande grupos.

(1) En primer lugar, de manera previa a la realización del AFC, es necesario preparar los datos y comprobar los requisitos necesarios para llevar a cabo un uso apropiado y exhaustivo de este procedimiento. Este análisis inicial engloba el análisis de la adecuación del uso de parcels cuando estos son requeridos para solventar posibles limitaciones de los datos. Se presentan en este subapartado las ventajas, desventajas y características básicas que han de tenerse en cuenta en el uso y manejo de los parcels como unidad de análisis. 
(2) Seguidamente, atendiendo a las características específicas del AFC, se especifican e identifican a priori los modelos a contrastar que, en nuestro caso, vendrán determinados en gran medida por los resultados obtenidos en los análisis realizados previamente en los diferentes estudios y adaptaciones de la SIS para adultos.

(3) Finalmente, una vez definidos los modelos teóricos con los que se trabaja, se estiman los parámetros pertinentes. A partir de estos resultados, se realiza una evaluación del ajuste de los datos, poniéndose de manifiesto cuál de las hipótesis planteadas refleja una menor diferencia entre la matriz de varianzas-covarianzas muestrales y la pronosticada por los modelos planteados.

\subsubsection{Comprobación de los requisitos previos: adecuación del uso de parcels}

Antes de realizar un análisis factorial conviene llevar a cabo una serie de comprobaciones para evitar problemas potenciales que puedan llevar a tomar decisiones inapropiadas en relación a los datos obtenidos y a malinterpretar la estructura factorial del constructo y la estructura interna del instrumento de medida. Realizar estos análisis preliminares permitirá conocer el grado de adecuación del uso del AFC así como tomar las medidas de control pertinente en aquellos casos en los que algunos de los supuestos sean violados. De esta manera, se optimizarán los resultados obtenidos y se incrementará el grado de exactitud de las interpretaciones derivadas.

En este trabajo, comprobaremos 10 requisitos clave, tomados de las aportaciones previas de numerosos autores (Arbuckle, 2002; Diamantopoulos y Siguaw, 2000; Arias, 2008; Gómez, 2010; Hatcher, 2006; Ibáñez, 2009; Jöreskog, 1993; Jöreskog y Sörbom, 1996a, 1996b, Lèvy y Varela, 2006), que deben ser cumplidos por los datos para el correcto uso de esta técnica de análisis. Estos requisitos han sido En la Tabla 62 se presentan las condiciones propuestas así como algunas observaciones a tener en cuenta.

Entre el amplio número requisitos incorporados y reconocidos por la mayoría de autores, encontramos que nuestros datos empíricos no se ajustan a dos de estos supuestos: el primero de ellos relacionado con la falta de normalidad y la presencia de outliers (criterio 3) y el segundo referente al número de indicadores (criterio 10); Bentler y Chu (1987) y Lomax (1982) proponen un máximo de 20-30 indicadores, contando nuestra escala con más de 60 ítems. 
Tabla 62. Requisitos previos para el uso del AFC

\begin{tabular}{ll}
\hline CONDICIÓN & OBSERVACIONES \\
1. Nivel de medida & $\begin{array}{l}\text { Indicadores en nivel de intervalo o de razón } \\
\text { (excepcionalmente ordinales) }\end{array}$ \\
2. Valores por indicador & $\begin{array}{l}\text { El número mínimo de indicadores por valor debería ser } 4 \\
\text { Distribución normal de los datos, control de outliers }\end{array}$ \\
4. Normalidad y outliers & Relaciones lineales y aditivas \\
5. Multicolinealidad & Ausencia de multicolinealidad \\
6. Variables relevantes & $\begin{array}{l}\text { Inclusión dentro del modelo de las variables relevantes } \\
\text { 7. Datos perdidos }\end{array}$ \\
Tratamiento adecuado de datos perdidos \\
8. Número mínimo de observaciones & $\begin{array}{l}\text { Al menos } 150 \text { observaciones, o } 5 \text { por cada parámetro a } \\
\text { estimar }\end{array}$ \\
9. Indicadores por variable latente & Más de 2 (preferible 4 o 5) \\
10. Numero de indicadores & No más de 30 \\
\hline
\end{tabular}

Una solución útil comúnmente empleada para resolver estos problemas es la parcelación de ítems (Arias et al., 2013; Hagtvet y Nasser, 2004; Nasser y Takahashi, 2003; Prats, 1990), especialmente indicada como proceso de simplificación y mejora de las propiedades de los datos en aquellos casos en los que se parte de un instrumento con más de 60 ítems (Arias, 2008).

Los parcels son definidos como un grupo de ítems homogéneos tratados en conjunto como una variable continua (más adecuado para el AFC que otras variables de naturaleza ordinal) que actúan como indicadores observables de las variables latentes (sustituyendo a los ítems de la escala) y que, precisamente, se caracterizan por disminuir el número de indicadores y mejorar la normalidad de los datos. Para su creación, han de sumarse o promediarse grupos de ítems que se sean conceptualmente similares y pertenezcan a una única dimensión de un constructo.

En nuestro caso, se hicieron grupos de tres ítems, siguiendo el orden de aparición en la escala y asegurando que agrupar en todos los casos ítems que pertenecieran a la misma subescala; creándose, finalmente, tres parcels para cada una de las áreas evaluadas (Tabla 63). No obstante, en las subescalas B y E uno de los parcels estuvo compuesto solo por dos ítems, ya que estas áreas presentan un número par de ítems. Esta situación de desequilibrio entre parcels hizo necesario trabajar con los promedios (y no con los sumatorios. 
Tabla 63. Distribución y estadísticos descriptivos de los parcels establecidos

\begin{tabular}{|c|c|c|c|c|c|}
\hline & Dimensiones & Parcels & Ítems & Promedio & DT \\
\hline \multirow{8}{*}{ 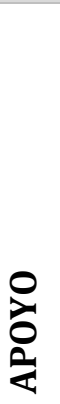 } & \multirow{3}{*}{ A. Hogar } & P_A1 & $\mathrm{A} 1, \mathrm{~A} 2, \mathrm{~A} 3$ & 6.65 & 3.33 \\
\hline & & P_A2 & $\mathrm{A} 4, \mathrm{~A} 5, \mathrm{~A} 6$ & 5.24 & 3.54 \\
\hline & & P_A3 & A7, A8, A9 & 6.21 & 3.64 \\
\hline & \multirow{3}{*}{ B. Comunidad } & P_B1 & B1, B2, B3 & 7.33 & 3.30 \\
\hline & & P_B2 & B4, B5, B6 & 7.74 & 3.03 \\
\hline & & P_B3 & B7, B8 & 7.45 & 3.36 \\
\hline & \multirow{3}{*}{ C. Participación Escolar } & P_C1 & $\mathrm{C} 1, \mathrm{C} 2, \mathrm{C} 3$ & 7.90 & 3.22 \\
\hline & & P_C2 & $\mathrm{C} 4, \mathrm{C} 5, \mathrm{C} 6$ & 7.43 & 3.08 \\
\hline \multirow{13}{*}{ 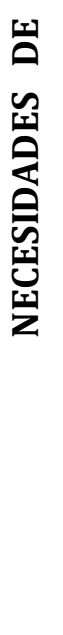 } & & P_C3 & $\mathrm{C} 7, \mathrm{C} 8, \mathrm{C} 9$ & 6.74 & 3.77 \\
\hline & \multirow{3}{*}{ D. Aprendizaje Escolar } & P_D1 & D1, D2, D3 & 9.72 & 2.52 \\
\hline & & P_D2 & D4, D5, D6 & 8.89 & 2.77 \\
\hline & & P_D3 & D7, D8, D9 & 8.67 & 2.75 \\
\hline & \multirow{3}{*}{ E. Salud y Seguridad } & P_E1 & E1, E2, E3 & 7.21 & 3.30 \\
\hline & & P_E2 & E4, E5, E6 & 8.15 & 3.01 \\
\hline & & P_E3 & E7, E8 & 8.11 & 3.28 \\
\hline & \multirow{3}{*}{ F. Social } & P_F1 & F1, F2, F3 & 7.21 & 3.47 \\
\hline & & P_F2 & F4, F5, F6 & 7.64 & 3.22 \\
\hline & & P_F3 & F7, F8, F9 & 7.48 & 3.35 \\
\hline & \multirow{3}{*}{ G. Defensa } & P_G1 & G1, G2, G3 & 7.77 & 3.10 \\
\hline & & P_G2 & G4, G5, G6 & 7.97 & 3.18 \\
\hline & & P_G3 & G7, G8, G9 & 8.06 & 3.12 \\
\hline
\end{tabular}

Aunque el uso de parcels conlleva algunos inconvenientes (Bandalos, 2002; Coffman y MacCallum, 2005; Meade y Kroustalis, 2006), sus ventajas han sido ampliamente demostradas (Arias, 2008; Bandalos 2002; Bandalos y Finney, 2001; Brown, 2006; Little, Cunningham, Shahar y Widaman, 2002) y, actualmente, se defiende que el uso de los mismos depende de la cada situación de análisis y de la naturaleza de la escala específica (Little, Rhemtulla, Gibson y Schoemann, 2013).

En este sentido, se destaca que, para reducir las limitaciones que puede conllevar su uso y optimizar su uso, es necesario que los parcels sean unidimensionales, ya que cada parcel funcionará como un único indicador representando a todos los ítems que incluye. Teniendo en cuenta esta argumentación, se realizaron una serie de análisis para comprobar la unidimensionalidad de los parcels y garantizar así la adecuación del uso de los mismos en nuestro estudio (Tabla 64). Como se esperaba, el primer eigenvalue (valor propio) de todos los parcels superó el valor 1 (el rango oscila entre 1.02 y 2.22) y, además, en todos los casos el primer factor explicaba más del $80 \%$ de la varianza, lo que resulta idóneo (suelen considerarse valores aceptables aquellos superiores al 60\%). 
No obstante, a pesar de esta primera aproximación absoluta a la unidimensionalidad de los parcels, se analizaron también los valores relativos para superar algunas de las limitaciones esta interpretación única de valores absolutos propuesta por Kaiser (1960) ya que, si bien es ampliamente utilizada, resulta demasiado conservadora y realiza una sobreestimación de componentes (Courtney, 2013). Así, se observó que se cumplieron también los criterios parciales establecidos: (1) el valor del primer eigenvalue era 4 veces superior al del segundo; y (2) la diferencia entre la cantidad de varianza explicada por el primer y el segundo factor era superior a 40.

Tabla 64. Evidencias de unidimensionalidad de los parcels

\begin{tabular}{|c|c|c|c|c|c|c|c|}
\hline & Criterios & $\begin{array}{c}\text { Eigenvalue } 1 \\
\text { (E1) }\end{array}$ & $\begin{array}{c}\text { Eigenvalue } 2 \\
\text { (E2) }\end{array}$ & E1/E2 & $\begin{array}{c}\text { \%Varianza } \\
\text { explicada E1 }\end{array}$ & $\begin{array}{c}\text { \%Varianza } \\
\text { explicada E2 }\end{array}$ & $\begin{array}{c}\text { \%Varianza } \\
\text { explicada E1 } \\
- \\
\text { \%Varianza } \\
\text { explicada E2 }\end{array}$ \\
\hline & & Mayor de 1 & Menor de 1 & $>4$ & $\begin{array}{c}\text { Mayor de } \\
60 \%\end{array}$ & $\begin{array}{c}\text { Menor de } \\
20 \%\end{array}$ & $>40$ \\
\hline \multirow{21}{*}{ 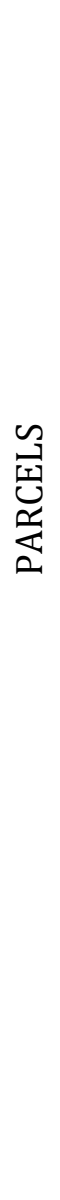 } & P_A1 & 2.55 & .29 & 8.79 & $85.01 \%$ & $9.75 \%$ & 75 \\
\hline & P_A2 & 2.50 & .35 & 7.14 & $83.43 \%$ & $11.83 \%$ & 72 \\
\hline & P_A3 & 2.51 & .24 & 10.45 & $83.97 \%$ & $8.10 \%$ & 76 \\
\hline & P_B1 & 2.62 & .21 & 12.47 & $87.49 \%$ & $7.28 \%$ & 80 \\
\hline & P_B2 & 2.63 & .20 & 13.15 & $87.77 \%$ & $6.91 \%$ & 81 \\
\hline & P_B3 & 1.77 & .22 & 8.04 & $88.92 \%$ & $11.07 \%$ & 78 \\
\hline & P_C1 & 2.52 & .33 & 7.63 & $84.27 \%$ & $11.18 \%$ & 73 \\
\hline & P_C2 & 2.27 & .44 & 5.16 & $75.79 \%$ & $14.81 \%$ & 61 \\
\hline & P_C3 & 2.68 & .24 & 11.16 & $89.36 \%$ & $9.06 \%$ & 80 \\
\hline & P_D1 & 2.69 & .17 & 15.82 & $89.69 \%$ & $5.87 \%$ & 84 \\
\hline & P_D2 & 2.59 & .22 & 11.77 & $86.38 \%$ & $7.32 \%$ & 79 \\
\hline & P_D3 & 2.47 & .27 & 9.14 & $82.61 \%$ & $9.14 \%$ & 73 \\
\hline & P_E1 & 2.46 & .27 & 9.11 & $82.16 \%$ & $9.10 \%$ & 73 \\
\hline & P_E2 & 2.54 & .28 & 9.07 & $84.89 \%$ & $9.63 \%$ & 75 \\
\hline & P_E3 & 1.79 & .20 & 8.95 & $89.60 \%$ & $10.39 \%$ & 79 \\
\hline & P_F1 & 2.48 & .33 & 7.51 & $82.81 \%$ & $11.27 \%$ & 72 \\
\hline & P_F2 & 2.43 & .34 & 7.14 & $81.16 \%$ & $11.60 \%$ & 70 \\
\hline & P_F3 & 2.34 & .38 & 6.15 & $78.17 \%$ & $12.97 \%$ & 65 \\
\hline & P_G1 & 2.50 & .41 & 6.09 & $83.50 \%$ & $13.74 \%$ & 70 \\
\hline & P_G2 & 2.59 & .23 & 11.26 & $86.53 \%$ & $7.74 \%$ & 79 \\
\hline & P_G3 & 2.51 & .30 & 8.36 & $83.67 \%$ & $10.26 \%$ & 73 \\
\hline
\end{tabular}


Por último, en cuanto a la idoneidad de cada parcel para ser sometido al análisis factorial, el análisis del Kaiser-Meyer-Olkin (KMO) mostró en todos los casos resultados superiores a 0.5 (considerado el límite inferior para aceptar la realización de un análisis factorial) y la prueba de esfericidad de Barlett presentó una p significativa $(<.001)$ en todos los parcels. Posteriormente, se analizó la idoneidad de someter estos parcels en su conjunto al análisis factorial, obteniéndose un índice KMO de .973 (muy adecuado) y una significación inferior al 1\% en el caso de la prueba de esfericidad de Barlett, quedando así garantizada la adecuación e idoneidad del uso de estos parcels.

En este sentido, analizamos a continuación los requisitos previos que han de cumplir los nuevos datos, obtenidos a partir del uso de los parcels, para poder ser sometidos a un AFC. Como veremos, el uso de los parcels mejoró considerablemente las propiedades de las variables observadas, pero no fue posible cumplir con el supuesto de normalidad multivariada y no pudo eliminarse por completo la presencia de outliers. Esta falta de normalidad no impide el uso de AFC, pero sí nos obliga a tomar medidas específicas de análisis, utilizando métodos de estimación susceptibles a la violación de este supuesto.

\section{Nivel de Medida}

Los parcels, al formarse a partir del promedio de los ítems, conforman unidades continuas, simplificando el trabajo con los ítems de naturaleza ordinal presentados y adecuando los datos de manera más precisa a la naturaleza propuesta para el uso del AFC.

\section{Valores por indicador}

Se recomienda que el número mínimo de indicadores sea cuatro para aumentar la probabilidad de que la distribución de los datos se acerque a la normalidad. En el caso de la SIS-C se cumple este requisito: los tres índices de medida que componen los ítems (tipo, frecuencia y tiempo diario de apoyo) tienen cinco opciones de respuesta (que oscilan entre 0 y 4) y son sumados para conseguir la puntuación global del mismo (0-12). En este sentido, al construirse los parcels a partir del promedio de los ítems, su rango de puntuaciones posibles coincide con el de los ítems.

\section{Normalidad y Outliers}

La mayoría de los métodos de estimación del AFC necesitan que los datos presenten normalidad multivariada. Para ello, González, Abad y Levy (2006) proponen 
comprobar en primer lugar si cada variable se distribuye normalmente, ya que su análisis resulta más sencillo y la normalidad univariante es una condición necesaria (aunque no suficiente) para la normalidad multivariada. Con este objetivo, presentamos en la Tabla 65 los datos sobre la asimetría y curtosis de cada uno de los parcels.

Tabla 65. Contraste de asimetría y curtosis de los parcels

\begin{tabular}{ccccccc}
\hline Parcels & \multicolumn{2}{c}{ Asimetría } & \multicolumn{2}{c}{ Curtosis } & \multicolumn{2}{c}{ Asimetría } \\
& $\mathbf{z}$ & $\mathbf{p}$ & $\mathbf{z}$ & $\mathbf{p}$ & \multicolumn{1}{c}{$\mathbf{X}^{2}$} & $\mathbf{p}$ \\
P_A1 & -2.621 & 0.009 & -12.769 & 0.000 & 169.917 & 0.000 \\
P_A2 & 1.010 & 0.312 & -18.054 & 0.000 & 326.959 & 0.000 \\
P_A3 & -0.958 & 0.338 & -20.494 & 0.000 & 420.925 & 0.000 \\
P_B1 & -6.388 & 0.000 & -5.585 & 0.000 & 72.006 & 0.000 \\
P_B2 & -7.401 & 0.000 & -1.614 & 0.106 & 57.384 & 0.000 \\
P_B3 & -5.245 & 0.000 & -6.467 & 0.000 & 69.337 & 0.000 \\
P_C1 & -7.500 & 0.000 & -2.629 & 0.009 & 63.167 & 0.000 \\
P_C2 & -5.757 & 0.000 & -5.316 & 0.000 & 61.407 & 0.000 \\
P_C3 & -3.012 & 0.009 & -18.023 & 0.000 & 333.898 & 0.000 \\
P_D1 & -11.754 & 0.000 & 5.225 & 0.000 & 165.461 & 0.000 \\
P_D2 & -8.092 & 0.000 & 0.025 & 0.980 & 65.475 & 0.000 \\
P_D3 & -8.522 & 0.000 & 1.986 & 0.047 & 76.572 & 0.000 \\
P_E1 & -3.909 & 0.000 & -8.854 & 0.000 & 93.663 & 0.000 \\
P_E2 & -7.215 & 0.000 & -1.025 & 0.305 & 53.104 & 0.000 \\
P_E3 & -7.262 & 0.000 & -2.127 & 0.033 & 57.257 & 0.000 \\
P_F1 & -4.319 & 0.000 & -9.769 & 0.000 & 114.090 & 0.000 \\
P_F2 & -5.294 & 0.000 & -6.431 & 0.000 & 69.378 & 0.000 \\
P_F3 & -4.545 & 0.000 & -7.968 & 0.000 & 84.141 & 0.000 \\
P_G1 & -4.969 & 0.000 & -5.893 & 0.000 & 59.420 & 0.000 \\
P_G2 & -5.391 & 0.000 & -5.778 & 0.000 & 62.445 & 0.000 \\
P_G3 & -5.758 & 0.000 & -4.928 & 0.000 & 57.447 & 0.000 \\
\hline & & & & & &
\end{tabular}

En general, predominan los parcels con asimetrías negativas, es decir, con puntuaciones altas, así como las distribuciones platicúrticas. Aunque los valores no resultan tan extremos que el caso de los ítems, estos reflejan una forma de la distribución muy similar a la que ofrece cada ítem tomado como referencia de manera particular. No obstante, no es suficiente con una mera descripción de la normalidad de los parcels, sino que es preciso comprobar de manera estadística si existe normalidad. Así, con el objetivo de comprobar el supuesto de normalidad univariada de cada parcel, se realiza la prueba de normalidad de Kolmogorov-Smirnov. Los resultados obtenidos se presentan a continuación en la Tabla 66. 
Tabla 66. Prueba de normalidad univariada

\begin{tabular}{ccc}
\hline Parcels & $\begin{array}{c}\text { Índice de Kolmogorov- } \\
\text { Smirnov }\end{array}$ & $\mathbf{p}$ \\
P_A1 & .075 & .000 \\
P_A2 & .078 & .000 \\
P_A3 & .079 & .000 \\
P_B1 & .112 & .000 \\
P_B2 & .130 & .000 \\
P_B3 & .098 & .000 \\
P_C1 & .110 & .000 \\
P_C2 & .102 & .000 \\
P_C3 & .082 & .000 \\
P_D1 & .183 & .000 \\
P_D2 & .131 & .000 \\
P_D3 & .113 & .000 \\
P_E1 & .086 & .000 \\
P_E2 & .101 & .000 \\
P_E3 & .118 & .000 \\
P_F1 & .084 & .000 \\
P_F2 & .088 & .000 \\
P_F3 & .089 & .000 \\
P_G1 & .086 & .000 \\
P_G2 & .103 & .000 \\
P_G3 & .103 & .000 \\
\hline
\end{tabular}

Tal y como se dijo anteriormente, la normalidad univariada no es requisito suficiente para poder obtener una adecuada normalidad multivariada pero sí necesario. En este sentido, al no encontrar resultados objetivos que avalen la normalidad univariada de los datos (todas las p son significativas), podemos concluir con certeza que no existe tampoco normalidad multivariada. No obstante, con el objetivo de corroborar estos resultados, se realizó el análisis de la normalidad multivariada, obteniéndose de nuevo valores de asimetría y curtosis inferiores significativas $(\mathrm{p}<.001)$ que marcaron la ausencia de normalidad multivariada.

En este sentido, es importante destacar de nuevo que, a pesar de la importancia de la normalidad de los datos cuando se utilizan pruebas de AFC, tomando las medidas adecuadas y escogiendo métodos de estimación específicos que permitan la violación de este supuesto, es posible realizar los análisis pertinentes para conocer la estructura interna de la escala de manera fiable.

Por su parte, el análisis de los outliers conlleva una serie de características y supuestos similares a los tenidos en cuenta para la normalidad. En los siguientes gráficos (Figuras 23-29) se encuentran outliers univariados en diversos de los parcels establecidos en las áreas 'Aprendizaje Escolar' (única subescala en la que se encontraron ítems con outliers) y 'Salud y Seguridad', lo que indica la presencias de outliers a nivel multivariante. 
Para su comprobación, se utilizó la prueba de Majalanobis al cuadrado $\left(\mathrm{D}^{2}\right)$ donde se observó la presencia de un alto número de datos con índices significativos. No obstante, el número de outliers encontrados no superó el 10\% de la muestra.

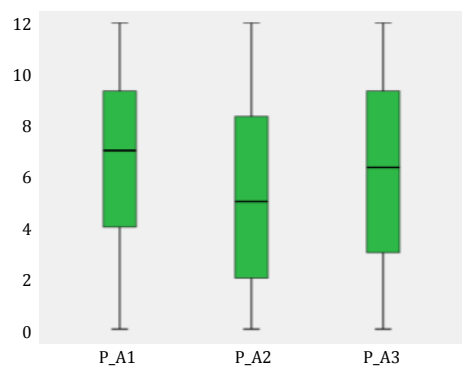

Figura 23. Outliers de los parcels. Subescala A

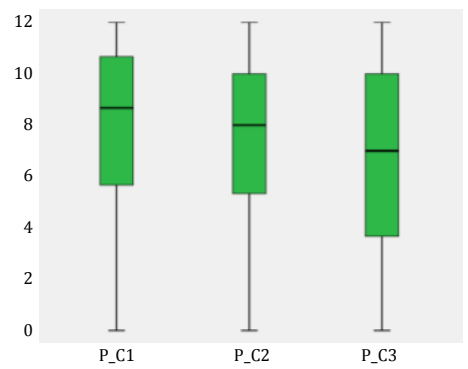

Figura 25. Outliers de los parcels. Subescala C

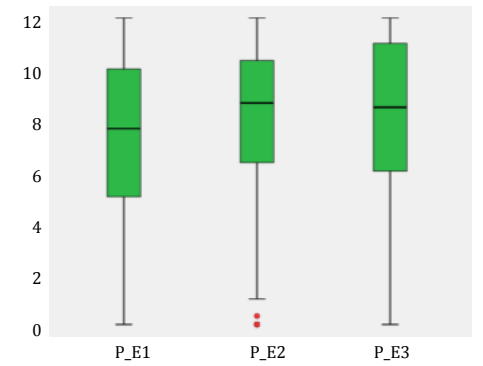

Figura 27. Outliers de los parcels. Subescala E

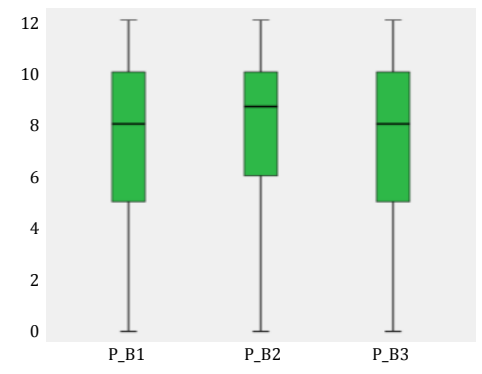

Figura 24. Outliers de los parcels. Subescala B

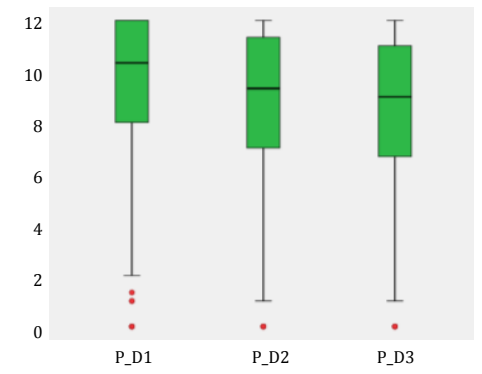

Figura 26. Outliers de los parcels. Subescala D

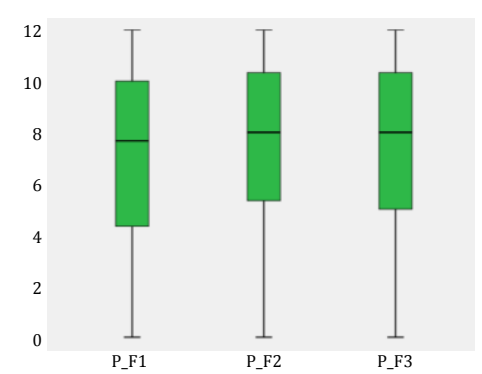

Figura 28. Outliers de los parcels. Subescala F

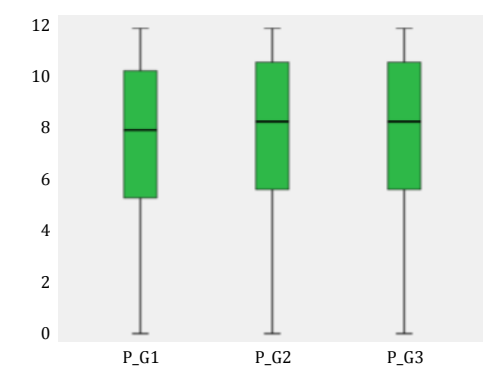

Figura 29. Outliers de los parcels. Subescala G 


\section{Linealidad}

El uso del AFC requiere relaciones lineales entre las variables. En las siguientes hojas se presentan como ejemplo las relaciones lineales existentes dentro de los parcels que componen cada una de las dimensiones. Se presentan gráficos de dispersión que reflejan la tendencia lineal en la relación de los parcels de la misma (Figuras 30-36).

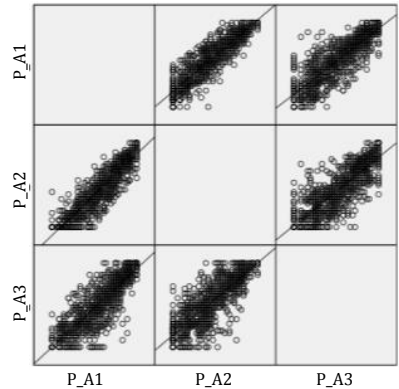

Figura 30. Relación entre parcels. Subescala A

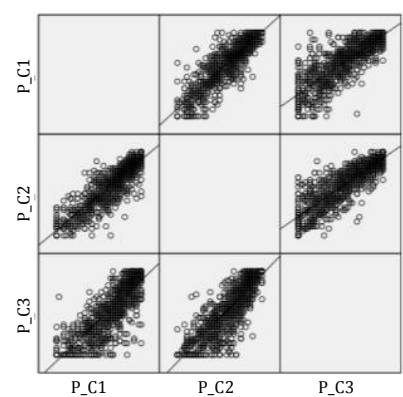

Figura 32. Relación entre parcels. Subescala C

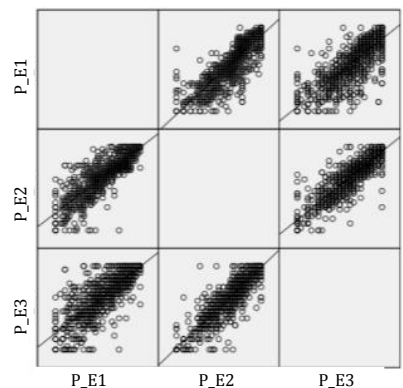

Figura 34. Relación entre parcels. Subescala E

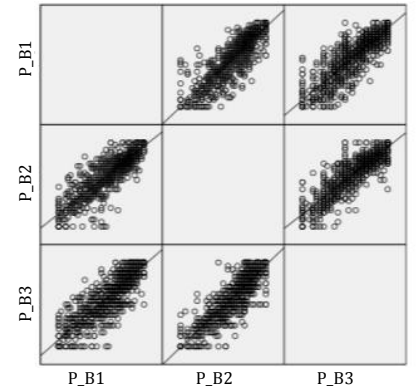

Figura 31. Relación entre parcels. Subescala B

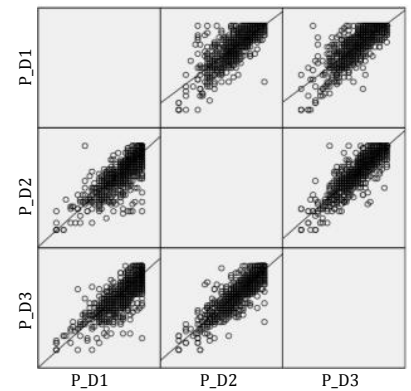

Figura 33. Relación entre parcels. Subescala D

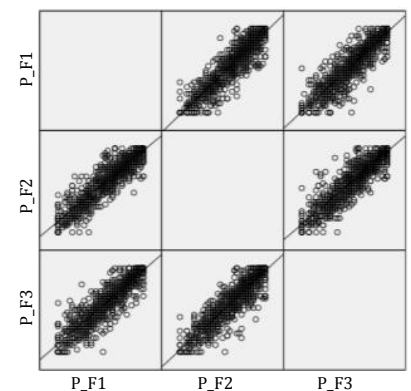

Figura 35. Relación entre parcels. Subescala F

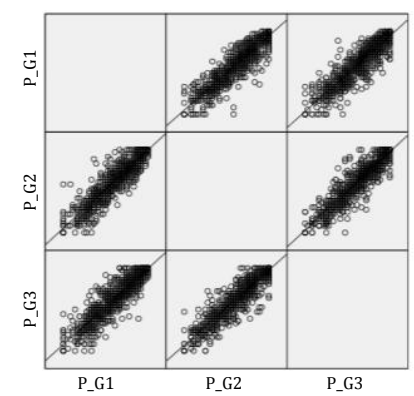

Figura 36. Relación entre parcels. Subescala G 


\section{Multicolinealidad}

Para realizar un AFC de manera apropiada, los datos deben estar libres de multicolinealidad. Según Arias (2008), existen dos modos principales de detectar la multicolinealidad: (a) examinar la matriz de correlaciones y observar variables con una correlación $\left(\mathrm{r}_{\mathrm{xy}}\right)$ superior a .90; y (b) calcular la correlación múltiple al cuadrado $\left(\mathrm{R}^{2}\right)$ entre cada variable y la suma de todas las demás; de nuevo valores superiores a .90 serán indicadores de multicolinealidad.

\section{a) Correlaciones entre indicadores}

En la Tabla 67 puede observarse como las correlaciones entre los parcels son altas, pero nunca superiores a .90. Las correlaciones más altas (que llegan a alcanzar correlaciones límites de .90) se encuentran entre parcels de la misma dimensión, reflejando una mayor convergencia de las puntuaciones otorgadas a los indicadores de la misma área de evaluación. Entre las distintas subescalas, las correlaciones son también altas, mostrando que todos los indicadores miden en la misma dirección, pero no se alcanzan correlaciones superiores a .86, lo que marca una ausencia clara de colinealidad.

Tabla 67. Correlaciones entre los parcels

\begin{tabular}{|c|c|c|c|c|c|c|c|c|c|c|c|c|c|c|c|c|c|c|c|c|c|}
\hline & P_A1 & P_A2 & P_A3 & P_B1 & P_B2 & P_B3 & P_C1 & P_C2 & P_C3 & P_D1 & P_D2 & P_D3 & P_E1 & P_E2 & P_E3 & P_F1 & P_F2 & P_F3 & P_G1 & P_G2 & P_G3 \\
\hline P_A1 & & & & & & & & & & & & & & & & & & & & & \\
\hline P_A2 & .90 & & & & & & & & & & & & & & & & & & & & \\
\hline P_A3 & .85 & .83 & & & & & & & & & & & & & & & & & & & \\
\hline P_B1 & .82 & .77 & .81 & & & & & & & & & & & & & & & & & & \\
\hline P_B2 & .73 & .67 & .75 & .87 & & & & & & & & & & & & & & & & & \\
\hline P_B3 & .79 & .74 & .80 & .87 & .88 & & & & & & & & & & & & & & & & \\
\hline P_C1 & .79 & .74 & .77 & .85 & .80 & .84 & & & & & & & & & & & & & & & \\
\hline P_C2 & .81 & .76 & .81 & .85 & .83 & .85 & .88 & & & & & & & & & & & & & & \\
\hline P_C3 & .81 & .79 & .84 & .79 & .72 & .83 & .82 & .85 & & & & & & & & & & & & & \\
\hline P_D1 & .59 & .52 & .60 & .67 & .70 & .67 & .74 & .74 & .65 & & & & & & & & & & & & \\
\hline P_D2 & .71 & .64 & .74 & .76 & .75 & .77 & .78 & .80 & .78 & .83 & & & & & & & & & & & \\
\hline P_D3 & .69 & .62 & .70 & .76 & .77 & .74 & .78 & .81 & .73 & .83 & .89 & & & & & & & & & & \\
\hline P_E1 & .75 & .71 & .79 & .80 & .81 & .81 & .77 & .81 & .77 & .67 & .78 & .78 & & & & & & & & & \\
\hline P_E2 & .71 & .64 & .71 & .79 & .82 & .79 & .78 & .82 & .73 & .72 & .79 & .82 & .85 & & & & & & & & \\
\hline P_E3 & .68 & .62 & .70 & .74 & .77 & .77 & .74 & .78 & .75 & .66 & .76 & .78 & .80 & .89 & & & & & & & \\
\hline P_F1 & .74 & .71 & .75 & .79 & .76 & .82 & .81 & .80 & .82 & .68 & .78 & .75 & .82 & .77 & .77 & & & & & & \\
\hline P_F2 & .73 & .70 & .74 & .79 & .78 & .81 & .81 & .81 & .79 & .69 & .77 & .76 & .82 & .80 & .80 & .90 & & & & & \\
\hline P_F3 & .72 & .69 & .73 & .78 & .76 & .81 & .79 & .80 & .81 & .69 & .78 & .77 & .80 & .82 & .84 & .90 & .90 & & & & \\
\hline P_G1 & .71 & .66 & .74 & .79 & .80 & .80 & .79 & .81 & .77 & .74 & .80 & .81 & .84 & .83 & .83 & .83 & .86 & .85 & & & \\
\hline P_G2 & .70 & .64 & .71 & .77 & .81 & .80 & .78 & .81 & .75 & .73 & .80 & .81 & .83 & .86 & .84 & .83 & .87 & .86 & .90 & & \\
\hline P_G3 & .67 & .63 & .71 & .75 & .79 & .79 & .76 & .80 & .76 & .75 & .82 & .81 & .83 & .84 & .83 & .82 & .85 & .84 & .90 & .90 & \\
\hline
\end{tabular}




\section{b) Correlación múltiple al cuadrado}

En la Tabla 68 se presentan los valores de $\mathrm{R}^{2}$ para cada uno de los parcels que, tal y como se esperaba, no son superiores a .90 . Asimismo, la medida $\mathrm{R}^{2}$ también refiere de manera explícita a la fiabilidad de los indicadores (Arias, 2008), por lo que el hecho de que todos los parcels obtengan valores sustancialmente elevados (.63-.88), pero sin llegar a superar los límites establecidos puede ser considerado, a su vez, como una evidencia más de la fiabilidad de los indicadores observables establecidos. Se presentan además en la tabla otros dos indicadores relacionados con la colinealidad que adquieren un buen ajuste de nuestros datos: (1) el índice de tolerancia (T), cuyos valores se obtienen de restar el $\mathrm{R}^{2}$ a la unidad y deben estar por encima de .10 para poder hablar de ausencia de colinealidad; y (2) el factor de inflación de la varianza (VIF), formulado a partir de la división de la unidad entre el índice T, que ha de presentar valores inferiores a 10.

Tabla 68. Valores de $\mathrm{R}^{2}$, nivel de tolerancia y factor de inflación de la varianza de los parcels

\begin{tabular}{|llcc}
\hline Parcels & $\mathbf{R}^{\mathbf{2}}$ & $\begin{array}{c}\text { T } \\
\left(\mathbf{1}-\mathbf{R}^{\mathbf{2}}\right.\end{array}$ & $\begin{array}{c}\text { VIF } \\
\mathbf{( 1 / t )}\end{array}$ \\
\hline P_A1 & .74 & .26 & 3.92 \\
P_A2 & .66 & .34 & 2.96 \\
P_A3 & .76 & .24 & 4.14 \\
P_B1 & .81 & .19 & 5.36 \\
P_B2 & .77 & .23 & 4.36 \\
P_B3 & .83 & .17 & 5.82 \\
P_C1 & .82 & .18 & 5.47 \\
P_C2 & .86 & .14 & 6.93 \\
P_C3 & .81 & .19 & 5.21 \\
P_D1 & .63 & .37 & 2.69 \\
P_D2 & 78 & .22 & 4.65 \\
P_D3 & .77 & .23 & 4.36 \\
P_E1 & .82 & .18 & 5.53 \\
P_E2 & .81 & .19 & 5.17 \\
P_E3 & .77 & .23 & 4.40 \\
P_F1 & .83 & .17 & 5.82 \\
P_F2 & .84 & .16 & 6.21 \\
P_F3 & .84 & .16 & 6.21 \\
P_G1 & .84 & .16 & 6.21 \\
P_G2 & .85 & .15 & 6.08 \\
P_G3 & .82 & .18 & 5.58 \\
\hline
\end{tabular}

\section{5. $\quad$ Variables relevantes}

Los modelos que se someterán a prueba incluirán únicamente aquellas variables recogidas en la revisión bibliográfica y que han resultado pertinentes en otros estudios. 


\section{6. $\quad$ Datos perdidos}

No se encontraron valores perdidos en ninguno de los parcels. Este hecho viene derivado de la falta de datos perdidos en los ítems. Los cuestionarios en los que no había sido contestado alguno de los 61 ítems de la las siete dimensiones centrales del instrumento (sección 1) y que, por tanto, contaban con datos perdidos, fueron eliminados antes de comenzar el estudio.

\section{Número mínimo de observaciones}

Según Kline (2010) se debe contar con un mínimo de 150 observaciones o al menos cinco por cada parámetro a estimar. En nuestro caso, los 814 sujetos con los que se cuenta para el análisis permiten superar los criterios descritos.

\section{Indicadores por variable latente}

Las investigaciones revelan la importancia de contar con al menos dos indicadores por cada variable latente, siendo ideal un número superior en la medida de lo posible. Con el objetivo de cumplir este criterio de la manera más eficaz posible, se aseguró que existieran al menos tres parcels para cada una de las áreas evaluadas.

\section{Numero de indicadores}

Este criterio, que aboga por un número de indicadores inferior a 60 para el correcto uso del AFC (Arias, 2008), fue conseguido con la mera creación de parcels, que agruparon los 61 ítems en 21 conjuntos, compuesto cada uno de ellos por una media de dos o tres ítems.

\subsubsection{Especificación e identificación de los modelos}

La especificación del modelo requiere usar todas las teorías relevantes que han intentado dar forma a la estructura del constructo de 'necesidades de apoyo' y proporcionar hipótesis al respecto. Teniendo en cuenta la revisión teórica realizada, se someterán a prueba tres modelos (Tabla 69), analizando así el concepto 'necesidades de apoyo' desde las tres perspectivas (unidimensional, correlacional y jerárquica) con las que han sido analizadas en la mayor parte de los constructos surgidos el ámbito de la discapacidad intelectual (e.g., CI, conducta adaptativa, calidad de vida). 
Concretamente, en la versión original de la SIS (Thompson et al., 2004) se comprobó la estructura correlacional de la escala, resultado que ha sido replicado en la adaptación de la SIS a otros países (e.g., Kuppens et al., 2010; Verdugo, Arias e Ibáñez, 2007). Sin embargo, en otras investigaciones se ha encontrado que la escala SIS respondía mejor a una sola dimensión (e.g., Harries et al., 2005), existiendo asimismo varios estudios que han intentado aportar una estructura jerárquica a la medición del constructo (e.g. Ibáñez, 2009).

Tabla 69. Modelos sometidos a prueba mediante AFC

\begin{tabular}{|c|c|c|c|}
\hline HIPÓTESIS & MODELO & $\begin{array}{c}\text { No } \\
\text { FACTORES } \\
\end{array}$ & DESCRIPCIÓN DEL MODELO \\
\hline H1 & $\begin{array}{c}\text { Modelo } \\
\text { Unidimensional }\end{array}$ & 1 & $\begin{array}{l}\text { Las necesidades de apoyo forman un } \\
\text { constructo unifactorial. }\end{array}$ \\
\hline $\mathrm{H} 2$ & $\begin{array}{l}\text { Modelo } \\
\text { Correlacional }\end{array}$ & 7 & $\begin{array}{l}\text { El constructo de 'necesidades de apoyo' se } \\
\text { compone de siete factores correlacionados } \\
\text { (hogar, comunidad, participación escolar, } \\
\text { aprendizaje escolar, salud y seguridad, social y } \\
\text { defensa-autorrepresentación) }\end{array}$ \\
\hline H3 & $\begin{array}{c}\text { Modelo } \\
\text { Jerárquico }\end{array}$ & 8 & $\begin{array}{l}\text { El constructo de 'necesidades de apoyo' } \\
\text { contiene siete factores de primer orden } \\
\text { (hogar, comunidad, participación escolar, } \\
\text { aprendizaje escolar, salud y seguridad, social y } \\
\text { defensa-autorrepresentación) y un factor de } \\
\text { segundo orden (necesidades de apoyo). }\end{array}$ \\
\hline
\end{tabular}

En cuanto a la identificación del modelo, existen dos condiciones básicas que han de ser tenidas en cuenta para identificar un modelo AFC (Arias, 2008; Kline, 2010). La primera de ellas hace referencia al hecho de que todas las variables latentes (factores y errores de medida) deberían tener una escala, lo que implica por lo general asignar un valor de 1.00 (Unit Loading Identification, ULI), usándose la misma estrategia para escalar factores. La segunda, por su parte, se asocia a la necesidad de contar con un modelo sobreidentificado (con un número de grados de libertad superior a 0), es decir, que el número parámetros a estimar ha de ser igual o inferior al número de observaciones. El número de observaciones es independiente del modelo sometido a prueba y se calcula a partir del número de variables dadas $(n=v(v+1) / 2)$. En nuestro caso, el número de variables es igual al número de parcels establecidos ( $\mathrm{v}=21)$, por lo que existen 231 observaciones (21 varianzas más las 210 covarianzas entre las variables observadas). Sin embargo, el número de parámetros a estimar dependerá de cada uno de los modelos propuestos. A continuación presentamos la especificación de cada uno de los modelos, incluyendo el cálculo y descripción de parámetros de todos ellos. 
a) Especificación e identificación del modelo 1: El constructo de 'necesidades de apoyo' es un constructo unidimensional

El primer modelo de medida (Figura 37) quedó definido por una variable latente exógena (independiente) y 21 indicadores. Cada uno de los indicadores es una variable continua con dos causas: el factor o variable latente exógena $\left(\xi_{\mathrm{x}}\right)$ que se supone que mide (i.e., 'necesidades de apoyo') y otras fuentes representadas por el término error $\left(\theta_{\delta}\right)$. A su vez, en esta figura se representan los pesos o cargas factoriales mediante la letra griega $\lambda_{\mathrm{x}}$. En este caso del modelo unidimensional, encontramos un modelo sobreidentificado con 189 grados de libertad, obtenidos de sustraer los 42 parámetros a estimar (21 varianzas del error de medida, 1 varianza del factor y 20 saturaciones factoriales o efectos directos del factor en los indicadores) de las 231 observaciones.

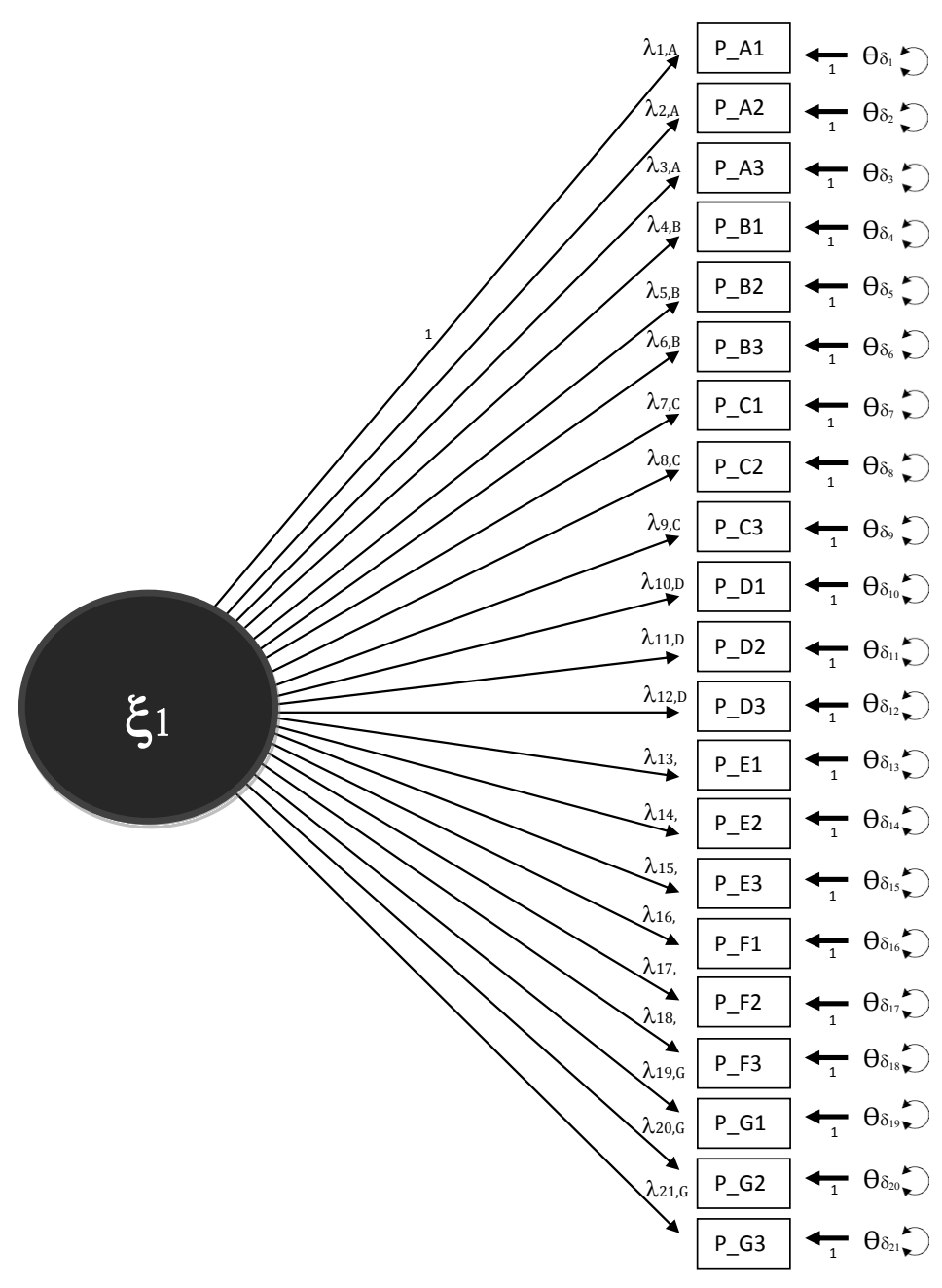

Figura 37. Especificación e identificación del modelo unidimensional (H1) 
b) Especificación e identificación del modelo 2: El constructo de 'necesidades de apoyo' es un constructo compuesto por dimensiones correlacionadas

El segundo modelo sometido a prueba (Figura 38) sostiene que las necesidades de apoyo se componen de siete factores correlacionados (i.e., las siete áreas de apoyo evaluadas en la sección principal de la escala). De nuevo, en este caso cada uno de los indicadores es una variable continua con dos causas: el factor o variable latente exógena $\left(\xi_{\mathrm{x}}\right)$ y otras fuentes representadas por el término error $\left(\theta_{\delta}\right)$, siendo $\lambda_{\mathrm{x}}$ los pesos o cargas factoriales de las variables latentes que en este caso son tres (i.e., habilidades conceptuales, sociales y practicas), representadas mediante las letras $\xi_{\mathrm{A}}, \xi_{\mathrm{B},}, \xi_{\mathrm{C}}, \xi_{\mathrm{D}}, \xi_{\mathrm{E}}, \xi_{\mathrm{F}}, \xi_{\mathrm{G}}$ Para el segundo modelo (modelo correlacional) los parámetros a estimar son 63 (21 varianzas del error de medida, 7 varianzas de los factores, 21 covarianzas de los factores y 14 saturaciones factoriales). Así, este segundo modelo es un modelo sobreidentificado con 168 grados de libertad.

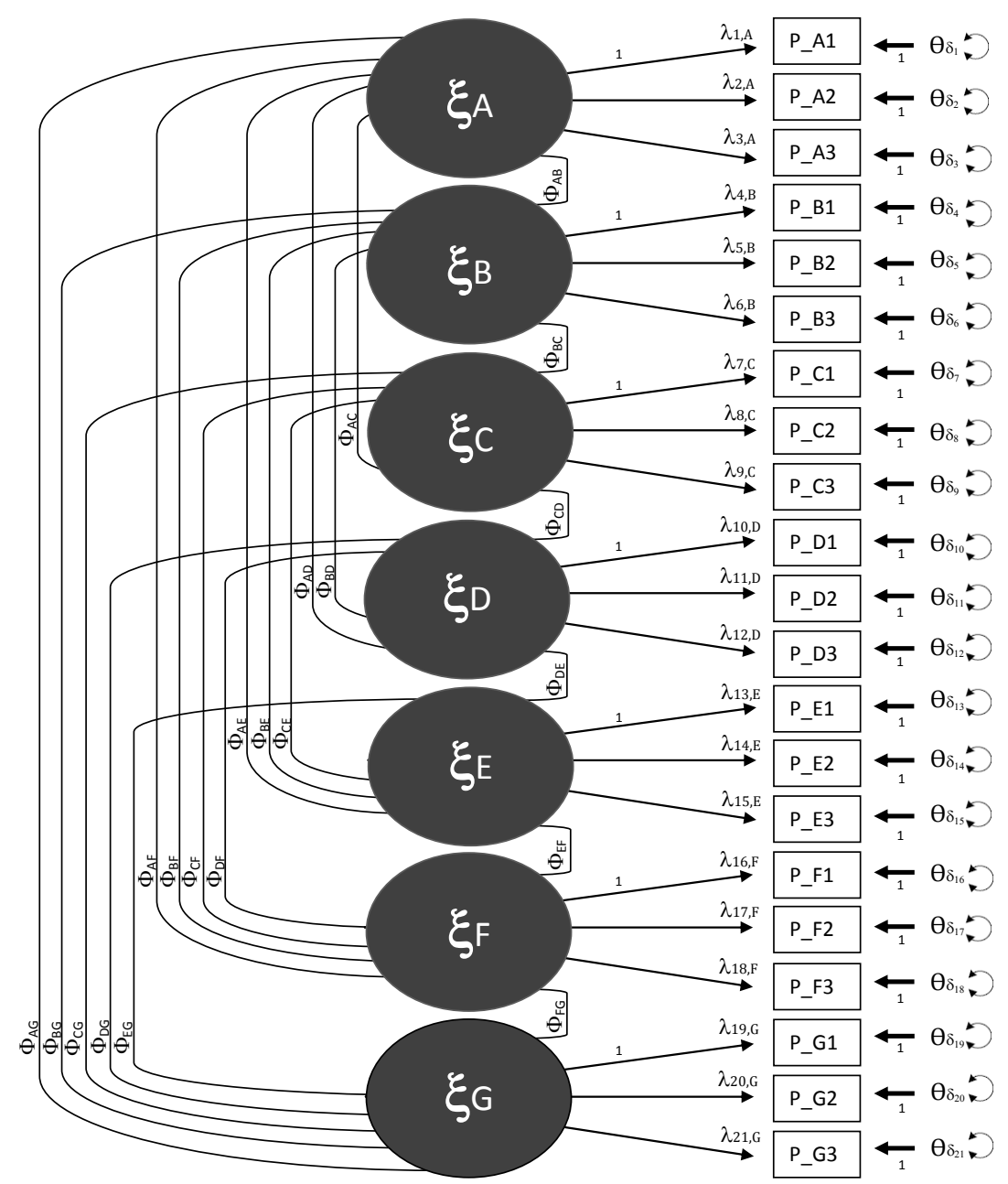

Figura 38. Especificación e identificación del modelo correlacional (H2) 
c) Especificación e identificación del modelo 3: El constructo de 'necesidades de apoyo' es un constructo jerárquico.

En este modelo (Figura 39) existe una única variable latente exógena (i.e., 'necesidades de apoyo'), representada mediante la letra $\xi_{1}$, y siete variables latentes endógenas (i.e., áreas evaluadas por la escala), representadas mediante las letras $\eta_{\mathrm{A}}, \eta_{\mathrm{B}}, \eta_{\mathrm{C}}, \eta_{\mathrm{D}}, \eta_{\mathrm{E}}, \eta_{\mathrm{F}}, \eta_{\mathrm{G}}$. Los efectos directos de la variable latente exógena sobre las variables latentes endógenas se representan mediante el símbolo $\gamma_{\mathrm{x}}$, siendo $\zeta_{\mathrm{x}}$ el error de medida de las variables endógenas. Además, en esta figura se representan también los pesos factoriales mediante la letra griega $\lambda$ x. Aquí el número de parámetros a estimar es 55 (1 varianza de la variable exógena, 7 errores de medida de las variables endógenas, 21 varianzas de los errores de medida, 20 efectos directos de las variables endógenas sobre los indicadores y 6 efectos directos de las variables exógenas sobre las endógenas). Por tanto, este es un modelo sobreidentificado con 176 grados de libertad, obtenidos de la resta entre el número de observaciones (231) y los parámetros a estimar (55).

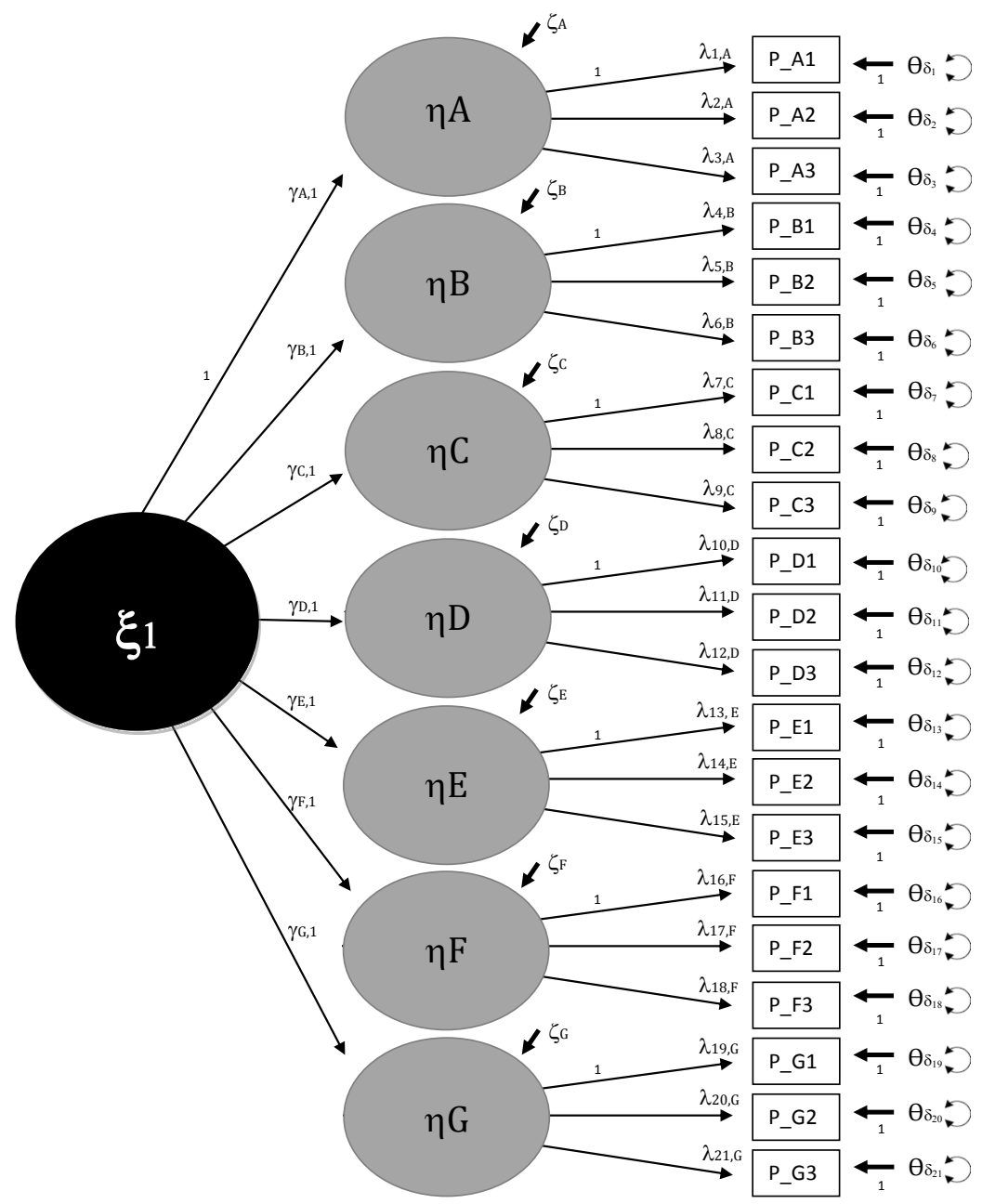

Figura 39. Especificación e identificación del modelo jerárquico (H3) 


\subsubsection{Estimación de parámetros y ajuste de los modelos}

El método de estimación de parámetros más utilizado para estimar los parámetros del modelo es el método de Máxima Verosimilitud [MV] (Hu y Bentler, 1999; Yuan, Bentler y Kano, 1997). No obstante, este método se basa en el supuesto de que los datos son continuos y están distribuidos normalmente y este criterio supuesto es frecuentemente violado, especialmente cuando son analizados datos de naturaleza categórica (Flora y Curran, 2004). Por su parte, Nasser y Takahashi (2003) afirman que, además, este método no provee una inferencia confiable cuando el número de variables analizado es extenso. Por tanto, cuando se trabaja con un número amplio de variables y se viola el supuesto de normalidad, como es nuestro caso, el uso del método MV puede resultar en hallazgos engañosos o conclusiones inválidas sobre la estructura factorial, por lo que conviene usar otro método de estimación de parámetros (Bernstein y Teng, 1989).

En este sentido, conviene señalar que existen métodos concretos, como el método de Mínimos Cuadrados Ponderados (Weighted Least Squares [WLS]), que son resistentes a la violación del supuesto de normalidad y resultan más apropiados cuando se trabaja con datos de naturaleza ordinal. Concretamente, el estudio de la estructura factorial de la SIS-C se llevó a cabo utilizando el método de Mínimos Cuadrados Ponderados Diagonalizados (Diagonally Weighted Least Squares [DWLS]) sobre la matriz de varianzas-covarianzas policóricas y la estimación de covarianzas asintóticas. El método DWLS es un derivado del WLS, también susceptible a la violación del supuesto de normalidad, pero tiene en cuenta únicamente las diagonales de las matrices de covarianzas. Esta peculiaridad permite reducir el número de sujetos participantes necesarios para realizar los análisis y proporciona un proceso de análisis más parsimonioso que el del WLS. A continuación, se presentan las soluciones estandarizadas obtenidas a partir de este método (DWLS) para cada uno de las tres hipótesis sometidas a prueba.

\section{a) Modelo Unidimensional (H1)}

En el primer modelo (Figura 40), los errores de medida oscilaron entre .14 (P_C2) y .40 (P_D1). La proporción de varianza de las variables observadas que es explicada por la variable latente exógena osciló, por tanto, entre .86 y .60 , presentando asimismo las saturaciones factoriales valores superiores a .77. Aunque descriptivamente estos datos pueden parecer adecuados, será necesario analizar los indicadores del modelo para poder determinar si el modelo empírico se ajusta al modelo propuesto. 


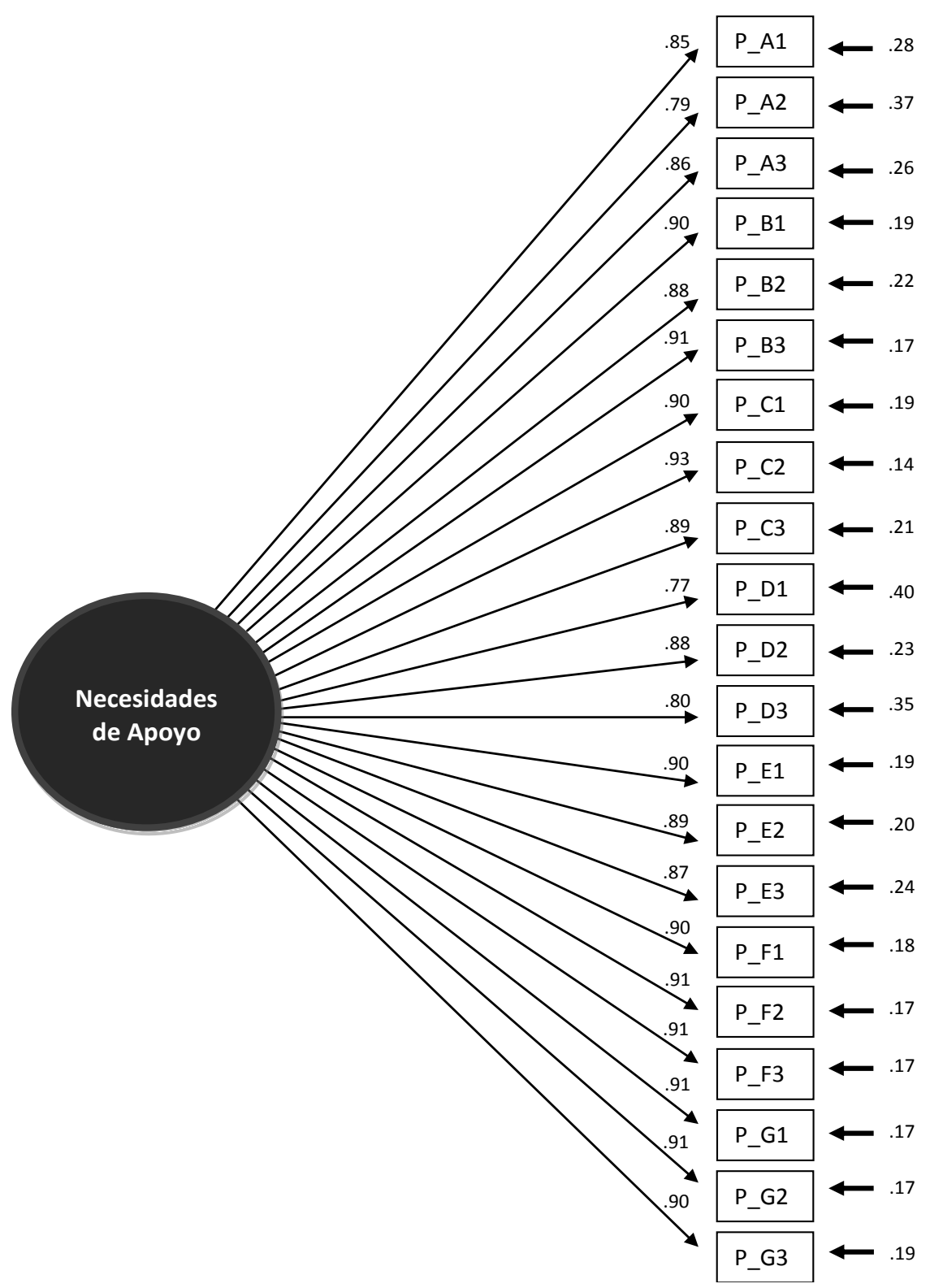

Figura 40. Representación factorial del modelo unidimensional (H1)

\section{b) Modelo Correlacional (H2)}

En el segundo modelo (Figura 41), los errores de medida oscilaron entre .07 (P_D2; P_G1; P_G2) y .27 (P_D1). A partir de este resultado, se puede afirmar que la proporción de varianza de las variables observadas que es explicada por la variable latente exógena oscila entre .93 y .73. Asimismo, todas las saturaciones factoriales presentaron valores superiores a .85. Por último, las covarianzas entre las variables latentes fluctuaron entre .83 y .95, representando una elevada correlación entre ellas. 


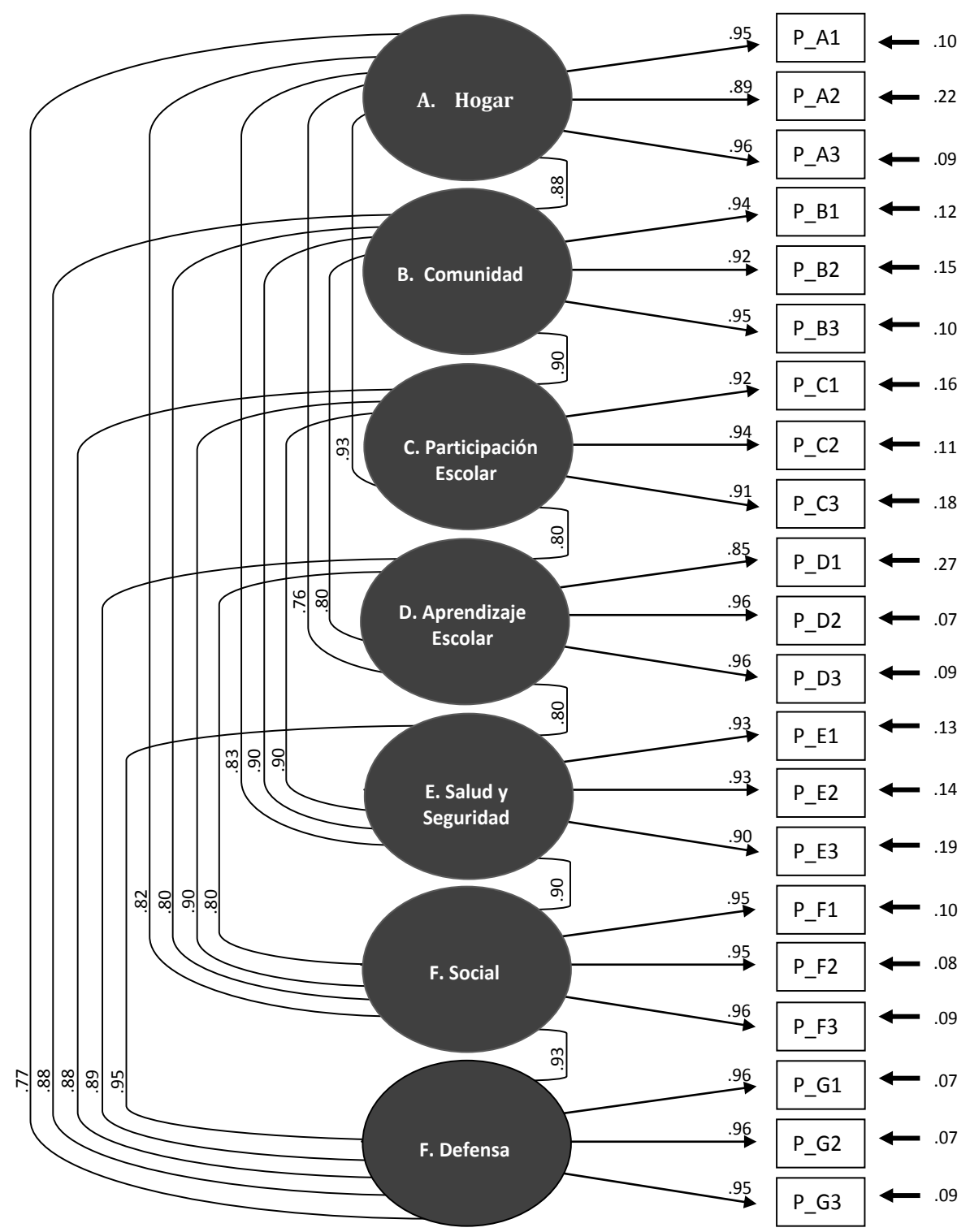

Figura 41. Representación factorial del modelo correlacional (H2)

\section{c) Modelo Jerárquico (H3)}

En relación al tercer modelo (Figura 42), los errores de medida de los indicadores oscilaron entre .07 (P_D2; P_G1; P_G2) y .27 (P_D1), por lo que se puede afirmar que la proporción de varianza de las variables observadas que es explicada por la variable latente endógena oscila entre .93 y .73; obteniéndose resultados similares al modelo anterior. Asimismo, los errores de las variables endógenas oscilan entre .04 y .23, por lo que la proporción de varianza de las variables endógenas que es explicada por la variable latente exógena oscila entre .96 y .77. Se observa que todas las saturaciones factoriales (tanto entre la variable latente exógena y la endógena, como entre ésta y los indicadores observables) presentan valores superiores a 85 . 


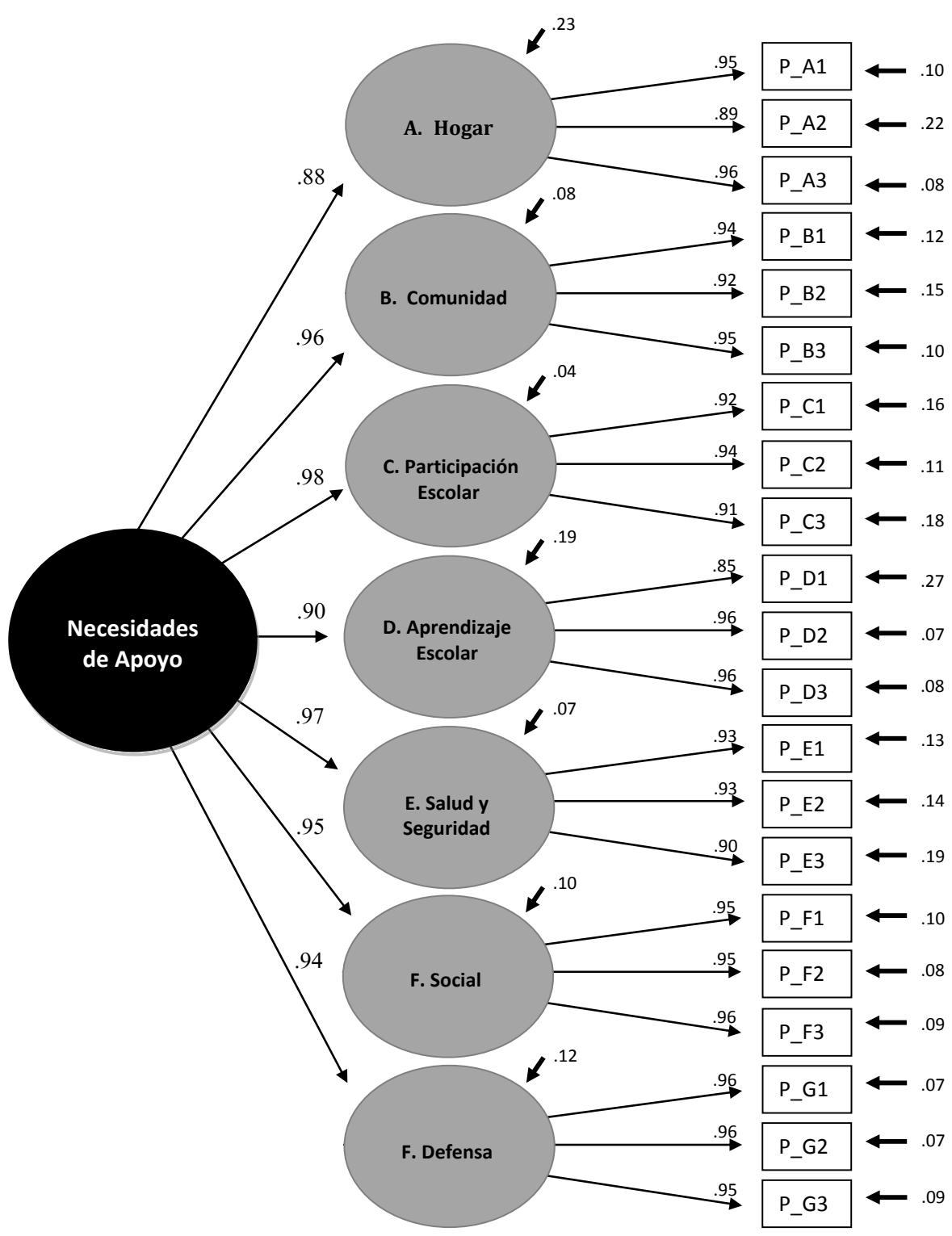

Figura 42. Representación factorial del modelo jerárquico (H3)

Para comprobar el ajuste de los modelos se tuvo en cuenta, en primer lugar, el índice de ajuste absoluto $\chi^{2}$, que busca comprobar que no existen diferencias significativas entre los datos empíricos y teóricos $\left(\mathrm{H}_{0}\right)$. Sin embargo, este criterio no suele cumplirse cuando se trabaja con muestras grandes, ya que a medida que incrementa el número de participantes la significación tiende a reducirse $(\mathrm{p}<.01)$, obligándonos a rechazar $\mathrm{H}_{0}(\mathrm{Hu}$ y Bentler, 1999). En estos casos, se toman como referencia la magnitud del $\chi^{2}$ (reflejándose un mayor ajuste a medida que este disminuye) y otros índices parciales comúnmente utilizados (Arias, 2008; Kline, 2010): (a) error cuadrático medio de aproximación (Root Mean Square error of Approximation [RSMEA]); (b) índice de Tucker-Lewis (TLI); (c) el índice de ajuste comparativo (Comparative Fit Index [CFI]); y (d) raíz del residuo 
cuadrático medio estandarizado (Standardized Root Mean Square Residual [SRMR]). Cómo interpretar cada uno de estos índices de ajuste y los resultados obtenidos para cada uno de los tres modelos planteados se presentan a continuación en la Tabla 70. Teniendo en cuenta los índices de ajuste parcial, podemos concluir que no pudo corroborarse la primera hipótesis planteada (correspondiente al modelo unidimensional), siendo, por el contrario, aceptables tanto la segunda (modelo correlacional) como la tercera (modelo jerárquico) hipótesis. No obstante, destacamos que el grado de ajuste fue considerablemente más alto en el caso del modelo correlacional, siendo ésta la teoría que aporta una explicación más amplia y parsimoniosa a la distribución de los datos.

Tabla 70. Resultados del análisis de los índices de ajuste

\begin{tabular}{|c|c|c|c|c|}
\hline ÍNDICES & INTERPRETACIÓN & $\begin{array}{c}\text { H1. Modelo } \\
\text { Unidimensional }\end{array}$ & $\begin{array}{c}\text { H2. Modelo } \\
\text { Correlacional }\end{array}$ & $\begin{array}{l}\text { H3. Modelo } \\
\text { Jerárquico }\end{array}$ \\
\hline$\chi^{2}(g l)$ & \multirow{2}{*}{$\begin{array}{l}\text { Para concluir que existe } \\
\text { ajuste adecuado hemos de } \\
\text { aceptar H0 (p>.01) }\end{array}$} & 4625.11 (189) & $981.57(168)$ & $1402.92(182)$ \\
\hline Significación & & $\mathrm{p}<.001$ & $\mathrm{p}<.001$ & $\mathrm{p}<.001$ \\
\hline RMSEA & $\begin{array}{l}\text { Valores entorno a } .05 \mathrm{se} \\
\text { consideran aceptables. } \\
\text { Pudiendo llegar aceptarse } \\
\text { valores inferiores a } 08 . \mathrm{El}\end{array}$ & .17 & .077 & .091 \\
\hline $\begin{array}{l}\text { Intervalo } \\
\text { RMSEA } \\
(90 \%)\end{array}$ & $\begin{array}{l}\text { modelo tiene que ser } \\
\text { necesariamente rechazado } \\
\text { si RMSEA >.10 }\end{array}$ & $(.17-.17)$ & $(.073-.082)$ & (086-.095) \\
\hline$T L I$ & Debe ser superior a .95 & .95 & .99 & 0.99 \\
\hline$C F I$ & Debe ser superior a .95 & .96 & .99 & .99 \\
\hline$S R M R$ & $\begin{array}{l}\text { Valores inferiores a } .05 \\
\text { indicaran un buen ajuste, } \\
\text { no siendo aceptables } \\
\text { valores por encima de } .08\end{array}$ & .047 & .020 & .033 \\
\hline
\end{tabular}

Finalmente, teniendo como referencia el buen ajuste del modelo correlacional, se comprobó que la consistencia interna del mismo fuera adecuada. Para ello, se analizaron dos índices: (1) la fiabilidad compuesta $\left(\rho_{c}\right)$ de cada variable latente planteada en este modelo, que representará la fiabilidad del constructo de manera similar al alfa de Cronbach; y (2) la varianza media extractada $\left(\rho_{\mathrm{v}}\right)$ que indica la cantidad de varianza que es capturada por cada una de las variables latentes. En ambos casos, el límite inferior permitido para poder hablar de una buena fiabilidad suele establecerse alrededor de $.50 \mathrm{o}$ .60 (Arias, 2008). Los resultados obtenidos en cada una de las variables latentes que componen el modelo correlacional (coincidiendo con las subescalas de la SIS-C) se presentación en la Tabla 71. Como se puede apreciar, en ambos casos se obtienen valores superiores a .85, permitiendo afirmar que modelo correlacional propuesto es fiable. 
Tabla 71. Fiabilidad compuesta y varianza media extractada

\begin{tabular}{clcc}
\hline \multicolumn{2}{l}{ Variables Latentes } & $\rho_{c}=\frac{(\Sigma \lambda)^{2}}{(\Sigma \lambda)^{2}+\Sigma(\theta)}$ & $\rho_{v}=\frac{\left(\Sigma \lambda^{2}\right)}{\left[\Sigma \lambda^{2}+\Sigma(\theta)\right]}$ \\
\hline A. Hogar & .950 & .865 \\
B. & Comunidad & .948 & .858 \\
C. & Participación Escolar & .957 & .880 \\
$D$. & Aprendizaje Escolar & .955 & .877 \\
E. Saludy Seguridad & .950 & .864 \\
F. Social & .955 & .877 \\
$G$. & Defensa & .945 & .850 \\
\hline
\end{tabular}

\subsubsection{Objetivo 3: ajuste de los datos al MCP (TRI)}

\subsubsection{Requisitos previos: análisis de la polaridad, la varianza explicada y de la unidimensionalidad}

Las asunciones subyacentes de los modelos de Rasch implican que todos los ítems trabajen en la misma dirección para la evaluación de un constructo determinado, que la varianza de las medidas sea compartida y que exista unidimensionalidad en cada subescala evaluada. La ausencia de estos supuestos previos reflejaría un mal ajuste de los datos a este modelo y las ventajas de su utilización desaparecerían, por lo que es necesario empezar el estudio de la SIS-C a través de la TRI asegurando estos principios.

En nuestro caso, estos datos pueden ser fácilmente extraídos de los análisis previos realizados en los apartados correspondientes a la TCT y el AFC, donde se ha puesto de manifiesto que todos los ítems trabajan en la misma dirección y que se distribuyen en siete factores unidimensionales. No obstante, se presentan en este momento el análisis de resultados realizado a través del programa Winsteps, incluyendo nuevas evidencias y aportando gráficos específicos para estas premisas, reflejando explícitamente la adecuación del uso de la metodología TRI.

En primer lugar, para conocer la polarización de los ítems se analizaron las correlaciones producto-momento de Pearson, que deben ser positivas y elevadas para poder garantizar que los ítems trabajan en una misma dirección. Haciendo un resumen de estos datos podemos decir que las correlaciones entre cada uno los ítems y la puntuación global de la escala a la que pertenecen alcanzaron en todos los casos puntuaciones superiores a .70 (Figura 43). 


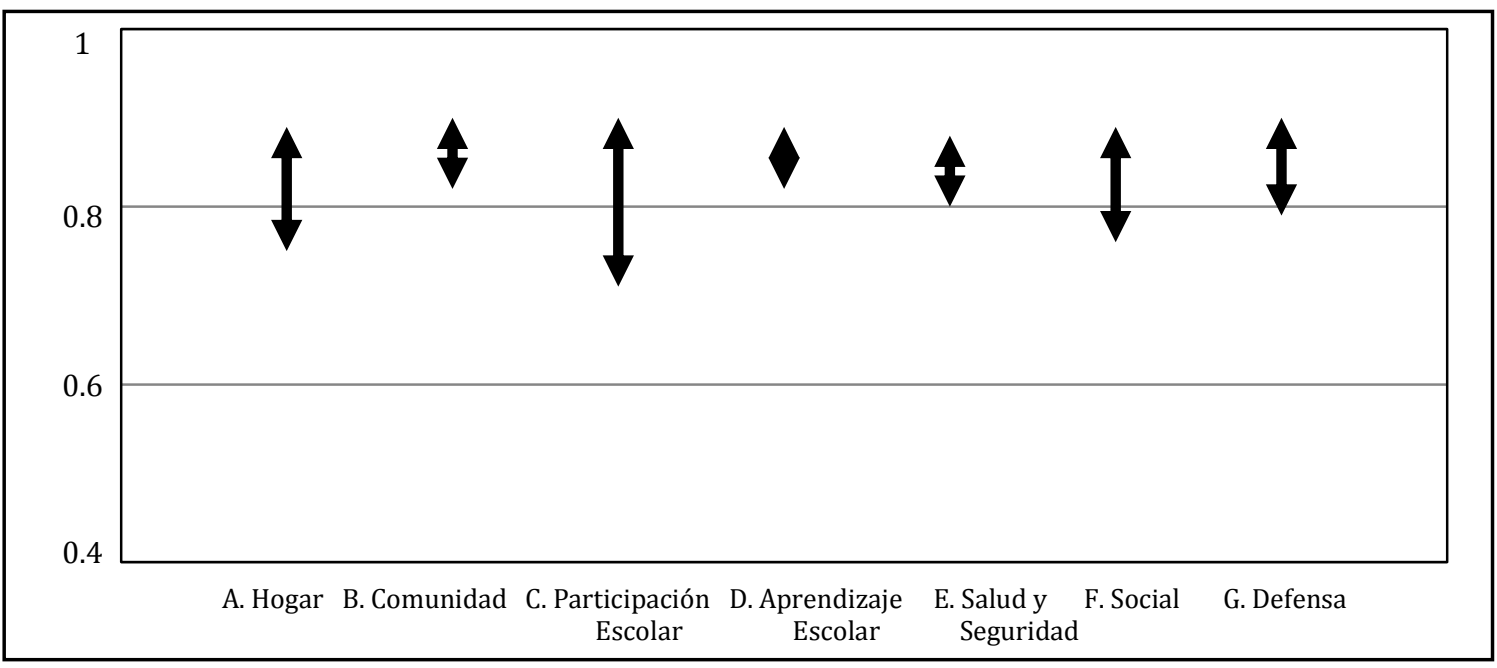

Figura 43. Análisis de la polaridad de los ítems

En cuanto a la unidimensionalidad y la cantidad de varianza explicada por los datos, se realizó un Análisis de Componentes Principales (ACP) para cada una de las dimensiones de la escala. Este proceso permite descomponer la matriz de correlaciones entre los ítems en relación con los residuales estandarizados (las diferencias entre los valores observados y los valores predichos por el modelo), lo que permitirá determinar si cada subescala es explicada por un único componente o si existen otras dimensiones potenciales. De manera complementaria, este análisis proporciona información exhaustiva sobre la cantidad de varianza explicada por las medidas (Figura 44).

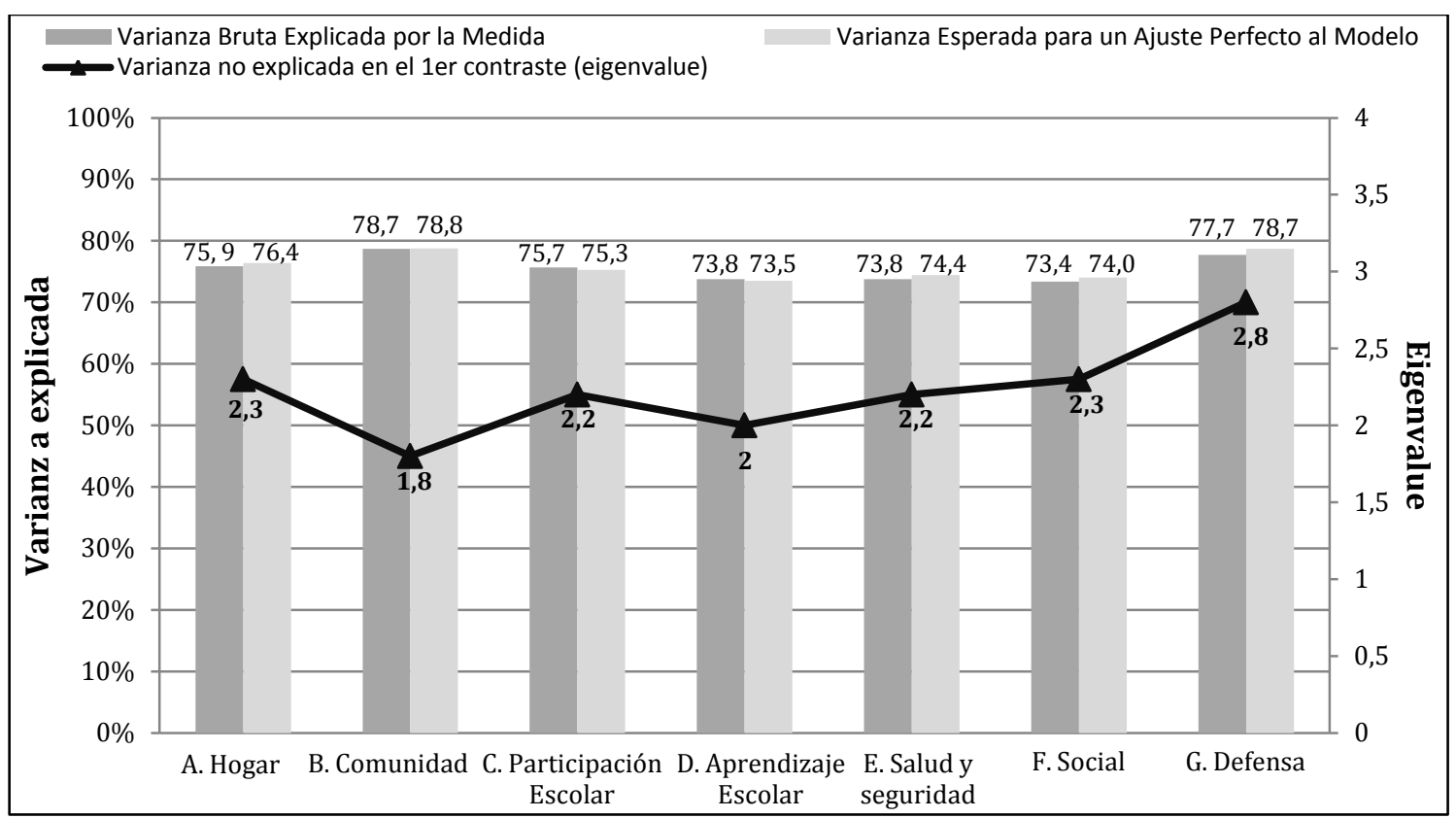

Figura 44. Varianza explicada por las medidas y unidimensionalidad de las subescalas 
El primer factor del análisis corresponde a la dimensión Rasch. Para considerar que hay unidimensionalidad, la varianza explicada por la medida de los datos deber ser igual o superior al 60\%, lo que ocurre en todas las dimensiones de la escala. A su vez, se puede observar que en todas las dimensiones del instrumento la varianza explicada por los datos es muy similar a la esperada si los datos se ajustaran perfectamente el modelo, lo que indica que la estimación de las medidas ha sido exitosa.

La segunda dimensión (o primer contraste de los residuos) indica si existen patrones en las diferencias dentro de los residuos suficientemente grandes como para sugerir que existe más de una dimensión. Si la varianza de la dimensión de Rasch fuera escasa, y a la vez fuera significativa en los sucesivos contrastes, la estructura podría ser multidimensionalidad. Suele adoptarse la regla de que la segunda dimensión deberá tener al menos 3 ítems (de acuerdo con su eigenvalue o valor propio) para poder ser considerada como una posible segunda dimensión (Linacre, 2005). En nuestros resultados, el valor propio del primer contraste de los residuales es siempre inferior a 3, reflejando la unidimensionalidad de todas las subescalas de la SIS-C.

Una vez analizadas estas tres asunciones principales, el siguiente paso a seguir corresponde al análisis de las categorías de respuesta, que también deben cumplir una serie de criterios para poder considerar que los ítems que componen el instrumento están siendo medidos y evaluados de manera pertinente.

\subsubsection{Adecuación de las categorías de respuesta}

Según Linacre (2002), el modo en que la variable de estudio es dividida en categorías para ser analizada afecta a la medida de las cualidades del test. Así, con el objeto de determinar si las categorías de respuesta de la SIS-C eran utilizadas de la manera que se esperaba, se llevó a cabo un diagnóstico exhaustivo de las categorías de respuesta.

Debido al complejo formato de respuesta de la escala, formado por tres índices de medida diferentes dentro de cada ítem (tipo, frecuencia y tiempo diario de apoyo) que presentan, su vez, un formato de respuesta de clasificación valorado en una escala de cinco opciones de respuesta (de 0 a 4), se optó por analizar la idoneidad de las categorías de respuesta teniendo en cuenta cada uno los tres índices de medida de manera independiente. 
Con esta finalidad, se examinaron los estadísticos de uso de las categorías (i.e., frecuencias de las categorías y medidas promedio), así como los umbrales de cada categoría. En este sentido, para evaluar la idoneidad de las categorías de respuesta en relación con la variable de medida, se han de tener en cuenta una serie de criterios: (1) al menos diez observaciones por categoría; (2) obtención de valores Outfit inferiores a 2; y (3) ordenación monotónica de los valores promedios de las categorías (la categoría inferior [i.e., '0'], no tiene transición anterior y la medida debe quedar calificada como 'ninguno').

Siguiendo las pautas de trabajo establecidas en el estudio piloto, se analizó en primer lugar el funcionamiento global de las categorías. En la Tabla 72 se muestra, de manera general, el funcionamiento de las categorías de respuesta, pudiéndose apreciar que las categorías de respuesta ' 3 ' y '4' referentes a los índices tipo de apoyo y frecuencia de apoyo cumplen los tres criterios expuestos correctamente. Aunque en el estudio piloto las categorías de respuesta ' 3 ' y ' 4 ' presentaban ciertas limitaciones a lo largo de los tres índices de medida, en el análisis final de la escala estos desajustes aparecen únicamente en el tiempo diario de apoyo.

Tabla 72. Idoneidad de las categorías de respuesta

\begin{tabular}{lcccc}
\hline & $\begin{array}{c}\text { Categoría } \\
\text { Respuesta }\end{array}$ & $\begin{array}{c}\text { Respuestas } \\
\text { Observadas }\end{array}$ & Outfit & $\begin{array}{c}\text { Puntos de } \\
\text { Transición } \\
\text { entre las } \\
\text { categorías }\end{array}$ \\
\hline \multirow{4}{*}{ Tipo de apoyo } & 0 & 4789 & 1.44 & Ninguno \\
& 1 & 6263 & 1.18 & -1.34 \\
& 2 & 10823 & .87 & -.77 \\
& 3 & 9359 & .75 & .81 \\
Frecuencia de & 4 & 16344 & 1.02 & 1.30 \\
apoyo & 0 & 4941 & 1.93 & Ninguno \\
& 1 & 4480 & .96 & -.70 \\
& 2 & 7858 & .87 & -.68 \\
& 3 & 7957 & .66 & -.60 \\
Tiempo diario & 4 & 20269 & 1.09 & .78 \\
de apoyo & 0 & 5648 & 1.19 & Ninguno \\
& 1 & 13000 & .97 & -1.84 \\
& 2 & 12944 & .84 & -.18 \\
& 3 & 5509 & .95 & 1.39 \\
& 4 & 10844 & 1.04 & .63 \\
\hline
\end{tabular}


Concretamente, los datos muestran que las categorías '3' y '4' de este tercer índice no obtienen una ordenación monotónica de los promedios de las categorías. En la Figura 45 se representa, de manera ilustrada, la falta de división existente entre el rango de actuación de ambas categorías.

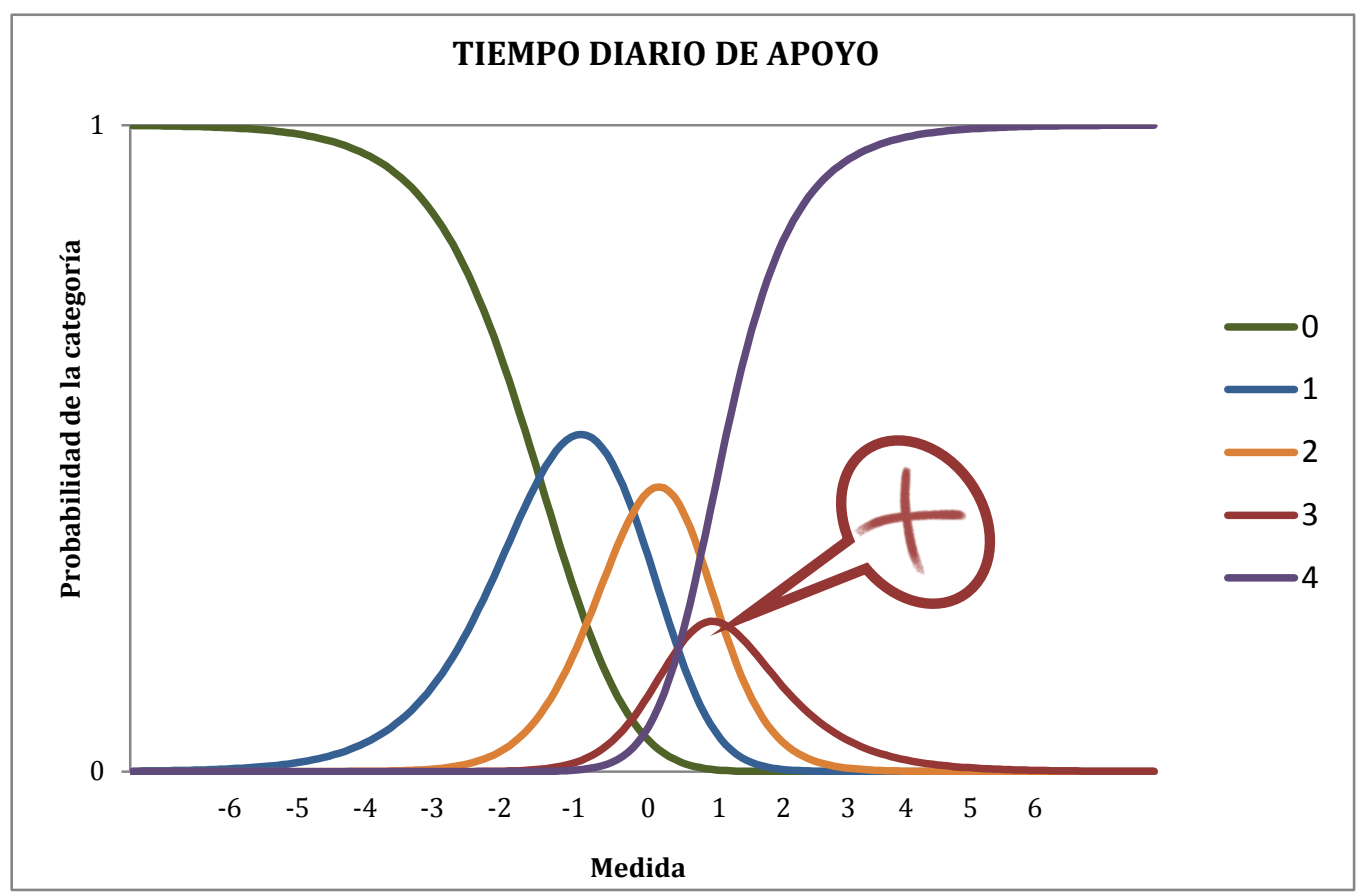

Figura 45. Representación de las categorías de respuesta del índice tiempo diario de apoyo

A la luz de estos resultados generales, cuyas conclusiones fueron repetidas en el análisis de las subescalas, y teniendo como referencia el Modelo de Crédito Parcial (que supone una independencia funcional de cada uno de los ítems), se analizó el funcionamiento de las categorías de respuesta en los 61 ítems que componen la escala de manera independiente.

Concretamente, se estudió la idoneidad de las categorías de respuesta ' 3 ' y '4' del índice tiempo de apoyo diario determinando así, específicamente, qué ítems estaban siendo perjudicados por esta medida y cuáles de ellos podrían verse beneficiados al colapsar estas categorías de respuesta (Tabla 73). Se observa que los ítems que presentaban un mal ajuste de las categorías anteriormente mencionadas mejoran sus propiedades tras colapsar las categorías de respuesta, influyendo en algunos casos incluso de manera positiva en las propiedades del resto de las categorías (como ocurre, por ejemplo, en el ítem B7 con la categoría de respuesta 0 ). 
Tabla 73. Ítems con una mala adecuación de las categorías de respuesta referentes al tiempo diario de apoyo

\begin{tabular}{|c|c|c|c|c|c|c|c|c|c|c|c|c|c|c|c|c|c|}
\hline \multirow{2}{*}{ ítems } & \multicolumn{4}{|c|}{ AJUSTE DE LAS CATEGORÍAS DE RESPUESTA } & \multicolumn{4}{|c|}{ AJUSTE DE LAS CATEGORÍAS COLAPSADAS } & \multirow[b]{2}{*}{ ítems } & \multicolumn{4}{|c|}{ AJUSTE DE LAS CATEGORÍAS DE RESPUESTA } & \multicolumn{4}{|c|}{ AJUSTE DE LAS CATEGORÍAS COLAPSADAS } \\
\hline & $\begin{array}{c}\text { Categ. } \\
\text { Respuesta }\end{array}$ & $\begin{array}{l}\text { Respuesta } \\
\text { Observada }\end{array}$ & Outfit & $\begin{array}{c}\text { Puntos de } \\
\text { Transic. }\end{array}$ & $\begin{array}{c}\text { Categ. } \\
\text { Respuesta }\end{array}$ & $\begin{array}{l}\text { Respuesta } \\
\text { Observada }\end{array}$ & Outfit & $\begin{array}{c}\text { Puntos de } \\
\text { Transic. }\end{array}$ & & $\begin{array}{c}\text { Categ. } \\
\text { Respuesta }\end{array}$ & $\begin{array}{l}\text { Respuesta } \\
\text { Observada }\end{array}$ & Outfit & $\begin{array}{c}\text { Puntos de } \\
\text { Transic. }\end{array}$ & $\begin{array}{c}\text { Categ. } \\
\text { Respuesta }\end{array}$ & $\begin{array}{l}\text { Respuesta } \\
\text { Observada }\end{array}$ & Outfit & $\begin{array}{c}\text { Puntos de } \\
\text { Transic. }\end{array}$ \\
\hline \multirow{4}{*}{$A 1$} & 0 & 42 & 1.38 & Ninguno & 0 & 42 & 1.50 & Ninguno & \multirow{4}{*}{ C4 } & 0 & 82 & .99 & Ninguno & 0 & 82 & 1.06 & Ninguno \\
\hline & 1 & 242 & .93 & -3.75 & 1 & 242 & .91 & -3.03 & & 1 & 237 & .95 & -2.82 & 1 & 237 & 1.04 & -2.36 \\
\hline & 2 & 261 & .94 & -.28 & 2 & 261 & .93 & .49 & & 2 & 308 & 1.26 & -.84 & 2 & 308 & 1.25 & -.24 \\
\hline & $\begin{array}{l}3 \\
4\end{array}$ & $\begin{array}{r}87 \\
130\end{array}$ & $\begin{array}{l}1.05 \\
1.39\end{array}$ & $\begin{array}{l}2.25 \\
1.78\end{array}$ & 3 & 201 & 1.18 & 2.53 & & $\begin{array}{l}3 \\
4\end{array}$ & $\begin{array}{l}79 \\
37\end{array}$ & $\begin{array}{l}1.38 \\
2.02\end{array}$ & $\begin{array}{l}1.73 \\
1.93\end{array}$ & 3 & 92 & 1.65 & 2.60 \\
\hline \multirow{5}{*}{$A 4$} & 0 & 109 & .76 & Ninguno & 0 & 109 & .74 & Ninguno & \multirow{5}{*}{ C5 } & 0 & 142 & .83 & Ninguno & 0 & 142 & .80 & Ninguno \\
\hline & 1 & 330 & .78 & -3.85 & 1 & 330 & .78 & -3.26 & & 1 & 237 & .63 & -1.91 & 1 & 237 & .58 & -.168 \\
\hline & 2 & 254 & .74 & -.58 & 2 & 254 & .79 & .08 & & 2 & 196 & .65 & -.20 & 2 & 196 & .71 & .20 \\
\hline & 3 & 43 & .72 & 2.32 & \multirow[t]{2}{*}{3} & \multirow[t]{2}{*}{53} & \multirow[t]{2}{*}{.89} & \multirow{2}{*}{3.18} & & 3 & 74 & .69 & 1.33 & \multirow[t]{2}{*}{3} & \multirow{2}{*}{144} & \multirow{2}{*}{.84} & 1.48 \\
\hline & 4 & 26 & .65 & 2.11 & & & & & & 4 & 94 & .93 & .77 & & & & 1.48 \\
\hline & 0 & 320 & 1.33 & Ninguno & 0 & 320 & 1.47 & Ninguno & & 0 & 107 & 1.55 & Ninguno & 0 & 107 & 1.47 & Ninguno \\
\hline & 1 & 246 & 1.03 & -2.02 & 1 & 246 & .99 & -1.93 & & 1 & 223 & .66 & -1.90 & 1 & 223 & .65 & -1.63 \\
\hline$A 6$ & 2 & 132 & 1.31 & -.18 & 2 & 132 & 1.34 & .07 & C7 & 2 & 172 & .57 & .08 & 2 & 172 & .62 & .50 \\
\hline & $\begin{array}{l}3 \\
4\end{array}$ & $\begin{array}{l}20 \\
44\end{array}$ & $\begin{array}{l}1.22 \\
2.17\end{array}$ & $\begin{array}{r}2.05 \\
.15\end{array}$ & 3 & 48 & 1.74 & 1.87 & & $\begin{array}{l}3 \\
4\end{array}$ & $\begin{array}{r}82 \\
159\end{array}$ & $\begin{array}{l}.92 \\
.97\end{array}$ & $\begin{array}{r}1.29 \\
.53\end{array}$ & 3 & 217 & 1.00 & 1.13 \\
\hline & 0 & 160 & 1.12 & Ninguno & 0 & 160 & 1.16 & Ninguno & & 0 & 150 & .92 & Ninguno & 0 & 150 & .89 & Ninguno \\
\hline & 1 & 287 & .85 & -2.68 & 1 & 287 & .89 & -2.27 & & 1 & 243 & .66 & -1.79 & 1 & 243 & .69 & -1.63 \\
\hline$A 7$ & 2 & 174 & .86 & -.01 & 2 & 174 & .91 & .50 & $C 8$ & 2 & 173 & .71 & .01 & 2 & 173 & .74 & .36 \\
\hline & 3 & 52 & 1.23 & 1.78 & 3 & 125 & 1.11 & 1.78 & & 3 & 60 & .55 & 1.44 & 3 & 153 & .89 & 1.27 \\
\hline & 4 & 89 & .93 & .90 & 3 & 125 & 1.11 & 1.78 & & 4 & 117 & .89 & .34 & 3 & 153 & .89 & 1.27 \\
\hline & 0 & 130 & 1.28 & Ninguno & 0 & 130 & 1.31 & Ninguno & & 0 & 47 & 1.68 & Ninguno & 0 & 47 & 1.59 & Ninguno \\
\hline & 1 & 297 & 1.06 & -3.02 & 1 & 297 & 1.06 & -2.54 & & 1 & 134 & .98 & -2.59 & 1 & 134 & .98 & -2.64 \\
\hline$A 9$ & 2 & 200 & .98 & -.12 & 2 & 200 & 1.04 & .44 & $D 7$ & 2 & 250 & 1.20 & -.88 & 2 & 250 & .91 & .20 \\
\hline & 3 & 56 & 1.51 & 1.92 & 3 & & & & & 3 & 95 & .85 & 1.78 & 3 & & & \\
\hline & 4 & 79 & 1.57 & 1.22 & 3 & 119 & 1.42 & 2.10 & & 4 & 126 & 1.09 & 1.69 & 3 & 261 & 1.04 & 2.44 \\
\hline & 0 & 45 & 1.17 & Ninguno & 0 & 45 & 1.17 & Ninguno & & 0 & 140 & 1.25 & Ninguno & 0 & 140 & 1.25 & Ninguno \\
\hline & 1 & 202 & 1.02 & -4.17 & 1 & 202 & .99 & -3.26 & & 1 & 330 & 1.48 & -2.87 & 1 & 330 & 1.51 & -2.64 \\
\hline$B 6$ & 2 & 356 & .95 & -1.22 & 2 & 356 & .98 & -.27 & $E 1$ & 2 & 147 & .93 & .15 & 2 & 147 & .97 & .50 \\
\hline & $\begin{array}{l}3 \\
4\end{array}$ & $\begin{array}{l}95 \\
50\end{array}$ & .83 & $\begin{array}{l}2.33 \\
3.06\end{array}$ & 3 & 104 & 1.37 & 3.54 & & $\begin{array}{l}3 \\
4\end{array}$ & $\begin{array}{l}44 \\
48\end{array}$ & 1.08 & 1.55 & 3 & 53 & 1.44 & 2.14 \\
\hline & 0 & 86 & 2.02 & Ninguno & 0 & 86 & 1.97 & Ninguno & & 0 & 89 & $\begin{array}{l}1.24 \\
1.29\end{array}$ & Ninguno & 0 & 89 & 1.36 & Ninguno \\
\hline & 1 & 252 & 1.07 & -3.27 & 1 & 252 & 1.04 & -2.70 & & 1 & 230 & 1.02 & -2.79 & 1 & 230 & .99 & -2.33 \\
\hline$B 7$ & 2 & 223 & .74 & -.26 & 2 & 223 & .99 & .39 & $E 2$ & 2 & 252 & .86 & -.56 & 2 & 252 & .96 & -.04 \\
\hline & $\begin{array}{l}3 \\
4\end{array}$ & $\begin{array}{r}81 \\
107\end{array}$ & $\begin{array}{r}.99 \\
1.46\end{array}$ & $\begin{array}{l}1.88 \\
1.65\end{array}$ & 3 & 147 & 1.22 & 2.31 & & $\begin{array}{l}3 \\
4\end{array}$ & $\begin{array}{l}64 \\
74\end{array}$ & $\begin{array}{r}.82 \\
1.13\end{array}$ & $\begin{array}{l}1.94 \\
1.40\end{array}$ & 3 & 99 & 1.05 & 2.37 \\
\hline & 0 & 91 & .75 & Ninguno & 0 & 91 & .69 & Ninguno & & 0 & 52 & 1.38 & Ninguno & 0 & 52 & 1.48 & Ninguno \\
\hline & 1 & 162 & .78 & -1.89 & 1 & 162 & .74 & -1.46 & & 1 & 232 & 1.08 & -3.23 & 1 & 232 & 1.03 & -2.66 \\
\hline$C 2$ & 2 & 255 & .72 & -.74 & 2 & 255 & .73 & -.20 & $E 3$ & 2 & 246 & .83 & -.29 & 2 & 246 & .94 & .34 \\
\hline & 3 & 119 & .58 & 1.31 & 3 & 211 & 89 & 166 & & 3 & 80 & .81 & 1.95 & 3 & 140 & 93 & 2.32 \\
\hline & 4 & 116 & 1.06 & 1.31 & 3 & 211 & .89 & 1.66 & & 4 & 90 & 1.04 & 1.57 & & & & \\
\hline
\end{tabular}


Tabla 73. Ítems con una mala adecuación de las categorías de respuesta referentes al tiempo diario de apoyo (continuación)

\begin{tabular}{|c|c|c|c|c|c|c|c|c|c|c|c|c|c|c|c|c|c|}
\hline \multirow{2}{*}{ ítems } & \multicolumn{4}{|c|}{ AJUSTE DE LAS CATEGORÍAS DE RESPUESTA } & \multicolumn{4}{|c|}{ AJUSTE DE LAS CATEGORÍAS COLAPSADAS } & \multirow{2}{*}{ ítems } & \multicolumn{4}{|c|}{ AJUSTE DE LAS CATEGORÍAS DE RESPUESTA } & \multicolumn{4}{|c|}{ AJUSTE DE LAS CATEGORÍAS COLAPSADAS } \\
\hline & $\begin{array}{c}\text { Categ. } \\
\text { Respuesta }\end{array}$ & $\begin{array}{l}\text { Respuesta } \\
\text { Observada }\end{array}$ & OUTFIT & $\begin{array}{c}\text { Puntos de } \\
\text { Transic. }\end{array}$ & $\begin{array}{c}\text { Categ. } \\
\text { Respuesta }\end{array}$ & $\begin{array}{l}\text { Respuesta } \\
\text { Observada }\end{array}$ & OUTFIT & $\begin{array}{c}\text { Puntos de } \\
\text { Transic. }\end{array}$ & & $\begin{array}{c}\text { Categ. } \\
\text { Respuesta }\end{array}$ & $\begin{array}{l}\text { Respuesta } \\
\text { Observada }\end{array}$ & OUTFIT & $\begin{array}{c}\text { Puntos de } \\
\text { Transic. }\end{array}$ & $\begin{array}{c}\text { Categ. } \\
\text { Respuesta }\end{array}$ & $\begin{array}{l}\text { Respuesta } \\
\text { Observada }\end{array}$ & OUTFIT & $\begin{array}{c}\text { Puntos de } \\
\text { Transic. }\end{array}$ \\
\hline \multirow{5}{*}{ E4 } & 0 & 53 & .81 & Ninguno & 0 & 53 & .82 & Ninguno & \multirow{5}{*}{ F7 } & 0 & 72 & .91 & Ninguno & 0 & 72 & .92 & Ninguno \\
\hline & 1 & 246 & .72 & -3.18 & 1 & 246 & .68 & -2.67 & & 1 & 188 & .60 & -2.27 & 1 & 188 & .56 & -1.81 \\
\hline & 2 & 225 & .57 & -.07 & 2 & 225 & .70 & .50 & & 2 & 195 & .48 & -.24 & 2 & 195 & .51 & .30 \\
\hline & 3 & 68 & 1.21 & 2.04 & \multirow[t]{2}{*}{3} & \multirow{2}{*}{146} & \multirow{2}{*}{1.14} & \multirow{2}{*}{2.18} & & 3 & 92 & .65 & 1.45 & 3 & & .79 & 1.51 \\
\hline & 4 & 117 & 1.29 & 1.21 & & & & & & 4 & 151 & .67 & 1.06 & 3 & 192 & .79 & 1.51 \\
\hline \multirow{4}{*}{$E 5$} & 0 & 57 & .87 & Ninguno & 0 & 57 & .91 & Ninguno & \multirow{4}{*}{ F9 } & 0 & 70 & 2.09 & Ninguno & 0 & 70 & 1.94 & Ninguno \\
\hline & 1 & 383 & .90 & -3.67 & 1 & 383 & .85 & -3.35 & & 1 & 247 & 1.44 & -2.52 & 1 & 247 & 1.49 & -2.14 \\
\hline & 2 & 141 & .73 & .82 & 2 & 141 & .81 & 1.25 & & 2 & 145 & .76 & .41 & 2 & 145 & 1.04 & .89 \\
\hline & $\begin{array}{l}3 \\
4\end{array}$ & 35 & $\begin{array}{r}.45 \\
125\end{array}$ & $\begin{array}{r}2.19 \\
66\end{array}$ & 3 & 89 & .99 & 2.10 & & 3 & 70 & .81 & 1.46 & 3 & 185 & 1.71 & 1.24 \\
\hline & 0 & 60 & .93 & Ninguno & 0 & 60 & .96 & Ninguno & & $\frac{4}{0}$ & $\begin{array}{r}100 \\
50\end{array}$ & $\frac{2.74}{1.15}$ & $\begin{array}{r}.03 \\
\text { Ninguno }\end{array}$ & 0 & 50 & 1.12 & Ninguno \\
\hline & 1 & 332 & .98 & -3.35 & 1 & 332 & .87 & -2.91 & & 1 & 225 & .67 & -3.14 & 1 & 225 & .67 & -2.57 \\
\hline E6 & 2 & 143 & .64 & .69 & 2 & 143 & .70 & 1.21 & $G 2$ & 2 & 186 & .58 & -.07 & 2 & 186 & .62 & .57 \\
\hline & $\begin{array}{l}3 \\
4\end{array}$ & $\begin{array}{r}63 \\
111\end{array}$ & $\begin{array}{r}.92 \\
1.16\end{array}$ & $\begin{array}{l}1.60 \\
1.06\end{array}$ & 3 & 135 & 1.18 & 1.70 & & $\begin{array}{l}3 \\
4\end{array}$ & $\begin{array}{r}83 \\
123\end{array}$ & $\begin{array}{l}.83 \\
.94\end{array}$ & $\begin{array}{l}1.65 \\
1.56\end{array}$ & 3 & 149 & 1.00 & 2.00 \\
\hline & 0 & 62 & .99 & Ninguno & 0 & 62 & 1.01 & Ninguno & & 0 & 38 & 1.16 & Ninguno & 0 & 38 & 1.13 & Ninguno \\
\hline & 1 & 303 & 1.26 & -3.16 & 1 & 303 & 1.10 & -2.71 & & 1 & 195 & .70 & -3.24 & 1 & 195 & .66 & -2.59 \\
\hline$E 7$ & 2 & 1551 & .70 & .56 & 2 & 151 & .76 & 1.09 & G3 & 2 & 211 & .63 & -.28 & 2 & 211 & .64 & .42 \\
\hline & 3 & 67 & .64 & 1.60 & & & & & & 3 & 92 & .65 & 1.77 & & & & \\
\hline & 4 & 126 & 1.18 & 1.00 & 3 & 154 & 1.03 & 1.62 & & 4 & 131 & .83 & 1.74 & 3 & 166 & .84 & 2.17 \\
\hline & 0 & 66 & .90 & Ninguno & 0 & 66 & .94 & Ninguno & & 0 & 90 & 1.13 & Ninguno & 0 & 90 & 1.15 & Ninguno \\
\hline & 1 & 246 & .74 & -2.86 & 1 & 246 & .76 & -2.37 & & 1 & 282 & .94 & -2.99 & 1 & 282 & .87 & -2.57 \\
\hline$E 8$ & 2 & 184 & .76 & .12 & 2 & 184 & .76 & .68 & G5 & 2 & 143 & .54 & .20 & 2 & 143 & .59 & .72 \\
\hline & 3 & 80 & .78 & 1.60 & 3 & & & & & 3 & 64 & .54 & 1.43 & 3 & 95 & & \\
\hline & 4 & 133 & 1.22 & 1.13 & 3 & 174 & .90 & 1.69 & & 4 & 88 & .78 & 1.36 & 3 & 95 & .83 & 1.84 \\
\hline & 0 & 124 & 1.51 & Ninguno & 0 & 124 & 1.56 & Ninguno & & 0 & 52 & 1.00 & Ninguno & 0 & 52 & 1.00 & Ninguno \\
\hline & 1 & 236 & .67 & -2.22 & 1 & 236 & .64 & -1.57 & & 1 & 238 & .83 & -3.17 & 1 & 238 & .77 & -2.67 \\
\hline$F 2$ & 2 & 175 & .54 & -.16 & 2 & 175 & .67 & .29 & G6 & 2 & 189 & .51 & -.03 & 2 & 89 & .56 & .55 \\
\hline & 3 & 75 & .78 & 1.29 & 3 & 112 & 07 & 157 & & 3 & 63 & .46 & 1.95 & $?$ & 121 & Q4 & 21 \\
\hline & 4 & 88 & .78 & 1.09 & 3 & 112 & .87 & 1.57 & & 4 & 125 & .98 & 1.25 & 3 & 131 & .84 & 2.11 \\
\hline & 0 & 83 & 1.83 & Ninguno & 0 & 83 & 1.72 & Ninguno & & 0 & 58 & 1.28 & Ninguno & 0 & 58 & 1.35 & Ninguno \\
\hline & 1 & 168 & .63 & -1.98 & 1 & 168 & .61 & -1.54 & & 1 & 226 & .61 & -2.93 & 1 & 226 & .58 & -2.0 \\
\hline F3 & 2 & 191 & .72 & -.36 & 2 & 191 & .96 & .17 & G8 & 2 & 166 & .82 & .05 & 2 & 166 & .78 & .66 \\
\hline & 3 & 96 & .68 & 1.34 & 3 & 205 & .86 & 1.37 & & 3 & 81 & .65 & 1.52 & 3 & 160 & 1.05 & 1.74 \\
\hline & $\frac{4}{0}$ & $\begin{array}{c}160 \\
78\end{array}$ & $\begin{array}{l}.83 \\
.89\end{array}$ & $\begin{array}{r}.99 \\
\text { Ninguno }\end{array}$ & 0 & 78 & .89 & Ninguno & & $\frac{4}{0}$ & $\frac{136}{32}$ & $\frac{1.28}{1.00}$ & $\begin{array}{r}1.36 \\
\text { Ninguno }\end{array}$ & 0 & 32 & .93 & Ninguno \\
\hline & 1 & 189 & .64 & -2.30 & 1 & 189 & .58 & -1.81 & & 1 & 184 & .76 & -3.36 & 1 & 184 & .73 & -2.69 \\
\hline F6 & 2 & 209 & .46 & -.39 & 2 & 209 & .51 & .17 & G9 & 2 & 230 & .75 & -.39 & 2 & 230 & .82 & .33 \\
\hline & 3 & $\begin{array}{r}99 \\
123\end{array}$ & .64 & 1.39 & 3 & 171 & .83 & 1.64 & & 3 & 91 & .63 & 1.93 & 3 & 164 & .88 & 2.36 \\
\hline
\end{tabular}




\subsubsection{Análisis de la fiabilidad y separación}

Wrigth y Masters (1982) proponen dos estadísticos globales para calcular la fiabilidad de una escala a nivel de grupo: el índice de fiabilidad para las personas y el índice de fiabilidad para los ítems. El primero de ellos ofrece una medida que indica el grado en que las puntuaciones de localización de las personas en la variable medida serían replicables si se les administrasen otros ítems con características similares, estimando a su vez la fiabilidad con que la puntuación en la escala refleja las diferencias entre personas en la variable. Para su cálculo, se toma la razón de la 'varianza verdadera de las personas' y su 'varianza observada'. El segundo índice proporciona una medida del grado de replicabilidad de la localización de los ítems en la variable medida si estos fueran administrados a otra muestra similar, estimando a su vez el grado en que las dificultades relativas de los ítems están diferenciadas a lo largo de la variable latente medida. Para su cálculo se toma la razón de la 'varianza verdadera de los ítems' y su 'varianza observada'. En ambos casos, teniendo en cuenta que la distribución de valores de ambos índices oscila entre 0 y 1 , se consideran aceptables valores superiores a .80 (Fox y Jones, 1998).

Por otro lado, calculamos también los índices de separación o amplitud de la muestra de personas y del conjunto de ítems en las variables evaluadas. Estos índices proporcionan una medida de esta separación en unidades de error estándar, debiendo tener un valor mínimo de 2 para considerar que estamos abarcando un rango suficientemente amplio tanto de dificultad de ítems evaluados como de habilidad de personas evaluadas. El conjunto de estos índices se presenta a continuación en la Tabla 74, donde podemos observar que las diferentes dimensiones y la escala en su conjunto presentan índices adecuados de fiabilidad y separación tanto en relación al análisis de las personas como el de los ítems.

Tabla 74. Índices de fiabilidad y separación de ítems y personas

\begin{tabular}{lccrc}
\hline \multirow{2}{*}{ Áreas evaluadas } & \multicolumn{2}{c}{ Fiabilidad } & \multicolumn{2}{c}{ Separación } \\
\cline { 2 - 5 } & Ítems & Personas & Ítems & Personas \\
\hline A. Hogar & 1.00 & .94 & 14.56 & 3.88 \\
B. Comunidad & .98 & .94 & 7.37 & 3.84 \\
C. Participación escolar & .99 & .93 & 12.78 & 3.64 \\
D. Aprendizaje escolar & .99 & .92 & 9.42 & 3.37 \\
E. Salud y seguridad & .99 & .92 & 10.17 & 3.36 \\
F. Social & .99 & .91 & 10.29 & 3.23 \\
G. Defensa & 1.00 & .93 & 16.04 & 3.72 \\
TOTAL & $\mathbf{1 . 0 0}$ & $\mathbf{. 9 8}$ & $\mathbf{1 5 . 5 7}$ & $\mathbf{7 . 3 5}$ \\
\hline
\end{tabular}




\section{4.3.4. Ajuste de los datos al modelo}

Tal y como afirman Prieto y Delgado (2003), el ajuste de los datos al modelo será crucial, pues sin él, los parámetros carecerán de significado teórico. En este sentido, Bond y Fox (2001) defienden que los resultados del ajuste de los ítems al modelo serán prueba en sí mismos de la validez del test. Concretamente, el ajuste global podrá estimarse a partir de los estadísticos de ajuste Infit y Outfit (Wright y Masters, 1982; Wilson, 2005). El Infit o estadístico de ajuste interno es sensible a comportamientos inesperados de aquellos ítems situados próximos al nivel de habilidad de los sujetos. El Outfit o estadístico de ajuste externo es sensible a comportamientos inesperados de aquellos ítems que se encuentran lejos del nivel de habilidad de los sujetos.

Los estadísticos de Media Cuadrática (MNSQ) del Infit y del Outfit, aportan información sobre si las respuestas de los sujetos se producen de acuerdo con el modelo. De ser así, los residuos serán pequeños y sus MNSQ se aproximarían al valor 1, lo que indicaría un perfecto ajuste. Los valores sustancialmente menores a $1(<.5)$ indican determinismo en los datos observados, mientras que valores sustancialmente mayores a 1 indican ruido (>1.5); así, el rango idóneo de los valores entre los que debe encontrarse el índice de ajuste interno oscila entre .5 y 1.5. Conviene señalar en este momento que, cuando el MNSQ (del Infit o Outfit) de un ítem se encuentra entre 1.5 y 2.0 se considera que es improductivo para la construcción de la medida, pero no distorsiona ni degrada la medida ni el constructo; son valores superiores a 2 los que indican distorsión o degradación de la medida (Linacre, 2002, 2005).

Además, para analizar el ajuste global contamos con dos estadígrafos estandarizados: los estadígrafos de Infit ZEMP y Outfit ZEMP. Los datos empíricos siempre tienen algún grado de desajuste al modelo y estos estadígrafos se ajustan a la muestra. Se trata de una estandarización empírica, basada en la distribución realmente observada localmente en la muestra sobre los datos que se calcula. Es decir, en los valores ZEMP de los estadígrafos Infit y Outfit se dividen entre su desviación estándar. La expectativa del modelo oscila entre los valores $-2 \mathrm{y}+2$. No obstante, aunque valores superiores a 2 en ZEMP son notoriamente imprescindibles, se considera inaceptable mantener un ítem cuando su valor es superior a 3.

Para comenzar, expondremos el ajuste de la escala y cada una de las dimensiones de la misma al modelo (Tabla 75), pasando posteriormente a realizar un análisis más exhaustivo de los ítems que lo componen (Tabla 76). 
Tabla 75. Resumen de ajuste global de las dimensiones y de la escala

\begin{tabular}{lcccrrr}
\hline \multirow{2}{*}{ DIMENSIONES } & \multicolumn{2}{c}{ INFIT } & & \multicolumn{2}{c}{ OUTFIT } \\
\cline { 2 - 3 } \cline { 6 - 7 } & MNSQ & ZEMP & & MNSQ & ZEMP \\
\hline A. Hogar & 1.05 & .10 & & 1.06 & -.10 \\
B. Comunidad & 1.01 & .00 & & 1.03 & .10 \\
C. Participación Escolar & 1.02 & .00 & & 1.02 & .00 \\
D. Aprendizaje Escolar & .99 & -.10 & & 1.03 & .10 \\
E. Salud y Seguridad & 1.03 & .10 & & 1.06 & .20 \\
F. Social & 1.03 & .00 & & 1.06 & .10 \\
G. Defensa & 1.05 & .10 & & 1.05 & .10 \\
TOTAL & $\mathbf{1 . 0 3}$ &. $\mathbf{1 0}$ & & $\mathbf{1 . 0 9}$ & $\mathbf{. 1 0}$ \\
\hline
\end{tabular}

El ajuste global de los datos, empleado para comprobar el ajuste de las dimensiones del instrumento así como de la propia escala, mostraron un buen funcionamiento en todos los casos. No obstante, para conocer con precisión el ajuste de los ítems que componen la escala al modelo planteado, se realiza de manera complementaria un análisis exhaustivo de los estadígrafos de ajuste para cada uno de los ítems. Los resultados obtenidos muestran que cuatro de los 61 ítems que componen la escala no se ajustan con precisión a las expectativas del modelo (tabla 76).

Tabla 76. Ajuste interno y externo de los ítems al modelo

\begin{tabular}{ccccccc}
\hline \multirow{2}{*}{ ÍTEMS } & \multirow{2}{*}{ Medida } & \multirow{2}{*}{ Error } & \multicolumn{2}{c}{ INFIT } & \multicolumn{2}{c}{ OUTFIT } \\
\cline { 4 - 7 } & & & MNSQ & ZEMP & MNSQ & ZEMP \\
\hline a6 & .66 & .02 & 1.83 & 2.1 & 2.00 & 1.5 \\
b7 & .05 & .02 & 1.36 & 2.1 & 1.45 & 2.4 \\
e1 & .49 & .02 & 1.36 & 1.8 & 1.58 & 2.1 \\
g1 & .88 & .02 & 1.81 & 2.4 & 2.00 & 2.5 \\
\hline
\end{tabular}

Nota: Ítem a6: Dormir o echarse la siesta; Ítem b7: Cumplir con las normas básicas de la comunidad, reglas y/o leyes; Ítem e1: Comunicar molestias y dolores relacionados con la salud y problemas médicos, incluyendo molestias y dolores; Ítem g1: Expresar preferencias.

En este sentido, se presentan a continuación una serie de gráficos (Figuras 46-59) en los que puede observarse de manera más global, visual y parsimoniosa la información referente al ajuste de los datos. Concretamente, se presentan dos gráficos para cada una de las subescalas evaluadas, haciendo referencia el primero de ellos a los estadígrafos MNSQ y ZEMP de cada ítem. Ambos gráficos representan conjuntamente el Infit (verde oscuro) y el Oufit (verde claro), proporcionándose en rojo (oscuro para el Infit y claro para el Oufit) aquellos ítems que se encuentran fuera de los valores esperados. 


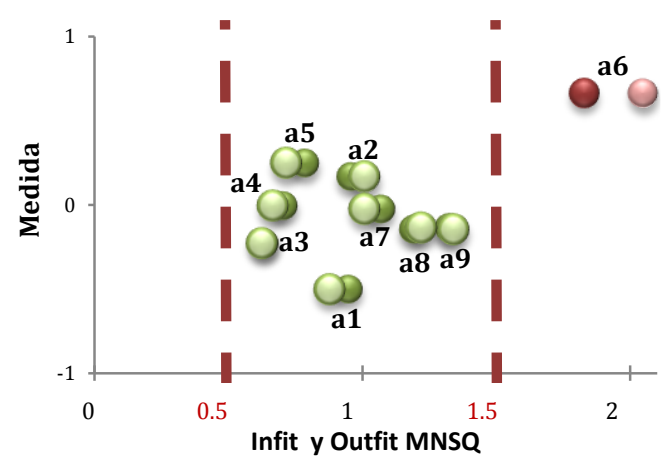

Figura 46. Infit y Outfit MNSQ. Subescala A

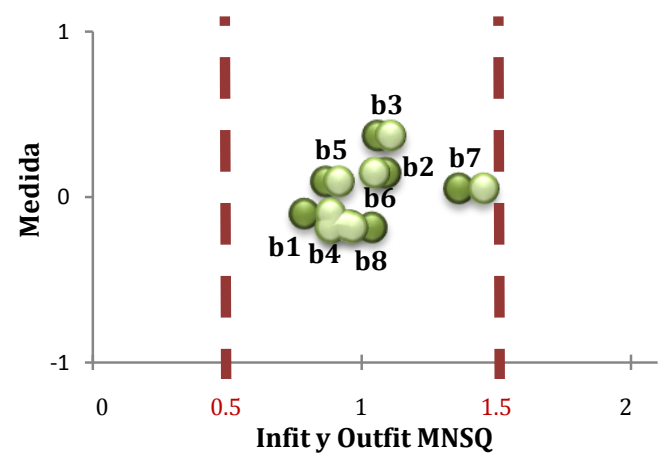

Figura 48. Infit y Outfit MNSQ. Subescala B

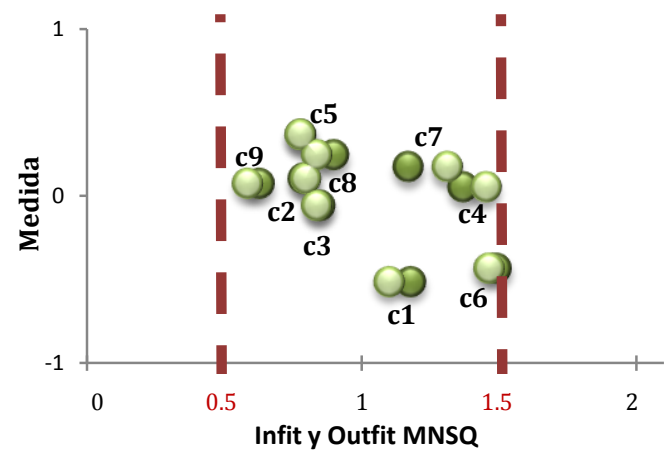

Figura 50. Infit y Outfit MNSQ. Subescala C

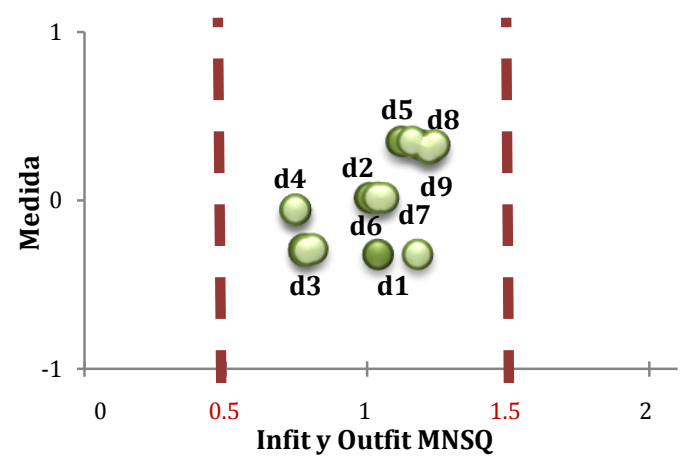

Figura 52. Infit y Outfit MNSQ. Subescala D

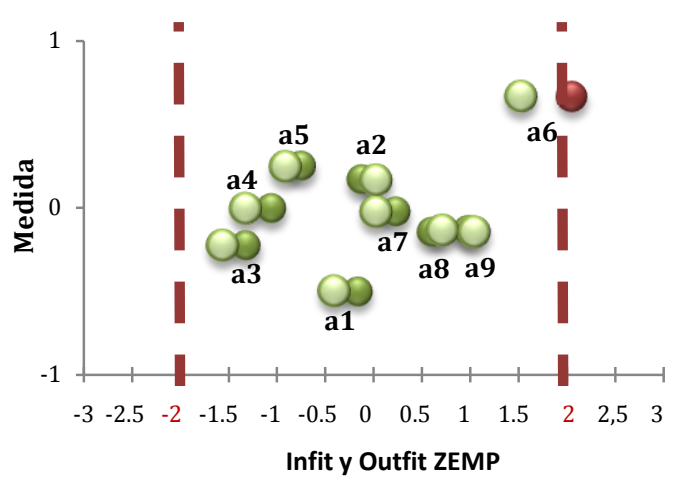

Figura 47. Infit y Outfit ZEMP. Subescala A

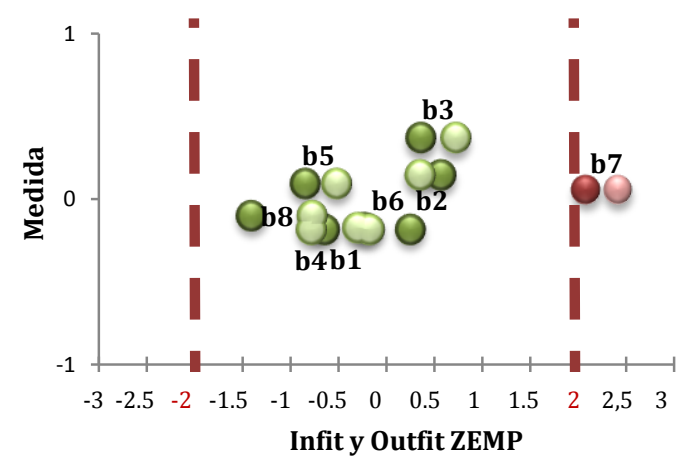

Figura 49. Infit y Outfit ZEMP. Subescala B

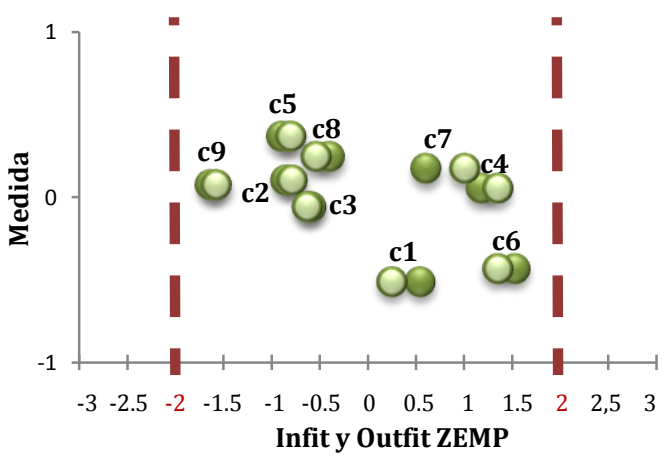

Figura 51. Infit y Outfit ZEMP. Subescala C

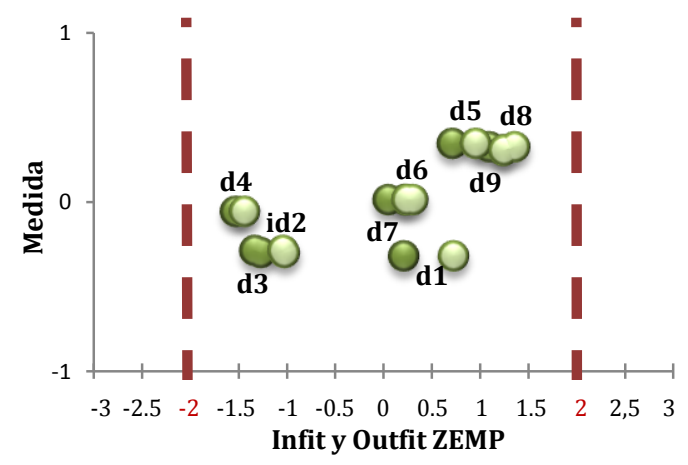

Figura 53. Infit y Outfit ZEMP. Subescala D 


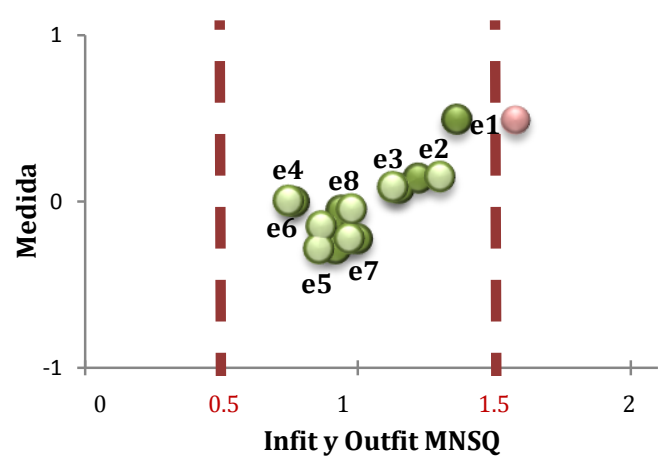

Figura 54. Infit y Outfit MNSQ. Subescala E

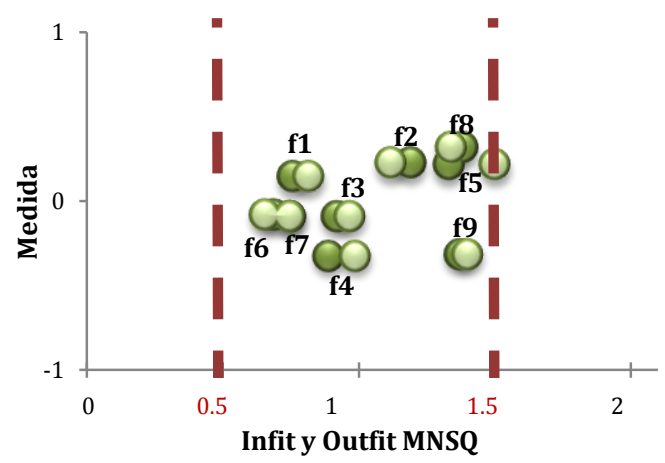

Figura 56. Infit y Outfit MNSQ. Subescala F

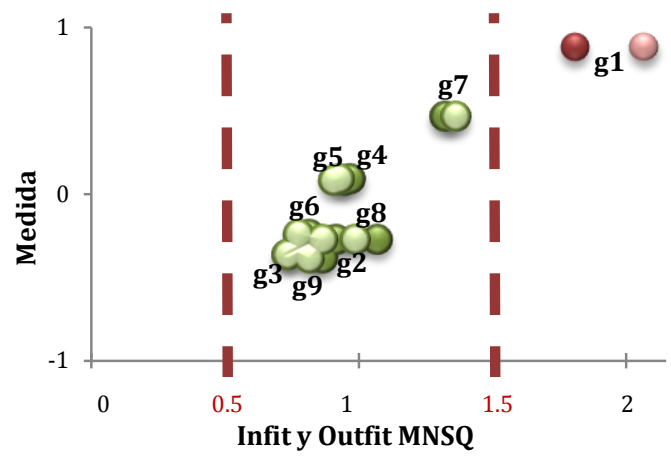

Figura 58. Infit y Outfit MNSQ. Subescala G

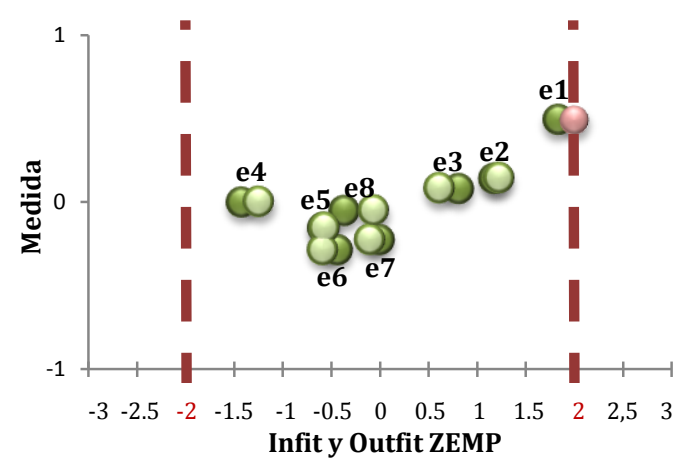

Figura 55. Infit y Outfit ZEMP. Subescala E

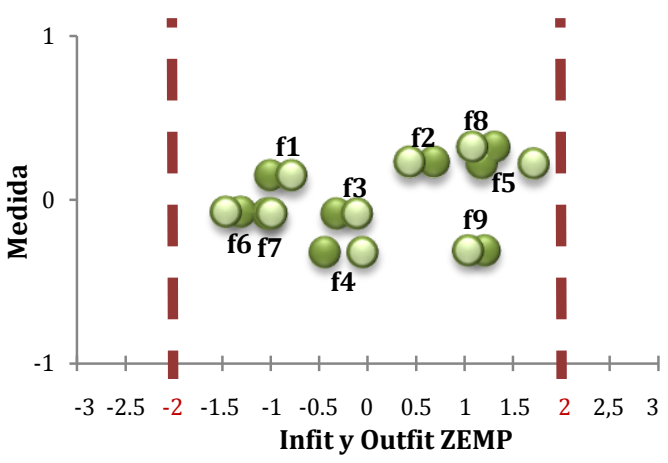

Figura 57. Infit y Outfit ZEMP. Subescala F

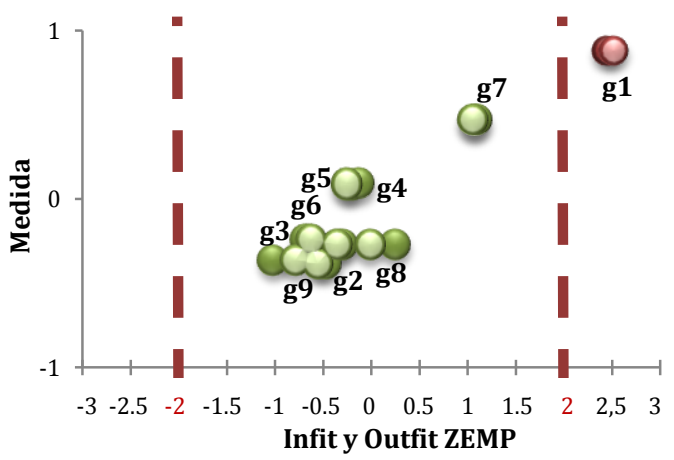

Figura 59. Infit y Outfit ZEMP. Subescala G

Se aprecia que los ítems que obtuvieron el ajuste esperado se encuentran distribuidos entre cinco de las siete dimensiones que componen la escala, no existiendo más de un ítem en ninguna de las dimensiones que manifieste una falta de ajuste. Asimismo, destacamos que, aún teniendo en cuenta aquellos ítems que obtienen valores Infit o Outfit superiores a lo deseable que no aportan mucha información, no se obtuvieron en ningún caso valores MNSQ superiores a 2 ni valores ZEMP superiores a 3, lo que reflejaría que el ítem está aportando más ruido que información útil y sería inaceptable mantenerlo. Teniendo esto en cuenta, podemos afirmar que no se encontró ningún ítem que perjudicase la medida del constructo y debiera ser indudablemente eliminado. 


\subsubsection{Calibración de los ítems: localización, discriminación y precisión}

El análisis de localización de los ítems de cada una de las dimensiones de la escala aparece representado por la dificultad expresada en logits. Se considera que la dificultad media de los ítems es cero y, a partir de este valor, los ítems se distribuyen en un continuo que se construye desde el polo positivo (el cual reflejaría menor dificultad del ítem) y el polo negativo (el cual reflejaría mayor dificultad). A continuación ofrecemos una serie de mapas ítem-persona (Figuras 60-61) que presentan de manera conjunta la distribución de los niveles de necesidades de apoyo de los sujetos (parte izquierda del gráfico) y el nivel de dificultad de los ítems (parte derecha del gráfico) de la escala en la que han puntuado los sujetos. Los ítems de logits negativos reflejarían mayor dificultad ya que, incluso aquellos sujetos con pocas necesidades de apoyo en la vida diaria (los que se encuentran más abajo en el continuo) necesitarían también apoyo para estas actividades; por su parte, los ítems con logits positivos reflejan menor dificultad ya que sólo los sujetos con muchas necesidades de apoyo (aquellos que se encuentran en la parte más alta del continuo) puntúan en este ítem. En general, podemos decir que para medir con poco error, el nivel de los ítems debe estar ajustado al nivel de las personas que los responden, abarcando el mayor rango posible.

Según los datos presentes en las Figura 60, todas las dimensiones recogen niveles de dificultad muy cercanos a la media (especialmente las dimensiones 'Comunidad' y 'Participación Escolar'], de tal manera que se produce efecto techo y efecto suelo; en otras palabras: no alcanzados o traspasados determinados niveles de necesidades de apoyo, los ítems de la escala no son capaces de discriminar de manera detallada las necesidades de apoyo de estas personas. Concretamente, la última dimensión, referente a las actividades de 'Defensa (autorrepresentación)', es la que mayor rango de dificultad aborda dentro de los ítems que la sustentan (desde -.39 hasta .80), seguida por la dimensión de participación escolar (desde -.61 hasta .38).

No obstante, si tenemos en cuenta los ítems de la SIS-C de manera conjunta (Figura 61) y analizamos la calibración de los ítems de manera global para compararla con el nivel de necesidades de apoyo de la muestra, obtenemos que los ítems sí recogen todos los niveles de habilidad de los sujetos evaluados, sí se distribuyen a lo largo de un continuo más amplio de necesidades que recoge los diferentes niveles de habilidad de los sujetos. Concretamente, los ítems de la dimensión 'Hogar' (mostrados en verde) resultan los más sencillos y los de 'Aprendizaje Escolar' (en color rojo) los más complejos. 

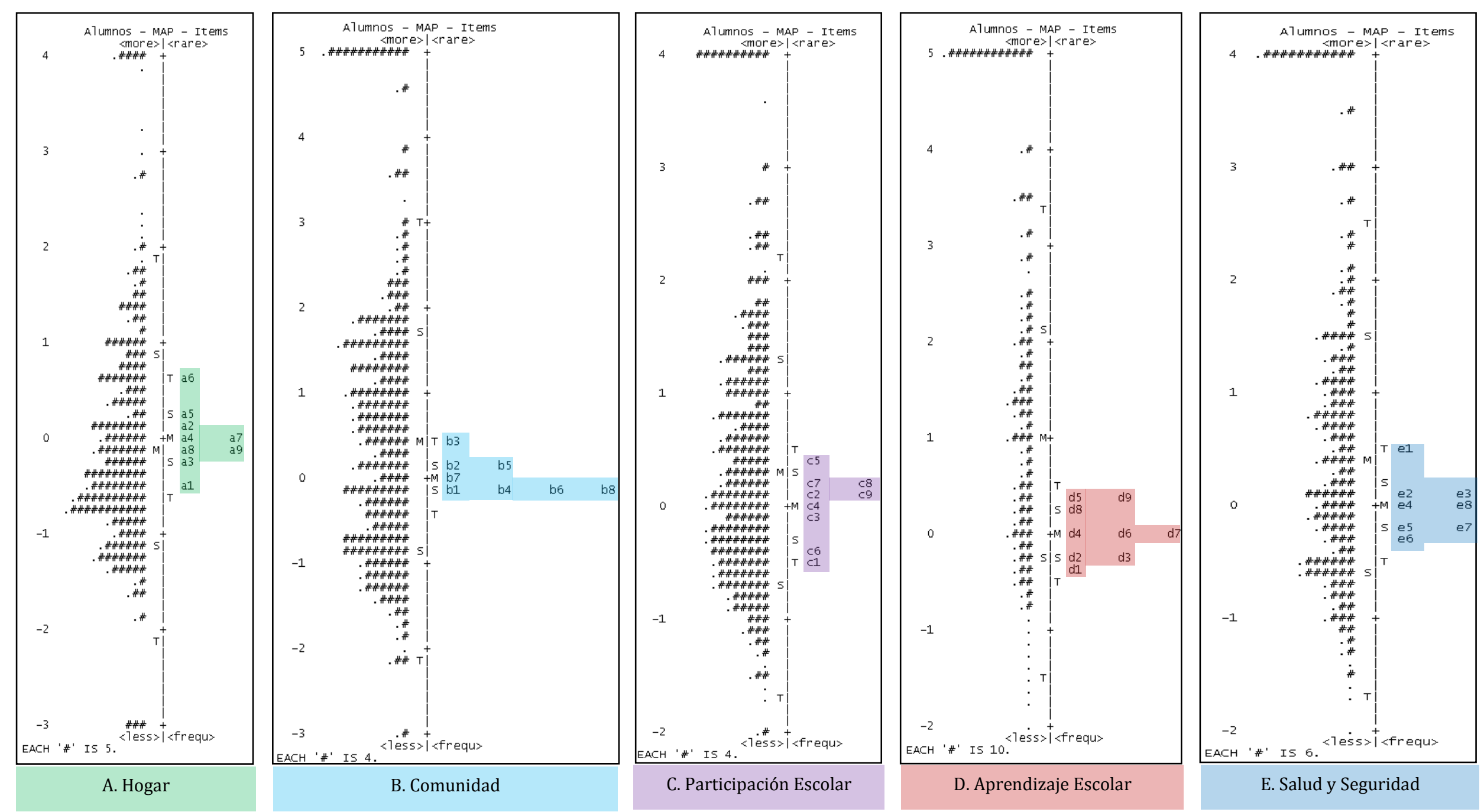

Figura 60. Dificultad de los ítems por dimensiones 


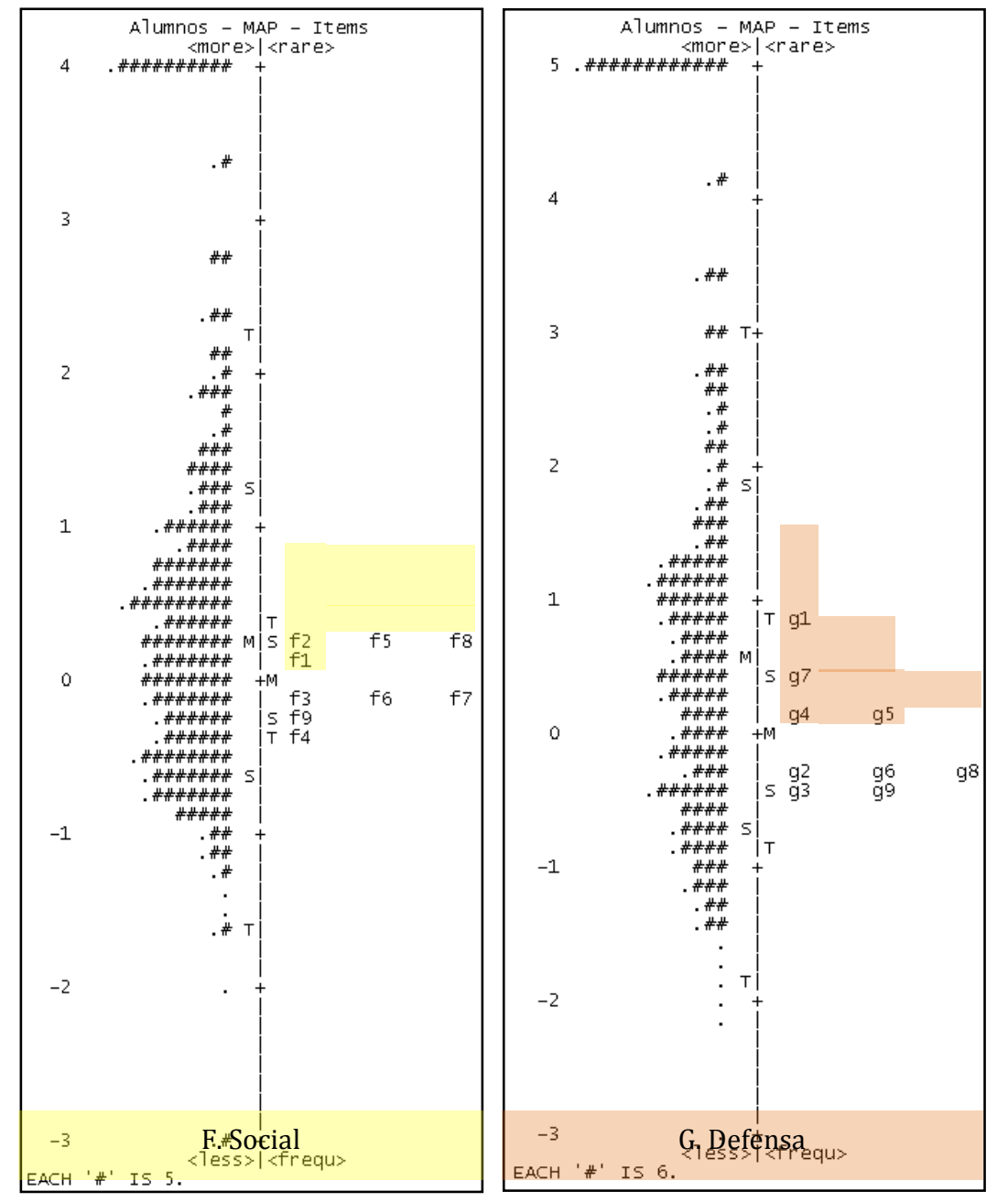

Figura 60. Dificultad de los ítems por dimensiones (continuación)

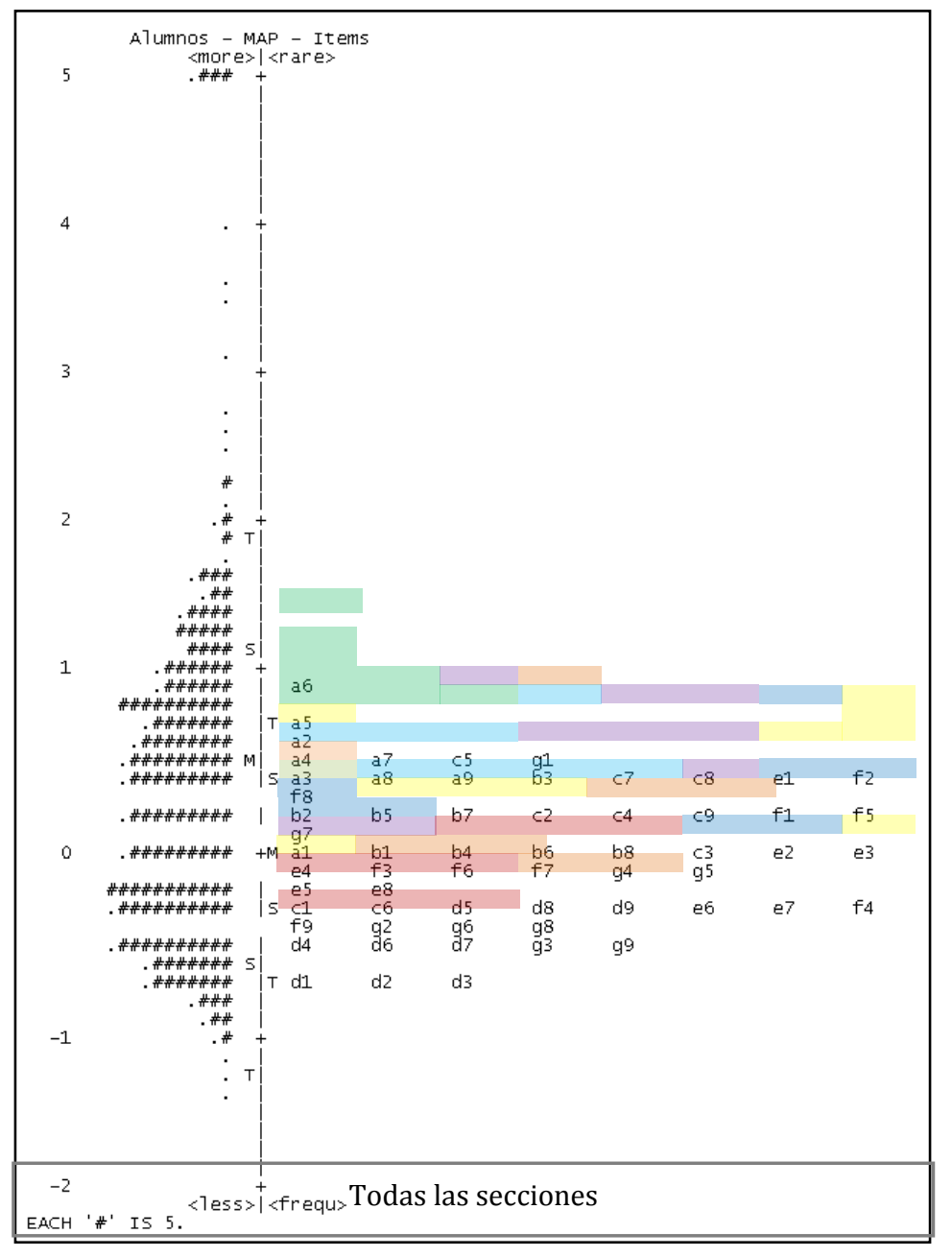

Figura 61.Dificultad general de los ítems de la SIS-C 
Realizando un análisis más exhaustivo de la calibración de los ítems, podemos decir que la relación entre la puntuación de un sujeto en cada ítem de la escala y el nivel del sujeto en el atributo medido (i.e., necesidades de apoyo) se describe mediante una función conocida como la Curva Característica del Ítem (CCI). Esta curva permite conocer la relación existente entre las respuestas a un ítem y el nivel que presenta el sujeto ante el atributo medido $(\theta)$. En el modelo de Rasch, la curva característica de cada ítem viene marcada por su índice de dificultad (parámetro $\beta$ ) que supone que el poder discriminativo de estos ítems es óptimo en todos los casos. Para que la CCI se ajuste al modelo, ésta no debe ser lineal, sino que ha de tener formar una ojiva. Esta forma en $S$ (sigmoidea) indica que la probabilidad de puntuaciones más altas aumenta en la medida que se eleven las necesidades de apoyo de la persona. A continuación, presentamos una serie de gráficos (Figuras 62-75) en los que se ilustran las curvas características de los ítems así como las Curvas Características de los Tests (CCT) relativas a cada una de las dimensiones, obtenidas a partir de la suma de las curvas características de los ítems que las componen. Se observa claramente cómo se mantiene en líneas generales la forma esperada, pero que los ítems reflejan un índice de dificultad en la medida muy similar, lo que ya pudo observarse más detalladamente en el análisis de localización.

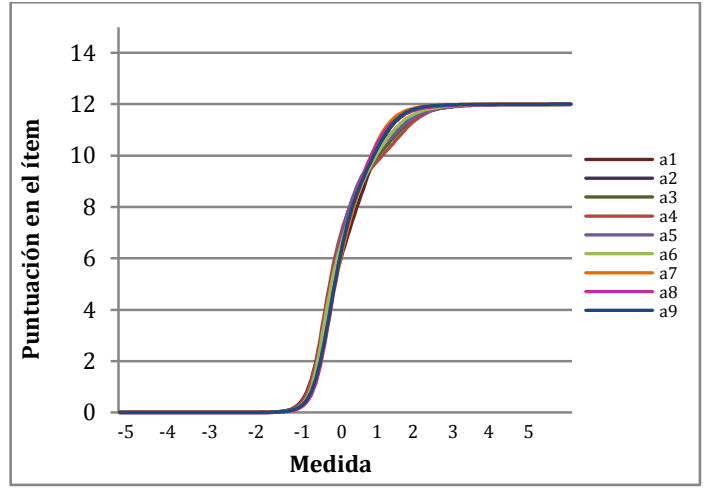

Figura 62. Curvas Características. Ítems Subescala A

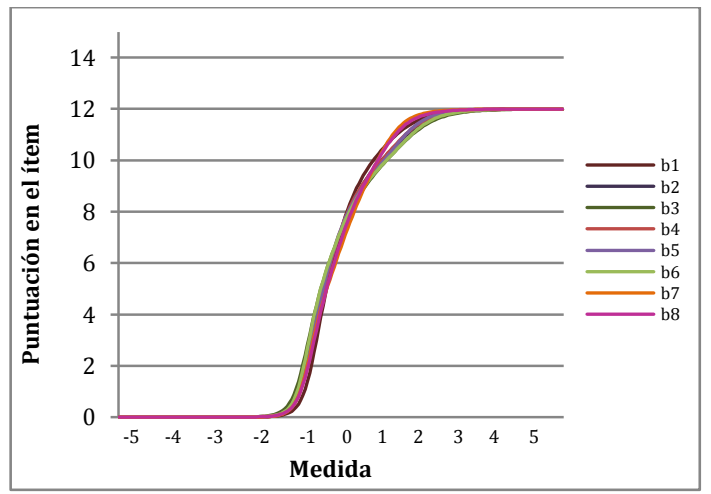

Figura 64. Curvas Características. Ítems Subescala B

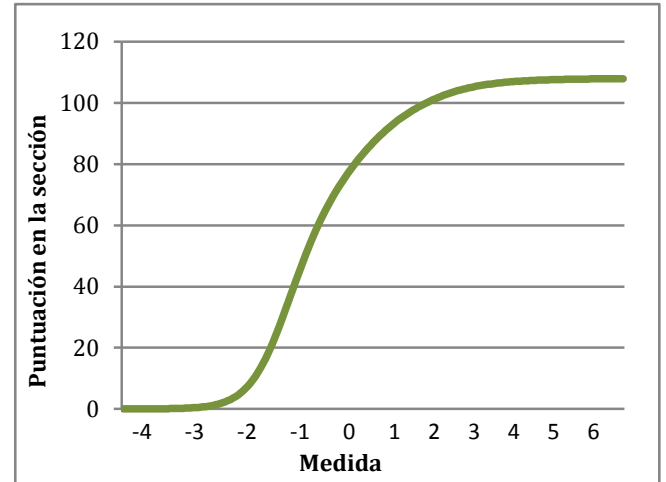

Figura 63. Curva Característica. Subescala A

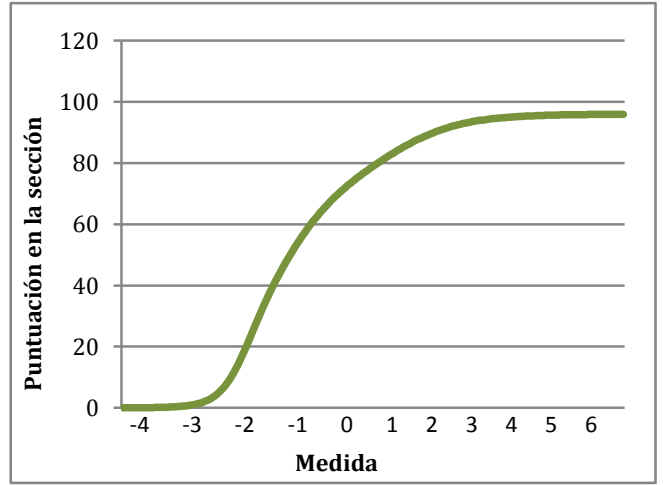

Figura 65. Curva Característica. Subescala B 


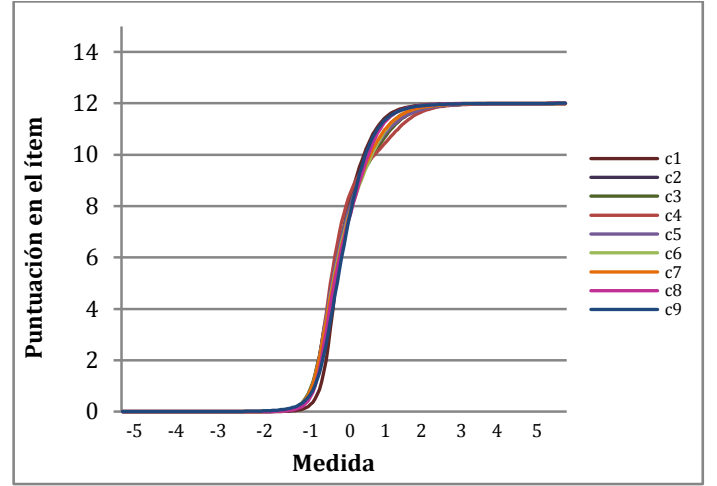

Figura 66. Curvas Características. Ítems Subescala C

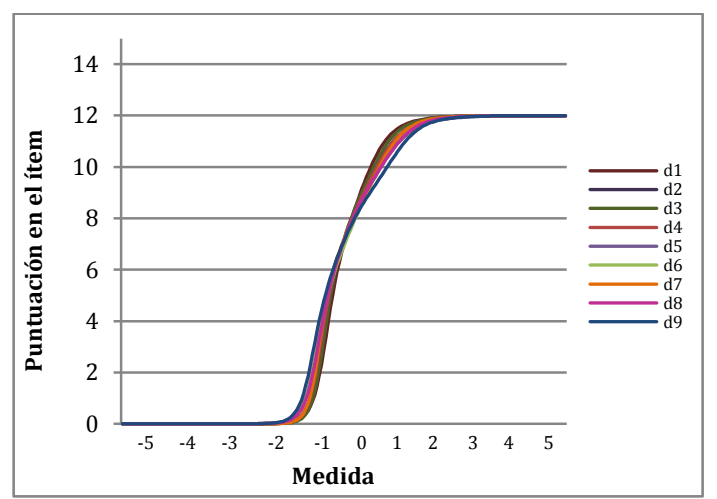

Figura 68. Curvas Características. Ítems Subescala D

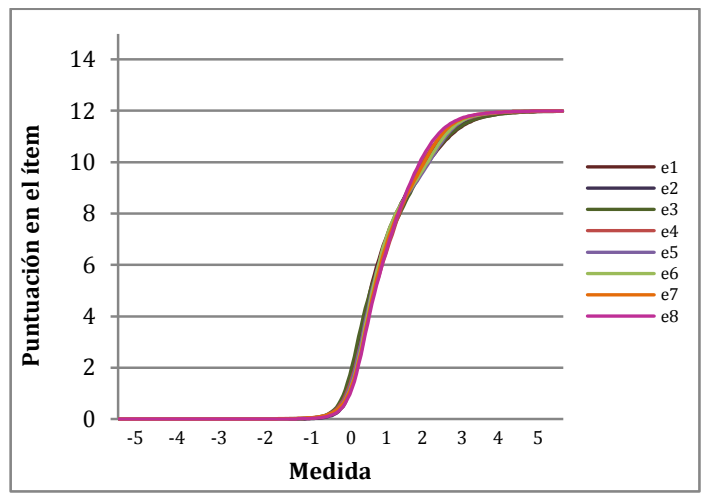

Figura 70. Curvas Características. Ítems Subescala E

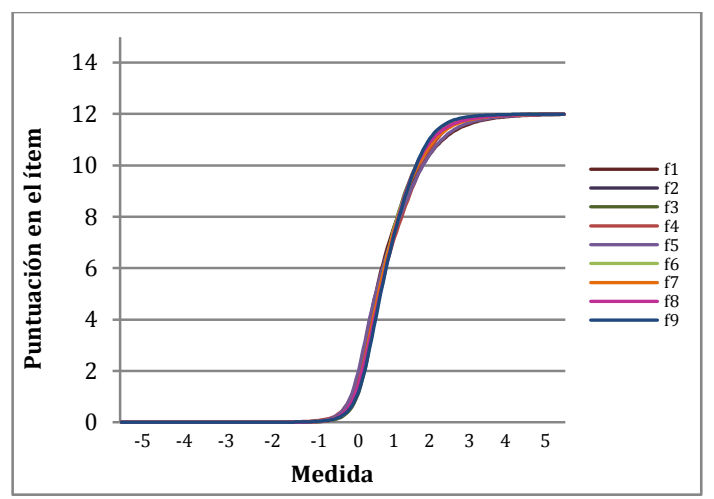

Figura 72. Curvas Características. Ítems Subescala F

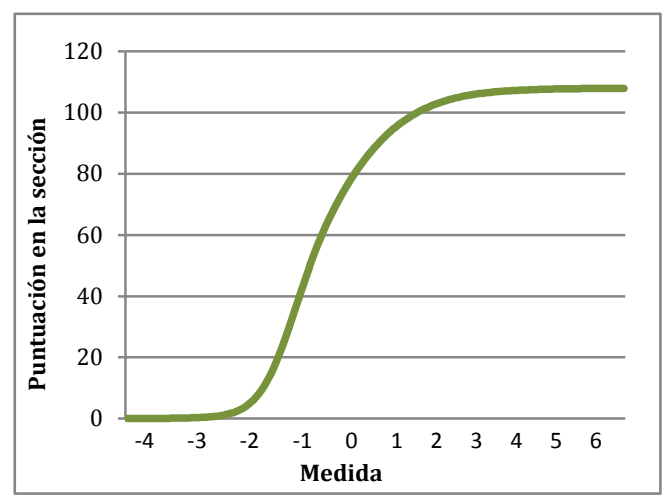

Figura 67. Curva Característica. Subescala C

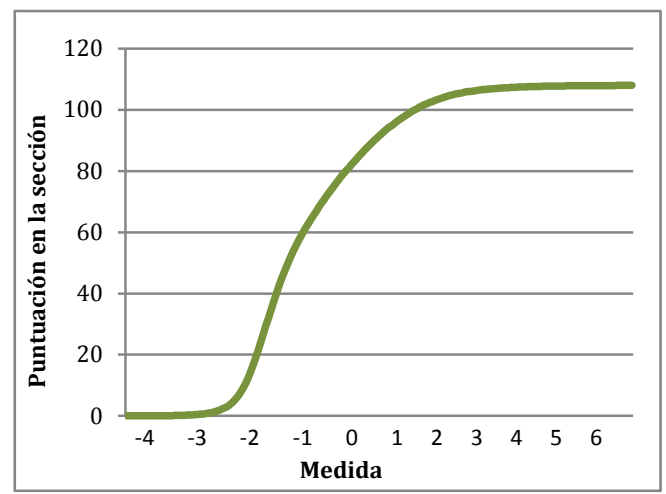

Figura 69. Curva Característica. Subescala D

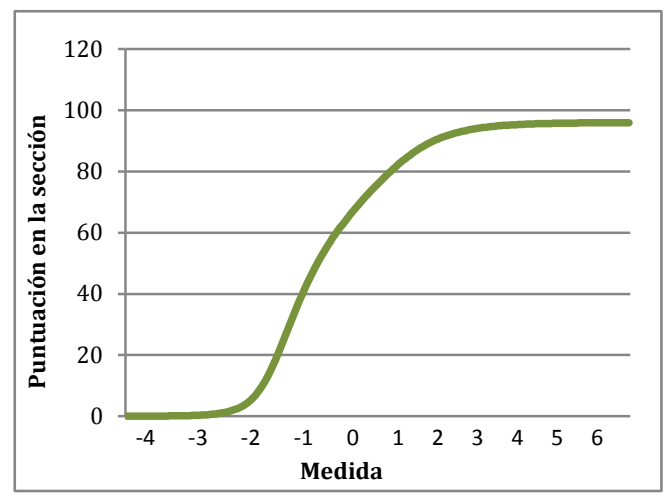

Figura 71. Curva Característica. Subescala E

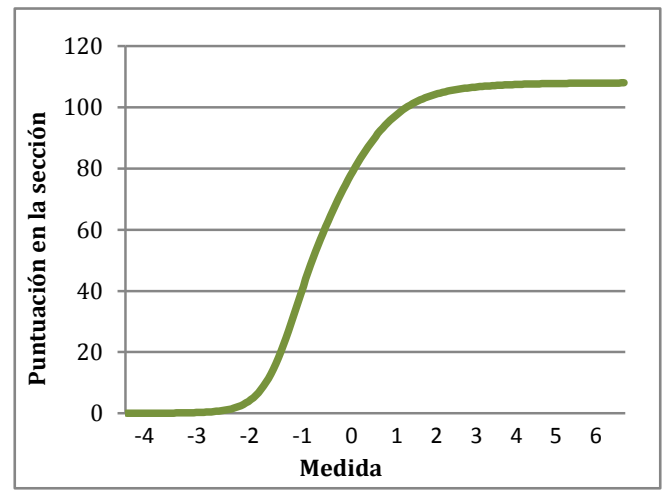

Figura 73. Curva Característica. Subescala F 


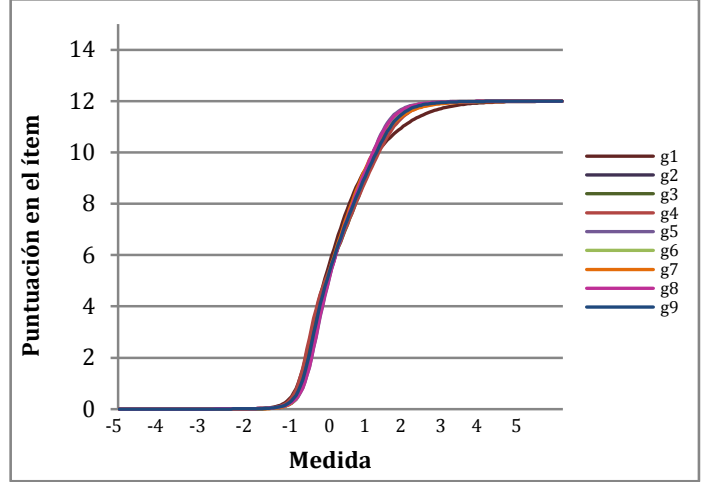

Figura 74. Curvas Características. Ítems Subescala G

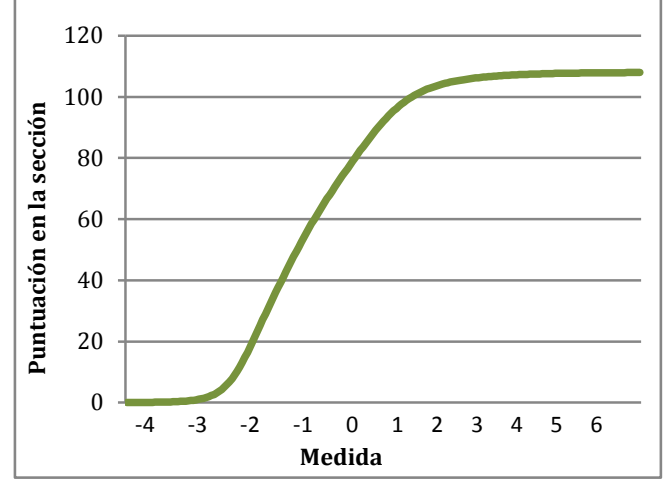

Figura 75. Curva Característica. Subescala G

Profundizando más dentro de este apartado, podemos conocer una estimación de la discriminación realizada a partir de la pendiente de la CCI, donde la expectativa del modelo es 1.00. Valores superiores a 1.00 en la estimación de discriminación indican mayor discriminación, siendo considerados idóneos los ítems con valores cercanos .90, y llegando a ser aceptables ítems con valores en torno a .70. En este sentido, la mayoría de los ítems de la escala tienen un poder de discriminación superior a 1, apareciendo valores inferiores a .70 sólo en tres de los ítems (Tabla 77).

Tabla 77. Estimación de la discriminación de los ítems

\begin{tabular}{|c|c|}
\hline Estimación de la discriminación & Ítems \\
\hline$>1.00$ & $\begin{array}{l}\text { a1,a2,a3,a4,a5 } \\
\text { b1,b2,b4,b5,b8 } \\
\text { c2,c3,c5,c8,c9 } \\
\text { d2.d3.d4.d6 } \\
\text { e4,e5,e6,e8 } \\
\text { f1,f3,f4,f6,f7 } \\
\text { g2,g3,g4,g5,g6,g9 }\end{array}$ \\
\hline $.90-1.00$ & $\begin{array}{l}\text { a7 } \\
\text { b3,b6, } \\
\text { c4 } \\
\text { d1,d7,d8 } \\
\text { e3,e7 } \\
\text { f2 } \\
\text { g8 }\end{array}$ \\
\hline $.70-.90$ & $\begin{array}{l}\text { a8, a9 } \\
\text { b7 } \\
\text { c1, c7 } \\
\text { d5,d9 } \\
\text { e1,e2 } \\
\text { f5,f8,f9 } \\
\text { g7 }\end{array}$ \\
\hline$<.70^{*}$ & $\mathrm{a} 6, \mathrm{c} 6, \mathrm{~g} 1$ \\
\hline
\end{tabular}

*Nota: Ítem a6: Dormir o echarse la siesta; Ítem c6: Participar en actividades de evaluación/examen requeridos por los sistemas de educación; Ítem g1: Expresar preferencias. 
En resumen, podemos decir que la curva característica ha sido capaz de explicarnos con precisión la probabilidad de que un sujeto con una determinadas habilidades/necesidades puntúe más o menos alto en cada uno de los ítems. Sin embargo, para conocer cuanta información fiable nos proporciona esta curva necesitamos conocer la función de información.

La Función de Información (FI) es, por tanto, una medida de fiabilidad, definida como el inverso del ETM, que nos indica en qué punto la curva característica nos aporta más información sobre los sujetos evaluados. Concretamente, ésta se define como la recíproca de la precisión con la que se estima un parámetro: a más precisión en la estimación de un parámetro más sabremos sobre el valor de ese parámetro. En este sentido, la Función de Información del Ítem (FII) nos permite conocer qué ítems resultan los más adecuados para estimar determinados niveles de necesidades de apoyo. Como puede apreciarse, estas curvas adoptan forma de campana para indicar la localización del ítem en el continuo de necesidades de apoyo (dentro de cada una de las subescalas) y su valor más alto se corresponde con el valor en el que la información aportada por el ítem es máxima. Por su parte, la Función de Información del Tests (FIT), que en nuestro caso hace referencia a cada una de las dimensiones evaluadas, es definida a través del resultado de la suma de las funciones de información de los ítems que lo componen, interpretándose de la misma manera.

En los siguientes gráficos (Figuras 76-89), proporcionamos la función de información de los ítems y de las diferentes subescalas de a SIS-C. En este caso, el eje horizontal $(\mathrm{X})$ aparece representada la dificultad de la medida y en el eje vertical (Y) la puntuación media obtenida

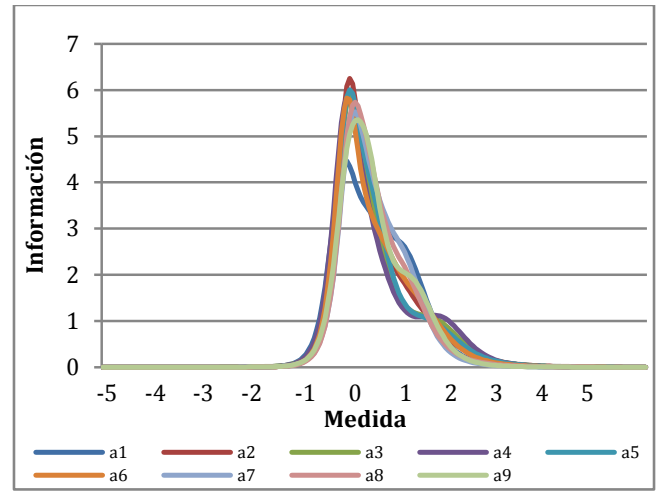

Figura 76. Función Información. Ítems Subescala A Figura 77. Función Información. Subescala A

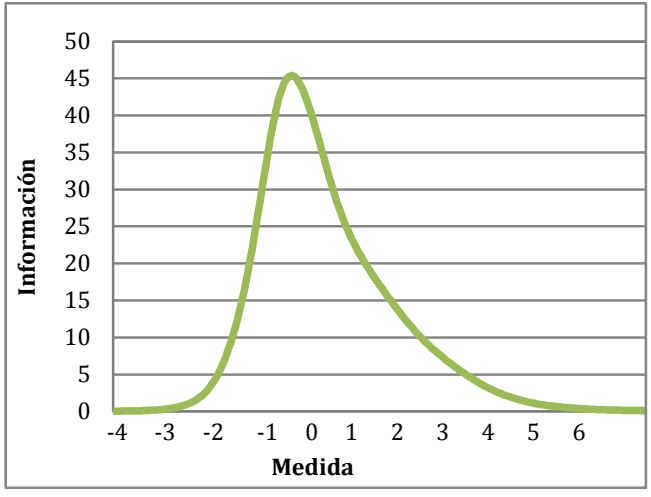




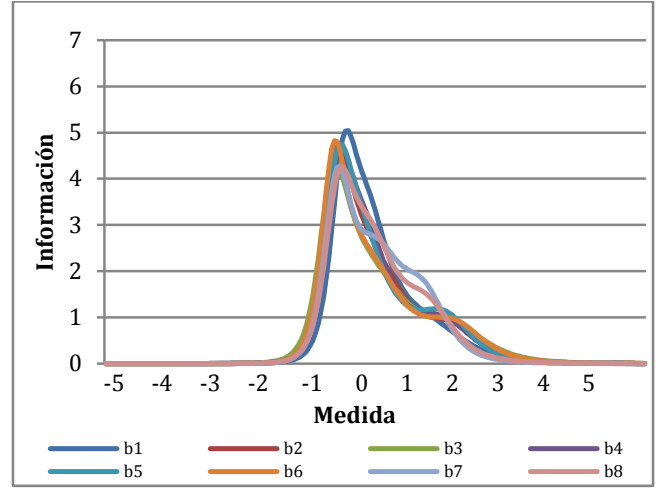

Figura 78. Función Información. Ítems Subescala B

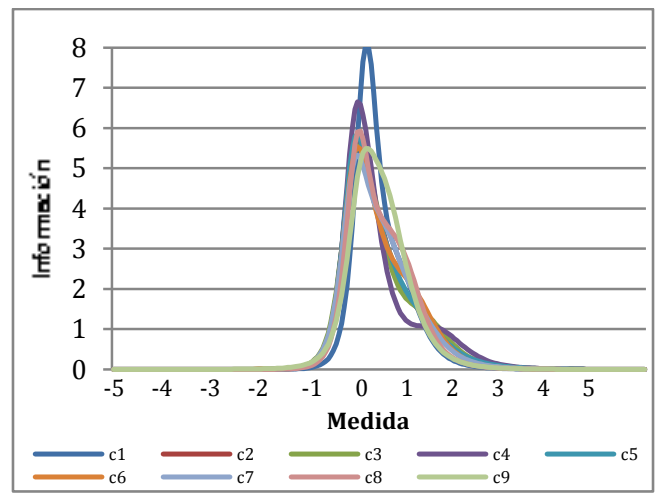

Figura 80. Función Información. Ítems Subescala C Figura 81. Función Información. Subescala C

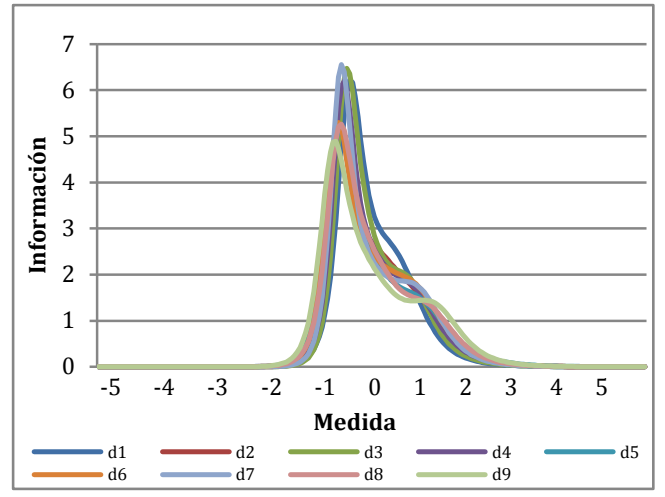

Figura 82. Función Información. Ítems Subescala D

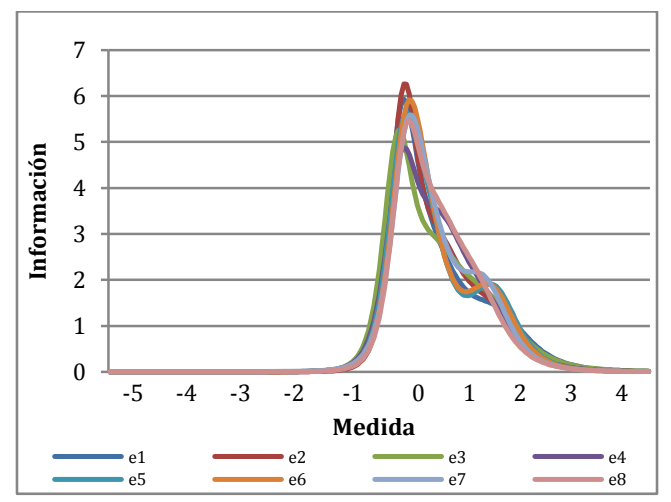

Figura 84. Función Información. Ítems Subescala E Figura 85. Función Información. Subescala E

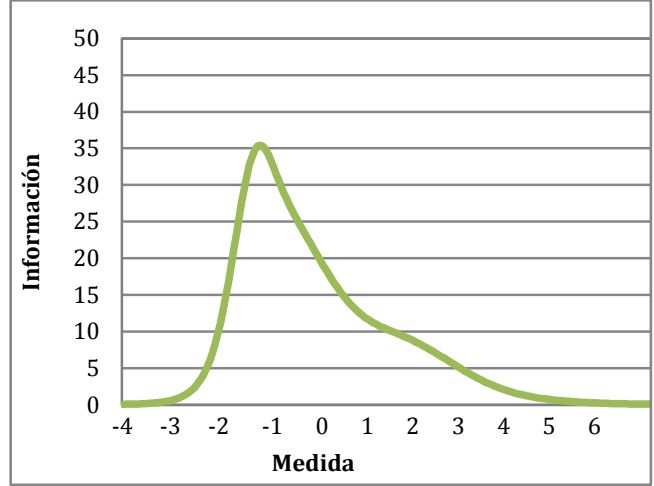

Figura 79. Función Información. Subescala B
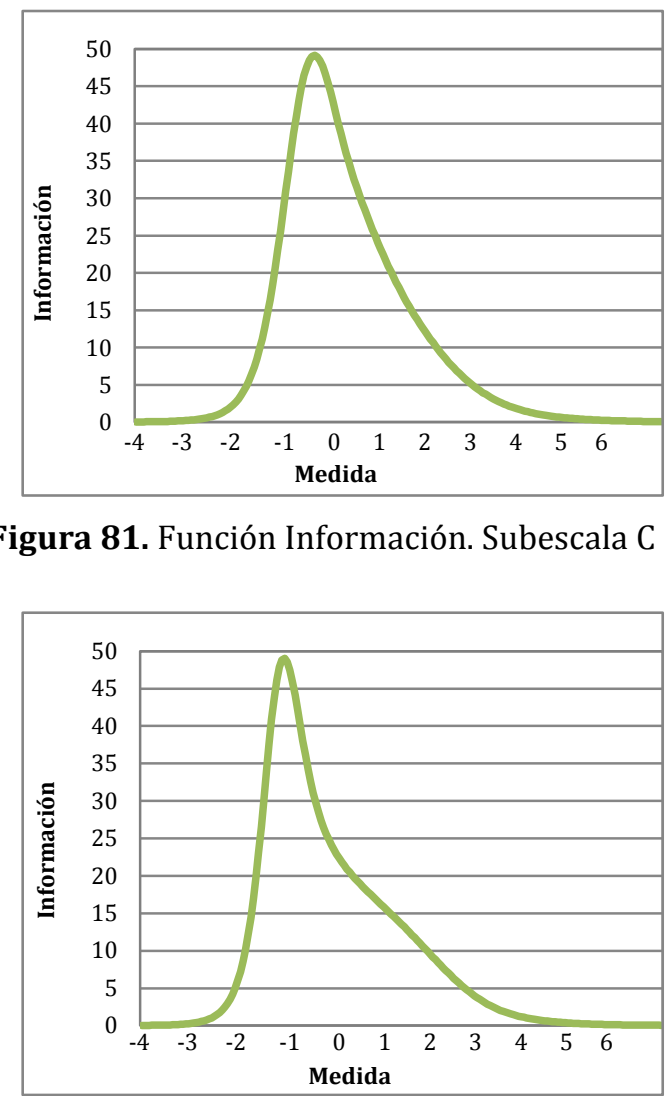

Figura 83. Función Información. Subescala D

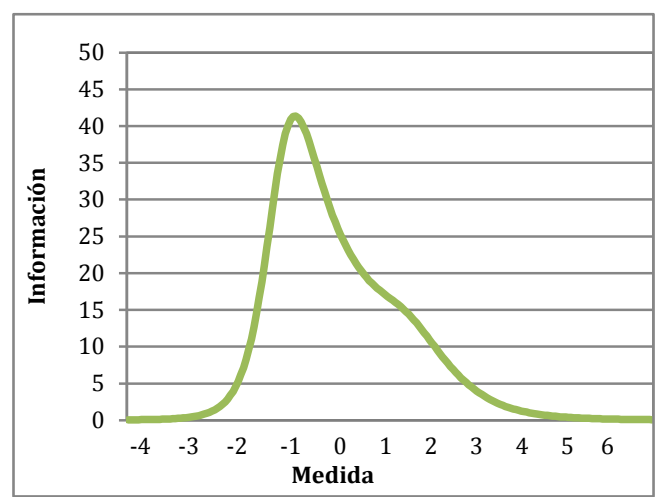




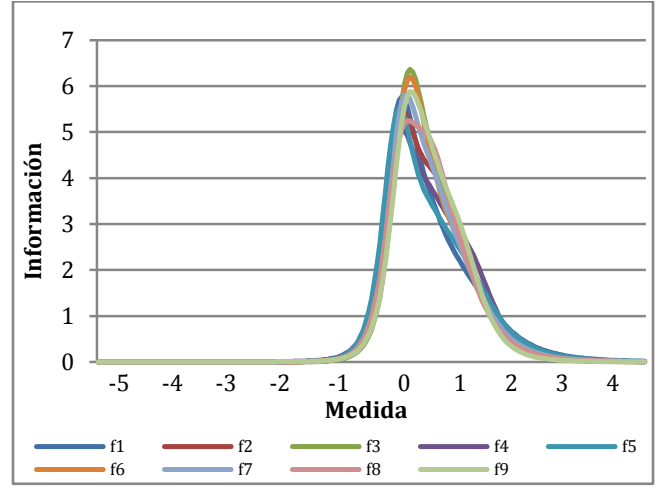

Figura 86. Función Información. Ítems Subescala F

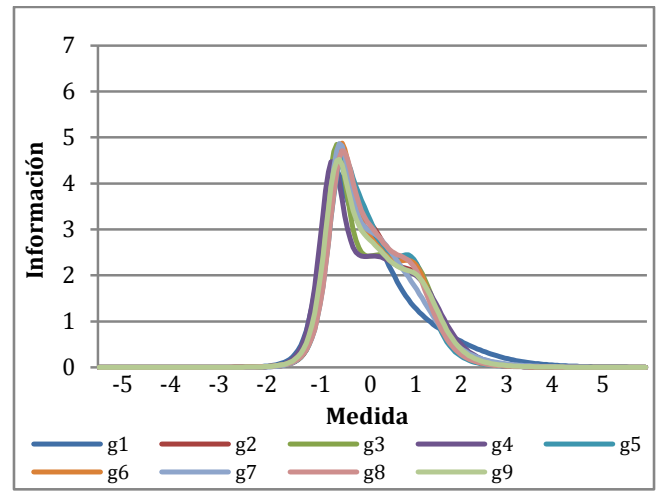

Figura 88. Función Información. Ítems Subescala G

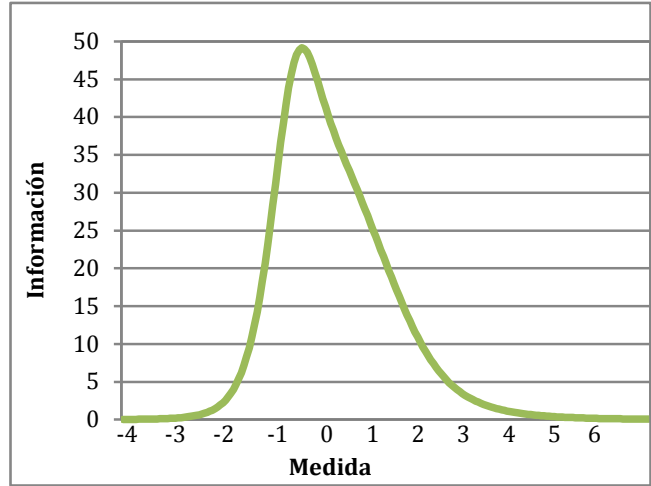

Figura 87. Función Información. Subescala F

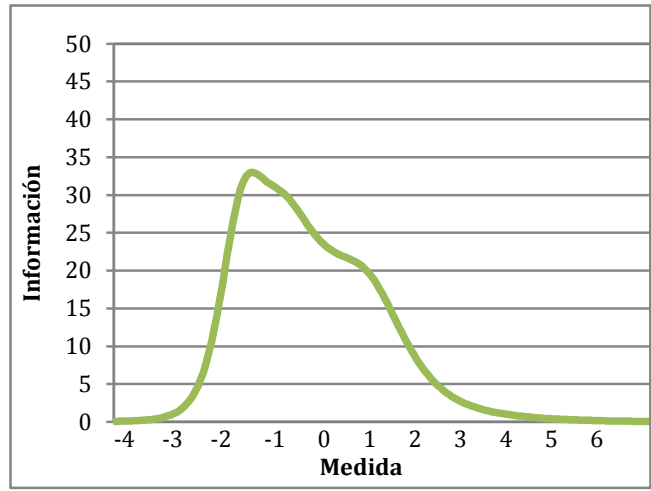

Figura 89. Función Información. Subescala G

De manera general, podemos observar que la función de información de todos los ítems no se aleja significativamente de la figura de una curva normal; por tanto, la función de información de cada una de las dimensiones, al estar formada por la suma de las funciones de los ítems que la integran, también adoptan este tipo de curva esperada por el modelo, pudiendo concluirse que no existe ningún ítem que esté contribuyendo negativamente a la función de información de ninguna de las áreas evaluadas. En este sentido, destacamos la función de información de la subescala G., relacionada con actividades de defensa y autorrepresentación, por ser aquella que se aleja en mayor medida de la curva normal deseada.

Por otro lado, con respecto al punto máximo de precisión de la medida, tanto los diferentes ítems como las subescalas que componen el instrumento son capaces de ofrecer mayor información cuando el nivel de necesidad de apoyo de la persona evaluada es medio-alto (logits negativos cercanos a cero). Estos resultados son coherentes con los resultados obtenidos previamente en los análisis de localización y discriminación de los ítems. 


\subsubsection{Análisis de la invarianza}

Una escala con buenas propiedades de medida debería estar formada por ítems que no tuvieran un funcionamiento diferencial en la evaluación de personas con diferentes características sociodemográficas pero el mismo nivel de competencia o habilidad en el constructo medido (Thissen, Steinberg y Wainer, 1993). En este sentido, una de las mayores ventajas de los modelos TRI es que nos permiten analizar el grado en que los ítems pueden distorsionar los resultados para los miembros de un grupo particular (Martínez-Arias, 1995), determinando si los ítems tienen significados notoriamente diferentes para los distintos o grupos o, lo que es lo mismo, si existe un Funcionamiento Diferencial de los Ítems (Diferencial Item Functioning [DIF]).

Con el objetivo de realizar este análisis de manera exhaustiva se analiza el DIF contrast. Este índice permite conocer el grado en que se alejan las medidas de las diferentes categorías, considerándose que existen diferencias significativas en aquellos casos en que el DIF contrast supera los .50 logits.

Concretamente, para conocer si existe un funcionamiento diferencial de los ítems en la SIS-C, tomamos como referencia la variable 'género' (es decir, entre hombres y mujeres), donde se espera que no haya diferencias, de manera coherente a lo encontrado en el análisis de las subescalas por TCT, y se incluye también una nueva variable no tenida en cuenta hasta el momento, la variable 'etiologías específicas' (donde se reflejaban cuatro categorías: síndrome de Down, autismo, parálisis cerebral y ninguno de los anteriores). Por otro lado, no se estudian las diferencias en el funcionamiento de los ítems para la variable 'nivel de discapacidad intelectual', ya que se supone que esta variable, por propia definición, sí influye de manera directa en el nivel de habilidad (o en este caso, de necesidad) de los sujetos. Lo mismo ocurre en el caso de la variable 'edad', para la que ya se plantea de antemano la necesidad de contar con un baremo diferenciado para los seis pares de edad que recoge el instrumento $(5-6 ; 7-8 ; 9-10 ; 11-12 ; 13-14 ; 15-16)$.

En este sentido, en el procedimiento seguido para conocer el funcionamiento de los ítems con relación a las variables 'género' y 'etiologías específicas', se analizaron cada uno de los ítems de las siete subescalas que componen el instrumento. A continuación, en las Figuras 90-103, se puede apreciar de manera sencilla que no existe un funcionamiento diferencial en relación al género, y sólo tres ítems (marcados en amarillo) presentaron un DIF contrast superior a .50 dependiendo de la etiología. Destaca que estas diferencias siempre implican al grupo con parálisis cerebral. 


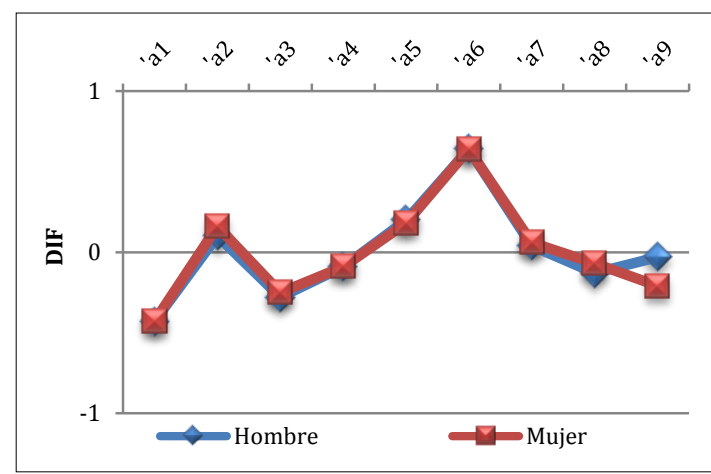

Figura 90. DIF según el género. Subescala A

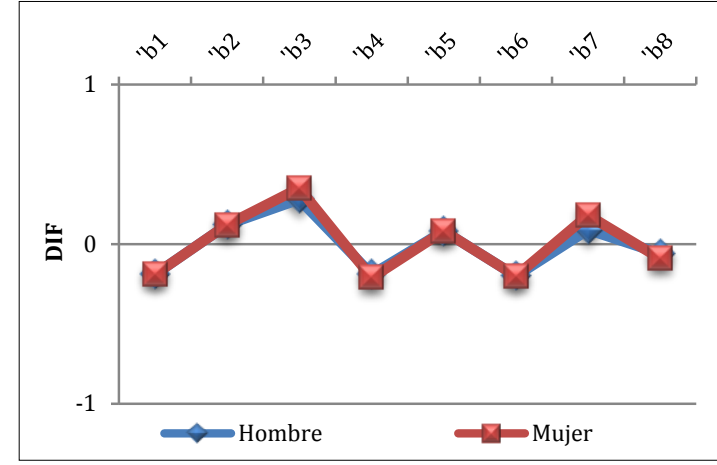

Figura 92. DIF según el género. Subescala B

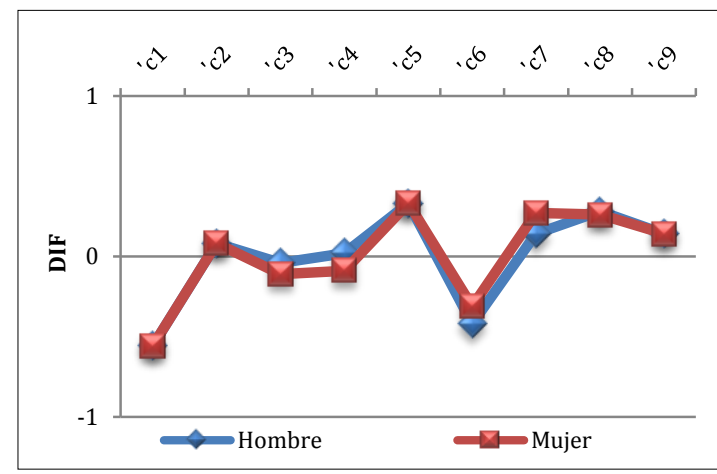

Figura 94. DIF según el género. Subescala $C$

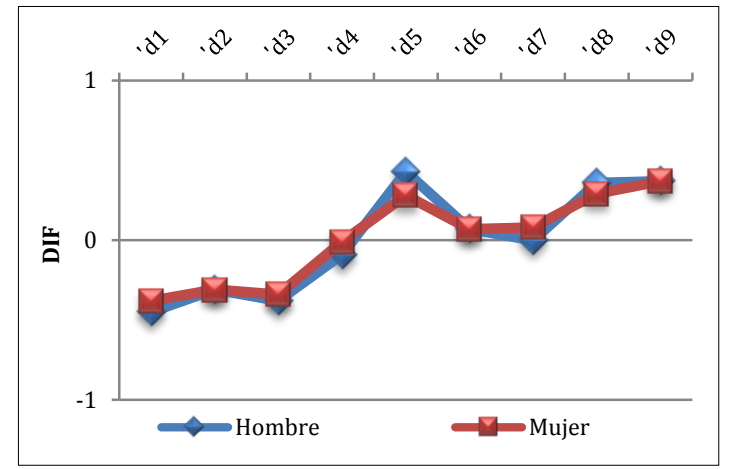

Figura 96. DIF según el género. Subescala D

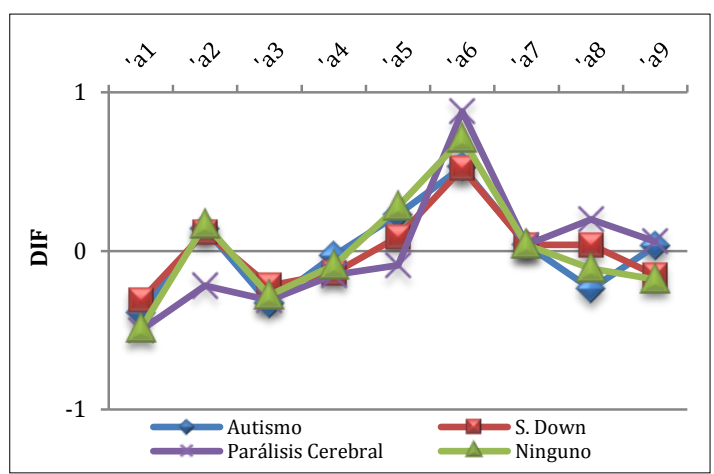

Figura 91. DIF según la etiología. Subescala A

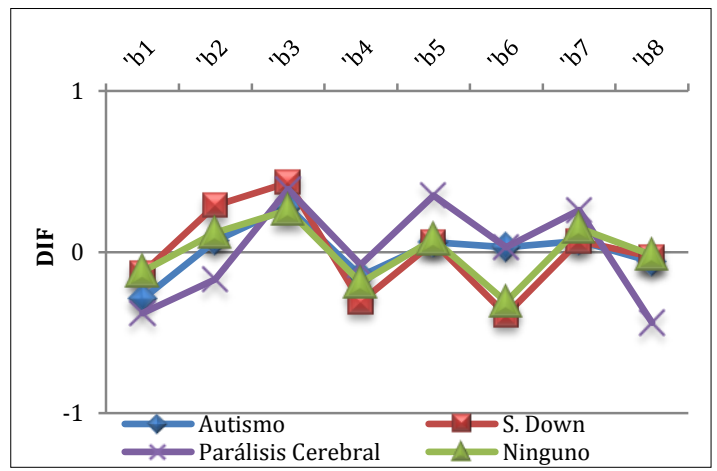

Figura 93. DIF según la etiología. Subescala B

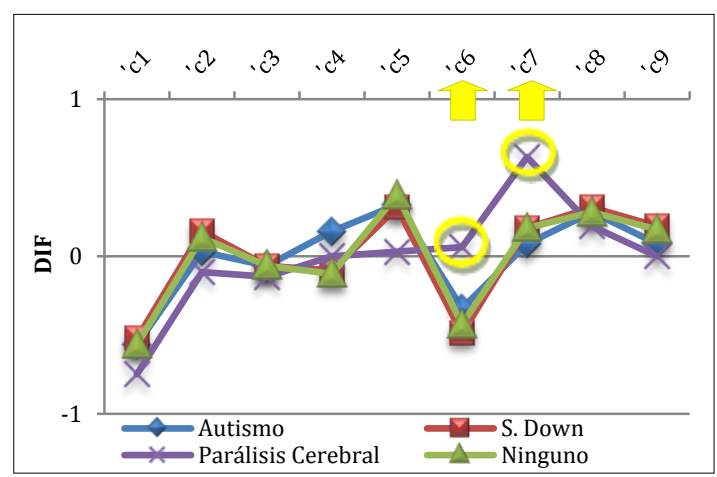

Figura 95. DIF según la etiología. Subescala C

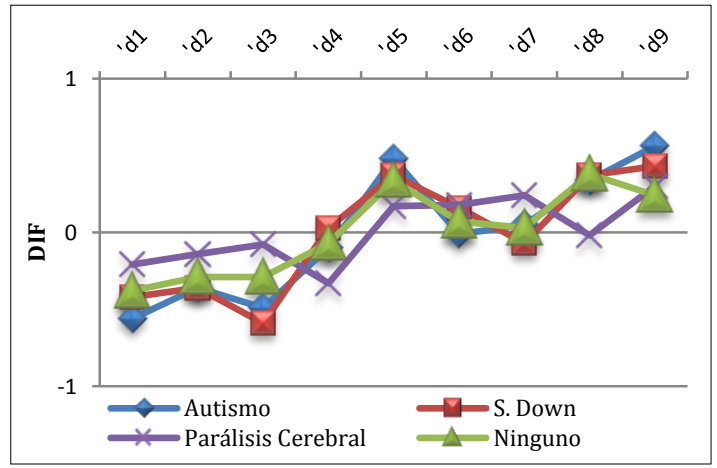

Figura 97. DIF según la etiología. Subescala D 


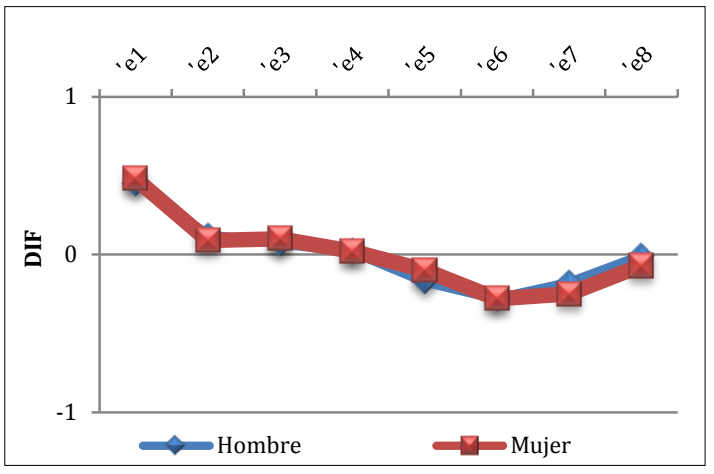

Figura 98. DIF según el género. Subescala E

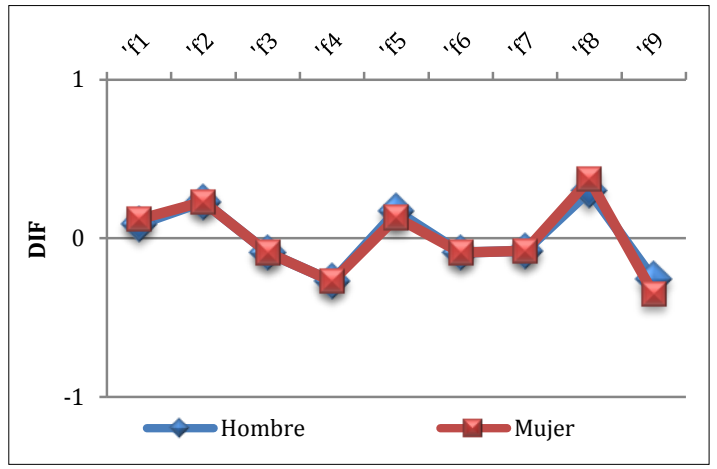

Figura 100. DIF según el género. Subescala $F$

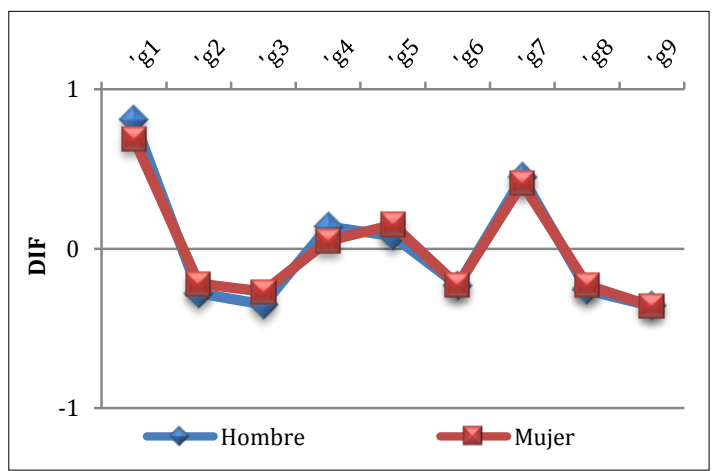

Figura 102. DIF según el género. Subescala G

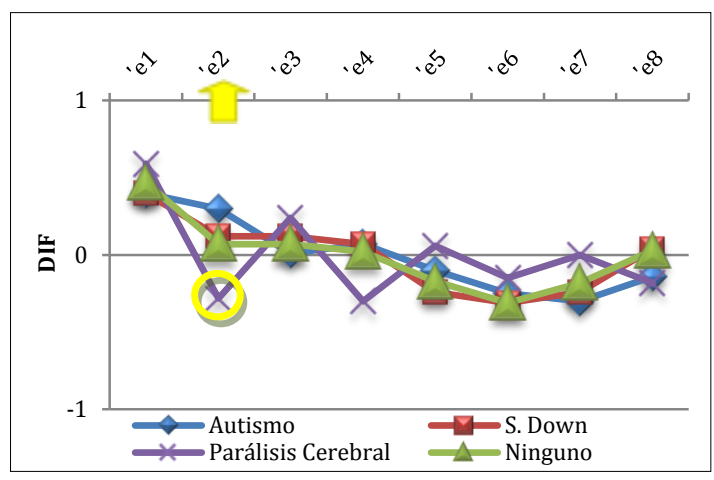

Figura 99. DIF según la etiología. Subescala E

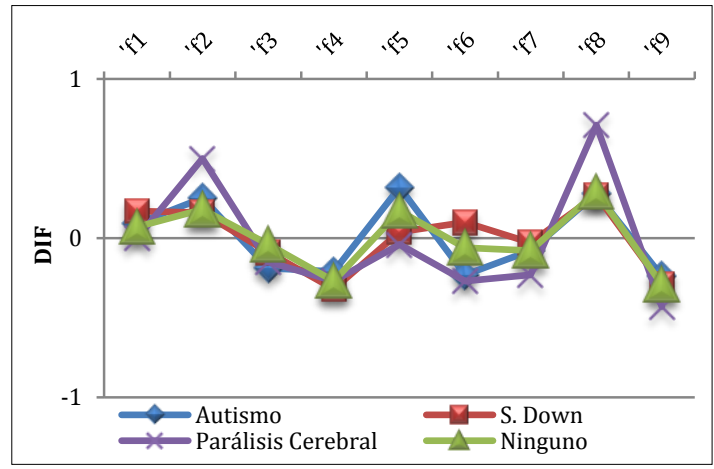

Figura 101. DIF según la etiología. Subescala $F$

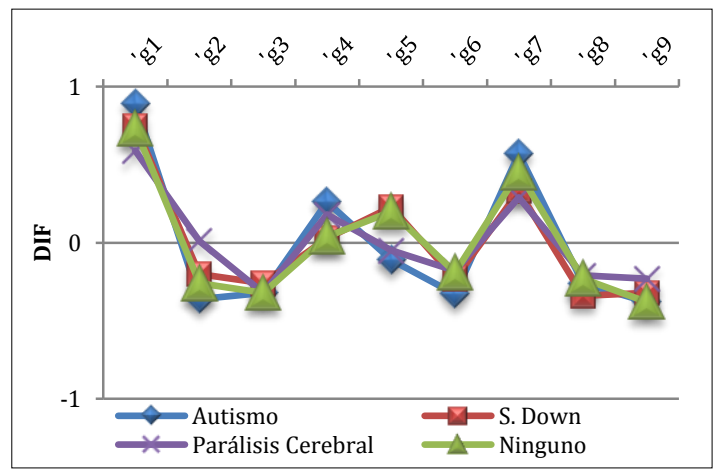

Figura 103. DIF según la etiología. Subescala G

Analizando estos gráficos, observamos que dos ítems de los tres que muestran un funcionamiento diferencial aluden a la comparación específica entre 'parálisis cerebral' y 'autismo' (Tabla 78). Por un lado, los alumnos con autismo manifiestan mayores necesidades de apoyo que los alumnos con parálisis cerebral para respetar las reglas del colegio (Ítem C7) y, por el contrario, presentan menos necesidades que estos en aquellas actividades relacionadas con el mantenimiento de la forma física (Ítem E2). Este hecho, unido al amplio número de ítems que presentan altos valores (.30-.40) en el contraste de las medidas entre estos dos grupos, indica que no ha de descartarse la posibilidad de seguir ahondando en este tema y analizar de manera más exhaustiva sí sería conveniente realizar baremos que atiendan a las características de estas dos de etiologías específicas. 
Tabla 78. Resumen de los ítems que presentan un funcionamiento diferencial (DIF contrast) para personas con autismo y parálisis cerebral

\begin{tabular}{|c|c|c|c|c|}
\hline DIMENSIÓN & ÍTEM & GRUPOS & $\begin{array}{c}\text { DIF } \\
\text { MEASURE }\end{array}$ & $\begin{array}{c}\text { DIF } \\
\text { CONTRAST }\end{array}$ \\
\hline \multirow{2}{*}{$\begin{array}{l}\text { C. Participación } \\
\text { Escolar }\end{array}$} & \multirow{2}{*}{$\begin{array}{l}\text { C7. Cumplir las reglas del aula } \\
\text { y de la escuela }\end{array}$} & Autismo & .08 & \multirow{2}{*}{.55} \\
\hline & & Parálisis Cerebral & .63 & \\
\hline \multirow{2}{*}{$\begin{array}{l}\text { E. Saludy } \\
\text { Seguridad }\end{array}$} & \multirow{2}{*}{ E2. Mantener la forma física } & Autismo & .30 & \multirow{2}{*}{.58} \\
\hline & & Parálisis Cerebral & -.28 & \\
\hline
\end{tabular}

\subsection{CONCLUSIONES DEL CAPÍTULO 4}

Las fases propuestas por Tassé y Craig (1999) para el proceso de traducción y adaptación de la SIS-C a otros países incluyen un proceso de validación completo que permita garantizar, a partir de un amplio número de aplicaciones, que las propiedades psicométricas del instrumento reflejan la medición del constructo determinado (i.e., 'necesidades de apoyo') en el contexto diana (i.e., España). De esta manera, los análisis iniciales referentes a la adecuación de las traducciones, el juicio de expertos y el estudio piloto, son condiciones necesarias pero no suficientes para adaptar y validar un instrumento en un entorno diferente a la original.

Por ello, en este segundo capítulo empírico se ha presentado el análisis de los datos obtenidos en la SIS-C por una muestra de 814 niños y adolescentes con discapacidad intelectual. Para aportar rigurosidad al estudio de las propiedades de la escala, se han seguido complementariamente las indicaciones de tres supuestos metodológicos diferentes (TCT, SEM y TRI), que han constituido los tres objetivos específicos de este capítulo. El uso de varias metodologías de análisis para la construcción de este instrumento ha permitido sacar conclusiones específicas acordes a las características concretas de cada una de ellas, obteniéndose una visión más completa del funcionamiento del instrumento.

Concretamente, la razón que ha promulgado el uso de la TCT residía en ofrecer, de manera prioritaria, un análisis del funcionamiento general de la escala. En primer lugar, se ha realizado un análisis de los indicadores observables (ítems), considerados la unidad básica de análisis dentro de la escala, comprobándose sus adecuados índices de discriminación (interna y externa), poder discriminativo, fiabilidad y validez. No obstante, si bien la precisión de la medida de los ítems es necesaria para un buen funcionamiento de 
la escala, no es condición suficiente. Por ello, se han ofrecido numerosas evidencias de fiabilidad en relación a la escala y sus dimensiones, teniendo en cuenta para ello la consistencia interna, la ausencia de error (ETM) y la estabilidad (temporal e interevaluadores). Por último, se ha analizado también la validez del instrumento, obtenida a partir del análisis de contenido, de criterio y de constructo, lo que ha reflejado un apropiado funcionamiento de la escala en población española y una buena relación entre las subescalas en las que ha sido dividida.

Por su parte, el AFC, realizado como complemento a la TCT bajo los supuestos de los SEM, ha permitido conocer la estructura factorial del instrumento, reflejando las relaciones entre las variables observables y las variables latentes. Tras la creación de 21 parcels unidimensionales y el uso de métodos robustos a la falta de normalidad de nuestros datos (DWLS), se rechazó la hipótesis de la unidimensionalidad. Por su parte, tanto el modelo correlacional como el modelo jerárquico resultaron aceptables para la explicación de la distribución de los datos, reflejando la multidimensionalidad del constructo 'necesidades de apoyo'. Al profundizar más en los resultados, se puede apreciar que el modelo correlacional obtiene mayores índices de ajuste (muestra menor cantidad de error en su medición), corroborándose la estructura teórica del constructo, establecida de manera previa a partir de los resultados de la validación de la SIS para adultos en la versión original (Thompson et al., 2004) y en diferentes adaptaciones (e.g., Kuppens et al., 2010; Schalock, Thompson et al., 2008), incluyendo la española (Verdugo, Arias e Ibáñez, 2007).

Finalmente, el uso adicional de la metodología TRI, realizado de manera específica a través del MCP, ha permitido un análisis más específico de cada uno de los ítems y del funcionamiento de las categorías de respuesta, poniendo sobre la mesa, de manera más rigurosa, sus características y sacando a la luz algunas de sus debilidades. Concretamente, de entre todos los análisis llevados a cabo, los estadísticos de ajuste interno (Infit) y externo (Outfit), la estimación de la precisión de la medida, realizada a través de las curvas características y el análisis de la invarianza (funcionamiento diferencial de los ítems), ha mostrado un grupo de ítems que no alcanzan los resultados idóneos esperados para obtener un buen ajuste. A pesar de estos resultados, que presentan la falta de capacidad de seis ítems para aportar información relevante sobre el constructo medido, no se han encontrado en ningún momento índices de ajuste inaceptables que pusieran de manifiesto la necesidad de eliminar los ítems de la escala. 
No obstante, aún teniendo en consideración los apropiados resultados obtenidos, es necesario hacer explícitas las limitaciones encontradas en el proceso de desarrollo de la investigación. Al igual que ocurría en el estudio piloto, el hecho de que el trabajo de campo requiera la participación de personas, ha hecho que se haya primado la voluntariedad de la participación ante la aleatorización, ha creado un sesgo en los datos derivado de la naturaleza incidental de la muestra. Aunque la muestra era amplia y puede ser considerada suficientemente representativa, aparece una mayor presencia de hombres que de mujeres y una significativa falta de normalidad en los datos. La ausencia del criterio de normalidad evidencias dificultan la generalización de los datos y ha de ser tenida en cuenta en los procedimientos a seguir en la validación y baremación de la escala. En este sentido, destacamos como punto fuerte que esta falta de normalidad fue identificada antes de comenzar a tomar decisiones prácticas sobre el análisis de datos, asegurándonos siempre de elegir procesos de análisis susceptibles a la violación de este supuesto (mediante el uso de pruebas no paramétricas en los análisis realizados a partir de la TCT, y la elección de métodos de estimación de parámetros específicos para el AFC).

En definitiva, estos resultados permiten concluir que la escala presenta suficientes garantías de fiabilidad y validez para evaluar las necesidades de apoyo de niños y adolescentes con discapacidad intelectual es apropiado en nuestro contexto. No obstante, es importante continuar discutiendo y reflexionando sobre sus propiedades para optimizar su funcionamiento. Los resultados obtenidos en este estudio serán comparados con los que se alcancen en las próximas adaptaciones de la escala a otros países, tomando decisiones comunes sobre posibles modificaciones que optimicen su funcionamiento y obteniendo, de esta manera, una escala ajustada a nuestro contexto que sea coherente, a su vez, con los estándares internacionales. 




\section{DISCUSIÓN}

El principal objetivo de esta tesis doctoral se encuentra directamente recogido en su título 'Desarrollo y validación de una escala de necesidades de apoyo para niños y adolescentes con discapacidad intelectual'. Tal y como se ha puesto de manifiesto a lo largo del trabajo presentado, la finalidad concreta de esta investigación es la adaptación en español de la Escala de Intensidad de Apoyos para Niños y Adolescentes (Support Intensity Scale for Children [SIS-C]). Se espera que este instrumento ofrezca información útil que contribuya al diseño eficaz de planes individualizados de apoyo desde edades tempranas, aportando gran valor a las intervenciones realizadas en este ámbito. Por tanto, resulta innegable la relevancia que tiene dedicar esfuerzos dirigidos a validar con precisión esta escala y a difundir sus implicaciones prácticas.

Para cerrar esta tesis doctoral y dar un sentido global a la información expuesta, se presenta a continuación una discusión científica derivada de las conclusiones teóricas y empíricas de esta investigación. Tras resumir las implicaciones de la concepción y evaluación de la discapacidad intelectual, se sintetizan los resultados del funcionamiento de SIS-C en España, comparándolos con aquellos obtenidos en investigaciones similares y reflexionando sobre su interés social. Asimismo, en la parte final de esta discusión, se presentan los puntos fuertes y limitaciones encontrados, dando paso a las futuras líneas de investigación. En este sentido, se pone de manifiesto que este trabajo recoge sólo una parte de los resultados de los proyectos $\mathrm{I}+\mathrm{D}$ de los que forma parte y se proponen los pasos a seguir en la investigación futura.

\section{A) CONCLUSIONES GENERALES}

Para aportar una visión general de la investigación en este ámbito, se ha realizado una revisión teórica sobre el papel que juegan los apoyos en la vida de las personas con discapacidad intelectual, ofreciendo una perspectiva longitudinal de su importancia como marco de referencia para la evaluación e intervención. La concepción actual deja atrás la perspectiva tradicional centrada en el déficit intelectual, interesándose por las fortalezas humanas y su desarrollo a través de los apoyos proporcionados por el contexto social (Shogren, 2013; Shogren et al., 2014), pudiendo así ser fácilmente enmarcada dentro de la 'psicología positiva' (Schalock, 2004; Shogren et al., 2006). 
Consecuentemente, la provisión de apoyos ha ido adquiriendo una mayor presencia en la investigación científica y en la filosofía que subyace en las organizaciones que trabajan con personas con discapacidad. Por ello, también se ha presentado en la parte teórica de este trabajo un análisis del cambio organizacional que está aconteciendo en nuestros días de manera coherente con esta evolución conceptual. El objetivo principal de los servicios de atención directa ya no reside en los cuidados asistenciales, sino en mejorar la inclusión y la calidad de vida de las personas con discapacidad. No obstante, si bien este nuevo paradigma de apoyos está cumpliendo su papel al guiar actitudes positivas hacia las personas con discapacidad y proporcionando pautas prácticas a los profesionales sobre qué observar, qué analizar, cómo estructurar su trabajo y cómo interpretar los resultados, aún hace falta desarrollar instrumentos y estrategias adecuados para la evaluación (Barr, 2007), que ayuden a las organizaciones a implantar los cambios necesarios para alinearse con los avances teóricos (Schalock et al., 2014).

A pesar de las evidencias sobre los beneficios de los programas de apoyos individualizados en el funcionamiento y bienestar de las personas con discapacidad intelectual, la revisión de literatura relativa a la creación de instrumentos de evaluación de necesidades de apoyo muestra que estos son aún escasos, lo que está suponiendo un retraso en la implantación de planes de apoyo. Destaca la carencia de estas herramientas en el contexto español, mayor que en otros países de habla inglesa, y, especialmente, su total ausencia en el ámbito infantil, dado que las intervenciones tempranas son consideradas indispensables para un adecuado desarrollo y una óptima transición a la vida adulta (Thompson, Wehmeyer, Hughes, Shogren, Palmer et al., 2014).

Tradicionalmente se intentó suplir esta limitación estimando las necesidades de apoyo a través de la evaluación y generalización de otros conceptos relacionados, como el constructo de 'conducta adaptativa' (e.g., Brown, Ouellette-Kuntz et al., 2009; Harries et al., 2005). Sin embargo, a pesar de que estos constructos correlacionan significativamente, resulta erróneo deducir que existe un único factor subyacente y que puedan usarse los mismos instrumentos de medida para ambos (Buntinx et al., 2006; Guillén, 2014; Schalock et al., 2010; Thompson, McGrew et al., 2002).

Por ello, Thompson et al. (2004) desarrollan una escala específica para evaluar necesidades de apoyo en adultos con discapacidad intelectual acorde al nuevo concepto de discapacidad: la SIS. Esta escala continua siendo hoy en día la herramienta más utilizada a nivel internacional para evaluar este constructo, a pesar de los intentos realizados para crear y mejorar otras escalas (e.g., Arnold et al., 2014a). 
A la luz de su buena acogida y funcionamiento internacional (Schalock, Thompson et al., 2008), incluyendo su uso en España (Giné et al., 2007; Verdugo, Arias et al., 2007), las organizaciones demandan ahora disponer de una herramienta de similares características centrada de manera específica en las actividades cotidianas de los niños y adolescentes (Thompson, Wehmeyer, Hughes, Shogren, Palmer et al., 2014).

De esta manera, desde la Asociación Americana de Discapacidades Intelectuales y del Desarrollo (American Association on Intellectual and Developmental Disabilities [AAIDD]) se comienzan a desarrollar un propuesta internacional (en inglés) para obtener un grupo de ítems de base común (Thompson et al., 2008), que permita alinear las evaluaciones e intervenciones realizadas y facilite la comparación de resultados a nivel internacional. Así, el desarrollo de la SIS-C se convierte en el primer esfuerzo por conocer las necesidades de apoyo de los niños y adolescentes con discapacidad intelectual, y requiere un nuevo proceso de adaptación que recoja a las peculiaridades de cada lengua y cultura. Concretamente, el estudio empírico de esta tesis ha estado orientado a desarrollar la Escala de Intensidad de Apoyos para Niños y Adolescentes (SIS-C), destinada a personas con discapacidad intelectual de entre 5 y 16 años, y a aportar evidencias de su funcionamiento en España.

Con el objetivo de unificar el proceso de adaptación de la escala a los países incluidos en el proyecto, los autores de la escala proponen seguir los pasos establecidos por Tassé y Craig (1999) para la adaptación de instrumentos a contextos diferentes del original. Este procedimiento lideró previamente la adaptación de la SIS a varios países (e.g., Buntinx, 2008; Lamoureux-Hébert and Morin, 2008), incluyendo la española, y continua siendo el referente en la adaptación de la versión para niños y adolescentes (Adam-Alcocer y Giné, 2013; Guillén et al., 2012).

Dicha propuesta de adaptación recoge siete pasos a seguir, los cuales han sido tratados de manera minuciosa a lo largo del estudio empírico de esta tesis doctoral: (1) traducción/adaptación inicial de los ítems; (2) consolidación de la traducción/adaptación; (3) validación de la versión preliminar; (4) revisión/ajustes; (5) estudio piloto; (6) revisión/ajustes tras el estudio piloto; y (7) análisis de la fiabilidad y validez. Los primeros seis pasos, focalizados en el desarrollo inicial del instrumento en España, han sido tratados en el capítulo 3, reservándose el capítulo 4 para el análisis final de su fiabilidad y validez (séptimo paso), llevado a cabo siguiendo tres metodologías diferentes: la Teoría Clásica de los Tests (TCT), los Modelos de Ecuaciones Estructurales (Structural Equation Modeling [SEM]) y la Teoría de Respuesta a los Ítems (TRI). 
Con respecto al primer propósito, la adaptación de los ítems de un test no representa una mera traducción literal de los enunciados, sino que engloba un proceso complejo de consideraciones gramaticales y semánticas para adaptar un test a una lengua y una cultura concretas, midiendo un constructo determinado en relación a las características específicas de la sociedad a la que se pretende adaptar (Muñiz et al., 2013).

Además, atendiendo a las recomendaciones de la Comisión Internacional de los Tests (International Test Comission [ITC]), deben llevarse a cabo procedimientos de investigación rigurosos que permitan adaptar el lenguaje de los enunciados propuestos a la población a la que van destinados, asegurándo que las evaluaciones no hayan sido mal configuradas por la falta de comprensión. Por ello, además de contar con las traducciones y retrotraducciones realizadas por profesionales bilingües, el proceso de adaptación de los ítems de la SIS-C en español ha estado coordinado por investigadores y profesionales de atención directa, que ayudaron durante todo el proceso a utilizar una terminología precisa $\mathrm{y}$, al mismo tiempo, accesible a todos.

De manera adicional, el análisis interjueces realizado puso de manifiesto el adecuado encuadre de los ítems en cada una de las áreas de evaluación en la que estos fueron originalmente ubicados, lo que puede ser entendido, a su vez, como una prueba de validez de su contenido.

Una vez que se contaba con una traducción previa de los ítems, y estas fueron revisadas por el equipo investigador para hacer las modificaciones finales, se aplicó la escala a una muestra piloto compuesta por 143 niños y adolescentes con discapacidad intelectual del contexto español, analizando los datos obtenidos a través de la TCT y la TRI para obtener resultados preliminares de fiabilidad y validez:

- En relación con la TCT, el análisis de los ítems fue realizado a partir del poder discriminativo y el índice de homogeneidad, garantizándose en todos los casos que los ítems contaban con una buena calidad psicométrica. Por su parte, la fiabilidad de las dimensiones y de la escala quedó demostrada a través de la consistencia interna (Alfa de Cronbach) y la fiabilidad interevaluadores, obteniéndose, a su vez, diversas evidencias de validez (de criterio y de constructo) que reflejaron el buen funcionamiento de la escala (Guillén et al., 2012). Posteriormente, con un tamaño de muestra mayor, estos resultados fueron replicados (Verdugo et al., 2014), realizándose de manera complementaria un Análisis de Componentes Principales (ACP), que también registró una adecuada validez. 
- Paralelamente, se analizó el funcionamiento preliminar del instrumento mediante el empleo de la TRI (Guillén et al., en prensa). Atendiendo al reducido número de sujetos y a la naturaleza politómica del formato de respuesta, se hizo necesario el uso de Modelos de Escalas de Clasificación (Rating Scale Model [RSM]) (Andrich, 1978), considerado como una ampliación del modelo de Rasch para ítems politómicos. Para llevar a cabo los análisis bajo esta perspectiva, se comprobó, en primer lugar, que los resultados cumplían las estimaciones previas de los criterios de la TRI, pasando posteriormente al análisis de la idoneidad del formato de respuesta y del ajuste de los datos al modelo. En lo que se refiere a la adecuación del formato de respuesta de la escala, se pudo observar que los valores más altos de las categorías de respuesta ' 3 ' y '4' no se ordenaban de la manera esperada en ninguno de los tres índices de medida: tipo, frecuencia y tiempo diario de apoyo. No obstante, al colapsar estas categorías de respuesta, se demostró que la estimación de las necesidades de apoyo no se veía perjudicada, por lo que se decidió mantener el formato de respuesta inicial hasta poder realizar análisis más exhaustivos. Por su parte, las evidencias de fiabilidad y validez del instrumento (obtenidas a partir del ajuste de los datos al modelo) pusieron de manifiesto que, aunque cinco ítems no recibían el grado de ajuste deseado, no existía ningún ítem que estuviera afectando de manera negativa a la medición del constructo de 'necesidades de apoyo'. Este hecho, unido a las buenas propiedades de los ítems obtenidas mediante TCT, nos permitió mantener, de manera preliminar, todos los ítems propuestos en la versión original.

Los resultados encontrados pusieron de manifiesto el adecuado funcionamiento del instrumento en nuestro contexto, considerando la importancia de continuar con su desarrollo y proponiendo pequeñas modificaciones formales para optimizar las propiedades de la escala. Tras realizar los ajustes pertinentes, se siguió aplicando el instrumento a niños y adolescentes con discapacidad intelectual hasta conseguir una muestra lo suficientemente representativa como para suplir las limitaciones del estudio piloto y realizar un estudio más detallado de los ítems.

Finalmente, se aplicó la escala a 833 participantes, considerándose válidos 814 de los casos para la validación final de la SIS-C en el contexto español. En relación al análisis de datos, de la misma manera que ocurría en el estudio piloto, se utilizó la TRI de manera adicional a la TCT. Esta vez, también se realizó un Análisis Factorial Confirmatorio (AFC) como complemento a la TCT, proporcionando evidencias de validez a la escala a través del análisis y comparación de los factores obtenidos empíricamente (y la relación entre los 
mismos) con la estructura teórica del constructo de 'necesidades de apoyo', comprobada previamente a través de la SIS. A continuación, se describe brevemente la justificación y descripción de los análisis llevados a cabo, resumiendo los resultados obtenidos y reflejando su relación con otras investigaciones relacionadas.

- Los primeros análisis realizados bajo la TCT pusieron de manifiesto, de manera descriptiva, las características de los datos. En este punto, quedó reflejada la falta de normalidad y la importancia de contar con estadísticos susceptibles a la violación de este supuesto para un buen análisis de los datos. Teniendo esta información presente a lo largo de todo el proceso, se llevaron a cabo diferentes estrategias de análisis para conocer el funcionamiento de la escala. De manera inicial, los análisis fueron realizados de manera específica atendiendo a cada uno de los ítems como unidad de análisis. Posteriormente, para aportar evidencias generales de la fiabilidad y validez, se tuvieron en cuenta de manera paralela las puntuaciones de las subescalas y la puntuación global del instrumento, recogiendo así evidencias de la capacidad y pertinencia de los ítems para trabajar conjuntamente en la evaluación de las necesidades de apoyo.

○ El análisis de la calidad e idoneidad de los ítems garantizó el buen funcionamiento de los mismos a nivel particular. En todos los casos, los ítems presentaron un adecuado poder discriminativo ( $>40 \%)$, superando asimismo los índices de discriminación (interna y externa), fiabilidad y validez el límite inferior establecido por la mayoría de autores (.20).

○ En cuanto al análisis de fiabilidad de los ítems en conjunto, tenidos en cuenta de manera general dentro de la escala y de manera específica dentro de su área de evaluación, se encontraron resultados excelentes. De manera inicial, se tomó como referencia el Alfa de Cronbach por su uso extendido y tradicional como indicador de consistencia interna, obteniéndose en todas las dimensiones de evaluación coeficientes superiores a .950. Igualmente, se analizaron otros índices relacionados que son más apropiados para conocer la fiabilidad de instrumentos que han sido divididos en diferentes dimensiones que se suman para obtener una puntuación global (alfa estratificado) y que tienen en cuenta que la naturaleza de la variable no es continua (alfa ordinal y theta de Armor). En todos los casos, los coeficientes obtenidos a través de nuestros datos fueron superiores a .990, siendo coherentes con los bajos índices de Error Típico de Medida (ETM) encontrados. Además, se analizó la fiabilidad del instrumento desde una perspectiva de estabilidad, utilizando dos aplicaciones diferenciadas para cada 
niño evaluado. Fue analizada en este sentido la fiabilidad interevaluadores ( $n=661)$, que implica la cumplimentación de dos profesionales diferenciados en el mismo momento temporal, y la fiabilidad test-retest $(n=32)$, donde se mantiene el mismo informante y se realizan las aplicaciones en dos momentos diferenciados. En los resultados, utilizando ambos procedimientos, se obtuvieron correlaciones significativas y superiores a .75 entre las dos evaluaciones, lo que puede ser categorizado como una excelente evidencia de fiabilidad.

- Se proporcionan también distintas evidencias de validez que abogan por la estrecha relación existente entre el instrumento de evaluación y el constructo teórico que pretende medir. En primer lugar, el minucioso proceso de revisión y elaboración de la escala, así como la rigurosa traducción y adaptación de los ítems llevada a cabo, aporta evidencias de la validez de contenido a la misma. Con relación a la validez criterial, se utilizó como criterio externo de ajuste una estimación inicial de los informantes sobre las necesidades de apoyo del niño o adolescente evaluado (incluyendo una estimación por cada una de las áreas evaluadas y una estimación general) en una escala tipo Likert (1-5). De nuevo, este análisis fue conducido a través de las diferentes subescalas para, finalmente, concluir con la correlación entre el criterio externo general y la puntuación global obtenida en la escala. Los resultados sobrepasan los límites aceptables y son superiores a .60, siendo considerada idónea la correlación general (.82). Por último, para aportar evidencias de la validez de constructo, se sometieron a prueba una serie de hipótesis relacionadas con la concepción teórica del constructos que fueron aceptadas de manera general:

Existen correlaciones altas y significativas entre la puntuación obtenida en cada una de las subescalas $(>.70)$ y entre éstas y la puntuación global del instrumento (>.89), mostrando que todas ellas trabajan en conjunto para la medición de un mismo constructo. Destaca que las dos correlaciones que menos correlacionan entre sí son aprendizaje escolar y actividades sociales ya que, si bien este hecho específico no era incluido en la hipótesis inicial, es coherente con la comprensión teórica del constructo.

Existen correlaciones significativas $(\mathrm{p}<.01)$ entre las puntuaciones en la escala y las necesidades excepcionales médicas y conductuales medidas de manera suplementaria por la escala, existiendo correlaciones superiores ante la presencia simultánea de ambas necesidades. Estos resultados coinciden con los obtenidos en la SIS para adultos y evidencian la relación entre los constructos del modelo teórico establecido para la concepción de la intensidad de apoyos (Thompson et al., 2004). 
No se encuentran diferencias significativas en las puntuaciones en necesidades de apoyo (ni en las subescalas ni en la puntuación total) dependiendo del género (hombre-mujer). Desde una concepción teórica, el género no sería una variable mediadora o moderadora de la intensidad de apoyos de la persona, siendo la SIS para adultos desarrollada desde esta perspectiva (Kuppens et al., 2010; Giné et al., 2007).

En relación con la edad, destacamos que ésta es la única hipótesis planteada que supone un distanciamiento del constructo relacionado con la vida adulta. Al contrario de lo planteado en el desarrollo de la SIS, la SIS-C sí relaciona la intensidad de las necesidades de apoyo de la persona con el momento evolutivo concreto en el que se encuentra. Los datos muestran que las necesidades de apoyo incrementan a medida que el niño se acerca a la adolescencia, necesitando progresivamente más apoyos que sus iguales sin discapacidad. No obstante, estas necesidades parecen descender a medida que el niño se aproxima a la transición a la vida adulta y va adquiriendo nuevas habilidades prácticas.

Existen diferencias significativas en función del nivel de discapacidad intelectual presentado. Desde la definición teórica de discapacidad, se afirma que el Cociente Intelectual (CI) y, especialmente, el grado de conducta adaptativa (junto con el entorno) determinarán en gran medida las intensidad de apoyos de la persona (APA, 2013). En este sentido, el hecho de que existan diferencias significativas en la puntuación de la escala (y en cada una de las áreas que evalúa) dependiendo del grado de discapacidad intelectual pone de manifiesto la capacidad del instrumento para discriminar necesidades de apoyo de personas con diferentes niveles de habilidad.

- Posteriormente, para obtener evidencias de validez basadas en la estructura interna, se llevó a cabo un AFC. Este método se incluye dentro de los Modelos de Ecuaciones Estructurales (Structural Equation Modeling [SEM]) y requiere de un planteamiento inicial de modelos teóricos, los cuales serán sometidos a prueba. Concretamente, las hipótesis propuestas, basadas en los planteamientos establecidos previamente en el análisis estructural de la SIS (Harries et al., 2005; Thompson et al., 2004; Verdugo Arias et al., 2007), fueron: (h1) las necesidades de apoyo son un constructo unifactorial; (h2) las necesidades de apoyo se componen de factores correlacionados (i.e., principales áreas de evaluación de necesidades de apoyo); y (h3) las necesidades de apoyo se componen de siete factores correlacionados (i.e., áreas de evaluación) y uno de segundo orden (i.e., necesidades de apoyo). 
Para someter a prueba estos modelos, se tomó la decisión de crear parcels como indicadores (que fueron creados promediando grupos pequeños de ítems dentro de cada dimensión para disminuir el amplio número de variables observables del que se partía), garantizando en todo caso la unidiomensionalidad de los mismos (e.g., diferencias entre el primer y el segundo eigenvalue superiores a 3) para evitar los posibles inconvenientes de su uso. No obstante, a la luz de la falta de normalidad de los parcels (que, en cualquier paso, fue superior a la normalidad obtenida teniendo en cuenta cada ítem de manera independiente), fue necesario tomar medidas específicas de estimación de parámetros, eligiéndose así como método de estimación de parámetros utilizado el Método de Mínimos Cuadrados Diagnolizados (Diagonally Weighted Least Squares [DWLS]).

Los distintos índices de bondad de ajuste pusieron de manifiesto que el modelo unifactorial resulta insuficiente para reproducir la matriz de covarianzas original, produciéndose un mejor ajuste en el caso de los modelos 2 y 3. No obstante, el Índice de Error de Aproximación (Root Mean Square error of Approximation, [RSMEA]) y la Raíz del Residuo Cuadrático Medio Estandarizado (Standardized Root Mean Square Residual [SRMR]) fueron inferiores en el caso del segundo modelo. Este hecho permite afirmar que las necesidades de apoyo forman, principalmente, un constructo de factores que correlacionan entre sí, pudiendo considerarse, complementariamente, la existencia de un constructo de orden superior que da cuenta de las relaciones entre los mismos. Estos resultados abogan por no usar únicamente un índice global de necesidades de apoyo, sino también una puntuación específica para cada una de las áreas evaluadas que ofrezca un perfil capaz de aportar pautas más exhaustivas sobre la intensidad de apoyo que ha de recibir cada persona en función de los distintos entornos.

- En último lugar, se calibró el instrumento bajo los supuestos de la TRI. El uso de esta metodología supone un elemento de gran innovación dentro de este campo de estudio ya que, si bien esta metodología está comenzando a ser comúnmente utilizada en la evaluación de otros constructos relacionados con la discapacidad intelectual, como la conducta adaptativa (Navas, Verdugo, Arias y Gómez, 2012) o la calidad de vida (Gómez, Arias, Verdugo y Navas, 2012), este tipo de análisis resultan pioneros dentro de la evaluación de las necesidades de apoyo. No obstante, los buenos resultados obtenidos en el estudio piloto en relación al análisis de datos a través de la TRI, nos animó a seguir investigando en esta línea. 
A pesar de las evidencias iniciales, su uso fue llevado a cabo con cautela ya que, mientras que el estudio piloto se enmarcó dentro del RSM, el amplio número de sujetos permitía llevar a cabo un estudio más profundo de los parámetros de los ítems a través del uso de Modelo de Crédito Parcial (Partial Credit Model [MCP]).

- Los análisis iniciales se dedicaron a conocer la adecuación real de esta metodología de trabajo a la naturaleza de nuestros datos. Con este objetivo, fueron analizadas varias de sus características: (a) la polaridad de los ítems, donde se obtuvieron correlaciones entre los ítems de cada subescala superiores a .70; (b) la cantidad de varianza explicada por las secciones, que obtuvo un porcentaje superior al 70\% en todos los casos; y (c) la unidimensionalidad de las subescalas, garantizada por la baja presencia de ítems dentro de las secciones potencialmente incluidos en una posible segunda dimensión $(<3)$.

- A propósito del análisis de la idoneidad del sistema de categorías de respuesta, se tomó como referencia el funcionamiento de cada uno de los índices de medida. Los resultados pusieron de manifiesto una falta de adecuación de las categorías de respuesta '3' y '4' en el índice tiempo diario de apoyo derivada de la falta de ordenación monotónica de las categorías, pero un buen funcionamiento de los índices tipo de apoyo y frecuencia de apoyo. Teniendo como referencia estos resultados $\mathrm{y}$ atendiendo a la posibilidad que ofrece el método MCP de analizar la adecuación de las categorías a cada ítem, se realizó un análisis exhaustivo del funcionamiento del sistema de respuesta en cada uno de los indicadores de la SIS-C, revelándose que 32 de los ítems (un 52\% del conjunto total de 61 ítems) presentaron limitaciones que podrían ser superadas si las categorías de respuesta mencionadas fueran colapsadas.

- Los índices de separación calculados tanto para ítems como para personas reflejaron que estábamos midiendo un rango lo suficientemente amplio tanto de habilidad de los sujetos (i.e., en nuestra muestra aparecían representados niveles de necesidades de apoyo tanto altos como medios y bajos) como de nivel de dificultad de los ítems (i.e., ítems en los que solo los sujetos con mayor nivel de habilidad adaptativa recibían la puntuación máxima en los que también aquellos sujetos con mas limitaciones recibían la puntación mínima). Complementariamente, los índices de fiabilidad fueron excelentes (oscilaron entre .91 y 1.00) permitiéndonos asumir la replicabilidad de la localización de los ítems en la variable medida si estos fueran administrados a otra muestra similar. 
- Para considerar que había un buen ajuste de los datos al modelo era necesario obtener índices de ajuste interno (Infit) y externo (Outfit) aceptables. Se analizó la Media Cuadrática (MNSQ) y la Z Empírica (ZEMP) de ambos índices. El estadístico MNSQ propone como idóneos valores en un rango de entre .5 y 1.5 (llegando a aceptar valores más altos, pero inferiores a 2.0) y el estadístico ZEMP busca obtener valores en un rango que oscile entre -2.0 y 2.0 (sugiriendo que sería inaceptable mantener valores superiores a 2.5). Los resultados mostraron el buen ajuste de la escala y sus dimensiones, manifestando, a su vez, que sólo cuatro de los 61 ítems (el 6.5\%) no obtuvieron los valores idóneos esperados, no reflejando en ningún momento valores superiores a lo aceptable.

- El análisis de la localización, discriminación y precisión de la medida, permitió observar el nivel medio de dificultad de las actividades presentadas en la escala como indicadores objetivos, poniéndose de manifiesto (a través de las Curvas Características y la Función de Información) la capacidad de los ítems para discriminar con mayor precisión en niveles de dificultad medios. En algunas ocasiones (especialmente en las áreas relacionadas con el entorno escolar), este hecho generaba un efecto suelo y un efecto techo que no permitían evaluar con nitidez las necesidades de apoyo de los sujetos. No obstante, en el análisis general de los ítems de manera conjunta, se pudo apreciar como el nivel medio de estas actividades recogía la gran parte del nivel de habilidad de los sujetos, corroborando que existía una separación suficiente entre estos. En este sentido, Thompson y Viriyangkura (2013) defienden que el nivel medio de dificultad de las actividades debe ser considerado como evidencia de su cotidianidad, reflejando que la diferencia entre ellas se explica como un asunto de entorno más que por el nivel de dificultad de la actividad.

- Por último, atendiendo a la invarianza, se partía de la hipótesis de que una escala compuesta por ítems de calidad no obtendrá un funcionamiento diferencial del ítem para sujetos con diferentes características sociodemográficas pero el mismo nivel de habilidad. En este sentido, y dejando a un lado variables independientes como la edad o el nivel de discapacidad intelectual, que se esperaba que sí influyeran en el nivel de habilidad del sujeto, se analizó la invarianza en relación a dos variables: género (hombre o mujer) y etiologías específicas (Down, autismo, parálisis cerebral o no especificada).

$>$ Teniendo en cuenta la variable 'género', los resultados pusieron de manifiesto que no existía un funcionamiento diferencial de los ítems dependiendo de la categoría de la variable (hombre-mujer) a la que perteneciesen los sujetos evaluados. Los datos obtenidos coinciden, por tanto, con los resultados esperados. 
Con relación a la variable 'etiologías específicas', se encontraron tres ítems que funcionaban de manera diferencial, dependiendo dos de ellos de si los sujetos tenían autismo o parálisis cerebral: el ítem C7, (cumplir las reglas del aula y de la escuela), en el que las personas con parálisis cerebral mostraban menos necesidades de apoyo que los alumnos con autismo; y el ítem E2 (mantener la forma física), donde las personas con autismo presentaban un facilidad mayor que las personas con discapacidad intelectual a la hora de cumplir con los requisitos necesarios para estar en buena forma. Asimismo, existen varios ítems en todas las áreas que, si bien no llegan a superar los límites necesarios para hablar de un funcionamiento diferencial de los ítems, sí se obtienen diferencias altas en relación al nivel de dificultad en el que se encuentra el ítem dependiendo de si la persona presenta autismo o una parálisis cerebral asociada a la discapacidad intelectual. Por ello, si bien solo existen tres ítems que estén reflejando esta diferenciación significativa, podría ser conveniente realizar una baremación específica para estos dos grupos de población, recogiendo sus características físicas y sociales específicas.

En definitiva, podemos decir que los resultados ponen de manifiesto que la escala tiene buenas propiedades psicométricas y sus ítems resultan apropiados para la evaluación de necesidades de apoyo de niños y adolescentes con discapacidad intelectual dentro del contexto español. Asimismo, es importante destacar que los resultados aquí obtenidos son comparables a los de otros estudios relacionados con la evaluación de necesidades de apoyo:

- En relación con la TCT, destacamos la obtención de resultados de fiabilidad y validez similares (aunque ligeramente superiores) que los encontrados previamente en las distintas validaciones de la SIS (e.g., Claes et al., 2009a; Giné et al., 2007; LamoureuxHébert y Morin, 2009; Morin y Cobigo, 2009; Schalock, Thompson et al., 2008; Thompson et al., 2004; Thompson, Tassé et al., 2008) así como a los encontrados en los estudios preliminares realizados para la SIS-C en España (Adam-Alcocer y Giné, 2013; Guillén et al., 2012) y en Estados Unidos (Thompson et al., 2014).

- Asimismo, los resultados del AFC confirman la estructura factorial correlacional de la escala obtenida en la SIS para adultos (Kuppens et al., 2010; Thompson et al., 2004; Verdugo, Arias et al., 2007), aportando por primera vez evidencias de la naturaleza de este constructo desde el ámbito infantil. 
Cabe destacar, sin embargo, que la estructura factorial correlacional encontrada en la SIS-C incluye la dimensión 'defensa', la cual fue considerada una subescala complementaria en la SIS por obtener puntuaciones sustancialmente diferente al resto de las áreas. No obstante, su especial interés dentro de la transición a la vida adulta de los jóvenes con discapacidad intelectual y los estudios recientes realizados con la SIS para incluir esta subescala como parte del índice y perfil general (Shogren, Thompson et al., 2014) ponen de manifiesto la coherencia de nuestros resultados. De manera adicional, la SIS-C ha permitido confirmar una estructura jerárquica del constructo, que aporta una explicación empírica a la importancia no solo del perfil de apoyos, sino también del índice global derivado del mismo.

- En cuanto a la TRI, destacamos que su uso innovador dentro del campo de las necesidades de apoyo resultó adecuado y positivo. Los resultados obtenidos a través de esta metodología reflejaron nuevos datos clave sobre el funcionamiento de la escala, aportando información más precisa y robusta sobre la calidad de los ítems, reflejando nuevos datos clave sobre su funcionamiento. Asimismo, los resultados fueron mejores en el análisis final que los encontrados en el estudio piloto (Guillén et al., 2012).

En resumen, los resultados obtenidos ponen de manifiesto la capacidad de la SIS-C para contribuir al avance de la concepción de las necesidades de apoyo para contribuir al avance de la concepción de las necesidades de apoyo y su repercusión en el trabajo con niños y jóvenes con discapacidad intelectual.

De la misma manera, que la SIS para adultos (Thompson et al., 2009), la escala para niños pretende contribuir a: (1) aportar una mayor apreciación del valor de la Planificación Centrada en la Persona (PCP) y una extendida implementación de este proceso, lo que contribuye a enfatizar el crecimiento personal, las elecciones, las decisiones y la capacitación (empowerment); (2) fomentar un enfoque ecológico hacia la discapacidad que hace cada vez mayor hincapié en el poder de las interacciones personaentorno y la mejora del funcionamiento humano mediante la aportación de los apoyos individualizados; (3) incluir un renovado énfasis en el bienestar personal, la calidad de vida y los resultados personales deseados; y (4) facilitar el conocimiento de una amplia variedad de estrategias de apoyo, incluyendo los avances de la tecnología asistida. 


\section{B) PUNTOS FUERTES Y LIMITACIONES}

Dentro de este apartado, comenzamos analizando los puntos fuertes de nuestro estudio con el objetivo concreto de dar valor al esfuerzo y rigurosidad con que el proceso de desarrollo del instrumento ha sido llevado a cabo. En este sentido, no solo se valoran los resultados obtenidos (que, en general, son más que adecuados para determinar una apropiada validación instrumentos de medida), sino también la precisión y eficacia del procedimiento realizado, que ha supuesto una primera aproximación a la evaluación de las necesidades de apoyo de niños y adolescentes con discapacidad intelectual.

La SIS-C está siendo uno de los trabajos pioneros en la evaluación de necesidades de apoyo infantiles y su desarrollo en español puede servir como referencia para optimizar el trabajo de los profesionales que trabajan con niños y adolescentes con discapacidad intelectual en nuestro contexto. Por ello, aunque las fortalezas de este proyecto han quedado patentes a lo largo de esta tesis, dedicamos un espacio específico para resumir los puntos fuertes y valorar el alto nivel científico del estudio realizado.

$\checkmark$ La revisión de literatura relacionada con el concepto de discapacidad intelectual ha sido muy amplia y completa. Se ha mantenido durante todo el proceso una búsqueda actualizada de todos los conceptos relacionados (e.g., apoyos, calidad de vida...) y de instrumentos de medida específicos sobre necesidades de apoyo en el contexto infantil, confirmando la innovación y auge de este tema de investigación.

$\checkmark$ Se ha realizado un proceso exhaustivo de adaptación de los ítems (que ya contaban con garantías de su adecuación e idoneidad en su contexto original) a partir de las pautas propuestas por autores de gran prestigio (Tassé y Craig, 1999). Estas fases son coherentes con las pautas de adaptación de instrumentos propuestas por la Comisión Internacional de los Tests (ITC) e incluyen en sus fases iniciales un juicio de expertos y un estudio piloto, asegurando desde el principio una buena adaptación del instrumento.

$\checkmark$ Se ha obtenido un tamaño de la muestra suficientemente elevado para la validación de una escala $(n=814)$. Todas las categorías de las variables sociodemográficas recogidas (género, edad, nivel de discapacidad intelectual, etiología, limitaciones asociadas, escolarización, colegio, vivienda, lengua, tecnologías asistenciales) han sido representadas, incluyendo la participación de 10 Comunidades Autónomas. Además, las diferentes categorías de la variable 'nivel de discapacidad intelectual' aparecen representadas dentro de cada uno de los seis pares de edad que recoge la SIS-C (5-16 años), lo que permitirá realizar un análisis pormenorizado por grupos de edad. 
$\checkmark$ La mayor parte de las aplicaciones del instrumento fueron llevadas a cabo en formato de entrevista, estando implicados miembros del equipo investigador en la gran mayoría, garantizándose así una buena comprensión del formato de cumplimentación y de la descripción de los ítems en todas ellas.

Se han realizados dobles aplicaciones. Concretamente, en 732 casos se contó con la participación de dos informantes; en 661 de esas ocasiones las entrevistas fueron realizadas de manera independiente, contribuyendo a conocer la fiabilidad interevaluadores del instrumento. Asimismo, en 32 de las aplicaciones que solo contaban con la colaboración de un informante, se realizaron dos entrevistas a éste en dos momentos temporales (con dos meses de diferencia), aportando así una doble evaluación que permite contribuir al análisis de fiabilidad a través del método de test-retest.

$\checkmark$ El análisis descriptivo de los datos, realizado de manera previa al análisis de las propiedades psicométricas de la escala, permitió localizar falta de normalidad en los datos y suplir la falta de ajuste de los datos a este supuesto mediante el uso exhaustivo de métodos de análisis robustos a la violación de este supuesto.

Los datos obtenidos tras la aplicación del instrumento han sido analizados a través de tres perspectivas metodológicas diferentes (TCT, SEM y TRI). Los diversos análisis realizados han aportado suficientes evidencias acerca de su fiabilidad y validez así como garantías sobre su adecuado funcionamiento para evaluar las necesidades de apoyo de los niños y adolescentes con discapacidad intelectual del contexto español, sugiriendo también pautas a tener en cuenta en la baremación del instrumento (consideraciones sobre etiologías específicas).

$\checkmark$ El desarrollo de la escala se fundamenta en los pilares de la SIS, con previas garantías de fiabilidad, validez y utilidad práctica. Asimismo, en la SIS-C se han incorporado ciertas mejoras obtenidas a partir del análisis de las limitaciones de la SIS (e.g., el formato de respuesta del índice frecuencia de apoyo ha sido simplificado y se ha incluido la escala suplementaria 'Protección y Defensa' dentro del perfil e índice general (Shogren, Thompson et al., 2014), lo que ha optimizado los resultados.

$\checkmark$ Por primera vez, se ha puesto de manifiesto la estructura del constructo de 'necesidades de apoyo' desde el punto de vista de datos recogidos en la infancia, corroborándose en gran medida los datos obtenidos en adultos. Este hecho aporta validez de doble dirección, ya que permite hablar de la pertinencia de contenido de la escala y a su vez, le da consistencia al constructo teórico desarrollado. 
No obstante, aunque este estudio cuenta con numerosos puntos fuertes y los objetivos generales se han alcanzado con éxito, no está exento de limitaciones. Entre ellas, destacamos la selección de la muestra que, como ya fue reflejado previamente en los capítulos empíricos, no fue una muestra aleatoria, sino una muestra incidental. Este hecho ha desembocado asimismo en otra serie de limitaciones: (1) una mayor presencia de hombres que de mujeres en la muestra; y (2) una mayor participación en el estudio de personas con discapacidades severas que ligeras, lo que ha provocado un alto porcentaje de puntuaciones altas que reflejaron falta de normalidad en los datos y efectos suelo y techo en la medida. A pesar de esta limitación, destacamos que el uso cauteloso de los datos y la toma de medidas específicas para la baremación asegurarán que no se realice una generalización indebida de los datos y que las limitaciones puedan ser superadas.

Asimismo, presentamos otra serie de limitaciones en el proceso de aplicación del instrumento y análisis de datos las cuáles darán paso a futuras líneas de investigación, que ofrecerán nuevas evidencias de la validez de la escala:

- Las dos aplicaciones necesarias para realizar análisis de la fiabilidad interevaluadores fueron realizadas en la mayor parte de los casos por el mismo entrevistador, lo que puede incrementar la correlación entre las puntuaciones. Por ello, sería interesante realizar un estudio más completo donde se realizasen comparaciones de aplicaciones llevadas a cabo por distintos entrevistadores.

- El número de sujetos participantes en el test-retest $(n=32)$ no es lo suficientemente amplio para sacar conclusiones definitivas sobre la estabilidad temporal de la medición de la escala; además, no fue posible controlar todas las variables que pudieran estar influyendo en las necesidades de apoyo de los niños evaluados durante los meses de espera entre las aplicaciones. Sería conveniente continuar ampliando la muestra de este estudio.

- La evaluación de las necesidades de apoyo extraordinarias (que una persona de la misma edad no necesita) que propone la escala se realizó desde una perspectiva subjetiva. La versión de la SIS-C utilizada no ofrece una descripción específica sobre las necesidades normativas, por lo que el punto que discernía las necesidades normativas de las extraordinarias dependía del criterio del entrevistador y/o el informante, variando en función de sus conocimientos previos y sus experiencias relacionadas con el desarrollo evolutivo de las personas sin discapacidad. 
- El criterio externo tenido en cuenta para el análisis de la validez criterial era también subjetivo y proporcionado por el mismo informante. Lo ideal sería utilizar un criterio externo objetivo de necesidades de apoyo con avaladas garantías, como podría ser otra escala o los resultados de un informe clínico.

- Los ítems de la subescala complementaria de necesidades excepcionales médicas y conductuales no han recibido un análisis exhaustivo sobre su adecuación y pertinencia dentro de la evaluación de necesidades de apoyo.

- Destaca, además, la posibilidad de haber realizado un análisis más exhaustivo del funcionamiento de las categorías de respuesta dentro de cada ítem, incluyendo el tipo y la frecuencia, ya que, aunque el funcionamiento general de estos índices dentro de cada dimensión resultó adecuado, podrían suponer limitaciones en algún ítem concreto.

- Los resultados ponen de manifiesto que existen tres ítems de la escala que obtienen recurrentemente falta de ajuste: A6, C6 y G1. Concretamente: (1) el ítem A6 (dormir o echarse la siesta) obtuvo un bajo índice de discriminación interna así como un bajo ajuste para el modelo de TRI (en el Infit y el Outfit) y una inadecuada discriminación (CCI); (2) el ítem C6 (participar en actividades de evaluación/examen requeridos por los sistemas de evaluación) recibió un bajo índice de discriminación interna y de fiabilidad. Además, a nivel de contenido su uso se solapa con el del ítem D7 (participar en actividades de evaluación de clase, como son los exámenes); y (3) el ítem G1 (expresar preferencias), que refleja un bajo ajuste para el modelo de TRI (tanto en el Infit como en el Outfit) y una inadecuada discriminación (CCI). Los ítems A6 y G1 fueron, además, inadecuados en el estudio piloto, siendo los dos primeros (A6 y C6) los ítems más problemáticos encontrados en el estudio piloto realizado en catalán (Adam-Alcocer y Giné, 2013).

- El análisis de la invarianza de los ítems presenta un ligero funcionamiento diferencial en relación a las personas con autismo (asociado de manera principal a limitaciones sociales) y parálisis cerebral (relacionado con dificultades físicas). En este sentido, sería necesario profundizar más en el estudio de la invarianza factorial a través de los Métodos de Ecuaciones Estructurales Multigrupo antes de sacar conclusiones sobre el uso del instrumento para evaluar necesidades de apoyo en estos colectivos.

- El análisis de los datos se ha hecho de manera general desde un punto de vista meramente cuantitativo, no realizándose un análisis exhaustivo sobre los comentarios cualitativos que los informantes aportaban al final de la escala los informantes, donde se reservaba un apartado para sus impresiones y recomendaciones. 
A pesar de las limitaciones planteadas, el grado de innovación y actualidad de los objetivos planteados y los resultados obtenidos en relación al desarrollo y validación de la SIS-C y pueden resultar de gran interés para la comunidad científica, sirviendo de referencia para otras investigaciones relacionadas.

Actualmente, no se dispone de otras herramientas o recursos válidos que pudieran ofrecer información individualizada sobre las necesidades de apoyo de los niños y adolescentes con discapacidad intelectual, por lo que la SIS-C se convierte en el único recurso de referencia tanto para la planificación de apoyos en la infancia como para la investigación necesaria en este área.

En cualquier caso, destacamos la necesidad de continuar investigando en esta dirección para conocer con mayor profundidad el funcionamiento y la utilidad práctica de la SIS-C, incluyendo su pertinencia y adecuación a nivel nacional e internacional. Examinar adicionalmente nuevas evidencias sobre la validez de este instrumento contribuirá a esclarecer el constructo de 'necesidades de apoyo' y optimizar su evaluación.

\section{C) LÍNEAS DE INVESTIGACIÓN FUTURAS}

Dentro de las principales líneas futuras de investigación relacionadas con el desarrollo final de la SIS-C, destaca, por un lado, la superación de las limitaciones del estudio señaladas en el apartado anterior y, por otro lado, la creación de baremos que permitan interpretar los resultados de la aplicación del instrumento.

Para la superación de las limitaciones asociadas a la validación del instrumento, se plantea continuar realizando investigación sobre las propiedades de la escala, proporcionando un proceso continuo de validación que pueda aportar nuevas evidencias de fiabilidad y validez de la escala y optimizar su funcionamiento.

Haciendo referencia a la creación de baremos, los resultados mostraron la existencia de diferencias significativas en las puntuaciones obtenidas en la escala por personas de edades diferentes. Por ello, se plantea elaborar baremos específicos para cada par de edad que permitan comparar las puntuaciones obtenidas por las personas evaluadas con las de su grupo de iguales, obteniéndose así una información más precisa sobre las necesidades de apoyo extraordinarias que presenta la persona evaluada. 
Asimismo, a partir del desarrollo de la SIS-C se abren líneas complementarias de investigación orientadas a seguir aumentando el conocimiento existente sobre las necesidades de apoyo y a aportar valor a la importancia de su evaluación en el diseño y planificación de apoyos individualizados. Destacamos, en este punto, los esfuerzos que ya se han empezado a realizar en la actualidad para la consecución de estos nuevos retos.

En primer lugar, reconociendo la importancia de los estudios interculturales y del conocimiento compartido, desde la AAIDD se ha impulsado una iniciativa destinada a comparar los datos obtenidos en las adaptaciones del instrumento llevadas a cabo en diferentes países. En este sentido, una muestra estándar de 450 participantes, obtenida de manera aleatoria a partir de las 814 aplicaciones realizadas en España, será incorporada a una base de datos internacional utilizada para analizar la invarianza transcultural del instrumento, valorándose la pertinencia de crear baremos comunes que faciliten la interpretación y el contraste de resultados. Destacamos, adicionalmente, la colaboración que se está iniciando con Argentina para el fomento de la adaptación y aplicación de la escala en otros países de habla hispana, facilitando el contraste de resultados entre países con el mismo idioma vehicular pero que se enmarcan en diferentes culturas.

Por otro lado, a la luz de las dificultades encontradas para estimar necesidades de apoyo extraordinarias derivadas de la discapacidad, discerniéndolas de aquellas necesidades típicas derivadas de la edad de los niños evaluados, se plantea una línea de investigación destinada a conocer las necesidades de apoyo típicas del desarrollo humano. En este sentido, desde la AAIDD se ha elaborado un listado detallado de indicadores que recogen las necesidades de apoyo normativas de los niños y adolescentes de entre 5 y 16 años, especificando esas necesidades atendiendo a los distintos pares de edad. El reto de esta línea consiste en probar la validez de esos indicadores, investigando su pertinencia en los diferentes países y realizando las modificaciones pertinentes antes de usarlos como referencia en la aplicación de la SIS-C. En España, desde el Instituto Universitario de Integración en la Comunidad (INICO) se ha iniciado el proceso de análisis de necesidades típicas a través de un proyecto de $\mathrm{I}+\mathrm{D}$, propuesto de manera complementaria a la validación de la SIS-C y financiado por la Junta de Castilla y León (SA120U13).

Llegados a este punto, resaltamos que la evaluación de las necesidades de apoyo solo constituye un componente más de un modelo multidimensional de evaluación de la discapacidad intelectual y no debe realizarse de manera aislada. Por ello, resulta interesante abogar por el estudio de la relación existente entre los diferentes componentes del modelo de evaluación planteado, sugiriéndose, por primera vez, la 
realización de este análisis desde una perspectiva infantil. Tras la reciente Convención de los Derechos Humanos (Naciones Unidas, 2006), donde se ponen de manifiesto de manera explícita los derechos de los niños con discapacidad, se han comenzado a desarrollar numerosas herramientas de evaluación para este colectivo, favoreciéndose el comienzo de esta línea de investigación.

Concretamente, la relación entre los constructos de necesidades de apoyo y conducta adaptativa, ya investigada en el ámbito adulto (Harries et al., 2005; Guscia et al., 2006; Thompson, McGrew et al., 2002; Thompson et al., 2004; Wehmeyer, 2009), ha comenzado a ser examinada en la infancia y adolescencia a través de la comparación de las puntuaciones de la DABS (Diagnostic Adaptive Behavior Scale) y la SIS-C (Guillén, 2014). Igualmente, la relación entre las puntuaciones en la SIS-C y aquellas obtenidas en la escala ARC-INICO de evaluación de la autodeterminación (Vicente et al., en prensa) cuenta ya con un estudio preliminar que pone de manifiesto la correlación inversa existente entre ambos constructos (Vicente, 2013).

No obstante, a pesar de que ya se han iniciado algunos estudios centrados en este objetivo, resaltamos la necesidad de seguir realizando aplicaciones conjuntas de estas escalas para poder obtener conclusiones generalizables. Asimismo, señalamos la importancia de incluir herramientas de evaluación de otros constructos diferentes relevantes. Por ejemplo, atendiendo a otra de las líneas de investigación principales del INICO, proponemos examinar la relación existente entre las necesidades de apoyo y la calidad de vida infantil una vez que se haya finalizado el desarrollo y validación de la KIDSLIFE, aún en proceso de desarrollo (Gómez et al., 2014).

De manera relacionada, la investigación no sólo debe centrarse en estudiar qué apoyos necesita la persona con discapacidad para potenciar el funcionamiento y la participación, sino también en analizar por qué las personas necesitan apoyos, pues ésta será la clave de su relación con las habilidades y la tendencia al riesgo (Greenspan, 2012). Teniendo en cuenta esta afirmación, resulta interesante examinar los posibles factores explicativos de las necesidades de apoyo de los niños y jóvenes con discapacidad intelectual, generando un modelo causal-explicativo. Conocer la influencia de diferentes variables mediadoras y moderadoras puede ser relevante para diseñar prácticas orientadas a la provisión de apoyos individualizados y asegurar la eficacia de los programas de intervención. 
En este sentido, no debemos olvidar que otra de las líneas de investigación derivadas de este estudio es utilizar las ventajas que confiere disponer de herramientas centradas en la evaluación individualizada de las personas con discapacidad intelectual. La SIS-C, destinada a proporcionar información ajustada sobre las necesidades y prioridades de intervención, supone el primer intento real para orientar la investigación hacia el diseño de estrategias basadas en la evidencia que se ajusten a las necesidades específicas de las personas con discapacidad intelectual y favorezcan su desarrollo y participación.

En definitiva, el desarrollo de estas futuras líneas de investigación, junto con las contribuciones derivadas del proyecto de investigación en el que se enmarca esta tesis doctoral, aportará a la comunidad científica y profesional un instrumento de medida correctamente baremado (SIS-C). Esta estrategia evaluativa, permitirá individualizar los apoyos proporcionados a las personas con discapacidad intelectual en los diferentes contextos cotidianos desde edades tempranas, mejorando así su inclusión y participación en el momento óptimo. Las intervenciones que logran buenos resultados en la infancia implican beneficios en la educación, la salud y la convivencia durante la vida adulta, pero no a la inversa. Por ello, apoyar a las personas con discapacidad desde la infancia conlleva un mayor rendimiento personal, económico y social que beneficia a toda la comunidad. 




\section{REFERENCIAS BIBLIOGRÁFICAS}

Abal, F. J. P., Lozzia, G. S., Aguerri, M, Galibert, M. S. y Attprresi, H. F. (2010). La escala aplicación de la teoría de respuesta a los ítems en tests de ejecución típica. Revista Colombiana de Psicología, 19(1), 111-122.

Abery, B. H. y Fahnestock, M. (1994). Enhancing the social inclusion of persons with developmental disabilities. En M. F. Hayden y B. H. Abery (Eds.), Challenges for a service system in transition (pp. 83-119). Baltimore, MD: Paul H.Brookes.

Adam-Alcocer, A. y Giné C. (2013). Escala d'Intensitat dels Suports per a Infants i Adolescents': Resultados de la prueba piloto. Revista de Psicologia, Ciències de l'Educació i de l'Esport, 31(1), 111-117.

Aguado, A. L. (1995). Historia de las deficiencias. Madrid: Escuela Libre, Fundación ONCE.

Ainscow, M. (1999). Understanding the development of inclusive school. Madrid: Narcea.

Ainscow, M. (2012). Haciendo que las escuelas sean más inclusivas: lecciones a partir del análisis de la investigación internacional. Revista Educación Inclusiva, 52(2), 27-50.

Alberta Government (2013). Individual support planning. A resource guide to assist with developing, implementing and monitoring individual supports plans. Recuperado de: http://humanservices.alberta.ca/pdd-online/documents/individual-supportplanning-guide.pdf

American Psychiatric Association. (1952). Diagnostic and statistical manual of mental disorders (DSM-I). Washington, DC: Autor.

American Psychiatric Association. (1968). Diagnostic and statistical manual of mental disorders (DSM-II). Washington, DC: Autor.

American Psychiatric Association. (1980). Diagnostic and statistical manual of mental disorders (DSM-III). Washington, DC: Autor.

American Psychiatric Association. (1987). Diagnostic and statistical manual of mental disorders (DSM-III-R). Washington, DC: Autor.

American Psychiatric Association. (1994). Diagnostic and statistical manual of mental disorders (DSM-IV). Washington, DC: Autor.

American Psychiatric Association. (2000). Diagnostic and statistical manual of mental disorders (DSM-IV-TR).Washington, DC: Autor. 
American Psychiatric Association. (2013). Diagnostic and statistical manual of mental disorders (DSM-5). Washington, DC: Autor.

American Psychological Association. (2010). Publication Manual of the American Psychological Association (6a ed.). Washington DC: Autor.

Andrews, A. B. (2004). Evaluation and Program Planning, 27(3), 275-285. doi: 10.1016/j.evalprogplan.2004.04.002

Andrich, D. (1978). A rating formulation for ordered response categories. Psychometrika, 43, 561-573. doi: 10.1007/Bf02293814

Andrich, D. (1988). Rasch models for measurement. Newbury Park, CA: Sage.

Arbuckle, J. L. (2000). Exploratory structural equation modeling. Fordham University. Department of Psychology colloquium series.

Argibay, J. C. (2009). Muestra en investigación cuantitativa. Revista Subjetividad y Procesos Cognitivos, 13, 13-29.

Arias, B. (2008). Desarrollo de un ejemplo de análisis factorial confirmatorio con LISREL, AMOS y SAS. En M. A. Verdugo, M. Crespo, M. Badia y B. Arias (Coords.). Metodología en la investigación sobre discapacidad. Introducción al uso de las ecuaciones estructurales (pp. 75-120). Salamanca: Publicaciones del INICO.

Arias, B., Arias, V. B. y Gómez, L. E. (2013). Calibración del Índice de Hiperactividad de Conners mediante el modelo de Rasch. Universitas Psychologica, 12(3), 957-970. doi:10.11144/Javeriana.UPSY12-3.cihc

Arias, B., Verdugo, M. A., Navas, P. y Gómez, L. (2013). Factor structure of the construct of adaptive behavior in children with and without intellectual disability. International Journal of Clinical and Health Psychology (13), 155-166. doi: 10.1016/S1697$2600(13) 70019-x$

Arnaiz, P. (2003). Educación Inclusiva, una escuela para todos. Málaga: Archidona Aljibe.

Arnold, B. R. y Matus, Y. E. (2000). Test translation and cultural equivalence methodologies for use with diverse populations. En I. Cuellar y F. A. Paniagua (Eds.), Handbook of multicultural mental health: Assessment and treatment of diverse populations (pp. 121-136). San Diego: Academic Press. 
Arnold, S., Riches, V. y Stancliffe, R. (2011). Intelligence is as intelligence does: Can additional support needs replace disability? Journal of Intellectual and Developmental Disability, 36(4), 258-262. doi: 10.3109/13668250.2011.617732

Arnold, S., Riches, V. y Stancliffe, R. (2014a). I-CAN: The classification and prediction of support needs. Journal of Applied Research in Intellectual Disabilities, 27(2), 97-111. doi: 10.1111/jar.12055

Arnold, S., Riches, V. y Stancliffe, R. (2014b). Support needs predict funding need better than adaptive behaviour. Journal of Applied Research in Intellectual Disabilities, 27(4), 352.

Aymerich, M., Berra, S., Guillamón, I., Herdman, M., Alonso, J., Ravens-Sieberer, U. y Rajmil, L. (2005). Desarrollo de la versión en español del KIDSCREEN, un cuestionario de calidad de vida para población infantil y adolescente. Gaceta Sanitaria, 19, 93-102.

Badia, M., Longo, E., Orgaz, B. y Gómez-Vela, M. (2013). The influence of participation in leisure activities on quality of life in Spanish children and adolescents with Cerebral Palsy. Research in Developmental Disabilities, 34(9), 2864-2871. doi: 10.1016/j.ridd.2013.06.017

Balboni, G., Tassé, M. J., Schalock, R. L., Borthwick-Duffy, S. A., Spreat, S., Thissen, D., ...Navas, P. (2014). The diagnostic adaptive behavior scale: Evaluating its diagnostic sensitivity and specificity. Research in Developmental Disabilities, 35, 2884-2893. doi: 10.1016/j.ridd.2014.07.032

Bandalos, D. L. (2002). The effects of item parceling on goodness-of-fit and parameter estimate bias in structural equation modeling. Structural Equation Modeling: A Multidisciplinary Journal, 9, 78-102. doi: 10.1207/S15328007SEM0901_5

Bandalos, D. L. y Finney, S. J. (2001). Item parceling issues in structural equation modeling. En G. A. Marcoulides y R. E. Schumacker (Eds.), New Development and Techniques in Structural Equation Modeling (pp. 269-296). Mahwah, NJ: Lawrence Erlbaum Publisher.

Barr, 0. (2007). It is not enough to know what to do. Journal of Intellectual Disabilities, 11 (2), 123-126. doi: 10.1177/1744629507076926

Batista-Foguet, J. M. y Coenders, G. (1998). Introducción a los modelos estructurales. El análisis factorial confirmatorio para la depuración de un cuestionario. En J. Renom (Ed.), Tratamiento informatizado de datos (pp. 229-286). Barcelona: Masson. 
Bentler, P. M. y Chu, C. (1987). Practical issues in structural modeling. Sociological Methods and Research, 16, 78-117. doi: 10.1177/0049124187016001004

Bernstein, I. H. y Teng, G. (1989). Factoring items and factoring scales are different: Spurious evidence for multidimensionality due to item categorization. Psychological Bulletin, 105, 467-477. doi: 10.1037/0033-2909.105.3.467

Bond, T. G. y Fox, C. M. (2001). Applying the Rasch model: Fundamental measurement in the human sciences. New Jersey: LEA.

Booth, T. y Ainscow, M. (2002). Index for inclusion: developing learning and participation in schools (ed. rev.). Bristol: Centre for Studies on Inclusive Education (CSIE).

Borthwick-Duffy, S. A. (1994). Review of Mental Retardation: Definition, Classification, and systems of supports. American Journal of Mental Retardation, 98, 541-544.

Borthwick-Duffy, S. A. (2007). Adaptive behavior. En J. W. Jacobson y J. A. Mulick y J. Rojahn (Eds.), Handbook on intellectual and developmental disabilities (pp. 279291). Washington, DC: American Psychological Association.

Bossaert, G., Kuppens, S., Buntinx, W., Molleman, C., Van Den Abeele, A. y Maes, B. (2009). Usefulness of the Supports Intensity Scale (SIS) for persons with other than intellectual disabilities. Research in Developmental Disabilities, 30 (6), 1306-1316. doi: 10.1016/j.ridd.2009.05.007

Braddock, D. (Ed.) (2002). Disability at the dawn of 21st century and the state of the states (pp. 1-62). Washington, DC: American Association of Mental Retardation.

Braddock, D., Hemp, R., Parish, S. y Westrich, J. (2008). The state of the states in developmental disabilities (7a ed.) Washington, DC: American Association on Mental Retardation.

Braddock, D. y Parish, S. L. (2002). An institutional history of disability. En D. Braddock (Ed.), Disability at the dawn of 21st century and the state of the states (pp. 1-62). Washington, DC: American Association of Mental Retardation.

Bradley, V. J. (1994). Evolution on a New Service Paradigm. En Bradley, V. J. y Blaney, B. (Eds.), Creating Individual Supports for People with Developmental Disabilities. Baltimore, MD: Paul H. Brookes Pub.

Bradshaw, J. (1972). A taxonomy of social need. In G. McLachland (Ed.), Portfolio for health. Problems and progress in medical care. London: Nuffield Provincial Hospital. 
Brislin, R. W. (1986). The wording and translation of research instruments. En W. L. Lonner y J. W. Berry (Eds.) Field Methods in Cross-Cultural Research. Newbury Park, CA: Sage.

Brown, T. A. (2006). Confirmatory factor analysis for applied research. New York: Guilford Press.

Brown, H. K., Ouellette-Kuntz, H., Bielska, I. y Elliott, D. (2009). Choosing a measure of support need: implications for research and policy. Journal of Intellectual Disability Research, 53, 949-954. doi: 10.1111/j.1365-2788.2009.01216.x

Brown, L., Sherbenou, R. J. y Johnsen, S. K. (1995). Test de inteligencia no verbal Toni2. Madrid: TEA.

Brown, M. C., Hanley, A. T., Nemeth, C., Epple, W., Bird, W. y Bontempo, A. (1986). The Developmental Disabilities Profile: Final report the design, development and testing of the core instrument. Albany: New York State Office of Mental Retardation and Developmental Disabilities.

Brown, R. I., Schalock, R. L. y Brown, I. (2009). Special issue: quality of life and its applications. Journal of Policy and Practice in Intellectual Disability, 6, 1-1. doi: 10.1111/j.1741-1130.2009.00204.x

Bruininks, R. H, Hill, B. K, Weatherman, R. F., Woodcock, R. W. (1986) Inventory for client and agency planning (ICAP). Allen, TX: DLM Teaching Resources.

Bruininks, R. H., McGrew, K. y Maruyama, G. (1988). Structure of adaptive behavior in samples with and without mental retardation. American Journal on Mental Retardation, 93(3), 265-272.

Bruininks, R. H., Morreau, L. E., Gilman, C. J. y Anderson, J. L. (1991). Adaptive Living Skills Curriculum. Manual. Allen, TX: DLM Teaching Resources.

Bruininks, R. H., Thurlow, M. y Gilman, C. J. (1987). Adaptive behavior and mental retardation. Journal of Special Education, 21(1), 69-88.

Bruininks, R. H., Woodcock, R. W., Weatherman, R. F. y Hill, B. K. (1985). Development and standardization of the Scales of Independent Behavior. Allen, TX: DLM Teaching Resources.

Bruininks, R. H., Woodcock, R., Weatherman, R. y Hill, B. K. (1996). Scales of Independent Behaviour-Revised. Allen, TX: DLM Teaching Resources. 
Bruner, J. Actos de significado. Madrid: Alianza, 1998

Buntinx, W. H. E. (2006a). The relationship between the WHO-ICF (International Classification of Functioning, Disability and Health) and the AAMR 2002 system. En H. N. Switzky y S. Greenspan (Eds.), What is mental retardation? Ideas for an evolving disability in the 21st century (ed. rev., pp. 301-322) Washington, DC: American Association on Mental Retardation.

Buntinx, W. H. E. (2006b). Schaal Intensiteit van Ondersteuningsbehoeften Handleiding. Utrecht: NGBZ

Buntinx, W. H. E. (2008). The Dutch Version of the Supports Intensity Scale. En R. L. Schalock, J. R. Thompson y M. J. Tassé (Eds.), Psychometric Properties of the Supports Intensity Scale (pp. 6-10). Washington, DC: American Association on Intellectual and Developmental Disabilities.

Buntinx, W. H. E. y Schalock, R. L. (2010). Models of disability, quality of life, and individualized supports: Implications for professional practice in intellectual disability. Journal of Policy and Practice in Intellectual Disabilities, 7(4), 283-294. doi: 10.1111/j.1741-1130.2010.00278.x

Buntinx, W., Van Unen, F., Speth, W. y Groot, W. (2006). The Supports Intensity Scale in the Netherlands: Psychometric properties and applications in practice. Journal of Applied Research in Intellectual disabilities, 19, 245-246.

Butterworth, J. (2002). From programs to supports. En R. L. Schalock, P. C. Baker y M. D. Croser (Eds.), Embarking on a new century: Mental retardation at the end of the 20th century (pp. 83-100). Washington, DC: American Association on Mental Retardation.

Byrne-Davis, L. M. T., Bennett, P. D. y Wilcock, G. K. W. (2006). How are quality of life ratings made? Toward a model of quality of life in people with dementia. Quality of Life Research, 15, 855-865. doi: 10.1007/s11136-005-5416-9

Campbell, A., Converse, P. y Rodgers, W. (1976). The quality of American life: Perceptions, evaluations and satisfactions. Nueva York: Russell Sage Foundation.

Carlucci, M. y Wright. D. B. (2012). Descriptive statistics. Graphical and numerical methods. En G. M. Breakwell, D. B., Wright y J. A. Smith (Eds.). Research Methods in Psychology (4a ed.) (pp. 163-190). London: Sage Publications. 
Carroll, J. B. (1997). The three-stratum theory of cognitive abilities. En D. P. Flanagan, J. L. Genshaft y P. L. Harrison (Eds.), Contemporary intellectual assessment: Theories, tests, and issues (pp. 122-130). Nueva York: Guilford Press.

Casado, D. (1991). Panorámica de la discapacidad. Barcelona: Intress.

Chacón, F. (1989). Necesidad social y servicios sociales. Papeles del Psicólogo, 41. Recuperado de:

http://www.papelesdelpsicologo.es/vernumero.asp?id=414

Chernyshenko, O. S., Stark, S., Chan, K., Drasgow, F. y Williams, B. (2001). Fitting item response theory models to two personality inventories: issues and insights. Multivariate Behavioral Research, 36, 523-562. doi: 10.1037/a0015899

Chiorino, O. (2004). Aplicación de la clasificación internacional del funcionamiento, de la discapacidad y de la salud para elaborar un perfil de necesidades de apoyo a una persona con parálisis cerebral. Siglo Cero, 35(1), 77-87.

Chou, Y. C., Lee, Y. C., Chang, S. C. y Yu, A. P. (2013). Evaluating the supports intensity scale as a potential assessment instrument for resource allocation for persons with intellectual disability. Research on Developmental Disabilities, 34(6), 2056-2063. doi: 10.1016/j.ridd.2013.03.013

Cicchetti, D. V. (1994). Guidelines, criteria, and rules of thumb for evaluating normed and standardized assessment instruments in psychology. Psychological Assessment, 6(4), 284-290. doi: 10.1037/1040-3590.6.4.284

Claes, C., Van Hove, G., van Loon, J., Vandevelde, S., y Schalock, R. L. (2009a). Evaluating the inter-respondent (consumer vs. staff) reliability and construct validity (SIS vs. Vineland) of the Supports Intensity Scale on a Dutch sample. Journal of Intellectual Disability Research, 53(4), 329-338. doi: 10.1111/j.1365-2788.2008.01149.x

Claes, C., Van Hove, G., van Loon, J., Vandevelde, S. y Schalock, R. L. (2009b). Quality of life measurement in the field of intellectual disabilities: Eight principles for assessing quality of life-related personal outcomes. Social Indicators Research, 98(1), 61-72. doi: 10.1007/s11205-009-9517-7

Claes, C., Van Hove, G., Vandevelde, S., van Loon, J. y Schalock, R. L. (2010). Personcentered Planning: Analysis of Research and Effectiveness. Intellectual and Developmental Disabilities, 48(6), 432-45. doi: 10.1352/1934-9556-48.6.432 
Claes, C., Van Hove, G., Vandevelde, S., van Loon, J. y Schalock, R. L. (2012). The influence of supports strategies, environmental factor, and client characteristic on quality of life-related personal outcomes. Research on Developmental Disabilities, 33(1), 96103. doi: 10.1016/j.ridd.2011.08.024

Coenders, G., Batista-Foguet, J. M. y Saris, W. E. (2005). Temas avanzados en modelos de ecuaciones estructurales. Madrid: La Muralla.

Coffman, D. L. y MacCallum, R. C. (2005). Using parcels to convert path analysis models into latent variable models. Multivariate Behavioral Research, 40 (2), 235-259. doi: $10.1207 / \mathrm{s} 15327906 \mathrm{mbr} 4002 \_4$

Colman, A. M. (2001). Dictionary of psychology. Oxford, England: Oxford University Press .

Colver, A. (2005). A shared framework and language for childhood disability. Developmental Medicine and Child Neurology, 47, 780-784. doi: 10.1017/S0012162205001635

Connor, D. J., Gabel, S. L., Gallagher, D. J. y Morton, M. (2008). Disability studies and inclusive education: implications for theory, research, and practice. International Journal of Inclusive Education, 12(5), 441-457. doi: 10.1080/13603110802377482

Cottini, L., Fedell, D., Leoni, M. y Croce. L., (2008). La Supports Intensity Scale nel panorama riabilitativo italiano: Standardizzazione italiana e procedure psicometriche. American Journal of Mental Retardation, Edizione Italiana, 6, 21-38.

Council on Quality \& Leadership. (2005). Personal outcome measures. Towson, MD: Autor.

Courtney, M. G. (2013). Determining the Number of Factors to Retain in EFA: Using the SPSS R-Menu v.2.0 to Make More Judicious Estimations Practical Assessment, Research y Evaluation, 18. Recuperado de: http://pareonline.net/pdf/v18n8.pdf

Crocker, L. y Algina, J. (2008). Introduction to Classical and Modern Test Theory (3a ed.). Fort Worth: Harcourt Brace Jovanovich.

Cruz, M., Jenaro, C., Pérez, M. C. y Robaina, N. (2010). Aplicabilidad de la escala de intensidad de apoyos (SIS), en población mexicana con enfermedad mental severa. Revista Latino-Americana da Enfermagem, 18(5), 975-982.

Cummins, R. A. (1997). Self-rated quality of life scales for people with an intellectual disability: a review. Journal of Applied Research in Intellectual Disabilities, 10, 199216. doi: 10.1111/j.1468-3148.1997.tb00017.x 
Cummins, R. A. (2000). Objective and subjective quality of life: An interactive model. Social Indicators Research, 52, 55-72. doi: 10.1023/A:1007027822521

Cummins, R. A. (2005). Moving from the quality of life concept to a theory. Journal of Intellectual Disability Research, 49, 699-706. doi: 10.1111/j.13652788.2005.00738.x

de Ayala, R. J. (2009). The theory and practice of Item Response Theory. Psychometrika, 75(4), 778-779. doi: 10.1007/s11336-010-9179-z

Declaración de Salamanca (1994). Conferencia mundial sobre necesidades educativas especiales: acceso y calidad. Recuperado de: http://mda.una.edu.ve/UserFiles/Declaracion de Salamanca 1994.pdf

DeJong, G. (1979). Independent Living: From Social Movement to Analytic Paradigm. Archives of Physical Medicine and Rehabilitation, 60, 435-446.

DeVellis, R. F. (2003). Scale development: theory and applications (2a ed.). Thousand Oaks, CA: Sage.

Diamantopoulos, A. y Siguaw, J. A. (2000). Introducing LISREL. Thousand Oaks, CA: Sage.

Dockrell, J., Peacey, N. y Lunt, I. (2002). Literature Review: Meeting the Needs of Children with Special Educational Needs. London: Audit Commission.

Donabedian, A. (1973). Aspects of Medical Care Administration: Specifying Requirements for Health Care Cambridge. Cambridge, MA: Harvard University Press.

Downing, J. y Peckmam-Hardin, K. (2007). Inclusive education: What makes it a good education for students with moderate to severe disabilities. Research and Practice for Persons with Severe Disabilities, 32, 16-30. doi: 10.2511/rpsd.32.1.16

Downing, S. M. (2006). Twelve Steps for Effective Test Development. In Downing, S. M. \& Haladyna, T. M. (Eds.). Handbook of Test Development (pp. 3-25). Mahwah, NJ: Lawrence.

Drake, R. E., Becker, D. R. y Mueser, K. T. (2003). A process of analysis of integrated and non-integrated approaches to supported employment. Journal of Vocational Rehabilitation, 18(1), 51-58.

Drake, R. E., Bond, G. R., y Becker, D. R. (2012). Individual Placement and Support: An Evidence-Based Approach to Supported Employment. Nueva York: Oxford University Press. 
Drucker, P. F. (1994). Managing for results. Nueva York: Harper and Row.

Durán, D., Echeita, G., Giné, C. Miquel, E., Ruiz, C. y Sandoval, M. (2005). Primeras experiencias de uso de la guía para la evaluación y mejora de la educación inclusiva (index for inclusion) en el estado español. Revista Iberoamericana sobre Calidad, Eficacia y Cambio en Educación, 3(1). Recuperado de: http://http://www.ice.deusto.es/rinace/reice/vol3n1 e/Duranetal.pdf

Echeita, G. y Verdugo, M. A. (Eds.) (2004). Declaración de Salamanca sobre necesidades educativas especiales 10 años después. Valoración y prospectiva. Salamanca: Publicaciones del INICO.

Embretson, S. E y Hershberger, S. L. (Eds) (1999) The New Rules of Measurement: What Every Psychologist Should Know. Mahwah, NJ: Lawrence Erlbaum Associates.

Embretson, S. E. y McCollam, K. M. (2000). A multicomponent Rasch model for covert processes. En M. Wilson y G. Engelhard (Eds.), Objective Measurement: Theory into Pratice (versión 5). Norwood, NJ: Ablex.

Embretson, S. E. y Reise, S. (2000). Item Response Theory for psychologists. Mahwah, NJ: Lawrence Erlbaum Associates.

Edwards, W. y Newman, J. R. (1982). Multiattribute evaluation. Newbury Park, CA: Sage.

Elosua, P. (2012). Tests publicados en España: usos, costumbres y asignaturas pendientes. Papeles del Psicólogo, 33 (1), 12-21.

Escurra, L. M. y Delgado, A. E. (2012). Análisis psicométrico de la Escala de Depresión CESD bajo el modelo de crédito parcial de Rasch. Persona (15), 173-190.

Fan, X. (1998). Item response theory and classical test theory: An empirical comparison of their item/person statistics. Educational and Psychological Measurement, 58, 357381. doi: $10.1177 / 0013164498058003001$

Felce, D. y Perry, J. (1995). Quality of life: Its definition and measurement. Research in Developmental Disabilities, 16, 51-74. doi: 10.1016/0891-4222(94)00028-8

Felce, D. y Perry, J. (1996). Assessment of quality of life. En R. L. Schalock (Ed.), Quality of life, Conceptualization and measurement, vol. 1 (pp. 63-73). Washington, DC: American Association on Mental Retardation.

Ferguson, P. M., Ferguson, D. L. y Brodsky, M. N. (2008). 'Away from public gaze': A history of the Fairview Training Center and the institutionalization of people with 
developmental disabilities in Oregon, 1908-2000. Monmouth, OR: Teaching Research Institute, Western Oregon University.

Fernández-Pulido. R. (2008). Modelos de medida y análisis factorial confirmatorio. En M. A. Verdugo, M. Crespo, M. Badia y B. Arias (Coords.). Metodología en la investigación sobre discapacidad. Introducción al uso de las ecuaciones estructurales (pp. 29-42). Salamanca: Publicaciones del INICO.

Ferrans, C., Zerwic, J., Wilbur, J. y Larson, J. (2005). Conceptual model of health-related quality of life. Journal of Nursing Scholarship, 37, 336-342. doi: 10.1111/j.15475069.2005.00058.x

Ferreira, A., Almeida, L. y Prieto, G. (2011). The role of processes and contents in human memory: An item response theory approach. Journal of Cognitive Psychology, 23, 873-885. doi: 10.1080/20445911.2011.584692

Ferreira, M. (2008): Modernidad, individuo y diversidad funcional: una in fundamentación ética. Intersticios: Revista sociológica de pensamiento crítico, 2(2). Recuperado de: http://www.intersticios.es/article/view/2719/2119

Fidalgo, A. M. (2005). Enfoque de la Teoría de Respuesta a los Ítems. En J. Muñiz, A. M. Fidalgo, García-Cueto, R. Martínez y T. Moreno (Eds.), Análisis de los ítems (pp.79131). Madrid: La Muralla.

Fidler, D. J. y Hodapp, R. M. (1998). The importance of typologies for science and service in mental retardation. Mental Retardation, 36, 489-495. doi: 10.1352/00476765(1998)036<0489:IOTFSA>2.0.CO;2

Finlay, W., Lyons, E. y Taylor, S. (2005) Rejecting the Label: A Social Constructionist Analysis. Mental Retardation, 43(2), 120-134. doi: 10.1352/0047-6765-(2005)43<120:RTLASC $>2.0 . C O ; 2$

Fischer, G. H. y Molenaar, I. W. (Eds.) (1995). Rasch Models: Foundations, Recent Developments, and Applications. Nueva York,, NY: Springer.

Flora, D. B. y Curran, P. J. (2004). An empirical evaluation of alternative methods of estimation for confirmatory factor analysis with ordinal data. Psychological Methods, 9, 466-491. doi: 10.1037/1082-989X.9.4.466

Florian, L. y McLaughlin, M. J. (Eds.) (2008). Disability Classification in Education: Issues and Perspectives. Thousand Oaks CA: Corwin Press. 
Foreman P, Bourke S, Mishra G. y Frost R. (2001). Assessing the Support Needs of Children with a Disability in Regular Classes. International Journal of Disability, Development and Education, 48(3), 239-352. doi: 10.1080/10349120120073395

Forkmann, T., Boecker, M., Wirtz, M., Glaesmer, H., Brähler, E., Norra, C. \& Gauggel, S. (2010). Validation of the Rasch-based Depression Screening in a large scale German general population sample. Health and Quality of Life Outcomes, 8(105). doi: 10.1186/1477-7525-8-105

Fortune, J., Agosta, J., y Bershadsky, J. (2011). Validity and reliability results regarding the SIS. Recuperado de: www.hsri.org/files/uploads/publications/SIS Reliability and Validity 2011.pdf

Fortune, J. Levelle, J., Meche, S., Severance, D., Smith, G. y Stern, J. (2008). SIS resource allocation: Four papers on issues and approaches. En R. L. Schalock, J. R. Thompson y M. J. Tassé, (Eds.) (2008). AAIDD SIS White Paper Series. Washington, DC: American Association on Intellectual and Developmental Disabilities.

Fox, C. M. y Jones, J. A. (1998). Uses of Rasch modeling in counseling psychology research. Journal of Counseling Psychology, 45, 30-45. doi: 10.1037/0022-0167.45.1.30

Gallagher, J. J. (197). Sacred and profane uses of labeling. Mental Retardation, 14(6), 2-3.

García, E. (1993). Introducción a la psicometría. Madrid: Siglo XXI.

Gardner, H. (1998). A multiplicity of intelligences. Scientific American, 9, 19-23.

Gilbert, T. F. (1978). Human competence. Nueva York: McGraw Hill.

Gilman, C. J., Morreau, L. E., Bruininks, R. H., Anderson, J. L., Montero, D. y Unamunzaga, E.(2002). Currículum de destrezas adaptativas (ALSC). Bilbao: Mensajero.

Giné, C. (2004). Servicios y calidad de vida para las personas con discapacidad intelectual. Siglo Cero, 35(2), 1-14.

Giné, C., Alomar, E., Balcells, A., Borràs, E., Carasa, P., Carbó, M., Font, J., ...Vidal, X. (2006). L'Escala d'Intensitat de Suports (EIS). Un instrument per promoure el benestar de les persones amb discapacitat intel-lectual. Suports, 10 (2), 66-72.

Giné, C., Alomar, E., Carasa, P., Font, J., García, M., Gordillo, ...González, M. (2007). Escala d'intensitat dels suports. Manual de l'usuari. Traducció i adaptació de Support Intensity Scale. Barcelona: Federació Catalana Pro Persones amb Retard Mental. 
Giné, C., Font, J., Guárdia-Olmos, Balcells-Balcells, A., Valls, J. y Carbó-Carrete, M. (2014). Using the SIS to better align the funding of residential services to assessed support needs. Research in Developmental Disabilities, 35(5), 1144-1151. doi: 10.1016/j.ridd.2014.01.028

Glidden, L. M. (2006). An update on label and definitional asynchrony: The missing mental and retardation in mental retardation. En H. N. Switzky y S. Greenspan (Eds.), What is mental retardation: Ideas for an evolving disability (ed. rev., pp. 39-49). Washington, DC: American Association on Mental Retardation.

Gómez, L. E. (2010). Evaluación de la calidad de vida en servicios sociales: Validación y calibración de la escala GENCAT. (Tesis doctoral). Salamanca: Universidad de Salamanca, Publicaciones del INICO.

Gómez, L. E., Arias, B., Verdugo, M. A. y Navas, P. (2011). An Outcomes-Based Assessment of Quality of Life in Social Services. Social Indicators Research, 106, 81-93. doi: 10.1007/s11205-011-9794-9

Gómez, L. E., Arias, B., Verdugo, M. A. y Navas, P. (2012). Application of the Rasch Rating Scale Model to the assessment of quality of persons with intellectual disability. Journal of Intellectual and Developmental Disability, 37(29), 141-150. doi: $10.3109 / 13668250.2012 .682647$

Gómez, L. E., Peña, E., Alcedo, M. A., Monsalve, A., Fontanil, Y., Verdugo, M. A., ...Arias, B. (2014). El constructo de calidad de vida en niños y adolescentes con discapacidades múltiples y profundas: propuestas para su evaluación. Siglo Cero, 45(1), 56-69.

Gómez, L. E., Verdugo, M. A. y Arias, B. (2010). Calidad de vida individual: avances en su conceptualización y retos emergentes en el ámbito de la discapacidad. Psicología Conductual, 18(3), 453-472.

Gómez, L. E., Verdugo, M. A., Arias, B. y Arias, V. (2011). A comparison of alternative models of individual quality of life for social service recipients. Social Indicators Research, 101, 109-125. doi: 10.1007/s11205-010-9639

Gómez-Vela M. y Verdugo, M. A. (2009). Cuestionario de Evaluación de la Calidad de Vida en Alumnos Adolescentes (CCVA). Madrid: CEPE. 
González, N., Abad, J. y Lévy, J.P. (2006). Normalidad y otros supuestos en análisis de covarianzas. En J. Lévy (Ed.), Modelización con estructuras de covarianzas en ciencias sociales. La Coruña: Netbiblo.

Goodey, C. F. (2005). Blockheads, roundheads, pointed heads: Intellectual disability and the brain before modern medicine. Journal of the History of the Behavioral Sciences, 41, 165-183. doi: 10.1002/jhbs.20081

Gottfredson, L. S. (2002). G: Highly general and highly practical. En R. J. Sternberg y E. L. Grigorenko (Eds.), The general factor of intelligence: How general is it? (pp. 331380). Mahwah, NJ: Erlbaum.

Gould, A. (1998). The Service Need Assessment Profile. Versión 1.0. [Computer Software and Manual]. Sydney, New South Wales: ATG and associates Pty Ltd.

Greenspan, S. (1997). Dead manual walking? Why the 1992 AAMR definition needs redoing. Education and Training in Mental Retardation and Developmental Disabilities, 32(2), 179-190.

Greenspan, S. (1999). A contextualism perspective on adaptive behavior. En R. L. Schalock (Eds.), Adaptive behavior and its measurement: Implications for the field of mental retardation (pp. 61-80). Washington, DC: American Association on Mental Retardation.

Greenspan, S. (2006). Mental retardation in the real world: Why the AAMR definition is not there yet. En H. N. Switzky y S. Greenspan (Eds.), What is Mental Retardation: Ideas for an evolving disability (ed. rev., pp.165-183). Washington, DC: American Association on Mental Retardation.

Greenspan, S. (2012). How do we know when it's raining out? Why existing conceptions of intellectual disability are all (or mostly) wet. Psychology in Intellectual and Developmental Disabilities 37 (2), 4-8.

Greenspan, S. y Driscoll, J. (1997). The role of intelligence in a broad model of personal competence. En D. P. Flanagan y P. T. Harrison (Eds.), Contemporary intellectual assessment: Theories, tests and issues (pp. 131-150). Nueva York: Guilford Press.

Greenspan, S. y Grandfield, J. M. (1992). Reconsidering the construct of mental retardation: Implications of a model social competence. American Journal of Mental Retardation, 96(4), 442-453. 
Greenspan, S., Loughlin, G. y Black, R. S. (2001). Credulity and gullibility in persons with developmental disorders: A framework for future research. International Review of Research in Mental Retardation, 24, 101-135. doi:10.1016/S00747750(01)800070.

Greenspan, S. y Love, P. E. (1997). Social intelligence and developmental disorder: Mental retardation, learning disabilities, and autism. En W. E. MacLean (Eds.), Elli's handbook of mental deficiency, psychological theory and research (pp. 311342).Mahwah, NJ: Lawrence Erlbaum Associates Publishers.

Greenspan, S. y Switzy, H. N. (2003). Forty years of American Association on Mental Retardation manuals. En H. N. Switzky y S. Greenspan (Eds.), What is mental retardation? Ideas for an evolving disability definition (pp. 38-63). Washington, DC: American Association on Mental Retardation.

Greenspan, S., Switzky, H. N. y Granfield, J. M. (1996). Everyday intelligence and adaptive behavior: A theoretical framework. En J. W. Jacobson y J. A. Mulick (Eds.), Manual of diagnosis and professional practice in mental retardation (pp.127-135).Washington, DC: American Psychological Association.

Grossman, H. J. (1973). Manual on terminology and classification in mental retardation. Washington, DC: American Association on Mental Deficiency.

Grossman, H. J. (1983). Classification in mental retardation. Washington, DC: American Association on Mental Deficiency.

Grupo de Atención Temprana (2000). Libro Blanco de la Atención Temprana. Madrid: Real Patronato sobre Discapacidad.

Grupo de Atención Temprana (2005). Recomendaciones técnicas para el desarrollo de la Atención Temprana. Madrid: Real Patronato sobre Discapacidad.

Guillén, V. (2014). Evaluación de la intensidad de apoyos en niños y adolescentes con discapacidad intelectual y su relación con la conducta adaptativa. Trabajo de Grado no publicado. Universidad de Salamanca.

Guillén, V., Verdugo, M. A. y Arias B. (2012). Evaluación de las necesidades de apoyo en niños y adolescentes con discapacidad intelectual. Estudio preliminar. En AMPANS, IV Premios de Investigación e Innovación sobre Personas con Discapacidad Intelectual. Trabajados Premiados 2012 (pp. 5-98). Manresa: AMPANS. 
Guillén, V., Verdugo, M. A., Arias B. y Vicente, E. (en prensa). Desarrollo de una escala de evaluación de necesidades de apoyo de niños y adolescentes con discapacidad intelectual. Anales de Psicología.

Guillén, V., Verdugo, M. A., Arias B. y Vicente, E. (2013). Influencia de los problemas de salud mental en las necesidades de apoyo de los niños y adolescentes con discapacidad intelectual. Comunicación presentada el 14 de Noviembre, en el X Seminario de Actualización metodológica en Investigación en Discapacidad (IX SAID) y XII Jornadas de la AEN de Salud Mental, Salamanca.

Guscia, R., Harries, J., Kirby, N., Nettelbeck, T. y Taplin, J. (2005). Reliability of the Service Need Assessment Profile (SNAP): A measure of support for people with disabilities. Journal of Intellectual and Developmental Disability, 30, 24-30. doi: $10.1080 / 13668250500033144$

Guscia, R., Harries, J., Kirby, N., Nettelbeck, T. y Taplin, J. (2006). Construct and criterion validities of the Service Need Assessment Profile (SNAP): A measure of support for people with disabilities. Journal of Intellectual and Developmental Disability, 31 (3), 148-155. doi: 10.1080/13668250600876442

Hagtvet, K. A. y Nasser, F. M. (2004). How well do item parcels represent conceptually defined latent constructs? A two-facet approach. Structural Equation Modeling: A Multidisciplinary Journal, 11, 168-193. doi: 10.1207/s15328007sem1102_2

Hahn, H. (1993). The Political Implications of Disability Definitions and Data. Journal of Disability Polity Studies, 4 (2), 41-52. doi: 10.1177/104420739300400203

Hair, J. F., Black, B., Babin, B., J., Anderson, R. E. y Tatham, R. L. (2006). Multivariate Data Analysis (6a ed.). Upper Saddle River, NJ: Pearson Education Inc.

Hambleton, R. K. (1996). Adaptación de tests para su uso en diferentes idiomas y culturas: fuentes de error, posibles soluciones y directrices prácticas. En J. Muñiz (Coord.), Psicometría (pp. 207-238). Madrid: Universitas.

Hambleton, R. K. y Bollwark, J. (1991). Adapting tests for use in different cultures: Technical issues and methods. Bulletin of theInternational Test Commission, 18, 332.

Hambleton, R. K. y Jones, R. W. (1993). Comparison of classical test theory and item response theory and their applications to test development. Educational 
Measurement: Issues and Practice, 12(3), 38-47. doi: 10.1111/j.17453992.1993.tb00543.x

Hambleton, R. K., Swaminathan, H. y Rogers, H. J. (1991). Fundamentals of item response theory. Newbury Park, CA: Sage.

Hammill, D. D., Brown, L. y Bryant, B. R. (1992). Evaluating the technical characteristics of tests: A consumer guide to tests in print (2a ed.). Austin, Tx: Pro-Ed.

Harré, R. y Lamb, R. (1988). The encyclopedic dictionary of psychology. Oxford, England: Blackwell.

Harries, J., Guscia, R., Kirby, N., Nettelbeck, T. y Taplin, J. (2005). Support needs and adaptive behaviors. American Journal on Mental Retardation, 110(5), 393-404. doi: 10.1352/0895-8017(2005)110[393:SNAAB]2.0.CO;2

Harrison, P. L. y Oakland, T. (2003). Adaptive Behavior Assessment System - Second Edition (ABAS II). San Antonio, TX: The Psychological Corporation.

Hatcher, L. (2006). A step-by-step approach to using SAS for factor analysis and structural equation modeling. Cary, NJ: The SAS Institute.

Hayden, M. F. y Neils, T. (2002). Self-advocacy. En R. L. Schalock, P.C. Baket y M. D. Croser (Eds.), Embarking on a new century: Mental Retardation at the end of the 20th century (pp. 221-234). Washington DC: American Association on Mental Retardation.

Heber, R. (1959). A manual on terminology and classification in mental retardation. American Journal on Mental Deficiency Monographs, 64(2).

Heber, R. (1961). A manual on terminology and classification on mental retardation (ed. rev.). Washington, DC: American Association on Mental Deficiency.

Hennike, J. M. (2002). NC-SNAP. Exceptional Parent, 32(9), 56-58.

Hennike, J. M., Myers, A. M., Realon, R. E. y Thompson, T. (2002). Developmental Disabilities Support Needs Assessment Profile. Butner, NC: Murdoch Centre Foundation.

Hennike, J. M., Myers, A. M., Realon, R. E. y Thompson, T. (2006). Development and validation of a needs-assessment instrument for persons with developmental disabilities. Journal of Developmental and Physical Disabilities, 18(2), 201-217. doi: 10.1007/s10882-006-9012-x

Hernández, F.L. (1995). Bases metodológicas de la investigación educativa. Barcelona: PPU. 
Hershberger, S. L. (2003). The growth of structural equation modeling: 1994-2001. Structural Equation Modeling, 10(1), 35-46. doi: 10.1207/S15328007SEM1001_2

Horn, J. L. y Cattell, R. B. (1966). Refinement and test of the theory of fluid and crystallized intelligence. Journal of Educational Psychology, 57(5), 253-270. doi: $10.1037 / \mathrm{h} 0023816$

Howard Research (2007). Need-based assessment tools environmental scan and literature review. Persons with developmental disabilities. Recuperado de:

http://humanservices.alberta.ca/documents/pdd-sis-environmental-scanliterature-review.pdf

Hu, L. y Bentler, P. M. (1999). Cutoff criteria for fit indexes in covariance structure analysis: Conventional criteria versus new alternatives. Structural Equation Modeling, 6, 1-55. doi: 10.1080/10705519909540118

Hughes, C., Thompson, J. R. y Wehmeyer, M. (2011). Development and Validation of the Supports Intensity Scale (SIS) for Children. Project funded by the U.S. Department of Education Institute of Educational Sciences (07/01/11 -06/30/15).

Hunter, S. y Ridley, J. (2007). Supported employment in Scotland: Some issues from research and implications for development. Learning Disability Review, 12(2), 3-13. doi: $10.1108 / 13595474200700012$

Ibáñez, A. (2009). Adaptación española de la Escala de Intensidad de Apoyos-SIS: Adecuación psicométrica y estructura factorial. (Tesis doctoral no publicada). Universidad de Salamanca, Salamanca.

Instituto de Medicina (1991). Disability in America: Toward a national agenda for prevention. Washington, DC: National Academy Press.

Jacobson, J. W (1994). Review of Mental Retardation: Definition, Classification, and systems of supports. American Journal of Mental Retardation, 98, 539-541.

Jacobson, J. W. y Mulick, J. A. (Eds.) (1996). Manual of diagnosis and professional practice in mental retardation. Washington, DC: American Psychological Association.

Janssen, C. G., Schuengel, C. y Stolk, J. (2005). Perspectives on quality of life of people with intellectual disabilities: interpretation of discrepancies between clients and caregivers. The Quality of Life Research, 14(1), 57-69. doi: 10.1007/s11136-004$1692-z$ 
Jenaro, C., Cruz, M., Pérez, M. C., Robaina, N. y Vega, V. (2011). La utilización de la Escala de Intensidad de Apoyos con poblaciones psiquiátricos: Propiedades psicométricas y utilidad para la planificación de prestación de servicios. Archives of Psychiatric Nursing, 25(5), 9-17. doi: 10.1016/j.apnu.2011.05.002.

Jenaro, C., Verdugo, M. A., Caballo, C., Balboni, G., Lachapelle, Y. y Otrebski, W. (2005). Cross-cultural study of person-centered quality of life domains and indicators: A replication. Journal of Intellectual Disability Research, 49, 734-739. doi: 10.1111/j.1365-2788.2005.00742.x

Jiménez, A. y Huete, A. (2010). Políticas públicas sobre discapacidad en España. Hacia una perspectiva basada en los derechos. Política y Sociedad, 47(1), 137-152.

Jiménez, P. (2009). Adaptación al contexto español de la SIS for Children de la AAIDD. Trabajo de Grado no publicado. Universidad de Salamanca.

Jones, L. V. y Thissen, D. (2007). A history and overview of psychometrics. En C.R. Rao y S. Sinharay (Eds), Handbook of Statistics, vol. 26 (pp. 1-22). Amsterdam: Elsevier

Jordán de Urríes, F. B., León, D., Hidalgo, F., Martínez, S. y Santamaría, M. (2014). Aproximación al análisis coste-beneficio entre empleo con apoyo y otros centros especiales de empleo mediante simulación comparativa con 24 trabajadores. Revista Española de Discapacidad, 2(1), 33-50. doi: /10.5569/2340-5104.02.01.02

Jöreskog, K. G. (1993). Testing structural e quation models. En K. A. Bollen y J. S. Lang (Eds.), Testing structural equation models (pp. 294-316). Newbury Park, CA: Sage.

Jöreskog, K. G. y Sörbom, D. (1996). LISREL 8: User's Reference Guide. Chicago, IL: Scientific Software International.

Jöreskog, K. G. y Sörbom, D. (2006). LISREL 8.80 for Windows [Computer Software]. Lincolnwood, IL: Scientific Software International, Inc.

Kaiser, H. F. (1960). The application of electronic computers to factor analysis. Educational and Psychological Measurement, 20, 141-151. doi: 10.1177/001316446002000116

Kamphaus, R. W. (1987). Conceptual and psychometric issues in the assessment of adaptive behavior. Journal of Special Education, 21(1), 27-35.

Kanner, L. (1957). Child psychiatry (3a ed.). Illinois: Charles E. Merrill.

Kaufman A. S. y Kaufman N. L. (1997). Batería de Evaluación de Kaufman para Niños. Manual técnico. Madrid: TEA. 
Kearny, D. S. y Healy, O. (2011). Investigating the relationship between challenging behavior, co-morbid psychopathology and social skills in adults with moderate to severe intellectual disabilities in Ireland. Research in Developmental Disabilities, 32, 1556-1563. doi: 10.1016/j.ridd.2011.01.053

Keith, K. D. y Schalock, R. L. (Eds.) (2000). Cross-cultural perspectives on quality of life. Washington DC: American Association on Mental Retardation.

Keeney, R. L. y Raiffa, H. (1976). Decisions with multiples objectives: Preferences and value tradeoff. Nueva York: John Wiley.

Kishi, G., Teelucksingh, B., Zollers, N., Park-Lee, S. y Meyer, L. (1988). Daily decisionmaking in community residences: A social comparison of adults with and without mental retardation. American Journal on Mental Retardation, 92(5), 430 - 435.

Kline, P. (1983). Personality: Measurement and theory. London: Hutchinson.

Kline, R. B. (2010). Principles and practice of structural equation modeling (3a ed.). New York: Guilford Press.

Kolen, M. J. (1981). Comparison of traditional and item response theory methods for equating tests. Journal of Educational Measurement, 18, 1-11. doi: 10.1111/j.17453984.1981.tb00838.x

Kotler, P. (1982). Marketing for Non-profit Organizations (2a ed.). New Jersey: PrenticeHall.

Kotler, P., Armstrong, G., Wong, V. y Saunders, J. (2008). Principles of Marketing (5a ed. europea). London: Pearson Education International.

Kreitler, S. y Kreitler, M. M. (2006). Multidimensional quality of life: a new measure of quality of life in adults. Social Indicators Research, 76, 5-33. doi: $10.1007 / \mathrm{s} 11205-005-4854-7$

Kuppens, S., Bossaert, G., Buntinx, W., Molleman, C. y van den Abeele, A. (2010). Factorial Validity of the Supports Intensity Scale (SIS). American Journal on Intellectual and Developmental Disabilities, 115, 327-339. doi: 10.1352/1944-7558-115.4.327

Laluvein, J. (2010). School inclusion and 'community of practice'. Internacional Journal of Inclusive Education, 14(1), 35-48. doi: 10.1080/13603110802500950

Lambert, N., Nihira, K. y Leland, H. (1993). AAMR Adaptive Behavior Scales-School2. Examiner's Manual (2a ed.). Austin, TX: Pro-Ed. 
Lamoureux-Hébert, M., y Morin, D. (2009). Translation and Cultural Adaptation of the Supports Intensity Scale in French. American Journal on Intellectual and Developmental Disabilities, 114, (1), 61-66. doi: 10.1352/2009.114:61-66

Landesman, S. y Ramey, C. (1989). Developmental psychology and mental retardation: Integrating scientific principles with treatment practices. American Psychologist, $44,409-415$.

Landis, J. y Koch, G. (1977). The measurement of observer agreement for categorical data. Biometrics, 33, 159-174.

Larson, S. Lakin, C., Anderson, L. y Kwak, N. (2001). Characteristics of and service use by persons with $M R / D D$ living in their own homes or with family members: NHIS-D Analysis (MR/DD Data Brief, 3, I). Minneapolis: Institute on Community Integration, University of Minnesota.

Lecavalier, L., Tasse, M. J. y Levesque, S. (2002). Assessment of mental retardation by school psychologists. Canadian Journal of School Psychology, 17(1), 97-107. doi:10.1177/(082957350201700108

Lévy, J. P. y Varela, J. (Coord.), Modelización con Estructuras de Covarianzas en Ciencias Sociales. Temas Esenciales, Avanzados y Aportaciones Especiales. A Coruña: Netbiblo.

Linacre, J. M. (2002). Optimizing rating scale category effectiveness. Journal of Applied Measurement, 3(1), 85-106.

Linacre, J. M. (2005). Dichotomous and politomous category information. Rasch Measurement Transactions, 19, 1005-1006.

Linacre, J. M. (2008). Winsteps. Rasch measurement computer program (versión 3.68) [Programa informático]. Chicago, IL: Winsteps.com.

Linn, R. L. y Gronlund, N. E. (2000). Measurement and assessment in teaching (8a ed.). Upper Saddle River, NJ: Prentice-Hall.

Little, T. D., Cunningham, W. A., Shahar, G. y Widaman K. F. (2002). To parcel or not to parcel: Exploring the question, weighing the merits. Structural Equation Modeling, 9, 151-173. doi: 10.1207/S15328007SEM0902_1 
Little, T. D., Rhemtulla, M., Gibson, K. y Schoemann, A. M. (2013). Why the items versus parcels controversy needn't be one. Psychological Methods, 18(3), 285-300. doi: $10.1037 / \mathrm{a} 0033266$

Llewellyn, G., Parmenter, T., Chan, J., Riches, V. y Hindmarsh, G. (2005). I-CAN: Instrument to classify support needs for people with disability. Sydney: University of Sydney.

Lomax, G. R. (1982). A guide to LISREL-type structural equation modeling. Behavior Research Methods and Instrumentation, 14, 1-8.

Lord, F. M. (1952). A theory of test scores. Psychometric Monograph, 7.

Lorenzo-Seva, U. y Ferrando, P. J. (2006). FACTOR: A computer program to fit the exploratory factor analysis model. Behavioral Research Methods, Instruments and Computers, 38(1), 88-91.

Luckasson, R., Borthwick-Duffy, S., Buntinx, W. H. E., Coulter, D. L., Craig, E. M., Reeve, A., ...Tassé, M. (2002). Mental Retardation: Definition, classification, and systems of supports (10a ed.). Washington, DC: American Association on Mental Retardation.

Luckasson, R., Coulter, D. A., Polloway, E. A., Reiss, S., Schalock, R. L., Snell, M. E., ...Stak, J. A. (1992). Mental Retardation: Definition, classification, and systems of supports (9a ed.). Washington, DC: American Association on Mental Retardation.

Luckasson, R. y Reeve, A. (2001). Naming, defining, and classifying in mental retardation. Mental Retardation, 39, 47-52. doi: 10.1352/0047-6765(2001)039<0047:NDACIM>2.0.CO;2.

Luckasson, R., Schalock, R. L., Snell, M. E. y Spitalnik, D. M. (1996). The 1992 AAMR definition and preschool children: Response from the committee on terminology and classification. Mental Retardation, 34, 247-253.

MacCallum, R. C. y Austin, J. T. (2000). Applications of structural equation modeling in psychological research. Annual Review of Psychology, 51, 201-222.

MacMillan, D. L., Gresham, E. M. y Siperstein, G. N. (1993). Conceptual and psychometric concerns about the 1992 AAMR definition of mental retardation. American Journal of Mental Retardation, 98(3), 325-335. doi: 10.1146/annurev.psych.51.1.201

Mangrulkar, L., Whitman, C. V. y Posner, M. (2001). Life Skills Approach to Child and Adolescent Healthy Human Development. Washington, DC: PAHO. 
Marti-Costa, S., y Serrano-García (1993). Needs assessment and community development: An ideological perspective. Prevention in Human Services, 3, 75-83. doi: 10.1300/J293v02n04_05

Martínez-Arias, M. R. (1995). Psicometría: Teoría de los tests psicológicos y educativos. Madrid: Síntesis.

Martínez-Arias, M. R. (1999). Los avances de la psicometría y la construcción de test. En F. Silva (ed.), Avances en evaluación psicológica (pp. 9-73). Valencia: Promolibro.

Martínez-Arias, M. R., Hernández, M. J. y Hernández, M. V. (2006). Psicometría. Madrid: Alianza.

Martínez-Figueira, E. (2013). Una mirada hacia la inclusión: barreras en el camino a la participación. Perspectiva Educacional, 52(2), 177-200. doi: 10.4151/07189729Vol.52-Iss.2 Art.101

Martorell, J. (1994). Programa de empleo con apoyo, experiencia de integración laboral en la empresa ordinaria con minusvalía. En M. C. Ortiz (Coord.) Integración sociolaboral de las personas con minusvalía (pp. 315-326). Madrid: Fundación Mapfre Medicina.

Maslow, A. (1943). A Theory of Human Motivation. Psychological Review, 50(4), 370-396.

Massoubre, C. Lang, F., Jaeger, B., Jullien M. y Pellet, J. (2002). La traduction des questionnaires des tests: Techniques et problèmes. Revue Canadienne de Psychiatrie, 47, 63-69.

Masters, G. N. (1982). A Rasch model for partial credit scoring. Psychometrika, 47(2),149174. doi: 10.1007/BF02296272.

McCarthy, D. (2006) Escalas McCarthy de aptitudes y psicomotricidad para niños. Madrid: TEA.

McConachie, H., Colver, A. F., Forsyth, R. J., Jarvis, S. N. y Parkinson, K. N. (2006). Participation of disabled children: how should it be characterised and measured? Disability and Rehabilitation, 28(18), 1157-1164.

Meade, A. W. y Kroustalis, C. M. (2006). Problems with item parceling for confirmatory factor analytic tests of measurement invariance. Organizational Research Methods, 9, 369-403. 
Mercer, J. (1992). The impact of changing paradigm of disability on mental retardation in the year 2000. En L. Rowitz (Ed.), Mental retardation in the year 2000 (pp. 15-38). Nueva York: Springer-Verlag.

Meyers, C., Nihira, K. y Zetlin, A. (1979). The measurement of adaptive behavior. En N. R. Ellis (Ed.), Handbook of mental deficiency: Psychological theory and research (2a ed., pp. 431-481). Hillsdale, NJ: Lawrence Erlbaum Associates.

McKillip, J. (1987). Need analysis: Tools for the human services and education. Newbury Park, CA: Sage.

Montero, D. (1993). Evaluación de la conducta adaptativa en personas con discapacidades. Adaptación y validación del ICAP. Bilbao: Mensajero.

Montero, D. (2003). Conducta adaptativa y discapacidad aquí y ahora: Algunas propuestas para la mejora de la práctica profesional. En M. A. Verdugo y F. B. Jordán de Urríes (Eds.), Investigación, innovación y cambio. V Jornadas Científicas de Investigación sobre Personas con Discapacidad (pp. 257-271). Salamanca: Amarú.

Montero, D. y Fernández-Pinto, I. (2013). ABAS-II. Sistema de evaluación de la conducta adaptativa. Madrid: TEA.

Moriña, A. (2004). Teoría y práctica de la educación inclusiva. Archidona. Aljibe.

Morizot, J., Ainsworth, A. T. y Reise, S. P. (2007). Toward modern psychometrics. Application of item response theory models in personality research. En R. W. Robins, R. C. Fraley y R. F. Krueger (Eds.), Handbook of Research Methods in Personality Psychology (pp. 407-423). Nueva York: Guilford Press.

Morreau, L. E. y Bruininks, R. H. (1991). Checklist of Adaptive Living Skills. Manual. Allen, TX: DLM Teaching Resources.

Morreau, L. E., Bruininks, R. y Montero, D. (2002). Inventario de destrezas adaptativas (CALS). Manual. Bilbao: Mensajero.

Muntaner, J. J. (2010). De la integración a la inclusión: un nuevo modelo educativo. En P. Arnaiz, M. Hurtado y F. Soto (Coords.). 25 años de Integración escolar en España: tecnología e inclusión en el ámbito educativo, laboral y comunitario. Murcia: Consejería de Educación, Formación y Empleo.

Muñiz, J. (1990). Teoría de Respuesta a los Ítems: un nuevo enfoque en la evaluación psicológica y educativa. Madrid: Pirámide. 
Muñiz, J. (1997). Introducción a la Teoría de Respuesta a los Ítems. Madrid: Pirámide.

Muñiz, J. (2003). Teoría Clásica de los Tests. Madrid: Pirámide.

Muñiz, J., Elousa, P. y Hambleton, R. K. (2013). Directrices para la traducción y adaptación de los test (2a ed.). Psycothema, 25(2), 151-157. doi: 10.7334/psicothema2013.24

Muñiz, J. y Hambleton, R. K. (1996). Directrices para la traducción y adaptación de los tests. Papeles del Psicólogo, 66, 63-70.

Naciones Unidas (1948). Declaración Universal de los Derechos Humanos. Recuperado de: http://www.un.org/es/documents/udhr/

Naciones Unidas (1971). Declaración de los Derechos del Retrasado Mental. Recuperado de: http://www.un.org/spanish/documents/instruments/docs sp.asp?type=conven

Naciones Unidas (1989). Convención sobre los Derechos de los Niños. Recuperado de: http://www.un.org/spanish/documents/instruments/docs sp.asp?type=conven

Naciones Unidas (1993). Normas Uniformes sobre la igualdad de oportunidades para las personas con discapacidad. Recuperado de: http://www.un.org/spanish/documents/instruments/docs sp.asp?type=conven

Naciones Unidas (2006). Convención sobre los derechos de las personas con discapacidad. Recuperado de: http://www.un.org/spanish/documents/instruments/docs sp.asp?type=conven

Naglieri, J. A. y Das, J. P. (1997). Cognitive Assessment System: Interpretive Handbook. Chicago: Riverside Publishing Company.

Nasser, F. y Takahashi, T. (2003). The effect of using item parcels on ad hoc goodness-of-fit indexes in confirmatory factor analysis: An Example using Sarason's reactions to tests. Applied Measurement in Education, 16(1), 75-97. doi: 10.1207/S15324818AME1601_4

Navas, P. (2012). Desarrollo y calibración de una escala de conducta adaptativa mediante modelos de Teoría de Respuesta a los Ítems. (Tesis doctoral no publicada). Universidad de Salamanca, Salamanca.

Navas, P., Gómez, L. E., Verdugo, M. A. y Schalock, R. L. (2012) Derechos de las personas con discapacidad intelectual: implicaciones de la convención de naciones unidas. Siglo Cero, 43(3), 7-28. 
Navas, P., Verdugo, M. A., Arias, B. y Gómez, L. E. (2010). La conducta adaptativa en personas con discapacidad intelectual. Siglo Cero, 41(3), 235, 28-48.

Navas, P., Verdugo, M. A., Arias, B. y Gómez, L. E. (2012). Development of an instrument for diagnosing significant limitations in adaptive behavior in early childhood. Research in Developmental Disabilities, 33(5), 1551-1559. doi: 10.1016/j.ridd.2012.03.006

Nering, M. y Ostini, R. (2010). Handbook of polytomous item response theory models. Nueva York: Routledge.

Nieckerns, J. M., Purga, A. J., y Noriega, P. P. (1980). Research methods for needs assessment. Washington, DC: University Press of America.

Nihira, K., Foster, R., Shellhaas, M. y Leland, H. (1967). AAMD Adaptive Behavior Checklist. Washington, DC: American Association on Mental Deficiency.

Nota, L., Ferrari, L., Soresi, S. y Wehmeyer, M. L. (2007). Self-determination, social abilities, and the quality of life of people with intellectual disabilities. Journal of Intellectual Disability Research, 51, 850-865. doi:10.1111/j.1365-2788.2006.00939.x

Nunnally, J. C. y Bernstein, I. H. (1994). Psychometric theory (3a Ed.). Nueva York: McGraw Hill.

O'Brien, J. (2004). If person-centred did not exist, valuing people would require its invention. Journal of Applied Research in Intellectual Disabilities, 17(1), 11-15. doi: 10.1111/j.1468-3148.2004.00178.x

Organización Mundial de la Salud (1948). Manual of the International statistical classification of disease, injuries and causes of death (6a ed.). Ginebra: Autor.

Organización Mundial de la Salud (1955). Manual of the International statistical classification of disease, injuries and causes of death (7a ed.). Ginebra: Autor.

Organización Mundial de la Salud (1967). Manual of the International statistical classification of disease, injuries and causes of death (6a ed.). Ginebra: Autor.

Organización Mundial de la Salud (1978). Manual of the International statistical classification of disease, injuries and causes of death (9a ed.). Ginebra: Autor.

Organización Mundial de la Salud (1980). International Classification of Impairments, Disabilities, and Handicaps. A manual of classification relating to the consequences of disease. Ginebra: Autor. 
Organización Mundial de la Salud (1993). Manual of the International statistical classification of disease, injuries and causes of death (10a ed.). Ginebra: Autor.

Organización Mundial de la Salud (2001). International Classification of Functioning, Disability and Health. Ginebra: Autor.

Organización Mundial de la Salud (2007). International Classification of Functioning, Disability and Health: Children and Youth version. Ginebra: Autor.

Orgaz, B. (2008). Introducción a la metodología SEM: Concepto y propósitos fundamentales. En M. A. Verdugo, M. Crespo, M. Badia y B. Arias (Eds.), Metodología de investigación sobre discapacidad. Introducción al uso de las ecuaciones estructurales (pp. 13-28). Salamanca: Publicaciones del INICO.

Ostini, R. y Nering, M. L. (2006). Polytomous item response theory models. Thousand Oak, CA: Sage.

Palacios, A. (2008). El modelo social de discapacidad: orígenes, caracterización y plasmación en la Convención de los Derechos de las Personas con Discapacidad. Madrid: Cinca.

Palacios, A., Romanach, J. (2006) El modelo de la diversidad. La Bioética y los Derechos Humanos como herramientas para alcanzar la plena dignidad en la diversidad funcional. España: Ediciones Diversitas- AIES.

Parkitny, L., Mcauley, J. H., Walton, D., Pena-Costa, L. O., Refshauge, K. M., Wand, B. M., ...Moseley, G. L. (2011). Rasch analysis supports the use of the depression, anxiety, and stress scales to measure mood in groups but not in individuals with chronic low back pain. Journal of Clinical Epidemiology, 66 (2), 189-198. doi: 10.1016/j.jclinepi.2011.05.010

Parsons, M. B., McCarn, J. E. y Reid, D. H. (1993). Evaluating and increasing meal-related choices throughout a servic setting for people with severe disabilities. Journal of the Association for Persons with Severe Handicaps, 18, 253-260. doi: 10.1177/154079699301800408

Pereda, S. (1987). Psicología Experimental: I Metodología. Madrid: Pirámide.

Pérez, M. P. (1991). Como detectar las necesidades de intervención socioeducativa. Madrid: Narcea.

Peters, C. C. y Van Voorhis, W. R. (1940). Statistical procedures and their mathematical bases. New York: McGraw-Hill. 
Petito, F. y Cummins, R. A. (2000). Quality of life in adolescence: the role of perceived control, parenting style and social support. Behaviour Change, 17(3), 196-207. doi: 10.1375/bech.17.3.196

Petry, K., Maes, B. y Vlaskamp, C. (2005). Domains of quality of life of people with profound multiple disabilities: the perspective of parents and direct support staff. Journal of Applied Research in Intellectual Disabilities, 18, 35-46. doi:_10.1111/j.14683148.2004.00209.x

Petry, K., Maes, B. y Vlaskamp, C. (2007). Support characteristics associated with the quality of life of people with profound intellectual and multiple disabilities: the perspective of parents and direct support staff. Journal of Policy and Practice in Intellectual Disabilities, 4, 104-110. doi: 10.1111/j.1741-1130.2007.00107.x

Pitz, G. F. y McKillip, U. (1984). Decisions analysis for program evaluators. Newbury Park, CA: Sage.

Pledger, C. (2003). Discourse on disability and rehabilitation issues: Opportunities for psychology. American Psychologist, 58, 279-284. doi: 10.1037/0003-066X.58.4.279

Prieto, G. y Delgado, A. R. (2000). Utilidad y representación en la psicometría actual. Metodología de las Ciencias del Comportamiento, 2(2), 111-127.

Prieto, G. y Delgado, A. R. (2003). Análisis de un test mediante el modelo de Rasch. Psicothema, 15(1), 94-100.

Prieto, G. y Delgado, A. (2010). Fiabilidad y validez. Papeles del Psicólogo, 31(1), 67-74.

Prieto, G. y Dias, A. (2004). Uso del modelo de Rasch para poner en la misma escala las puntuaciones de distintos tests. Actualidades en Psicología, 19(106) ,5-23.

Puig de la Bellacasa, R. (1990). Concepciones, paradigmas, y evolución de las mentalidades sobre la discapacidad. En Discapacidad e información (pp. 63-96). Madrid: Real Patronato de Prevención y de Atención a Personas con Minusvalía.

Rahtz, D. R., Sirgy, M. J. y Lee, D. J. (2004). Further validation and extension of the quality of life/community-health care model and measures. Social Indicators Research, 69, 167-198. doi: 10.1023/B:SOCI.0000033592.58120.9b

Rapley, M. (2004). The social construction of intellectual disability. Cambridge, UK: Cambridge University Press. 
Rasch, G. (1960). Probabilistic models for some intelligence and attainment tests. Copenhague, Dinamarca: Danish Institute for Educational Research.

Ravens-Sieberer, U., Auquier, P., Erhart, M., Gosch, A., Rajmil, L., Bruil, L, ...The European KIDSCREEN Group (2007). The KIDSCREEN-27 quality of life measure for children and adolescents: psychometric results from a cross-cultural survey in 13 European countries. Quality of Life Research, 16, 1347-1356. doi: 10.1111/j.15244733.2007.00291.x

Reid, C. A., Kolakowsky-Hayner, S. A., Lewis, A. N. y Armstrong, A. J. (2007). Modern psychometric methodology: Applications of item response theory. Rehabilitation Counselling Bulletin, 50(3), 177-188. doi: 10.1177/00343552070500030501

Reise, S. P. (1999). Personality measurement: issues viewed through the eyes of IRT. En S. E. Embretson y S. L. Herschberger (eds.), The new rules of measurement: What every psychology and educator should know (pp. 219-241). Mahwah, NJ: Erlbaum.

Renty, J. y Roeyers, H. (2006). Quality of life in high-functioning adults with autism spectrum disorder: The predictive value of disability and support characteristics. Autism, 10, 511 -524. doi: 10.1177/1362361306066604

Riches, V., Parmenter, T., Llewellyn, G., Hindmarsh, G. y Chan, J. (2009a). I-CAN: A New Instrument to Classify Support Needs for People with Disability: Part I. Journal of Applied Research in Intellectual Disabilities, 22(4), 326-339. doi: 10.1111/j.14683148.2008.00466.x

Riches, V., Parmenter, T., Llewellyn, G., Hindmarsh, G. y Chan, J. (2009b). The Reliability, Validity and Practical Utility of Measuring Supports using the I-CAN Instrument: Part II. Journal of Applied Research in Intellectual Disabilities. 22(4), 340-353. doi: 10.1111/j.1468-3148.2008.00467.x

Rodríguez, S. y Ferreira, M. (2008): Diversidad funcional: sobre lo normal y lo patológico en torno a la condición social de discapacidad. Revista Internacional de Sociología. Recuperado de: http://www.um.es/discatif/TEORIA/DF SRDyMAVF.pdf

Rojas, A. J., González, A., Padilla, J. L. y Pérez, C. (2000). Comparación de estrategias de ajuste de los datos al modelo de crédito parcial. Psicothema, 12 (2), 296-302.

Rojas, A. J. y Pérez, C. (2001). Nuevos modelos para la medición de actitudes. Valencia: Promolibro. 
Romañach, J. (2010). Diversidad funcional y derechos humanos en España: un reto para el futuro. Revista Internacional de Éticas Aplicadas, 2, 71-87. Recuperado de: http://www.dilemata.net/revista/index.php/dilemata/article/view/20/20

Romanach, J. y Lobato, M. (2005). Diversidad funcional, nuevo término para la lucha por la dignidad en la diversidad del ser humano. Recuperado de: http://www.forovidaindependiente.org/node/45

Rouse, M., Henderson, K. y Danielson, L. (2008). Concluding thoughts: on perspectives and purposes of disability classification systems in education. En Florian, L., y McLaughlin, M. J. (Eds.), Disability classification in education: issues and perspectives (pp. 263-269). Thousand Oaks, CA: Corwin Press.

Roy, A., Matthews, H., Clifford, P., Fowler, V. y Martin, D. M. (2002). Health of the Nation Outcome Scales for People with Learning Disabilities (HoNOS-LD). British Journal of Psychiatry, 180, 61-66. doi: 10.1192/pb.22.10.640

Sabeh, E., Verdugo, M. A., Prieto, G. y Contini, N. (2009). CVI-CVIP: Cuestionario de evaluación de la calidad de vida en la infancia. Madrid: CEPE.

Salvia, J. e Isseldyke, J. (1995). Assessment (6a ed.). Boston: Houghton Mifflin.

Sanders, K. Y. (2006). Overprotection and lowered expectations of persons with disabilities: the unforeseen consequences. Work Reading Mass, 27(2), 181-188.

Sandoval, M., López, M. L., Miquel, E., Durán, D., Giné, C. y Echeíta, G. (2002). Index for inclusion. Una guía para la evaluación y mejora de la educación inclusiva. Contextos educativos, 5, 227-238.

SAS Institute (2007). SAS (versión 9.13). [Programa informático]. Cary, NC: SAS Institute.

Schalock, R. L. (1995a). Implicaciones para la investigación de la definición, clasificación y sistemas de apoyo de la AAMR de 1992. Siglo Cero, 26(1), 5-13.

Schalock, R. L. (1995b). Outcome-based evaluation. Nueva York: Plenum Press.

Schalock, R. L. (1996). Reconsidering the conceptualization and measurement of quality of life. En R. Schalock (Ed.) Quality of life: Conceptualization and measurement, vol 1 (pp. 123-139). Washington, DC: American Association on Mental Retardation.

Schalock, R. L. (1999). Adaptive behavior and its measurement: Implications for the field of mental retardation. Washington, DC: American Association on Mental Retardation. 
Schalock, R. L. (2000). Three decades of quality of life. Focus on Autism and others Developmental Disabilities, 15, 116-127. doi: 10.1177/108835760001500207

Schalock, R. L. (2004). The emerging disability paradigm and its implications for policy and practice. Journal of Disability Policy Studies, 14, 204-215. doi: 10.1177/10442073040140040201

Schalock, R. L. (2011). The evolving understanding of the construct of intellectual disability. Journal of Intellectual \& Developmental Disability, 36, 227-237. doi: $10.3109 / 13668250.2011 .624087$

Schalock, R. L., Borthwick-Duffy, S. A., Bradley, V. J., Buntinx, W. H. E, Coulter, D., Craig, E. M., ...Yeager, M. H. (2010). Intellectual disability: Definition, classification, and systems of supports (11a ed.). Washington, DC: American Association on Intellectual and Developmental Disabilities.

Schalock, R. L., Borthwick-Duffy, S. A., Bradley, V. J., Buntinx, W. H. E, Coulter, D., Craig, E. M., ...Yeager, M. H. (2012). User's guide (to accompany the 11th edition of intellectual disability). Washington, DC: American Association on Intellectual and Developmental Disabilities.

Schalock, R. L., Gardner, J. F. y Bradley, V. J. (2007). Quality of life for people with intellectual and other developmental disabilities. Applications across individuals, organizations, communities, and systems. Washington, DC: American Association on Intellectual and Developmental Disabilities.

Schalock, R. L., Keith, K. D., Verdugo, M. A. y Gómez, L. E. (2010). Quality of life model development in the field of intellectual disability. En R. Kober (Ed.), Quality of life for people with intellectual disability. Nueva York: Springer.

Schalock, R. L. y Luckasson, R. (2004). AAMR's definition, classification, and systems of supports and its relation to international trends and issues in the field of intellectual disabilities. Journal of Policy and Practice in Intellectual Disability, 1, 136-146. doi: 10.1111/j.1741-1130.2004.04028.x

Schalock, R. L. y Luckasson, R. (2013a). What's at Stake in the Lives of People With Intellectual Disability? Part I: The Power of Naming, Defining, Diagnosing, Classifying, and Planning Supports. Intellectual and Developmental Disabilities, 51, 86-93. doi: 10.1352/1934-9556-51.2.086 
Schalock, R. L. y Luckasson, R. (2013b). What's at Stake in the Lives of People With Intellectual Disability? Part II: Recommendations for Naming, Defining, Diagnosing, Classifying, and Planning Supports. Intellectual and Developmental Disabilities, 51, 94-101. doi: 10.1352/1934-9556-51.2.094

Schalock, R. L., Luckasson, R. A., Shogren, K. A. BortwickDuffy, S., Bradley, V., Buntinx, W. H. W., ...Yeager, M. H. (2007). The renaming of mental retardation: understanding the change to the term intellectual disability. Intellectual and Developmental Disabilities, 45(2), 116-124. doi: 10.1352/1934-9556(2007)45-[116:TROMRU]2.0.CO;2

Schalock, R. L., Thompson, J. R. y Tassé, M. J. (Eds.) (2008). International Implementation of the Supports Intensity Scale. Washington, DC: American Association on Intellectual and Developmental Disabilities.

Schalock, R. L. y Verdugo, M. A. (2002). Quality of life for human service practitioners. Washington, DC: American Association on Mental Retardation.

Schalock, R. L. y Verdugo, M. A. (2007). El concepto de calidad de vida en los servicios y apoyos para personas con discapacidad intelectual. Siglo Cero, 38, 21-36.

Schalock, R. L. y Verdugo, M. A. (2008). Quality of life: from concept to application in the field of intellectual disabilities. Evaluation and Program Planning, 31, 181-190.

Schalock, R. L., y Verdugo, M. A. (2012). A leadership guide to redefining ID/DD organizations: Eight successful change strategies. Baltimore, MD: Brookes Publishing Co.

Schalock R. L. y Verdugo M. A. (2013a). The impact of the quality of life concept on the field of intellectual disability. Intellectual and Developmental Disabilities, 51(4), 273-286. doi: 10.1352/1934-9556-51.4.273

Schalock R. L. y Verdugo M. A. (2013b). The Transformation of Disabilities Organizations. Intellectual and Developmental Disabilities, 51(4), 273-286. doi: 10.1352/19349556-51.4.273

Schalock, R. L. y Verdugo, M. A. (2014). Quality of life as a change agent. En R. I. Brown y R. M. Faragher (Eds.), Intellectual disability. Knowledge application to other social and educational challenges (pp. 19-34). Hauppauge, NY: Nova Science Publishers. 
Schalock, R. L., Verdugo, M. A., Bonham, G. S., Fantova, F. y van Loon, J. (2008). Enhancing personal outcomes: Organizational strategies, guidelines, and examples. Journal of Policy and Practice in Intellectual Disabilities, 5(4), 276-285. doi: 10.1111/j.17411130.2007.00135.x

Schalock, R. L., Verdugo, M. A. y Gómez, L. E. (2011). Evidence-based practices in the field of intellectual and developmental disabilities: An international consensus approach. Evaluation and Program Planning, 34, 273-282. doi: 10.1016/j.evalprogplan.2010.10.004

Schalock, R. L., Verdugo, M. A., Jenaro, C., Wang, M., Wehmeyer, M., Xu, J. y Lachapelle, Y. (2005). Cross-cultural study of quality of life indicators. American Journal on Mental Retardation, 110, 298-311.

Scheerenberger, R. (1983). A history of mental retardation: A quarter century of progress. Baltimore, MD: Paul H. Brookes.

Schmeiser, C. B. y Welch, C. J. (2006). Test development. En R. L. Brennan (Ed.), Educational measurement (4a ed., pp. 307-353). Washington DC: American Council on Education.

Shevin, M. y Klein, N. (2004). The importance of choice-making skills for students with severe disabilities. Research and Practice for Persons with Severe Disabilities, 29(3), 161-168. doi: 10.2511/rpsd.29.3.161

Schippers, A. y van Boheemen, M. (2009). Family Quality of Life Empowered by Family-Oriented Support. Journal of Policy and Practice in Intellectual Disabilities 6, 19-24. doi: 10.1111/j.1741-1130.2008.00195.x

Schroeder, S. R., Gertz, G. y Velazquez, F. (2002). Final project report: Usage of the term 'mental retardation': Language, image and public education. Lawrence: University of Kansas, Center on Developmental Disabilities.

Seligman, M. (1998). Building human strength: Psychology's forgotten mission. APA Monitor, 29(1) 1.

Shogren, K. A. (2013). Considering context: An integrative concept for promoting outcomes in the intellectual disability field. Intellectual and Developmental Disabilities, 51 (2), 132-137. doi: 10.1352/1934-9556-51.2.132 
Shogren, K. A., Bradley, V. J., Gomez, S. C., Yeager, M. H., Schalock, R. L., Borthwick-Duffy, W. H. E., ...Wehmeyer, M. L. (2009). Public policy and the enhancement of desired outcomes for persons with intellectual disability. Intellectual and Developmental Disabilities, 47(4), 307-319.doi: 10.1352/1934-9556-47.4.307

Shogren, K. A., Luckasson, R. y Schalock, R. L. (2014). The definition of 'context' and its application in the field of intellectual disability. Journal of Policy and Practice in Intellectual Disabilities, 11(2), 109-116. doi: 10.1111/jppi.12077

Shogren, K. A., Thompson, J. R., Wehmeyer, M. L., Chapman, T., Tasse, M. J. y McLaughlin, C. A. (2014). Reliability and validity of the supplemental protection and advocacy scale of the Supports Intensity Scale. Inclusion, 2(2), 100-109. doi: 10.1352/23266988-2.2.100

Shogren, K. A. y Turnbull, H. R. (2010) Public Policy and Outcomes for Persons With Intellectual Disability: Extending and Expanding the Public Policy Framework of AAIDD's 11th Edition of 'Intellectual Disability: Definition, Classification, and Systems of Support'. Intellectual and Developmental Disabilities, 8(5), 375-386. doi: 10.1352/1934-9556-48.5.375

Shogren, K., Wehmeyer, M., Buchanan, C. y López, S. (2006). The Application of Positive Psychology and Self-Determination to Research in Intellectual Disability: A Content Analysis of 30 Years of Literature. Research and Practice for Persons with Severe Disabilities, 31 (4), 338-345.

Shogren, K. A., Wehmeyer, M. L., Palmer, S. B. y Paek, Y. (2013). Exploring personal and school environment characteristics that predict self-determination. Exceptionality, 21, 147-157. doi: 10.1080/09362835.2013.802231

Simeonsson, R., Granlund, M. y Bjork-Akesson, E. (2006). The concept and classification of mental retardation: What is mental retardation? En Switzky, H. N. y Greenspan, S. (Eds.), What is mental retardation? Ideas for an evolving disability in the 21st century (ed. rev., pp. 247-267). Washington, DC: American Association on Mental Retardation.

Smit, W., Sabbe, B. y Prinzie, P. (2011). Reliability and validity of the Supports Intensity Scale (SIS) measured in adults with physical disabilities. Journal of Developmental and Physical Disabilities, 23, 277-287. doi: 10.1007/s10882-011-9227-3 
Smith, G. A., Prouty, R. y Lakin, K. C. (2001). Trends and milestones: Medicate long-term services for people with developmental disabilities: that was then, this is now. Mental Retardation, 39, 488-491. doi: 10.1352/0047-6765(2001)039<0488:MLTSFP $>2.0 . C O ; 2$

Snell, M. E. y Drake, G. P. (1994). Replacing cascades with supported education. Journal of Special Education, 27(4), 393-409. doi:10.1177/002246699402700403

Snell, M. E., Luckasson, R. y Borthwick-Duffy, S. A. (2009). Characteristics and needs of people with intellectual disability who have higher IQs. Intellectual and Developmental Disabilities, 47(3), 220-233. doi: 10.1352/1934-9556-47.3.220

Snell, M. E y Voorhees, M. D. (2006).On being labeled with mental retardation. En H. N. Switzky y S. Greenspan (Eds.), What is mental retardation: Ideas for an evolving disability (pp. 61-80). Washington, DC: American Association on Mental Retardation.

Solano-Flores, G., Backhoff, E. y Contreras-Nino, L. A. (2009). Theory of test translation error. International Journal of Testing, 9(2), 78-91. doi: 10.1080/15305050902880835

Stainton, T. (2001). Reason and value: The thoughts of Plato and Aristotle and the construction of intellectual disability. Mental Retardation, 39, 452-460. doi: 10.1352/0047-6765(2001)039<0452:RAVTTO>2.0.CO;2

Stancliffe, R. J. (2001). Living with support in the community: Predictors of choice and selfdetermination. Mental Retardation and Developmental Disabilities Research Reviews, 7(2), 91-98. doi: 10.1002/mrdd.1013

Stancliffe, R. J., Abery, B. H. y Smith, J. (2000). Personal control and the ecology of community living settings: Beyond living-unit size and type. American Journal on Mental Retardation, 105, 431-454. doi: 10.1352/0895-8017(2000)105<0431:PCATEO>2.0.CO;2

Stancliffe R. J., Abery B. H., Springborg H. y Elkin, S. (2000). Substitute decision-making and personal control: implications for self-determination. Mental Retardation 38(5), 407-421. doi: 10.1352/0047-6765(2000)038<0407:SDAPCI>2.0.CO;2

Stancliffe, R. J., y Keane, S. (2000). Outcomes and costs of community living: A matched comparison of group homes and semi-independent living. Journal of Intellectual and developmental disability, 25, 281-305. doi:10.1080/13668250020019584 
Sparrow, S., Cicchetti, D y Balla, D. (2005). Adaptive Behavior Scales, Second Edition (Vineland-II). Circle Pines, MN: American Guidance Service.

Spearman, C. (1904). General intelligence, objectively determined and measured. American Journal of Psychology, 15, 201-293.

SPSS (2010). IBM SPSS PASW Statistics (versión 20). [Programa informático] Chicago, IL: SPSS, Inc.

Sternberg, R. J. (1985). Beyond IQ: A triarchic theory of intelligence. London: Cambridge University Press.

Sturmey, P. (1999). Classification: Concepts, progress and future. En N. Bouras (Ed.), Psychiatric and behavioral disorders in developmental disabilities and mental retardation (pp. 3-17). Cambridge: Cambridge University Press.

Summers, J. A., Poston, D. J., Turnbull, A. P., Marquis, J., Hoffman, L., Mannan, H. y Wang, M. (2005). Conceptualizing and measuring family quality of life. Journal of Intellectual Disability Research, 49, 777-783. doi: 10.1111/j.1365-2788.2005.00751.x

Switzy, H. N. y Greenspan, S. (2003). Can so many diverse ideas be integrated? Multiparidigmatic models of understanding mental Retardation. En H. N. Switzky y S. Greenspan (Eds.), What is mental retardation? Ideas for an evolving disability definition (pp. 387-405). Washington, DC: American Association on Mental Retardation.

Taillefer, M. C., Dupuis, G., Roberge, M. A. y LeMay, S. (2003). Health-related quality of life models: Systematic review of the literature. Social Indicators Research, 64, 293-323.doi: 10.1023/A:1024740307643

Tamarit, J. (2006) Calidad FEAPS: Un modelo para la calidad de vida desde la ética y la calidad del servicio. En: Verdugo, M. A. y Jordán F. B. (Coords.), Rompiendo inercias. Claves para avanzar (pp. 163-195). Salamanca. Amarú.

Tassé, M. J. (2009). Adaptive behavior assessment and the diagnosis of mental retardation in capital cases. Applied Neuropsychology, 16(2), 114-123. doi: 10.1080/09084280902864451

Tassé, M. J. (2013). Adaptive behavior. En Michael L. Wehmeyer (Ed.), The Oxford Handbook of Positive Psychology and Disability (pp. 105-115). Nueva York: Oxford University Press. 
Tassé, M. J. y Craig, E. M. (1999). Critical issues in the cross-cultural assessment of adaptive behavior. En R. L. Schalock (Ed.), Adaptive behavior and its measurement: Implications for the field of mental retardation. Washington, DC: American Association on Mental Retardation.

Tassé, M. J., Schalock, R. L., Balboni, G., Bersani, H., Duffy, S. A., De Valenzuela, J. S., ...Zhang, D. (en prensa). Diagnostic Adaptive Behavior Scale: User's Manual. Washington, DC: American Association on Intellectual and Developmental Disabilities.

Tassé, M. J., Schalock, R. L., Balboni, G., Bersani, H., Borthwick-Duffy, S. A., Spreat. S., ...Zhang, D. (2012). The construct of adaptive behavior: Its conceptualization, measurement, and use in the field of intellectual disability. American Journal on Intellectual and Developmental Disabilities, 117, 291-303. doi: 10.1352/1944-7558117.4.291

Tassé, M. J., Schalock, R. L., Thompson, J. R. y Wehmeyer, M. (2005). Guidelines for interviewing people with disabilities: Supports Intensity Scale. Washington, DC: American Association on Mental Retardation.

Taylor, R. L. (2002). Assessment of exceptional students (6a ed.) Boston: Allyn and Bacon.

Taylor, S. J. (2001). The continuum and its current controversies in the USA. Journal of Intellectual and Developmental Disability, 26 (1), 15-33. Tejedor, F. J. (1990) Perspectiva metodológica de diagnóstico y evaluación de necesidades en el ámbito educativo. Revista de Investigación Educativa, 8, 15-37.

Thissen, D., Steinberg, L. y Wainer, H. (1993). Detection of differential item functioning using the parameters of item response models. En P. W. Holland y H. Wainer (Eds.), Differential item funcionting (pp. 67-113). Hillsdale, NJ: Lawrence Erbalum Associates.

Thompson, B. (2004). Exploratory and confirmatory factor analysis: Understanding concepts and applications. Washington, DC: American Psychological Association.

Thompson, J. E. y Wehmeyer, M. L. (2008). Historical and legal issues in developmental disabilities. En H. P. Parette y G. R. Peterson-Karlan (Eds.), Research based practices in developmental disabilities (2a ed., pp. 13-42). Austin, TX: ProEd.

Thompson, J. R., Bradley, V. J., Buntinx, W. H. W, Schalock, R. L., Shogren, K. A, Snell, M. E., ...Yeager, M. H. (2009). Conceptualizing supports and support needs of people with 
intellectual disability. Intellectual and developmental disabilities, 47(2), 135-146. doi: 10.1352/1934-9556-47.2.135

Thompson, J. R., Bryant, B., Campbell, E. M., Craig, E. M., Hughes, C., Rotholz, D. A., ...Wehmeyer, M. L. (2004). Supports Intensity Scale user's manual. Washington, DC: American Association on Mental Retardation.

Thompson, J. R., Hughes, C., Schalock, R. L., Silverman, W., Tassé, M. J., Bryant, B., ...Campbell, E. M. (2002). Integrating supports in assessment and planning. Mental Retardation, 40 (5), 390-405. doi: 10.1352/0047-6765(2002)040<0390:ISIAAP>2.0.CO;2

Thompson, J. R., McGrew, K. S. y Bruininks, R. H. (1999). Adaptive and maladaptive behavior: Functional and structural characteristics. En R. L. Schalock (Ed.), Adaptive Behavior and its measurement (pp. 15-38). Washington, DC: American Association on Mental Retardation.

Thompson, J. R., McGrew, K. S. y Bruininks, R. H. (2002). Pieces of the puzzle: Measuring the personal competence and support needs of persons with mental retardation and related developmental disabilities. Peabody Journal of Education, 77(2), 21-7.

Thompson, J. R., Tassé, M. J., y McLaughlin, C. A. (2008). Interrater reliability of the Supports Intensity Scale (SIS). American Journal of Mental Retardation, 113, 231237. doi: 10.1352/0895-8017(2008)113[231:IROTSI]2.0.CO;2

Thompson, J. R. y Viriyangkura, Y. (2013). Supports and support needs. En Michael L. Wehmeyer (Ed.), The Oxford Handbook of Positive Psychology and Disability (pp. 317-337). Nueva York: Oxford University Press.

Thompson J. R., Wehmeyer, M., Copeland, S., Little, T.D., Patton, J. R., Polloway, E., ...Tassé, M. (2008). Supports Intensity Scale for Children. Field Test. Version 1.0. Washington, DC: American Association on Intellectual and Developmental Disabilities.

Thompson, J. R., Wehmeyer, M. L. y Hughes, C. (2010). Mind the gap! Implications of person-environment fit models of intellectual disability for students, educators, and schools. Exceptionality, 18, 168-181. doi: 10.1080/09362835.2010.513919

Thompson, J. R., Wehmeyer, M., Hughes, C., Copeland, S. Little, T.D., Obremski, S., ...Tassé, M. (2012). Supports Intensity Scale for Children. Version 3.0. Washington, DC: American Association on Intellectual and Developmental Disabilities. 
Thompson J. R., Wehmeyer, M., Hughes, Shogren, K. A., Little, T.D., Copeland, C., ...Tassé, M. (2014). Supports Intensity Scale for Children. Version 5.0. Washington, DC: American Association on Intellectual and Developmental Disabilities.

Thompson, J. R., Wehmeyer, M. L., Hughes, C., Shogren, K. A., Palmer, S. B. y Seo, H. (2014) The Supports Intensity Scale-Children's Version: Preliminary Reliability and Validity. Inclusion, 2(2), 140-149. doi: 10.1352/2326-6988-2.2.140

Toboso, M. y Arnau, M. S. (2008). La discapacidad dentro del enfoque de capacidades y funcionamientos. Araucaria. Revista Iberoamericana de Filosofía, Política y Humanidades, 20, 64-94.

Trent, J. (1994). Inventing the feeble mind: A history of mental retardation in the United States. Berkeley: University of California Press.

van der Linden, W. J. y Hambleton, R. K. (1997). Item response theory: Brief history, common models, and extensions. En W. J. van der Linden y R. K. Hambleton (Eds.), Handbook of modern item response theory (pp. 1-28). Nueva York: Springer

van Loon, J. (2006a). Autodeterminación para todos. La autodeterminación en Arduin. Siglo Cero, 37 (4), 35-47.

van Loon, J. (2006b). Los apoyos en Arduin. Las diversas facetas de los apoyos y la implementación de la SIS en una organización de servicios. Siglo Cero, 37(4), 17-34.

van Loon, J. (2008). Aligning quality of life domains and indicators with SIS Data. En Schalock, R. L., J. R. Thompson y M. J. Tassé (Eds). Relating Supports Intensity Scale Information to Individual Support Plans (pp. 10-13). Washington DC: American Association on Intellectual and Developmental Disabilities.

van Loon, J. (2009a). Un sistema de apoyos centrado en la persona. En M. A. Verdugo, T. Nieto, F. B. Jordán de Urríes y M. Crespo (Eds.). Mejorando los resultados personales para una vida de calidad (pp. 323-346). Salamanca: Amarú.

van Loon, J. (2009b). Uso de la escala de intensidad de apoyos en la práctica: asignación de recursos y planificación de apoyos individuales basados en la escala de intensidad de apoyos. Siglo Cero, 40 (1), 54-66.

van Loon, J. (2014). Improving Quality of Life, Fulfilling Rights. The use of the POS-A in support plans for people with intellectual disabilities. Comunicación presentada por C. Claes el 17 de Julio, en el Congreso Europeo de la IASSID (4a ed.), Viena. 
van Loon, J., Bonham, G. S., Peterson, D. D., Schalock, R. L., Claes, C. y Decramer, A. E. M. (2013). The use of evidence-based outcomes in systems and organizations providing services and supports to persons with intellectual disability. Evaluation and Program Planning, 36(1), 80-87. doi: 10.1016/j.evalprogplan.2012.08.002

van Loon, J., Claes, C., Vandevelde, S., Van Hove, G. y Schalock, R. (2010). Assessing individual support needs to enhance personal outcomes. Exceptionality, 18, 193202. doi: 10.1080/09362835.2010.513924

van Loon, J. y Van Hove, G. (2001). Emancipation and self-determination of people with learning disabilities and down-sizing institutional care. Disability and Society, 16(2), 233-254. doi: 10.1080/09687590120035825

van Loon, J., Van Hove, J., Schalock, R. L. y Claes, C. (2008). Personal outcomes scale. Gent: Stichting Arduin, Universiteit Gent.

Velarde, E. y Ávila, C. (2002). Methods for quality of life assessment. Salud Pública, 44, 448-463. doi: 10.1590/S0036-36342002000400009

Verdugo, M. A. (1994). El cambio de paradigma en la concepción del retraso mental: la nueva definición de la AAMR. Siglo Cero, 25(5), 5-24.

Verdugo, M. A. (1996). Programa de Orientación al Trabajo (POT). Programas conductuales alternativos. Salamanca: Amarú.

Verdugo, M. A. (1999). Avances conceptuales y del futuro inmediato: Revisión de la definición de 1992 de la AAMR. Siglo Cero, 30(5), 27-32.

Verdugo, M. A. (2000). Programa de Habilidades de la Vida Diaria (PVD). Programas conductuales alternativos. Salamanca: Amarú.

Verdugo, M. A. (2003a). Análisis de la definición de discapacidad intelectual de la AAMR de 2002. Siglo Cero, 34(1), 5-20.

Verdugo, M. A. (2003b). A step ahead in the paradigm shift. En H. N. Switzky y S. Greenspan (Eds.), What is mental retardation? Ideas for an evolving disability definition (pp. 296-308). Washington, DC.: American Association on Mental Retardation.

Verdugo, M. A. (2009). El cambio educativo desde la perspectiva de calidad de vida. Revista de Educación, 349, 23-43. doi: 10-4438/1988-592X-RE-2010-358-086 
Verdugo, M. A. (2012). Programa de Habilidades Sociales (PHS). Programas conductuales alternativos (2 ${ }^{\mathrm{a}}$ ed.). Salamanca: Amarú.

Verdugo, M. A., Arias, B., Gómez L. E. y Schalock, R. L. (2009). Formulario de la Escala GENCAT de Calidad de vida. Manual de aplicación de la Escala GENCAT de Calidad de vida. Barcelona: Departamento de Acción Social y Ciudadanía de Cataluña.

Verdugo, M. A., Arias, B., Guillén, V. y Vicente, E. (2014). La Escala de Intensidad de Apoyos para Niños y Adolescentes (SIS-C) en el contexto español. Siglo Cero, 45(1)24-40.

Verdugo, M. A., Arias, B. e Ibáñez, A. (2007). Escala de Intensidad de Apoyos (SIS). Manual. Adaptación española. Madrid: TEA.

Verdugo, M. A., Arias, B., Ibáñez, A. y Gómez, L. E. (2006). Validation of the Spanish version of the Supports Intensity Scale. Journal of Applied Research in Intellectual Disabilities, 19 (3), 274.

Verdugo, M. A., Arias, B., Ibáñez, A. y Schalock, R. L. (2010). Adaptation and psychometric properties of the Spanish version of the Supports Intensity Scale (SIS). American Journal of Intellectual and Developmental Disabilities, 115(6), 496-503. doi: 10.1352/1944-7558-115.6.496

Verdugo, M. A., Arias, B. y Navas, P. (2014). La Escala de Diagnóstico de la Conducta Adaptativa (DABS): Aplicaciones prácticas. Siglo Cero, 45(1), 8-23.

Verdugo, M. A., Arias, B. y Navas, P. (en prensa). Escala de Diagnóstico de Conducta Adaptativa (DABS). Manual del usuario. Madrid: TEA.

Verdugo, M. A., Benito, M. C., Orgaz, B., Jordán de Urríes, F. B., Martín, R. y Santamaría, M. (2012). Influencia de un programa de empleo con apoyo en la calidad de vida percibida de sus usuarios. Siglo Cero, 43(3), 69-83.

Verdugo, M. A., Gómez, L. E. y Arias, B. (2009). Escala FUMAT de evaluación de la calidad de vida de personas mayores y con discapacidad. Salamanca: Publicaciones del INICO.

Verdugo, M. A., Gómez, L. E., Arias, B., Navas, P. y Schalock, R. L. (2014). Measuring quality of life in people with intellectual and multiple disabilities: Validation of the San Martin Scale. Research in Developmental Disabilities, 35, 75-86. doi: 10.1016/j.ridd.2013.10.025 
Verdugo, M. A., Gómez, L. E., Arias, B., Santamaría, M., Clavero, D, y Tamarit, J. (2013). Escala INICO-FEAPS: Evaluación integral de la calidad de vida de personas con discapacidad intelectual o del desarrollo. Salamanca: Publicaciones del INICO.

Verdugo, M. A., Gómez, L. E., Arias, B., Santamaría, M., Navallas, E., Fernández, S. e Hierro, I. (2013). Evaluación de la calidad de vida en personas con discapacidades significativas: la Escala San Martín. Siglo Cero, 44(4), 6-20.

Verdugo, M. A., Gómez, L. E., Arias, B., Santamaría, M., Navallas, E., Fernández, S. e Hierro, I. (2014). Escala San Martín. Evaluación de la calidad de vida de las personas con discapacidades significativa. Santander: INICO-FOSM.

Verdugo, M. A., Gómez, L. E., Arias, B. y Schalock, R. L. (2009). Escala INTEGRAL de Calidad de Vida. Madrid. CEPE.

Verdugo, M. A., Gómez, L. E., Arias, B. y Schalock, R. L. (2010). The integral quality of life scale: Development, validity and use. En R. Kober (Ed.), Enhancing the quality of life of people with intellectual disabilities (pp. 47-60). Dordrecht: Springer.

Verdugo, M. A., Gómez-Vela, M., Fernández-Pulido, R., Vicente, E., Wehmeyer, M., Badia, M., ...Guillén, V. (2013). ¿Cómo evaluar la autodeterminación? Escala ARC-INICO de evaluación de la autodeterminación. Siglo Cero, 44(4), 21-39.

Verdugo, M. A., Guillén, V. y Vicente, E. (2014). Discapacidad intelectual. En L. Ezpeleta y J. Toro (Eds.), Manual de psicopatología del desarrollo (pp.169-190). Barcelona: Pirámide.

Verdugo, M. A., Ibáñez A. y Arias, B. (2007). La Escala de Intensidad de Apoyos (SIS): Adaptación inicial al contexto español y análisis de sus propiedades psicométricas. Siglo Cero, 38 (2), 5-16.

Verdugo, M. A., Navas, P., Gómez, L. E. y Schalock, R. L. (2012). The concept of quality of life and its role in enhancing human rights in the field of intellectual disability. Journal of Intellectual Disability Research, 56(11), 1036-1045. doi: 10.1111/j.13652788.2012.01585.x

Verdugo, M. A., Jordán de Urríes, F. B., Jenaro, C., Caballo, C. y Crespo M. (2006). Quality of life of workers with an intellectual disability in supported employment. Journal of Applied Research in Intellectual Disabilities, 19(4), 309-316. doi: 10.1111/j.14683148.2006.00277.x 
Verdugo, M. A. y Schalock., R. L. (2010). Últimos avances en el enfoque y concepción de las personas con discapacidad intelectual. Siglo Cero, 41(4), 7-21.

Verdugo, M. A., Schalock, R. L., Thompson, J. y Guillén, V. (2013). Discapacidad intelectual: definición, clasificación y sistemas de apoyos. En M. A. Verdugo y Schalock, R. L. (Coords.), Discapacidad e Inclusión. Manual para la Docencia (pp. 89-110) Salamanca: Amarú.

Vicente (2013). Evaluación de la autodeterminación en adolescentes con discapacidad intelectual. Análisis de factores asociados. (Tesis doctoral no publicada). Universidad de Salamanca, Salamanca.

Vicente, E., Verdugo, M. A., Gómez-Vela, M. Fernández-Pulido, R. y Guillén, V. (en prensa). Propiedades psicométricas de la Escala ARC-INICO para evaluar la autodeterminación. Revista Española de Orientación y Psicopedagogía (REOP). Aceptado para su publicación.

Vig, S., (2005). Classification versus labeling. En J. W. Jacobson, R. M. Fox y J. A. Mullik (Eds.), Controlversial Therapies for Developmental Disabilities. Fad, Fashion, and Science in Professional Practice. Londres: Lawrence Earlbaum Associates.

Vygotsky, L. S. (1979). Desarrollo de los procesos psicológicos superiores. Barcelona: Grijalbo-Critica.

Wang, M., Schalock, R. L., Verdugo, M. A. y Jenaro, C. (2010). Examining the factor structure and hierarchical nature of the quality of life construct. American Journal on Intellectual and Developmental Disabilities, 115, 218-233. doi: 10.1352/1944-7558115.3.218

Warnock, M. (1990). Informe sobre necesidades educativas especiales. Siglo Cero, noㅜㄹㅇ, $12-24$.

Wechsler, D. (2012). Escala de inteligencia de Wechsler IV. Manual de aplicación y corrección. Madrid: NCS Pearson.

Wehmeyer, M. L. (1996a). Self-determination as an educational outcome: Why is it important to children, youth and adults with disabilities? En D. J. Sands y M. L. Wehmeyer (Eds.), Self-determination across the life span: Independence and choice for people with disabilities (pp. 17-36). Baltimore: Brookes. 
Wehmeyer, M. L. y Bolding, N. (1999). Self-determination across living and working environments: A matched-samples study of adults with mental retardation. Mental Retardation, 37,353 -363. doi:10.1352/0047-6765(1999)037

Wehmeyer, M. L. y Bolding, N. (2001). Enhanced self-determination of adults with mental retardation as an outcome of moving to community-based work or living environments. Journal of Intellectual Disability Research, 45, 1-13. doi:10.1046/j.1365-2788.2001.00342.x

Wehmeyer, M. L., Buntinx, W., Lachapelle, Y., Luckasson, R., Schalock, R. L., Verdugo, M. A., ...Yeager, M. H. (2008). The intellectual disability construct and its relation to human functioning. Intellectual and Developmental Disabilities, 46(4), 311-318. doi: 10.1352/2008.46:311-318.

Wehmeyer, M. L., Chapman, T. E., Little, T. D., Thompson, J. R., Schalock, R. L. y Tasse, M. J. (2009). The efficacy of the Supports Intensity Scale (SIS) to predict extraordinary support needs. American Journal on Mental Retardation, 114, 3-14. doi: 10.1352/2009.114:3-14

Wehmeyer, M. L. y Metzler, C.A. (1995). How self-determined are people with mental retardation? The National Consumer Survey. Mental Retardation, 33, 111 -119.

Wehmeyer, M. L. y Garner, N. W. (2003). The impact of personal characteristics of people with intellectual and developmental disability on self-determination and autonomous functioning. Journal of Applied Research in Intellectual Disabilities, 16, 255-265. doi:10.1046/j.1468-3148.2003.00161.x

Weiss, J. A, Lunsky, Y., Tassé, M. J. y Durbin, J. (2009). Support for the construct validity of the Supports Intensity Scale based on clinician rankings of need. Research in Developmental Disabilities 30(5), 933-41. doi: 10.1016/j.ridd.2009.01.007

Werner, S., Edwards, M. y Baum, N. T. (2009). Family quality of life before and after out-ofhome placement of a family member with an intellectual disability. Journal of Policy and Practice in Intellectual Disabilities, 6, 32-39. doi: 10.1111/j.17411130.2008.00196.x

West, M. D. y Parent, W. S. (1992). Consumer choice and empowerment in supported employment services: Issues and strategies. Journal of the Association for Persons with Severe Handicaps, 17, 47-52. doi: 10.1177/154079699201700109 
Widaman, K. F., Borthwick-Duffy, S. A. y Little, T. D. (1991). The structure and development of adaptive behaviors. International Review of Research in Mental Retardation, 17, 1-54. doi: 10.1016/S0074-7750(08)60102-0

Widaman, K. F., Gibbs, K. W. y Geary, D. C. (1987). The structure of adaptive behavior: Replication across fourteen samples of non profoundly retarded persons. American Journal of Mental Deficiency, 91, 348-360.

Widaman, K. F. y McGrew., K. S. (1996). The structure of adaptive behavior. En J. W. Jacobson y J. A. Mulick (Eds.), Manual of diagnosis and professional practice in mental retardation (pp. 97-110). Washington, DC: American Psychological Association.

Widaman, K. E., Stacy, A. W. y Borthwick-Duffy, S. A. (1993). Construct validity of dimensions of adaptive behavior: A multitrait-multimethod evaluation. American Journal on Mental Retardation, 98(2), 219-234.

Wile, D. (1996). Why doers do. Performance and Instruction, 35(1), 30-35.

Wilson, M. (2005). Constructing measures: An item response modeling approach. Mahwah, NJ: Lawrence Erlbaum Associates.

Witkin, B. R. (1977). Need assessment kits, models and tools. Evaluations Technology, 17, 5-18.

Witkin, B. R. (1984). Assessing needs in educational and social programs. San Francisco: Jossey-Bass.

Witkin, B. R. y Altschuld J. (1995). Planning and conducting needs assessments. Thousand Oaks, CA: Sage.

Wolfensberger, W. (1972). The principle of normalization in human services. Toronto: National Institute on Mental Retardation.

Wright, D. y Digby, A. (Eds.). (1996). From idiocy to mental deficiency. London: Routledge.

Wright, B. D. y Masters, G. N. (1982). Rating scale analysis. Chicago, IL: MESA Press.

Wright, B. D. y Stone, M. H. (1999). Measurement essentials (2a ed.). Wilmington, DE: Wide Range, Inc.

Xeniditis, K., Slade, M., Thornicroft, G. y Bouras, N. (2003). Camberwell Assessment of Need for Adults with Developmental and Intellectual Disabilities (CANDID). London: Gaskell Publications. 
Yuan, K. H., y Bentler, P. M. (2007). Structural equation modeling. En C. R. Rao y S. Sinharay (Eds), Handbook of Statistics (pp. 297-358). Amsterdam: Elsevier.

Yuan, K. H., Bentler, P. M. y Kano, Y. (1997). On averaging variables in a confirmatory factor analysis model. Behaviormetrika, 24(1), 71-83.

Zuna, N. I., Turnbull, A. y Summers, J. A. (2009). Family quality of life: moving from measurement to application. Journal of Policy and Practice in Intellectual Disabilities, 6, 25-31. doi: 10.1111/j.1741-1130.2008.00199.x 



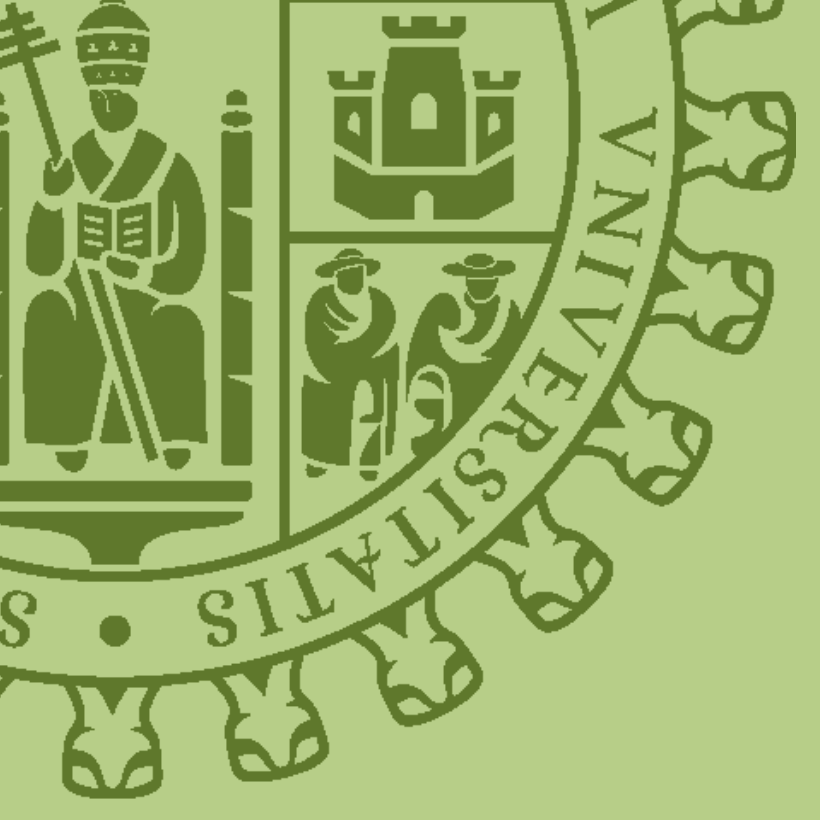

